\title{
INTERREGIONAL \\ INTERACTION IN \\ ANCIENT \\ MESOAMERICA
}





\section{INTERREGIONAL INTERACTION IN ANCIENT MESOAMERICA}

EDITED BY

Joshua D. Englehardt

AND Michael D. Carrasco

University Press of Colorado

Louisville 
(C) 2019 by University Press of Colorado

Published by University Press of Colorado

245 Century Circle, Suite 202

Louisville, Colorado 80027

All rights reserved

Printed in the United States of America

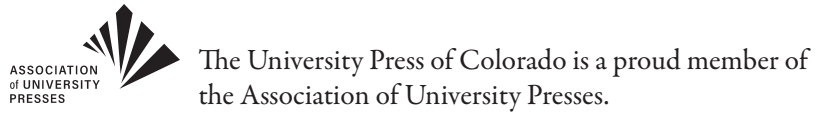

The University Press of Colorado is a cooperative publishing enterprise supported, in part, by Adams State University, Colorado State University, Fort Lewis College, Metropolitan State University of Denver, University of Colorado, University of Northern Colorado, Utah State University, and Western State Colorado University.

$\infty$ This paper meets the requirements of the ANSI/NISO Z 39.48-1992 (Permanence of Paper).

ISBN: 978-I-60732-835-3 (cloth)

ISBN: 978-1-60732-836-o (ebook)

DOI: https://doi.org/10.5876/9781607328360

Library of Congress Cataloging-in-Publication Data

Names: Englehardt, Joshua, editor. | Carrasco, Michael, editor.

Title: Interregional interaction in ancient Mesoamerica / edited by Joshua D. Englehardt and Michael D. Carrasco.

Description: Louisville : University Press of Colorado, [2019] | Includes bibliographical references and index.

Identifiers: LCCN 2019000679 | ISBN 9781607328353 (cloth) | ISBN 9781607328360 (ebook) Subjects: LCSH: Indians of Mexico-Social conditions. | Indians of Central America-Social conditions. | Indians of Mexico-Antiquities. | Indians of Central America-Antiquities. | Social archaeology-Mexico. | Social archaeology-Central America. | Mexico-Antiquities. | Central America-Antiquities.

Classification: LCC F1219.3.S57 N49 2019 | DDC 972/.01-dc23

LC record available at https://lccn.loc.gov/2019000679

An electronic version of this book is freely available, thanks to the support of libraries working with Knowledge Unlatched. $\mathrm{KU}$ is a collaborative initiative designed to make high-quality books open access for the public good. The open access ISBN for the PDF version of this book is 978-I-60732-983-I; for the ePUB version the open access ISBN is 978-I-60732982-4. More information about the initiative and links to the open-access version can be found at www.knowledgeunlatched.org.

Cover image credits: by Linda Schele, ( David Schele, photo courtesy Ancient Americas at LACMA $(t o p)$; courtesy of the Mesoamerican Corpus of Formative Period Art and Writing (Michael D. Carrasco and Joshua D. Englehardt) (bottom). 


\section{Contents}

List of Figures vii

List of Tables $\quad$ xiii

Introduction: Interaction and the Making of Ancient Mesoamerica Joshua D. Englehardt and Michael D. Carrasco 3

I. The Prehispanic Mesoamerican World: Framing Interaction Gary M. Feinman $\quad 34$

2. Interaction and Exchange in Early Formative Western and Central Mesoamerica: New Data from Coastal Oaxaca Guy David Hepp $\quad$ I

3. The Role of Interregional Interaction in Mesoamerican Script Development Joshua D. Englehardt and Michael D. Carrasco 83

4. Hieroglyphic Ch'olan to Ch'orti': Tracing Linguistic and Social Interactions into Eastern Ch'olan

$$
\text { Kerry M. Hull } \quad \text { II } 8
$$


5. Reframing the Tripod: A Foreign Form Adopted by the Early Classic Maya D. Bryan Schaeffer $\quad 149$

6. Across the Hills, toward the Ocean: Teotihuacan-Style Monuments in Guerrero, Mexico

$$
\text { Jesper Nielsen, Elizabeth Jiménez Garcia, and Iván Rivera } \quad 176
$$

7. A Sprinkling of Culture: Contact and Connections between the Tuxtlas Region and the Coastal Maya Philip J. Arnold III and Lourdes Budar $\quad 210$

8. Zaragoza-Oyameles Obsidian Projectile Points: Cantona's Place in Early Classic Period Long-Distance Gift Exchange and Interaction Charles L.F. Knight 240

9. Interregional Interaction of the Chalchihuites Culture in Northwest Mesoamerica during the Classic and Postclassic Periods JoséLuis Punzo Díaz 262

Io. Round and Round We Go: Cholula, Rotating Power Structures, Social Stability, and Trade in Mesoamerica Timothy J. Knab and John M. D. Pohl 292

II. The Movement of Metal Goods in the Mesoamerican Late Postclassic Period: A Case Study from the Templo Mayor in Tenochtitlán Niklas Schulze and Blanca E. Maldonado 313

I2. Competitive versus Peaceful Interaction

$$
\text { Joyce Marcus 34I }
$$

Conclusion: The World as They Knew It: The Interaction Sphere Concept in Current Mesoamerican Archaeology

$$
\text { David Freidel } \quad 365
$$

Contributors $\quad 383$

Index 391 


\section{Figures}

o.I. Map of Mesoamerica, detailing rough areal divisions and key regions and sites discussed in this volume

2.I. Map of key Early Formative period sites in Mesoamerica

2.2. A reconstruction of the Tlacuache phase ceramic assemblage

2.3. A comparison of Tlacuache, Barra, and Tierras Largas vessel types by percentage

2.4. Jar remnants from the Op. LCi2 $\mathrm{H}$ midden

2.5. Semispherical bowl remnants 58

2.6. Decorated Tlacuache assemblage vessel fragments from various contexts 59

2.7. Tlacuache grater bowl remnants

2.8. Partially reconstructed bottle recovered as offering with an adult male burial

2.9. Remnants of a probable effigy vessel from near Structure 2 domestic context

2.I0. Capacha phase vessels

2.II. Tlacuache ceramics from various contexts at La Consentida that bear evidence of the "sunburst" motif

2.I2. Fragment of a probable belted vessel from child burial at La Consentida 
2.13. Results of X-ray fluorescence analysis of forty-five obsidian samples from La Consentida

2.I4. Map with locations of La Consentida and the site's six known obsidian sources

2.15. Figurine and musical instrument fragments suggesting interregional connections

3.I. Middle Formative period vegetal headdress element

3.2. The vegetal headdress element in various Mesoamerican iconographic and script traditions

3.3. Vegetal headdress as year-bearer glyph in Zapotec script

3.4. The vegetal headdress element in both iconographic and glyphic contexts in Zapotec texts

3.5. Formative period tri-lobed maize headdress imagery

3.6. Tri-lobed maize headdress imagery in Late Formative and Classic period Izapan and Maya art and script

3.7. Throne-mat combinations in Olmec and Mayan script

3.8. The Lazy-S motif in Mesoamerican art and scripts

3.9. The Lazy-S in iconographic contexts with distinct semantic values

3.Io. Variable conventions in Mesoamerican scripts; speech scrolls vs. columnar organization

4.I. Map of Mesoamerica around A D I500 with sites and languages discussed in the chapter

4.2. Late seventh-century example of the OHL logogram at Palenque on the West Panel of the Temple of the Inscriptions (B7)

4.3. CHAK-xi-wi-te-i, chak xiwitei (Dresden 49C)

4.4. Possible PIK, pik 'skirt' logogram on the East Panel of the Temple of the Inscriptions, Palenque $\left(\mathrm{R}_{7}\right)$

4.5. Early Classic greenstone mask with the spelling $\mathbf{k o}^{2}$-mu-ti, kok muut, 'harpy eagle'

4.6. The name of Chak Ak' Paat Yuk, the ak' meaning 'turkey', on La Corona, Element $56\left(\mathrm{pF}_{2}-\mathrm{pE}_{3}\right)$

5.I. Early Classic tripod purportedly from the Maya lowlands, whose lid has a hieroglyphic script that describes this vase as containing the "cacao drink" of a king 
5.2. Two incised tripod vessels from Teotihuacan with large nubbin supports 152

5.3. Drawing of various ceramic vessel forms from Teotihuacan

5.4. Conical tripod supports innovated during the Late Tlamimilolpa phase I54

5.5. Talud Tablero-style tripod supports, Late Xolalpan phase

5.6. Tripod from Kaminaljuyú depicting central Mexican ruler with Maya jadeite jewelry and a central Mexican headdress

5.7. Tripod vessel with Teotihuacan iconography reportedly from the Maya area

5.8. Tripod from Kaminaljuyú, Mound A, Tomb A-I

5.9. (a) Tripod from Tikal with Maya hieroglyphs on the lid; (b) example of tripod vessel with lid and bird's head from Teotihuacan

5.IO. Tripod from dedication cache at Becan, Campeche

5.II. Tripod vessel from Oxkintok, Yucatán

5.I2. Scene incised on blackware tripod vessel located in Problematical Deposit 50 at Tikal

6.I. Maps showing the state of Guerrero in the wider geographical context of Mesoamerica and the major rivers and modern towns and cities as well as archaeological sites mentioned in the text

6.2. Monuments from northern Guerrero

6.3. Examples of Teotihuacan Storm gods or Storm god impersonators holding darts or a lightning bolt dart in front of them

6.4. Unprovenanced stela, reportedly from Guerrero and currently in the Sala Teotihuacan, Museo Nacional de Antropología in Mexico City

6.5. The stela from San Miguel Totolapan, front and back

6.6. The archaeological site of Cerro de los Monos, Guerrero

6.7. Early photographs showing Cerro de los Monos Column I and 2 and Sculpture I

6.8. Comparison of Teotihuacan-style ballcourt markers or battle standards

6.9. Roll-out drawings of the carved monuments from Cerro de los Monos

6.ro. Quechomictlipan Monument I

7.I. Regional map detailing locations of sites mentioned in the text

7.2. The Tuxtla Statuette

7.3. Stela-Base-Throne Complex in situ at Piedra Labrada 
7.4. Piedra Labrada Stela I

7.5. La Perla del Golfo carved stone block 220

7.6. One of the three boxes of Matacanela 22I

7.7. Stelae Bases in situ, Complex 2 of Piedra Labrada 222

7.8. Some examples of Tuxtlas Polychrome 225

7.9. Hollow figurine from La Joya 230

8.I. Location of Cantona in relation to Teotihuacan and obsidian sources in central Mexico 24I

8.2. Limits of Cantona in relation to the general area of the ZaragozaOyameles Obsidian Survey, Puebla, Mexico

8.3. Specific limits of the 2012-2014 seasons of the Zaragoza-Oyameles Obsidian Survey 246

8.4. Zaragoza-Oyameles projectile points in the central Mexican Stemmed-A and Stemmed-B style

8.5. (a) Zaragoza-Oyameles stemmed-A style point exhibiting upper-left to lower-right diagonal flaking pattern; (b) ovate-shaped point exhibiting lower-left to upper-right diagonal flaking pattern

9.I. Map of the principal sites associated with the Chalchihuites culture $\quad 264$

9.2. The Hall of Columns at Alta Vista 266

9.3. Comparative chronologies from Zacatecas, Durango and Sinaloa $\quad 269$

9.4. The Chalchihuites chronology in Durango with associated ceramic types

9.5. La Ferrería Structure 7 (La Pirámide)

9.6. La Ferrería Structure I (La Casa de los Dirigentes)

9.7. La Ferrería iron pyrite mirrors and other items from Kelley's excavations in the I950s

9.8. Copper objects found by Kelley in la Ferrería 28I

9.9. Cliff dwelling, Cueva del Maguey, Durango 282

IO.I. A view of the city of Cholula to the east as seen from the summit of the Great Pyramid

10.2. Artistic interpretation of the Temple of Quetzalcoatl based on written accounts and images appearing in various pictographic documents

I0.3. Print by Bernard Picart portrays Quetzalcoatl at Cholula being venerated as the "Mercury" of the Mexicans 
I0.4. The annual market held in the main plaza of San Pedro Cholula in conjunction with the feast of the Virgin of the Remedies

I0.5. The image of San Miguel de Tianguisnahuac is dressed in his greenplumed finery in preparation for the procession of the barrio saints throughout the city before they are presented at the sanctuary of the Virgin of the Remedies

Io.6. At the close of the celebration for the Virgin of the Remedies, thousands of participants in the festivities descend from the Virgin's shrine at the summit of the Great Pyramid to participate in a feast sponsored by the mayordomo

I0.7. Celebrants share in platters of cecina, salt beef, grilled on an open fire; rajas, grilled peeled strips of poblano peppers and white cheese with toasted handmade tortillas while consuming fruit drinks as well as the more traditional atole and aguardiente.

Io.8. The climax of the feast of the Virgin of the Remedies is a massive fireworks display

I0.9. As the mayordomos of San Bernardino Tlaxcalantzingo arrive to participate in the feast, they set aside their silver staffs of office

II.I. The northward diffusion of metallurgy from regions in Central or South America via maritime and/or terrestrial trade routes

II.2. Mesoamerican deities associated with metal

II.3. Examples of different Mesoamerican bell typologies

II.4. Examples of the most common bell forms from the offerings of the Templo Mayor

II.5. Metal tributes mentioned in the Matrícula de Tributos

II.6. Traders transporting and selling goods, including bells, needles, textiles and personal ornaments of gold and obsidian

I2.I. The Yucatán Peninsula, divided into sixteen autonomous provinces, at AD I550-I580

I2.2. The Valley of Oaxaca, showing three competing centers-San José Mogote, Yegüih, and Tilcajete-one in each subvalley

12.3. The position of San José Mogote's Monument 3, a carved stone that served as the threshold for the corridor, ensured that anyone entering the corridor would have stepped on the body of a sacrificial victim

I2.4. Calakmul's core area (its hexagonal lattice of subjects) and its many neighbors and subjects 
I2.5. Stela I of Nakbe, which shows two lords, once reached 3.4 meters in height

I2.6. Top: The Snake head, or Kaan, sign. Bottom: The Snake Head Polity emblem glyph can be translated as "Divine Lord of the Snake Polity"

I2.7. Carved steps from a Dzibanche stairway, showing prisoners defeated by a divine lord of the Snake Polity 


\section{Tables}

2.I. AMS radiocarbon dates from La Consentida. Calibrated with IntCal I3 curve by $\mathrm{OxCal} 4.2$ and reported with both $\mathrm{I} \sigma$ and $2 \sigma$ probability

3.I. Phonological aspects of early writing or ancestral script as compared with four Mesoamerican language families

4.I. Proposed loanwords into Hieroglyphic Cholan and their source languages

7.I. Number of Stela-Base-Throne Complexes (SBTCs) at selected sites

II.I. Mexican copper, lead, and tin production from the years 1942, 1953, and 1954 



\section{INTERREGIONAL \\ INTERACTION IN \\ ANCIENT \\ MESOAMERICA}





\title{
Introduction
}

\section{Interaction and the Making of Ancient Mesoamerica}

\author{
Joshua D. Englehardt and Michael D. Carrasco
}

In archaeology, "interaction" is often treated as if it were a self-explanatory and self-evident concept. But this is not the case. Interaction may take many forms: material exchange or emulation, conquest or colonization, long-distance or local, direct or indirect, multidirectional or unidirectional, among other modalities (see Joyce Marcus, chapter I2 in this volume). Like the phrase "sociocultural process," the term "interaction" seeks to cover an indefinite, complex set of historically contingent processes. Thus, although the term "interaction" may be taken to mean the diffuse social processes that operate between individuals or groups, and generally indicates some kind of social contact, as a rule it suggests nothing specific about the nature of the contact or the particular relationships between interacting units (Caldwell 1964; Parkinson 2002:394). Scalar issues (see, e.g., Neitzel 2000; Peterson and Drennan 2003) further exacerbate the difficulties in scholarly interpretations of interaction. Nonetheless, the concept of interaction at times has been used as a "miracle elixir" to account for similarities in diverse suites of material and visual culture from different regions (e.g., diffusionism), and to extrapolate the specific relations that existed between the interacting cultural groups (e.g., subordinate vs. dominant, core vs. periphery, "mother culture," etc.). Yet interaction, if conceived of solely as a reactionary event, such as the collision of billiard balls (see Wolf 1982:6), is on its own incapable of solving the theoretical, methodological, or evidentiary problems associated with a fragmentary archaeological record and the limitations that this fact presents for the study of ancient societies. 
Despite these conceptual difficulties - or perhaps because of them-critically examining the role of interaction in the complex societies of the past has long been a core area of investigation in archaeology and related disciplines, both in Mesoamerican contexts and beyond. For as Gil Stein (2002:903) notes, interregional interaction is among the most significant recurring forms of social process - defined here as the dynamic patterns of societal activities within a given sociocultural context (cf. Bain 1932:10). Researchers working in many areas of the world have recognized that interaction may serve as a catalyst for cultural innovation, a phenomenon capable of stimulating changes in material and symbolic culture of both kind and degree, particularly in terms of the evolution of sociocultural complexity and economic systems (see, e.g., Cherry 1986; Demarest 1989; Flannery 1968; Goldstein 2000; Hirth and Pillsbury 2013; Lesure 2004; Miller 1983; Renfrew 1972; Rosenswig 2010; Schortman and Urban 1992). As such, a comparative, cross-cultural focus on the multiple forms that interaction may take and its developmental consequences is at the very heart of anthropological archaeology.

In Mesoamerican studies, Paul Kirchhoff's (1943) original conception of Mesoamerica (figure O.I) as a region of communal cultural traits presumes interaction as the mechanism behind these commonalities. The region encompassed many cultures that shared a core suite of characteristics despite having developed in distinct environments. In spite of certain topographic and logistical limitations, there appears to have been a great deal of long-distance communication and exchange from very early points in Mesoamerican history (see Gary M. Feinman, chapter $\mathrm{I}$ in this volume). In a sense, one might conceive of Kirchhoff's view of Mesoamerica as falling in line with the concept of interaction sphere (Caldwell 1964; cf. Altschul 1978; Freidel 1979; Possehl 2007; Struever 1972). Thus, interregional interaction and cultural exchange has been a common topic of discussion in the scholarly literature on Mesoamerica, and its study remains salient precisely because it speaks to the core of what defines the region as a heuristic concept. Unsurprisingly, then, scholars from a variety of disciplines have critically examined the role that interregional interaction played in the development of regional cultures; material, political, economic, ritual, artistic, and linguistic interaction have all been examined in multiple Mesoamerican cultural and temporal contexts.

For example, within the Formative period (ca. 2000 B C-AD 250), long-distance obsidian exchange, the dissemination of "Olmec" (or "Olmec-style") iconography, and the adoption of Mixe-Zoque ritual vocabularies have proven fertile ground for research (see, e.g., Campbell and Kaufmann 1976; Clark and Lee 1984; Ebert et al. 2015; Grove 1993; Justeson et al. 1985; Wichmann 1995, 1999). In Classic period (AD 250-950) Mesoamerica, the material exchange of "prestige goods," possible 


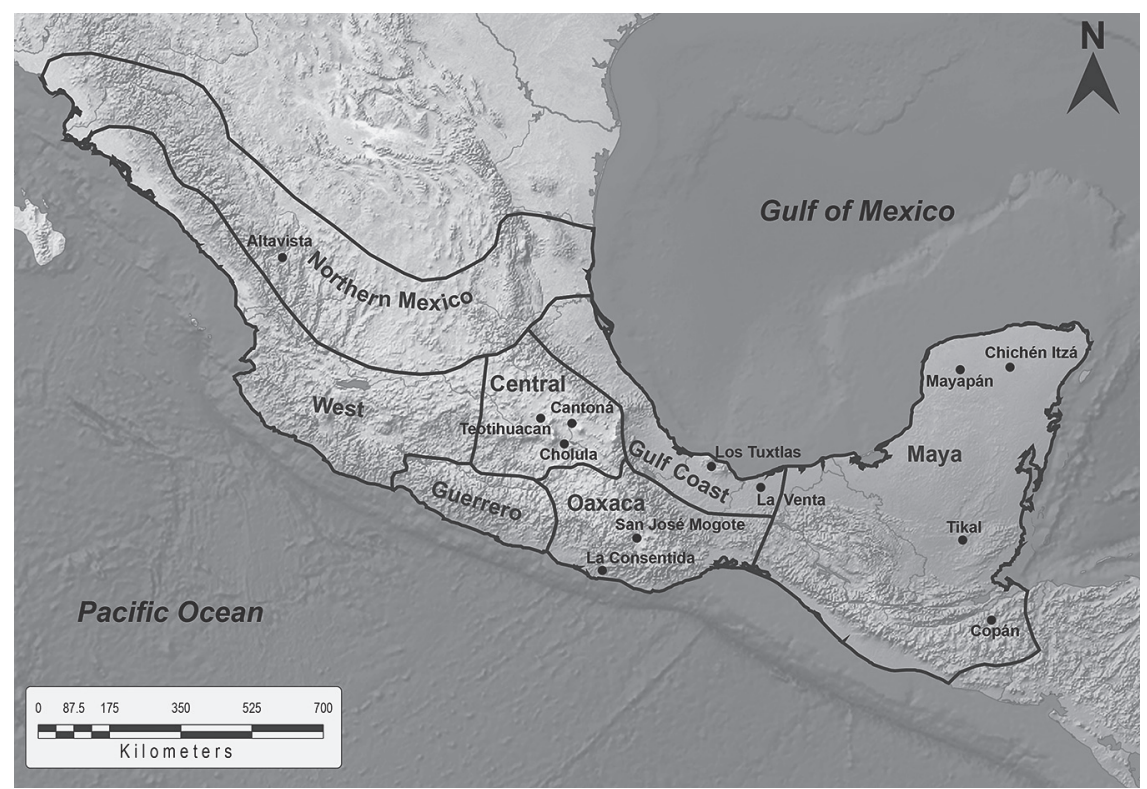

FIGURE O.I. Map of Mesoamerica, detailing rough areal divisions and key regions and sites discussed in this volume.

conquests, and marriage alliances between the Maya and Teotihuacan, and among later Mixtec and Zapotec cultures, has been treated extensively (e.g., Braswell 2003a; Gómez Chávez and Spence 20I2; Martin and Grube 2000; Nielsen 2006; Pohl 2003a, 2003b; Stuart 2000). In Postclassic period (AD 950-I519) contexts, investigations have focused on a number of episodes of interaction, including the spread of Mixteca-Puebla "international style" ceramics, the specific relationships between particular sites (e.g., Chichén Itzá and Tula), and the impact of Aztec pochteca-professional long-distance traveling merchants (e.g., Berdan 1988; Berdan et al. 1996; Kowalski and Kristan-Graham 20II; Pohl 2003c; Pohl and Byland 1994; Smith I991, 201ra; Smith and Berdan 2003), as well as the use of Nahuatl as a language of interregional exchange.

Thus, multiple lines of evidence attest to the critical role that interregional interaction played in the development and sociocultural dynamics of virtually all Mesoamerican cultures. Yet in many contexts within Mesoamerica, the precise nature of this role remains obscure. Of course, as Gary M. Feinman (chapter I in this volume) points out, neither this fact, nor the conceptual complications outlined above, renders the consideration of interaction a futile endeavor. Indeed, 
research conducted over the past three decades has added substantial detail to the material, visual, and ethnographic records of the region. Moreover, interdisciplinary methodologies have emerged that offer researchers the opportunity to present and engage data in a new light, and to bring other lines of evidence to bear on fundamental research questions. Investigators are now better equipped to contribute to a more detailed understanding of the ways that interregional interaction may spark cultural innovation and shifting cultural dynamics. In short, the data are ripe for fresh analyses that allow for a more nuanced consideration of the role of interregional interaction on cultural genesis, praxis, persistence, and change in Mesoamerican contexts. As archaeologists, anthropologists, art historians, linguists, cultural geographers, and others apply new methodologies and data to past and present considerations regarding the significance of interregional interaction, there is great potential to shed new light on the processual dynamics that produced not only a multitude of individual cultures but, in many respects, a shared, panMesoamerican culture as well. It is for precisely this reason that this volume adopts a conjunctive approach that juxtaposes distinct contexts, disciplinary perspectives, and methodologies.

To that end, this volume explores the role of interregional interaction in the dynamic sociocultural processes that shaped the pre-Columbian societies of Mesoamerica. Building on previous scholarship, as well as our expanding awareness of the evidentiary record, the interdisciplinary contributions collected here explore how interaction impacted cultural development and social processes in various Mesoamerican contexts. Although "process" (like "interaction") is a vague term, here we are most interested in those sociocultural processes that relate to the generation, consolidation, and communication of ideas and technologies; the exchange of material culture; and the structuration of behavioral practices. Contributions focus on interaction less as an explicative framework, and more in terms of its potential to facilitate the sharing of cultural processes. Specifically, they explore its role in the construction of indigenous epistemologies and systems of shared ideologies; the production of regional or "international" artistic and architectural styles; shifting sociopolitical patterns; and diachronic changes in cultural practices, meanings, and values. In this sense, this volume examines the critical question of how interregional interaction in a sense "created" what we now label "Mesoamerica."

Contributions represent, and are informed by, a variety of methodological, temporal, and regional vantage points. Juxtaposing interregional patterns derived from different lines of evidence (e.g., archaeological, linguistic, art historical) in discrete contexts forces the analyst to attend specifically to the complex relationships among historical actors, social structures, and material culture to produce detailed 
and compelling analyses. Accordingly, the contributors to this volume seek to move beyond simplistic conceptions (e.g., an over-reliance on "diffusion," "migration," or "conquest") in constructing explanations of interaction between and among ancient societies. More specifically, the conjunctive, interdisciplinary approach advocated here reveals further degrees of complexity in historical episodes of interregional and cultural exchange.

For example, José Luis Punzo Díaz (chapter 9) considers interaction in the underexplored region of northwestern Mesoamerica. His analysis surpasses previous treatments that viewed areal cultures as passive, "peripheral" recipients whose developmental dynamics stemmed from interaction with more "active" core centers (e.g., Teotihuacan) external to the region itself. Likewise, D. Bryan Schaeffer (chapter 5) and Philip J. Arnold III and Lourdes Budar (chapter 7) reexamine interaction between the Maya lowlands and other sites and regions (Teotihuacan and Los Tuxtlas, respectively). Schaeffer elucidates aspects of cultural agency in these traditions, thereby contributing to a broader scholarly discourse (e.g., Braswell 2003a) that seeks to question traditional conceptions of the historical relationship between these cultures as one of unidirectional influence (cf. Stuart 2000). Further, Schaeffer's art historical examination of the tripod vessel adds nuance to conventional understandings of that form as indexical of external impact and/or central Mexican influence. Arnold and Budar's (chapter 7) analysis of three lines of material evidence likewise reveals the significance of local considerations in regional cultural developments and potential variability in historical exchange relationships. Their consideration of new evidence (e.g., improved chronologies, better-established stylistic sequences) identifies heretofore undisclosed-or unexplored—cultural linkages and allows researchers to move beyond prior models. The chapters by Kerry M. Hull (chapter 4), and Joshua D. Englehardt and Michael D. Carrasco (chapter 3), in offering analyses of linguistic and iconographic (and scribal) interaction, respectively, place in relief the broader factors that underlay interaction and exchange. Treatments such as these, that consider alternative evidentiary lines from distinct methodological perspectives, serve to further contextualize the diverse and heterogeneous processes implicated in the investigation of interregional interaction.

These examples, among others in this volume, illustrate how the present collection moves beyond received scholarship by providing a holistic consideration of interaction throughout Mesoamerican history, and its integral role in cultural development and regional dynamics. Accordingly, the contributors to this collection maintain that novel approaches to a topic that has historically been a staple of archaeological research offer great potential for advancing archaeological understanding of past cultural lifeways. Of course, neither this introduction nor this volume pretends to offer a new "theory of everything" or conclusively resolve the 
difficulties inherent in treating the multifaceted and at times imprecise concepts of interaction and sociocultural process. Nonetheless, the conjunctive, interdisciplinary approaches presented here contribute to a greater scholarly comprehension of the terms themselves, as well as the specific examples under consideration. In the remainder of this introduction, we explain and justify this assertion through discussions of what it means to study interaction in the archaeological record from a broad interdisciplinary perspective, and how and why new data and methodologies can meaningfully contribute to advancing research, scholarly debate, and understanding of the complex and varied sociocultural processes at the heart of this volume.

\section{ON BILLIARD BALLS: CONCEPTUALIZING AND IDENTIFYING THE ROLE OF INTERACTION IN CULTURAL PROCESS}

As Rosenswig (2010:3) notes, the "interregional exchange of goods and ideas is a distinctly human practice that qualitatively separates us from other creatures on earth." But, he continues, archaeological treatments of how interaction affected the organization and cultural dynamics of interacting societies are often insufficient, and ultimately fail to provide satisfying answers to this critical query. Likewise, responses to the question of motivation, or "why" interaction occurs, are often reduced to one-dimensional tautologies, such as a nebulous "desire for resources that are not locally available" (Rosenswig 2010:3). Frequently, it seems, interaction is viewed as both cause and effect of various cultural processes, as a prime mover and a catchall capable of at once describing and explaining the variable material configurations observable in limited archaeological datasets. As Stein (2002:903) summarizes, "precisely because it is so common and relatively easy to identify in the archaeological record, archaeologists ... have overemphasized the importance of ... interaction as a primary cause of social evolutionary change."

Nonetheless, it remains safe to assume that a shared assemblage of cultural traits is indicative of the existence of some form (or forms) of communication, intercourse, or articulation that enabled such sharing. That is, archaeologists commonly infer interaction from the presence of shared forms, styles, and symbols, whose very presence conveniently justifies and explains both the inferred interaction and the presence of shared material culture shared. Such conclusions may seem obvious and eminently reasonable at first glance. Yet the presence of formally similar archaeological evidence at discrete sites or within distinct regions does not in and of itself equate to interaction-nor does identifying such shared material culture alone constitute an archaeological study (or explanation) of interaction. ${ }^{1}$ Perhaps more importantly the identification of interaction does not confirm that cultural 
meaning is shared, even in those cases where exchange or its directional flow is clear-precisely because the act of exchange is also one of appropriation, translation, and reinterpretation. Rather, the discussion of interaction is reduced to mere descriptive accounts (or worse, speculation) that are incapable of elucidating the actual process and virtually guarantee that researchers cannot produce credible explanations (cf. Smith 201rb:595-596). Such causal-functional treatments render interaction a vague and self-explanatory concept. In the end, explanations derived from such a conception are just as simplistic as the models of unidirectional diffusion and migration proffered by Franz Boas, V. Gordon Childe, and others-and subsequently discarded—so long ago.

The causal-functional perspective is, in large measure, predicated on what may be labeled the "billiard-ball" view of the past (see Wolf 1982:6). This reductionist idea conceived of ethnicity, language, and material culture as traits that were packaged into neatly bounded societies and "careened across the landscape" (and into one another) "like self-contained billiard balls" (Anthony 2010:I08). Historical events, therefore, invariably were directly interrelated (cf. Hodder 1987:2). This viewpoint hearkens back to the culture history paradigm, and necessarily presupposes interaction (more specifically, diffusion) as the mechanism by which sharing occurred, thus resulting in a circular argument: if one views cultures as suites of traits, and if those traits are shared, interaction is inferred (Gary M. Feinman, personal communication, 2016).

Apart from affirming the consequent, such a conception is unsatisfactory on many levels. From a philosophical-epistemological perspective, implying causality to direct sources-particularly a single element or process-is problematic. Such an inference exceeds impressional cause, despite whatever historical or empirical evidence exists to suggest a causal relationship (see, e.g., Hume 1999). Extending the billiard ball analogy, it is erroneous to automatically assume that one ball striking another causes the other's movement (i.e., to say that A causes B, in strict terms). ${ }^{2}$ Although such a philosophical discussion it slightly outside the scope of this volume, one point is cogent: it does not matter what the billiard ball thinks — or how it conceives of the causality of its own motion-it rolls where it is pushed, in accordance with its own vector. Of course, the billiard-ball model is not entirely an apt analogy. We concur with Hodder's (1987:2) critique of the metaphor: the definition of the entities (the balls), and the interrelationships between them, is fluid, since these factors are contingent on a set of historically particular circumstances. In other words, human action is not governed by Newtonian laws of motion. Regardless, even if we accept the analogy, to our minds the moment of intersection, or what happens when the billiard balls touch, is what is most significant, and holds the most explanatory power. 
Thus, the sharing of material goods across the landscape should not be seen purely as either the cause or effect of interaction. Rather, the phenomenon is indexical of the process itself. How the specific process of interaction is related to other sociocultural dynamics-what happens when (and after) the billiard balls touch-is what concerns us and is a far more fruitful avenue of inquiry. For example, in Formative period Mesoamerica, it is often argued that emerging elites co-opted "Olmec" symbolism to bolster their burgeoning authority through association with the prestige of this culture (see, e.g., Demarest 1989; Flannery 1968:III; Rosenswig 2010; cf. Flannery and Marcus 2000; Pool 1997). Although the movement of ostensibly "Olmec" goods across Mesoamerica is archaeologically evident (Blomster et al. 2005; Cheetham 2007, 2010; Cheetham et al. 2009), this fact does not imply that the primacy of Olmec culture-or interaction with the Olmec-caused, or can be directly correlated with, particular sociocultural processes in other cultures. In any case, the functions and meanings of shared material culture may vary. As Rosenswig (2010:49) suggests, shared Olmec imagery "may have been employed in locally specific ways" (see also Grove 1993; Lesure 2004). As John Clark (2004:208) points out, through interaction across geographic regions or cultural groups, ideas may "become enmeshed with material goods and agentive decisions in generative ways; ideas can be represented by things, and things can prompt ideas, symbols, and meanings not previously instantiated in goods" (cf. Renfrew 200I). In other words, ideas about things are both social and dynamic. Exchange may thus act as something of a feedback loop that provides an opportunity to reinterpret the social meanings reflected in material objects. In this sense, a shared complex of material culture, although indexical of interaction, is neither cause nor effect of that (or other) processes, but rather both cause and effect of higher-order dynamics.

Further, although the interrelationship of historical events should not be an a priori supposition, it is a fact that all past human societies were both material and historical (Zborover 2015:I). As Hodder (1987:2) concludes, integrating historical and archaeological perspectives "involves an attempt at particular and total description, and it does not oppose such description to explanation and general theory." Thus, it is not a given that archaeological methods of studying historical events, episodes, or processes (such as interaction) should be "epistemologically distinctive" from those employed in other disciplines that study similar phenomena (Zborover 2015:3). In this sense, an integrative consideration of archaeological phenomena-such as that proposed in this volume-is capable of providing clues as to both the mechanisms behind and the underlying explanation of a specific instance of cultural exchange or interaction-addressing both the "how" and "why" of the issue.

As this brief discussion makes plain, there are many ways of approaching and understanding interaction among human groups: as a sociocultural process (in 
both synchronic and diachronic terms), as an historical event, and/or as catalyst, cause, effect, and/or correlate (or some combination of these) of larger, higher-order dynamics. Although this volume, and the contributions presented herein, does not seek to present a monolithic vision of interaction, we hold that Hume's notion of constant conjunction - at the meeting of the billiard balls themselves-is a far more productive way of conceiving of and understanding episodes of interaction. While this perspective may be more preferable theoretically, in practical terms it renders the identification of the archaeological correlates of interaction — and its processual implications-slightly more problematic. Because sharing can occur in many ways, observable patterns of formally, technologically, and/or stylistically similar material culture may be the result of any number of factors and present a variety of material manifestations in various sociocultural aspects, from the political-economic to the ritual-symbolic. To resolve this dilemma, researchers need an established set of criteria that allow for the evaluation of the empirical strength or plausibility of a given argument (Smith 20Irb:595). For this reason, many suggest that it is preferable to start with a model $(\mathrm{s})$ that help $(\mathrm{s})$ explore and organize the data rather than entirely working from the bottom up.

\section{MODELING INTERACTION IN ANCIENT SOCIETIES}

As should be clear from the above discussion, like many contemporary approaches, we reject causal-functional treatments of interaction in the archaeological record as unsustainable. Rather, the contributors to this volume conceive of cultural elements in the archaeological record as the result of patterns of action or behavior in the past-even if, as Clarke (1973:17) charges, archaeologists deduce such unobservable behavioral patterns from "indirect traces in bad samples." From this viewpoint, archaeology is positioned to interpret material culture with the aim of understanding historical processes such as interaction in terms of their role in cultural change, rather than as phenomena whose taxonomical study confirms the existence of a series of preconceived categories and self-evident explanations. Such interpretation, however, requires the use of models. As such, we turn below to a brief discussion of several models often employed in archaeological treatments of interaction.

Despite its inherent problems, the causal-functional perspective is still commonly applied —albeit in a distilled form—as an implicit paradigm for interaction in complex societies, particularly by those models that treat migration and trade as prime movers. Although migration models have moved beyond the simplistic conceptions of the billiard-ball analogy (Anthony 2010:108), Burmeister (2000:539) notes that the attribution of patterns in material data "to migration as opposed to diffusion or trade is still a major problem." Migration-based models thus remain 
underdeveloped in theoretical and methodological terms, despite a wealth of research in various contexts (see, e.g., Anthony 1990, 1992, 1997; Cameron 1995; Champion 1990; Chapman and Hamerow 1997; Stark et al. 1995). Härke (1998) suggests that the difficulty is perhaps one of attitude on the part of archaeologists, who are reluctant to consider models that most see as diffusion-based. Burmeister (2000:540; echoing Anthony [1992:174]) points out that "the development of a method for establishing archaeological proof of migration" is key to furthering models that contribute to a better theoretical understanding of migration as an element of cultural behavior (cf. Rouse 1986). We would agree in principle that archaeologists should not be too quick to ignore migration-based perspectives on interaction due to some perceived association with outmoded ideas of culture history. ${ }^{3}$

Although the recent investigations cited above present excellent arguments and case studies, such models remain open to criticism as reductionist. Further, it remains unclear how the models successfully resolve any number of issues that have plagued migration-based explanations of archaeological phenomena, ${ }^{4}$ such as the identification of solid archaeological indicators. Finally, migration models tend to privilege external dynamics over the transformational capacity of internal social, political, and economic processes. In this sense, at their core migration-based models continue to rely on what for all purposes appear to be direct cause-effect relationships and thus are prone to the same sort of causal-functional tautologies that characterize the diffusionist perspective. One important outlier is Beekman and Christensen's (2003) excellent study of Postclassic period Nahua migrations. Although this article is a paragon of dealing with complex issues related to population movement, it remains the exception rather than the rule. It does bear mention, however, that Beekman and Christensen (2003:113) advocate an analysis of interaction based on "multiple intersecting lines of data"-underlining the value of the approach adopted in this volume.

Trade-based models, grounded in economic anthropology, have long been deployed in archaeological studies of interaction. In many ways, trade models attempt to address the problem of privileging external factors noted above, and consider interaction at a number of different scales, from local to global, and in terms of distinct modalities (e.g., reciprocal, redistributive, market). Renfrew (1977) insisted that it is important to study trade precisely because the institution of a trade network is both a causal factor for cultural change as well as a sociocultural process. ${ }^{5}$ The identification of exchange systems in the archaeological record has been operationalized in a number of ways, from the interaction sphere (Altschul 1978; Freidel 1979; Struever 1972), to marriage alliances (Martin and Grube 2000; Pohl 2003b), to markets and distribution systems (Smith 1999; see also the papers collected in Garraty and Stark 2015 or Hirth and Pillsbury 2013). Trade-based 
approaches to interaction often have produced more sophisticated conceptions of empirical indicators and the interpretation of shared patterns or assemblages of cultural traits evidenced in artifactual remains. Archaeological considerations of exchange systems thus have resulted in models that are often more theoretically and methodologically refined than traditional migration-based approaches.

Nonetheless, trade-based models are also open to specific critiques. For example, many-particularly those that focus on market exchange-are susceptible to embracing a formalist view of economics (see Polanyi 1944), despite an avowed anthropological focus on the emic, culturally specific practices of premodern societies. ${ }^{6}$ Further, markets and market exchange, as distributional systems, may be more appropriately identified as mechanisms for rather than explanations (or causal factors) of interaction. In this sense, such models run the risk of confusing (or conflating) cause and effect. Finally, such models often focus more on overtly materialeconomic interaction, leaving aside the significant, yet less archaeologically visible, component of symbolic exchange. Theories of ritual economy and models dealing with the exchange of prestige goods recently have arisen to counter this trend (e.g., Clark and Blake 1994; Henrich and Gil-White 200r; McAnany and Wells 2008; Sabloff 2008; Watanabe 2007; Wells 2006; Wells and Davis-Salazar 2007). Prestige goods theory, however, was developed primarily to understand the political relationships between interacting groups. Analyses based on the ritual exchange of prestige goods have therefore most often focused on the development of sociopolitical power, hierarchical rank, and stratification that accompanied the centralized control of social value (e.g., Hayden 1998; Helms 1993, 1994).

More recent conceptions of trade and exchange relationships-and, to an extent, migration patterns-are subsumed under the wider umbrella of World Systems approaches. World Systems Theory (WST), derived from Wallerstein's (1974, 2004) analysis of premodern capitalist systems, have enjoyed a broad popularity in many contexts, both in Mesoamerica and beyond (see, e.g., Alexander 1999; Algaze 1993; Chase-Dunn and Hall 1991; Feinman 1999; Frank 1993; Hall and Chase-Dunn 1993; Kardulias and Hall 2008; Kepecs et al. 1994; Kepecs and Kohl 2003). World Systems Theory treats exchange networks and cultural processes as parts of larger, overarching political, economic, and social systems of core-periphery relations. In doing so, WST is able to account for a variety of internal and external factors at multiple scales in the identification and subsequent explanation of interaction in the archaeological record, from local trade to wider studies of empires and conquest (cf. Berdan et al. 1996; Sinopoli 1994).

Although appealing in terms of their breadth, explanatory potential, and theoretical sophistication, WST-derived models of interaction have received extensive criticism (e.g., Schortman and Urban 1994, 1999; Stein 1999). Like the trade-based 
approach, WST often appears to privilege a certain type of interaction (economic) over others (e.g., symbolic). As with any systemic model, WST is also susceptible to discounting the agency of individual social actors. In a similar sense, many archaeologists have criticized WST's perceived undervaluing of the role or potential influence of "peripheral" areas within the system. Finally, WST frequently is critiqued for attempting to "shoehorn" precapitalist (or non-western) economies into a descriptive-explanatory framework that was developed specifically to treat the development of an explicitly capitalist economic system. Of course, archaeologists base many models on analogies derived from contemporary or more recent historical contexts. Critiques of WST that focus on the supposedly inappropriate application of modern analyses in ancient settings often fail to account for more current attempts to refine Wallerstein's original formulation and extend the explicative potential of World Systems analyses (see Kardulias and Hall 2008). Yet in Mesoamerican contexts, it is undeniable that a significant amount of scholarship adopts models that rely on the active participation of a "core" culture or site-be it "Olmec," Teotihuacan, or Aztec - to explain regional dynamics as the imposition of "core" material culture on passive "peripheral" sites via interaction. Of course, recent perspectives on WST or trade models (e.g., Blanton and Feinman 1984; Peregrine and Feinman 1996; see also the papers collected in Smith and Berdan 2003) have attempted to overcome such conceptual problems, but in many cases the problems inherent in the models themselves remain, to varying degrees. The ultimate success or utility of those attempts, therefore, remains open to debate.

Recently, archaeologists have developed models based on Social Network Analysis (SNA; see Scott 2013; Wasserman and Faust 1994; Wellman and Berkowitz 1988) in an attempt to address the difficulties inherent in migration, trade, and WST approaches. Social Network Analysis, derived from sociological theory, focuses primarily on the social relations between sets of actors, whether individuals or groups (cf. Blanton et al. 1996). It is perhaps best to conceive of SNA as a set of analytic methods specifically oriented toward the elucidation of relational aspects of variable social structures among populations. Although sympathetic with general systems theory, in SNA explications of the processual causes and effects of interaction between human groups are mitigated by a series of variables particular to the network itself. These may include centralization, degrees of closeness between nodes, scale, density, boundedness, integration, interdependence, and reach, among others. In this sense, social network analyses seek to include both particular descriptions and total (or general) explanations (cf. Hodder 1987:2; Kardulias and Hall 2008:572-573). Like WST, SNA is thus equipped to consider distinct types of interaction in varying modes at multiple scales. ${ }^{7}$ As Gary M. Feinman (personal communication, 2016) notes, these two contemporary frames (WST and SNA-and 
others, such as migration or trade) are not necessarily mutually exclusive, as a point of reference, but they both operate differently and offer more interpretive and explanatory potentiality than culture history or diffusionism. In practical terms, researchers have employed SNA with success in a variety of discrete contexts (e.g., Brughmans 2013; Golitko and Feinman 2015; Knappett 2013; Mills et al. 2013).

\section{BotTOM-Up OR TOP-DOWn?}

This brief review of archaeological models cannot possibly do justice to the complexity of their respective contents, and of course there are a variety of other models for interaction that we do not detail. Our intention in this exercise is not to offer a definitive list of all possibilities. Similarly, we offer critiques of these models not because we purport to proffer a superior model, but rather to highlight that any model can offer advantages, but that each necessarily carries disadvantages that may serve to limit its interpretive potential. Further, there is a very real danger of the model overdetermining the data or creating categories relevant only to the specific questions of a particular research agenda. This is of course true for any explanatory model, archaeological or otherwise. We enunciate this platitude to introduce a wider point: although interpretation and cross-cultural comparison require the use of models, starting with a specific model of interaction necessarily presupposes a certain mode, dynamic, or directionality (e.g., core-periphery; cf. Stein 2002:903-904). Of course, almost any "traditional" archaeological model of cultural exchange is susceptible to this type of bias. The principal difficulty lies in another obvious fact: intercultural contacts and interregional patterns of interaction are rarely one-dimensional. Therefore, the relationship between such phenomena and wider processes often cannot be explained fully by using only one model, no matter how scientific, systematic, or multidimensional that model may be. In this sense, departing from a top-down, specifically archaeological model of interaction often limits the possibilities to consider how shared material culture is negotiated in or between distinct cultures, agents, or contexts.

The recent theoretical and methodological trends noted above seek to counter these problematicals. Such revisions in no way suggest the weakness of current models. Rather, the recognition of limitations and appropriate revision of prior frameworks are integral components of theory building (Kardulias and Hall 2008:574). We do not seek to create a "straw man" argument here, nor do we suggest that all approaches to (or models of) interaction in ancient Mesoamerica implicitly accept, for example, a core-periphery dichotomy. In the event, however, one might ask if models, like typologies, are "necessary evils" in archaeological research, in which we trade off certain advantages for less desirable aspects. We agree that archaeologists 
need models to interpret and explain patterns in the material record suggestive of interaction. Nevertheless, it is prudent to avoid converting such models into static and preconceived theoretical-methodological straitjackets that are applicable in all contexts (see Pauketat 2007).

To avoid this temptation, archaeologists often have turned to adopting and adapting models from other disciplines - similar to the application of WST or SNA to archaeological questions. For example, Michael Smith (201rb:595), suggests that art history may offer useful methods and concepts that can be applied in archaeological research. A number of scholars in this field have developed ways of thinking about issues of interest to the archaeological study of interaction (e.g., Baxandall 1985; Kubler 1962; Panofsky 1955; Pasztory 1989, among others). This is particularly true in terms of the consideration of shared styles and/or symbolic content as both indexical and specifically indicative of intercultural exchange (despite inherent difficulties in the empirical quantification of such aspects). Further, contemporary art history is decidedly materialist in focus (e.g., Klein 1982; Morphy 2010; Yonan 20II). Finally, researchers in art history regularly treat episodes of interaction, particularly in studies that consider non-Western and pre-Columbian foci.

Likewise, linguistics provides a number of conceptual models that may be profitably applied in archaeology. Indeed, there is a long history of examining archaeological and linguistic correlations in the material record (e.g., Beekman and Christensen 2003; Bellwood 1979, 2001; Bellwood and Renfrew 2002; Kaufman 1976; Josserand 1975; Josserand and Hopkins 1999; Renfrew 1987). Nonetheless, as Kerry M. Hull (chapter 4 in this volume) notes, like archaeological data, linguistic evidence is rarely complete or conclusive, and the two data sets often contradict each other. Further, archaeologists rarely adopt or integrate linguistic models into their own theoretical conceptualizations of interaction-or at the least, the actual use of linguistic methodologies in archaeology is quite limited. ${ }^{8}$ Rather, researchers generally prefer to marshal linguistic evidence that supports archaeological claims (or vice versa). In this sense, true intersections of interdisciplinary models are not as common as one might hope or expect. ${ }^{9}$ One could be forgiven for thinking that archaeological calls to consider theoretical models from other disciplines is not unlike archaeologists' complaints regarding typologies: we pay lip service to the inherent limitations of our current conceptual toolkit, yet we continue to employ the very models that we recognize as flawed. These considerations are intensely personal for us, insofar as our own research is located at the intersection of archaeology and art history. Moreover, as we suggest in chapter 3, the adoption of linguistic terminology (see Haspelmath 2009; Haspelmath and Tadmor 2009) and conceptions of interaction may clarify several problematical issues that arise in archaeological treatments of the subject. 
Finally, we would like to add a note regarding the archaeometric techniques that are often employed to infer interaction-for example, on the basis of a common source for objects or their constituent materials found in geographically distinct locations (e.g., Blomster et al. 2005; Cheetham 2007, 2010; Cheetham et al. 2009). There is no doubt that archaeometric methods have contributed substantially to archaeological research, particularly in terms of empirically grounding interpretive inferences. Although archaeometry is a fundamental tool for gaining a fine-grain understanding of material relationships, it cannot in itself account for or explain the interaction that its techniques assist in identifying. Additionally, archaeometric studies are often particularly prone to overlooking the broader sociocultural processes of which such interaction was a part (the investigations cited above are notable exceptions). This critique is related to the broader difficulty noted previously regarding the study of interaction itself: we risk converting the description of a phenomenon, however detailed, into the explanation of that phenomenon.

In the end, models that assist in explaining interaction in the past wind up doing very similar things in the majority of cases. A given model-be it based on WST, SNA, trade, migration, or something else-may be capable of explaining relationships (or mechanisms of interaction) more robustly than another in a specific context. Nevertheless, we would argue that there is no single, unified theory (or model) capable of explaining interaction in all contexts. Monolithic theoretical models that depart from a normative position (e.g., classical economics) or assume the smoothness of human interaction will ultimately fall short in their total explanatory power, precisely because distinct modes of interaction operate in different ways and for discrete purposes, and leave behind variable material traces. Ultimately, however, all approaches must eventually account for that fact that in a given case feature A may be found earlier in culture $\mathrm{X}$ than in culture Y (or region, site, etc.). Treatments must also be able to describe and explain the significance of this fact in terms of the individual behaviors and sociocultural processes at play in societies in the past. In terms of this volume, the majority of chapters are perhaps less concerned with the specific mechanisms by which interaction took place, and more focused on the processual outcomes of such interaction, its material manifestations, and its relationship to wider sociocultural dynamics. In this sense, all strive to contribute to a broader discussion on interaction in the Mesoamerican past, in order to improve extant models and conceptualizations. We hold that it is only via critical, integrative approaches that researchers can aspire to particular and total description and explanation of archaeological phenomena. 


\section{STRUCTURE AND ORGANIZATION OF THIS VOLUME}

Spanning the geographic and temporal extent of Mesoamerica, the chapters in this volume critically interrogate the above issues as well as many others. The contributions treat various historical episodes of interaction, and they marshal a wealth of information of different kinds in their analyses. Individually, the contributions advance the study of Mesoamerican cultural dynamics beyond strictly archaeological approaches. Each of the chapters raises significant questions about the ways in which interregional interaction and sociocultural structure simultaneously constrain and enable one another. In doing so, contributors provide insight into how sociopolitical, ritual-religious, economic, and other culturally constructed institutions fed into ancient systems of interregional interaction and many times were themselves created by such interaction. As a group, they provide a holistic approach to the study of interaction and cultural dynamics, exploring the strong conceptual ties between these intimately related processes. By juxtaposing various lines of evidence and distinct methodological approaches, the chapters move beyond monolithic or singular emphases. Thus, the volume seeks to achieve a multidimensional perspective, allowing for a rich understanding of the larger cultural systems that at once reflected interregional interaction and produced cultural meaning in ancient Mesoamerica.

To achieve this goal, contributors critically examine specific case studies that highlight the interactive and integrated nature of the region and its cultures. The chapters build on and amplify earlier research to engage such sociocultural phenomena as movement, migration, symbolic exchange, linguistic borrowing, scribal practices, trade systems, and material interaction in their role as catalysts for variability in cultural systems. Individual chapters adopt interdisciplinary treatments of interregional interaction, presenting a variety of case studies drawn from multiple spatial, temporal, and cultural contexts, including previously understudied regions and temporal periods, such as northwestern Mesoamerica and the "initial" Early Formative period (ca. 2000-1500 BC). Contributors combine perspectives and methodologies from diverse fields of study to further scholarly understanding of the role of interregional interaction in the creation of cultural paradigms, artistic production, systems of material and economic exchange, shared ritual-religious practices and belief systems, technological development and change, linguistic evolution, and specific human activities and agentive decisions in the Mesoamerican past.

The volume is comprised of fourteen chapters, including the introduction and conclusion. Individual chapters treat the primary topic of interregional interaction and cultural dynamics on various scales, ranging from panregional (chapters I-3), macroregional (chapters 4-6; 9; II-I2), to microregional or site-specific (chapters $7-8 ;$ I0). These fourteen chapters examine in multiple ways and at several 
interconnected degrees the dynamic cultural processes that contributed to the development of Mesoamerica as a complex whole throughout its history, as well as the developmental trajectories and dynamic sociocultural processes at play in its various constituent cultures. In addition to scalar variability, chapters examine diverse indicators of interregional interaction, and vary in their approaches and evidentiary focus. Primary data sets examined include ceramics (chapters 2, 5), scribal practices (chapter 3), linguistics (chapter 4), iconography and symbolism (chapters 6-7, 10), obsidian and lithics (chapter 8), settlement patterns (chapter 9), and metals (chapter iI). Methodological treatments range from "traditional" archaeological analyses (chapters 7,9 ) to art historical (chapters 5-6), linguistic (chapter 4 ), and archaeometric (chapter 8) techniques, as well as multidimensional, crossdisciplinary analytic methods that examine a combination of data sets within variable interpretive frameworks (chapters 2-3, IO-II).

Due to the diverse nature of the individual contributions, chapters are arranged in rough chronological order based on their primary temporal focus, progressing through the Formative (2000 BC-AD 250; chapters 2-4), Classic (AD 250-950; chapters 5-8), and Postclassic (AD 950-I52I; chapters 9-II) periods-though overlaps and diverse temporal foci are evident in some chapters (e.g., 4, 7, 9). Finally, chapters I and I2, by Gary M. Feinman and Joyce Marcus, respectively, are slightly more theoretical in nature, and thus serve-along with this introduction and David Freidel's conclusions-to bind together a complex discussion and diverse perspectives into a coherent whole.

As editors, we have designed the volume so that each contributor offers a unique methodological approach to interaction or investigates particular temporal or spatial foci. We have further tried to balance specific case studies against the theoretical discussion of diverse and heterogeneous processes that underlie interaction and exchange. We simultaneously seek to emphasize the diversity of approaches to the range of data presented in individual contributions while underscoring points of commonality among the chapters. In this sense, one may conceive of the studies collected here as distinct voices in an ongoing dialogue among the contributors, with individual chapters at once standing alone and complementing each other.

\section{CONCLUDING THOUGHTS}

No single volume can possibly account for or offer definitive conclusions to the critical queries that continue to surround the archaeological study on interaction and its relationships with dynamic cultural processes. It is precisely because of the complex and polymorphic nature of interaction that in this volume we bring together a diverse set of perspectives to contemplate core questions regarding interaction and 
to highlight the need for a multidisciplinary approach to the subject. We believe that through this synergy we can begin to capture some of the complexity that archaeologists and researchers in kindred disciplines confront when researching interregional interaction. Moreover, we view such a conjunctive approach as more informative and insightful than looking at any one context in detail or focusing on a specific data set from a single methodological perspective. This is because a holistic, interdisciplinary approach and the application of transdisciplinary methods to multidimensional data sets bring to light new data, methodologies, and perspectives that contribute to contemporary academic debate. By providing a greater range of empirical data and offering novel conceptualizations of fundamental issues, integrating approaches provoke pertinent questions and have the potential to refine current theoretical models that relate interregional interaction with cultural processes in variable contexts. Researchers are thus better equipped to create explanations that more faithfully reflect culturally, spatially, or temporally specific configurations, modes, and dynamics in patterns of interaction. We therefore contend that the adoption of such an approach not only makes this volume unique, but also complements previous treatments.

Further, the critical reassessment of previous models and commonly held assumptions raises theoretically important questions that go beyond typical archaeological treatments of the effects of interaction. Such questions focus attention on the construction, negotiation, and transformation of cultural identity, ethnicity, individual agency, the continuity of regional traditions, and shared geographic and cultural spaces. For example, do distinct forms and modes of intercultural exchange (e.g., reciprocal or unidirectional) have similar effects across contexts, or are outcomes contingent on historical-cultural particulars? How can we reconcile the cultural mapping of Mesoamerica, which usually depicts clear demarcations of linguistic and/or ethnic divisions, with the evident overlap in spheres of interaction and shared traits? How did geographic and ecological diversity facilitate interregional interaction and/or pan-Mesoamerican culture, and how does this factor in to considerations of cultural dynamics at distinct scales?

In this volume, neither we nor the contributors pretend to respond definitively to these queries. However, the dialogue contained herein greatly assists in thinking through these issues, offering new directions, and creating a nuanced understanding of the role of interaction and its interface with dynamic cultural processes in preColumbian societies. For example, Timothy J. Knab and John M. D. Pohl's analysis (chapter Io) of the motivations behind interregional exchange, in terms of the rotating power structures that they identify in contemporary and prehispanic Cholula, contributes to a greater understanding of how agents employed interaction to forge communal identities in shared cultural spaces. Their chapter also questions 
traditional models of Mexica hegemony in the Postclassic Mesoamerican world, suggesting that forms and modes of interaction are indeed contextually contingent. Marcus reaches a similar conclusion regarding contingency in her examination of distinct modes of interaction in two regions. In addition, Marcus further contextualizes the role of interaction in localized power competitions, highlighting the transformative potential of competitive interaction at the local scale-a capacity often overlooked in traditional explanations that privilege unidirectional, extraregional exchange. Charles L. F. Knight's (chapter 8) treatment of obsidian exchange involving the site of Cantona similarly interrogates questions of hegemony and unidirectionality in considerations of interaction. His analysis-like those of D. Bryan Schaeffer (chapter 5), Philip J. Arnold III and Lourdes Budar (chapter 7), and Jesper Nielsen et al. (chapter 6)-contributes to a fuller understanding of Classic period webs of interaction and regional traditions. These authors make clear that cultural exchange between southeastern and central Mesoamerica at this time was far more complex and dynamic than many have previously considered, involving numerous independent polities beyond the umbra and gravitational pull of Teotihuacan and/ or the Maya lowlands.

On the other hand, the chapter by Kerry M. Hull, as well as our own contribution, places in relief the difficulties inherent in the mapping of archaeological cultures. Although the circumscription of such cultures is often clearly demarcated on maps, the linguistic and art historical analyses presented in these chapters reveal new data that highlight overlapping interaction spheres and add to scholarly interpretations of, for example, "Olmec" influence throughout the region. Moreover, our chapter offers suggestions for a new analytic vocabulary, based on linguistic terminology, which has the potential to add precision to archaeological conceptualizations of interaction. Finally, Guy David Hepp's chapter 2 introduces new evidence on the Early Formative period in coastal Oaxaca, providing much-needed data that speaks to the Archaic-Formative period transition. His analysis of exchange relationships involving the site of La Consentida not only carries significant implications for the development of the Red-on-Buff ceramic horizon, but also sheds light on the origins of cultural and linguistic divides between Otomanguean and Mije-Soke groups. Hepp's chapter thus illuminates multiple issues that complement both other chapters and previous studies, including those related to cultural mapping, interaction spheres, and the scale and directionality of interregional interaction during a crucial yet understudied transitional period in Mesoamerican history.

These are but a few examples of the insights and new understandings that emerge from the conjunctive, interdisciplinary perspectives espoused in this volume. Each author marshals different types of evidence and theoretical approaches, and all provide a unique perspective in the dialogue surrounding the relationships between 
interaction and cultural dynamics, as well as the place of interaction studies in archaeological investigation. The common thread that serves to bind together the disparate chapters and foci presented in this volume is that all authors seek to question traditional conceptions and models of interaction in a wealth of discrete Mesoamerican contexts. The fact that individual contributions are not explicitly limited to a single spatial or temporal context or specific case study-and that many chapters explore regions and/or temporal contexts infrequently treated in previous investigations-enhances this critical interrogation by expanding its scope and providing new comparative data that feed into improved theoretical models. Indeed, the integrative approach advanced here underlines the need to create new conceptual models capable of further elucidating the complex, multifaceted relationship between interaction and cultural processes in the contexts of any number of ancient societies. Thus, building on received scholarship regarding interaction and sociocultural process, this volume seeks to contribute to contemporary debate by placing in relief multiple contexts, bringing to light new evidence, and offering novel approaches that may be applied in cross-cultural perspectives to improve understanding of a phenomenon that remains of great archaeological interest, in pre-Columbian Mesoamerica and beyond.

\section{NOTES}

I. Of course, demonstrating these patterns is an important step in the research process-as long as identification is not conflated with explanation of the phenomena.

2. It is, however, difficult to completely discredit the notion of causality, although this may be due to terminological confusion or the conflation of "causality" with "correlation."

3. This is especially cogent given the insight now provided by genetic research that in many instances clearly indicates migration events.

4. For example, the explanation of similar suites of material culture on Crete and mainland Greece in the Late Bronze Age (see, e.g., Matthäus 1980; Wright 2006; cf. Bouzek 1996; Dickinson 1996). At its heart, as Voutsaki (1999) notes, such an explanation boils down to a nebulous "diffused Minoan influence." In Mesoamerica, a similar problematical is evident in discussions of Teotihuacan "influence" throughout the Early Classic period. That is, the appearance of talud-tablero architecture or the tripod vessel form is often viewed as unilaterally indicative of a specifically "Teotihuacan" or a more nebulous "Central Mexican" presence and influence in the Early Classic period Maya lowlands and elsewhere (e.g., Ball 1983; Bove 1990; Cheek 1977; Demarest and Foias 1993; Sanders 1977; cf. Bove and Medrano 2003; Braswell 2003b; McKillop 2004:182-186; Pendergast 2003).

5. Although it may appear that this conception falls in line with our view of interaction as both cause and effect of higher-order dynamics, in truth Renfrew's position, in our 
reading, is more aligned with the causal-functional perspective, insofar as it conceives of the materialized (or institutionalized) trade network itself as a cause, be it proximate or ultimate.

6. Some readers may interpret this critique as somehow antithetical to cross-cultural comparison. We would take issue with such a reading, since we argue throughout that such comparison is at the heart of anthropological archaeology. However, such comparisons must be based on a culturally relative, anthropological understanding of the data on their own terms-not on contemporary or formalist perceptions of what constitutes, for example, a "market" or "mercantile system." That is, generalizing, top-down approaches to archaeological explanation do offer more comparative potential, but scholars must not lose sight of individual developments that are unique to particular sociocultural contexts, since such variable historical particularities are also a core focus of anthropological archaeology. Thus, if archaeologists seek to offer interpretations specific to the societies under investigation, it seems reasonable to at least try to develop an emic model before imposing more generalizable comparative categories based on debatable criteria.

7. Indeed, one might consider prestige goods theory itself as a type of Social Network Analysis.

8. That archaeologists use linguistic models for migration to support explanations for changes in material culture (see, e.g., Renfrew 1987) is not the same as truly integrating or using linguistic models or methods.

9. Although Smith (20rib:595) gives a nod to the possibility, he ultimately admits that a full consideration of the potentialities of art historical models in archaeological studies of style and interaction are "beyond the scope" of his chapter.

\section{REFERENCES}

Alexander, Rani T. 1999. “The Emerging World System and Colonial Yucatan: The Archaeology of Core-Periphery Integration, 1780-1847." In World-Systems Theory in Practice: Leadership, Production, and Exchange, edited by P. Nick Kardulias, 103-I24. AltaMira Press, Lanham, MD.

Algaze, Guillermo. 1993. The Uruk World System: The Dynamics of Early Mesopotamian Civilization. University of Chicago Press, Chicago.

Altschul, Jeffrey H. 1978. “The Development of the Chacoan Interaction Sphere.” Journal of Anthropological Research 34(I):109-I46.

Anthony, David W. 1990. "Migration in Archeology: The Baby and the Bathwater." American Anthropologist 92(4):895-914.

Anthony, David W. 1992. “The Bath Refilled: Migration in Archeology Again.” American Anthropologist 94(I):174-176. 
Anthony, David W. 1997. "Prehistoric Migration as Social Process." In Migrations and Invasions in Archaeological Explanation, edited by John Chapman and Helena Hamerow, 21-32. BAR International Series 664. Archaeopress, Oxford.

Anthony, David W. 2010. The Horse, the Wheel, and Language: How Bronze-Age Riders from the Eurasian Steppes Shaped the Modern World. Princeton University Press, Princeton.

Bain, Read. 1932. “The Concept of Social Process.” Publications of the American Sociological Society 27:10-I8.

Ball, Joseph W. 1983. “Teotihuacan, the Maya, and Ceramic Interchange: A Contextual Perspective." In Highland-Lowland Interaction in Mesoamerica: Interdisciplinary Approaches, edited by Arthur G. Miller, I25-145. Dumbarton Oaks, Washington, DC.

Baxandall, Michael. 1985. Patterns of Intention: On the Historical Explanation of Pictures. Yale University Press, New Haven.

Beekman, Christopher S., and Alexander F. Christensen. 2003. "Controlling for Doubt and Uncertainty through Multiple Lines of Evidence: A New Look at the Mesoamerican Nahua Migrations." Journal of Archaeological Method and Theory Io(2):III-I64.

Bellwood, Peter S. 1979. Man's Conquest of the Pacific: The Prehistory of Southeast Asia and Oceania. Oxford University Press, Oxford.

Bellwood, Peter S. 200r. "Early Agriculturalist Population Diasporas? Farming, Languages and Genes." Annual Review of Anthropology 30:181-207.

Bellwood, Peter S., and Colin Renfrew, eds. 2002. Examining the Farming/Language Dispersal Hypothesis. McDonald Institute monographs, McDonald Institute for Archaeological Research, Cambridge.

Berdan, Frances F. 1988. "Principles of Regional and Long-Distance Trade in the Aztec Empire." In Smoke and Mist: Mesoamerican Studies in Memory of Thelma D. Sullivan, edited by J. Kathryn Josserand and Karin Dakin, 639-656. British Archaeological Reports, International Series, no. 402. Archaeopress, Oxford.

Berdan, Frances F., Richard E. Blanton, Elizabeth H. Boone, Mary G. Hodge, Michael E. Smith, and Emily Umberger, eds. 1996. Aztec Imperial Strategies. Dumbarton Oaks, Washington, DC.

Blanton, Richard, and Gary M. Feinman. 1984. “The Mesoamerican World System.” American Anthropologist 86(3):673-682.

Blanton, Richard E., Gary M. Feinman, Stephen A. Kowalewski, and Peter N. Peregrine. 1996. "A Dual-Processual Theory for the Evolution of Mesoamerican Civilization." Current Anthropology 37(I):I-I4.

Blomster, Jeffrey P., Hector Neff, and Michael D. Glascock. 2005. "Olmec Pottery Production and Export in Ancient Mexico Determined through Elemental Analysis." Science 307(5712):1068-1072. 
Bouzek, Jan. 1996. "Mycenaean Greece and Minoan Crete: The Problem of Migrations." Cretan Studies 5:85-90.

Bove, Frederick J. 1990. “The Teotihuacan-Kaminaljuyu-Tikal Connection: A View from the South Coast of Guatemala." In The Sixth Palenque Round Table Ig86, edited by Merle G. Robertson and Virginia M. Fields, I35-I42. University of Oklahoma Press, Norman.

Bove, Frederick J., and Sonia Medrano Busto. 2003. “Teotihuacan, Militarism, and Pacific Guatemala." In The Maya and Teotihuacan: Reinterpreting Early Classic Interaction, edited by Geoffrey E. Braswell, 45-80. University of Texas Press, Austin.

Braswell, Geoffrey E., ed. 2003a. The Maya and Teotihuacan: Reinterpreting Early Classic Interaction. University of Texas Press, Austin.

Braswell, Geoffrey E. 2003b. "Understanding Early Classic Interaction between Kaminaljuyu and Central Mexico." In The Maya and Teotihuacan: Reinterpreting Early Classic Interaction, edited by Geoffrey E. Braswell, IO5-I42. University of Texas Press, Austin.

Brughmans, Tom. 2013. “Thinking through Networks: A Review of Formal Network Methods in Archaeology." Journal of Archaeological Method and Theory 20(4):623-662.

Burmeister, Stefan. 2000. "Archaeology and Migration: Approaches to an Archaeological Proof of Migration." Current Anthropology 4I(4):539-567.

Caldwell, Joseph R. 1964. “Interaction Spheres in Prehistory.” Illinois State Museum Scientific Papers I2(6):133-193.

Cameron, Catherine M. 1995. "Migration and the Movement of Southwestern Peoples." Journal of Anthropological Archaeology I4(2):104-I24.

Campbell, Lyle R., and Terrence S. Kaufman. 1976. "A Linguistic Look at the Olmecs." American Antiquity 4I(I):80-89.

Champion, Timothy. 1990. “Migration Revived.” Journal of Danish Archaeology 9:214-218. Chapman, John, and Helena Hamerow. 1997. "On the Move Again: Migrations and Invasions in Archaeological Explanation." In Migrations and Invasions in Archaeological Explanation, edited by John Chapman and Helena Hamerow, I-IO. BAR International Series 664. Archaeopress, Oxford.

Chase-Dunn, Christopher K., and Thomas D. Hall. 1991. Core/Periphery Relations in Precapitalist Worlds. Westview Press, Boulder.

Cheek, Charles D. 1977. “Teotihuacan Influence at Kaminaljuyu.” In Teotihuacan and Kaminaljuyu, edited by William T. Sanders and Joseph W. Michels, 44I-452. Pennsylvania State University Press, State College.

Cheetham, David. 2007. Cantón Corralito: Objects from a Possible Gulf Olmec Colony. FAMSI, Crystal River, FL.

Cheetham, David. 2010. "Cultural Imperatives in Clay: Early Olmec Carved Pottery from San Lorenzo and Cantón Corralito." Ancient Mesoamerica 2I(I):I65-185. 
Cheetham, David, Susana E. Gonzalez, Richard J. Behl, Michael D. Coe, Richard A. Diehl, and Hector Neff. 2009. "Petrographic Analyses of Early Formative Olmec Carved Pottery." Mexicon 3I(3):69-72.

Cherry, John F. 1986. "Polities and Palaces." In Peer Polity Interaction and Socio-Political Change, edited by Colin Renfrew and John F. Cherry, 19-45. Cambridge University Press, Cambridge.

Clark, John E. 2004. "The Birth of Mesoamerican Metaphysics: Sedentism, Engagement, and Moral Superiority." In Rethinking Materiality: The Engagement of Mind with the Material World, edited by Elizabeth DeMarrais, Christopher Gosden, and Colin Renfrew, 205-224. McDonald Institute Monographs, McDonald Institute for Archaeological Research, Cambridge.

Clark, John E., and Michael Blake. 1994. "The Power of Prestige: Competitive Generosity and the Emergence of Rank Societies in Lowland Mesoamerica." In Factional Competition and Political Development in the New World, edited by Elizabeth M. Brumfiel and James W. Fox, 17-30. Cambridge University Press, Cambridge.

Clark, John E., and Thomas A. Lee Jr. 1984. "Formative Obsidian Exchange and the Emergence of Public Economies in Chiapas, Mexico." In Trade and Exchange in Early Mesoamerica, edited by Kenneth G. Hirth, 235-274. University of New Mexico Press, Albuquerque.

Clarke, David L. 1973. "Archaeology: The Loss of Innocence." Antiquity 47(I85):6-18.

Demarest, Arthur A. 1989. "The Olmec and the Rise of Civilization in Eastern Mesoamerica." In Regional Perspectives on the Olmec, edited by Robert J. Sharer and David C. Grove, 303-344. National Gallery of Art, Washington, DC.

Demarest, Arthur A., and Antonia E. Foias. 1993. "Mesoamerican Horizons and the Cultural Transformations of Maya Civilization.” In Latin American Horizons, edited by Don S. Rice, I47-191. Dumbarton Oaks, Washington, DC.

Dickinson, Oliver T. P. K. 1996. "Minoans in Mainland Greece, Mycenaeans in Crete?" Cretan Studies 5:63-7I.

Ebert, Claire, E. M. Dennison, Kenneth G. Hirth, Sarah B. McClure, and Douglas J. Kennett. 2015. "Formative Period Obsidian Exchange along the Pacific Coast of Mesoamerica." Archaeometry 57(SI):54-73.

Feinman, Gary M. 1999. “The Changing Structure of Macroregional Mesoamerica: The Classic-Postclassic Transition in the Valley of Oaxaca." In World-Systems Theory in Practice: Leadership, Production, and Exchange, edited by P. Nick Kardulias, 53-62. AltaMira Press, Lanham, MD.

Flannery, Kent V. 1968. “The Olmec and the Valley of Oaxaca: A Model for Interregional Interaction in Formative Times." In Dumbarton Oaks Conference on the Olmec, edited by Elizabeth P. Benson, 79-117. Dumbarton Oaks, Washington, DC. 
Flannery, Kent V., and Joyce Marcus. 2000. "Formative Mexican Chiefdoms and the Myth of the 'Mother Culture." Journal of Anthropological Archaeology I9(I):I-37.

Frank, Andre G. 1993. "Bronze Age World System Cycles." Current Anthropology $34(4): 383-429$.

Freidel, David A. 1979. "Culture Areas and Interaction Spheres: Contrasting Approaches to the Emergence of Civilization in the Maya Lowlands." American Antiquity 44(I):36-54.

Garraty, Christopher P., and Barbara L. Stark, eds. 2015. Archaeological Approaches to Market Exchange in Ancient Societies. University Press of Colorado, Boulder.

Goldstein, Paul S. 2000. "Exotic Goods and Everyday Chiefs: Long-Distance Exchange and Indigenous Sociopolitical Development in the South Central Andes." Latin American Antiquity II (4):335-36I.

Golitko, Mark, and Gary M. Feinman. 2015. "Procurement and Distribution of PreHispanic Mesoamerican Obsidian 900 B C-AD 1520: A Social Network Analysis." Journal of Archaeological Method and Theory 22(I):206-247.

Gómez Chávez, Sergio, and Michael W. Spence. 2012. "Interaction among the Complex Societies of Classic-Period Mesoamerica." In The Oxford Handbook of Mesoamerican Archaeology, edited by Deborah L. Nichols. Oxford University Press, Oxford.

Grove, David C. 1993. “'Olmec' Horizons in Formative Period Mesoamerica: Diffusion or Social Evolution?” In Latin American Horizons, edited by Don S. Rice, 83-III. Dumbarton Oaks, Washington, DC.

Hall, Thomas D., and Christopher K. Chase-Dunn. 1993. "The World-Systems Perspective and Archaeology: Forward into the Past.” Journal of Archaeological Research I(2):I2I-I43.

Härke, Heinrich. 1998. “Archaeologists and Migrations: A Problem of Attitude?" Current Anthropology 39(I):19-45.

Haspelmath, Martin. 2009. "Lexical Borrowing: Concepts and Issues." In Loanwords in the World's Languages: A Comparative Handbook, edited by Martin Haspelmath and Uri Tadmor, 35-54. Mouton de Gruyter, Berlin.

Haspelmath, Martin, and Uri Tadmor, eds. 2009. Lexical Borrowing in Cross-Linguistic Perspective. Mouton de Gruyter, Berlin.

Hayden, Brian. 1998. "Practical and Prestige Technologies: The Evolution of Material Systems." Journal of Archaeological Method and Theory 5(I):I-55.

Helms, Mary. 1993. Craft and the Kingly Ideal: Art, Trade, and Power. University of Texas Press, Austin.

Helms, Mary. 1994. "Chiefdom Rivalries, Control, and External Contacts in Lower Central America." In Factional Competition and Political Development in the New World, edited by Elizabeth M. Brumfiel and James W. Fox, 55-60. Cambridge University Press, Cambridge. 
Henrich, Joseph, and Francisco J. Gil-White. 200r. "The Evolution of Prestige: Freely Conferred Deference as a Mechanism for Enhancing the Benefits of Cultural Transmission." Evolution and Human Behavior 22(3):165-196.

Hirth, Kenneth G., and Joanne Pillsbury, eds. 2013. Merchants, Markets, and Exchange in the Pre-Columbian World. Dumbarton Oaks, Washington, DC.

Hodder, Ian. 1987. “The Contribution of the Long Term." In Archaeology as Long-Term History, edited by Ian Hodder, I-8. Cambridge University Press, Cambridge.

Hume, David. 1999. An Enquiry Concerning Human Understanding, edited by Tom L. Beauchamp. Oxford University Press, Oxford.

Josserand, J. Kathryn. 1975. "Archaeological and Linguistic Correlations for Mayan Prehistory." In Actas del XL Congreso Internacional de Americanistas, 501-510. Instituto Nacional de Antropología e Historia, Mexico City.

Josserand, J. Kathryn, and Nicholas A. Hopkins. 1999. "Classic Maya Social Interaction and Linguistic Practice: Evidence from Hieroglyphic Inscriptions and Mayan Languages." Paper presented at the 1999 Palenque Round Table, Palenque.

Justeson, John S., William M. Norman, Lyle R. Campbell, and Terrence S. Kaufman. 1985. The Foreign Impact on Lowland Mayan Language and Script. Middle American Research Institute Publication 53. Tulane University, New Orleans.

Kardulias, P. Nick, and Thomas D. Hall. 2008. "Archaeology and World-Systems Analysis." World Archaeology 40(4):572-583.

Kaufman, Terrence S. 1976. "Archaeological and Linguistic Correlations in Mayaland and Associated Areas of Mesoamerica." World Archaeology 8(I):IOI-II 8.

Kepecs, Susan, Gary M. Feinman, and Sylviane Boucher. 1994. "Chichen Itza and Its Hinterland: A World-Systems Perspective.” Ancient Mesoamerica 5(2):141-158.

Kepecs, Susan, and Philip L. Kohl. 2003. "Conceptualizing Macroregional Interaction: World-Systems Theory and the Archaeological Record." In The Postclassic Mesoamerican World, edited by Michael E. Smith and Frances F. Berdan, I4-20. University of Utah Press, Salt Lake City.

Kirchhoff, Paul. 1943. "Mesoamerica." Acta Americana 1:92-107.

Klein, Cecilia F. 1982. "The Relation of Mesoamerican Art History to Archaeology in the United States." In Pre-Columbian Art History: Selected Readings, edited by Alana Cordy-Collins, I-6. Peak Publications, Palo Alto, CA.

Knappett, Carl, ed. 2013. Network Analysis in Archaeology: New Approaches to Regional Interaction. Oxford University Press, Oxford.

Kowalski, Jeff K., and Cynthia Kristan-Graham, eds. 20Ir. Twin Tollans: Chichén Itzá, Tula, and the Epiclassic to Early Postclassic Mesoamerican World. Dumbarton Oaks, Washington, DC. 
Kubler, George. 1962. The Shape of Time: Remarks on the History of Things. Yale University Press, New Haven.

Lesure, Richard G. 2004. "Shared Art Styles and Long-Distance Contact in Early Mesoamerica." In Mesoamerican Archaeology: Theory and Practice, edited by Julia A. Hendon and Rosemary A. Joyce, 73-96. Blackwell, Malden, MA.

Martin, Simon, and Nikolai Grube. 2000. "Chronicle of the Maya Kings and Queens: Deciphering the Dynasties of the Ancient Maya." Thames and Hudson, London.

Matthäus, Hartmut. 1980. "Minoan Influence on the Greek Mainland during the Sixteenth Century BC and the Origins of Mycenaean Civilization." In Minoan Foreign Relations at the Beginning of the Late Bronze Age, edited by Philip P. Betancourt, 37-44. Temple University Aegean Symposium 5. Temple University, Philadelphia.

McAnany, Patricia A., and E. Christian Wells. 2008. "Toward a Theory of Ritual Economy." In Dimensions of Ritual Economy, edited by E. Christian Wells and Patricia A. McAnany, I-16. Research in Economic Anthropology, vol. 27. JAI Press, Bingley, UK.

McKillop, Heather I. 2004. The Ancient Maya: New Perspectives. W. W. Norton and Co., New York.

Miller, Arthur G., ed. 1983. Highland-Lowland Interaction in Mesoamerica: Interdisciplinary Approaches. Dumbarton Oaks, Washington, DC.

Mills, Barbara J., Jeffrey J. Clark, Matthew A. Peeples, W. R. Haas Jr., John M. Roberts Jr., J. Brett Hill, Deborah L. Huntley, Lewis Borck, Ronald L. Breiger, Aaron Clauset, and M. Steven Shackley. 2013. "Transformation of Social Networks in the Late Prehispanic US Southwest." Proceedings of the National Academy of Sciences IIO(I5):5785-5790.

Morphy, Howard. 2010. “Art as Action, Art as Evidence." In The Oxford Handbook to Material Culture Studies, edited by Dan Hicks and Mary C. Beaudry, 265-290. Oxford University Press, Oxford.

Neitzel, Jill. 2000. "What Is a Regional System? Issues of Scale and Interaction in the Prehistoric Southwest." In The Archaeology of Regional Interaction: Religion, Warfare, and Exchange across the American Southwest and Beyond, edited by Michelle Hegmon, 25-40. University Press of Colorado, Boulder.

Nielsen, Jesper. 2006. "The Coming of the Torch: Observations on Teotihuacan Iconography in Early Classic Tikal.” In Maya Ethnicity: The Construction of Ethnic Identity from Preclassic to Modern Times, edited by Frauke Sachse, 19-30. Acta Mesoamericana, vol. 19. Verlag Anton Saurwein, Munich, Germany.

Panofsky, Erwin. 1955. "Iconography and Iconology: An Introduction to the Study of Renaissance Art." In Meaning in the Visual Arts, edited by Erwin Panofsky, 26-54. Doubleday, New York. 
Parkinson, William A. 2002. "Integration, Interaction, and Tribal 'Cycling': The Transition to the Copper Age on the Great Hungarian Plain." In The Archaeology of Tribal Societies, edited by William A. Parkinson, 391-438. International Monographs in Prehistory, Ann Arbor.

Pasztory, Esther. 1989. "Identity and Difference: The Uses and Meanings of Ethnic Styles." In Cultural Differentiation and Cultural Identity in the Visual Arts, edited by Susan J. Barnes and Walter S. Melion, I5-38. National Gallery of Art, Washington, DC.

Pauketat, Timothy R. 2007. Chiefdoms and Other Archaeological Delusions. AltaMira Press, Lanham, MD.

Pendergast, David M. 2003. “Teotihuacan at Altun Ha: Did It Make a Difference?” In The Maya and Teotihuacan: Reinterpreting Early Classic Interaction, edited by Geoffrey E. Braswell, 235-247. University of Texas Press, Austin.

Peregrine, Peter N., and Gary M. Feinman. 1996. Pre-Columbian World Systems. Prehistory Press, Madison.

Peterson, Christian, and Robert Drennan. 2003. "Communities, Settlements, Sites, and Surveys: Regional Scale Analysis of Prehistoric Human Interaction.” American Antiquity 70(I):5-30.

Pohl, John M. D. 2003a. "Creation Stories, Hero Cults, and Alliance Building: Confederacies of Central and Southern Mexico." In The Postclassic Mesoamerican World, edited by Michael E. Smith and Frances F. Berdan, 6I-66. University of Utah Press, Salt Lake City.

Pohl, John M. D. 2003b. "Royal Marriage and Confederacy Building among the Eastern Nahuas, Mixtes, and Zapotecs." In The Postclassic Mesoamerican World, edited by Michael E. Smith and Frances F. Berdan, 243-248. University of Utah Press, Salt Lake City.

Pohl, John M. D. 2003c. "Ritual and Iconographic Variability in Mixteca-Puebla Polychrome Pottery." In The Postclassic Mesoamerican World, edited by Michael E. Smith and Frances F. Berdan, 20I-206. University of Utah Press, Salt Lake City.

Pohl, John M. D., and Bruce E. Byland. 1994. “The Mixteca-Puebla Style and Early Postclassic Socio-Political Interaction." In Mixteca-Puebla: Discoveries and Research in Mesoamerican Art and Archaeology, edited by Henry B. Nicholson and Eloise Quiñones Keber, 189-199. Labyrinthos, Culver City, CA.

Polanyi, Karl. 1944. The Great Transformation: The Political and Economic Origins of Our Time. Beacon Press, Boston.

Pool, Christopher S. 1997. Olmec Archaeology and Early Mesoamerica. Cambridge University Press, Cambridge.

Possehl, Gregory L. 2007. "The Middle Asian Interaction Sphere: Trade and Contact in the 3rd Millennium в C." Expedition 49(I):40-42.

Renfrew, Colin. 1972. The Emergence of Civilisation: The Cyclades and the Aegean in the Third Millennium BC. Methuen, London. 
Renfrew, Colin. 1977. "Alternative Models for Exchange and Spatial Distribution.” In Exchange Systems in Prehistory, edited by Timothy K. Earle and Jonathon E. Ericson, 71-90. Academic Press, New York.

Renfrew, Colin. 1987. Archaeology and Language: The Puzzle of Indo-European Origins. Cambridge University Press.

Renfrew, Colin. 200I. "Symbol before Concept: Material Engagement and the Early Development of Society." In Archaeological Theory Today, edited by Ian Hodder, I22-I4O. Polity, Oxford.

Rosenswig, Robert M. 2010. The Beginnings of Mesoamerican Civilization: Inter-Regional Interaction and the Olmec. Cambridge University Press, Cambridge.

Rouse, Irving. 1986. Migrations in Prehistory: Inferring Population Movement from Cultural Remains. Yale University Press, New Haven.

Sabloff, Jeremy A. 2008. "Considerations of Ritual Economy." In Dimensions of Ritual Economy, edited by E. Christian Wells and Patricia A. McAnany, 269-277. Research in Economic Anthropology, vol. 27. JAI Press, Bingley, UK.

Sanders, William T. 1977. "Ethnographic Analogy and the Teotihuacan Horizon Style." In Teotihuacan and Kaminaljuyu, edited by William T. Sanders and Joseph W. Michels, 397-410. Pennsylvania State University Press, State College.

Schortman, Edward M., and Patricia A. Urban, eds. 1992. Resources, Power, and Interregional Interaction. Springer, New York.

Schortman, Edwin M., and Patricia A. Urban. 1994. "Living on the Edge: Core/ Periphery Relations in Ancient Southeastern Mesoamerica." Current Anthropology $35(4): 40 \mathrm{I}-430$.

Schortman, Edwin M., and Patricia A. Urban. 1999. "Thoughts on the Periphery: The Ideological Consequences of Core/Periphery Relations." In World-Systems Theory in Practice: Leadership, Production, and Exchange, edited by P. Nick Kardulias, I25-152. AltaMira Press, Lanham, MD.

Scott, John. 2013. Social Network Analysis. 3rd ed. Sage, London.

Sinopoli, Carla M. 1994. “The Archaeology of Empires.” Annual Review of Anthropology 23:159-180.

Smith, Michael E. 1991. "Long-Distance Trade under the Aztec Empire: The Archaeological Evidence." Ancient Mesoamerica I (2):153-169.

Smith, Michael E. 2orra. The Aztecs. 3rd ed. Wiley-Blackwell, Oxford.

Smith, Michael E. 20rıb. “Tula and Chichén Itzá: Are We Asking the Right Questions?” In Twin Tollans: Chichén Itzá, Tula, and the Epiclassic to Early Postclassic Mesoamerican World, edited by Jeff K. Kowalski and Cynthia Kristan-Graham, 579-617. Dumbarton Oaks, Washington, DC. 
Smith, Michael E., and Frances F. Berdan, eds. 2003. The Postclassic Mesoamerican World. University of Utah Press, Salt Lake City.

Smith, Monica. 1999. “The Role of Ordinary Goods in Premodern Exchange.” Journal of Archaeological Method and Theory 6(2):109-132.

Stark, Miriam T., Jeffery J. Clark, and Mark D. Elson. 1995. "Causes and Consequences of Migration in the 13 th Century." Journal of Anthropological Archaeology $\mathrm{I} 4(2): 2 \mathrm{I} 2-246$.

Stein, Gil J. 1999. Rethinking World-Systems: Diasporas, Colonies, and Interaction in Uruk Mesopotamia. University of Arizona Press, Tucson.

Stein, Gil J. 2002. "From Passive Periphery to Active Agents: Emerging Perspectives in the Archaeology of Interregional Interaction." American Anthropologist I04(3):903-916.

Struever, Stuart. 1972. “The Hopewell Interaction Sphere in Riverine-Western Great Lakes Culture History.” In Contemporary Archaeology, edited by Mark P. Leone, 303-315. Southern Illinois University Press, Carbondale.

Stuart, David. 2000. “'The Arrival of Strangers': Teotihuacán and Tollan in Classic Maya History." In Mesoamerica's Classic Heritage: From Teotihuacán to the Aztecs, edited by Davíd Carrasco, Lindsay Jones, and Scott Sessions, 465-514. University Press of Colorado, Boulder.

Voutsaki, Sofia. 1999. "Mortuary Display, Prestige, and Identity in the Shaft Grave Era." In Eliten in der Bronzezeit: Ergebnisse zweier Kolloquien in Mainz und Athen, Vol. I, edited by Imma Kilian-Dirlmeier and M. Egg, IO3-II8. Romisch-Germanischen Zentralmuseums, Mainz, Germany.

Wallerstein, Immanuel. 1974. The Modern World-System I: Capitalist Agriculture and the Origins of the European World-Economy in the Sixteenth Century. Academic Press, New York.

Wallerstein, Immanuel. 2004. World-Systems Analysis: An Introduction. Duke University Press, Durham.

Wasserman, Stanley, and Katherine Faust. 1994. Social Network Analysis: Methods and Applications. Structural Analysis in the Social Sciences No. 8. Cambridge University Press, Cambridge.

Watanabe, John M. 2007. "Ritual Economy and the Negotiation of Autarky and Interdependence in a Ritual Mode of Production." In Mesoamerican Ritual Economy: Archaeological and Ethnological Perspectives, edited by E. Christian Wells and Karla L. Davis-Salazar, 301-322. University Press of Colorado, Boulder.

Wellman, Barry, and S. D. Berkowitz. 1988. Social Structures: A Network Approach. Cambridge University Press, Cambridge.

Wells, E. Christian. 2006. "Recent Trends in Theorizing Prehispanic Mesoamerican Economies." Journal of Archaeological Research I4(4):265-312. 
Wells, E. Christian, and Karla L. Davis-Salazar. 2007. "Mesoamerican Ritual Economy: Materialization as Ritual and Economic Process." In Mesoamerican Ritual Economy: Archaeological and Ethnological Perspectives, edited by E. Christian Wells and Karla L. Davis-Salazar, I-28. University Press of Colorado, Boulder.

Wichmann, Søren. 1995. The Relationship among the Mixe-Zoquean Languages of Mexico. University of Utah Press, Salt Lake City.

Wichmann, Søren. 1999. “A Conservative Look at Diffusion Involving Mixe-Zoquean Languages." In Archaeology and Language II: Archaeological Data and Linguistic Hypotheses, edited by Roger Blench and Matthew Spriggs, 297-323. Routledge, New York. Wolf, Eric R. 1982. Europe and the People without History. University of California Press, Berkeley.

Wright, James C. 2006. "The Formation of the Mycenaean Palace." In Ancient Greece: From the Mycenaean Palaces to the Age of Homer, edited by Sigrid Deger-Jalkotzy and Irene S. Lemos, 7-52. Edinburgh Leventis Studies 3. Edinburgh University Press, Edinburgh.

Yonan, Michael. 201. "Toward a Fusion of Art History and Material Culture Studies." West 86th: A Journal of Decorative Arts, Design History, and Material Culture I8(2):232-248.

Zborover, Danny. 2015. "From 'i-Eye' to Bruce Byland: Literate Societies and Integrative Approaches in Oaxaca." In Bridging the Gaps: Integrating Archaeology and History in Oaxaca, Mexico, edited by Danny Zborover and Peter Kroefges, I-54. University Press of Colorado, Boulder. 


\title{
Chapter 1
}

\section{The Prehispanic Mesoamerican World}

\author{
Framing Interaction
}

GARY M. FEINMAN

In many ways Mesoamerica is the most different of the world's early civilizations. It arose in a land where communication was exceptionally difficult and natural disaster was frequent; its occupants had a wealth of domestic plants but few domestic animals.

HenRY WRight (1989:99)

Scholarly interpretations of prehispanic Mesoamerican civilization are characterized by a paradox. On the one hand, as Wright's description highlights, the combination of a rugged topographic landscape and the absence of beasts of burden would seem to peg the Mesoamerican macroregion as the heartland of early civilization most apt to be characterized by intensively local patterns of interaction and limited broad-scale communication-a geographical realm where economic production was geared largely for immediate, proximate consumption, as John Clark (1986) proposed for obsidian blades at Teotihuacan. On the other hand, for the last century grand narratives regarding the prehispanic Mesoamerican past are ripe with inferences and debates over cross-continent, long-distance interconnections, including, but not limited to, the Olmec Horizon (e.g., Grove 1993), the relations between Tula and Chichén Itzá (e.g., Kowalski and Kristan-Graham 2007), the question of Mesoamerican links with the indigenous peoples of the southwestern United States (e.g., Mathien and McGuire 1986), the possible role of Teotihuacan in the rise of Classic Maya polities (Braswell [ed.] 2003), and the long-distance introduction of metalworking technology into Mesoamerica (e.g., Hosler 2003). 
Many of the aforementioned episodes of proposed long-distance ancient Mesoamerican interaction are reexamined in this volume, and new perspectives and data are brought to the fore in the chapters. My aim in this chapter is not to critique nor to review the component essays. Rather, I endeavor to frame and contextualize the examination of interaction in deep historical settings in which we rely heavily on the archaeological record (e.g., Shryock and Lord Smail 20II), with a principal focus on prehispanic Mesoamerica. Although I do not have concrete answers, my intent is to raise why, whither, and how questions. More precisely, why is the study of interaction important for understanding the ancient Mesoamerican world? Why is it necessary to investigate such processes? How significant a process was interaction, especially long-distance networks of interpersonal interconnection, over time and space? And how can we most productively position ourselves to examine patterns and modes of prehispanic interaction? Although long-distance networks of movement and communication seem to have been an important feature of the pre-Columbian Mesoamerican world, they have never been easy to document or convincingly interpret. Thus, as illustrated and debated across this collection, careful reconsideration and reframing of how we think about interaction are in order.

\section{WHY INVESTIGATE INTERACTION?}

As Joyce Marcus (chapter I2 in this volume) argues, long-distance interaction probably rarely can solely account (or be the prime mover) for the emergence of new local institutions, such as the rise of a state level of governance. Yet this recognition does not render the documentation and elucidation of different modes and intensities of interaction moot. For as Marcus outlines, "interaction comes in many forms: long-distance versus local, peaceful versus hostile, direct versus indirect, long-term versus short-term, multidirectional versus unidirectional, and transformative versus nontransformative," and it is the variation in these networks of communication, interpersonal relations, and economic transfers over time and space that yields a much fuller perspective on the nature of human histories and how they varied and changed. Human worlds "constitute a manifold, a totality of interconnected processes, and inquiries that disassemble this totality into bits and then fail to reassemble it falsify reality" (Wolf $1982: 3$ ).

Over the last decades-since Eric Wolf's (1982:6) metaphorical billiard ball analogy questioned the applicability of the primordial bounded cultural (ethnic) units typified by the construction of time-space grids of shared norms presumed by the culture historical approach (Flannery 1967; Trigger 1989:186-195) - archaeologists increasingly have recognized the importance of the relative openness of human social networks and macroregional-scale interactions for understanding ancient worlds (e.g., 
Blanton and Feinman 1984; Green and Perlman 1985; Hall et al. 2011; Sherratt 1993; M. L. Smith 2005, 2007). The recent advent and broad application of bioarchaeological and compositional analysis technologies, along with the implementation of social network approaches to archaeological data (Knappett 2013; Kristiansen 2014:19), have only strengthened the empirical foundation for the significance of ancient interaction. As we move forward, divergent and shifting patterns of interaction may yield important clues both for key changes in the balances of power across ancient worlds over time and for understanding major historical differences between global macroregions (e.g., Frankema 2015; Golitko and Feinman 2015; Turchin et al. 2006). Furthermore, the volume and modes of long-distance flows of people, materials, and information may have significant implications for regional-scale, and even more local, structures and relations (e.g., Chase-Dunn and Hall 1993; Willey 1999).

The investigation of the spatial correlates of past social and economic relations has the potentially useful effect of raising important research problems (e.g., Mills et al. 2013; Renfrew 1981). The definition of relevant networks over broad spatial ranges is significant, as a broadening body of research indicates that the position of people and institutions in established network structures affects the outcomes of interactions (e.g., Schortman 2014). That is, where and how a particular person or place is situated in a larger network of connections often is a key factor in the influence and subsequent history of that nodal individual, population, or location (e.g., Borgatti et al. 1998; Brughmans 2013).

\section{LONG-DISTANCE INTERACTION: PREHISPANIC MESOAMERICA}

A long-standing perspective on prehispanic Mesoamerica consistently framed this ancient world as one in which people tended to "stay at home" stymied by limited transport options and rugged landscapes (e.g., Sanders and Webster 1988:542-543; Webster 1985). From this vantage, local economic production was premised as basically the sole foundation of political power with longer-distance relations having only minimal importance, especially for the sizable nonelite segment of these populations. Of course, no one would argue the converse. Clearly, in ancient Mesoamerica, as in most preindustrial contexts, local production and social networks undoubtedly were primary in the great majority of historical cases. Yet, for prehispanic Mesoamerica, increasing bodies of evidence now can be marshaled to support the view that long-distance interactions could also be highly significant, and their relative importance varied over time and space (e.g., Blanton et al. 1996; Golitko and Feinman 2015).

Interactions over distance and cultural mobility were unquestionably a key aspect of the Late Postclassic (ca. AD I250-1520) Mesoamerican world (Smith and 
Berdan eds. 2003). Significant migrations (Beekman and Christensen 2003) have been evidenced, as well as the transmission of biological (Ragsdale and Edgar 2015), symbolic (Boone and Smith 2003; Pohl 2003; M. E. Smith 2003; Smith and HeathSmith 1980), and material (Berdan 2003; Berdan et al. 2003; Braswell 2003) information across the macroregion. In Mesoamerica, the Late Postclassic has long been seen as a time of increasing commercialization (Blanton and Fargher 2012; Blanton et al. 2005; Blanton and Feinman 1984; Kepecs 2003; Smith and Berdan 2000) and expanding market connections (Blanton 1996; Blanton and Fargher 2012), an interpretation that has been supported by a recent analysis of a large sample of sourced obsidian (Golitko and Feinman 2015), in which that era was judged to have greater connectivity than during any prior period in the prehispanic sequence.

Nevertheless, long-distance interactions, shared symbol and communication systems (Joshua D. Englehardt and Michael D. Carrasco, chapter 3 in this volume; Kerry M. Hull, chapter 4 in this volume), ritual practices, and even economic transfers through diverse modes of exchange (Guy David Hepp, chapter 2 in this volume; Charles L. F. Knight, chapter 8 in this volume; see also Blanton et al. 2005; Ebert et al. 2015; Hirth 2013), including marketplace exchange networks (Feinman and Nicholas 2010; Masson and Freidel 2013; Stark and Ossa 2010), began in the Mesoamerican world long before the Late Postclassic period. The long-distance movement of obsidian (Golitko and Feinman 2015) serves to document these interactive practices and processes, though the specific modes of transfer are more difficult to discern. At the same time, and perhaps unexpectedly, the findings of this analysis allow us (Golitko and Feinman 2015:227-232) to illustrate how variable these networks of interaction were over time.

For example, the principal routes between the Maya region (southeastern Mesoamerica) and the rest of the macroregion (western Mesoamerica) shifted several times from one coast to the other during the prehispanic period. Likewise, in a more recent study of sourced obsidian from Mesoamerica, my colleagues and I (Feinman et al. 2019) noted that whereas most of the obsidian that crossed between these two segments of Mesoamerica prior to the Early Classic period were moved from east (the Maya region) to west, the directionality of obsidian transfers shifted by the Classic period so that it was mainly obsidian from the Gulf, central Mexico, and Michoacán that moved to the east after that time (cf. Charles L. F. Knight, chapter 8 in this volume). These changes illustrate not only that ancient communities and their economies were neither entirely local nor static but that, given the utility and abundance of obsidian at most prehispanic Mesoamerican sites, shifts in long-distance networks and relations likely had important local political and demographic implications (e.g., Golitko et al. 2012). For example, given the importance of Aztec-era marketplaces in Mesoamerica (e.g., Blanton 1996), a key question is just how important and variable 
was this institution and the associated modes of transfer across time and space (e.g., Feinman and Garraty 2010; Garraty and Stark ed. 2010; King ed. 2015).

\section{EXAMINING INTERACTION: TOWARD MORE SYSTEMATIC APPROACHES}

With mounting evidence that human socioeconomic networks in the past generally were neither static nor tightly bounded (e.g., Golitko and Feinman 2015; M. L. Smith 2005), the examination and refinement of the nature, modes, and directionality of interactions that interconnected households, settlements, market systems, and polities across space become key analytical parameters for studying and explaining history and the diverse paths that it has taken. As Wolf (1982:ix) eloquently stated: "it was clear to me from the start that ... an analytic history could not be developed out of the study of a single culture or nation, a single culture area, or even a single continent at one period in time." Human populations construct their cultural practices through connectivity with others, and not in isolation.

Yet, for the distant past, empirically systematic and convincing elucidations of interaction have not always been easy to achieve. For one, almost by definition, examinations of interaction require the analysis of multiscalar sets of data, which often require lengthy, even multigenerational, episodes of study to amass. Another challenge is conceptual, as the archaeological study of interaction has been a key focus for researchers, who have approached the topic from a diversity of theoretical frames that often bring alternative interpretive logics to the relevant empirical/evidential records (Bauer and Agbe-Davies 2010:30-36; Emberling 2016; Schortman and Urban 1987). Given the broad array of cultural practices and behaviors that are encompassed by the term "interaction"; the consequent necessity to specify and refine the nature, timing, and directionality of these interconnections; and the broad suites of evidence that can be productively brought to bear to the study of these processes, I devote the remainder of this chapter to a discussion of four tenets intended to strengthen and synthesize how we document, specify, and interpret past patterns of interaction.

\section{Moving beyond Classification, Diffusion, and Traits}

Archaeological frames for the examination of interaction have their roots in a cultural historical paradigm focused principally on the classification of cultural traditions across geographic landscapes (e.g., Bauer and Agbe-Davies 2010:30-36; Jones 2008; Trigger 1984). Cultures were defined as relatively closed, spatially static, and largely homogeneous entities defined by a roster of traits. Although the potential for change was envisioned as potentially sparked by the introduction of new traits 
through migration or diffusion, the prime focus of the archaeological enterprise was the tracking of aggregated traits or other cultural styles or symbols over time and space. Subsequent archaeological perspectives have downplayed the classificatory aims of the earlier cultural historical approach toward the examination of internal processes of change; nevertheless they have continued to be grounded in the equation of sets of material traits and features with ethnic and cultural units that largely were presumed to be bounded, uniform, and mostly autonomous of other similar units. Wolf's (1982:6) "billiard balls" remained critical units of analysis despite shifts in problem focus.

Yet the presumption that in the past cultural or ethnic units were clearly bounded, largely homogeneous, and basically continuous in time, and so easily identifiable in the past is now in a practical sense untenable (e.g., Barth 1969; Green and Perlman 1985; Jones 1997, 2008:328-329; M. E. Smith 2007:59I-60I; M. L. Smith 2005). Such notions are poorly aligned with the historical record of human affiliation, while increasingly rich archaeological, architectural, and other relevant sets of information reveal far greater diversity (often rather continuous patterns of variation) and nuance in material assemblages over time and space, so that the definition of discrete, homogeneous units becomes harder to justify (e.g., Blanton 2015). Add to these challenges the wide array of practices subsumed under the rubric of interaction and the lack of explicit agreed-upon ways to discriminate these modes of interaction, and it becomes evident to me that we must analytically move beyond bottom-up recognitions of shared styles, symbols, and forms if we want to construct credible scenarios for past patterns of historical interaction. To do this requires the repositioning and examination of interaction and networks in a broader context, one that expands beyond conceptual foci on classification, isolated artifacts, traits, and diffusion. As Kristiansen (2014:19) asserts, "the theoretical and historical implications of this knowledge revolution will be profound, as it lifts the forces of historical change away from the local context onto a much larger geographical scale of multiple local interactions, creating a constant flux of connectivity and productivity without fixed boundaries."

\section{Relying on Multiple Evidentiary Sources With Focus on the More Definitive}

When we study the past, we can discern patterns of interaction using a wide array of empirical evidence. As archaeology tends to lack clear-cut interpretive formulae for deriving consensual sense of these data, reliance on a diversity of evidential sources to underpin inferred patterns of interaction (e.g., Lightfoot 1995:199) seems like a prudent, if not essential, step (as applied by many of the authors in this volume). 
Nevertheless, at least for the unraveling of economic networks, I see the most direct lines of argument through global advances that have been made in the sourcing of obsidian, metal, gemstones (such as turquoise and jade), building stone, and pottery. Such investigations yield relatively firm, even potentially quantifiable, measures of long-distance patterns of interaction. Archaeological compositional research-when taken in conjunction with targeted residue analyses (e.g., Crown and Hurst 2009), quantitative linguistic studies, and biodistance and ancient DNA approaches-provides investigators with analytical paths toward more convincing models of ancient interaction and networks that are now on the immediate horizon (e.g., Kristiansen 2014).

Analyses of stylistic parallels between sites and how they changed over time certainly can and should have a role in such investigations of interaction. Yet convincing use of such stylistic data requires consensually acknowledged means for their interpretation. At present, the inferential steps between the notation of stylistic parallels and specific modes of interaction are sketchy, perhaps even speculative, in many cases. A shift from bottom-up discussions of similar styles to the greater use of explicit top-down models that evaluate material similarities and dissimilarities in relation to alternative patterns of interaction (exchange, demographic mobility, military conquest) would seem to be a more explicit way to proceed, which also could easily integrate multiple lines of evidence (M. E. Smith 2007:595-596) as a basis to evaluate alternative working hypotheses (Chamberlin 1965).

\section{Framing Questions, Assessing Models}

Bottom-up comparisons of stylistic attributes are difficult to evaluate because the relationship to different modes of interaction are not straightforward to assess. But, in addition, as noted above, the relationship between material cultural style and cultural affiliation or identity is not transparent either (e.g., Jones 1997). As Michael Smith (2007:593) argues, "at our current state of knowledge, it is simply impossible to determine, a priori, the conditions that determine whether past ethnicity was expressed in material culture or not." Patterned variation in material culture can reflect ethnicity, but it also may signal other kinds of identity (status, gender, profession) or other kinds of sociopolitical factors that are not tied to identity at all. Furthermore, when we look at stylistic attributes, even judgments regarding what degree of similarity is meaningful are far from clear cut. Only through the crafting of explicit objective criteria for the comparison of material culture will scholars free our investigations from the morass of unverifiable, subjective interpretations.

The repertoire of available theoretical models for the examination of long-distance patterns of interaction is not entirely unflawed. Yet current conceptual approaches 
have far surpassed initial, albeit seminal, archaeological efforts at modeling interaction (e.g., Renfrew 1975). Current applications tend to be more sensitive to scale and, through multiple working hypotheses, better able to eclipse the problem of equifinality. Recent approaches have helped define and distinguish different patterns of conquest and imperialism (e.g., Costin 2011; Earle and Smith 2012; Nash and Williams 2004; Smith and Montiel 200I; Stark and Chance 20I2) as well as other kinds of macroscale politicoeconomic interdependencies (e.g., Blanton and Fargher 20I2; Blanton et al. 2005; Kepecs and Kohl 2003; M. E. Smith 2007; Smith and Berdan 2000). Such models, when applied in appropriate contexts with explicitly defined terms, become a basis for outlining sets of test implications, which give analytical structure to the diverse arrays of data that archaeologists traditionally apply to assess and evaluate patterns and modes of interaction. As conceptual frames, these macroscale models represent a means to define and distinguish a suite of interactive social mechanisms (sensu Hedström and Swedberg 1996:283) that link polities through political conquest, economic transactions, and information exchange.

More specifically, it is important to emphasize that World Systems models (e.g., Chase-Dunn and Hall 1993) have been somewhat mischaracterized in archaeology as unidirectional, denying influence and agency to the people in outlying regions (e.g., Stein 2002, 2007), and/or as typological, a direct derivative of Immanuel Wallerstein's (1974) earlier model for the rise of capitalism in Europe. In fact, such misconceptions have been explicitly and repeatedly addressed and refuted (e.g., Blanton and Feinman 1984; Galaty 20II; Hall et al. 20II; Kepecs and Kohl 2003), so that current macroregional approaches account for a range of different relations between the populations of interacting regions. Basically, the crux of World Systems approaches is that the linkages between regions, based on divisions of labor and patterns of interaction, are indeed important for domestic economies, labor mobilization, and potentially the funding of power. Renewed applications of social network analyses provide tools to assess and illuminate the nature of these relations as well as shifts in them over time (e.g., Mills et al. 2013). Applications of social network analyses (e.g., Brughmans 2013) to goods-based approaches undertaken at the macroscale (e.g., Blanton et al. 2005) should be especially informative. In regard to the movement of materials, the types of merchant diaspora models advanced by Gil Stein (2002) for ancient Mesopotamia actually can easily be subsumed into the aforementioned macroregional frames, rather than viewing them as strict alternatives. Merchants from one area could establish residence in another area, thereby facilitating economic interaction between the two regions.

Examinations of the prehispanic Mesoamerican world have been the foundation for the building and expansion of World Systems theory more generally. For example, Wallerstein's (1974:41-42) rather stark dichotomy between luxury and staple 
goods does not serve well in Mesoamerica (see also Schneider 1977:21) where "bulk luxuries" (Kepecs 2003:130), highly valued exotic goods that were not restricted to a small elite segment of the population (such as cotton cloth, obsidian, cacao), were a key part of macroregional interactions during the Late Postclassic period and, for some goods, even before (Blanton et al. 2005:274-275; Golitko and Feinman 2015).

\section{Considering InTERACTION IN CONTEXT}

Regardless of the specific bodies of evidence used to probe the existence and kinds of interactions, it is important to consider those data in the broader societal context that includes the nature of the relevant sites, where they fit in the surrounding hinterlands, and how the specific populations involved were organized. In particular, stylistic comparisons considered independently of those broader spheres of evidence can lead to imaginative interpretive propositions with little basis in historical reality.

For example, decades ago, researchers advanced the notion that the Olmec Horizon could be accounted for by proselytizing missionaries or military expeditions (e.g., Coe 1965) sent out from the Gulf Coast across Mesoamerica, spreading stylistic traditions across the macroregion (see Flannery 1968:79-80; Marcus 2007 for critiques of these views). Yet proselytizing religions were never part of the prehispanic Mesoamerican world, even much later in time, and the supply chains necessary to support such wide-ranging war parties (needed to conquer distant lands) would have been near impossible to sustain at Preclassic levels of population (e.g., Hassig 1995). Although a uniformly accepted explanation for Preclassic patterns of interaction across Mesoamerica remains out of reach (e.g., Pool 2009), consideration of this period in a broader cultural context and with an enhanced archaeological record over the last decades has enabled the great majority of the research community to rule out proselytizing missionaries and widespread military conquest as credible explanations for this time.

\section{SYNTHETIC THOUGHTS}

In advancing a new paradigmatic lens for archaeology, Kristiansen (2014:2I) places networks and interaction at the center of how we frame and integrate the study of the past. Such a radical reconceptualization has merit and makes a certain degree of sense given the long-standing biases toward localism that have dominated how we traditionally think about early sedentary peoples, especially in diverse and rugged settings such as Mesoamerica. In the face of empirical investigations along many analytical dimensions (including the contributions to this volume), it is an appropriate time to reject these long-standing presumptions and recognize that the 
prehispanic Mesoamerican world was generally not characterized by impermeable boundaries nor closed systems but rather by extensive socioeconomic networks. For the prehispanic Mesoamerican world, intercommunity, and even extraregional, connectivities were significant from the area's colonization through the commercialized world of the Postclassic.

Nevertheless, across Mesoamerica, patterns of interconnection shifted over time. Generally, the volume of material exchanges increased over time (Drennan 1984a, 1984b), as did the spatial extent of the networks, but shifts did not necessarily occur in a uniform, unidirectional manner (e.g., Golitko and Feinman 2015). The kinds of goods transferred across long distances also changed over time with precious, exotic goods more prevalent in the Preclassic transfers, while staples and "bulk luxuries" basically increased in volumetric significance beginning in the later Preclassic and continuing into the Late Postclassic (Blanton et al. 2005).

Demographic mobility also was a key aspect of prehispanic Mesoamerican interaction. The rapid population growth rates documented early in the histories of key Mesoamerican cities, such as Monte Albán (Feinman et al. 1985), Teotihuacan (Cowgill 1997, 2015:6I), and Tenochtitlán, as well as others, cannot be explained through natural increases alone, so that in-migration to these centers must have bolstered the observed growth. Repeatedly, across the Mesoamerican macroregion, regional capitals drew in people from near hinterlands and sometimes farther afield. Most important, such movements evidence that political territories and borders were not fixed and that successful centers and rulers drew people to expanding heartlands. Likewise, the significant ebbs and flows of urban centers across Mesoamerica during the Classic-Postclassic transition also are in accord with models that link demographic fluidity with transitions in political and economic power. It is significant that these cycles across the macroregion often were timed with different patterns of shared information exchange and networks (Blanton et al. 1996; Boone and Smith 2003; Willey 1999). Clearly, further model building is needed to understand different modes of information sharing and their relation to political and ideological interaction (e.g., M. E. Smith 2007:599).

Finally, as we begin to understand the complexities of the prehispanic Mesoamerican world, it will become increasingly important to understand how it is similar and different to other preindustrial worlds (e.g., Kohl and Chernykh 2003). Were there widespread cycles of growth and decline, and if so, how similar were they to such synchronous episodes (e.g., Turchin and Hall 2003) in other regions? Only through such investigations can we come to delineate the roots of more contemporary eras of globalization, and whether the understanding of early World Systems holds useful clues for explicating and adapting to the interconnected world of the present. 


\section{REFERENCES}

Barth, Fredrik. 1969. Ethnic Groups and Boundaries: The Social Organization of Culture Difference. Allen and Unwin, London.

Bauer, Alexander A., and Anna S. Agbe-Davies. 2010. "Trade and Interaction in Archaeology." In Social Archaeologies of Trade and Exchange: Exploring Relationships among People, Places, and Things, edited by Alexander A. Bauer and Anna S. AgbeDavies, 29-47. Left Coast Press, Walnut Creek, CA.

Beekman, Christopher S., and Alexander F. Christensen. 2003. "Controlling for Doubt and Uncertainty through Multiple Lines of Evidence: A New Look at the Mesoamerican Nahua Migrations." Journal of Archaeological Method and Theory Io(2):III-I64.

Berdan, Frances F. 2003. “The Economy of Postclassic Mesoamerica." In The Postclassic Mesoamerican World, edited by Michael E. Smith and Frances F. Berdan, 93-95. University of Utah Press, Salt Lake City.

Berdan, Frances F., Marilyn A. Masson, Janine Gasco, and Michael E. Smith. 2003. "An International Economy." In The Postclassic Mesoamerican World, edited by Michael E. Smith and Frances F. Berdan, 96-108. University of Utah Press, Salt Lake City.

Blanton, Richard E. 1996. "The Basin of Mexico Market System and the Growth of Empire." In Aztec Imperial Strategies, by Frances F. Berdan, Richard E. Blanton, Elizabeth Hill Boone, Mary G. Hodge, Michael E. Smith, and Emily Umberger, 47-84. Dumbarton Oaks, Washington, DC.

Blanton, Richard E. 2015. "Theories of Ethnicity and the Dynamics of Ethnic Change in Multiethnic Societies." Proceedings of the National Academy of Sciences II2(30):9176-918I. Blanton, Richard E., and Lane F. Fargher. 2012. "Market Cooperation and the Evolution of the Prehispanic Mesoamerican World-System." In Routledge Handbook of WorldSystems Analysis: Theory and Research, edited by Salvatore J. Borbones and Christopher K. Chase-Dunn, II-20. Routledge, New York.

Blanton, Richard E., Lane F. Fargher, and Verenice Y. Heredia Espinoza. 2005. "The Mesoamerican World of Goods and Its Transformation." In Settlement, Subsistence, and Social Complexity: Essays Honoring the Legacy of Jeffrey R. Parsons, edited by Richard E. Blanton, 260-294. Cotsen Institute of Archaeology, University of California, Los Angeles. Blanton, Richard E., and Gary M. Feinman. 1984. "The Mesoamerican World System.” American Anthropologist 86(3):673-682.

Blanton, Richard E., Gary M. Feinman, Stephen A. Kowalewski, and Peter N. Peregrine. 1996. "A Dual-Processual Theory for the Evolution of Mesoamerican Civilization." Current Anthropology 37(I):I-I4.

Boone, Elizabeth H., and Michael E. Smith. 2003. "Postclassic International Styles and Symbol Sets." In The Postclassic Mesoamerican World, edited by Michael E. Smith and Frances F. Berdan, I86-193. University of Utah Press, Salt Lake City. 
Borgatti, Stephen P., Candace Jones, and Martin G. Everett. 1998. "Network Measures of Social Capital." Connections 21(2):27-36.

Braswell, Geoffrey E. 2003. “Obsidian Exchange Spheres.” In The Postclassic Mesoamerican World, edited by Michael E. Smith and Frances F. Berdan, I3I-I58. University of Utah Press, Salt Lake City.

Braswell, Geoffrey E., ed. 2003. The Maya and Teotihuacan: Reinterpreting Early Classic Interaction. University of Texas Press, Austin.

Brughmans, Tom. 2013. "Thinking through Networks: A Review of Formal Network Methods in Archaeology." Journal of Archaeological Method and Theory 20(4):623-662.

Chamberlin, Thomas C. 1965. “The Method of Multiple Working Hypotheses.” Science I48(367I):754-759.

Chase-Dunn, Christopher, and Thomas D. Hall. 1993. "Comparing World-Systems: Concepts and Working Hypotheses.” Social Forces $7 \mathrm{I}(4): 85 \mathrm{I}-886$.

Clark, John E. 1986. "From Mountains to Molehills: A Critical Review of Teotihuacan's Obsidian Industry." In Research in Economic Anthropology, Supplement 2, edited by Barry L. Isaac, 23-74. JAI Press, Greenwich, CT.

Coe, Michael D. 1965. “The Olmec Style and Its Distribution.” In Handbook of Middle American Indians, Vol. 3, Archaeology of Southern Mesoamerica, Pt. 2, edited by Gordon R. Willey, 739-775. University of Texas Press, Austin.

Costin, Cathy Lynne. 201 . "Hybrid Objects, Hybrid Social Identities: Style and Social Structure in the Late Horizon Andes." In Identity Crisis: Archaeological Perspectives on Social Identity, edited by Lindsay Amundsen-Meyer, Nicole Engel, and Sean Pickering, 2II-225. Proceedings of the 42nd Annual Chacmool Archaeology Conference, University of Calgary, Calgary.

Cowgill, George L. 1997. "State and Society at Teotihuacan, Mexico." Annual Review of Anthropology 26:129-161.

Cowgill, George L. 2015. Ancient Teotihuacan: Early Urbanism in Central Mexico. Cambridge University Press, Cambridge.

Crown, Patricia L., and W. Jeffrey Hurst. 2009. "Evidence of Cacao Use in the Prehispanic American Southwest." Proceedings of the National Academy of Sciences 106(7):2110-2113.

Drennan, Robert D. 1984a. "Long-Distance Movement of Goods in the Mesoamerican Formative and Classic." American Antiquity 49(I):27-43.

Drennan, Robert D. 1984b. "Long-Distance Transport Costs in Pre-Hispanic Mesoamerica." American Anthropologist 86(I):105-II2.

Earle, Timothy, and Michael E. Smith. 2012. "Household Economies under the Aztec and Inka Empires: A Comparison.” In The Comparative Archaeology of Complex Societies, edited by Michael E. Smith, 238-284. Cambridge University Press, Cambridge. 
Ebert, Claire E., Mark Dennison, Kenneth G. Hirth, Sarah B. McClure, and Douglas J. Kennett. 2015. "Formative Period Obsidian Exchange along the Pacific Coast of Mesoamerica." Archaeometry 57(SI):54-73.

Emberling, Geoff. 2016. "Counternarratives: The Archaeology of the Long Term and the Large Scale." In Social Theory in Archaeology and Ancient History: The Present and Future of Counternarratives, edited by Geoff Emberling, 3-16. Cambridge University Press, New York. Feinman, Gary M., and Christopher P. Garraty. 2010. "Preindustrial Markets and Marketing: Archaeological Perspectives." Annual Review of Anthropology 39:167-191.

Feinman, Gary M., Mark Golitko, and Linda M. Nicholas. 2019. "A Network Analysis of Prehispanic Obsidian Exchange: Implications for Macroregional Dynamics and Ancient Economies." In Social Network Analysis in Economic Archaeology-Perspectives from the New World, edited by Tim Kerig, Christian Mader, Katerina Ragkou, Michaela Reinfeld, and Tomáš Zachar, 13-36. Habelt-Verlag, Bonn.

Feinman, Gary M., Stephen A. Kowalewski, Laura Finsten, Richard E. Blanton, and Linda Nicholas. 1985. "Long-Term Demographic Change: A Perspective from the Valley of Oaxaca, Mexico." Journal of Field Archaeology I2(3):333-362.

Feinman, Gary M., and Linda M. Nicholas. 2010. "A Multiscalar Perspective on Market Exchange in the Classic-Period Valley of Oaxaca." In Archaeological Approaches to Market Exchange in Ancient Societies, edited by Christopher P. Garraty and Barbara L. Stark, 85-98. University Press of Colorado, Boulder.

Flannery, Kent V. 1967. "Culture History v. Cultural Process: A Debate in American Archaeology." Scientific American 217(2):119-122.

Flannery, Kent V. 1968. "The Olmec and the Valley of Oaxaca: A Model for Inter-Regional Interaction in Formative Times." In Dumbarton Oaks Conference on the Olmec, edited by Elizabeth Benson, 79-ıIo. Dumbarton Oaks, Washington, DC.

Frankema, Ewout. 2015. “The Biogeographic Roots of World Inequality: Animals, Disease, and Human Settlement Patterns in Africa and the Americas before I492." World Development 70:274-285.

Galaty, Michael L. 20ır. "World-Systems Analysis and Anthropology: A New Détente?” Reviews in Anthropology 4O(I):3-26.

Garraty, Christopher P., and Barbara L. Stark, eds. 2010. Archaeological Approaches to Market Exchange in Ancient Societies. University Press of Colorado, Boulder.

Golitko, Mark, and Gary M. Feinman. 2015. "Procurement and Distribution of PreHispanic Mesoamerican Obsidian 900 B C-AD I520: A Social Network Analysis." Journal of Archaeological Method and Theory 22(I):206-247.

Golitko, Mark, James Meierhoff, Gary M. Feinman, and P. Ryan Williams. 2012. "Complexities of Collapse: The Evidence of Maya Obsidian as Revealed by Social Network Graphical Analysis." Antiquity 86(332):507-523. 
Green, Stanton W., and Stephen M. Perlman. 1985. "Frontiers, Boundaries, and Open Social Systems." In The Archaeology of Frontiers and Boundaries, edited by Stanton W. Green and Stephen M. Perlman, 3-I3. Academic Press, Orlando.

Grove, David C. 1993. “'Olmec' Horizons in Formative Period Mesoamerica: Diffusion or Social Evolution?" In Latin American Horizons, edited by Don S. Rice, 83-III. Dumbarton Oaks, Washington, DC.

Hall, Thomas D., P. Nick Kardulias, and Christopher Chase-Dunn. 20Ir. "World-Systems Analysis and Archaeology: Continuing the Dialogue." Journal of Archaeological Research I9(3):233-279.

Hassig, Ross. 1995. Aztec Warfare: Imperial Expansion and Political Control. University of Oklahoma Press, Norman.

Hedström, Peter, and Richard Swedberg. 1996. "Social Mechanisms." Acta Sociologica 39:28I-308.

Hirth, Kenneth G. 2013. “The Merchant's World: Commercial Diversity and the Economics of Interregional Exchange in Highland Mesoamerica." In Merchants, Markets, and Exchange in the Pre-Columbian World, edited by Kenneth G. Hirth and Joanne Pillsbury, 85-112. Dumbarton Oaks, Washington, DC.

Hosler, Dorothy. 2003. "Metal Production." In The Postclassic Mesoamerican World, edited by Michael E. Smith and Frances F. Berdan, I59-171. University of Utah Press, Salt Lake City. Jones, Siân. 1997. The Archaeology of Ethnicity: Constructing Identities in the Past and Present. Routledge, New York.

Jones, Siân. 2008. “Ethnicity: Theoretical Approaches, Methodological Implications." In Handbook of Archaeological Theories, edited by R. Alexander Bentley, Herbert D. G. Maschner, and Christopher Chippendale, 32I-333. Altamira, Lanham, MD.

Kepecs, Susan. 2003. "Salt Sources and Production." In The Postclassic Mesoamerican World, edited by Michael E. Smith and Frances F. Berdan, I26-I30. University of Utah Press, Salt Lake City.

Kepecs, Susan, and Phil Kohl. 2003. "Conceptualizing Macroregional Interaction: WorldSystems Theory and the Archaeological Record.” In The Postclassic Mesoamerican World, edited by Michael E. Smith and Frances F. Berdan, I4-20. University of Utah Press, Salt Lake City.

King, Eleanor M., ed. 2015. The Ancient Maya Marketplace: The Archaeology of Transient Space. University of Arizona Press, Tucson.

Knappett, Carl, ed. 2013. Network Analysis in Archaeology: New Approaches to Regional Interaction. Oxford University Press, Oxford.

Kohl, Philip L., and Evgenij N. Chernykh. 2003. "Different Hemispheres, Different Worlds." In The Postclassic Mesoamerican World, edited by Michael E. Smith and Frances F. Berdan, 307-312. University of Utah Press, Salt Lake City. 
Kowalski, Jeff Karl, and Cynthia Kristan-Graham, eds. 2007. Twin Tollans: Chichén Itzá, Tula, and the Epiclassic to Early Postclassic Mesoamerican World. Dumbarton Oaks, Washington, DC.

Kristiansen, Kristian. 2014. "Towards a New Paradigm? The Third Science Revolution and Its Possible Consequences in Archaeology." Current Swedish Archaeology 22:1 I-34.

Lightfoot, Kent G. 1995. "Culture Contact Studies: Redefining the Relationship between Prehistoric and Historical Archaeology." American Antiquity 60(2):199-217.

Marcus, Joyce. 2007. “Great Art Styles and the Rise of Complex Societies.” In Gordon R. Willey and American Archaeology: Contemporary Perspectives, edited by Jeremy A. Sabloff and William L. Fash, 72-104. University of Oklahoma Press, Norman.

Masson, Marilyn A., and David A. Freidel. 2013. "Wide Open Spaces: A Long View of the Importance of Maya Market Exchange." In Merchants, Markets, and Exchange in the Pre-Columbian World, edited by Kenneth G. Hirth and Joanne Pillsbury, 20I-228. Dumbarton Oaks, Washington, DC.

Mathien, Frances J., and Randall H. McGuire, eds. 1986. Ripples in the Chichimec Sea: New Considerations of Southwestern-Mesoamerican Interactions. Southern Illinois University Press, Carbondale.

Mills, Barbara J., Jeffrey J. Clark, Matthew A. Peeples, W. R. Haas Jr., John M. Roberts Jr., J. Brett Hill, Deborah L. Huntley, Lewis Borck, Ronald L. Breiger, Aaron Clauset, and M. Steven Shackley. 2013. "Transformation of Social Networks in the Late Prehispanic US Southwest." Proceedings of the National Academy of Sciences IIO(I5):5785-5790.

Nash, Donna J., and Patrick Ryan Williams. 2004. "Architecture and Power on the WariTiwanaku Frontier." In Foundations of Power in the Andes, edited by Kevin J. Vaughn, Dennis Ogburn, and Christina A. Conlee, I5I-174. Archaeological Papers of the American Anthropological Association 14, Washington, DC.

Pohl, John M. D. 2003. "Ritual and Iconographic Variability in Mixteca-Puebla Polychrome Pottery." In The Postclassic Mesoamerican World, edited by Michael E. Smith and Frances F. Berdan, 20I-206. University of Utah Press, Salt Lake City.

Pool, Christopher A. 2009. "Asking More and Better Questions: Olmec Archaeology for the Next Katun." Ancient Mesoamerica 20(2):24I-252.

Ragsdale, Corey S., and Heather J. H. Edgar. 2015. "Cultural Interaction and Biological Distance in Postclassic Period Mexico." American Journal of Physical Anthropology I57(I):I2I-I33.

Renfrew, Colin. 1975. “Trade as an Action at a Distance: Questions of Interaction and Communication." In Ancient Civilization and Trade, edited by Jeremy A. Sabloff and C. C. Lamberg-Karlovsky, 5-39. University of New Mexico Press, Albuquerque.

Renfrew, Colin. 1981. "Space, Time, and Man." Transactions of the Institute of British Geographers 6(3):257-278. 
Sanders, William T., and David Webster. 1988. “The Mesoamerican Urban Tradition.” American Anthropologist 90(3):521-546.

Schneider, Jane. 1977. “Was There a Pre-capitalist World System?” Peasant Studies 6:20-29.

Schortman, Edward M. 2014. "Networks of Power in Archaeology." Annual Review of Anthropology 43:167-182.

Schortman, Edward M., and Patricia A. Urban. 1987. "Modeling Interregional Interaction in Prehistory." Advances in Archaeological Method and Theory I1:37-95.

Sherratt, Andrew. 1993. "What Would a Bronze-Age World System Look Like? Relations between Temperate Europe and the Mediterranean in Later Prehistory." Journal of European Archaeology I (2): I- 58 .

Shryock, Andrew, and Daniel Lord Smail, eds. 20r r. Deep History: The Architecture of Past and Present. University of California Press, Berkeley.

Smith, Michael E. 2003. "Information Networks in Postclassic Mesoamerica." In The Postclassic Mesoamerican World, edited by Michael E. Smith and Frances F. Berdan, I8I-185. University of Utah Press, Salt Lake City.

Smith, Michael E. 2007. “Tula and Chichén Itzá: Are We Asking the Right Questions?” In Twin Tollans: Chichén Itzá, Tula, and the Epiclassic to Early Postclassic Mesoamerican World, edited by Jeff Karl Kowalski and Cynthia Kristan-Graham, 579-617. Dumbarton Oaks, Washington, DC.

Smith, Michael E., and Frances F. Berdan. 2000. "The Postclassic Mesoamerican World System." Current Anthropology 4I(2):283-286.

Smith, Michael E., and Frances F. Berdan, eds. 2003. The Postclassic Mesoamerican World. University of Utah Press, Salt Lake City.

Smith, Michael E., and Cynthia M. Heath-Smith. 1980. "Waves of Influence in Postclassic Mesoamerica? A Critique of the Mixteca-Puebla Concept." Anthropology 4:15-50.

Smith, Michael E., and Lisa Montiel. 200r. "The Archaeological Study of Empires and Imperialism in Prehispanic Central Mexico." Journal of Anthropological Archaeology $20(3): 245-284$.

Smith, Monica L. 2005. "Networks, Territories, and the Cartography of Ancient States." Annals of the Association of American Geographers 95:832-849.

Smith, Monica L. 2007. "Territories, Corridors, and Networks: A Biological Model for the Premodern State." Complexity i2:28-35.

Stark, Barbara L., and John K. Chance. 2012. “The Strategies of Provincials in Empires.” In The Comparative Archaeology of Complex Societies, edited by Michael E. Smith, 192-237. Cambridge University Press, Cambridge. 
Stark, Barbara L., and Alanna Ossa. 2010. "Origins and Development of Mesoamerican Marketplaces: Evidence from South-Central Veracruz, Mexico.” In Archaeological Approaches to Market Exchange in Ancient Societies, edited by Christopher P. Garraty and Barbara L. Stark, 99-126. University Press of Colorado, Boulder.

Stein, Gil J. 2002. "From Passive Periphery to Active Agents: Emerging Perspectives in the Archaeology of Interregional Interaction." American Anthropologist 104(3):903-916.

Stein, Gil J. 2007. "World Systems Theory and Alternative Modes of Interaction in the Archaeology of Culture Contact." In Studies in Culture Contact: Interaction, Culture Change, and Archaeology, edited by James G. Cusick, 220-255. Center for Archaeological Investigations, Occasional Paper 25, Southern Illinois University, Carbondale.

Trigger, Bruce G. 1984. “Archaeology at the Crossroads: What's New?” Annual Review of Anthropology 13:275-300.

Trigger, Bruce G. 1989. A History of Archaeological Thought. Cambridge University Press, Cambridge.

Turchin, Peter, Jonathan M. Adams, and Thomas D. Hall. 2006. "East-West Orientation of Historical Empires and Modern States." Journal of World-Systems Research I2(2):219-229.

Turchin, Peter, and Thomas D. Hall. 2003. "Spatial Synchrony among and within World-Systems: Insights from Theoretical Ecology.” Journal of World-Systems Research 9(1):37-64.

Wallerstein, Immanuel. 1974. The Modern World-System: Capitalist Agriculture and the Origins of the European World-Economy in the Sixteenth Century. Academic Press, New York.

Webster, David. 1985. "Surplus, Labor, and Stress in Late Classic Maya Society." Journal of Anthropological Research 4I(4):375-399.

Willey, Gordon R. 1999. "Styles and State Formation." Latin American Antiquity IO(I):86-90.

Wolf, Eric R. 1982. Europe and the People without History. University of California Press, Berkeley.

Wright, Henry T. 1989. "The Rise of Civilizations: Mesopotamia to Mesoamerica.” Archaeology 42(I):46-48, $96-100$. 


\title{
Chapter 2
}

\section{Interaction and Exchange in Early Formative Western and Central Mesoamerica}

\author{
New Data from Coastal Oaxaca
}

GuY DAVId HepP

The archaeology of Mesoamerica's Early Formative period (2000-1000 cal в ) is, in many ways, a quest to better understand networks of interaction and exchange encouraging shared sociocultural characteristics that came to distinguish the region in subsequent centuries (e.g., Drennan 1984; Flannery 1968; Joyce 2004; Lesure 2004; Zeitlin 1994). In recent decades, Paul Kirchhoff's (1943) original list of shared traits for defining Mesoamerica has been revised (e.g., Clark 1991:22) or replaced by one of "shared practices" (Joyce 2004:3). Foremost among these practices, according to Rosemary Joyce (2004:4), were "subsistence production," "longdistance exchange," "cosmology and ritual," and "social stratification." As Joyce (2004:3) pointed out, the culture area model has largely been laid to rest because it does not help us to distinguish which traits or practices are most important or explain their origins or interconnectedness. Despite these revisions to diffusionist thinking, mounting evidence suggests that many areas of Mesoamerica shared significant sociocultural changes during the Archaic-Formative transition (Clark and Cheetham 2002; Clark et al. 2007). Unfortunately, most of our information about that watershed moment of historical transformation is based on research in only a few regions, including highland Mexico (Flannery and Marcus 2003; MacNeish 1972; Niederberger 1979; Piña Chan 1958), the Gulf Coast (e.g., Arnold 2009; Cyphers and Zurita-Noguera 2012), and the Soconusco region of Chiapas and Guatemala (e.g., Blake and Clark 1999; Clark 2004; Lesure 201I). Increasingly, new research from lowland areas (e.g., Inomata et al. 2013; Lohse 2010) and coastal 


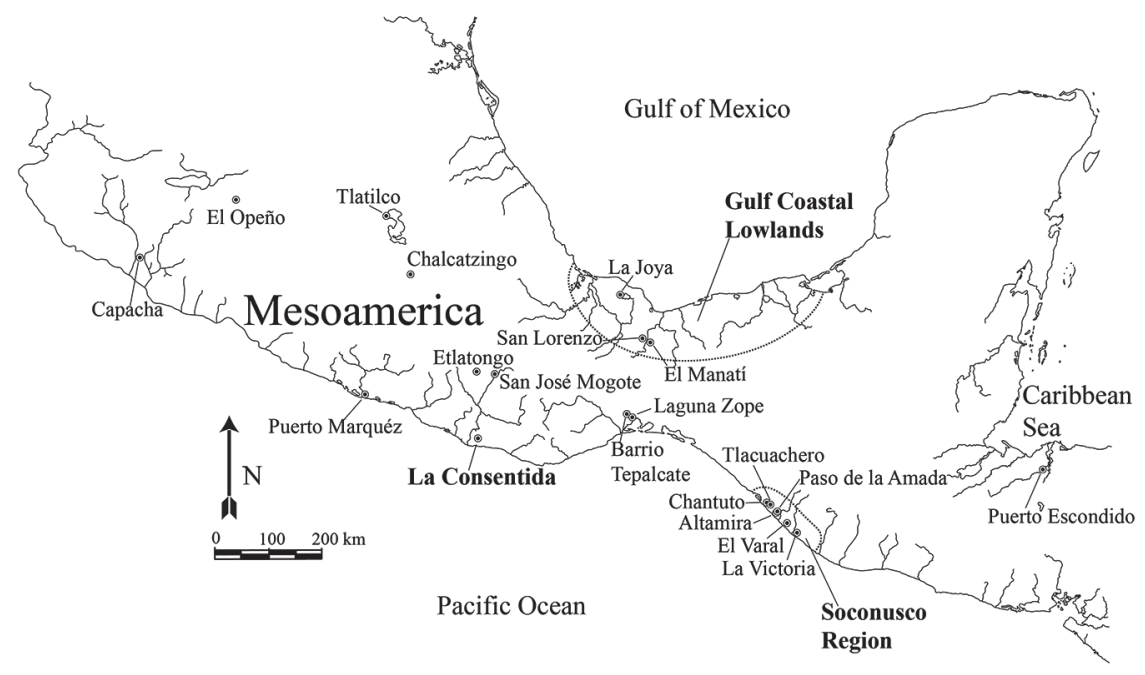

FIGURE 2.I. Map of key Early Formative period sites in Mesoamerica.

zones outside of the Gulf Coast and Soconusco hotspots (e.g., Hepp 2015; Joyce and Henderson 200I) has begun to broaden the data set for this time of widespread change. In this chapter, I present evidence for relationships of interaction and exchange held by the people of La Consentida, an Early Formative period village site on the western coast of Oaxaca, Mexico (figure 2.I).

Originally rediscovered by archaeologists in the 1980 s (see A. Joyce 1991, 2005), La Consentida is located in Oaxaca's lower Río Verde Valley. The site has been the focus of concerted investigation since 2008 (Hepp 2011a, 2014, 2015). Six radiocarbon samples (1947-1530 cal BC) from secure contexts such as hearths sealed between platform fill layers and burned food adhering to the interior of a cooking jar from a midden (table 2.I) have demonstrated the site's early chronological position relative to other Mesoamerican villages (Hepp 2015). A seventh sample, which dates to the Middle Formative (1000-400 cal B C), came from a near-surface context and was likely contaminated by a surface burning event subsequent to site abandonment. Investigations at the site have been coordinated to answer a central research question, namely, what were the nature of and relationships between practices of mobility, subsistence, and social organization at La Consentida during the initial Early Formative period?

Despite the focus that this research has placed on evidence for the establishment of sedentism and changing dietary practices, the analysis of numerous artifact classes has also provided tantalizing evidence that this early village was not an anachronistic 
TABLE 2.I. AMS radiocarbon dates from La Consentida ${ }^{a}$

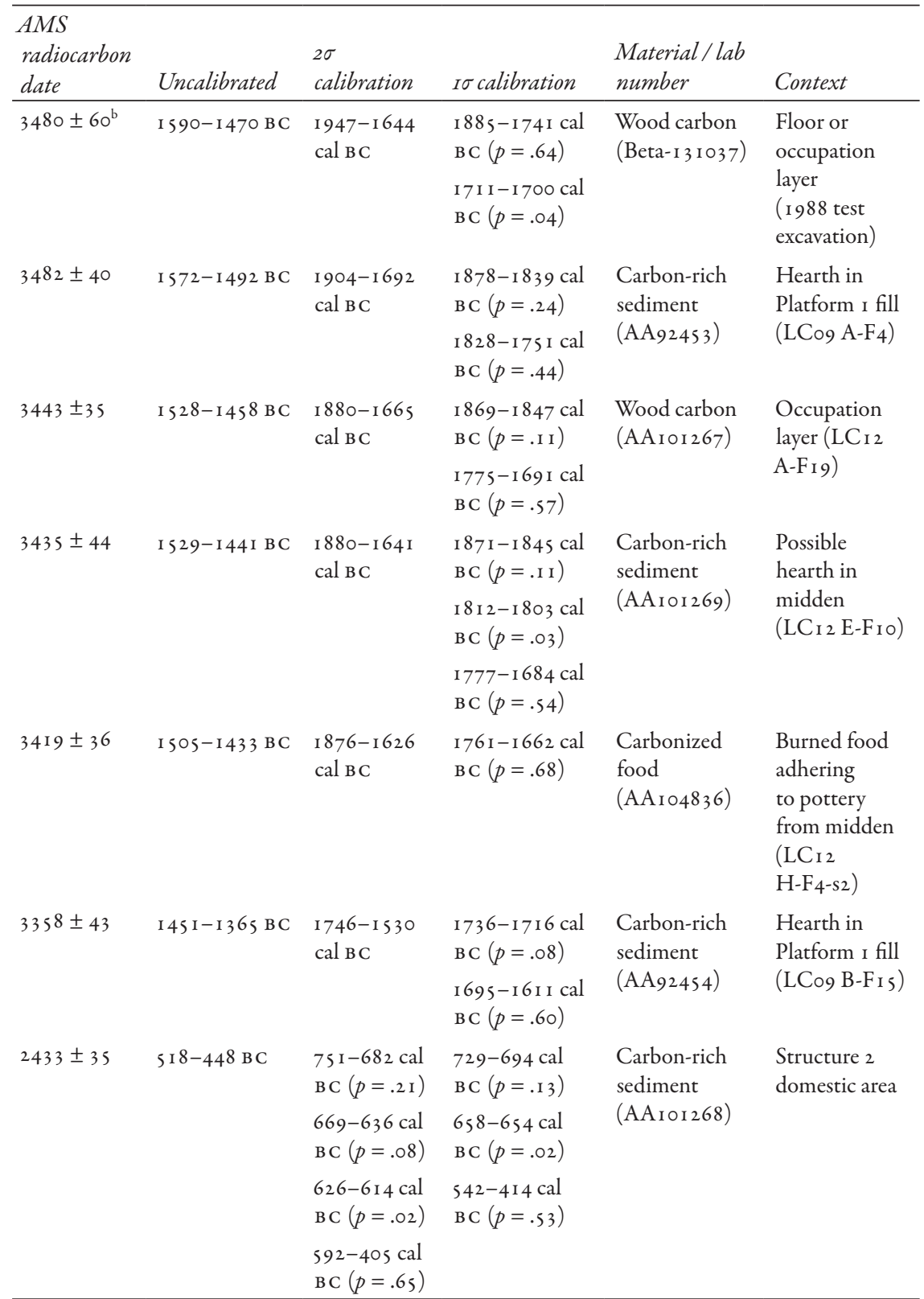

${ }^{a}$ Calibrated with IntCal 13 curve by OxCal 4.2 and reported with both $\sigma \sigma$ and $2 \sigma$ probability.

${ }^{b}$ A. Joyce 2005:17. 
isolate, but was instead part of an interregional network of interacting communities. In this chapter, I will place particular emphasis on ceramic and lithic evidence for La Consentida's relationships of interregional interaction and exchange. This discussion hinges upon describing vessel forms and decorative styles found in the Tlacuache phase (1950-1500 cal B C) ceramic assemblage, the early and well-dated collection of pottery recovered from La Consentida (Hepp 2015). I will argue that the evidence of ceramic style and of obsidian sourcing indicates interaction with central Mexico, highland Oaxaca, and west Mexico. I conclude that the Tlacuache assemblage is an early example of the Red-on-Buff ceramic horizon, a pottery tradition from western Mesoamerica emphasizing jars and simple, geometric decorations painted with red pigment (see Winter 1992:27-28). As a matter of conjecture, I also suggest that La Consentida's ties to west Mexico evince a broader exchange relationship that saw some of Mesoamerica's earliest pottery inspired by contact with areas further afield, perhaps including South America (see Ford 1969; Kelly 1980).

\section{COMPARING TLACUACHE, BARRA, AND TIERRAS LARGAS CERAMIC ASSEMBLAGES}

Studying Mesoamerica's earliest pottery is relevant for improving our understandings of the relationships between technology, subsistence, communal activity, and networks of exchange in the origins of farming villages and political complexity. The Soconusco region's Barra phase (1900-1700 cal B C) ceramics are generally accepted as the earliest pottery in Pacific coastal Mesoamerica. Barra pottery is "remarkably sophisticated," is often decorated, and is frequently reminiscent of plants such as gourds (Clark and Blake 1994:25). Clark (2004; Clark and Blake 1994; Clark et al. 2007:25), and others have suggested that these ceramics were instrumental in competitive feasting that promoted social complexity in the Soconusco. In Oaxaca, the Espiridión (1900-1650 cal B C) and Tierras Largas (1650-1500 cal B C) phases-the former of which lacks radiocarbon dates and is now questioned by some as distinct from Tierras Largas, - - have previously been recognized as producing the region's earliest ceramics and some of the first examples of the Red-on-Buff horizon (Flannery and Marcus 1994; Winter 1992:27-28). ${ }^{1}$ Tlacuache pottery, so far clearly defined only at La Consentida, appears to predate Tierras Largas by two or three centuries (Hepp 2015:table I.2). A few nearby sites in the lower Río Verde Valley contain redeposited Early Formative materials, and future work should help to refine understandings of early ceramics in the region (see Gillespie 1987; Grove I988; A. Joyce et al. 2009:349-350; Zárate Morán 1995).

Tlacuache ceramics share with their highland Oaxacan counterparts a vessel form ratio that differs strongly from the more tecomate-emphasizing and 


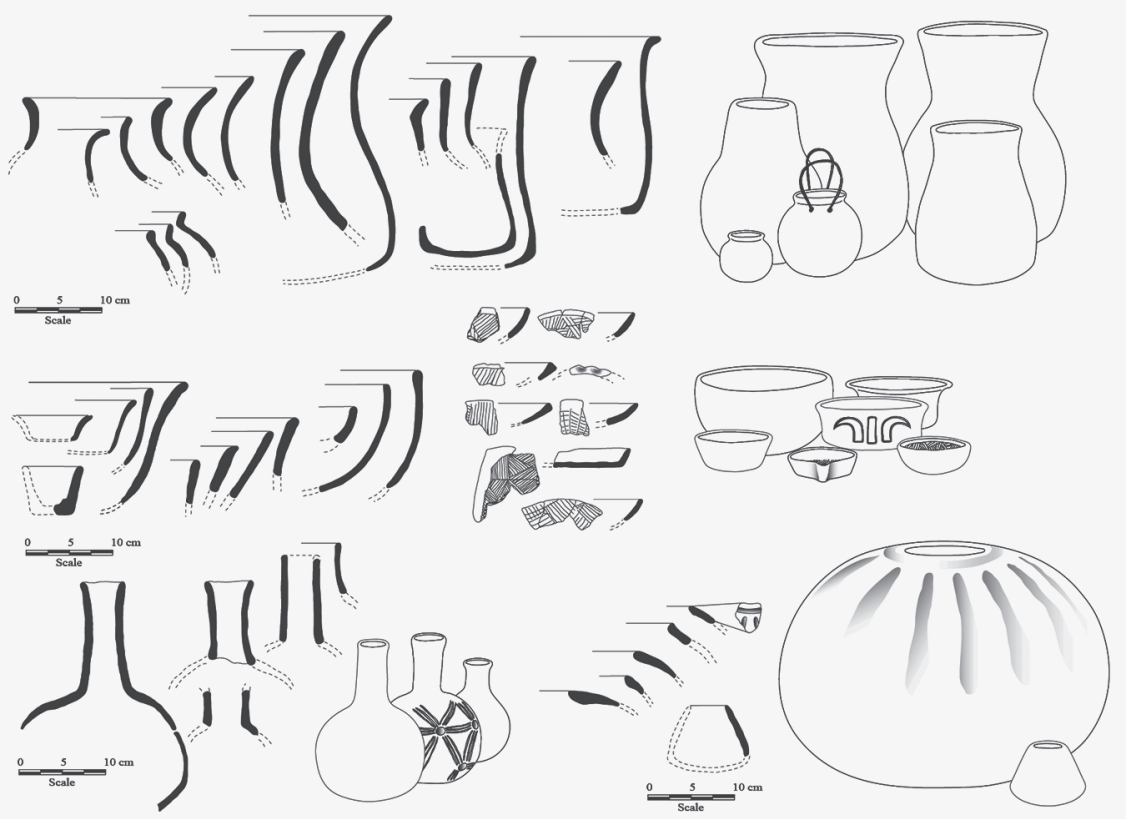

FIGURE 2.2. A reconstruction of the Tlacuache phase ceramic assemblage.

decorated Barra tradition. Both the Tlacuache and Tierras Largas assemblages contain fewer phytomorphic (or "plant-like") vessels than does the Barra assemblage (Clark and Blake 1994; Flannery and Marcus 1994:55-10I). Tlacuache ceramics, though apparently contemporaneous with the Barra phase, instead consist mainly of jars, followed in relative emphasis by bowls, bottles, and more specific variants of these basic types (figure 2.2). Tecomates and probable phytomorphs are present at La Consentida, though they are rare. Figure 2.3 demonstrates differences in the relative frequencies of vessel forms between the Tlacuache, Barra, and Tierras Largas phases. Of note are the similarities in vessel form ratios between Tierras Largas and Tlacuache, both of which are quite different from the Barra assemblage, which lacks jars and bottles. ${ }^{2}$ Important differences between the Tlacuache and Tierras Largas assemblages include the higher percengtages of bottles and tecomates in the former. As the higher frequency of bottles and the presence of grater bowls suggests, the Tlacuache assemblage is more formally diverse than Tierras Largas. Alhough Tierras Largas and Tlacuache ceramics have relatively similar vessel form ratios, the assemblages differ in terms of both plastic and painted decoration styles. 


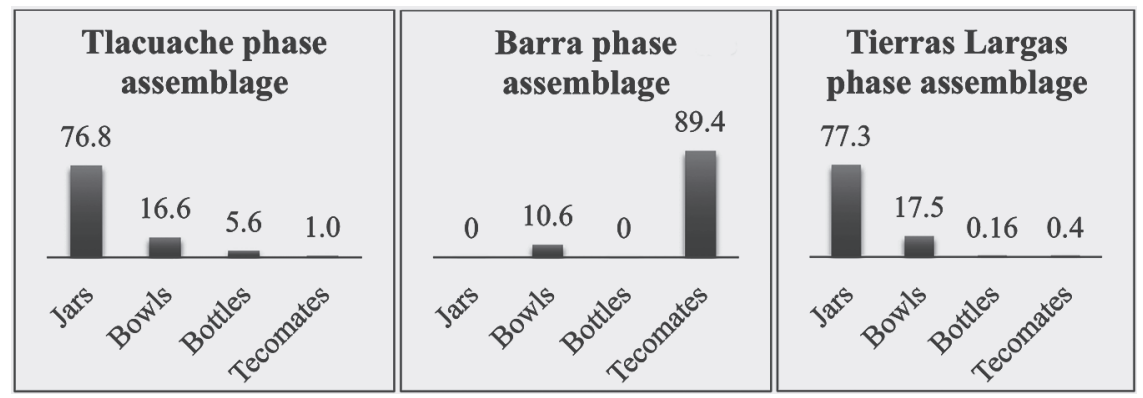

FIGURE 2.3. A comparison of Tlacuache, Barra, and Tierras Largas vessel types by percentage.

Tlacuache ceramics generally lack the red-painted interior designs of the Tierras Largas assemblage (e.g., Flannery and Marcus 1994:figs. 8.22-8.26). Additionally, "rocker stamping" found on some Tierras Largas vessels (e.g., Flannery and Marcus 1994:fig. 8.18) is absent from the Tlacuache assemblage. Both assemblages share the use of red paint and/or slip for exterior decoration. Vessel forms of greatest similarity between the Tlacuache and Tierras Largas collections are generic types also found among early ceramics of central and western Mesoamerica, rather than particularly diagnostic forms. Statistical analyses demonstrate that ceramics from the Barra, Tierras Largas, and Tlacuache phases differ significantly and demand to be assigned to discrete assemblages. ${ }^{3}$

Ceramics from one La Consentida midden in particular $\left(\mathrm{LC}_{12} \mathrm{H}_{-} \mathrm{F}_{4}\right)$ consisted almost entirely (93\%) of jars, most of which are globular in form. The rapid deposition of the context is indicated by cross-fitting fragments from as much as $60 \mathrm{~cm}$ apart in excavated depth. ${ }^{4}$ Vessels from this area (e.g., figure 2.4) appear formally similar to Tierras Largas phase globular jars (Flannery and Marcus 1994:frontispiece A, 45-IOI; Rámirez Urrea 1993:figs. 48, 57-59). Some Tierras Largas jars have rounded bases, however, while most Tlacuache vessel bases are flatter (see Rámirez Urrea 1993:figs. 36, 38). Undecorated semispherical bowls from this same midden (figure 2.5a) are also similar to Tierras Largas examples. Neither the jars nor the bowls are very diagnostic Early Formative vessels, however. Tlacuache jars are also similar to some from Tlatilco (e.g., Piña Chan 1958:figs. 36.c, 4r.b) and Zohapilco (Niederberger 1976:lám. LIX). Four small fragments of finely burnished and slipped "kidney-shaped bowls" (figure 2.5b) from another midden (LCI2 E-F9-si) also appear similar to Tierras Largas vessels (cf. Flannery and Marcus I994:fig. 7.2). Again, such bowls are not a particularly diagnostic type, as they also appear at Zohapilco (Niederberger 1976:lám. LII.ı6, 25, lám. LIV.16, foto 37) and at Tlatilco (Piña Chan 1958:fig. 40j, lám. 21). 

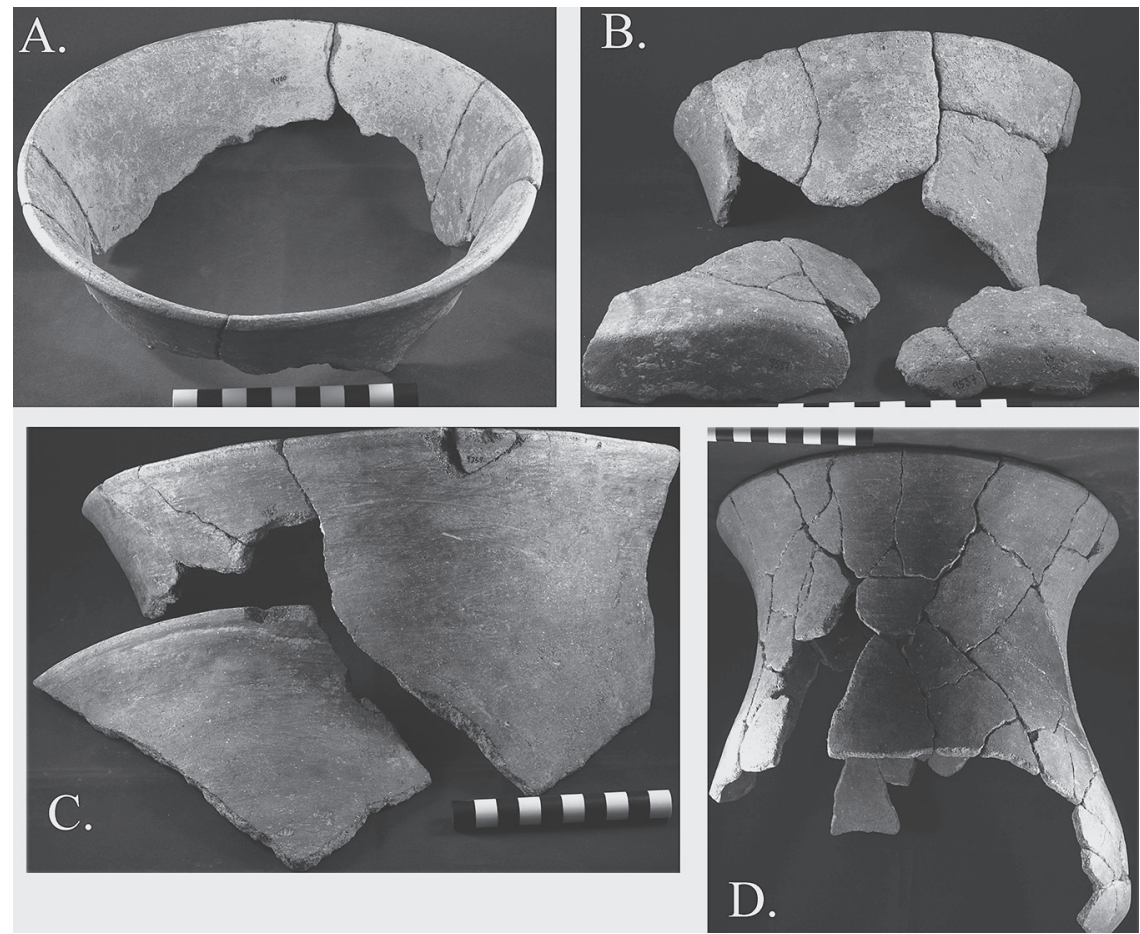

FIGURE 2.4. Jar remnants from the Op. LCi2 H midden: (a) Jar rim; (b) jar rim, neck, and base; (c) partial jar; (d) largely reconstructed jar.

Relatively little is known about Purrón phase (1900-I680 cal BC) pottery from the Tehuacán Valley (though see Clark and Gosser 1995; García Cook and Merino Carrión 2005). The few remains of this tradition that have been recovered show close parallels with Espiridión and Tierras Largas, and thus also with Tlacuache. Particular similarities between Tlacuache and Purrón appear in the form of globular jars (e.g., García Cook and Merino Carrión 200s:fig. 2), which are also the vessels showing most similarity between Tlacuache and the Early Formative highland Oaxacan wares. Key differences between Tlacuache and Purrón pottery include the apparently higher percentage of tecomates among the latter (García Cook and Merino Carrión 2005), and the greater prevalence of decorated or slipped vessels and the significant numbers of ceramic figurines associated with the former (Hepp 20I5:ch. 7).

The similarities between coastal and highland undecorated utilitarian cooking jars and semispherical bowls, despite marked dissimilarity between the decorated 

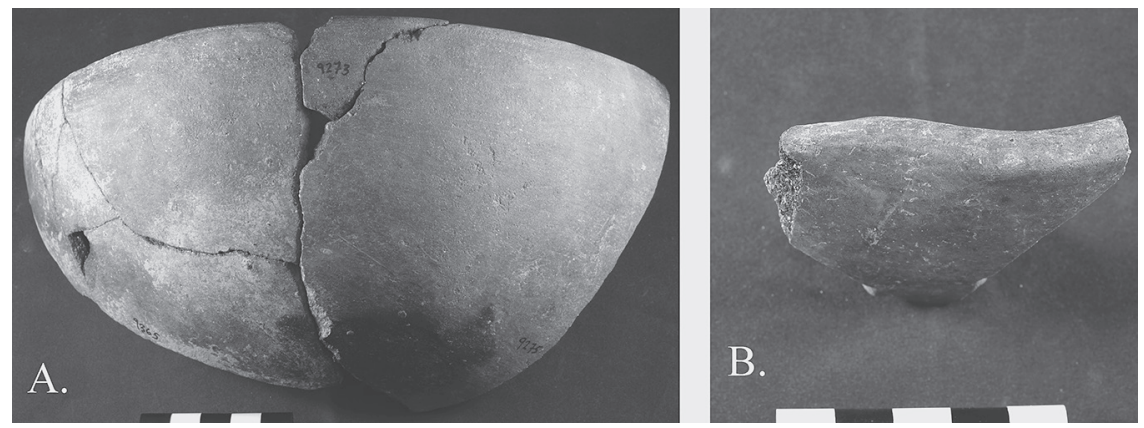

FiguRE 2.5. Semispherical bowl remnants: (a) Partial semispherical bowl from Op. LCi2 H midden; (b) rim fragment of semispherical "kidney-shaped" bowl from Op. LCi2 E midden.

vessels of these traditions, deserve some explanation. For example, contrast the style of some decorated Tlacuache wares (figure 2.6) with those from the Tierras Largas phase (Flannery and Marcus 1994:figs. 8.22-8.27, 8.30, 8.31, and 8.34; Rámirez Urrea 1993:figs. 62-65). One interpretation of this discrepancy is that only La Consentida's utilitarian wares adhered to traditions of manufacture shared with highland Oaxacan and central Mexican communities. Isabel Kelly (1980; see also Anawalt 1998) suggested that there may have been an extensive interaction network involving trade along the Pacific coast of Mesoamerica. Such a network, likely utilizing watercraft, could explain why decorated wares from early coastal sites such as La Consentida share more in common with traditions far to the west than they do with highland Oaxacan ceramics. If fancy serving vessels such as decorated bowls and bottles were meant for public display employing motifs meaningful to visitors from nearby and distant coastal zones sharing in that decorative tradition, it could also explain why such vessels appear in probable feasting middens (e.g., LCI2 E-FI6 through $\mathrm{E}-\mathrm{F}_{9}$ ) rather than in cooking middens ( $\left.\mathrm{LC}_{12} \mathrm{H}-\mathrm{F}_{4}\right)$. I will revisit the issue of interaction with west Mexico in a separate section below.

Although some of La Consentida's ceramics suggest interaction with highland Oaxaca and western Mexico, other vessels are of a style whose interregional affiliations are more difficult to trace. Small grater bowls from the site (figure 2.7) come in various forms, including as rounded conical bowls with flat bottoms and (more rarely) as conical bowls with pouring spouts, as square bowls, and as semispherical bowls. Some examples exhibit considerable use wear. The two most complete of these ashtray-sized vessels were recovered as offerings with children's burials. These grater bowls are not totally without counterparts in other regions. Vessels bearing similar weaving-inspired incised motifs are found in highland Oaxaca (Flannery and Marcus I994:figs. I2.142 and I2.143; Marcus and Flannery 1996:96), 

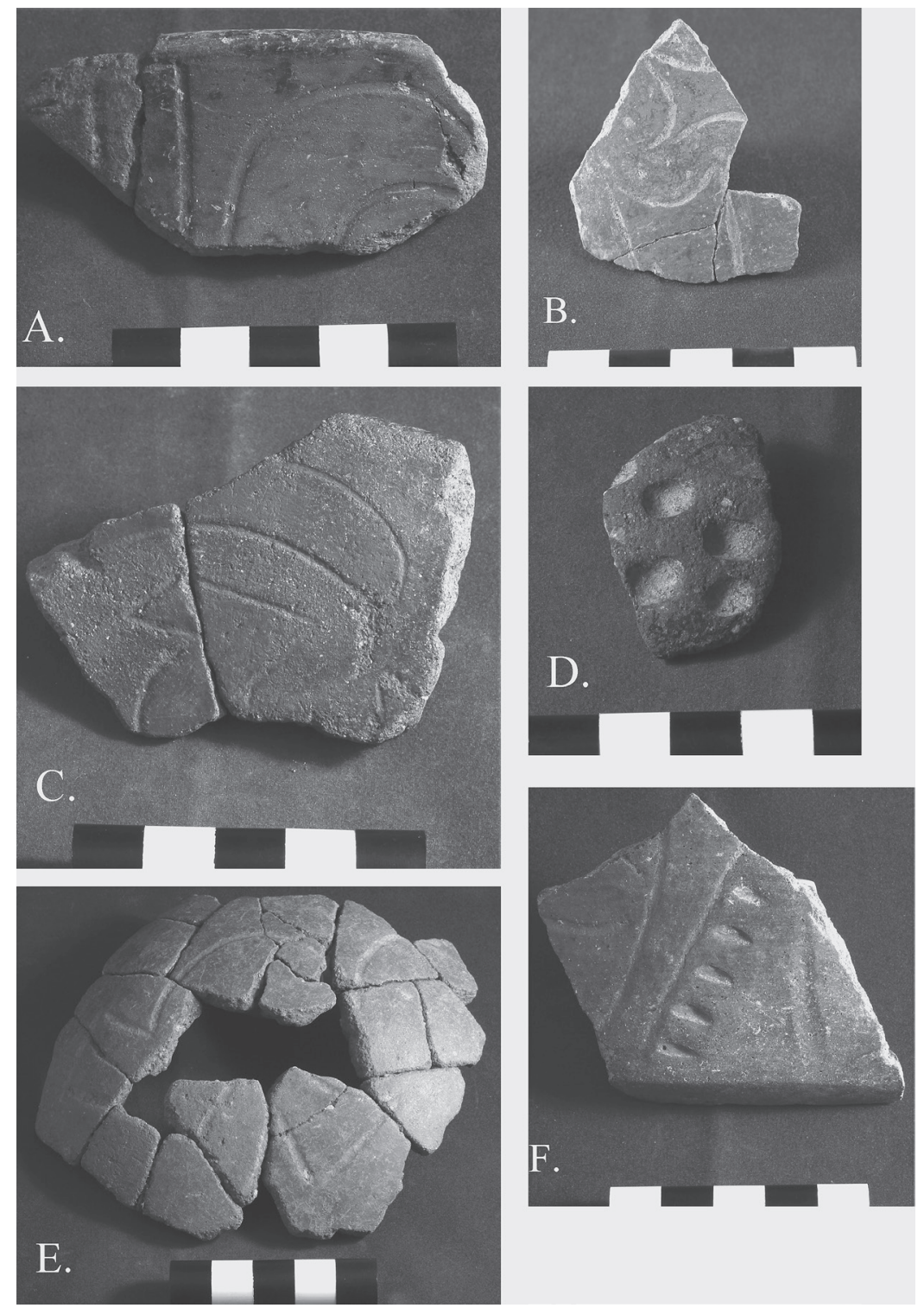

FIGURE 2.6. Decorated Tlacuache assemblage vessel fragments from various contexts. 
at Cantón Corralito (Cheetham 2010:180), and elsewhere. For example, Rosenswig (2010:157-159) discussed grater bowls from the Soconusco region as a vessel type specific to the Middle Formative Conchas phase (1000-850 cal BC). Although Conchas phase grater bowls and Tlacuache grater bowls share the basic feature of interior incision, Conchas examples are larger, have more complex silhouette shapes, and sometimes lack incisions extending across the entire interior bottom of the vessel. This leads me to infer that their uses may have differed. Also unlike the Conchas phase examples, Tlacuache grater bowls lack applique supports. Geometric designs on Formative period vessels in various regions sometimes appear on the exterior of vessels (e.g., Cheetham 2010:180), while Tlacuache grater bowls bear their incisions on the interior base and sometimes on the interior wall all the way to the rim. Grove (1984:42, 80-81, I03) has also discussed bowls with interior incising from Chalcatzingo. Notably, these bowls appear to have been decorative rather than utilitarian (at least as pertains to their incised designs) and have rounded bottoms. Like the Conchas phase examples, the Chalcatzingo vessels do not represent good analogs for La Consentida's grater bowls, which were in some cases extensively used to grate, and even to pour (see figure $2.7 \mathrm{~b}$ ), some substance or substances.

Formative period grater bowls with interior incising are also found in highland Oaxaca, but are rare, executed in gray rather than brown paste, and occur in later phases such as San José and Guadalupe (see Flannery and Marcus 1994:figs. 12.74, I2.IOI). Perhaps the best-known examples of grater bowls among later Oaxacan ceramics can be found in the G-12 type of the Pe (500-100 B C) and Nisa (100 BC$A D$ 200) phases (see Caso et al. 1967:fig. 130b; A. Joyce 2010:150, I87, fig. 5.7C). Much later examples also occur in the Xoo phase ( $\mathrm{AD} 500-800$ ), and these again tend to be gray wares (Martínez López et al. 2000:165-166). The bowl shown in figure 2.7 a has rim notching similar to that of some nongrater Tierras Largas phase semispherical bowls (cf. Flannery and Marcus 1994:fig. 8.9). Some of the interiorincised bowls at Tlatilco (e.g., Piña Chan 1958:figs. 38a, 38b, see also geometric designs demonstrated in fig. 47) have incisions similar to Tlacuache grater bowls, though the examples from La Consentida appear smaller and lack tripod supports. As with the Tlatilco examples, Zohapilco bowls with interior incision in geometric patterns are somewhat similar to Tlacuache grater bowls (Niederberger 1976:láms. XXXVI, XLV.22, and LI). Despite minor similarities with decorative patterns on vessels from other regions, the La Consentida grater bowls seem to be a relatively distinctive type. Regarding comparison with west Mexico (see discussion below), Kelly (1980:31) noted that both the Capacha and Opeño phase (approx. I450-II50 cal BC) ceramics lack grater bowls.

Given consistencies in the form and placement of the interior incisions of the Tlacuache grater bowls, it seems certain that they served some food-processing or 

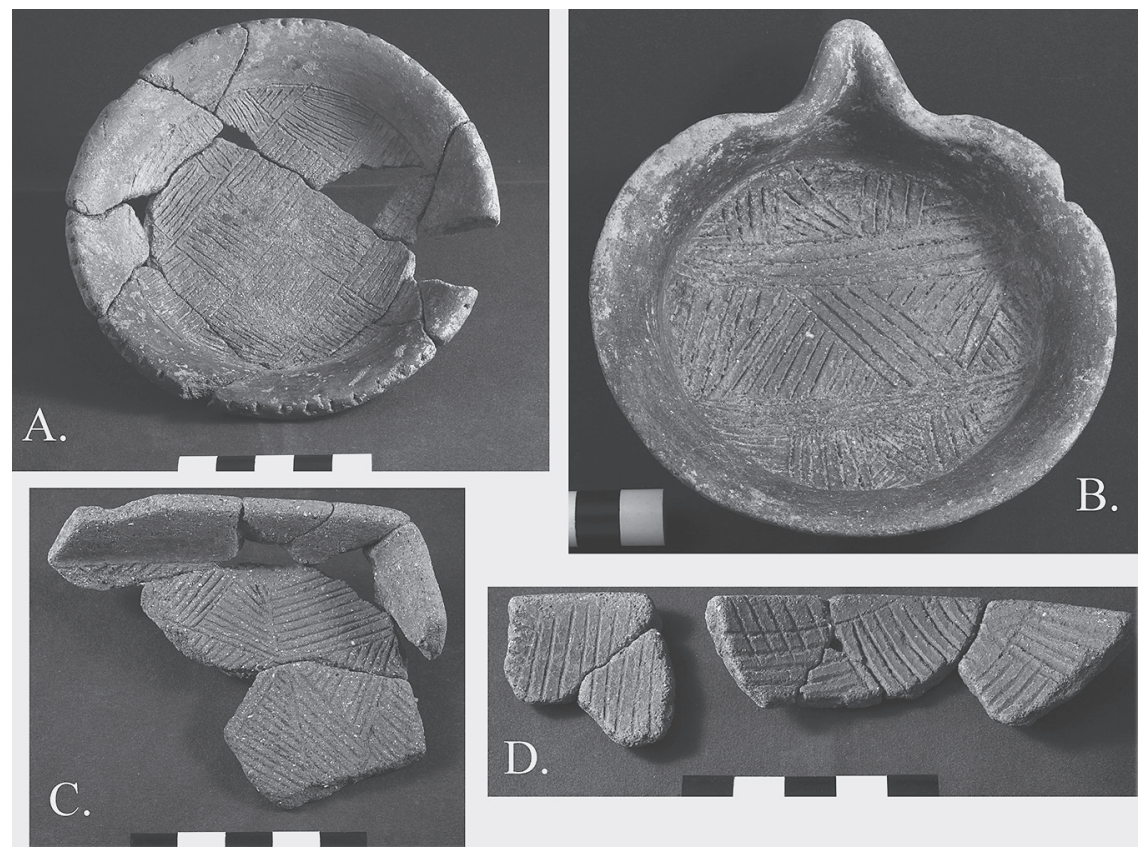

FIGURE 2.7. Tlacuache grater bowl remnants: (a) Nearly complete grater bowl with extensive use wear interred as offering with a child burial; (b) complete grater bowl with spout recovered as offering with a child burial; (c) partial square grater bowl from domestic context; (d) semispherical grater bowl rim fragments from domestic context.

crafting need. Because the complex, incised designs in these bowls were carefully executed (likely drawing inspiration from the geometric patterns of woven basketry), their artistic value must also have been significant. The fact that two examples (figures $2.7 \mathrm{a}$ and $\mathrm{b}$ ) were recovered with child burials may suggest that grater bowls were used to process children's food and perhaps aided in weaning. ${ }^{5}$ Notably, the children buried with La Consentida's two most complete grater bowls were of weaning age, according to the onset of linear enamel hypoplasias identified in the overall population (Hepp et al. 2017). A future absorbed residue analysis may be the only way to definitively identify the uses of these vessels (see Morell-Hart et al. 2014; Seinfeld et al. 2009). The Ojochi (1750-I550 cal вС) and Bajío phase ceramics of the Gulf Coast are combined into a single phase by some researchers (e.g., Arnold 2003; Rodríguez Martínez et al. 1997:82 [cited in Arnold 2003]). These ceramics (YPM ANT 255088, 255093, 255099, 25510I, 255105, 255109; 255207, 255221) include long-necked bottles, sherd disks, zoned and impressed banded decoration, globular 


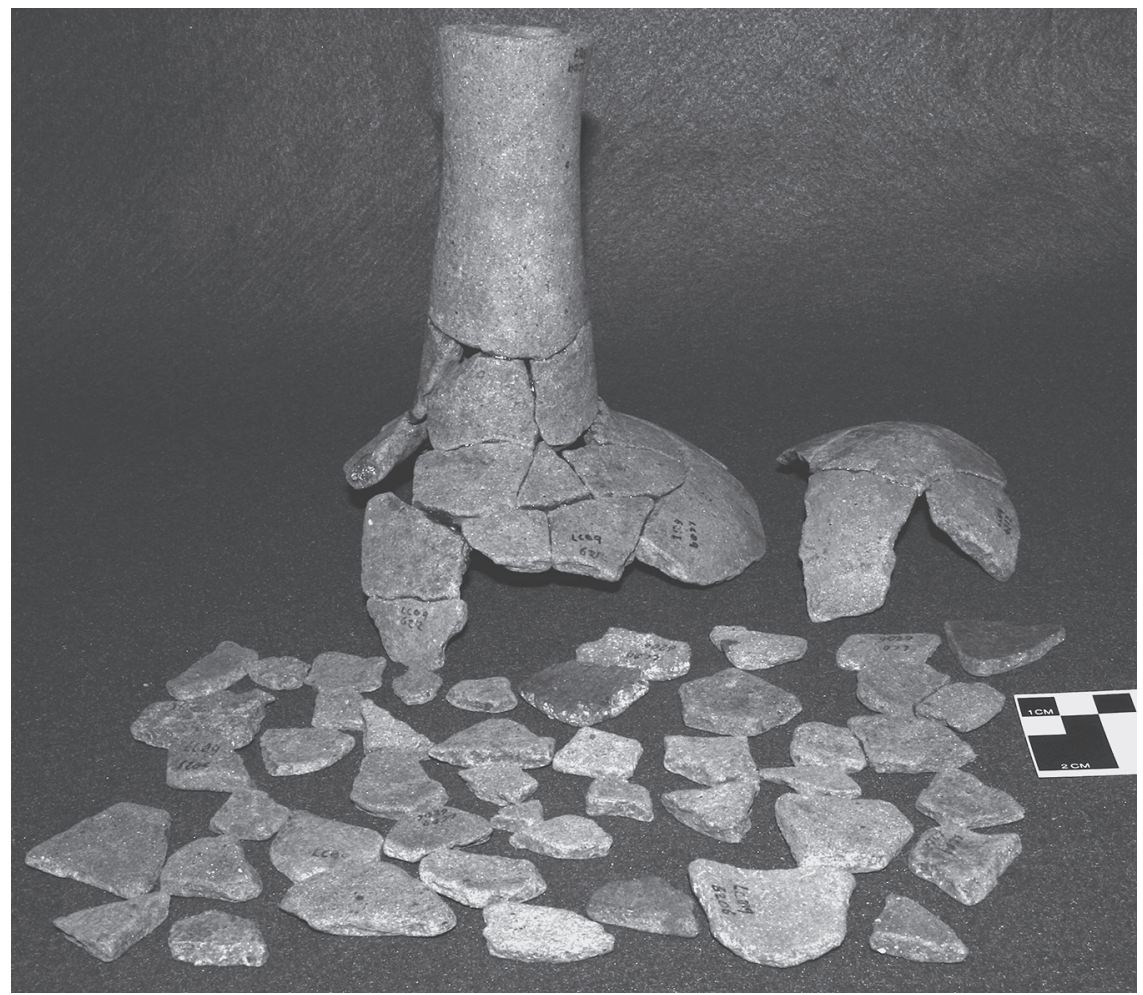

FIGURE 2.8. Partially reconstructed bottle recovered as offering with an adult male burial.

jars, decorated tecomates, and phytomorphs that appear similar to some Tlacuache wares (figure 2.8). ${ }^{6}$ Powis and colleagues (2011:8597, 8599) noted that an Ojochi bottle and a Bajío "necked jar" and "open bowl" tested positive for cacao. Bottles emulating plants, bearing "geometric designs painted in red," and which were used for cacao consumption have also been identified in the coastal Honduran Ocotillo phase (Joyce and Henderson 2007:645). Bottles from La Consentida generally resemble these cacao vessels, though residue analysis is necessary to identify their uses. As demonstrated by Powis and colleagues (2007, 2008), some early Soconusco ceramics were also used for cacao, emphasizing that chocolate was widely consumed in the Early Formative regardless of specific vessel types used to contain it.

Additional parallels between the La Consentida ceramics and those from other Early Formative sites are evident. The probable effigy vessel shown in figure 2.9, for instance, appears to be similar to one discussed by Piña Chan (1958:32) from a burial at Tlatilco. A few bottles from Tlatilco (e.g., Piña Chan 1958:figs. 34i, j, k, 


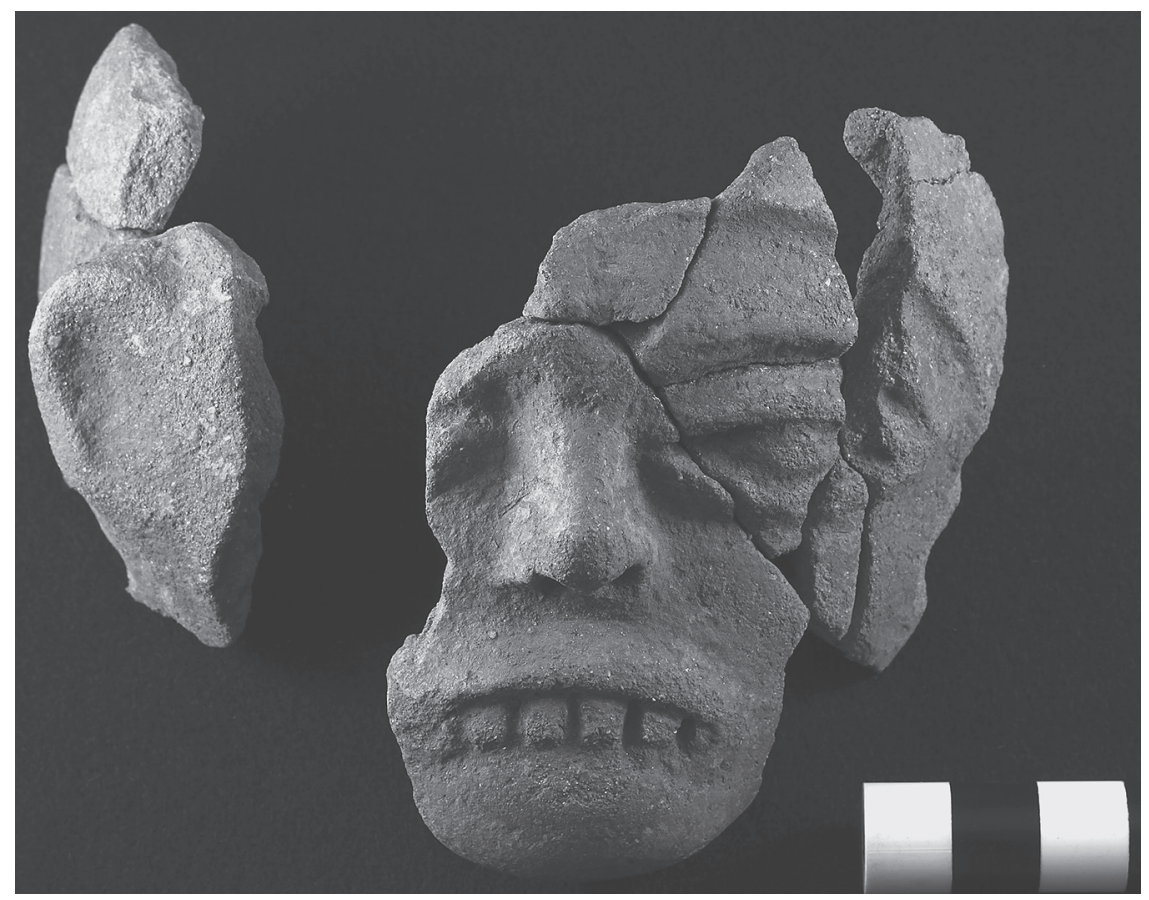

FIGURE 2.9. Remnants of a probable effigy vessel from near Structure 2 domestic context.

35v, w, 37ñ , o, p, r, s, 39y, z, a $\left.\mathrm{a}^{1}, \mathrm{~b}^{1}, 43 \mathrm{r}, 44 \mathrm{k}, 46 \mathrm{f}\right)$ also resemble Tlacuache bottles. Although some of the bold, geometric designs of the Tlatilco vessels are reminiscent of Tlacuache examples, the Olmec-inspired iconography found at Tlatilco is absent at La Consentida, as the site's entire occupation appears to predate the Olmecoid horizon. Similar bottles were also recovered at Zohapilco, and likely date to the Manantial phase (approx. I250-1050 cal в C; Niederberger 1976:lám. XXXVI.II, I2).

Early radiocarbon dates from La Consentida are unequivocally associated with both mounded earthen architecture and pottery. For example, carbonized food remains from the interior of a jar fragment found in a primary midden deposit returned an AMS radiocarbon date of $3419 \pm 36$ (AAro 4836 ; carbonized food; $\delta_{13} \mathrm{C},-\mathrm{I} 5.5$ ) or $1876-{ }_{162} 6 \mathrm{cal} \mathrm{B} \mathrm{C} \mathrm{(see} \mathrm{table} \mathrm{2.I).} \mathrm{These} \mathrm{early} \mathrm{dates} \mathrm{for} \mathrm{the} \mathrm{Tlacuache}$ assemblage, when considered in conjunction with basic differences between it and the Barra assemblage, force us to question the argument that Mesoamerica's earliest ceramics were introduced from Central America along the Pacific coast of Chiapas and Guatemala (Clark and Blake 1994; Lowe 2007). Certainly, early Central American ceramics are likely candidates for influencing some of Mesoamerica's first 
potters (see Bradley 1994; Hoopes 1994). In addition to those southeastwardly connections, however, a very early ceramic tradition seems to have appeared west of the Isthmus of Tehuantepec by at least $1900 \mathrm{cal}$ B C. As I will discuss below, Tlacuache ceramics seem to exemplify the Red-on-Buff horizon, rather than the Early Formative Soconusco tradition incorporating pottery from the Barra and Locona (1700-1550 cal BC) phases (see Clark 1991; Winter 1992:27-28). These Red-on-Buff and Soconusco ceramic macrotraditions may relate to broad patterns of cultural and linguistic distribution (Clark 1991; Josserand et al. 1984; Winter 1992; Winter and Sánchez Santiago 2014a).

\section{CERAMIC EVIDENCE FOR A PACIFIC COASTAL INTERACTION NETWORK}

Decades ago, Kelly (1980:37) suggested that archaeologists should explore what she believed was a Formative period Pacific coastal interaction sphere in western Mesoamerica, which perhaps brought ceramic technology and decorative inspiration northward out of lower Central America and South America. Citing evidence for a broadly dispersed ceramic tradition with ties to the Capacha phase, Kelly believed that west Mexican decorative motifs likely had Formative period counterparts in coastal zones further to the southeast. She noted (37) that Capacha may have been merely one of several "landfalls along the Pacific coast" of this tradition and that a lack of information from early deposits in other coastal areas (such as Oaxaca and Guerrero) represented a challenge to understanding that potential interaction network. Decorative elements found in La Consentida's Tlacuache phase ceramics may be related to this poorly defined western macrotradition.

Although decorated vessels are relatively rare at La Consentida, various middens have provided a good sample of the decorative styles used at the site. One of the most compelling pieces of evidence for including La Consentida in a broad Pacific coastal interaction area with distant western traditions can be found in the "sunburst" decorations on some vessels of Colima's Capacha phase bottles and jars (figure 2.10) and on several decorated fragments from La Consentida (figure 2.II). At La Consentida, sunburst designs appear on bottles (e.g., figure 2.Ira, which represents a probable bottle fragment from an eroded or redeposited midden context) and on other sherds from unidentified vessel types. Although different in form than the elaborate "stirrup" bottles and jars of the Capacha phase, the decoration on Tlacuache bottles nonetheless bears a striking similarity to some Capacha examples (see Kelly 1974, 1980:figs. 15-19, 21, 24, 25; Mountjoy 1994, 1998:fig. 2). The most elaborate Capacha vessels (e.g., figure 2.I0b) may come from later deposits than more basic forms and often lack good provenience due to the looting of tombs and other burials (Kelly 1974, 1980; Mountjoy 1994). While 


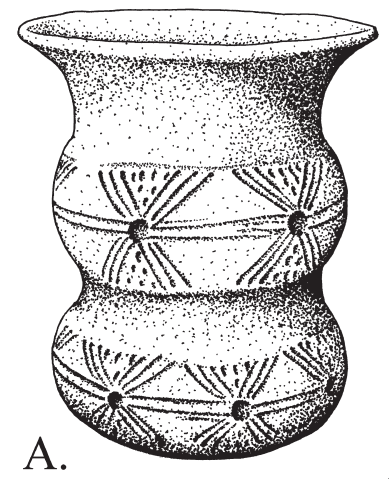

B.

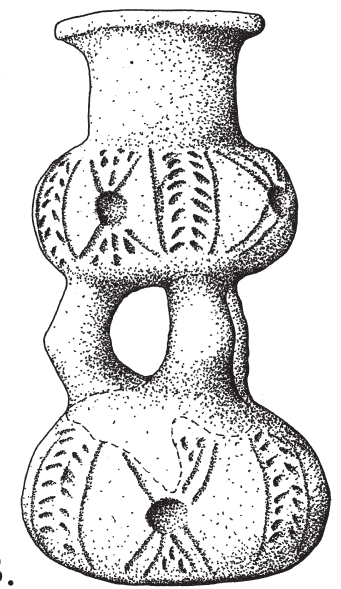

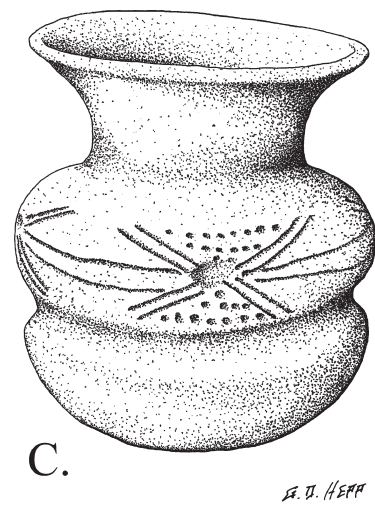

FIGURE 2.10. Capacha phase vessels: (a) belted jar (redrawn by the author after Mountjoy 1994:40, no scale); (b) stirrup or double jar (redrawn by the author after Mountjoy 1994:4I, no scale); (c) belted jar (redrawn by the author after Schmidt Schoenberg 2006:29, no scale).

some Capacha forms are not recognized in the Tlacuache collection, a few fragments of composite silhouette or "belted" vessels (e.g., figure 2.I2) indicate that more complex vessels existed at $\mathrm{La}$ Consentida but are not well understood due to fragmentation. Impressed, teardrop-shaped dots or dashes (e.g., figure 2.6f) on Tlacuache vessels are also similar to some Capacha designs and those on Middle Formative ceramics from Jalisco's Mascota Valley (see Kelly 1974, 1980:figs. 18, 21, 26, 29; Mountjoy 2012:figs. 119, 280).

Mountjoy (1994, 2006; personal communication 2015) has voiced skepticism regarding the early dates originally attributed to Capacha by Kelly and has suggested that the phase belongs instead to the Middle Formative. Kelly (1974, 1980:4, 18-19) herself described the dismal conditions under which the dating for the phase was secured. Mountjoy agrees that similarities between the Tlacuache and Capacha sunburst designs are suggestive of possible interaction between the two regions, however. La Consentida's early dates indicate that a direct association between Capacha and Tlacuache is unlikely, even if Kelly's initial dates are accepted without Mountjoy's modifications. I do not argue that La Consentida's ceramics represent direct contact with or importation of ceramics from west Mexico, or vice versa. Rather, I agree with Kelly (1980:37; see also Anawalt 1998) that certain decorative styles among Pacific coastal traditions beg further investigation into a possible interaction network including these regions and exemplifying early Red-on-Buff pottery 


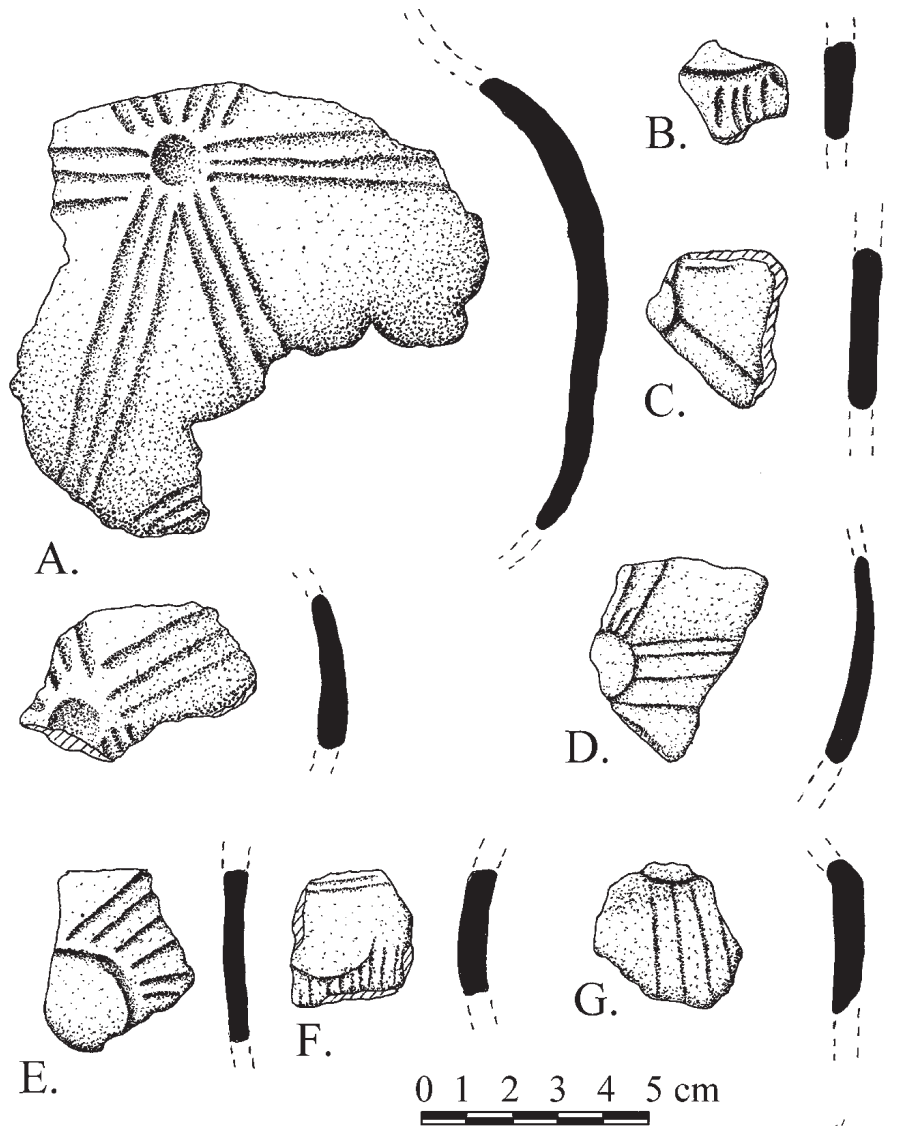

FIGURE 2.II. Tlacuache ceramics from various contexts at La Consentida that bear the "sunburst" motif.

(Clark 1991; Winter 1992:27-28). The earliest ceramics from much of Pacific coastal Mesoamerica (west of the Isthmus of Tehuantepec) are poorly understood, and it may be that a more systematic study of them would indicate that ceramic traditions in the intervening areas between Oaxaca and west Mexico share even more in common with the Tlacuache phase (see Brush 1965, 1969; Kelly 1980; Mountjoy 1994; Williams 2007).

Although the Tlacuache sunburst motif is similar to that found on some Capacha wares, a more general similarity can be seen between the simple, bold, geometric and impressed decorative style of the La Consentida vessels and those of both the Capacha and Opeño phases (e.g., Kelly 1980:fig. 30; Mountjoy 1994; Oliveros 1974; 


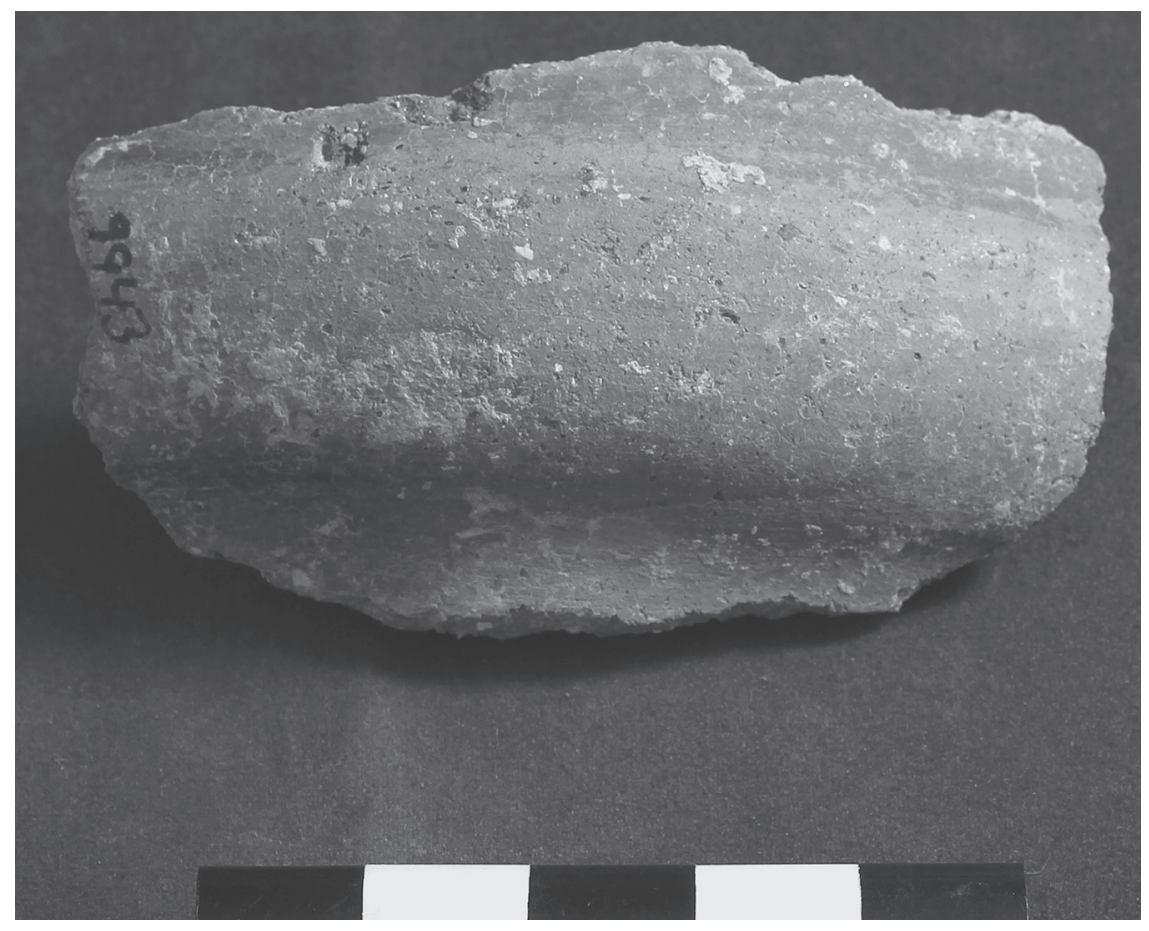

FIGURE 2.I 2. Fragment of a probable belted vessel from child burial at La Consentida.

Williams 2007). Unfortunately, the friable, sandy medium brown paste from which many Tlacuache wares were constructed means that sherds tend to be small and eroded, leaving designs rarely visible in their entirety. Nevertheless, when they are somewhat well preserved, these vessels are notable for their finely slipped and burnished surfaces and geometric, impressed designs. In general, the Tlacuache phase decorative motifs seem to have at least as much in common with west Mexican ceramics as they do with Barra or Tierras Largas phase wares (Clark and Blake 1994; Flannery and Marcus 1994).

Patterns of ceramic decoration and basic vessel form may also suggest similarities with areas even more distant than west Mexico. James Ford's (1969; see also Anawalt 1998) extensive comparison of Formative cultures in the New World provides some useful points of comparison between La Consentida and other early villages in the Americas. Decorated sherds from Valdivia, for example, bear a resemblance to some of the La Consentida ceramics (Ford I969:fig. 14). Bottles from early Machalilla contexts in Ecuador and Tehuacán deposits in central Mexico 
appear similar to the La Consentida examples (Ford 1969:fig. I8i, chart 16). More recently, Anawalt (1998) summarized the evidence for contact between west Mexico and Ecuador during Early Formative through Postclassic (AD 900-I52I) times, which includes patterns of attire and figurine iconography, in addition to ceramics. Although archaeological discussions of long-distance interaction and "diffusion" of technology have fallen from favor in recent decades, strong cases for such interactions can be made when multiple and diverse lines of evidence are considered together. Given the available data, it is not yet possible to make any strong claims about connections between La Consentida and distant areas such as Machalilla and Valdivia, though Kelly (1980) found such potential crossties intriguing.

\section{OBSIDIAN IMPORTATION}

Following the 2009 fieldwork at La Consentida, forty obsidian flakes were selected for X-ray Fluorescence (XRF) sourcing analysis at the University of Missouri Archaeometry Laboratory (MURR) (Glascock 2011; Hepp 20IIb; Williams 2012: 92-97). These artifacts were largely from fill, redeposited midden, and burial fill contexts. A few others were associated with early, dated hearths (LCo9 A-F 4 and LCo9 B-FI5). Results of this XRF study are consistent with an analysis of five pieces of obsidian collected during test excavations at the site in 1988 (Joyce et al. 1995). Figure 2.13 summarizes the sources of the forty-five samples analyzed by these two studies. These XRF data indicate La Consentida's involvement in an extensive trade network stretching to central and Gulf coastal Mexico (figure 2.14).

Obsidian sourcing results from La Consentida provide an opportunity for comparison with other early Oaxacan sites. For example, Blomster and Glascock (2010:189) determined that somewhat later Early Formative communities in the Nochixtlán Valley imported their obsidian from several sources, including Paredón, Otumba, Guadalupe Victoria, El Chayal, and Ixtepeque. At La Consentida, the lack of obsidian imported from Central America indicates different interregional relationships from those held by Early Formative communities in the Mixteca Alta, the Valley of Oaxaca, the southern Isthmus of Tehuantepec, or the Soconusco (Blomster and Glascock 2010:189; Clark and Salcedo Romero 1989; Pires-Ferreira 1978, 2009:293; Zeitlin 1982). Zeitlin (1982:266-267) noted that obsidian used in the southern Isthmus of Tehuantepec during the Early Formative included material from Guadalupe Victoria and the Guatemalan source of El Chayal. Blomster and Glascock (2010:189) found that Cruz A and Cruz B phase communities in the Mixteca Alta imported up to 5 percent of their obsidian from El Chayal. In highland Oaxaca, Blomster and Glascock (2010:192) noted a transition away from the Early Formative use of "low-quality" Guadalupe Victoria 


\section{La Consentida obsidian sources $(n=45)$}

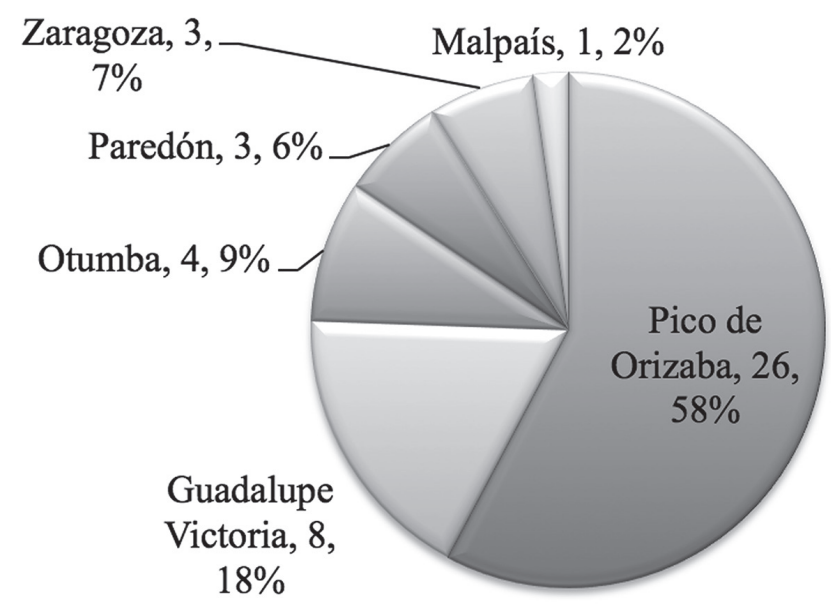

FIGURE 2.13. Results of X-ray fluorescence analysis of forty-five obsidian samples from La Consentida. Results include five samples published by Joyce and colleagues (1995:6).

obsidian and toward an emphasis on central Mexican sources such as Paredón in later Formative times. The greater emphasis at La Consentida on Guadalupe Victoria over Paredón material is therefore consistent with the site's early date. Blomster and Glascock (2010:192) also noted discrepancies between regions of highland Oaxaca, where people in the Nochixtlán Valley used little west Mexican material (such as that from Ucaréo), while Valley of Oaxaca communities employed more obsidian from western sources in addition to that from Zaragoza and Otumba (cf. Charles L. F. Knight, chapter 8 in this volume). The lack of west Mexican obsidian at La Consentida is intriguing given the ceramic decoration styles discussed above, which suggest that the regions were somehow in contact.

\section{OTHER ICONOGRAPHIC AND MATERIAL EVIDENCE FOR INTERACTION}

Although the best data for La Consentida's networks of interregional interaction comes from ceramic comparisons and obsidian sourcing, it is worthwhile to mention additional evidence for connections with other areas. Greenstone beads were prestige items traded throughout Mesoamerica during the Formative period (Carballo 2009:492; Joyce 1991:I41, 2013:24; Tremain 2014). It is not yet clear whether several greenstone beads from La Consentida are made from jadeite, serpentine, or some combination of materials, but they show considerable variability 


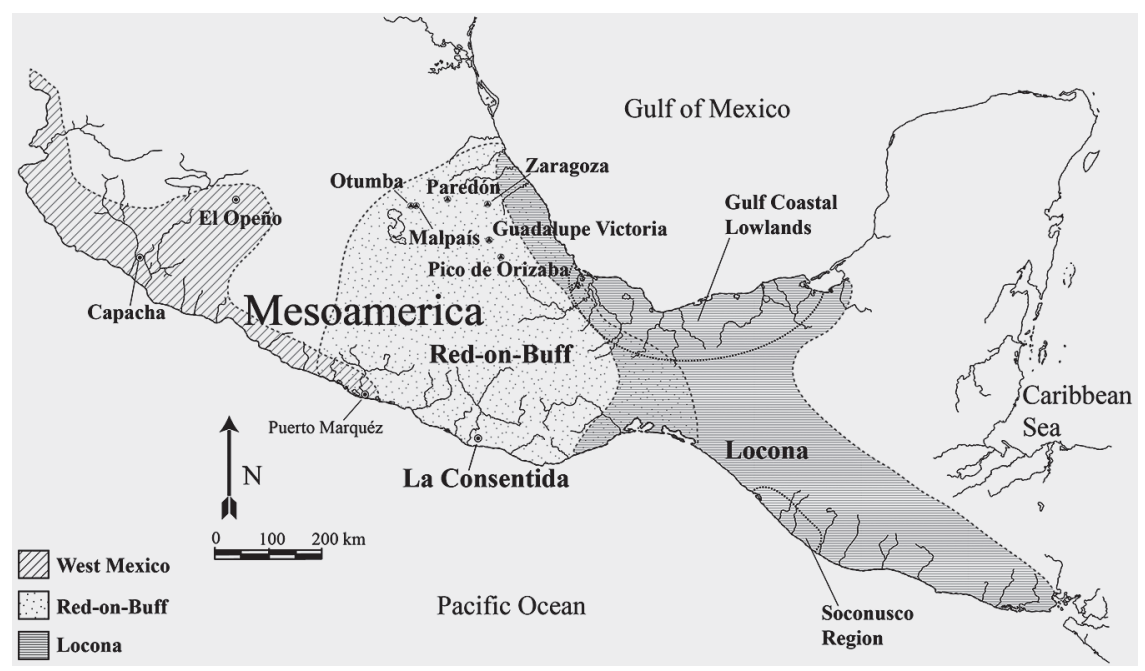

FIGURE 2.14. Map with locations of La Consentida, the site's six known obsidian sources, and approximate areas of Locona, Red-on-Buff, and west Mexican (Capacha and Opeño) ceramic traditions.

in color and texture. Other greenish stone items recovered at the site, such as a small axe or adze, may be made from fine-grained basalt. Although greenstone distributions recorded thus far at La Consentida (Hepp 2015:table 7.I) do not easily lend themselves to discussions of hierarchical social inequality, the presence of the apparently diverse material types from which these artifacts are made suggests down-theline interaction with distant regions such as central Mexico, the Gulf Coast, and Guatemala (Gendron et al. 2002; Pool 2013; Reilly 1995). Other worked stone such as small, one-handed manos from La Consentida are similar to those at Zohapilco (Niederberger 1976:láms. XXVIII.2, XXIX.I) and Tierras Largas phase sites in the Valley of Oaxaca (Winter and Sánchez Santiago 20I4b:IO-II). I do not suggest that manos were imported to La Consentida, but rather that they demonstrate stylistic and perhaps functional similarities with those found elsewhere.

Figurines and musical instruments may also indicate La Consentida's relationships with distant regions. One figurine (figure 2.15a) is reminiscent of Cruz A examples from the Mixteca Alta (Jeffrey Blomster, personal communication 20I5). At Zohapilco, Christine Niederberger (1976:lám. II.16-18) found ceramic aviform artifacts from various Formative period phases that are similar to musical instruments from La Consentida (e.g., figure 2.15b). Such bird instruments are also similar to Tierras Largas examples from highland Oaxaca, by virtue of their top-oriented 

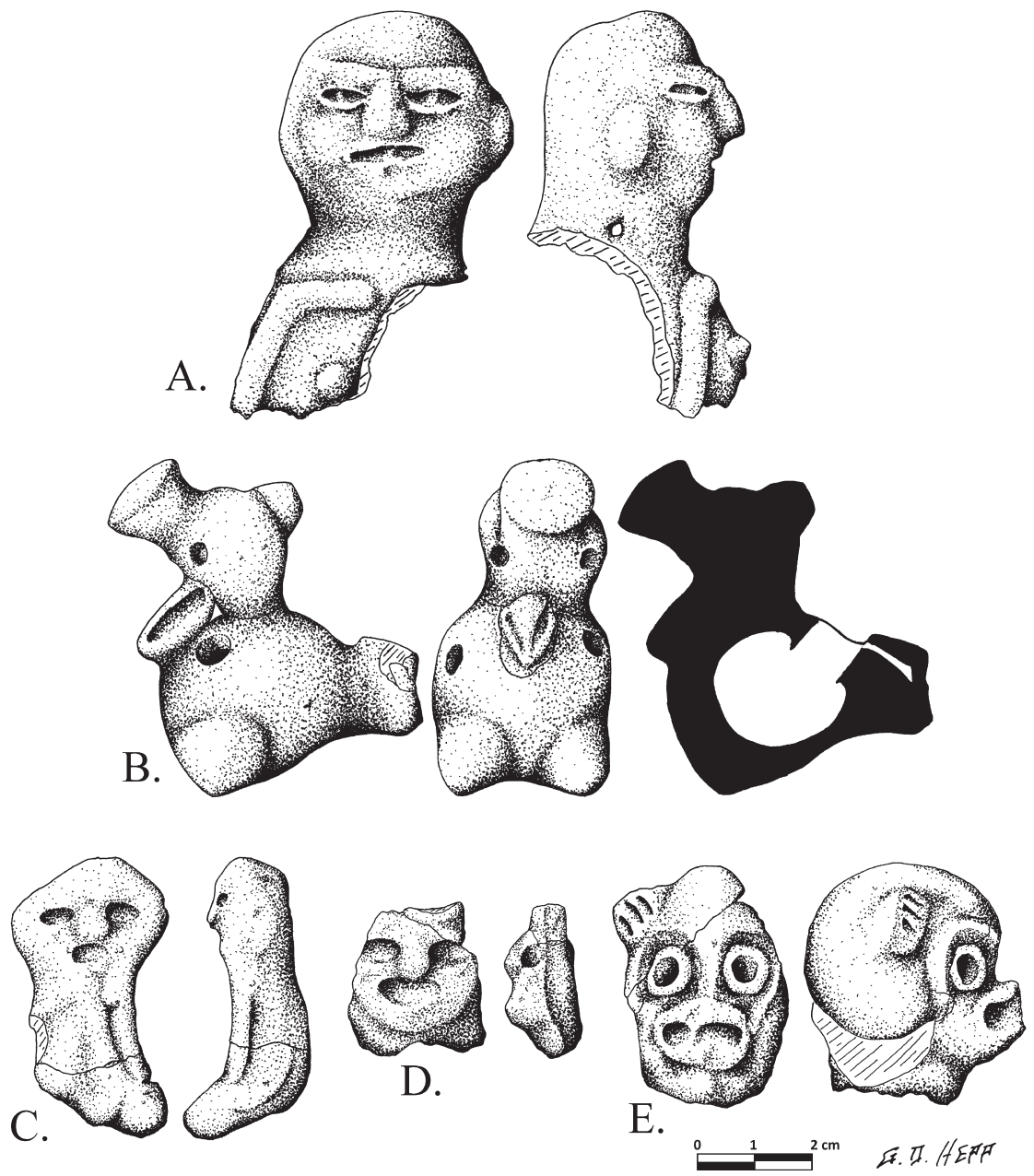

FIGURE 2.15. Figurine and musical instrument fragments suggesting interregional connections: (a) partial anthropomorph from hearth or shell pit in midden; (b) bird ocarina from a ceremonial cache; (c) anthropomorph from edge of domestic building; (d) anthropomorph from edge of domestic building; (e) probable monkey from near domestic building.

apertures (Hepp et al. 20I4; Rámirez Urrea 1993:I43). One of the earliest anthropomorphic figurines at Zohapilco (Niederberger 1976:lám. XCV, foto 16) perhaps shares stylistic similarities with La Consentida’s simplest anthropomorphs (figures 2.I5c and d). Another figurine from La Consentida appears to represent a monkey (figure 2.I5e). The shape of this artifact's head is consistent with those of capuchins 
and spider monkeys (Marroig and Cheverud 2005:fig. 2). One recent study (OrtizMartínez and Rico-Gray 2007) suggested that spider monkeys today sometimes live as far north as the southern Isthmus of Tehuantepec. People of the western Oaxaca coast may have seen monkeys in nearby areas, been aware of monkeys elsewhere, or imported monkeys or monkey skins from outside the region. Based on the paste of the figurines and instruments discussed here, there is no reason to suspect that any were imported.

\section{CONCLUSIONS}

A significant interpretation that arises from La Consentida's early dates relates to current explanations for how ceramics originated in Mesoamerica. Clark (e.g., Clark and Blake 1994) has argued that some of Mesoamerica's earliest ceramics arrived as a fully realized technological and stylistic tradition from Central America. On the basis of carbon dates recovered in context with Tlacuache sherds, ceramics from La Consentida represent well-dated examples of a pottery tradition contemporary with the Barra phase but formally dissimilar to it. I suggest that early ceramics of western Mesoamerica-including Tlacuache, Tierras Largas, Espiridión, Purrón, and west Mexican phases such as Capacha and Opeño-exemplify what other archaeologists have termed the Red-on-Buff horizon (see Clark 1991; Winter 1992:27-28; Winter and Sánchez Santiago 2014a). This interpretation explains why La Consentida's Tlacuache ceramics share little in common with the tecomate-emphasizing Barra phase (Clark and Blake 1994). Such marked differences between western Mesoamerican Red-on-Buff ceramics and the earliest Soconusco pottery may represent ancient cultural and linguistic divides between speakers of Otomanguean and Mije-Sokean languages, as well as independent origins of ceramic technology itself (see Clark 1991; Josserand et al. 1984; Winter and Sánchez Santiago 2014a). Based on available evidence, including AMS radiocarbon dates from secure contexts (table 2.I), Tlacuache ceramics represent one of the earliest-known example of the Red-on-Buff horizon in Mesoamerica. Given the vessel form variety present at the site, however, earlier examples must exist, perhaps in underexplored regions of coastal Oaxaca and Guerrero.

Evidence for the exchange of pottery styles, obsidian, greenstone, and iconography suggests a complex network of interregional relationships in which La Consentida was involved. In some cases, these exchange relationships appear to contradict one another. XRF sourcing has determined that La Consentida's obsidian was imported from central Mexican and Gulf Coast sources. The lack of west Mexican and Central American obsidian sets La Consentida apart from some of its Early Formative period contemporaries and sites occupied shortly thereafter 
(Blomster and Glascock 2010; Clark and Salcedo Romero 1989; Zeitlin 1982). This pattern seems at odds with ceramic decoration styles that suggest ties to west Mexico, as well as with the presence of greenstone possibly imported from Central America. What these various lines of evidence do clearly demonstrate is that La Consentida was well integrated into broad interaction networks. It is not yet clear what goods La Consentida exported in exchange for imported materials, though research in the areas surrounding the site is beginning to provide promising results. For example, Lock and colleagues (2014; see also Goman et al. 2005) noted that carbon dates in the salt flats adjacent to La Consentida suggest possible Early Formative salt procurement. Salt may have been a valuable trade good for exchange with people providing imported obsidian and greenstone, though the occupational history of La Consentida is not consistent with the "special use" salt procurement practices identified at some early coastal sites, such as El Varal (Lesure 2009).

Kelly (1980:37; see also Anawalt 1998) believed that the Capacha phase corroborated the hypothesis of Ford (1969:166), who argued that the early ceramics of Pacific coastal Mexico should have more in common with early South American pottery from "Puerto Hormiga, Machalilla, or Valdivia" than with the early traditions of central Mexico, such as that of the Tehuacán Valley. Kelly (1980:37) wrote that the sunburst motif appeared to be unique to Capacha, but as I have discussed, she also predicted other "landfalls" of this decorative style along the Pacific coast. I believe that the presence of the sunburst motif at La Consentida strongly suggests that Kelly's predictions about a Pacific coastal interaction network need to be revisited. It appears that two contemporaneous ceramic traditions coexisted in Early Formative Mesoamerica. This interpretation suggests that the Soconusco's Barra and Locona phase pottery, perhaps introduced through Central America, met with a contemporaneous Red-on-Buff horizon that included the Tlacuache, Tierras Largas, and other western ceramic traditions and emphasized the use of jars, bowls, and bottles over that of tecomates (Clark 1991; Winter 1992:27-28; Winter and Sánchez Santiago 2014a). Intriguingly, Tlacuache wares seem to combine the decorative motifs of a coastal tradition with the utilitarian wares of highland Mesoamerica. This seems not to fit with Kelly's predictions, and merits further investigation into the influences on vessel form and decorative style at the site.

It is worthwhile, I think, to make a final point about identifying ancient networks of interaction and establishing chronologies on the basis of artifact comparisons. There are numerous similarities in ceramic styles between La Consentida's Tlacuache phase and those of other regions such as the Valley of Oaxaca, central Mexico, and west Mexico. None of these other phases, however, contains all of the vessel forms and decorative motifs identified in the Tlacuache assemblage. This finding serves as a warning against facile associations between Tlacuache and other 
traditions such as Tierras Largas. Numerous Early Formative ceramic traditions, which seem to exemplify the Red-on-Buff horizon, include similar styles of jars, bottles, semispherical kidney-shaped bowls, and interior-incised bowls (Clark 1991; Winter 1992:27-28). Rather than indicating direct ties between the Tlacuache and Tierras Largas ceramic traditions, for example, these stylistic similarities indicate broad patterns of interaction and exchange across large geographic areas (see proposed ceramic interaction map in Clark 1991:fig. 8). Perhaps most significant, ceramics from La Consentida appear consistent with the presence of two initial Early Formative period traditions (Barra/Locona and Red-on-Buff), the former coming north from Central America via the Soconusco, and the latter developing in or arriving to western Mesoamerica and exemplified by the Tlacuache assemblage as one of its earliest known variants to date (Clark 1991; Winter 1992:27-28). These two early ceramic horizons may serve as material evidence for macroregional patterns of southeastern and northwestern Mesoamerican cultural diversity, perhaps including divisions between the Otomanguean and Mije-Sokean language families (Josserand et al. 1984; Lowe 1977; Winter and Sánchez Santiago 2014a). Such panregional cultural patterns have long been the subject of research and speculation by archaeologists, linguists, and sociocultural anthropologists, but they remain poorly understood in terms of their ancient histories. Evidence for interaction from La Consentida and other early village sites may help to improve that situation.

ACKNOWLEDGMENTS. The research presented here was made possible by funding from the National Science Foundation (Grant \#: BCS-1213955), a Fulbright-García Robles scholarship (Grantee ID: 34115725), the Colorado Archaeological Society, and the University of Colorado at Boulder. Thanks are due to the Instituto Nacional de Antropología e Historia, for permitting this work, and to the people of coastal Oaxaca for their collaboration. I am also grateful to the editors of this volume for inviting me to participate and to the anonymous reviewers who provided helpful feedback.

\section{NOTES}

I. Marcus Winter (personal communication, 2013) suggests that Espiridión should be incorporated into the Tierras Largas phase, due to similarities in the ceramics.

2. Comparison based on published reports of Barra phase vessel ratios (Clark and Blake 1994:25) and my own estimated percentages from several Tierras Largas contexts (Flannery and Marcus 1994:tables I0.I, I0.2, and II.I). Tierras Largas percentages based on counts of diagnostic sherds, and Tlacuache ratios based on grams of diagnostic sherds. Tierras Largas percentages do not add up to roo due to unidentified sherds counted in aforementioned tables. 
3. Although the nonexistence of jars and bottles in the Barra assemblage and the very low percentages of tecomates in the other assemblages make a Chi-square test useless, a Fisher's exact test demonstrates that these phases differ in a statistically significant way. When just the Tlacuache and Tierras Largas phases are compared using a Fisher's exact test, the differences between them are statistically significant $(p<0.000 \mathrm{I})$. All statistical tests were performed using JMP ${ }^{\mathrm{TM}}$ Pro II.

4. See Hepp (2015:95-18I) for a detailed discussion of excavations at La Consentida.

5. According to Bartolomé and Barabas (1996:170-172), modern Chatino children are weaned at about two years of age and quickly take on mature social roles. For example, girls begin making tortillas by three or four years old. Modern Zapotecs also wean early and transition their children to adult foods and economic roles quickly (Nader 1969:356; Parsons 1936:85-86; Sellen 200I; Taylor 1960:192, 195, 328). Although such information conflicts with the interpretation that La Consentida's grater bowls were used in weaning, it is important to remember that this ancient community had very different dietary practices than do modern groups (see Hepp et al. 2017).

6. Various type specimens for Ojochi and Bajío phase ceramics. Courtesy of the Peabody Museum of Natural History, Division of Anthropology, Yale University; http://peabody .yale.edu.

\section{REFERENCES}

Anawalt, Patricia Rieff 1998. "They Came to Trade Exquisite Things: Ancient West Mexican-Ecuadorian Contacts." In Ancient West Mexico: Art and Archaeology of the Unknown Past, edited by Richard F. Townsend, 232-249. Art Institute of Chicago, Chicago.

Arnold, Philip J., III. 2003. "Early Formative Pottery from the Tuxtla Mountains and Implications for Gulf Olmec Origins." Latin American Antiquity I4(I):29-46.

Arnold, Philip J., III. 2009. "Settlement and Subsistence among the Early Formative Gulf Olmec." Journal of Anthropological Archaeology 28(4):397-4II.

Bartolomé, Miguel A., and Alicia M. Barabas. 1996. Tierra de la palabra: Historia y etnografía de los Chatinos de Oaxaca. 2nd ed. Instituto Oaxaqueño de las Culturas, INAH, Mexico City.

Blake, Michael, and John E. Clark. 1999. “The Emergence of Hereditary Inequality: The Case of Pacific Coastal Chiapas, Mexico." In Pacific Latin America in Prehistory: The Evolution of Archaic and Formative Cultures, edited by Michael Blake, 55-73. Washington State University Press, Pullman.

Blomster, Jeffrey P., and Michael D. Glascock. 2010. "Procurement and Consumption of Obsidian in the Early Formative Mixteca Alta: A View from the Nochixtlán Valley, 
Oaxaca, Mexico." In Crossing the Straits: Prehispanic Obsidian Source Exploitation in the North Pacific Rim, edited by Yaroslav V. Kuzmin and Michael D. Glascock, 183-200. Archaeopress, Oxford.

Bradley, John E. 1994. "Trondadora Vieja: An Archaic and Early Formative Site in the Arenal Region." In Archaeology, Volcanism, and Remote Sensing in the Arenal Region, Costa Rica, edited by Payson D. Sheets and Brian R. McKee, 73-86. University of Texas Press, Austin.

Brush, Charles F. 1965. "Pox Pottery: Earliest Identified Mexican Ceramic." Science 149(3680):194-195.

Brush, Charles F. 1969. A Contribution to the Archaeology of Coastal Guerrero, Mexico. PhD dissertation. Columbia University, New York City. University Microfilms, Ann Arbor.

Carballo, David M. 2009. "Household and Status in Formative Central Mexico: Domestic Structures, Assemblages, and Practices at La Laguna, Tlaxcala." Latin American Antiquity 20(3):473-502.

Caso, Alfanso, Ignacio Bernal, and Jorge R. Acosta. 1967. La cerámica de Monte Albán. Vol. I2. INAH, Mexico City.

Cheetham, David. 2010. "Cultural Imperatives in Clay: Early Olmec Carved Pottery from San Lorenzo and Cantón Corralito." Ancient Mesoamerica 2I(I):165-I85.

Clark, John E. 1991. "The Beginnings of Mesoamerica: Apologia for the Soconusco Early Formative." In The Formation of Complex Society in Southeastern Mesoamerica, edited by William R. Fowler Jr., I3-26. CRC Press, Boca Raton.

Clark, John E. 2004. "Mesoamerica Goes Public: Early Ceremonial Centers, Leaders, and Communities." In Mesoamerican Archaeology: Theory and Practice, edited by Julia A. Hendon and Rosemary A. Joyce, 43-72. Blackwell, Malden.

Clark, John E., and Michael Blake. 1994. "The Power of Prestige: Competitive Generosity and the Emergence of Rank Society in Lowland Mesoamerica." In Factional Competition and Political Development in the New World, edited by Elizabeth M. Brumfiel and John W. Fox, 17-30. Cambridge University Press, Cambridge.

Clark, John E., and David Cheetham. 2002. "Mesoamerica's Tribal Foundations." In The Archaeology of Tribal Societies, edited by William A. Parkinson, 278-339. International Monographs in Prehistory, Ann Arbor.

Clark, John E., and Dennis C. Gosser. 1995. "Reinventing Mesoamerica’s First Pottery." In The Emergence of Pottery: Technology and Innovation in Ancient Societies, edited by William Barnett and John W. Hoopes, 209-221. Smithsonian Institution Press, Washington, DC.

Clark, John E., Mary E. Pye, and Dennis C. Gosser. 2007. “Thermolithics and Corn Dependency in Mesoamerica." In Archaeology, Art, and Ethnogenesis in Mesoamerican Prehistory: Papers in Honor of Gareth W. Lowe, edited by Lynneth S. Lowe and Mary E. Pye, 23-42. Brigham Young University Press, Provo. 
Clark, John E., and Tamara Salcedo Romero. 1989. “Ocós Obsidian Distribution in Chiapas, Mexico." In New Frontiers in the Archaeology of the Pacific Coast of Southern Mesoamerica, edited by Frederick J. Bove and Lynette Heller, 15-24. Arizona State University Press, Tempe.

Cyphers, Ann, and Judith Zurita-Noguera. 2012. "Early Olmec Wetland Mounds: Investing Energy to Produce Energy." In Early New World Monumentality, edited by Richard L. Burger and Robert M. Rosenswig, 138-173. University Press of Florida, Gainesville.

Drennan, Robert D. 1984. "Long-Distance Movement of Goods in the Mesoamerican Formative and Classic." American Antiquity 49(I):27-43.

Flannery, Kent V. 1968. “The Olmec and the Valley of Oaxaca: A Model for Interregional Interaction in Formative Times." In Dumbarton Oaks Conference on the Olmec, October 28 th and 29th, 1967, edited by Elizabeth P. Benson, 79-117. Dumbarton Oaks, Washington, DC.

Flannery, Kent V., and Joyce Marcus. 1994. Early Formative Pottery of the Valley of Oaxaca, Mexico. University of Michigan Press, Ann Arbor.

Flannery, Kent V., and Joyce Marcus, eds. 2003. The Cloud People: Divergent Evolution of the Zapotec and Mixtec Civilizations. Percheron Press, New York.

Ford, James A. 1969. A Comparison of Formative Cultures in the Americas. Vol. II. Smithsonian Contributions to Anthropology. Smithsonian Institution Press, Washington, DC.

García Cook, Ángel, and Beatriz Leonor Merino Carrión. 2005. "El inicio de la producción alfarera en el México Antiguo." In La producción alfarera en el México Antiguo I, edited by Beatriz Leonor Merino Carrión and Angel García Cook, 73-II9. Instituto Nacional de Antropología e Historia, Mexico City.

Gendron, François, David C. Smith, and Aïcha Gendron-Badou. 2002. "Discovery of Jadeite-Jade in Guatemala Confirmed by Non-Destructive Raman Microscopy." Journal of Archaeological Science 29(8):837-85 I.

Gillespie, Susan D. 1987. Excavaciones en Charco Redondo 1986. Informe al Consejo de Arqueología y al Centro INAH Oaxaca, Mexico.

Glascock, Michael D. 20II. X-ray Fluorescence Analysis of Obsidian Artifacts from La Consentida, Oaxaca, Mexico. Report produced at University of Missouri Archaeometry Laboratory, Columbia.

Goman, Michelle, Arthur A. Joyce, and Raymond G. Mueller. 2005. "Stratigraphic Evidence for Anthropogenically Induced Environmental Change from Oaxaca, Mexico.” Quaternary Research 63(3):250-260.

Grove, David C. 1984. Chacatzingo: Excavations on the Olmec Frontier. Thames and Hudson, London. 
Grove, David C. 1988. Archaeological Investigations on the Pacific Coast of Oaxaca. Report submitted to the National Geographic Society, University of Illinois, Urbana-Champaign.

Hepp, Guy David. 20ria. "El Proyecto La Consentida 2009." In El Proyecto Río Verde: Informe Técnico de la Temporada de 2009, edited by Sarah B. Barber and Arthur A. Joyce, I46-I84. Informe al Consejo de Arqueología y al Centro INAH Oaxaca, Mexico.

Hepp, Guy David. 2orrb. "Análisis de los artefactos de La Consentida." In El Proyecto Rio Verde: Informe Técnico de la Temporada de 2009, edited by Sarah B. Barber and Arthur A. Joyce, 289-314. Informe al Consejo de Arqueología y al Centro INAH Oaxaca, Mexico.

Hepp, Guy David. 2014. "La Consentida: Among Mesoamerica's Earliest for Ceramics and Earthen Architecture." Paper presented at the 79th Annual Meeting of the Society for American Archaeology, Austin, TX.

Hepp, Guy David. 2015. La Consentida: Initial Early Formative Period Settlement, Subsistence, and Social Organization on the Pacific Coast of Oaxaca, Mexico. Unpublished $\mathrm{PhD}$ dissertation, Department of Anthropology, University of Colorado, Boulder.

Hepp, Guy David, Sarah B. Barber, and Arthur A. Joyce. 2014. "Communing with Nature, the Ancestors, and the Neighbors: Ancient Ceramic Musical Instruments from Coastal Oaxaca, Mexico." World Archaeology 46(3):380-399.

Hepp, Guy David, Paul A. Sandberg, and José Aguilar. 2017. “Death on the Early Formative Oaxaca Coast: The Human Remains of La Consentida." Journal of Archaeological Science: Reports 13:703-711.

Hoopes, John W. 1994. "Ceramic Analysis and Culture History in the Arenal Region." In Archaeology, Volcanism, and Remote Sensing in the Arenal Region, Costa Rica, edited by Payson Sheets and Brian R. McKee, 158-210. University of Texas Press, Austin.

Inomata, Takeshi, Daniela Triadan, Kazuo Aoyama, Victor Castillo, and Hitoshi Yonenobu. 2013. "Early Ceremonial Constructions at Ceibal, Guatemala, and the Origins of Lowland Maya Civilization." Science 340(26):467-47I.

Josserand, J. Kathryn, Marcus Winter, and Nicholas A. Hopkins, eds. 1984. Essays in Otomanguean Culture History. Department of Anthropology, Vanderbilt University, Nashville.

Joyce, Arthur A. 1991. Formative Period Occupation in the Lower Rio Verde Valley, Oaxaca, Mexico: Interregional Interaction and Social Change. Unpublished $\mathrm{PhD}$ dissertation, Department of Anthropology, Rutgers, the State University of New Jersey, New Brunswick.

Joyce, Arthur A. 2005. "La Arqueología del Bajo Río Verde." Acervos: Boletín de los Archivos y Bibliotecas de Oaxaca 7(29):16-36.

Joyce, Arthur A. 2010. Mixtecs, Zapotecs, and Chatinos: Ancient Peoples of Southern Mexico. Wiley-Blackwell, Malden. 
Joyce, Arthur A. 2013. "Polity and Ecology in Formative Period Coastal Oaxaca: An Introduction." In Polity and Ecology in Formative Period Coastal Oaxaca, edited by Arthur A. Joyce, I-4I. University Press of Colorado, Boulder.

Joyce, Arthur A., J. Michael Elam, Michael D. Glascock, Hector Neff, and Marcus Winter. 1995. "Exchange Implications of Obsidian Source Analysis from the Lower Río Verde Valley, Oaxaca, Mexico." Latin American Antiquity 6(I):3-15.

Joyce, Arthur A., Maxine Oland, and Peter Kroefges. 2009. "Recorrido Regional de Superficie." In El Proyecto Rio Verde, edited by Arthur A. Joyce and Marc N. Levine, 322-353. Informe Final Entregado al Consejo de Arqueología y el Centro INAH Oaxaca, Mexico. Joyce, Rosemary A. 2004. "Mesoamerica: A Working Model for Archaeology." In Mesoamerican Archaeology: Theory and Practice, edited by Julia A. Hendon and Rosemary A. Joyce, I-42. Blackwell, Malden.

Joyce, Rosemary A., and John S. Henderson. 200I. "Beginnings of Village Life in Eastern Mesoamerica." Latin American Antiquity I2(I):5-23.

Joyce, Rosemary A., and John S. Henderson. 2007. "From Feasting to Cuisine: Implications of Archaeological Research in an Early Honduran Village.” American Anthropologist Io9 (4):642-653.

Kelly, Isabel. 1974. “Stirrup Pots from Colima: Some Implications.” In The Archaeology of West Mexico, edited by Betty Bell, 206-211. Sociedad de Estudios Avanzados del Occidente de México, Ajijic, Jalisco, Mexico.

Kelly, Isabel. 1980. Ceramic Sequence in Colima: Capacha, an Early Phase. Anthropological Papers of the University of Arizona, No. 37. University of Arizona Press, Tucson.

Kirchhoff, Paul. 1943. "Mesoamérica: Sus límites geográficos, composición étnica y caracteres culturales." Acta Americana I(I):92-107.

Lesure, Richard G. 2004. "Shared Art Styles and Long-Distance Contact in Early Mesoamerica." In Mesoamerican Archaeology, edited by Julia A. Hendon and Rosemary A. Joyce, 73-96. Blakwell, Malden.

Lesure, Richard G., ed. 2009. Settlement and Subsistence in Early Formative Soconusco: El Varal and the Problem of Inter-Site Assemblage Variation. Cotsen Institute of Archaeology Press, Los Angeles.

Lesure, Richard G., ed. 2011. Early Mesoamerican Social Transformations. University of California Press, Berkeley.

Lock, Gracie, Michelle Goman, Arthur A. Joyce, Victor Emmanuel Salazar Chavez, and Guy David Hepp. 2014. "Salinas: Expanding Our Understanding of Prehistoric Land Use in the Coastal Zone of the Lower Río Verde Valley, Oaxaca, Mexico." Paper presented at the Association of American Geographers Annual Meeting, Tampa, FL.

Lohse, Jon C. 2010. "Archaic Origins of the Lowland Maya." Latin American Antiquity $2 \mathrm{I}(3): 3 \mathrm{I} 2-352$. 
Lowe, Gareth W. 1977. "The Mixe-Zoque as Competing Neighbors of the Early Lowland Maya." In The Origins of Maya Civilization, edited by Richard E. W. Adams, 197-248. University of New Mexico Press, Albuquerque.

Lowe, Gareth W. 2007. "Early Formative Chiapas: The Beginnings of Civilization in the Central Depression of Chiapas." In Archaeology, Art, and Ethnogenesis in Mesoamerican Prehistory: Papers in Honor of Gareth W. Lowe, edited by Lynneth S. Lowe and Mary E. Pye, 63-108. Brigham Young University, Provo.

MacNeish, Richard S. 1972. "The Evolution of Community Patterns in the Tehuacán Valley of Mexico and Speculations about the Cultural Process." In Man, Settlement, and Urbanism, edited by Peter J. Ucko, Ruth Tringham, and G. W. Dimbleby, 67-93. Duckworth, London.

Marcus, Joyce, and Kent V. Flannery. 1996. Zapotec Civilization: How Urban Society Evolved in Mexico's Oaxaca Valley. Thames and Hudson, London.

Marroig, Gabriel, and James A. Cheverud. 2005. "Size as a Line of Least Evolutionary Resistance: Diet and Adaptive Morphological Radiation in New World Monkeys.” Evolution 59(5):1128-1142.

Martínez López, Cira, Robert Markens, Marcus Winter, and Michael D. Lind. 2000. Cerámica de la fase Xoo (Epoca Monte Albán IIIB-IV) del Valle de Oaxaca. Instituto Nacional de Antropología e Historia, Oaxaca.

Morell-Hart, Shanti, Rosemary A. Joyce, and John S. Henderson. 20I4. "Multi-Proxy Analysis of Plant Use at Formative Period Los Naranjos, Honduras." Latin American Antiquity 25(I):65-8I.

Mountjoy, Joseph B. 1994. "Capacha: Una cultura enigmática del Occidente de México.” Arqueologia Mexicana 2(9):39-42.

Mountjoy, Joseph B. 1998. "The Evolution of Complex Societies in West Mexico: A Comparative Perspective." In Ancient West Mexico: Art and Archaeology of the Unknown Past, edited by Richard F. Townsend, 250-265. Art Institute of Chicago, Chicago.

Mountjoy, Joseph B. 2006. "Excavation of Two Middle Formative Cemeteries in the Mascota Valley of Jalisco, México." Electronic document, Foundation for the Advancement of Mesoamerican Studies, Inc., http://www.famsi.org/reports/03009/, accessed August 30, 2015.

Mountjoy, Joseph B. 2012. El Pantano y otros sitios del Formativo Medio en el Valle de Mascota, Jalisco. Secretaría de Cultura, Gobierno de Jalisco, Guadalajara.

Nader, Laura. 1969. "The Zapotec of Oaxaca." In Handbook of Middle American Indians (Ethnology, I), edited by Evon Z. Vogt, 329-359. University of Texas Press, Austin.

Niederberger, Christine. 1976. Zohapilco: Cinco milenios de ocupación humana en un sitio lacustre de la Cuenca de México. Colección Científica 30. INAH, Mexico City. 
Niederberger, Christine. 1979. "Early Sedentary Economy in the Basin of Mexico." Science 203(4376):13I-I42.

Oliveros, José Arturo. 1974. “Nuevas exploraciones en el Opeño, Michoacán.” In The Archaeology of West Mexico, edited by Betty Bell, I82-201. Sociedad de Estudios Avanzados del Occidente de México, A.C., Ajijic, Jalisco, Mexico.

Ortiz-Martínez, Teresita, and Victor Rico-Gray. 2007. “Spider Monkeys (Ateles geoffroyi vellerosus) in a Tropical Deciduous Forest in Tehuantepec, Oaxaca, Mexico.” Southwestern Naturalist 52(3):393-399.

Parsons, Elsie Clews. 1936. Mitla, Town of the Souls, and Other Zapoteco-Speaking Pueblos of Oaxaca, Mexico. University of Chicago Press, Chicago.

Piña Chan, Roman. 1958. Tlatilco. Serie Investigaciones, vol. I. Instituto Nacional de Antropología e Historia, Mexico City.

Pires-Ferreira, Jane W. 1978. "Obsidian Exchange Networks: Inferences and Speculations on the Development of Social Organization in Formative Mesoamerica." In Cultural Continuity in Mesoamerica, edited by David L. Browman, 49-78. Mouton Publishers, The Hague.

Pires-Ferreira, Jane W. 2009. “Obsidian Exchange in Formative Mesoamerica." In The Early Mesoamerican Village: Updated Edition, edited by Kent V. Flannery, 292-306. Left Coast Press, Walnut Creek.

Pool, Christopher A. 2013. "Coastal Oaxaca and Formative Developments in Mesoamerica." In Polity and Ecology in Formative Period Coastal Oaxaca, edited by Arthur A. Joyce. 30I-328. University Press of Colorado, Boulder.

Powis, Terry G., Ann Cyphers, Nilesh W. Gaikwad, Louis Grivetti, and Kong Cheong. 2011. "Cacao Use and the San Lorenzo Olmec." Proceedings of the National Academy of Sciences I08(2I):8595-8600.

Powis, Terry G., W. Jeffrey Hurst, Ma. del Carmen Rodríguez Martínez, Ponciano Ortiz Ceballos, Michael Blake, David Cheetham, Michael D. Coe, and John G. Hodgson. 2007. “Oldest Chocolate in the New World." Antiquity Project Gallery 8I(314): https:// www.antiquity.ac.uk/projgall/powis314/.

Powis, Terry G., W. Jeffrey Hurst, Ma. del Carmen Rodríguez Martínez, Ponciano Ortiz Ceballos, Michael Blake, David Cheetham, Michael D. Coe, and John G. Hodgson. 2008. "The Origins of Cacao Use in Mesoamerica." Mexicon 30(2):35-38.

Rámirez Urrea, Susana. 1993. Hacienda Blanca: Una aldea a través del tiempo, en el Valle de Etla, Oaxaca. Unpublished BA thesis, Universidad Autónoma de Guadalajara, Guadalajara.

Reilly, F. Kent, III. 1995. "Art, Ritual, and Rulership in the Olmec World.” In The Olmec World: Ritual and Rulership, 27-47. Art Museum, Princeton University, Princeton. 
Rodríguez Martínez, Ma. del Carmen, and Ponciano Ortiz Ceballos. 1997. "Olmec Ritual and Sacred Geography at Manatí." In Olmec to Aztec: Settlement Patterns in the Ancient GulfLowlands, edited by Barbara L. Stark and Philip J. Arnold III, 68-95. University of Arizona Press, Tucson.

Rosenswig, Robert M. 2010. The Beginnings of Mesoamerican Civilization: Inter-Regional Interaction and the Olmec. Cambridge University Press, Cambridge.

Schmidt Schoenberg, Paul. 2006. “La época prehispánica en Guerrero." Arqueología Mexicana 82:28-37.

Seinfeld, Daniel M., Christopher von Nagy, and Mary E. D. Pohl. 2009. "Determining Olmec Maize Use through Bulk Stable Carbon Isotope Analysis.” Journal of Archaeological Science 36(II):2560-2565.

Sellen, Daniel W. 200I. "Comparison of Infant Feeding Patterns Reported for Nonindustrial Populations with Current Recommendations." Journal of Nutrition I3I(I0):2707-2715.

Taylor, Robert B. 1960. Teotitlan del Valle: A Typical Mesoamerican Community. Unpublished $\mathrm{PhD}$ dissertation, University of Oregon, Eugene.

Tremain, Cara Grace. 20I4. "Pre-Columbian 'Jade': Towards an Improved Identification of Green-Colored Stone in Mesoamerica." Lithic Technology 39(3):137-150.

Williams, David Thomas. 20I2. "Typological and Geochemical Analysis of Obsidian Artifacts: A Diachronic Study from the Lower Río Verde Valley, Oaxaca, Mexico." Unpublished MA thesis, University of Colorado, Boulder.

Williams, Eduardo. 2007. "Prehispanic West México: A Mesoamerican Culture Area. Foundation for the Advancement of Mesoamerican Studies, Inc., Crystal River, FL." Electronic document, http://www.famsi.org/research/williams/, accessed August 30, 2015. Winter, Marcus. 1992. Oaxaca: The Archaeological Record. P.G.O., Oaxaca, Mexico.

Winter, Marcus, and Gonzalo Sánchez Santiago, eds. 2014a Panorama arqueológico: Dos Oaxacas. Centro INAH Oaxaca, Oaxaca, Mexico.

Winter, Marcus, and Gonzalo Sánchez Santiago. 2014b. “Introducción: Dos Oaxacas.” In Panorama arqueológico: Dos Oaxacas, edited by Marcus Winter and Gonzalo Sánchez Santiago, I-30. Centro INAH Oaxaca, Oaxaca, Mexico.

Zárate Morán, Roberto. 1995. "El Corozal, un sitio arqueológico en la Costa del Pacífico de Oaxaca." Cuadernos del Sur: Ciencias Sociales 3(10):9-36.

Zeitlin, Robert N. 1982. “Toward a More Comprehensive Model of Interregional Commodity Distribution: Political Variables and Prehistoric Obsidian Procurement in Mesoamerica." American Antiquity 47(2):260-275.

Zeitlin, Robert N. 1994. "Accounting for the Prehistoric Long-Distance Movement of Goods with a Measure of Style." World Archaeology 26(2):208-234. 


\title{
Chapter 3
}

\section{The Role of Interregional Interaction in Mesoamerican Script Development}

\author{
Joshua D. Englehardt and Michael D. Carrasco
}

Current scholarship on the emergence of writing systems in Mesoamerican strongly suggests that interregional interaction played an integral role in facilitating the development of Mesoamerican scripts and iconographies during the Middle to Late Formative period (ca. I000 BC-AD 250; see, e.g., Houston 2004; Justeson 2012; Justeson and Matthews 1990; Robertson 2004, among others). In two other venues we have examined the nature of signs in Middle Formative scripts and iconography and the formation of Mesoamerican script conventions, respectively (Carrasco and Englehardt 2015, in press). In this chapter we turn to a series of key examples from the Middle Formative period, including the knotted vegetal headdress, Ajaw glyph variants, and Lazy-S, to examine more precisely how "exchange" or the transfer of signs occurred. To understand how such interchange works in the context of visual signs, we adopt linguistic concepts such as borrowing, copying, transferring, translation, and transmutation to account for the different means by which a specific sign may enter a particular system - whether or not that system corresponds to a particular language group - and the complex changes in meaning, form, and context that it might undergo. Like writing conventions or sign categories, the mechanisms of sign exchange enabled complex reuses, innovations, and recontextualizations ${ }^{1}$ of specific signs that greatly enriched sign inventories and layers of meaning that accreted as signs were circulated among and between distinct scribal and artistic traditions.

By focusing on these issues we hope to transcend models that uncritically posit the seamless flow of signs from one system to the next and likewise those that a 
priori reject connections. ${ }^{2}$ That is to say, signs came with meanings tied to the semantics of specific terms, but also arrived within the additional aura of the donor system (or culture), which lent a significance that stood apart from the core semantic field of the denoted word. In Mesoamerican contexts this additional layer often has allowed for the identification of "prestige" donor cultures, in this case the Gulf Cost Olmec, in the same way that loanwords indicate the direction of borrowing (e.g., Mije-Sokean in the Middle Formative or Nahuatl in the Postclassic periods).

Many scholars accept the role that interaction played in the development of Mesoamerican and other writing systems (see, e.g., Fields 1991; Joyce et al. 1991; Justeson et al. 1985; Reilly 1996; Schmandt-Besserat 2007, 2010). They correctly cite the existence of common visual elements and formal features across regional scripts and iconographies as proof of historical connections between groups, which may also be reflected in common suites of material culture or linguistic features (see the chapters by Kerry M. Hull [chapter 4], Philip J. Arnold III and Lourdes Budar [chapter 7], and Charles L. F. Knight [chapter 8], in this volume). As in similar cases worldwide, more refined chronological understanding of particular historic traditions permits the inference of the directional flow of iconography, styles, and symbolism. Nonetheless, the way in which interaction figured in initial script development and the mechanisms through which interaction may have promoted sign recontextualization or adaptation remains relatively understudied, in Mesoamerica at least. That is, while it is sometimes apparent that a motif is shared across regions, it is unclear how this came to be the case.

For example, Chinese writing prompted Koreans to develop Han'gŭl, which was a system better capable of representing the sounds and structure of their language. Nevertheless, Chinese characters have continued to function in the system to signal what might be called a prestige literacy (Kim-Renaud 1997). Similarly the development of various systems in Japan (Lurie 20II; Seeley 199I), particular the kana systems, attempted to facilitate the writing of Japanese, a language that, like Korean, is rich in verbal morphology and quite unlike the monosyllabic words and limited affixation in Classical Chinese. In the case of the kana, however, each syllabogram's form was based in part on Chinese characters. These two well-known examples provide clear instances of how a prestige system (Chinese writing) came to influence, indeed prompt, the innovation of the Japanese and Korean writing systems. Chinese provided signs as well as the conventions and methods of writing to each recipient culture. Convincing arguments have been made for the presence of a similar process in the innovation of Egyptian Hieroglyphics (Schmandt-Besserat 2010). Working from these instances of script innovation, Lacadena (2010) suggests an analogous developmental trajectory for the Maya script. Based on phonological information revealed with an understanding of the historic and formal development of the 
Maya syllabary, he argues that it resulted as a response to contact with Mije-Sokean speakers and Epi-Olmec writing.

In this chapter, we explore an earlier moment in the development of Mesoamerican script and iconographic systems to focus in on the initial innovation of writing and interregional interaction's role in this process. ${ }^{3}$ We seek to identify the role played by interaction in script development and the relationship between incipient writing and contemporaneous iconographic systems in the late Early to Middle Formative period ( $1400-400 \mathrm{BC}$ ). To that end, we examine key examples in which signs and conventions from an iconographic system have been recontextualized in Mesoamerican scripts. Accordingly, we are particularly interested in how the selection of signs, their curation in new contexts, and subsequent changes in meaning (e.g., more phonologically restricted readings and/or narrowed meanings) actually occurred. This recontextualization is key to what we call the "transmutation" of signs from a pictorial mode to visual words. Here we follow Jakobson's (1959:233) sense of transmutation, especially as developed in the work of Carlo Severi (2014:57-58).

As Jakobson (1959:233) defined it, transmutation (or intersemiotic translation) "is an interpretation of verbal signs by means of signs of nonverbal sign systems." Severi (2014:47) extends this idea to include the process in which "the interpretation of signs belonging to a nonverbal system can also be realized by means of signs belonging to another nonverbal system." He suggests that we consider that "a statement or a notion usually expressed through words can be first 'translated' into images, and then further 'translated' (one should say 'transmutated') into music or ritual gestures." By "words" he would seem to mean verbal signs which would appear to be limited to the verbal signs of speech. If so, then writing should be considered along with other nonverbal signs, although one very closely linked to the representation of words. It is important to note that pictorial signs and writing are both nonverbal signs if one considers verbal signs truly present only in speech. In this way the process of transmutation occurs initially in the representation of words in writing. That writing is a nonverbal sign might appear counterintuitive, but it only underscores how easily and commonly language and writing are conflated, as if the medium of writing were transparent. From this perspective writing is a transmutation of a verbal sign into a more-or-less equivalent visual sign, albeit one that is highly regularized and deployed within a relatively rigid set of conventions that often are indexical to the temporal progression of speech. In this way, the movement from pictorial sign to written sign is also a transmutation, one greatly facilitated by the recontextualization of a sign within script conventions.

In viewing the situation as such, the debate of what is writing recedes to reveal the far-more-interesting question of how a plurality of sign systems works both in relation to verbal signs and in relation to one another. Accordingly, in this 
chapter we address the mechanisms that allowed for the creation of a diversity of Mesoamerican scripts and iconographies and how these systems interacted through the processes of recontextualization and transmutation. In this sense, we center on questions of "how" rather than "why." We focus specifically on the range of processes by which signs were transferred from one system to another-whether this is from a pictorial system into a writing system or between pictorial systems.

The disciplinary perspectives of epigraphy, linguistics, and art history provide several ways to approach these issues. Most scholars working on Mesoamerican scripts do not restrict themselves to any particular method. However, in this study, so as to better bring out the possible role of interaction in script development, we wish to emphasize an approach rooted in linguistic and semiotic perspectives. To that end, we introduce a number of terms adapted from the linguistic study of loanwords (Haspelmath 2008, 2009; Haspelmath and Tadmor 2009) and translation (Jakobson 1959:233). The evidence explored here suggests that interregional interaction fostered script diversification by creating a situation in which adopting systems utilized transferred or copied iconic elements in new contexts, in some cases to develop word signs or logograms. Such recontextualized signs likely conveyed not only their original semantic value but also a symbolic connection to their source, lending the sign whatever prestige came with the source system. Interaction thus promoted conditions conducive to the recontextualization of iconic elements that allowed for their transmutation and productivity within the emergent structures of incipient writing.

\section{THE EMERGENCE OF MESOAMERICAN WRITING}

Transmutation: Abstraction and IConic Recontextualization Investigations of the origins and development of scripts center on the processes through which icons were excised from pictorial contexts and incorporated into the new structure of writing. ${ }^{4}$ Current models of script development in Mesoamerica posit that the critical transition from iconography to phonetic writing involved the divorce of signs from a pictorial matrix and their subsequent incorporation within a linguistic framework and the new conventions of writing, which usually took the form of various linear formats along the vertical and horizontal axes. These conventions became the primary organizational principles for signs and their interpretation (see, e.g., Carrasco and Englehardt 2015:638, in press; Houston 2004:284; Justeson 1986:442, 2012; Justeson and Matthews 1990; Justeson et al. 1985:35-36).

Late Early to Middle Formative period iconography and its continued development in the Late Formative system (or several different, perhaps competing systems $s^{5}$ ) suggest that an ancestral system widely shared throughout Mesoamerica 
was the basis on which subsequent scripts developed (Houston 2004:286; Justeson 2012:838; Lacadena 2010; Mora-Marín 2001:444-446). When a sign system is employed over time in multiple contexts, there is a potential for an increased abstraction between an iconic component within that system and its referent (or object) (Justeson et al. 1985:34; cf. Robertson 2004). Such abstraction transforms what had originally functioned as an element of iconography or iconic sign into a conventional sign, "visual word," or logogram (Cohen and Dehaene 2004; Dehaene 2009). In tandem with the transference (or transmutation) of pictorial signs to logograms, several organizational formats (writing conventions) were developed. Consequently, the interpretive framework necessarily shifted from one based on the pictorial conventions of the ancestral system to one that utilized the advantages conventional signs afforded an incipient script. This process was facilitated by the developing conventions of writing, which were critical for repositioning formerly iconic signs into structures that marked them as words, as opposed to visual objects. Thus, the generation of abstraction both between the sign and its referent and between the signs themselves is a core feature of script development in Mesoamerica and elsewhere (Houston 2004; Justeson 1986, 2012; Justeson and Matthews 1990; Schmandt-Besserat 2010).

The transmutation of a pictorial or primarily iconic system to a more symbolic one relied also on the adoption of conventions that marked text as such and that were distinct (judging from surviving examples) from pictorial conventions. In other words, the developing conventions of writing prompted viewers (or readers) to change interpretive modes. As Justeson (1986:439) explains, since "the interpretive conventions of any one prior system are inadequate to encode or decode the message, external or higher-order integrative conventions must be invoked." Thus, the process was at least twofold in that both signs and conventions were adopted, copied, or developed. The evidence does not provide a definitive sequence of this development, but the linear demands of presenting language or information highly contingent on language provide a hypothesis for approaching the linearity of early texts in which this convention is itself indexical of the sequential nature of language, even if individual signs may not correspond to linguistic units (see Justeson 1986:439). The fact that diverse, seemingly unrelated Mesoamerican scripts nevertheless evidence linear and or recombinatory conventions similar to other world writing systems suggests the iconicity of the conventions themselves (Carrasco and Englehardt in press).

The potential interpretive tension that derives from the processes of abstraction and recontextualization thus demands the reinterpretation of visual signs linguistically in order to determine more precisely the contextual and significant relationships among icons (Justeson 1986:439; Justeson et al. 1985:34; cf. Robinson 2003; Rogers 2005). Depending on the contexts in which a sign is deployed, multiple 
interpretations of that sign may emerge, since the meaning of the sign is no longer tethered solely to an iconic significance within a wider aesthetic program or overarching compositional framework. The difference between the use of a sign in a pictorial versus a writing system therefore lies not in its phonetic value but rather in its function within particular contexts. This recontextualization and transmutation of ancestral signs permit a scribe or reader "to derive the meaning of a sign or sign sequence via the phonetic or word (i.e., linguistic) values associated with the sign(s)" (Carrasco and Englehardt 2015:638). In this sense, writing emerges through a process of semiosis when new meanings or grammatical-linguistic values adhere to a sign that previously depended on visual conventions to interpret both the visual message and the relationship between constituent signs. It is at precisely this point-when meaning may be derived on a basis of features other than iconic value(s) and pictorial compositional structures-that a movement toward linguistic codification and potential phoneticism began in Mesoamerican visual notational systems.

\section{Conceptualizing the Role of Interaction in Script Development}

Through interaction, things and ideas are shared across geographic regions or cultural groups. Ideas may thus entwine with material goods in generative ways, prompting the emergence of different interpretive conventions in which artifacts may assume new meanings (Clark 2004; Renfrew 200I). ${ }^{6}$ For example, emerging Mesoamerican elites adopted a Middle Formative material-symbolic-linguistic complex to bolster their developing authority, ostensibly through association with "Olmec" prestige (see, e.g., Clark 2004; Clark and Blake 1994; Demarest 1989; Flannery 1968:II; Lowe 1989; Mora-Marín 2001:33-36; Reilly 1995; Rosenswig 2010). Over time, however, as the objects and iconography of this adopted complex were deployed in different cultural contexts, they came to acquire a greater degree of specific reference to local systems, and functioned within distinct culturally explicit contexts. A clear instance of this process of semiosis are the divergent yet symbolically related twenty-day names fundamental to the 260 -day scared calendar used throughout Mesoamerica. For example, the central Mexican day name 'Flower' is equivalent to the Maya day name 'Ajaw', one of whose original forms is a stylized flower. Examples such as Puma/Jaguar, Wind, and Death, among others, maintain even clearer symbolic overlaps and suggest a common point of origin. Outside the context of the calendar, the knotted vegetal headdress discussed below illustrates this process well. To put it somewhat differently, while the specific meaning of things or elements in iconography—like day signs or the vegetal headdress-often 
remained relatively constant, shifts in the contextual frameworks in which they were interpreted opened new possibilities for recontextualization, reinterpretation, or transmutation, which produced new, locally specific meanings that often maintained some connections to the original referent.

These processes were at play in the development of Mesoamerican scripts. Scholars of Mesoamerica generally accept that the widespread distribution of a Formative period "Olmec" iconographic complex across the region indicates extensive interregional interaction, likely due to the spread of what Reilly (1995:29-30) has labeled the Middle Formative symbolic-ceremonial complex. ${ }^{8}$ Nonetheless, as Lesure (2004:74) notes "Olmec iconography was widely but unevenly distributed across Mesoamerica. In some periods and places it seems very pure; in others, it is mixed with more localized themes and styles." Thus, although interregional interaction is inferred, as Rosenswig (2010:49) observes, "the uses and meanings of Olmec imagery may have been employed in locally specific ways" (cf. Grove 1999; Lesure 2000).

In this sense, there are multiple ways of understanding interaction, exchange, and information transfer across cultures. In archaeology, stylistic and iconographic similarities have been critical aids in accessing exchange, as have material analyses of archaeological indicators of interaction. While these latter studies provide conclusive evidence on actual exchanges, style and iconography have been seemingly more difficult to quantify, since there is always variation and it is difficult to know at what point variation is meaningful and represents difference, or, alternately, is the natural result of repetition of the form without significant changes in meaning. The study of linguistic exchange, particularly loanwords and translation theory, has dealt with similar issues and offers avenues for approaching the adaptation of signs from one system into another. Martin Haspelmath (2008, 2009; Haspelmath and Tadmor 2009) discusses the basic problem of terminology for describing loanwords and suggests alternatives to the term "borrowing" that are potentially productive in the study of the transference of iconic signs from one system to their use as visual words (logograms) in another. He suggests that transfer, transference, or copying more accurately describe "borrowing" (since there is no expectation that the word will be returned or that it is missing from the donor system). Likewise he sees "adopt," "impose," and "retain" as more precise terminology for describing the nature of such an exchange.

Beyond offering a more precise terminology for describing exchange, the study of loanwords provides ways of approaching the adoption of specific signs (what Matras [2007] and Sakel [2007] might term "matter borrowing") as well as the copying of larger patterns, such as the conventions of a script (i.e., "pattern borrowing;" cf. Matras 2007; Sakel 2007). Adapting this to scripts, we could then make the distinction between the transfer of a specific sign versus the transfer of 
larger iconographic or scriptural conventions. As Haspelmath (2009:37) explains: "Loanwords are always words (i.e., lexemes) in the narrow sense, not lexical phrases, and they are normally unanalyzable units in the recipient language. The corresponding source word in the donor language, by contrast, may be complex or even phrasal, but this internal structure is lost when the word enters the recipient language ... However, when a language borrows multiple complex words from another language, the elements may recur with a similar meaning, so that the morphological structure may be reconstituted." "This pattern in linguistic borrowing provides a parallel example with which to develop more specific ways of discussing visual sign exchanges between groups. First, it suggests that the copying of signs (whether visual or linguistic) is highly complex and requires discerning the nature of the exchange. Second, it indicates that in addition to single signs larger portions of the structural system may be copied or transferred. In this case the amount borrowed is more than just a matter of quantity but it potentially changes the nature of the exchange along lines outlined by Haspelmath and others. That is, the donors and recipients analyze components of the system in similar ways because such a large amount of the system has been transferred.

Thus, the concepts of "purity" and "local styles" noted by Grove (1999), Lesure (2000:74), and others are likely better detangled from formal characteristics and linked more to the extent that (or degree to which) the donor system is transferred or copied into the recipient one, a process that also speaks to the recontextualization of signs to express locally specific ideas. One might justifiably ask if an iconographic style is ever pure, or what we mean when we discuss a "pure" style. We argue that style and iconography are never "pure," but this fact does not make them any less tied to specific cultural ideas or meanings-especially those connected to a dominant or prestige culture. Indeed, the spread of a certain style or iconographic system may be seen as a valedictory reproduction of a dominant discourse, even when ostensibly "foreign" styles are incorporated into localized canons (cf. D. Bryan Schaeffer, chapter $s$ in this volume; Jesper Nielsen et al., chapter 6 in this volume). ${ }^{10}$ For example, during the Renaissance the Vatican commissioned many works that display a more or less unified style and codified iconographic system that were emulated by others outside of Rome. Nonetheless, great differences in both style and iconography still existed across Christendom (cf. Panofsky 1960). Likewise, the adoption of Buddhist motifs or Confucian ideas into Korean (Best 2007) and Japanese aesthetic and political-institutional structures speak to a similar directional flow, yet with variability (Guth Kanda 1985; Paine and Soper 1992). In each of these cases stylistic "purity" (or lack thereof) is irrelevant to the central question of directional flow; nor does it allow for an understanding of how either Korea or Japan translated these forms into specific social, religious, or aesthetic systems. In some cases, like the 
scripts mentioned previously, there were significant changes in form yet one would still be able to identify the direction of the influence.

Thus, the problems that arise with the idea of pure versus local style are precisely why loanword terminology and theories of translation are so useful, particularly the concepts of copying and transmutation. The act of copying is an agentive one in which the question of "purity" is beside the point and would in any case be predicated only on the extent to which the copyist needs to preserve or understands the sign within the context of the donor system. ${ }^{11}$ In this sense, long-term interaction between diverse audiences potentially resulted in multiple realizations of a given sign. Within new contexts, different interpretive principles may induce the codification of iconic elements with culturally specific grammatical and linguistic values - and perhaps instantiated meanings previously unassociated with them. In the transcultural, translinguistic, or transregional circumstances brought about through interaction, a shared pictorial system is ripe for recontextualization, the establishment of more discrete organizational frameworks, and the imposition of new values within the emergent structure of writing. Interaction thus fostered recontextualization and transmutation by creating the conditions for scribes to copy and repurpose both shared content and structures. Below, we explore several illustrative examples that document the role of Formative period interregional interaction in the development of various Mesoamerican writing systems.

\section{EVIDENCE FOR INTERACTION IN MESOAMERICAN ICONOGRAPHY AND SCRIPTS}

\section{Knotted Vegetal Headdresses}

The knotted vegetal headdress is a common motif in Middle Formative period iconography, occurring on a number of media, most clearly in celt iconography (figure 3.I). This element, first explored by Virginia Fields (199I) and which David Stuart (2015) has labeled "the royal headband" was a potent symbol of authority, also appearing in a number of subsequent Mesoamerican iconographic systems and scripts to denote rank or political power (figure 3.2). In many examples, supernaturals, rulers, or persons of high rank wear a knotted element; a circular ornament or ear spool; and, in most cases, a vegetal diadem on the front of the headdress, thus confirming the association of this element with secular and/or ritual authority. This link is particularly clear in Aztec representations (figure 3.2f-g), in which emperors are depicted wearing the headdress, which itself may stand alone as a visual representation of the emperor (see pl. I6a of the Tovar Codex). In the context of the Maya writing system (figure $3.2 \mathrm{~m}$ ), although the motif is modified from its Middle Formative precursor, the association of the headdress with rulers and elites remains 
FigURE 3.I. Middle Formative period vegetal headdress element (shaded) on the Humboldt (a) and Covarrubias (b) celts (drawings by Michael D. Carrasco).
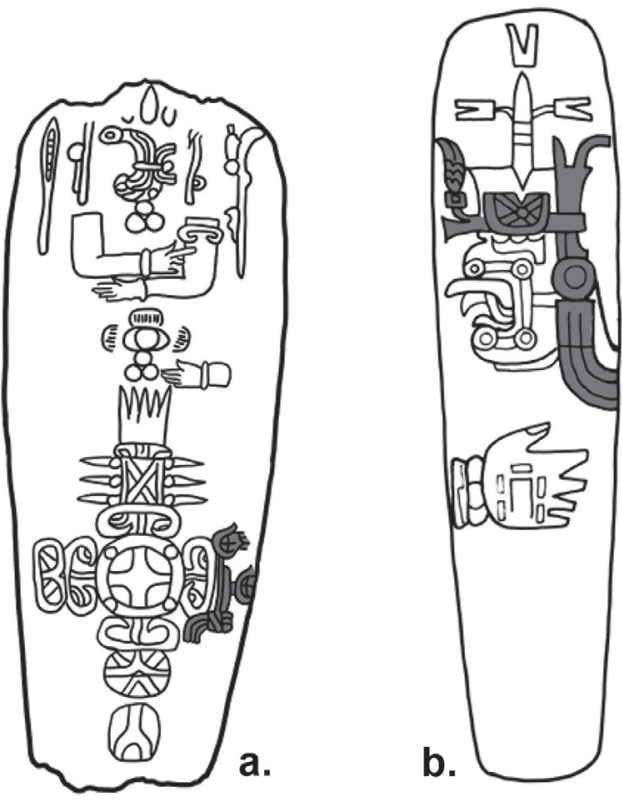

(Fields I99I). In the Formative and Early Classic material, the similarities very clearly tie this headdress in iconography to Olmec forms, from which it is abstracted into the headband form. In the Maya script the headband is one of several ways of writing ajaw, 'king' or 'ruler'. The association between a headband and rulership is also found in expressions using the word buun (T6o, lit. 'bark paper'), such as k'ablaj sak buun, 'the white paper headband was tied', or k'al huun naah, 'accession house' (lit. headband-tying house). Thus, in a variety of artistic traditions and scripts spanning the Formative through the Postclassic periods, the motif maintained a great degree of formal and semantic continuity.

Examples of this motif in the Late Formative Zapotec tradition are particularly cogent. In Zapotec iconography, the vegetal headdress likewise functioned as an indicator of rank or status, worn by the individuals depicted on the inscribed orthostats from Monte Albán Building J (figure 3.2d) and by supernaturals (figure 3.2e). The strong formal and contextual similarities between these examples and the headdresses in Middle Formative Olmec art suggest that the motif was transferred into the Zapotec tradition through interaction with Olmec groups, possibly to reinforce the emergent authority of rulers through association with Olmec prestige, as Flannery (1968) and others have posited. This is an even more plausible interpretation when one considers the use of the vegetal headdress 


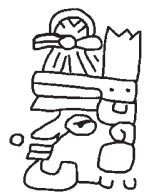

a.

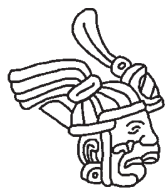

b.

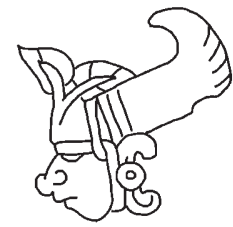

C.

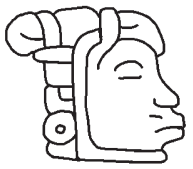

d.

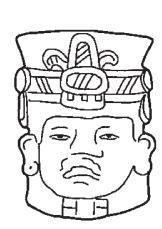

e.

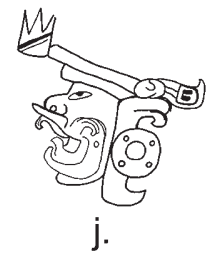

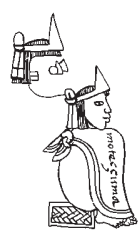

f.

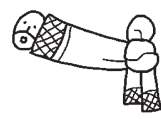

$\mathrm{k}$.

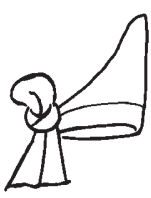

g.

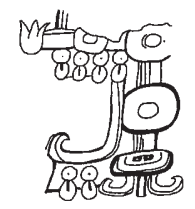

h.

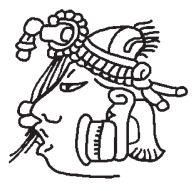

i.

FIGURE 3.2. The vegetal headdress element in various Mesoamerican iconographic and script traditions: (a) Epi-Olmec, La Mojarra Stela I; (b) Isthmian stone yugo, Late Formative; (c) Izapa Stela 25; (d) Zapotec, Monte Albán Building J (drawing courtesy Javier Urcid); (e) Zapotec, Yagul urn; (f) Aztec, Codex Mendoza; (g) Aztec, Tovar Codex pl. I6a; (h) Maya, San Bartolo west wall individual P2I; (i) Maya, Early Classic vase; (j) Maya, Cival Structure I-sub I; (k) Maya royal headband (after Stuart 20I5); (1) Maya, Late Formative jade pectoral; (m) Classic Maya glyph T60 HUUN, huun, 'paper headband' (after John Montgomery) (drawings by Michael D. Carrasco).

motif in the Zapotec script during the Formative and Early Classic periods, where it was deployed as the year-bearer glyph (figure 3.3; cf. Urcid 1992:115, 2001:113; Whittaker 1980:26). In these contexts, the element retains formal continuity; early (e.g., Danibaan and Pe phases, ca. 500-100 B C) examples of the year-bearer headdress in Zapotec writing (figure 3.3a-c; cf. Urcid 2001:II5-II6, figs. 4.4, 4.6; Whittaker 1980:205) are, formally, virtually identical to those observed in Middle Formative celt iconography, particularly the headdress on the Humboldt celt (figure 3.ra; cf. Stuart 2015). Within the Zapotec script, however, the motif was recontextualized and, in later contexts, abstracted to a degree that formal continuity was less apparent (e.g., Late Classic Peche and Xoo phases; see Urcid 2001:116, fig. 4.5, 425 , fig. 6.II). It is possible, however, that semantic continuity existed. Stuart (I99I) suggests that the year-bearer functioned as a logogram that signified the "ruler 


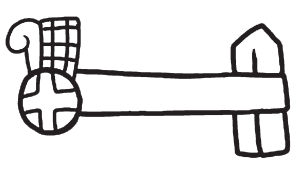

a.

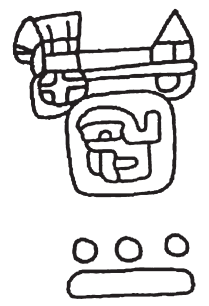

d.

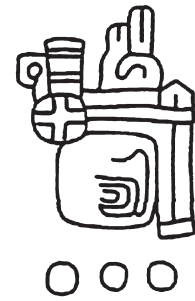

e.

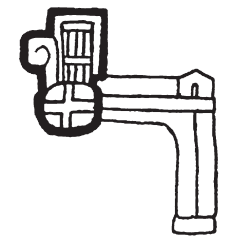

b.

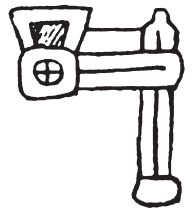

c.

FIGURE 3.3. Vegetal headdress as year-bearer glyph in Zapotec script: (a-f) Monte Albán South Platform, Late Formative; (g) Monte Albán East Platform, Early Classic (Urcid 200I:II5-II7, figs. 4.4-4.7, courtesy Javier Urcid).

[referring to the bearer] of the year" (cf. Urcid 2001:1r3). Nonetheless, as was the case for the word ajaw in the Maya script, the headband was used as a visual word (logogram) in Zapotec writing, and the element acquired a narrower semantic range of 'ruler of the year' and a specific phonetic articulation, even if that linguistic value remains undeciphered.

Within the Zapotec tradition the knotted vegetal headdress thus served two semantically related functions in distinct contexts. In some instances, the motif occurs as both an iconic representation of rank and as year-bearer within the same textual composition (figure 3.4). Given the high degree of formal and seemingly semantic similarity between the "original" Middle Formative motif and its iterations in Late Formative and Early Classic period Zapotec art and writing (vis-à-vis the relatively more abstracted versions evident in other contemporaneous traditions and within later Zapotec texts) independent invention of this sign is unlikely. ${ }^{12}$ Therefore, the most logical explanation, especially in light of the parallel example in Maya art and writing, is that the visual element was copied directly from a preexisting symbol set, and subsequently deployed within the Zapotec iconographic and script tradition. ${ }^{13}$ 


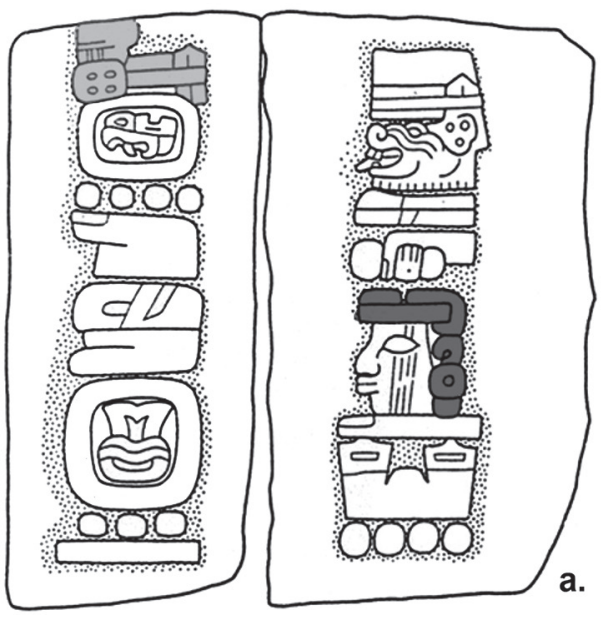

b.

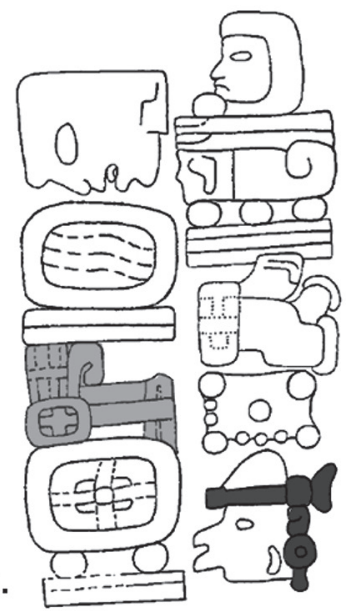

FIGURE 3.4. The vegetal headdress element in both iconographic (dark gray overlay) and glyphic (light gray overlay) contexts in Zapotec texts: (a) Monte Albán Stelae I2-I3; and (b) Stone M21, originally from Monte Albán Building L-sub facade (Urcid 2005:fig. I.19, courtesy Javier Urcid).

\section{Classic Maya $A J A W$ Glyph Variants}

A related recontextualization of Formative period headdress imagery is that of the tri-lobed maize headdress, which Fields (199I) suggests formed the basis of the Classic Maya Jester God Headdress, a potent symbol of rank and authority (cf. Mora-Marín 2001:544-545, figs. 5.2-5.3; Schele 1999). This element is common in Middle Formative iconography (figure 3.5) and appears in subsequent iconographic systems, particularly those of the south coast and Maya lowlands. Of particular note in these examples is the deity effigy wearing a tri-lobed vegetal cap that crowns the headdress (figure 3.5a, c), which finds continuity in Late Formative and Early Classic Izapan and Maya art (figure 3.6a-d; see also figure 3.2l). In the Maya script, the Jester God Headdress is evident on certain variants of the glyph ajaw ('lord', royal title; figure 3.6e-f). The deity effigy with a tri-lobed cap in these variants clearly had roots in earlier imagery associated with a Middle Formative maize god (or supernatural associated with sprouting vegetation), again suggesting that interaction with the Formative period symbolic-ceremonial complex was intimately related to the development of this glyph. In some calendrical variations of ajaw (as a day sign and with a distinct variation of the Jester God Headdress; figure $3.6 \mathrm{~g}-\mathrm{h}$ ), one observes a knotted element redolent of the vegetal headdress discussed above. 


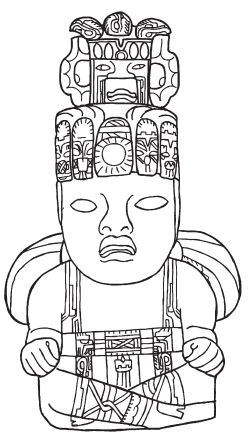

a.

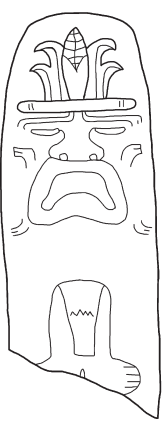

b.

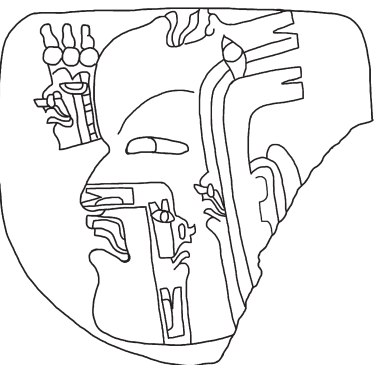

C.

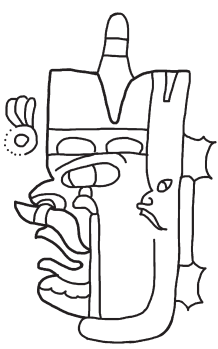

d.

FIGURE 3.5. Formative period tri-lobed maize headdress imagery: (a) Dumbarton Oaks jade figure; (b) El Sitio celt; (c) unprovenanced jade plaque in the Museo Nacional de Antropología (MNA-10-9656); (d) detail of celt from La Venta Offering 1942-c (drawings by Michael D. Carrasco).

The mat-throne version of the ajaw glyph is particularly instructive. In a separate paper, we have argued that the $\mathrm{CS}_{\text {II }}-\mathrm{CS}_{22}$ pairing on the Cascajal Block (figure $3.7 \mathrm{a}$ ) represents the pan-Mesoamerican throne-mat kenning semantically associated with rulership. The combination of mat and throne to form a visual kenning for 'rulership' occurs in nearly all Mesoamerican visual cultures and literary traditions (Carrasco and Englehardt 2015:640-647, figs. 4-8, 10). This mat-throne combination also appears in the Tr68 (584.687a) ajaw logogram in the Maya script (figure $3.7 \mathrm{~b}-\mathrm{d}$; cf. Lacadena 1995; Mora-Marín 2001:607, fig. 6.24). It is particularly noteworthy that this ajaw glyph variant appears in one of the texts in the San Bartolo murals (figure 3.7b), the earliest-known example of Maya writing (Saturno et al. 2006:1282, fig. 4). The mat and throne elements in these examples are formally similar and, in semantic and functional terms, practically identical. We therefore suggest that "visual lexicalization" is the source of the Maya sign, possibly derived from the "closeness of the original CS ${ }_{11}-\mathrm{CS}_{22}$ kenning structure" (Carrasco and Englehardt 2015:650). Such striking formal and sematic continuity between signs in distinct scripts strongly implies interaction between the groups that employed the sign in discrete contexts. In the development of both of these ajaw variants, Maya scribes recontextualized and linguistically codified an originally iconic motif whose form and semantic content remained relatively constant over time. Thus, like the knotted headdress, the foliated diadem seems to have been adopted by the Maya to serve within a range of imagery denoting rulership to such a degree that in some cases it, too, functions as a glyph for ajaw. The existence of three different glyphs—-jester god, headband, and throne-for 


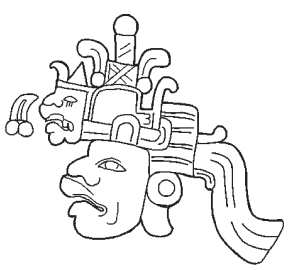

a.

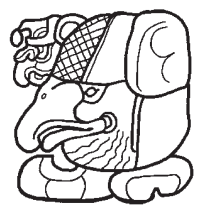

e.

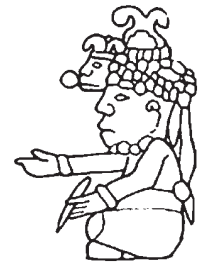

b.

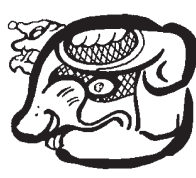

f.

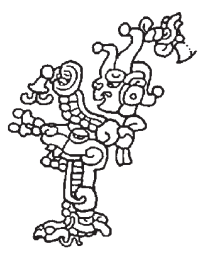

c.

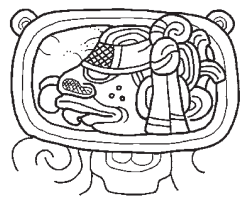

g.

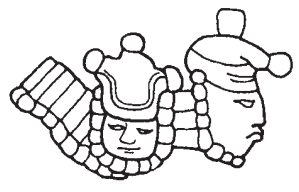

d.

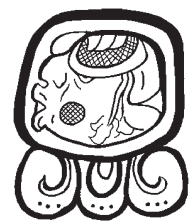

h.

FIGURE 3.6. Tri-lobed maize headdress imagery in Late Formative and Classic period Izapan and Maya art and script: (a) detail of the Shook panel; (b) Izapa Stela 5; (c) Leiden plaque; (d) detail of oval palace tablet, Palenque; (e) T747b AJAW 'lord,' royal title;

(f) T 747b AJAW 'lord', royal title; (g-h) T533v AJAW day sign (drawings by Michael D. Carrasco).

this term is also interesting, especially since in each case the motivation for their iconography appears based on earlier Middle Formative signs.

\section{The LAZY-S}

Another instance of formal and semantic continuity evident in a Middle Formative motif redeployed in subsequent scripts is the Lazy-S. Kent Reilly (1996) has convincingly demonstrated that this motif represents a rain cloud, and formed the basis for the Classic Maya sign T632. The Lazy-S appears in a number of iconographic and script systems in essentially indistinguishable forms and with identical semantic functions (figure 3.8). In both glyphic and iconographic contexts, one observes droplets of liquid flowing from the motif (e.g., figure $3.8 \mathrm{~b}-\mathrm{d}$ ), often over vegetal motifs, as in the Zapotec example (figure 3.8c; cf. Urcid 2005:fig. 7.6). ${ }^{14}$ Reilly's (1996:414, fig. 3) identification of the Lazy-S-cloud substitution set is further supported by the appearance of the motif on an effigy vessel of a Middle Formative rain deity (figure 3.8a; see Taube 2009), as well as the rain falling from the motif over Chaak, the Maya rain god on p. 68a of the Dresden Codex (figure $3.8 \mathrm{~d}^{15}$ ). In iconographic contexts, an association between the Lazy-S and rain or water also appears in designs on western Mesoamerican Teuchitlán ceramics from central Jalisco, as 


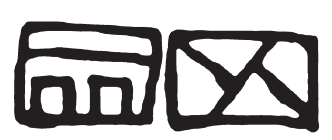

a.

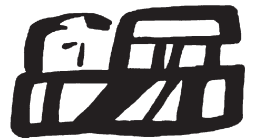

b.

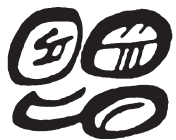

c.

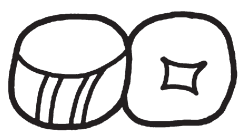

d.

FIGURE 3.7. Throne-mat combinations in Olmec and Mayan script: (a) CSII-CS22 'throne-mat' kenning on the Cascajal Block; (b) glyph block pA7, San Bartolo Structure Sub-V; (c) Tr68:130 AJAW-wa (ajaw) 'lord', royal title; (d) Tr68 (584.687a) AJAW 'lord', royal title (drawings by Michael $\mathrm{D}$. Carrasco).

well as in several other examples from Michoacán and Guanajuato (Heredia and Englehardt 2016). ${ }^{16}$ In the Maya script, the Lazy-S element at the heart of T632 variants-with a confirmed reading of MUYAL (muyal, 'cloud'; Houston and Stuart 1990) - in Late Formative, Classic, and Postclassic texts (figure 3.8e-g; see also Stone 1996:405, fig. 4) attests to the formal and semantic endurance of the motif through time and in discrete contexts.

Like the knotted vegetal headdress, the Lazy-S appears to have acquired a second value in the Zapotec tradition. The motif appears inset in the funerary box of the personage carved on jamb 2, tomb I from San Lázaro Etla (figure 3.9a; cf. Urcid 2005:fig. 5.49). Although its meaning is not entirely clear in this case, it is possible that the motif carries a value distinct from that in other Zapotec texts (cf. figure 3.8c), perhaps as a locative. In the much later contexts of the Mixtec Codex Bodley, the Lazy-S occurs on the facade of the Temple of Lady 9 Grass at Chalcatongo (figure 3.9b). In the Mixtec case, the motif is most securely identified as xonecuilli (John M. D. Pohl, personal communication, 2014). This symbol is a Postclassic iteration of the original Middle Formative motif (Angulo Villaseñor 2002:17) that is associated with the stars, possibly specifically with the Southern Cross, the Pleiades, or Ursa Major (Aveni 2001:36-37, fig. 12; Rivas Castro and Lechuga García 2002:62-63; Tezozómoc 1980:573). ${ }^{17}$ The association of the motif with stars, as heavenly bodies, and its secondary association with thunder (cf. Angulo Villaseñor 2002:17 n3) again suggest that a tenuous, indirect link to the original semantic value of the Lazy-S motif remained, even as the sign was recontextualized within discrete artistic and scribal traditions.

\section{ArChaeological-Linguistic Correlations}

Iconic recontextualization or transmutation may occur in variable contexts and is itself contextualized within the interrelated, long-term processes of linguistic diversification and script development. In this sense, historical linguistic data frame the spatial and temporal contexts of the interaction involved in the emergence of Mesoamerican writing, and may provide clues regarding the temporal contexts in 


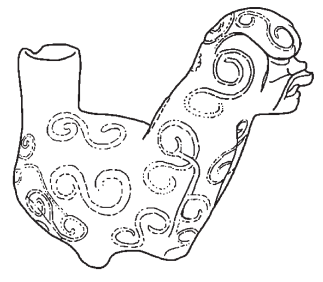

a.

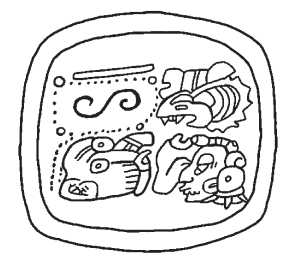

d.

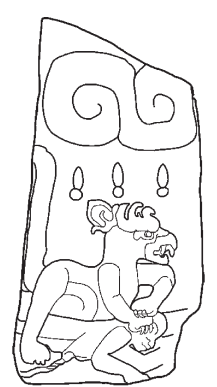

b.

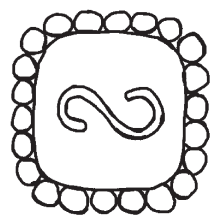

e.

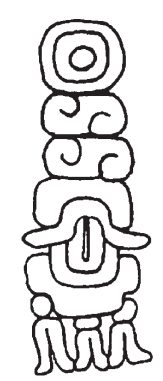

c.

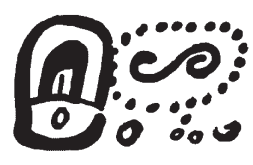

f.
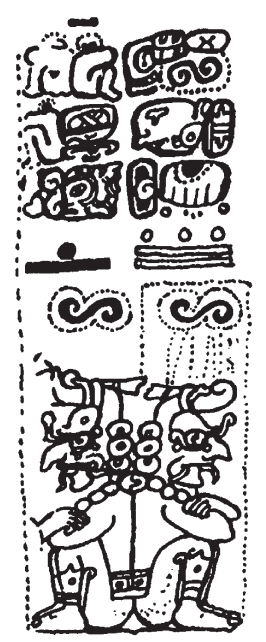

g.

FIGURE 3.8. The Lazy-S motif in Mesoamerican art and scripts: (a) vessel with effigy of Olmec rain god (after Taube 2009:29, fig. 5); (b) Chalcatzingo Monument 31; (c) detail of text on stone in the Friedenberg collection (Urcid 2005:fig. 7.6, courtesy Javier Urcid); (d) detail of Maya text on jade plaque currently in the Cleveland Museum of Art (after Stone 1996:404, fig. 3; cf. Mora-Marín 2001:734, fig. Ar.36); (e) T632 MUYAL, muyal, 'cloud'; (f) $e k$ ' muyal construction with T632 on p. 38a of the Dresden Codex; (g) detail of Dresden Codex p. 68a (drawing by J. Antonio Villacorta) (drawings a, b, d-f by Michael D. Carrasco).

which pictorial interpretive matrices ceased to function as the sole organizing framework for systems of visual communication. Specialists in Mesoamerican linguistics have seen the widespread diffusion of Mije-Soke vocabulary across regional language families as an indicator of extensive interaction during the Formative period (Campbell and Kaufman 1976; Campbell et al. 1986; Justeson et al. 1985:23; Kaufman 1976; Wichmann 1995, 1999; Wichmann et al. 2008; see also Kerry M. Hull, chapter 4 in this volume). More recently, Alfonso Lacadena (2010) has demonstrated the close relationship between Mije-Soke linguistic structures and the development of syllabic signs in early Mesoamerican scripts (table 3.I). Finally, the existence of graphic representations of lexical calques ${ }^{18}$ in Maya writing (see Helmke 2013) strongly suggests that linguistic interaction among users of distinct iconographic and writing systems was occurring in tandem with processes of script development.

Linguistic data thus suggest that contemporaneous linguistic interaction was just as crucial to script development as the spread of the Formative period iconography and 

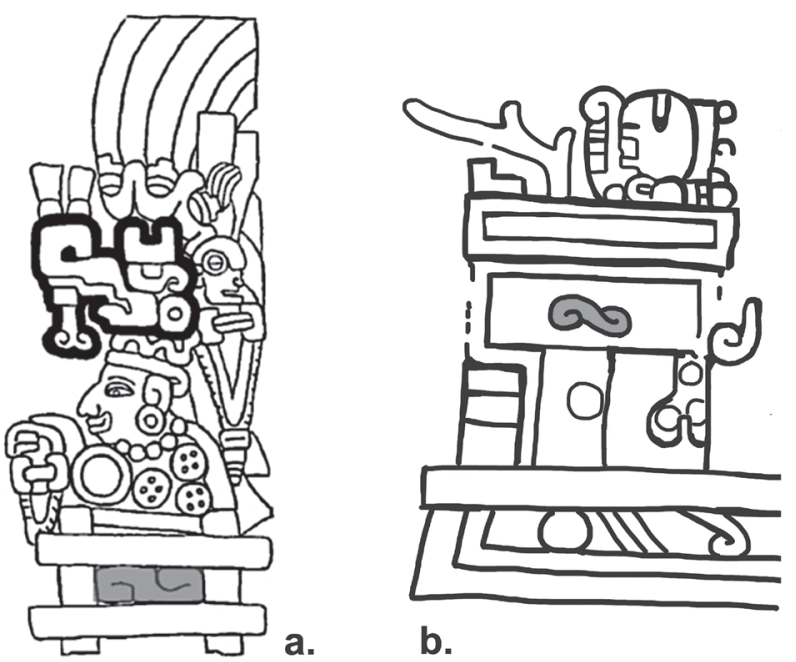

a.

b.

FIGURE 3.9. The Lazy-S in iconographic contexts with distinct semantic values: (a) in base of funerary box (light-gray overlay) of personage carved on San Lázaro Etla Tomb I, jamb 2 (Urcid 2005:fig. 5.49, courtesy Javier Urcid); (b) on facade of the temple (light-gray overlay) of the oracle Lady 9 Grass, Chalcatongo (Ñuu Ndeyá), Codex Bodley p. 35 (drawing by Michael D. Carrasco).

symbolism upon which we are suggesting writing is based. Further, these data match well with archaeological evidence-particularly ceramics and obsidian - that indicates extensive interregional exchange networks extending into the Early Formative period and supports the notion that linguistic, artistic, and material interaction were coeval (Blomster et al. 2005; Cheetham 2007, 2010; Cheetham et al. 2009; Demarest 1989; Flannery 1968; Rosenswig 2010:235, fig. 7.2; Wichmann et al. 2008:679, figs. 2ab; cf. Justeson et al. 1985:4; Kaufman 1976; Lesure 2004; see also Guy David Hepp, chapter 2 in this volume; Kerry M. Hull, chapter 4 in this volume). ${ }^{19}$

\section{VARiability in SCRibal Conventions}

A second line of ancillary evidence suggestive of interaction's role in script development is related to evident variability in scribal conventions among distinct Mesoamerican scripts. In these writing systems, there are two primary conventions for presenting a written text and/or glyphic elements: speech scrolls and linearcolumnar organization (see figure 3.I0). There are two significant points to stress here. First, both conventions appear in the Middle Formative period, at the moment 
TABLE 3.r. Phonological aspects of early writing or ancestral script as compared with four Mesoamerican language families.

\begin{tabular}{|c|c|c|c|c|}
\hline Ancestral Script ${ }^{a}$ & Mayan & Oto-Mangue & Nabuatl & Mije-Soke \\
\hline$/ \mathrm{m} /$, no $/ \mathrm{b}^{\prime} /$ & $/ \mathrm{b}^{\prime} /, / \mathrm{m} /$ & $/ \mathrm{b}^{\prime} /, / \mathrm{m} /$ & $/ \mathrm{m} /$, no $/ \mathrm{b}^{\prime} /$ & $/ \mathrm{m} /$, no $/ \mathrm{b}^{\prime} /$ \\
\hline $\mathrm{no} / \mathrm{ch} /(\check{c})$ & $/ \mathrm{ch} /(\check{c})$ & $/ \mathrm{ch} /(\breve{c})$ & $/ \mathrm{ch} /(\check{c})$ & no $/ \mathrm{ch} /(\check{c})$ \\
\hline no /l/ & $/ 1 /$ & $/ 1 /$ & no /1/ & no /1/ \\
\hline no $/ \mathrm{x} /(\check{s})$ & $/ \mathrm{x} /(\breve{s})$ & $/ \mathrm{x} /(\check{s})$ & $/ \mathrm{x} /(\breve{s})$ & no $/ \mathrm{x} /(\check{s})$ \\
\hline $\begin{array}{l}\text { no glottal } \\
\text { consonants }\end{array}$ & $\mathrm{C}^{\prime}$ & no C' & no C' & no C' \\
\hline one back spirant & two back spirants & one back spirant & no back spirants? & one back spirant \\
\hline
\end{tabular}

Source: After Lacadena 2010:36, table 3.

${ }^{a}$ Shading $=$ coincidence.

of writing's development, in two of the earliest exemplars of Mesoamerican texts: the San Andrés cylinder seal, and the Cascajal Block (Figure 3.10a, i). These examples suggest that both conventions were present at an exceptionally early date, and that scribes were experimenting with distinct methods of textually representing speech. Second, and more significant to the present discussion, the presence of both conventions in a variety of Mesoamerican scripts suggests that scribes of diverse systems were familiar with these distinct conventions. Such familiarity was likely achieved through interaction. The presence of speech or sound scrolls in systems that primarily employed linear-columnar conventions (e.g., the Mayan script, see figure 3.rob, d) - and vice versa-indicates that scribes in discrete contexts were interacting with one another, or at the least were conversant with scripts that employed variable conventions. Insofar as it allowed scribes to achieve distinct conceptualizations of the textual representation of visual elements, the knowledge of and/or experimentation with different ways of visually representing grammatical-linguistic elements was critical to the processes involved in script development. In this sense, variable scribal conventions among regional scripts illustrate the concept of "pattern borrowing" (or transference) detailed by Matras (2007), Sakel (2007), and others.

\section{DISCUSSION: TRACING INTERACTION IN MESOAMERICAN SCRIPT DEVELOPMENT}

Although it is generally accepted that interaction played a critical role in the emergence of Mesoamerican writing systems, tracing such interaction and its role in script development in concrete terms has proven difficult. No established method exists to quantify transformations in iconic elements as they are recontextualized in scripts, and determining significant changes in meaning is not always as straightforward as 


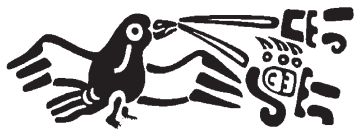

a.

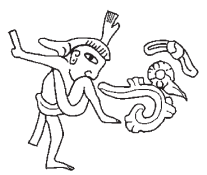

c.

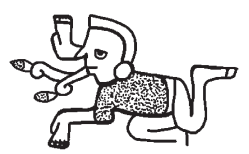

g.

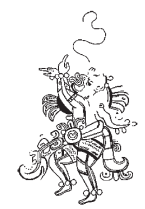

b.

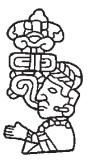

e.

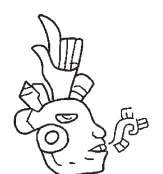

f.

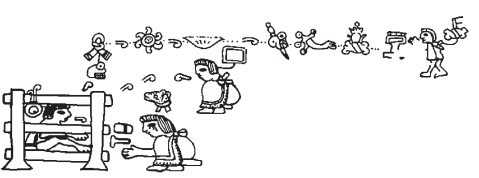

h.

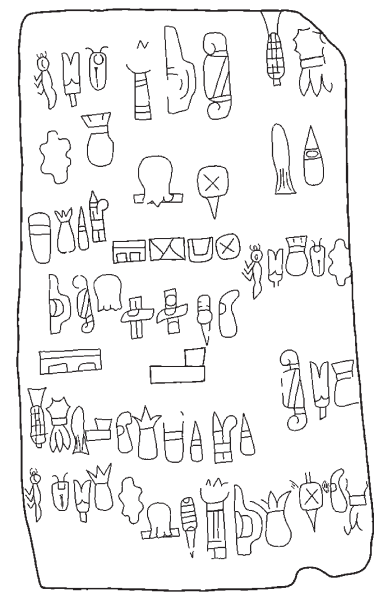

i.

FigURE 3.Io. Variable conventions in Mesoamerican scripts; speech scrolls vs. columnar organization: (a) San Andrés cylinder seal (after drawing by Ayax Moreno in Pohl et al. 2002:1985, fig. 2); (b) detail of dwarf with speech scroll and columnar text on San Bartolo west wall mural (after Taube et al. 2010); (c) detail of mural from Portico 2, Tepantitla, Teotihuacan; (d) seated figure with speech scroll and columnar text on Late Classic Maya ceramic vase (see also vases $\mathrm{K}_{41}$ I8, $\mathrm{K}_{1398}, \mathrm{~K}_{1453}$, $\mathrm{K}_{5094}$ ); (e) female figure with glyphic speech scroll on Late Classic Zapotec Lápida de Santiago Matatlán; (f) profile head with speech scroll on Zapotec Lápida de Bazán; (g) individual with speech scroll, Codex Selden p. 7; (h) text emanating from speech scroll of prisoner, Codex Xolotl pl. 8; (i) the Cascajal Block (drawings by Michael D. Carrasco).

in the examples presented above. Nor is there an accepted technique to objectively determine degrees of distance between recontextualized signs and their original iconic referents. Understanding the relationship between interaction and innovative reformulations of shared motifs is further complicated by the fact that these processes are intertwined in the complementary historical trajectories of linguistic diversification and script development (Carrasco and Englehardt 2015:647).

Writing systems, as conservative entities, retain features related to their own history, including historical episodes of transfer and/or interaction with other scripts or systems of visual notation (Lacadena 1995, 2010). The existence of shared elements and motifs in culturally or geographically distinct scripts or representational systems is therefore most parsimoniously explained by interaction between the groups that employed those systems. ${ }^{20}$ Although care must be taken in postulating the nature of the relationship between those groups or systems (i.e., not necessarily 
"genetic"; see Proskouriakoff 1968, 1971; Quirarte 2007), it follows that shared elements are in most cases a product of dissemination or transfer from system A to system B. In addition to a core pictographic and ideographic visual vocabulary, early Mesoamerican scripts also initially shared underlying narrative conventions that framed interpretations of a given iconographic composition, as we have argued elsewhere. But these narratives changed over time, as they spread to increasingly diverse spatial and cultural contexts. As the narratives changed, so too did the system(s) of interpretation.

In this sense, interaction is identifiable through shared formal features, orthographic conventions, and linguistic aspects shared among Mesoamerica scripts and iconographies in both synchronic and diachronic contexts. Interaction may be further inferred from the presence of shared general characteristics of the systems, the shared graphic designs of the signs that comprise those systems, "intermediate" visual forms and/or texts that are legible in two distinct languages, "frozen" semantic values that continue to be employed in scripts and/or the presence of fossilized reading values (belonging to the original donor), or identifiable problems of adaptation ${ }^{21}$ of the donor script (which was created originally to write a different language; Lacadena 2010; Mora-Marín 200I; cf. Justeson 1986, 2012). Justeson et al. (1985) distinguish between shared formal traits that develop from independent invention and those that result from inherited or diffused innovations. We agree with their conclusion that a greater degree of arbitrariness of a shared feature indicates greater likelihood of common descent from an ancestral iconographic system or script ${ }^{22}$ (see also Justeson 1986; Justeson and Matthews 1990). Moreover, as Reilly (1991:151) notes, the identification of elements of an antecedent iconographic system within a later script must be predicated on the testable hypothesis that certain elements of the writing system can be visually identified in iconographic contexts (or some other Mesoamerican or scribal tradition) and that these elements perform similar functions in both the "donor" and "recipient" systems. In those cases, linguistic data (and shifts) latently related to script development are critical to deducing "new" potential semantic values or syntactical functions of specific visual elements. In that sense, we concur with Justeson et al. (1985:4), and others, that linguistic interaction is coeval and positively correlated with material cultural and iconographic exchange (cf. Wichmann 1999; Wichmann et al. 2008; see also Kerry M. Hull, chapter 4 in this volume).

Nonetheless, modifications in the formal or stylistic aspects of the visual elements that comprise an incipient script system-or that are shared between contemporaneous scripts and iconography-could suggest specific functional changes of those elements as "ancestral" icons were excised from pictorial contexts and potentially acquired new values or functions when reformulated or redeployed in discrete contexts. Modifications in the formal characteristics of shared signs (e.g., 
the addition of new visual elements to preexisting icons, the reshaping or simplification of distinctive sign forms) may thus reflect recodification stemming from recontextualization (Lacadena 1995). Often, the new features of a recontextualized sign drew on the iconicity of the original while adding culturally specific visual or linguistic markers - or semantic mnemonic information - in order to aid in identification of the sign and its meaning.

Thus, formal, stylistic, and functional similarities and differences in visual data suggest trends in the nature, extent, temporality, and directionality of the processes of regional iconographic interaction. Likewise, interaction is recognizable through identifiable variant forms of ancestral icons-shared widely across Mesoamerica-recontextualized within new, locally specific, and ostensibly grammatical and linguistic organizational frameworks. From a diachronic perspective, patterns are apparent in the data, which suggest the origins and directions of influences on incipient scribal traditions. These patterns illustrate the association of Formative period interregional interaction with the recontextualization involved in the development of various Mesoamerican scripts. As we have detailed above, patterns of transfer, copying, and interaction evident in the distribution of signs and conventions show that by the Middle Formative period such processes were at play.

The careful reader will note that we have explicitly not commented on the specific mechanisms of exchange. This is due primarily to the early dates of the majority of the examples we discuss. Thus, any suggestion regarding the actual processes or modes of interaction would be purely conjectural. Nonetheless, Formative period material interaction (particularly ceramics and obsidian) is clearly evident archaeologically (see, e.g., Rosenswig 2010:235-24I). This fact, coupled with a scholarly consensus that linguistic and artistic exchange occurred in tandem with material trade (see, e.g., Kaufman 1976; Lesure 2004), strongly suggests that iconography, aesthetic and scribal conventions, and writing itself were among the items or concepts being exchanged. This process would be analogous to the Formative period transfer of ceramic technologies, manufacturing techniques, or lithic industries-all of which have been extensively documented in the archaeological record in Mesoamerica (e.g., Blomster et al. 2005; Cheetham 2007, 2010; Grove 1993; Nelson and Clark 1998; Rosenswig 2010). Although Flannery's (1976:285) "Real Mesoamerican Archaeologist" would disapprove, it seems more and more likely that intangible "ideas" were, in fact, exchanged along with material goods.

It is likewise probable that the knowledge required to produce and understand writing and scripts, like advanced iconography, would have been considered a prestige good (Clark and Blake 1994; Hayden 1998; Helms 1993; Plourde 2009). ${ }^{23}$ Conceiving of a script itself as a prestige good squares well with current conceptions of writing in other contexts (see, e.g., Baines 2004; John M. D. Pohl, personal 
communication, 2016). Further, such a conception naturally complements previous models (e.g., Demarest 1989; Flannery 1968) that view interregional exchange in the Formative period as linked to attempts to emulate or co-opt the prestige of the Gulf Coast Olmec, as discussed above. This possibility is particularly tantalizing for those instances in which extensive material, linguistic, and iconographic interaction with the Olmec and/or Mije-Soke speakers is evident, such as the Maya and Zapotec cases (see, e.g., Fields 1991; Justeson et al. 1985; Pohl et al. 2008; Quirarte 2007; Reilly 1991, 1996; Wichmann 1999; Wichmann et al. 2008). Of course, the paucity of evidence that speaks directly to early scripts severely complicates the archaeological validation of such a conception.

The examples we have presented illustrate formal and semantic continuity in various Middle Formative period iconographic motifs that were broadly distributed across Mesoamerica and widely shared among contemporaneous and subsequent artistic traditions and scripts. As Lacadena (2010:29) notes, writing systems are among the most conservative aspects of culture and highly resistant to change. It is therefore unlikely that such an evident degree of significant permanence-as well as shared sign inventories, formal traits, and orthographic conventions (see Justeson et al. 1985:41, table 16; Mora-Marín 200I:25-26, 355-360, tables I.I-I.5)—would have developed independently within diverse Mesoamerican writing systems during Formative period script diversification. Rather, the very intransience of these characteristics across scripts and through time suggests a historical relationship among them that both reflects and stems from extensive interregional interaction (cf. Justeson and Matthews 1990; Mora-Marín 2001:25-26, 245-259).

Of course, we do not suggest that writing always emerges from the crucible of interaction. Nor does the identification of interaction in itself account for the development of writing. Rather, we hold that interregional interaction in part drove the processes of recontextualization and transmutation in Mesoamerican contexts. Although script development is not necessarily predicated entirely upon interaction, it is evident that interaction has the potential to act as a catalyst for the transference of signs and the generation of visual words from the iconography of the donor system. The reformulation and redeployment of shared motifs in distinct contexts potentially effect a structural transformation that gives rise to new frameworks in which to determine meaning and establish distinct, culturally specific connotations and/or grammatical-linguistic values. In this sense, the evident recontextualization of the motifs discussed above in one or more subsequent script traditions is key. Once severed from Formative period artistic canons and larger contextualizing programs, these motifs were enclosed within the emergent textuallinguistic conventions and organizational schemes of writing. In these new contexts, scribes were able to organize elements on a nonpictorial basis within a new syntax 
in which grammatical principles played a larger role in their interpretation than their relationship to overarching iconographic structures.

\section{CONCLUSIONS}

In this chapter, we have argued that interaction played a crucial role in the development of writing in Mesoamerica. Although many scholars have noted the existence of common visual elements across writing systems in the region-and suggested that such commonalities are indicative of interaction-the processes by which such shared motifs were incorporated into incipient writing and the question of how interaction factored in to script development remain relatively understudied. The critical transition from art to writing therefore eludes adequate explanation. Our goal in this contribution is to illuminate precisely this process of transition, thereby filling in lacunae in our understanding of the complex and highly contextualized developmental processes involved in Mesoamerican script development.

The numerous formal, ideological, ideographic, and representational-conventional associations that exist between Late Formative imagery, subsequent regional script traditions, and an antecedent Middle Formative iconographic complex imply historical relationships between differing representational systems that employed shared elements and motifs, which can only be explained by the prior transfer or diffusion of the antecedents to the same iconographic and scribal depictions and conventions. In Mesoamerica this source would appear to be the Middle Formative symbolic-ceremonial complex (Reilly 1995:29-30). Middle Formative period symbols of power and authority—artifactual, iconographic, and linguistic — were widely shared throughout Mesoamerica and subsequently adopted and deployed in differing spatial, temporal, and cultural contexts. In this sense, Mesoamerican scripts and systems of visual notation shared a common iconographic base, in terms of a collective core pictographic and ideographic visual vocabulary. In other words, interaction established a common iconographic complex that by necessity was understood similarly by linguistically diverse groups and/or a bilingual elite. This put the prestige or common strata imagery and conventions (or content and structure, to use linguistic terms) into conversation with local systems, conventions, and needs. This aspect of the process is perhaps the most difficult to fully dissect. It would, however, appear that common strata signs were redeployed and repurposed to achieve local goals, potentially imbued with new values and constrained within narrower, more culturally specific frameworks. Thus, multiple recontextualized interpretations and transmutations of the same sign emerged, facilitating the processes of script development and diversification. Although speculative, these possibilities-especially when considered in conjunction with other lines of evidence-offer a potential glimpse into 
the role of interaction in the development of Mesoamerican writing, in both primary and secondary contexts. In any case, it is clear that further research is necessary if we hope to resolve the various issues that emerge from studies such as the present one.

The list of motifs examined here is by no means exhaustive. There are numerous other signs that present similar genealogies entailing interaction and transference, such as crossed bands, the quatrefoil portal glyph, the Jester God diadem or fleur-de-lis element, seating glyphs, and a visual complex related to autosacrifice and bloodletting, to name but a few. These, like the examples presented here, also beg the question of what pressures, social or otherwise, were compelling the innovation of new and more conventional means of visual communication. They also illustrate the interplay between iconography and early writing, as Denise Schmandt-Besserat (2007) suggests. The limited examples that we have presented and discussed here serve to elucidate the role of interaction in the origins and development of writing, thereby illuminating the poorly understood processes behind script development in general and adding to a better theoretical understanding of the origins and role of writing in ancient Mesoamerica.

ACKNowledgments. We thank Javier Urcid, and two anonymous reviewers, for comments and suggestions that substantially improved this chapter.

\section{NOTES}

I. This term refers to the deployment of a sign excised from pictorial structures in emerging scribal convention (Carrasco and Englehardt 2015:638).

2. E.g., the principle of disjunction (see Knight 2013:71-75; Kubler 1962; Panofsky 1960; cf. Quilter 1996). This theory was developed in relation to the specific historical circumstances of "Western" art history that was then generalized to the rest of the world despite the lack of systemic supporting evidence. Esther Pasztory (2005:103) sees the changing meaning of forms as a kind of translation and in this respect is similar to what we suggest here.

3. A secondary concern is the function of interaction in adjacent script development.

4. Not all signs in all Mesoamerican scripts were derived from such a process, but as we have noted elsewhere (Carrasco and Englehardt 2015:650-652) a continuous dialogue between art and script appears to have been a hallmark of Mesoamerican writing systems, as it was in other contexts (cf. Schmandt-Besserat 2007, 2010). Indeed, the range of processes by which sign transference occurred among pictorial and writing systems could be diagramed as $\mathrm{P}>\mathrm{W}, \mathrm{P}>\mathrm{P}$, and still others $\mathrm{W}>\mathrm{W}$ and even $\mathrm{W}>\mathrm{P}$ in some examples.

5. Indeed, shared iconography of the Middle Formative often presents a greater degree of consistency compared to the heterogeneity of surviving contemporaneous textual examples. One might speculate that the success of specific iconographic systems was part of the process 
that led toward a writing system that was closely aligned to this iconography. As Justeson (1986:439) notes, writing likely develops "not within a single graphic system, but rather via conjoint use of more than one graphic system in a single context."

6. Material goods obviously would not exist without ideas. On one level, there is an intrinsic idea that motivates the creation of an artifact, which then produces new ideas about it. If a thing is of high saliency or is a higher-order symbolic object, then its interpretation is contingent on what the viewer brings to the sign, but the sign nevertheless determines the interpretant (a kind of understanding of the sign/object relationship). It is in this experience of the representamen-interpretant relationship that semiosis may occur, but this potentiality exists with each interaction between viewer and sign. The difference is that within the donor culture the meaning is more constrained by habit, while in the recipient culture the meaning - though restrained by the donor-likely becomes further narrowed based on the specific needs that prompted the borrowing in the first place, which leads to a change in the relation between sign and object.

7. Many scholars have rightly noted the problematic nature of the term "Olmec"-or "Olmec style," "Olmecoid," etc. (see, e.g., Flannery and Marcus 1994, 2000; Grove 1989, I993, 1997; Lesure 2004; Pool 2007; Rosenswig 2010). Some (e.g., Flannery and Marcus 1994:390; Grove 1997:88; Rosenswig 2010:48-49) have suggested replacing such problematical terms with semantically neutral language such as "horizon styles." In this chapter, we use the term "Olmec" to refer to an art style prevalent in the Middle Formative period in various regions of Mesoamerica, and, following Rosenswig (2010:49), the use of this term here does not imply anything about the relative levels of complexity of the various groups that shared in this artistic tradition, nor do we imply primacy for the Formative period archaeological culture of the Gulf Coast. In this sense, we do not suggest that the Olmec culture "invented" writing in Mesoamerica, or that all regional scripts developed directly from an ancestral, specifically Olmec writing system. In other words, ours is not an "Olmec-centrist," "mother culture," or "traditionalist" argument.

8. An extensive literature exits on this topic from discussions of shared iconography and epigraphy (Fields 1991; Houston 2004; Joyce et al. 1991; Justeson 1986, 2012; Justeson and Matthews 1990; Lesure 2004; Mora-Marín 2001; Stuart 2015), to the movement of ceramics (Blomster et al. 2005; Cheetham et al. 2009) and lithics (Ebert et al. 2014) to historical linguistics that show the dispersal of Mije-Sokean loanwords into adjacent languages (Justeson et al. 1985).

9. Haspelmath (2009:37) provides examples of this process in the transference of signs and concepts between Japanese and Chinese languages and scripts:

This is the case with the numerous Japanese loans based on Chinese compounds. For example, Japanese borrowed kokumin 国民 'citizen' from Chinese guó-mín [country-people] 国民 (cf. Schmidt, Japanese subdatabase), 
but it also borrowed other words with the element kok(u) 'country' (e.g., kok-ka 国家 'nation', koku-ō 国王 'king') and other words with the element min 'people' (e.g., minshū 民衆 'population', jūmin 住民 'inhabitant'). As a result of these multiple borrowings, many of the original Chinese compounds are again transparent in Japanese, and can be regarded as analyzable.

Io. And as Kerry M. Hull (chapter 4 in this volume) quotes Brown (1987:376): "the directionality of borrowing, if it takes place, will more likely be a subordinate group borrowing from a superordinate group."

II. In Mesoamerican scripts, drastic changes in meaning were not always a by-product of the recontextualization or reformulation of a transferred iconic element, and semantic content could (and often did) remain constant across iconographic and writing systems (e.g., the Lazy-S motif; see below and Reilly 1996). Nonetheless, recontextualization did potentially result in the assignation of "new" linguistic values-even if these simply codified prior identical semantic meanings in the language of the adopting system-and/or grammatical frameworks in which individual motifs were interpreted.

I2. It is likely that headdresses as symbols of rank predated their representation in either art or writing. Nonetheless, this fact alone cannot account for the striking formal and semantic continuity between motifs across time and space.

13. This begs the question of what was specific about the Zapotec system that prompted the use of the knotted vegetal headdress motif as the year-bearer glyph. We would tentatively suggest that that recontextualization in this case stemmed from the particularities of the Zapotec calendar. In the Late Formative period, distinct calendrical systems were developing: the Long Count in the Gulf Coast and Maya lowlands (the "southeastern branch"), and the yearbearer system in the "Oaxacan branch" (cf. Justeson 1986:438, fig. I; Mora-Marín 2001:fig. I.I). The Zapotec script is the first in which the year-bearer system-common in the later Mixtec and Aztec scripts of central Mexico - appears. Further, the integration of calendrical elements in names may have occurred at an exceptionally early date in Oaxaca (e.g., San José Mogote Monument 3, ca. 600-400 B C; Marcus 1992:36; cf. Houston 2004:276, 292-293), and there is some evidence for the diffusion of Zapotec calendrical terms into other scripts (see Justeson et al. 1985). Thus, one might argue that the need to represent the calendar-either because year-bearer system was invented in this region, or because calendrical "name-tagging" originated among the Zapotecs—created a context that necessitated the extraction of signs from iconography and their transmutation within the emergent structural conventions of a writing system. Unfortunately, there is a paucity of evidence from these spatial and temporal contexts that speaks to these processes, or the precise moment of transition.

I4. See also the Chalcatzingo "water dancing group," in which rain falls over crocodilian figures perched atop the Lazy-S and surrounded by sprouting vegetation (Reilly 1996:415, fig.4). 
I5. For further glyphic associations between the motif and Chaak and rain, see Stone (1996:405, figs. 4a, 5a, 407-408, fig. 9).

16. The authors have also observed the motif on ceramic vessels currently in Mexico's Museo Nacional de Antropología from the northwestern Mesoamerican sites of Altavista and La Quemada, although semantic content is unclear in these cases.

17. Further associations of the xonecuilli motif are with worms, a scepter held by the god Quetzalcoatl, and a type of bread ritually offered to Xochipilli during the festivals of Macuilxóchitl (Angulo Villaseñor 2002:17n3; Rivas Castro and Lechuga García 2002:67, fig. 6; José Luis Punzo Díaz, personal communication, 2014).

I8. As Helmke (2013:I) explains, calques "form a specific subset of linguistic borrowing in which reliance is placed on literal translations of a foreign expression, phrase, or juxtaposition of words, rather than the direct phonetic adoption of a single foreign lexical item as a loanword. It is in this respect that calques have been thought of as 'loan translations."

19. Such interaction continued well into the Classic period and beyond throughout Mesoamerica, as the other chapters in this volume attest. It is likely that such sustained exchange continued to affect extant scripts, as well as the development of additional Mesoamerican writing systems that emerged in later temporal contexts.

20. We do not suggest that this is always the case, or that shared elements invariably indicate interaction.

2I. E.g., potential or suggested syntactical or functional values of a particular sign that do not correspond to prior visual readings or the interpretive-organizational frameworks of the ancestral system.

22. Although the conventions of the Middle Formative iconographic complex were, in many respects, the conventions of a true script (Carrasco and Englehardt 2015; Justeson 2012; Mora-Marín 200I:23), we do not suggest that all Mesoamerican scripts descended directly from this system. Rather, the fact that so many of these conventions were shared by subsequent scripts in the region (Justeson et al. 1985:41, table 16) suggests that the precursor complex provided the common representational and-initially-interpretive framework that was adopted and modified by other cultures in the process of script diversification.

23. Mora-Marín (200I) discusses the social contexts of inscribed, portable objects that contained texts or iconography in these terms.

\section{REFERENCES}

Angulo Villaseñor, Jorge. 2002. "Identificación de Venus con unos mitos cosmogónicos expresados en los relieves de Chalcatzingo." In Iconografía Mexicana III: Las representaciones de los astros, edited by Beatríz Barba de Piña Chan, I5-28. Colección Científica, INAH, Mexico City. 
Aveni, Anthony F. 200I. Skywatchers. University of Texas Press, Austin.

Baines, John. 2004. “The Earliest Egyptian Writing: Development, Context, Purpose.” In The First Writing: Script Invention as History and Process, edited by Stephen D. Houston, 150-189. Cambridge University Press, Cambridge.

Best, Jonathan W. 2007. A History of the Early Korean Kingdom of Paekche. Harvard East Asian Monographs 256. Harvard University Asia Center, Cambridge.

Blomster, Jeffrey P., Hector Neff, and Michael D. Glascock. 2005. “Olmec Pottery Production and Export in Ancient Mexico Determined through Elemental Analysis." Science 307(5712):1068-1072.

Campbell, Lyle R., and Terrence S. Kaufman. 1976. "A Linguistic Look at the Olmecs." American Antiquity 4I(I):80-89.

Campbell, Lyle R., Terrence S. Kaufman, and Thomas C. Smith-Stark. 1986. "MesoAmerica as a Linguistic Area." Language 62(3):530-553.

Carrasco, Michael D., and Joshua D. Englehardt. 2015. "Diphrastic Kennings on the Cascajal Block and the Emergence of Mesoamerican Writing." Cambridge Archaeological Journal 25(3):635-656.

Carrasco, Michael D., and Joshua D. Englehardt. In press. "Conventions and Linguistic Tropes in Olmec Art and Writing." In The Chinese Writing System and its Dialogue with Sumerian, Egyptian, and Mesoamerican Writing Systems, edited by Kuang Yu Chen and Dietrich Tschanz. Rutgers University Press, New Brunswick.

Cheetham, David. 2007. Cantón Corralito: Objects from a Possible GulfOlmec Colony. FAMSI, Crystal River, FL.

Cheetham, David. 20I0. "Cultural Imperatives in Clay: Early Olmec Carved Pottery from San Lorenzo and Cantón Corralito." Ancient Mesoamerica 2I(I):165-185.

Cheetham, David, Susana E. Gonzalez, Richard J. Behl, Michael D. Coe, Richard A. Diehl, and Hector Neff. 2009. "Petrographic Analyses of Early Formative Olmec Carved Pottery." Mexicon 31(3):69-72.

Clark, John E. 2004. "The Birth of Mesoamerican Metaphysics: Sedentism, Engagement, and Moral Superiority." In Rethinking Materiality: The Engagement of Mind with the Material World, edited by Elizabeth DeMarrais, Christopher Gosden, and Colin Renfrew, 205-224. McDonald Institute Monographs, McDonald Institute for Archaeological Research, Cambridge.

Clark, John E., and Michael Blake. 1994. "The Power of Prestige: Competitive Generosity and the Emergence of Rank Societies in Lowland Mesoamerica." In Factional Competition and Political Development in the New World, edited by Elizabeth M. Brumfiel and James W. Fox, 17-30. Cambridge University Press, Cambridge. 
Cohen, Laurent, and Stanislas Dehaene. 2004. "Specialization within the Ventral Stream: The Case for the Visual Word Form Area." NeuroImage 22(I):466-476.

Dehaene, Stanislas. 2009. Reading in the Brain: The Science and Evolution of a Human Invention. Viking, New York.

Demarest, Arthur A. 1989. "The Olmec and the Rise of Civilization in Eastern Mesoamerica." In Regional Perspectives on the Olmec, edited by Robert J. Sharer and David C. Grove, 303-344. National Gallery of Art, Washington, DC.

Ebert, Claire E., Mark Dennison, Kenneth G. Hirth, Sarah B. McClure, and Douglas J. Kennett. 2014. "Formative Period Obsidian Exchange along the Pacific Coast of Mesoamerica." Archaeometry 57(SI):54-73.

Fields, Virginia M. 1991. “The Iconographic Heritage of the Maya Jester God.” In Sixth Palenque Roundtable, Ig86, edited by Merle Green Robertson and Virginia M. Fields, 167-174. University of Oklahoma Press, Norman.

Flannery, Kent V. 1968. "The Olmec and the Valley of Oaxaca: A Model for Interregional Interaction in Formative Times." In Dumbarton Oaks Conference on the Olmec, edited by Elizabeth P. Benson, 79-117. Dumbarton Oaks, Washington, DC.

Flannery, Kent V., ed. 1976. The Early Mesoamerican Village. Academic Press, New York. Flannery, Kent V., and Joyce Marcus. 1994. Early Formative Pottery of the Valley of Oaxaca, Mexico. Memoirs of the Museum of Anthropology 27. University of Michigan, Ann Arbor.

Flannery, Kent V., and Joyce Marcus. 2000. "Formative Mexican Chiefdoms and the Myth of the "Mother Culture." Journal of Anthropological Archaeology I9(I):I-37.

Grove, David C. 1989. “Olmec: What's in a Name?” In Regional Perspectives on the Olmec, edited by Robert J. Sharer and David C. Grove, 8-I4. National Gallery of Art, Washington, DC.

Grove, David C. 1993. "'Olmec' Horizons in Formative Period Mesoamerica: Diffusion or Social Evolution?" In Latin American Horizons, edited by Don S. Rice, 83-III. Dumbarton Oaks, Washington, DC.

Grove, David. 1997. "Olmec Archaeology: A Half Century of Research and Its Accomplishments." Journal of World Prehistory II(I):5I-IOI.

Grove, David. 1999. "Public Monuments and Sacred Mountains: Observations on Three Formative Period Sacred Landscapes." In Social Patterns in Preclassic Mesoamerica, edited by David C. Grove and Rosemary A. Joyce, 255-299. Dumbarton Oaks, Washington, DC.

Guth Kanda, Christine. 1985. Shinzō: Hachiman Imagery and Its Development. Harvard East Asian Monographs iı. Harvard University Asia Center, Cambridge.

Haspelmath, Martin. 2008. "Loanword Typology: Steps toward a Systematic CrossLinguistic Study of Lexical Borrowability." In Aspects of Language Contact: New Theoretical, Methodological, and Empirical Findings with Special Focus on Romancisation 
Processes, edited by Thomas Stolz, Dik Bakker, and Rosa Salas Palomo, 43-62. Mouton de Gruyter, Berlin.

Haspelmath, Martin. 2009. "Lexical Borrowing: Concepts and Issues." In Loanwords in the World's Languages: A Comparative Handbook, edited by Martin Haspelmath and Uri Tadmor, 35-54. Mouton de Gruyter, Berlin.

Haspelmath, Martin, and Uri Tadmor, eds. 2009. Lexical Borrowing in Cross-Linguistic Perspective. Mouton de Gruyter, Berlin.

Hayden, Brian. 1998. "Practical and Prestige Technologies: The Evolution of Material Systems." Journal of Archaeological Method and Theory 5(I): I-55.

Helmke, Christophe. 2013. "Mesoamerican Lexical Calques in Ancient Maya Writing and Imagery.” PARI Journal I4(2):I-I5.

Helms, Mary. 1993. Craft and the Kingly Ideal: Art, Trade, and Power. University of Texas Press, Austin.

Heredia Espinoza, Verenice Y., and Joshua D. Englehardt. 2016. "Simbolismo panmesoamericano en la iconografía cerámica de la tradición teuchitlán, Jalisco." Travaux et Recherches dans les Amériques du Centre 68:9-34.

Houston, Stephen D. 2004. "Writing in Early Mesoamerica." In The First Writing: Script Invention as History and Process, edited by Stephen D. Houston, 274-312. Cambridge University Press, Cambridge.

Houston, Stephen D., and David Stuart. 1990. “T632 as Muyal, 'Cloud.” Central Tennessean Notes in Maya Epigraphy i. Nashville.

Jakobson, Roman. 1959. “On Linguistic Aspects of Translation.” In On Translation, edited by Reuben A. Brower, 232-239. Harvard Studies in Comparative Literature 23. Harvard University Press, Cambridge.

Joyce, Rosemary A., Richard Edging, Karl Lorenz, and Susan. D. Gillespie. 1991. "Olmec Bloodletting: An Iconographic Study." In Sixth Palenque Roundtable, Ig86, edited by Merle Green Robertson and Virginia M. Fields, I43-I50. University of Oklahoma Press, Norman.

Justeson, John S. 1986. “The Origin of Writing Systems: Preclassic Mesoamerica.” World Archaeology $_{\text {17 }}(3): 437-458$.

Justeson, John S. 2012. "Early Mesoamerican Writing Systems." In The Oxford Handbook of Mesoamerican Archaeology, edited by Deborah L. Nichols, 830-844. Oxford University Press, Oxford.

Justeson, John S., and Peter L. Matthews. 1990. "Evolutionary Trends in Mesoamerican Hieroglyphic Writing." Visible Language 24(I):88-132.

Justeson, John S., William M. Norman, Lyle R. Campbell, and Terrence S. Kaufman. 1985. The Foreign Impact on Lowland Mayan Language and Script. Middle American Research Institute Publication 53. Tulane University, New Orleans. 
Kaufman, Terrence S. 1976. "Archaeological and Linguistic Correlations in Mayaland and Associated Areas of Mesoamerica." World Archaeology 8(I):IOI-II8.

Kim-Renaud, Young-Key, ed. 1997. The Korean Alphabet: Its History and Structure. University of Hawai'i Press, Honolulu.

Knight, Vernon J. 2013. Iconographic Method in New World Prehistory. Cambridge University Press, Cambridge.

Kubler, George. 1962. The Shape of Time. Yale University Press, New Haven.

Lacadena, Alfonso. 1995. Evolución formal de las grafias escriturarias mayas: Implicaciones históricas y culturales. Unpublished PhD dissertation, Facultad de Historia, Universidad Complutense de Madrid.

Lacadena, Alfonso. 2010. "Historical Implications of the Presence of Non-Mayan Linguistic Features in Maya Script." In The Maya and Their Neighbours: Internal and External Contacts through Time. Proceedings of the Ioth European Maya Conference, Leiden, December 2005, edited by Laura van Broekhoven, Rogelio Valencia Rivera, Benjamin Vis, and Frauke Sachse, 29-39. Acta Mesoamericana, No. 23. Anton Saurwein, Markt Schwaben.

Lesure, Richard G. 2000. "Animal Imagery, Cultural Unities, and Ideologies of Inequality in Early Formative Mesoamerica." In Olmec Art and Archaeology in Mesoamerica: Developments in Formative Period Social Complexity, edited by John E. Clark and Mary E. Pye, 193-215. National Gallery of Art, Washington, DC.

Lesure, Richard G. 2004. "Shared Art Styles and Long-Distance Contact in Early Mesoamerica." In Mesoamerican Archaeology: Theory and Practice, edited by Julia A. Hendon and Rosemary A. Joyce, 73-96. Blackwell, Malden, MA.

Lowe, Gareth W. 1989. "Algunas aclaraciones sobre la presencia olmeca y maya en el Preclásico de Chiapas." In El Preclásico o Formativo, avances y perspectivas, edited by Miguel Carmona, 363-385. Museo Nacional de Antropología-INAH, Mexico City.

Lurie, David B. 20I. Realms of Literacy: Early Japan and the History of Writing. Harvard East Asian Monographs 335. Harvard University Asia Center, Cambridge.

Marcus, Joyce. 1992. Mesoamerican Writing Systems: Propaganda, Myth, and History in Four Ancient Civilizations. Princeton University Press, Princeton.

Matras, Yaron. 2007. “The Borrowability of Structural Categories." In Grammatical Borrowing in Cross-Linguistic Perspective, edited by Yaron Matras and Jeanette Sakel, 3I-74. Mouton de Gruyter, Berlin.

Mora-Marín, David. 200I. The Grammar, Orthography, Content, and Social Context of Late Preclassic Portable Texts. PhD dissertation. State University of New York, Albany. University Microfilms, Ann Arbor. 
Nelson, Fred W., Jr., and John E. Clark. 1998. "Obsidian Production and Exchange in Eastern Mesoamerica." In Rutas de intercambio en Mesoamérica, Vol. 3: Coloquio Pedro Bosch-Gimpera, edited by Evelyn Childs Rattray, 277-333. UNAM, Mexico City.

Paine, Robert T., and Alexander C. Soper. 1992. The Art and Architecture of Japan. 3 rd ed. Yale University Press Pelican History of Art. Yale University Press, New Haven.

Panofsky, Erwin. 1960. Renaissance and Renascences In Western Art. Almqvist and Wiksell, Stockholm.

Pasztory, Esther. 2005. Thinking with Things: Toward a New Vision of Art. University of Texas Press, Austin.

Plourde, Aimée M. 2009. "Prestige Goods and the Formation of Political Hierarchy: A Costly Signaling Model." In Pattern and Process in Cultural Evolution, edited by Stephen Shennan, 265-276. University of California Press, Berkeley.

Pohl, Mary E. D., J. Kathryn Josserand, Kevin O. Pope, and Christopher von Nagy. 2008.

"La U olmeca y el desarrollo de la escritura en Mesoamérica." In Olmeca: Balance y perspectivas, edited by Maria Teresa Uriarte and Rebecca González Lauck, 685-694. CONACULTA/INAH/NWAF, Mexico City.

Pohl, Mary E. D., Kevin O. Pope, and Christopher von Nagy. 2002. "Olmec Origins of Mesoamerican Writing." Science 298(5600):1984-1987.

Pool, Christopher S. 1997. Olmec Archaeology and Early Mesoamerica. Cambridge University Press, Cambridge.

Proskouriakoff, Tatiana. 1968. "Olmec and Maya Art: Problems of their Stylistic Relation.” In Dumbarton Oaks Conference on the Olmec, edited by Elizabeth P. Benson, II9-I34. Dumbarton Oaks, Washington, DC.

Proskouriakoff, Tatiana. 1971. "El arte maya y el modelo genético de cultura." In Desarrollo cultural de los mayas, edited by Evon Z. Vogt y Alberto Ruz Lhuillier, 187-202. Centro de Estudios Mayas, UNAM, Mexico City.

Quilter, Jeffrey. 1996. "Continuity and Disjunction in Pre-Columbian Art and Culture." RES: Anthropology and Aesthetics 29/30:303-317.

Quirarte, Jacinto. 2007. "Revisiting the Relationship between Izapa, Olmec, and Maya Art." In Archaeology, Art, and Ethnogenesis in Mesoamerican Prehistory: Papers in Honor of Gareth W. Lowe, edited by Lynnette S. Lowe and Mary E. Pye, 247-276. Papers of the New World Archaeological Foundation, No. 68. Brigham Young University, Provo, Utah.

Reilly, F. Kent, III. 199I. "Olmec Iconographic Influences on the Symbols of Maya Rulership: An Examination of Possible Sources." In Sixth Palenque Roundtable, I986, edited by Merle G. Robertson and Virginia M. Fields, I5I-166. University of Oklahoma Press, Norman. 
Reilly, F. Kent, III. 1995. “Art, Ritual, and Rulership in the Olmec World.” In The Olmec World: Ritual and Rulership, 27-47. Art Museum, Princeton University, Princeton.

Reilly, F. Kent, III. 1996. “The Lazy-S: A Formative Period Iconographic Loan to Maya Hieroglyphic Writing." In Eighth Palenque Round Table, I993, edited by Merle Green Robertson, Martha J. Macri, and Janet McHargue, 413-424. Pre-Colombian Art Research Institute, San Francisco.

Renfrew, Colin. 200I. "Symbol before Concept: Material Engagement and the Early Development of Society." In Archaeological Theory Today, edited by Ian Hodder, I22-I40. Polity, Oxford.

Rivas Castro, Francisco, and María del Carmen Lechuga García. 2002. "Representación de una constelación en un petrograbado del Cerro del Cabrito, Naucalpan, México.” In Iconografía mexicana III: Las Representaciones de los astros, edited by Beatríz Barba de Piña Chan, 6I-72. Colección Científica, INAH, Mexico City.

Robertson, John S. 2004. "The Possibility and Actuality of Writing." In The First Writing: Script Invention as History and Process, edited by Stephen D. Houston, 16-38. Cambridge University Press, Cambridge.

Robinson, Andrew. 2003. "The Origins of Writing." In Communication in History: Technology, Culture, Society, edited by David Crowley and Paul Heyer, 33-43. Allyn and Bacon, New York.

Rogers, Henry. 2005. Writing Systems: A Linguistic Approach. Blackwell, Oxford.

Rosenswig, Robert M. 2010. The Beginnings of Mesoamerican Civilization: Inter-Regional Interaction and the Olmec. Cambridge University Press, Cambridge.

Sakel, Jeanette. 2007. “Types of Loan: Matter and Pattern." In Grammatical Borrowing in Cross-Linguistic Perspective, edited by Yaron Matras and Jeanette Sakel, I5-30. Mouton de Gruyter, Berlin.

Saturno, William A., David Stuart, and Boris Beltrán. 2006. "Early Maya Writing at San Bartolo, Guatemala." Science 3II(5765):1281-I283.

Schele, Linda. 1999. "Sprouts and the Early Symbolism of Rulers in Mesoamerica." In The Emergence of Lowland Maya Civilization: The Transition from the Preclassic to Early Classic, A Conference at Hildesheim, Germany, November 19g2, edited by Nikolai Grube, 117-135. Acta Mesoamericana, No. 8. Anton Saurwein, Markt Schwaben.

Schmandt-Besserat, Denise. 2007. When Writing Met Art: From Symbol to Story. University of Texas Press, Austin.

Schmandt-Besserat, Denise. 2010. How Writing Came About. University of Texas Press, Austin.

Seeley, Christopher. 1991. A History of Writing in Japan. University of Hawai'i Press, Honolulu. 
Severi, Carlo. 2014. "Transmutating Beings: A Proposal for an Anthropology of Thought." HAU: Journal of Ethnographic Theory 4(2):4I-7I.

Stone, Andrea J. 1996. “The Cleveland Plaque: Cloudy Places of the Maya Realm.” In Eighth Palenque Round Table, I993, edited by Merle Green Robertson, Martha J. Macri, and Janet McHargue, 403-4I2. Pre-Colombian Art Research Institute, San Francisco.

Stuart, David. 1991. "Ruler Names in Zapotec Inscriptions." Paper presented at the roundtable "Art and Writing: Recording Knowledge in Pre-Columbian America." Dumbarton Oaks, Washington, DC, March 23-24.

Stuart, David. 2015. “The Royal Headband: A Pan-Mesoamerican Hieroglyph.” Electronic document, https:// decipherment.wordpress.com/2015/oI/26/the-royal-headband-a-pa n-mesoamerican-hieroglyph-for-ruler/, accessed January 31, 2015.

Taube, Karl A. 2000. The Writing System of Ancient Teotihuacan. Ancient America No. I. Center for Ancient American Studies, Barnardsville, NC.

Taube, Karl A. 2009. "El Díos de la Lluvia Olmeca." Arqueología Mexicana 96:26-29.

Taube, Karl A., William A. Saturno, David Stuart, and Heather Hurst. 2010. The Murals of San Bartolo, El Petén, Guatemala, Part 2: The West Wall. Ancient America No. Io. Center for Ancient American Studies, Barnardsville, North Carolina.

Tezozómoc, Alvaro Hernando, 1980. Crónica mexicana. Porrúa, Mexico City.

Urcid, Javier. 1992. Zapotec Hieroglyphic Writing. 2 Vols. Unpublished PhD dissertation, Department of Anthropology, Yale University.

Urcid, Javier. 2001. Zapotec Hieroglyphic Writing. Studies in Pre-Colombian Art and Archaeology, No. 34. Dumbarton Oaks, Washington, DC.

Urcid, Javier. 2005. Zapotec Writing: Knowledge, Power, and Memory in Ancient Oaxaca. FAMSI, Crystal River, FL.

Whittaker, Gordon. 1980. The Hieroglyphs from Monte Albán. Unpublished PhD dissertation, Department of Anthropology, Yale University.

Wichmann, Søren. 1995. The Relationship Among the Mixe-Zoquean Languages of Mexico. University of Utah Press, Salt Lake City.

Wichmann, Søren. 1999. "A Conservative Look at Diffusion Involving Mixe-Zoquean Languages." In Archaeology and Language II: Archaeological Data and Linguistic Hypotheses, edited by Roger Blench and Matthew Spriggs, 297-323. Routledge, New York.

Wichmann, Søren, Dmitri Beliaev, and Albert Davletshin. 2008. "Posibles correlaciones lingüísticas y arqueológicas vinculadas con los Olmecas.” In Olmeca: Balance y perspectivas, edited by María Teresa Uriarte and Rebecca González Lauck, 667-683. CONACULTA/INAH/NWAF, Mexico City. 


\section{Chapter 4}

\section{Hieroglyphic Ch'olan to Chorti' \\ Tracing Linguistic and Social Interactions into Eastern Cholan}

Kerry M. Hull

Linguistic research over the last fifty years has allowed major advances in our understanding of linguistic interactions within the Mesoamerican sphere. A growing trend in the field of Mesoamerican studies is incorporating a multidisciplinary approach to reconstructing ancient society. This study traces the social and linguistic interactions of Ch'olan Mayan languages over the last 2000 years. Focusing principally on Eastern Ch'olan, I discuss the nature of contact and linguistic sharing from the Early Classic period to colonial times, beginning with the language underlying the Maya hieroglyphic script, which I term Hieroglyphic Ch'olan. Drawing on a wealth of data from other studies, as well as my own fieldwork data, I reconstruct the processes of lexical borrowing involving Ch'olan languages through social contact and ideological appropriation in the multilingual and multiethnic world of ancient Mesoamerica. New Ch'orti' data are also provided showing Ch'orti' to be engaged in lexical borrowing with a variety of other languages. This study brings together evidence of the major role Ch'olan languages played as a lexical donor as well as the eclectic nature of Ch'olan in borrowing from other languages at times. What becomes apparent is that Ch'olan languages have had a disproportionally large impact on both Mayan and non-Mayan languages for millennia, while still being active in their adoption of foreign terms.

Historical linguistics provides a wealth of evidence concerning the social and linguistic interactions of ancient Mesoamerica. This chapter focuses on the role Ch'olan languages, primarily Eastern, have played in influencing (and being influenced 
by) other Mesoamerican languages. This study surveys the movement of lexemes between languages and investigates viable scenarios for determining the motivation and direction of borrowing. Hieroglyphic Ch'olan was the source of lexical sharing into various Mayan and non-Mayan languages, yet was also open to incorporating foreign terms at the same time, mainly from Mije-Sokean and Nawa ${ }^{1}$ languages. Trade and market economies, Olmec influence, migrations, and perhaps the politics of non-Maya sites such as Teotihuacan could be factors in understanding Hieroglyphic Ch'olan's lexical interactions. In the Postclassic period, however, two daughter languages, Ch'olti' and Ch'orti', also had an inordinately large lexical impact on other Mesoamerican languages. This study primarily discusses linguistic interaction between Ch'orti' and other languages in order to flesh out many of the borrowing processes and social, political, and geographical factors that were involved. In part, the high percentage of loanwords from Ch'olan is linked to the status Ch'olan languages (as well as Yukatekan to a lesser extent) enjoyed during the Classic period as the language of the hieroglyphic script.

\section{MAYAN LANGUAGE HISTORY}

Proto-Mayan appears to have been in use by 2000 BC (Kaufman 1976). There are thirty-one Mayan languages, several extinct or soon to be so, all deriving from Proto-Mayan. Proto-Mayan split into five major subgroups-Wastekan, Yukatekan, Greater Q'anjob'alan, Eastern Mayan, and Greater Tzeltalan (to which Ch'olan belongs) (Kaufman and Norman 1984:78) - perhaps as early as 2000 B C, by which time lexicostatistical dates indicate "some regional dialectal differences had already diverged into several Mayan languages" (Dahlin et al. 2007).

The movement of Cholan and Yukatekan speakers in the Early Preclassic is still a matter of considerable debate. Kaufman believes Yukatekan speakers started moving toward the north into the Yucatán around I000 B C. J. Kathryn Josserand (1975:505) puts that migration at a later date, based partially on the use of Chicanel ceramics, which she associates with Yukatekan speakers who date to the Late Preclassic. It seems that by 100 B C there were Ch'olan-Tzeltalan speakers as far south as the Copán region (Kaufman 1976:108), or by a few hundred years later. Wichmann (2002) has found strongly Eastern Cholan features in the inscriptions at Copán, suggesting the presences of Eastern Ch'olan speakers by at least the seventh century AD. These migrations eventually located Yukatekan speakers in the north and Ch'olan speakers in the south. Epigraphic data supports this idea, but would isolate Yukatek even farther north, extending the area where Ch'olan was used in the Classic period.

Ch'olan and Tzeltalan probably diverged around AD o (Dahlin et al. 2007:374). The language underlying Maya hieroglyphic writing, Hieroglyphic Ch'olan, emerges 
by AD 200 (Houston et al. 2000). Kaufman (1976:110) dates the breakup of Ch'olan into Ch'orti' and Ch'ol-Chontal around AD 600. Wichmann (2006:283), however, notes an earlier "Eastern verses Western Ch'olan differentiation" in place by $\mathrm{AD}$ 400 that precedes the formal split about AD 600. In the model of Houston et al. (2000), the Western branches of Ch'olan became Ch'ol and Acalan (later becoming Chontal) while the Eastern branch developed into Ch'olti' and Ch'orti' - two languages whose line of linguistic parentage is still a matter of debate today.

Tzeltalan speakers during the Classic period (AD 250-900) are found in the west, where Tzeltalan features have been noted in the inscriptions. Several Tzeltalan traits have also been identified by Wichmann, Lacadena, and others. For example, the spelling of WINIK-li, ${ }^{2}$ winik [i]l for the "winal" glyph on Tila Stela B may be an attempt to show a Tzeltal or Tzotzil form winikil used in a series of month names (Lacadena and Wichmann 2005:36). Inscriptions from other sites near present-day speakers of Tzeltal such as Chinkultik and Tonina have specific Tzeltalan features, suggesting an extended occupation of those areas.

Other linguistic features recently described as Tzeltalan have been noted in inscriptions at Pomoná and Joloniel, in addition to the one just mentioned at Tila, all areas thought to have had Ch'ol speakers. Hopkins et al. (2008:83-84) has noted that historical sources place Ch'ol speakers "along the Tulijá River and in the highland areas that were to become the modern municipios of Tila and Tumbalá, Chiapas" but that forced migrations and resettlements reduced the populations to mainly the municipios of Tila and Tumbalá. This leaves open the possibility of Tzeltalan speakers in Joloniel at an early date.

Epigraphic data shows a limited area of Yukatekan influence in hieroglyphic writing, primarily in the northern Yucatán, areas in the west of possible Tzeltalan influence, a western zone of West Ch'olan features, and a stronger impact of Eastern Ch'olan languages in the eastern parts of the Maya lowlands.

\section{YUKATEKAN AND CH'OLAN INTERACTIONS}

Ch'olan and Yukatekan languages (see figure 4.I), which separated around $2000 \mathrm{BC}$, have had a long and substantial linguistic influence on each other lexically (Justeson et al. 1985:9-20; Kaufman and Norman 1984:145-I47; Wichmann and Brown 2003:58). Yukatekan speakers and Ch'olan speakers have shared geographical boundaries in the past and even today. These boundaries at the time the arrival of the Spanish were nearly the same as they were in the Late Classic period, as Fox and Justeson (1982) have shown. Another even more important reason for their high degree of lexical sharing is that both languages were main players in Classic Maya civilization, ${ }^{3}$ Ch'olan as a prestige language (see below) and Yukatek as possibly a 


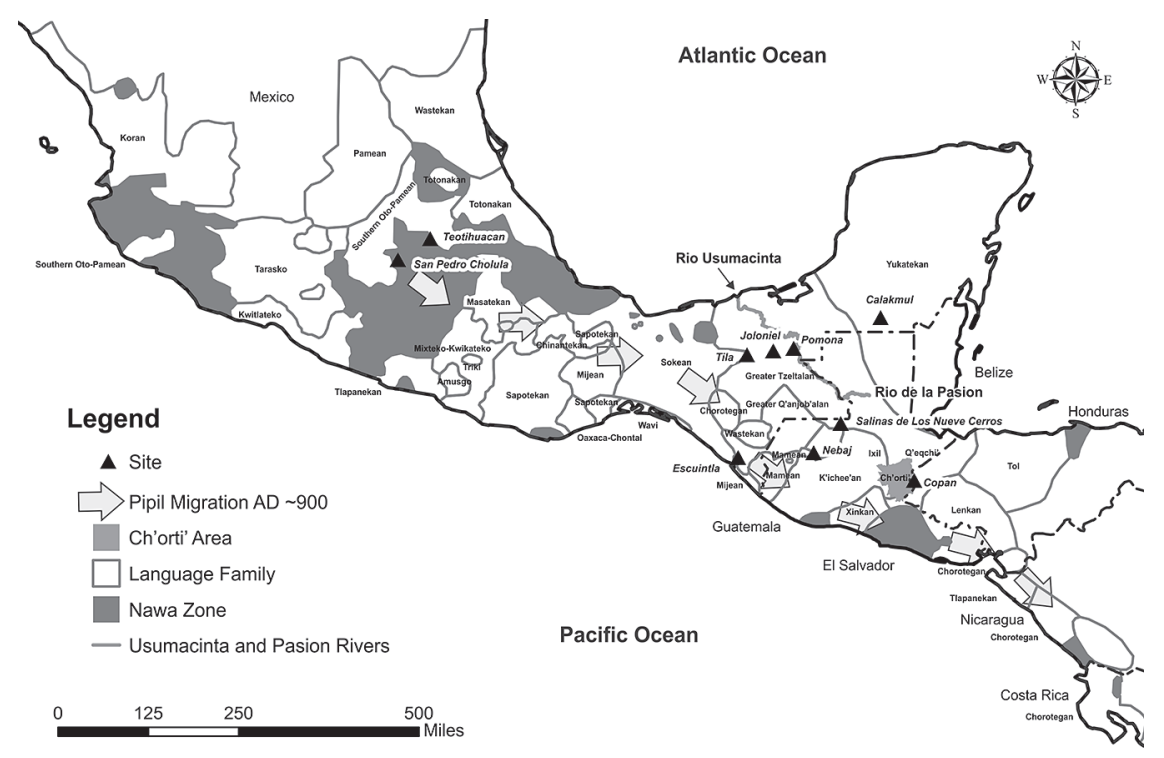

FIGURE 4.I. Map of Mesoamerica around AD I500 with sites and languages discussed in the chapter (adapted from Kaufman and Justeson 2007:194, fig. I).

literary language (see Lacadena and Wichmann 2002:313). Indeed, contact between Yukatekan and Ch'olan-Tzeltalan languages must have been considerable since they share a sizable portion of their lexicon, though the Yukatekan influence came later in the Classic period (Campbell and Kaufman 1985:193). Also, as Danny Law has noted, they share sound changes from Common Mayan. While their genetic relationships are highly divergent, they have undergone similar phonological changes, such as $\mathrm{pM} /{ }^{*} \mathrm{q} />/ \mathrm{k} /$ and $\mathrm{pM} /{ }^{*} \mathrm{r} />/ \mathrm{y} /$, yet this similarity likely took place due to linguistic contact after their differentiation (Law 2009:222-223). Law also points out that they have similar pronominal systems, stressing that while it is nearly impossible to determine the direction of borrowing with the shared ergative pronouns between Yukatek and Ch'olan, it seems that the absolutive pronouns originated in Ch'olan (Law 2009:228).

It is clear from recent epigraphic studies (Lacadena and Wichmann 2002; Wichmann 2002) that the main language found in the hieroglyphic inscriptions is Ch'olan, but mixed with a sizable portion of Yukatekan vocabulary. ${ }^{4}$ Yukatekan words and morphology grow over time in the northern Yucatán. This increasing presence of Yukatekan grammar and vocabulary is found in the Dresden and Madrid Codices, as Wald (2004), Lacadena (1997), and others have convincingly 
demonstrated. Wichmann and Brown (2003:58) argue that the presence of strong Ch'olan and Yukatekan features in the Madrid and Dresden Codices suggests a possible lingua franca based on these two languages: "Given the robust tendency for lingua francas to underlie formation of linguistic areas (Brown 1999:157, I6I), a lowland lingua franca might have facilitated the great amount of convergence between Ch'olan and Yukatekan."

While Ch'olan and Yukatekan enjoyed a high degree of status during the Late Classic throughout the Maya lowlands, Fox and Justeson (1982) have suggested a strong Yukatekan influence in many of the major cities in the lowlands. Yet it is Ch'olan that is the more common source of lexical and morphological borrowing into other languages. However, once Ch'olan's influence waned starting in Postclassic times, other languages increased in their influence as donors, even to the point that, as Law (2009) has pointed out, certain innovations such as the inclusive/inclusive pronouns did not originate with Ch'olan speakers nor were they adopted by them.

\section{SOCIAL STRATIFICATION AND LINGUISTIC INTERACTION}

Ch'olan languages have been the source of borrowings for millennia, in large part due to the status of Hieroglyphic Ch'olan in the Classic period as a prestige language, as Houston et al. (2000) have proposed (cf. Wichmann 2006:55). Houston et al. (2000) term the prestige language of the hieroglyphs "Classical Ch'olti." According to Robertson and Law (2009:294), Classical Ch'olti' "was a common prestige language spoken through the Classic Maya cultural area-with the proviso that, like other prestige languages, it was learned by non-Ch'oltian speakers who participated in the literate Classic Mayan culture." Houston et al. (2000:335) further explain their understanding of a prestige language: "The medium of script retards change in written language by recording, in tomes of acknowledged prestige, the linguistic habits of previous generations. In contrast, low speech is often a localized phenomenon, conditioned by slang and invigorated by changing usage. A prestige language is one that is preponderantly high, written, employed by trained scribes and exegetes, and suitable for formal or liturgical settings."

If the notion of a "prestige language" is valid for the hieroglyphic script, this would certainly inform questions of linguistic borrowings as one might expect it would much more likely be a lexical donor language rather than the recipient. Indeed, Matras (2012:19) notes two primary factors that cause contact-induced linguistic change: "gaps" in the receiving language system or "social prestige" on the part of the donor language. It is necessary to state, however, that language contact, even in superstrate/substrate situations, does not always produce large-scale 
borrowing. Some indigenous languages, in fact, resist the adoption of foreign elements. For example, Nivaclé and Chorote, languages of Brazil, according to Campbell and Grondona (2012:337), "have very few loanwords from Spanish and, on the other hand, deploy native linguistic resources to create new words to accommodate concepts acquired through contact with Spanish culture." The authors further explain: "Nivaclé and Chorote do not allow items of acculturation to impose foreign lexical material on these languages, but rather impose their own linguistic resources on newly acquired items." Yet, it must be recognized that the directionality of borrowing, if it takes place, will more likely be a subordinate group borrowing from a superordinate group (Brown 1987:376).

Prestige borrowings are often what Law terms "high culture" terms: "words for cosmological, ritual or scientific concepts such as calendrical terms (Brown 1987), deity names, and so forth (Justeson et al. 1985; Wichmann and Brown 2003), lending support to the idea that Classic Maya civilization was an important force in the circulation of linguistic material in the region" (Law 2014:27). Many such well-diffused words of dominant culture that can be identified from Classic period Maya society have strong affinities to Ch'olan. Kaufman has argued that terms that he labels "Classic Maya culture words," such as "moon, debt, numeral classifier for persons, rabbit, trap, 400, 8000 , star, eleven, female relative, cornfield, bean, word, atole, heart, name" all derived principally from Ch'olan, "usually displacing a protoMayan word" (Kaufman 1976:109). Kaufman further notes: "besides the usual kind of lexical borrowing between adjacent languages, in the Mayan region there is one language group which has had vastly more lexical and phonetic influence than any other-Cholan" (Kaufman 1976:112).

\section{LINGUISTIC INTERACTIONS WITH HIEROGLYPHIC CH'OLAN}

Hieroglyphic Ch'olan, however, was not insulated from outside linguistic influence, despite its status as a prestige language. In fact, Hieroglyphic Ch'olan adopted numerous loanwords, principally from Sokean languages or Nawa. Beyond issues of status as a prestige language, Hieroglyphic Ch'olan also interacted lexically with other languages due to contact and areal diffusion. ${ }^{5}$

The intellectual and cultural sharing from the Early Classic period must be evaluated against an Olmec backdrop. The Olmec civilization had an extensive influence on many other Mesoamerican languages (Campbell and Kaufman 1976:82). Today there is strong consensus that the language of the Olmecs was Mije-Sokean (Campbell and Kaufman 1976:82), but it was evidently a combination of political clout or prestige as well as adopted cultural features that facilitated Mije-Sokean borrowings into early stages of Mayan languages. ${ }^{6}$ The borrowing of cultural 
features can be seen in the pervasive borrowing of terms related to cultigens from Mije-Sokean into other languages in Mesoamerica and is evidence of a Mije-SokeanOlmec connection as the Olmecs were, as Campbell and Kaufman (1976:83) state, the "first highly civilized agriculturalists of Mesoamerica."

Apart from ideologically or resource-related borrowings, social contact with Classic period ruling culture is another mechanism for linguistic sharing. Since Mesoamerican languages on the whole only minimally borrow from each other, Kaufman (2001:7) points out, "any amount of borrowing that permeates a whole language or dialect area is evidence of a serious amount of language contact." What languages have left a linguistic fingerprint in Hieroglyphic Ch'olan? Primarily Mije-Sokean and Nawa. Loanwords from these two languages are readily detectable in the hieroglyphic script. Before discussing Mije-Sokean and Nawa words in Hieroglyphic Cholan, it would seem prudent to describe the methods for determining the source language in borrowing, the chronology of the event, and, if possible, the motivation or social interaction facilitating the loan.

Kaufman (2003:29) has remarked: "Whenever a word is borrowed from one language into another, this reflects interaction among the speakers of the two languages. By knowing what changes a form has undergone before and after borrowing, scholars can identify who borrowed the word from whom, and the relative time that the borrowing was made. A set of such borrowings can also suggest features of the cultural interaction that led to their adoption." There are various tools for understanding loanwords within Mesoamerican languages, such as glottochronology (still a controversial method), phonology, distributional evidence, and syllable structure.

Determining the approximate date for when specific borrowings take place is often possible through glottochronology. Knowledge of sound changes and when they occurred within a language family can also be very instructive, such as with the term lukum, which generally means 'earthworm' or 'intestinal worm' in many north, central, and south Mayan languages. Brown and Witkowski (1982:104) note that the center of origin for the diffusion of the term affected Q'anjob'al and Jakaltek later in Mayan history before the ${ }^{*} \mathrm{q}>\mathrm{k}$ shift in central and north Mayan (cf. Brown and Witkowski 1979). Also, the expected form in Q'eqchi' is luqum, but the only attested form is lukum, which likely comes from a Ch'olan or north Mayan language source.

Foreign terms in Mayan languages are often recognizable due to their syllable structure. Proto-Mayan was usually monosyllabic. As Campbell (2013:62) notes, "Words which violate the typical phonological patterns (canonical forms, morpheme structures, syllable structure, phonotactics) of a language are likely to be loans." Campbell and Kaufman (1976:84) identify numerous polysyllabic terms 
in proto-Mije-Sokean that are found in various Mayan languages but whose syllable structure does not conform to the common monosyllabic root forms of proto-Mayan: 'cacao' *kakawa, 'gourd' *tsima, 'squash' tsiwa, 'tomato' *koya, and 'guava' * patay.

Phonological and distributional evidence can point to diffusion of terms, often resulting from contact between language groups. Determining the nature of that contact is the challenge from strictly a historical linguistic standpoint. Fortunately other lines of evidence, such as archaeological, historical, ethnographic, and so on, can corroborate assumptions or offer new ideas on defining the type of contact.

Indo-European studies have strongly benefited from a merger of archaeological and linguistic data. However, when dealing with distant past civilizations, both archaeological and linguistic data are incomplete and rarely conclusive, so determinations made by comparing two (or more) lacking data sets must be tempered by this reality. The possible conflicting nature of archaeological and linguistic evidence has played out for decades in the debate over where Proto-Indo-European arose. J. P. Mallory (1976) argues that shortcomings of accurately reconstructing Indo-European culture by archaeologists and overinterpretations of linguistic data have compounded the difficulty in securely identifying the "homeland" for the Proto-Indo-Europeans. More recent studies involving DNA and more sophisticated linguistic analyses point to a date circa 4000 BC and to herders in the PonticCaspian steppe north of the Black Sea as the earliest Proto-Indo-Europeans (Chang et al. 2015). Phylogenic studies by Gray and Atkinson (2003) support a dating of between $3000 \mathrm{BC}$ and $2000 \mathrm{BC}$. The most prominent competing idea to the steppe theory is that Neolithic farms left from Anatolia, taking their language and agricultural knowledge with them, around 9500-8000 BC. Recent models based on vocabulary evolution have been shown to support the earlier dates proposed by the Anatolian hypothesis (Bouckaert et al. 2012:957). Note, however, that both theories claim that archaeological evidence supports their linguistic claims (Bouckaert et al. 2012:960; Chang et al. 2015:195). Nevertheless, there is inherent value in assessing the Indo-European migrations by correlating linguistic and archaeological data (see Renfrew 1987).

As Witkowski and Brown (1978:943) have noted: “The unraveling of detailed relationships between archaeological cultures and ethnic-linguistic groups that existed thousands of years ago in Mesoamerica will undoubtedly be a very complex undertaking, but one which should prove rewarding." A productive example of this type of interdisciplinary approach to understanding linguistic interactions would be Kaufman's 1976 study "Archaeological and Linguistic Correlations in Mayaland and Associated Areas of Meso-America." More of such studies are needed in historical Mayan language research. 


\section{LOANWORDS INTO HIEROGLYPHIC CH'OLAN}

Numerous loanwords can be found in Maya hieroglyphic writing. Boot (2009) identifies several loanwords that appear in the hieroglyphic script: yum 'boss, master; father', unen 'child of father', chi'k 'coati', tzima' 'calabash', patah 'guava', ul 'atole, pom 'incense', patan 'tribute, service' (cf. Macri and Looper 2003:289), and ko'haw 'helmet' (cf. Macri and Looper 2003:290-29I). The suggested source language for each of these loanwords is given in table 4.I.

Eight of the eleven loanwords in table 4.I are from Mije-Sokean languages, two from Nawa, ${ }^{8}$ and one (kakawa) ${ }^{9}$ from either Proto-Mije-Sokean or Nawa. The appearance of Mije-Sokean words is not surprising (based on the above discussion) considering the Olmecs most likely spoke Mije-Sokean. While Boot (2009) only mentioned two to three Nawa loans, others have been suggested. Macri and Looper (2003:288-289) have also identified several other terms that may be of Nahuatl origin. ${ }^{10}$ Glyph T506/774 reads obl and is likely a loanword from the Classical Nahuatl yo:li. Early occurrences of the OHL logogram date to AD 683 Palenque on the Temple of the Inscriptions west panel ( $\mathrm{B}_{7}, \mathrm{O}_{9}$; see figure 4.2$)$, but no examples are known from before early seventh century (289). ${ }^{11}$

Furthermore, in the Postclassic Dresden Codex, Nahuatl god names appear, ${ }^{12}$ first identified by Whittaker (1986). Two of the three god names are fully spelled out phonetically: ta-wi-si-ka-la, tawiskal (Dresden 48C) and ka-ka-tu-na-la, kaktunal (Dresden 50A), whereas one combines logographic and syllabic information: CHAK-xi-wi-te-i, chak xiwitei (Dresden ${ }_{49} \mathrm{C}$; figure 4.3). Tawiskal corresponds to the Aztec deity Tlahuizcalpantecuhtli (Whittaker 1986:57), while Kaktunal, according to Whittaker, refers to the Aztec deity Kaktonal (1986). The final name chak xiwitei is a hybrid form, consisting of Yukatekan term chak 'great' and a form corresponding to either the Nahuatl $x i$ : $b u(i) t l$ 'comet' or less likely $x i b u(i)$ $t l$ 'year' (Macri and Looper 2003:293). Thus, the Dresden Codex displays the use of Yukatekan, Ch'olan, and Nahuatl vocabulary within its pages. While the Venus Tables in the Dresden Codex contain several mentions of Nahuatl god names, the grammar of those sections is decidedly Ch'olan (Wald 2004:57). ${ }^{13}$

At what point, however, did Nawa words begin entering into Hieroglyphic Ch'olan? The question is a complicated one on several fronts. There is still some debate as to when Uto-Aztecan Nawa speakers would have entered into the Valley of Mexico (see Beekman and Christensen 2003:116-118), so determining at what point we can confidently posit a Nawa presence in Mesoamerica becomes crucial. In Kaufman's (200I:I) view the data speak loudly: "Linguistic facts preclude the presence of Nawa in the Valley of Mexico before $500 \mathrm{CE}$," insisting then on a post-AD 500 date (closer to $\mathrm{AD} 600$ ) for any Nawa borrowings to or from Mayan languages. 
TABLE 4.r. Proposed loanwords into Hieroglyphic Ch'olan and their source languages.

\begin{tabular}{llll}
\hline $\begin{array}{l}\text { Glyphic } \\
\text { Ch'olan }\end{array}$ & Gloss & $\begin{array}{l}\text { Suggested Donor } \\
\text { Language }\end{array}$ & Donor Language Form \\
\hline yum & boss, master; father & Mije-Sokean & ${ }^{*}$ 'omi (Wichmann I 995:262) \\
unen & child of father & Mije-Sokean & ${ }^{*}$ 'unV(k) (Proto-Mije-Sokean) (Wichmann \\
I 995:225) \\
\end{tabular}

Teotihuacan has been suggested as a possible source of Nawa loanwords (see Dakin and Wichmann 2000) - assuming of course a Nawa language was spoken there, which is a problematic and complicated question. Due to Teotihuacan's power and influence in Mesoamerica from the first century AD, Teotihuacan would have been in an ideal position to influence neighboring languages. Unfortunately, the site of Teotihuacan has no clearly identifiable writing system to indicate language affiliation. Many of the symbols and parts of the iconography, however, may contain linguistic material. In Taube's (2000) study on Teotihuacan "writing," he finds Nahuatl in Teotihuacan glyphs and iconography, offering the best evidence yet of the use of Nahuatl at the site, in spite of Kaufman's assertion that Nawa was not even in the Valley of Mexico until roughly AD 500, which corresponds to the time of the start of the collapse of the Teotihuacan civilization. According to Kaufman (1976:115), "The Teotihuacanos can hardly have spoken Nahua." Kaufman (2001:7) instead sees Totonac or Mije-Sokean as the best candidates for the language of Teotihuacan. 
FIGURE 4.2. Late seventh-century example of the OHL logogram at Palenque on the West Panel of the Temple of the Inscriptions (B7) (drawing after Asa Hull, after original by Linda Schele).

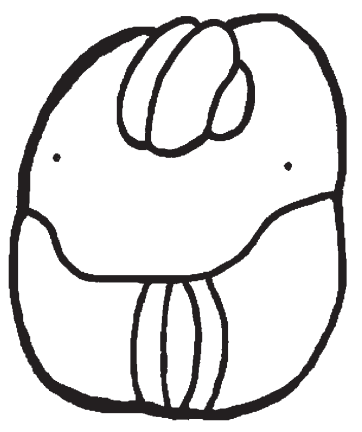

FIGURE 4.3.

CHAK-xi-wi-te-i, chak xiwitei

(Dresden 49C) (drawing by Asa Hull, after original by

Karl Taube).

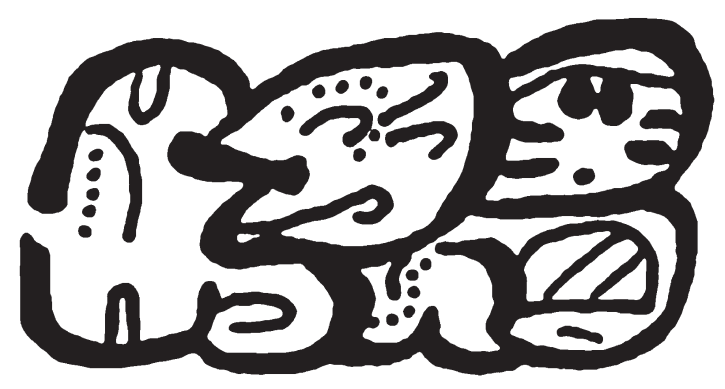

One datable, possible Nawa loanword appears in the writings at the site of Palenque, Mexico. On the East Panel of the Temple of the Inscriptions ( $\mathrm{R}_{7}$; figure 4.4) the term pik 'skirt' ${ }^{\prime}$ appears in a ritual where the ruler Pakal presents various offerings to their patron gods. Today the term pik 'skirt' is diffused into Yukatekan, Ch'olan, and some highland languages, and may be a Nahuatl loan. Kaufman (2003:1105) sees it as a Common Mayan term and lists reflexes of the *peeq in Yukatek, Mopan, Ch'orti', Ch'ol, Tzeltal, and Q'eqchi'. However, it is possible that pik is related to the Nahuat $p i: k i$ "to arrange, to put together, to tie together with string to make something with netting, to assemble, to build" (Campbell 1985:39I). ${ }^{15}$ If $p$ ik is a loan from Nawa, it should predate the early seventh century $\mathrm{AD}$ date mentioned in the inscription. ${ }^{16}$

The earliest clear loanwords from Nawa into Hieroglyphic Ch'olan are in the mid-seventh century AD, which postdates the demise of Teotihuacan (cf. Macri and Looper 2003:293). ${ }^{17}$ Perhaps then it was the mysterious collapse itself of the Teotihuacan that spurred emigration ${ }^{18}$ and additional social contact that played some role in Nawa words finding their way into Maya texts in the seventh century. Another possibility is for contact with Nawa speakers from other regions of Mexico or Guatemala (Macri 2005:324). Regardless of the precise method for borrowing, 


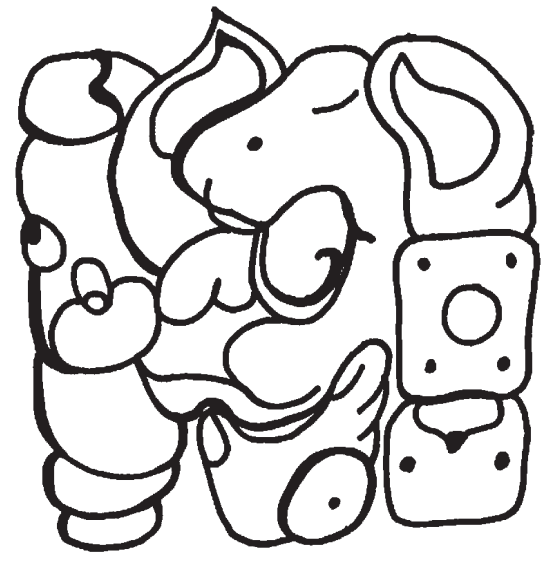

Figure 4.4. Possible PIK, $p i k$ 'skirt' logogram on the East Panel of the Temple of the Inscriptions, Palenque (R7) (drawing after Asa Hull, after original by Linda Schele).

Nawa clearly had an influence of Hieroglyphic Ch'olan, suggestive of increased interactions among these groups (Macri 2010:208).

One possible Nawa term from the Early Classic period could push our dating of Nawa interaction with Hieroglyphic Ch'olan back considerably further: kok or koht 'eagle'. The word kobt 'eagle' is found in K'iche', Uspanteko, Kaqchikel, and Yukatek Mayan (Dakin 2003:276-277; cf. Hull and Fergus 2009:90). Dakin suggests the term originates from a Proto-Uto-Aztecan form ${ }^{*} k^{w} a$-raja-wi, which appears as cuauh-tli in Nahuatl (see also Justeson et al. 1985:21-28; Kaufman 2003:608; Smith and Berdan 2003:298, 382). The fact that ko: $t$ was borrowed into Yukatek but into none of its sister languages suggests a later date for borrowing into the Yukatekan branch. ${ }^{19}$ Significantly, kot ("coht") was also borrowed into Ch'olti' (Morán [1695] 1935), even though the language also contained the form t'iw. As Hull and Fergus have noted (2009:90-9I), "it is not possible to determine if they were synonyms (perhaps one a native term and the other a borrowing) existing simultaneously in the language or if they referred to different species of eagles." A possible cognate term kok appears in Tzeltalan as kok mut (lit. 'eagle-bird') referring to the Harpy Eagle (Hunn 1977:I42). Kok-mut has a considerable time depth in Mayan, possibly appearing on an Early Classic greenstone mask as $\mathbf{k o}^{\mathbf{2}}$-mu-ti, $k o k$ muut (figure 4.5). If kok is cognate to the Nawa form (and there are several reasons one could argue it is not), this would be by far the earliest Nawa term in Hieroglyphic Ch'olan.

\section{LINGUISTIC INTERACTION WITH CH'OLTI' AND CH'ORTI'}

The final aspect I wish to discuss is the linguistic interaction with two of Hieroglyphic Ch'olan's daughter languages: Ch'olti' and Ch'orti'. The last Ch'olti' 


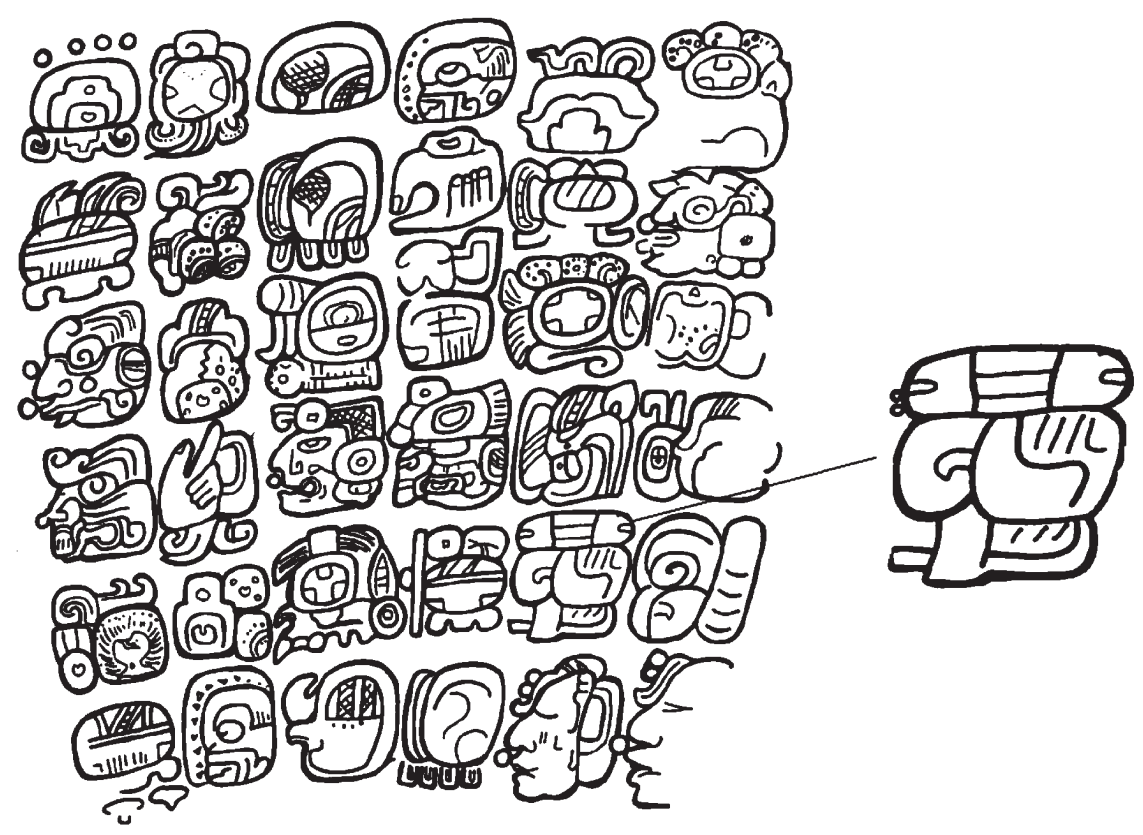

FIGURE 4 -5. Early Classic greenstone mask with the spelling ko ${ }^{2}$-mu-ti, kok muut, 'harpy eagle' (drawing of mask by Michael D. Carrasco; cut-out glyph drawing by Michael D. Carrasco with alterations).

speaker died in the seventeenth century, and there are about 10-12,000 speakers of Ch'orti' today. Both languages have enjoyed considerable linguistic interactions with other Mayan and non-Mayan languages, part of which relates to geographical proximity and social interactions.

Nahuatl has made fairly significant lexical contributions to Ch'orti'. Many Nahuatl terms used by the Ch'orti' today, however, were first borrowed into Spanish during the colonial period for administrative purposes (cf. Dakin 2010:224; Kaufman and Justeson 2007:199), for items unknown to Europeans, and other reasons..$^{20}$ For example, the term apante in Ch'orti' is from the Nahuatl äpan 'on the water' and apantli 'ditch of water', but in Ch'orti' means 'farming with irrigation in the dry season.' This term was clearly diffused in colonial Spanish first before entering into Ch'orti. ${ }^{21}$ Evidence for this earlier borrowing into Spanish comes from the fact that Ch'orti' already has the term payja' with precisely the same meaning. It is therefore most likely that apante spread through Spanish and is now being used simultaneously with payja?

Other avenues for borrowing were possible contact with Pipil and other Nawaspeaking groups who migrated south into southern Mexico and down as far as 
Nicaragua. The Pipil migrated from central Mexico at approximately AD 900 (Kaufman 1976:116; 2001:5, I3; cf. figure 4.I). Pipil speakers were well established in Escuintla, Guatemala, at the time of the conquest. Pipil was also proximate to Ch'orti' in El Salvador as parts of north Honduras (Fowler 1981:476-508, 1985:37). The following is a discussion of terms that derive from Nahuatl and are common in Ch'orti' today.

The archaic Nahuatl form *ilamat 'old woman' (today ilamab) appears in Ch'orti' as ilama. Stress in Nahuatl falls on the penultimate syllable, which was also borrowed into the Ch'orti' term (iláma), even though stress standardly resides on the ultimate syllable in Ch'orti'.

The Nahuatl term tékpan (lit. 'lord-place'), meaning 'palace', was borrowed by the Ch'orti' and applied to 'church'. From this base, Ch'orti' has derived other grammatical forms and variations of meaning. For example, the intransitive verb tekpani was derived signifying 'to perform a "promise" ceremony' as well as 'to fast.' Also, the compound noun tekpan-tun (lit. 'church-stone') in Ch'orti' means a 'place where ceremonies are performed.'

The Nahuatl term mazätl 'deer' appears in early printed Ch'orti' sources from the nineteenth century (Membreño I897; Suárez 1892). Membreño (1897) writes the term as 'Masahá for venado (deer). In Membreño's manuscript, he consistently represents a final glottal stop orthographically as $h V$ (e.g., "Tehé" for te" tree'). Thus, he was writing masa', the same pronunciation found today in Ch'orti' for 'deer.'22

The term for 'city' in modern Ch'orti' is chinam, a Nahuatl borrowing (chinamitl). What term this replaced is unknown, and there is no other way to express 'city' in Ch'orti'. Additionally, the idea of a 'country' or 'nation' is simply noj chinam, lit. 'big city'.

One term well diffused in Mesoamerica today is the term nagual 'spirit, alter-ego', deriving from the Nahuatl nābualli 'familiar, nagual; sorcerer, witch, apparition' (Bierhorst 1985:222). In Ch'orti', nawal is one of the principal words for speaking of one's 'spirit' as well as evil spirits and sorcerers. It is likely but not certain that this term came through Spanish into Ch'orti' due to its wide distribution across languages in Mesoamerica. Indeed, so common is the term 'nagual' that it has even entered English dictionaries today.

Ch'orti' has a cognate of a form that traces back to Proto-Uto-Aztecan: tojtole' 'rooster.' Indeed, the morphemic structure of the term hints strongly that it is a loanword. Dakin (2003:28I) lists various cognates in Tequistlatec - dulu 'turkey', Jicaque tolo, and Huave tel 'female turkey. In archaic Nahuatl *to:-lo:-tl was a more general term for 'bird' and cognate to the proto-Sokean *tu:nu:k (Dakin 2003:28I; cf. Campbell and Kaufman 1976:86). Campbell and Kaufman (1976:83) note that cognates such as tunuk'/tuluk' for 'turkey' in Tzeltal, Tzotzil, Chuj, Jakaltek, and 
Motozintlek are likely loans, "and comparison to Pzo [Proto-Sokean] *tu?nuk 'turkey' proves it to be so."23 Kaufman (1976:116) views *tu?nuk 'turkey' as a MijeSokean loan into various Mesoamerican languages.

Turkey domestication has generally been accepted to have begun in Mesoamerica and spread later to the American Southwest (McKusick 1980; Reed 1951), though Breitburg (1993:153) believes that turkeys were first domesticated by groups of Anasazi-Mogollon and only later were they introduced into Mesoamerica. Recent DNA and archaeological studies have established "at least two occurrences of turkey domestication in pre-contact America, one involving the South Mexican wild turkey, likely in south-central Mexico, and a second involving Rio Grande / Eastern wild turkey populations, with a subsequent introduction of domesticated stocks into the Southwest proper" (Speller et al. 2010:28II). Archaeological evidence places turkeys in Mesoamerica between 800 and 400 BC (Álvarez 1976). According to Speller et al. (2010:2807), domestic turkey stocks were established by at least AD I80 in the Teotihuacan Valley. The authors also indicate that domestic stocks of turkey appear in the archaeological record in the Southwest around 200 BC-AD 500. For the Maya area, Campbell and Kaufman (1976:83) cite a personal communication from Michael Coe that turkeys were domesticated around $\mathrm{AD} 300$.

Epigraphic evidence shows several terms for 'turkey' were in use in the hieroglyphic script. On Nim Li Punit Stela is the word is spelled phonetically a-k'a-cha, ak'ach, a Western Maya term (Kaufman 2003:63I). A turkey head logograph on a La Corona panel was thought to be read ak'ach until just recently. Houston et al. (in preparation) now read it as AK', ak', a well-diffused form in Eastern Mayan languages (see figure 4.6; see also Kaufman 2003:630). On the La Corona panel it appears in the name Chak Ak' Paat Kuy in conjunction with events dating to the late seventh century. A later term in the Dresden $\operatorname{Codex}\left({ }_{17} \mathrm{C}-3\right)$ appears as ku-tzu, kutz, a Greater lowland term especially common in Yukatekan languages. A third term, u-lu-mu, ulum 'turkey' also turns up in the Dresden Codex (46B-I). Thus, three individual terms are found in the hieroglyphic texts dating from the late seventh century to the around the time of the conquest. In Ch'orti', ak'ach, deriving from *'ak'aach, is now used for 'chicken' and separate terms for tom turkeys, ajtzo', and turkey hen utu' chumpi' are standard. Similarly, tojtole', a term for 'turkey' stretching back to Proto-Uto-Aztecan now means 'rooster' in Ch'orti'. In both cases, words for 'turkey' semantically shifted to other fowl: chickens and roosters.

There is also evidence for nineteenth-century sources that Ch'orti' also borrowed from neighboring non-Mayan languages. Membreño (1859-192I) - a lawyer, judge, and once president of Honduras-compiled a list of Ch'orti' terms that were published in 1897 . He borrowed heavily from Ruano Suárez's (1892) word list in Ch'orti'. 

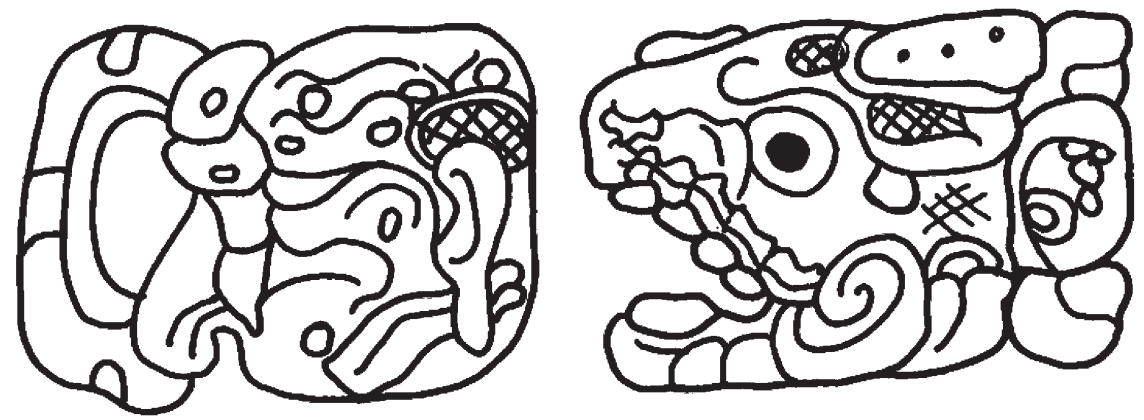

FIG URE 4.6. The name of Chak Ak' Paat Yuk, the ak' meaning 'turkey', on La Corona, Element $56\left(\mathrm{pF}_{2}-\mathrm{pE}_{3}\right)$ (drawing after Asa Hull, after original by David Stuart).

Membreño's Ch'orti' data contain a number of foreign terms not found in Ch'orti' and that do not look to be Mayan (original orthography retained):

\begin{tabular}{ll}
\hline Meaning & "Chorti”" \\
\hline Uno & Yuté \\
Cinco & Guajté \\
Doce & Astoraj \\
Nosotros & Guercá \\
Alargar & Lonón \\
Llegar & Matoá \\
Reverdecer & Hunshatrocan \\
Sonar & Ajeán \\
Taparse & Mostabá \\
Tomar & Auchij \\
Cuando & Jarì
\end{tabular}

The two numbers 'one' ( $y u-t e$ ') and 'five' (waj-te') appear to contain the general numeral classifier -te', but the expected form for 'one' is jun and for 'five' jo'. The number twelve ("Doce") Astoraj is clearly a borrowing from another language. Each of the remaining terms above given by Membreño have no immediate cognates in Ch'orti', Ch'olti', or other Mayan languages and would appear to be loanwords. However, I have been unable to identify any of them from neighboring languages, so more work needs to be done here.

Membreño also provided several sentences in Ch'orti', one of which has several possible loanwords whose donor is unclear: “Tecpán uchen tinará mutajijón ñuti 
maira é christiano" for which the translation is given "La iglesia es grande: cabe mucha gente" (The church is large: it fits many people). "Tecpán” is a loanword from Nahuatl, meaning 'church' and was discussed above. Much of what follows, however, is opaque. The final three words of the phrase, maira é christiano, correspond to much a gente (many people) in his translation. The four intervening terms uchen tinará mutajijón ñuti must relate to grande (big) and cabe (fit). But none of these four terms is recognizable in modern Ch'orti' today and are all, therefore, likely loanwords from an as-yet-unidentified source.

While many other examples could be cited, Nahuatl and other non-Mayan languages have clearly had an impact on the lexicon of Ch'orti' stemming from contact well before the arrival of the Spaniards in addition to considerable borrowing in and since the colonial period.

Ch'orti' has also participated in sharing various terms with other Mesoamerican languages with which it has had contact. For example, Xinka has borrowed primarily from Ch'orti' among the lowland Mayan languages (Campbell 1972:190). ${ }^{24}$ Ch'orti' and other Ch'olan languages have also had a surprisingly sustained influence on many highland Mayan languages, in particular Q'eqchi' and Ixil.

\section{CH'OLAN AND Q'EQCHI' INTERACTION}

The Q'eqchi' language has borrowed a substantial number of lexical items from Ch'olan languages in the last two millennia. The Q'eqchi' today primarily reside in the Alta Verapaz of Guatemala, with other communities in Baja Verapaz, El Quiche, and parts of Belize (among others). There is corroborating evidence from archaeology and linguistics that the interaction between Q'eqchi' and Ch'olan languages began in Classic period times. For example, Black-and-White-on-Red pottery appears in the Q'eqchi' area from the Maya lowlands around AD 700-1000 (Wichmann and Hull 2009:876; cf. King 1974:13-14). The direction of borrowing is almost always from Ch'olan to Q'eqchi', suggesting the cultural dominance of Ch'olan. Wichmann and Brown (2003:68-69) have noted that the type of borrowings occur in areas such as architecture, religion, foods, technical implements, and the economy.

Justeson et al. (1985:9) documented 24 Q'eqchi' lexical borrowings from the lowland Mayan Languages of Yukatekan and Ch'olan, suggesting to these authors that Ch'olan speakers "were prominent in the formation of ancient lowland Maya civilization." Q'eqchi' has also borrowed considerably from other Mayan languages. Wichmann and Cecil Brown (2003:65-69) noted 134 cases of borrowing or possible borrowing into Q'eqchi' from other Mayan languages. They also determined that when Q'eqchi' borrowed a lexical term, the donor subgroup was Ch'olan about 
70 percent of the time, and if Yukatekan was added, that number increased to over 80 percent. Quite remarkably, as Wichmann and Hull (2009) have noted, Q'eqchi' has borrowed about is percent of its overall lexicon, 4 percent of which comes from Ch'olan and Yukatekan.

Wichmann and Hull (2009) have also identified thirty additional cases of possible borrowings into Q'eqchi' from Ch'olan. They note that many of the borrowings from Spanish relate to material culture. However, many of the terms borrowed from Cholan languages dealt with human domain over nature. Furthermore, Wichmann and Brown (2003) earlier showed that Ch'olan and Yukatekan loanwords commonly correlated with material and culinary culture, with edible animals, and with production or provision of food.

In short, an analysis of Ch'olan borrowings into Q'eqchi' reveals that the most common type of words borrowed are those relating to new ways to dominate nature. Borrowings from Spanish, on the other hand, most often related to man-made objects, usually those introduced by Western culture (Wichmann and Hull 2009).

The term mayuy in Ch'orti' presents an interesting case for tracing the direction of the loan. In Ch'orti', mayuy refers to "a kind of haze, smoke, or cloud that carries no moisture and settles on the mountain sides. It sometimes comes as far down as the valley floor, often just before rainy season. It can also be the name for the smoke from burning fields (some consultants said mayuy was the same as b'utz', 'smoke'). Others use them together at times as b'utz' mayuy' (Hull 2000). Several hieroglyphic examples of this term are known, one as the name of a captive from Naranjo, Yax Mayuy Chan Chaak, and another an individual from Laxtunich, Mayuy K'awiil (cf. Lacadena 2004:I49). Kaufman (2003:478) notes that the only other language to have this precise form is Eastern K'iche' (Rabinal), and he views it more likely that Ch'orti' borrowed it from Eastern K'iche.25 However, due to the close genetic relationship (lexically and grammatically) between hieroglyphic Ch'olan and Ch'orti', it might be more prudent to assume K'iche' may have borrowed it from Ch'orti', all things being equal.

While it is often impossible to distinguish which Ch'olan language early borrowings came from, what is certain is that Ch'olti' has had a significant linguistic impact on Q'eqchi'. For instance, the term k'anti' (lit. 'yellow-mouth') meaning 'snake' appears in Q'eqchi' but without the expected phonological changes from Proto-Mayan, signaling by its phonological shape a Ch'olti' or a Ch'orti' borrowing (Brown and Witkowski 1982:103; Kaufman 1976:110-11I). Wichmann and Brown (2003:69) have noted Ch'olti' has contributed "a disproportionally large number of loans to Q'eqchii' ... especially remarkable in light of the fact that we possess only very limited lexical data for the language." Of the I34 possible Mayan-language loans into Q'eqchi', 59 are from Ch'olti'. 
There was considerable influence on Q'eqchi' from Ch'olti' due to contact because of their proximity right into the colonial period, and likely much earlier. That influence would soon disappear, however. In the first half of the seventeenth century, population estimates for Ch'olti' speakers, often early on referred to as "Manche Chol," are given as high as 30,000 (though Thompson [1990:63] suggested a much lower number of 10,000 ). Disease killed most children under sixteen in 1678 in and around the town of San Lucas Tzalac. After more tumultuous times involving revolts and reductions (cf. Thompson 1990:63), Ch'olti' speakers were forced to migrate to the Rabinal area in the highlands, putting them in contact with various highland Maya groups.

\section{CH'OLAN AND IXIL}

Ixil presents another interesting case of borrowing from Ch'olan. Ixil is spoken in the Guatemalan highlands in San Juan Cotzal, Nebaj, and San Gaspar Chajul. Present-day Ixil communities do not border any Ch'olan language groups, yet the Ixil language shares a high degree of lexical items with Ch'olan languages. Ch'orti' alone has also donated ten documented terms into Ixil (Wichmann and Brown 2003:59).

While nearly two-thirds of Ixil loans come from Q'anjob'alan (which does share geographical boarders with Ixil), Ch'olan, which does not, is still responsible for 39.4 percent of Ixil's lexical loans.

For example, Wichmann and Brown (2003) have argued that the resulting forms in cases of velar stops before /e/ being palatalized in Ixil could also signal a Ch'olan donor. Wichmann and Brown (2003:63) state that since these groups have been in direct contact for centuries, this would suggest these borrowing happened at quite an early period, possibly even back in Classic period times, "when the influence of Ch'olan on other Mayan languages would have been at its peak."

Another example of borrowing from Ch'orti' and Ch'olti' is their shared term k'anti', a type of snake, mentioned above as a Q'eqchi' borrowing also. Brown and Witkowski (1982:103) remark the Chajul dialect of Ixil has this term, but not the expected reflex of it, which would be * q'an-či $i$, clearly signaling a borrowing from Ch'orti' or Ch'olti'.

The fact that Ixil has been geographically distant from Ch'olan languages since the extinction of Ch'olti' forces us to look to an earlier time period. Maya hieroglyphs on Nebaj ceramics suggest closer contact in pre-Columbian times. The relatively high degree of borrowing from Ch'olan into Ixil would also suggest a reasonable amount of contact before the colonial period. 


\section{TRADE AND LEXICAL BORROWING}

Within the Mesoamerican phylum one would expect at least a moderate degree of areal influences among the various languages and language groups (cf. Witkowski and Brown 1978:942). Linguistic work in the last fifty years has greatly contributed to our understanding of migrations, trade, and social contact in Mesoamerica. Ceramic distribution also attests to large-scale interactions, irrespective of political boundaries (Clayton 2005; Englehardt 2010:70). These sustained interactions among past Mesoamerican groups have resulted in considerable linguistic sharing, a substantial portion of which is readily attributable to trade. Expansive trade networks were in place, both long (Andrews 1984:827) and short (Bower 1993:358) distance, of goods and materials such as obsidian, salt, cacao beans, cotton and cotton mantles, tobacco, agave, pyrite, ceramics, shells, and spices, and parrot feathers, all of which could have brought different languages and societies in contact (Dahlin et al. 2007:366; Tourtellot and Sabloff 1972). For example, salt was widely traded but only produced in significant quantities in a few places, mainly Salinas de los Nueve Cerros (Dillon 1977), Stingray Lagoon, and Punta Ycacos Lagoon in Belize (McKillop 1995:216, 223). The largest producer, Salinas de los Nueve Cerros, supplied the Chiapas lowlands, the central Petén, and was traded north (Andrews 1983:100). Salt was one of the major trade items moving down the Caribbean coast in the Late Classic period and was possibly the earliest item to be traded in bulk before the Spanish arrival (Andrews 1980:31-32). Epigraphic evidence for the term 'salt' atz'aam, has recently surfaced at the site of Calakmul (Martin 2012:68-69). In addition, trade items such as salt, ${ }^{26}$ cacao beans, and cotton mantles were themselves used as mediums of exchange or currency (Berdan et al. 2003). Indeed, ancient markets (k'iwik in Hieroglyphic Ch'olan) throughout Mesoamerica were also likely loci for sustained interactions among different language groups (Dahlin et al. 1987).

Coastaland riverinetrade routes played an important part of ancient Mesoamerican interactions (Guderjan 1995; McKillop and Healy 1989). Archaeological evidence of docks in the Maya area has been found, such as at Laguna de On (Wharton 1998:67) and Blue Creek (Barrett and Guderjan 2006). The Usumacinta-Pasión River was also a well-established trade route in the Classic period (Braswell 2014) that facilitated trade and contact for central hubs such as Cancuen (Demarest 2004:163). The vast array of rivers, inlets, and coastal waters greatly facilitated trade, contact, and linguistic sharing throughout ancient Mesoamerica.

The linguistic contact outlined in this chapter shows a considerable Olmec influence on both Nawa and Mayan vocabulary, indicative of the Olmec's regional status as well as its material influence in the form of agricultural practices and products. In addition, evidence of market economies tracing back to proto-Mije-Sokean also suggests cultural sharing in this area from the Olmecs and their language. Thus, 
Campbell and Kaufman (1976:88) note terms in Proto-Mije-Sokean related to a market economy such as *to' $k$ 'to sell something' and *yoh 'to buy something.' Furthermore, an early Nawa term for 'market', tiyankis(-tli), is likely a loan since it cannot be analyzed morphologically (Kaufman 200I:I2), perhaps indicating an outside influence relating to markets.

By the end of the Early Classic period, however, the influence of Nawa languages becomes more pronounced. Only part of this burgeoning Nawa influence is attributable to the arrival of Nawa-speaking groups into the Valley of Mexico, however, since some borrowing from Nawa seems to precede this event.

\section{CONCLUSION}

The rise of the Classic period Maya in the lowlands marks yet another shift in ideological and linguistic borrowing as Ch'olan becomes a major donor of lexical material to other languages-something that continued through the colonial period. As I have shown, one of reasons why Ch'olan languages have been a major player in lexical sharing is in part due to the status of Hieroglyphic Ch'olan throughout the Classic period. Eastern Ch'olan languages have also had a remarkable impact on neighboring Mayan and non-Mayan languages alike. Yet Hieroglyphic Ch'olan, Ch'olti', and Ch'orti' readily borrowed from other languages from very early times.

As Classic period Maya civilization begins to dissolve during the "collapse," a remarkable resurgence of Nawa linguistic proliferation takes place due to the southern migrations (discussed above) of Nawa speakers beginning around AD 900 (Kaufman 2001:5, 13). The culminating influence of Nawa is felt throughout the region again thanks in large part to its adoption by Spanish administrative structures, resulting in a fresh wave of Nahuatl terms entering Mayan and non-Mayan languages in Mesoamerica.

The linguistic and social landscape of ancient Mesoamerica is one of long-term, sustained interaction indicative of a highly fluid social interchange of goods, ideas, and the words to express them.

\section{NOTES}

I. Following Martha Macri's (2010:210 n2) definitions, in this study I differentiate between "Nahuatl" - the "Uto-Aztecan language spoken in Mexico from within a few centuries of the Spanish conquest" and "Nawa"- "languages in a group that includes Nahuatl and any closely related language variety that proceeds it."

2. In this chapter, in hieroglyphic transcriptions capital letters in bold represent logograms. Small-case letters in bold represent syllables. An apostrophe represents a glottal stop 
as does "?" in certain citations. In transcriptions / h/ represents a glottal aspirate and / $/$ / represents a velar aspirate. Long vowels are shown by “:”, a dash over the vowel (e.g., "o”), or by a reduplicated vowel (e.g., "oo", depending on the source of the data).

3. Brown (1987:375) notes that "considerable loanword evidence has been assembled showing that linguistic interaction between Cholan and Yucatecan languages was of such an intensity during the last two millennia that it is now virtually certain that speakers of both languages, to the exclusion of speakers of other Mayan languages, were co-bearers of Classic Maya civilization (Justeson et al. 1985). For the most part this evidence takes the form of a large number of lexical items found in no Mayan languages other than Cholan and Yucatecan which were innovated either by Cholan or Yucatecan speakers and then diffused from one group to the other."

4. Of the 125 epigraphic nouns and adjectives that are sufficiently spelled out in the hieroglyphs and whose etymologies are understood, Ch'olan language dominates, with "a fair amount of the known lexicon of Yukatekan origin" (Kaufman 2003:33).

5. As Law (2014:3) notes, "There is an impressive amount of linguistic influence in Mayan languages from non-Mayan languages (particularly Nawa and Mixe-Zoquean), though interaction with Oto-Manguean and Totonacan, as well as Xinkan and Lenkan is also evident." Some of these outside borrowings are described below.

6. Brian Stross (1982) found various correlations between Mije-Sokean languages and the origins of Landa's Maya "alphabet" as well as numerous cognates relating to glyphic readings.

7. Conversely, Hill argues that recent work on historical phonology for Aztecan and Proto-Sokean allows now for an "autochthonous Uto-Aztecan origin of much of the maize cultivation vocabulary" that would run counter to Campbell and Kaufman's (1976) claims.

8. Other Nawa loans are possible in Hieroglyphic Ch'olan: ko 'place of' (Nahuatl-co) (ex. Uaxactun Stela I4), kosat 'jewel' (Nahuatl cozcat'[l]) (ex. Tikal Stela 3r: L2), and kot 'eagle, raptor' (Nahuatl cuaubtli) (ex. Comalcalco Urn 26 Pendant I4) (see Boot 2009). Many other possible examples could be cited.

9. The origin of the term kakaw 'cacao', first deciphered by David Stuart (1988) in the hieroglyphic script has been contentiously debated by numerous scholars. Dakin and Wichmann provide evidence that kakaw was a Nawa loan (Dakin 1995; Dakin and Wichmann 2000; Wichmann 1998). However, Campbell and Kaufman (1976:84) claim the term *kakaw (a) harkens back to proto-Mije-Sokean, and Justeson et al. (1985) argued for its links to the Olmec. More recently Kaufman and Justeson (2007) have made further persuasive arguments supporting a proto-Mije-Sokean origin for the term, since kakaw is attested epigraphically by the fifth century AD on a pot from Río Azul that generally precedes most models of when Nawa speakers arrived in the Valley of Mexico. Note also that Macri (2005) proposes that other terms in the inscription on the Río Azul pot are also analyzable as Nawa forms. However, viable Mayan interpretations are available (see Hull 20I0:24I-244). It seems unlikely it has any relation to the fall of Teotihuacan (Macri and Looper 2003:286; but see Dakin and 
Wichmann 2000) and to the arrival of Nawa speakers in the sixth century in the Valley of Mexico. Therefore, unless a much earlier influence of Nawa can be posited in Mesoamerica (see Dakin 200I; Hill 200I; Wichmann 1998), Mije-Sokean may be the more likely source for this term.

Io. Macri has elsewhere suggested a Nahuatl origin for a Maya hieroglyphic sign, the xo syllable, which she argues is acrophonically derived from the Nahuatl term xochitl 'flower' (Macri 2000).

II. Although less compelling, another Nahuatl borrowing suggested by Macri and Looper (2003:29I-292) is the compound i-yu-wa-la, iyuwal, ostensibly an adverb in the inscriptions at Copán. Macri and Looper link this to the Nahuatl conjunction i:bua:n, which connects sentences and words just as the English "and." However, Nahuatl and cognate Pipil examples function conjunctively whereas iyuwal is a temporal adverb, so this identification remains somewhat tenuous. The reflexes of the Classic period iyual in modern Mayan languages also function adverbially (e.g., Yukatekan iwal and Acalan Chontal yuual).

I2. The presence of Nahuatl terms needs not be interpreted too far in viewing Nahuatl as a substrate language to Ch'olan in the Postclassic period (Lacadena and Wichmann 2002:28I; Wald i994).

I3. Wichmann (2006:55) also notes that "we might expect to find that Ch'olti' gains special relevance when it comes to looking at the Postclassic codices."

I4. David Stuart (2005:166) has suggested the reading of $p i k$ for this glyphic compound.

15. Another possibility is that pik is connected to the Nahuatl pixcatle "envoltura" ("wrapping') (Karttunen 1983:193).

16. The term pik also appears in the Dresden Codex (2D).

17. Macri and Looper (2003:293) propose the "Mexican Gulf Coast area (Veracruz and Tabasco), the isthmian zone of Chiapas, or the Guatemalan Pacific slope. Not only are these areas generally contiguous with or directly accessible by water routes to the Maya areas associated with the Nahua loanwords noted earlier, but there is historical evidence for Nahua populations in these areas." However, if the term kakaw is a Nawa term, then that pushes the dating of Nawa's influence on Hieroglyphic Ch'olan back to the mid-fifth century based on epigraphic evidence (see below).

I8. Alvin Luckenbach and Richard Levy (1980:459) discuss "unknown disruptions which culminated in the Teotihuacan 'diaspora' around AD 600-700."

19. Lakantun (Lacandon) and Mopan have t'iiw (cf. pM t'iiw, Kaufman 2003:606). Lakantun also has ko't ma'x for 'harpy eagle' (Hull and Fergus 2015:field notes). Charles Hofling (2014:187) also gives koot as 'big eagle' in Lakantun.

20. A few examples would be capolin 'cherry', chachalaca 'chachalaca' (genus Ortalis), elotl (Sp. elote) 'ear of corn', and mecatle (Sp. mecate) 'cord, rope'.

2I. Spanish dictionaries often contain the term. In Real Academia Española, Asociación de Academias de la Lengua Española's (2014) Diccionario de la Lengua Española, apante is 
given as "Acequia o lugar que mantiene humedad en el verano" ("Ditch or place that keeps moisture in the summer").

22. Note that Ch'orti' already had a term for 'deer,' chij, when masa' was borrowed from Nahuatl. chij is Mayan and derives from the pM *kehj (Kaufman 2003:593). But when the Nahuatl masa' term entered the language, chij semantically broadened to then encompass various four-legged animals, thus taking on the more general meaning it has today of 'beast.' Ironically, mazātl in Nahuatl also means 'Beast, four-legged creature' (Bierhorst 1985:208), precisely the meaning the replaced native Ch'orti' term then acquired.

23. Brian Stubbs (personal communication, 2015) reconstructs * $t o L i$ for 'domestic fowl' in Proto-Uto-Aztecan but believes forms with " $\mathrm{n}$ " are distinct since "the differing second syllable justifies separate etyma."

24. Campbell (1972:190) notes that loans into Xinka involved various words relating to buying and selling, which suggest commercial contact between the Xinka and the Ch'orti'.

25. If mayuy was borrowed from K'iche' it may have come into Ch'orti' around AD I200, when, according to Campbell and Kaufman (1985:193), groups of K'iche'an speakers made their way into the southern and eastern sections of Guatemala.

26. In the sixteenth century in the central highlands of Mexico a document refers to salt as moneda menudo (small money) (Andrews 1983:13-14).

\section{REFERENCES}

Álvarez, Ticul. 1976. "Restos óseos de las excavaciones de Tlatilco, Estado de México." In Apuntes para la arqueología, México. Instituto Nacional de Antropología e Historia, Mexico City.

Andrews, Anthony P. 1980. "The Salt Trade of the Ancient Maya." Archaeology 33(4):24-33.

Andrews, Anthony P. 1983. Maya Salt Production and Trade. University of Arizona Press, Tucson.

Andrews, Anthony P. 1984. "Long-Distance Exchange among the Maya: A Comment on Marcus." American Antiquity 49(4):826-828.

Barrett, Jason W., and Thomas H. Guderjan. 2006. "An Ancient Maya Dock and Dam at Blue Creek, Rio Hondo, Belize." Latin American Antiquity 7 (2):227-239.

Beekman, Christopher S., and Alexander F. Christenen. 2003. "Controlling for Doubt and Uncertainty through Multiple Lines of Evidence: A New Look at the Mesoamerican Nahua Migrations." Journal of Archaeological Method and Theory Io(2):11 I-164.

Berdan, Frances F, Marilyn A. Masson, Janine Gasco, and Michael E. Smith. 2003. “The International Economy." In The Postclassic Mesoamerican World, edited by Michael E. Smith and Frances F. Berdan, 96-116. University of Utah Press, Salt Lake City. 
Bierhorst, John. 1985. A Nahuatl-English Dictionary and Concordance to the Cantares Mexicanos: With an Analytic Transcription and Grammatical Notes. Stanford University Press, Stanford.

Boot, Erik. 2009. "The Updated Preliminary Classic Maya-English, English-Classic Maya Vocabulary of Hieroglyphic Readings." Electronic document, http://www.mesoweb .com/resources/vocabulary/Vocabulary-2009.or.pdf.

Bouckaert, Remco, Philippe Lemey, Michael Dunn, Simon J. Greenhill, Alexander V. Alekseyenko, Alexei J. Drummond, Russell D. Gray, Marc A. Suchard, and Quentin D. Atkinson. 2012. "Mapping the Origins and Expansion of the Indo-European Language Family." Science 337(6097):957-960.

Bower, B. 1993. “Ancient Maya Trade: Tracing Salty Swamps." Science News I44(22):358-359. Braswell, Geoffrey E. 2014. The Maya and Their Central American Neighbors: Settlement Patterns, Architecture, Hieroglyphic Texts, and Ceramics. Routledge, New York.

Breitburg, Emanuel. 1993. "The Evolution of Turkey Domestication in the Greater Southwest and Mesoamerica." In Culture and Contact: Charles C. Di Peso's Gran Chichimeca, edited by Anne I. Woosley and John C. Ravesloot, 153-172. University of New Mexico Press, Albuquerque.

Brown, Cecil H. 1987. “The Linguistic History of Mayan Year ('ha?ab').” Anthropological Linguistics 29(4):362-388.

Brown, Cecil H. 1999. Lexical Acculturation in Native American Languages. Oxford University Press, New York.

Brown, Cecil H., and Stanley R. Witkowski. 1979. "Aspects of the Phonological History of Mayan-Zoquean." International Journal of American Linguistics 45(I):34-47.

Brown, Cecil H., and Stanley R. Witkowski. 1982. "Growth and Development of Folk Zoological Life-Forms in the Mayan Language Family." American Ethnologist 9(I):97-I12.

Campbell, Lyle. 1972. "Mayan Loan Words in Xinca." International Journal of American Linguistics 38(3):187-190.

Campbell, Lyle. 1985. The Pipil Language of El Salvador. Mouton Grammar Library I. Mouton Publishers, Berlin.

Campbell, Lyle. 2013. Historical Linguistics: An Introduction. Edinburgh University Press, Edinburgh.

Campbell, Lyle, and Verónica Grondona. 2012. "Linguistic Acculturation in Nivaclé and Chorote." International Journal of American Linguistics 78(3):335-367.

Campbell, Lyle, and Terrence Kaufman. 1976. "A Linguistic Look at the Olmecs." American Antiquity 4I(I):80-89.

Campbell, Lyle, and Terrence Kaufman. 1985. "Mayan Linguistics: Where Are We Now?" Annual Review of Anthropology 14:187-198. 
Chang, Will, Chundra Cathcart, David Hall, and Andrew Garrett. 2015. "AncestryConstrained Phylogenetic Analysis Supports the Indo-European Steppe Hypothesis.” Language 9I(I):194-244.

Clayton, Sarah C. 2005. "Interregional Relationships in Mesoamerica: Interpreting Maya Ceramics at Teotihuacan." Latin American Antiquity 16(4):427-448.

Dahlin, Bruce H., Christopher T. Jensen, Richard E. Terry, David R. Wright, and Timothy Beach. 2007. "In Search of an Ancient Maya Market." Latin American Antiquity I8(4):363-384.

Dahlin, Bruce H., Robin Quizar, and Andrea Dahlin. 1987. "Linguistic Divergence and the Collapse of Preclassic Civilization in Southern Mesoamerica." American Antiquity $52(2): 367-382$.

Dakin, Karen. 200I. "Animals and Vegetables, Uto-Aztecan Noun Derivation, Semantic Classification, and Cultural History." In Historical Linguistics 19g9: Selected Papers from the 13th International Conference on Historical Linguistic, Vancouver, 9-13 August Iggg, edited by Laurel J. Brinton. I05-117. John Benjamins, Amsterdam.

Dakin, Karen. 2003. "Uto-Aztecan in the Linguistic Stratigraphy of Mesoamerican Prehistory." In Language Contacts in Prehistory: Studies in Stratigraphy, edited by Henning Anderse, 259-287. John Benjamins, Amsterdam.

Dakin, Karen. 2010. "Linguistic Evidence for Historical Contacts between Nahuas and Northern Lowland Mayan Speakers." In Astronomers, Scribes, and Priests: Intellectual Interchange between the Northern Maya Lowlands and Highland Mexico in the Late Postclassic Period, edited by Gabrielle Vail and Christine L. Hernández, 217-240. Dumbarton Oaks, Washington, DC.

Dakin, Karen, and Søren Wichmann. 2000. "Cacao and Chocolate: An Uto-Aztecan Perspective." Ancient Mesoamerica II(I):55-75.

Demarest, Arthur. 2004. Ancient Maya: The Rise and Fall of a Rainforest Civilization. Cambridge University Press, Cambridge.

Dillon, Brian D. 1977. Salinas de los Nueve Cerros, Alta Verapaz, Guatemala: Preliminary Archaeological Investigations. Ballena Press Studies in Mesoamerican Art, Archaeology and Ethnohistory 2. Ballena Press, Socorro, NM.

Englehardt, Joshua D. 2010. "Crossing the Usumacinta: Stylistic Variability and Dynamic Boundaries in the Preclassic and Early Classic Period Northwest Maya Lowlands." Archaeological Review from Cambridge 25(2):57-76.

Fowler, William R., Jr. 1981. The Pipil-Nicarao of Central America. Unpublished PhD dissertation, Department of Archaeology, University of Calgary.

Fowler, William R., Jr. 1985. "Ethnohistoric Sources on the Pipil-Nicarao of Central America: A Critical Analysis." Ethnohistory 32(I):37-62. 
Fox, James A., and John S. Justeson. 1982. "A Cholan Calendar in the Gates Collection.” Manuscript on file, Department of Anthropology, University at Albany.

Gray, Russell D., and Quentin D. Atkinson. 2003. "Language-Tree Divergence Times Support the Anatolian Theory of Indo-European Origin." Nature 426:435-439.

Guderjan, Thomas H. 1995. "Maya Settlement and Trade on Ambergris Caye, Belize." Ancient Mesoamerica 6:147-159.

Hill, Jane H. 200I. "Uto-Aztecan and the Mesoamerican Linguistic Area." Paper presented at the rooth Annual Meeting of the American Anthropological Association, Washington, DC.

Hofling, Charles A. 20I4. Lacandon-Maya-Spanish-English Dictionary. University of Utah Press, Salt Lake City.

Hopkins, Nicholas A.r99r. "Classic and Modern Relationship Terms and the 'Child of Mother' Glyph (TI:606.23).” In Sixth Palenque Round Table, Ig86, edited by Merle G. Robertson and Virginia M. Fields, 255-265. University of Oklahoma Press, Norman.

Hopkins, Nicholas A., Ausencio Cruz Guzmán, and J. Kathryn Josserand. 2008. "Chol (Mayan) Vocabulary from 1789 ." International Journal of American Linguistics $7 \mathrm{I}(\mathrm{I}): 83-\mathrm{II} 4$.

Houston, Stephen, John Robertson, and David Stuart. 2000. “The Language of Classic Maya Inscriptions." Current Anthropology 4I(3):32I-356.

Houston, Stephen, David Stuart, and Marc Zender. In preparation. "The Reanalysis of a La Corona King's Name.” To appear in La Corona Notes.

Hull, Kerry. 2000. Cosmological and Ritual Language in Chorti. Research report submitted to the Foundation for the Advancement of Mesoamerican Studies, Inc. Electronic document, http://www.famsi.org/reports/99036/index.html, accessed December 7, 2018.

Hull, Kerry. 2010. "An Epigraphic Dietary Analysis of Classic-Period Maya Foodstuffs." In Pre-Columbian Foodways: Interdisciplinary Approaches to the Roles of Consumables and Ritual Performance, edited by John E. Staller and Michael D. Carrasco, 235-256. Springer, New York.

Hull, Kerry, and Rob Fergus. 2009. "Eagles in Mesoamerican Thought and Mythology." Reitaku Review 15:83-134.

Hull, Kerry, and Rob Fergus. 2015. Lacandon Maya field notes from 2015 fieldwork in Metzabok, Chiapas, Mexico.

Hunn, Eugene S. 1997. Tzeltal Folk Zoology: The Classification of Discontinuities in Nature. Academic Press, New York.

Josserand, J. Kathryn. 1975. "Archaeological and Linguistic Correlations for Maya Prehistory.” In Actas del XLI Congreso Internacional de Americanistas I:50I-5IO. Instituto Nacional de Antropología e Historia, Mexico City. 
Justeson, John S., William M. Norman, Lyle R. Campbell, and Terrence S. Kaufman. 1985. The Foreign Impact on Lowland Mayan Language and Script. Middle American Research Institute Publication 53. Tulane University, New Orleans.

Kaufman, Terrence S. 1974. Idiomas de Mesoamérica. Seminario de Integración Social 33. Editorial Joseé de Pineda Ibarra, Guatemala City.

Kaufman, Terrence S. 1976. "Archaeological and Linguistic Correlations in Mayaland and Associated Areas of Meso-America." World Archaeology 8(I):IOI-II8.

Kaufman, Terrence S. 200I. "The History of the Nawa Language Group: From the Earliest Times to the Sixteenth Century: Some Initial Results." Electronic document, http:// www.albany.edu/pdlma/Nawa.pdf, accessed November 6, 2015.

Kaufman, Terrence S. 2003. A Preliminary Mayan Etymological Dictionary. Research report submitted to the Foundation for the Advancement of Mesoamerican Studies, Inc. Electronic document, http://www.famsi.org/reports/orosi/pmed.pdf, accessed November 6, 2015.

Kaufman, Terrence S., and John S. Justeson. 2007. "The History of the Word for Cacao in Ancient Mesoamerica." Ancient Mesoamerica I8:193-237.

Kaufman, Terrence S., and William M. Norman. 1984. "An Outline of Proto-Cholan Phonology, Morphology, and Vocabulary." In Phoneticism in Maya Hieroglyphic Writing, edited by John S. Justeson and Lyle Campbell, 77-166. Institute of Mesoamerican Studies, Albany.

Karttunen, Frances. 1983. An Analytical Dictionary of Nahuatl. University of Oklahoma Press, Norman.

King, Arden R. 1974. Coban and the Verapaz: History and Cultural Process in Northern Guatemala. Middle American Research Institute Publication 37. Tulane University, New Orleans.

Lacadena, Alfonso. 1997. “Bilingüismo en el Códice de Madrid.” In Los investigadores de la cultura maya, I84-204. Publicaciones de la Universidad Autónoma de Campeche No. 5. Campeche, Mexico.

Lacadena, Alfonso. 2004. "Passive Voice in Classic Mayan Text: CV-h-C-aj and -n-aj Constructions." In The Linguistics of Maya Writing, edited by Søren Wichmann, 165-194. University of Utah Press, Salt Lake City.

Lacadena, Alfonso, and Søren Wichmann. 2002. "The Distribution of Lowland Maya Languages in the Classic Period." In La organización social entre los mayas prehispánicos, coloniales y modernos: Memoria de la Tercera Mesa Redondo de Palenque, Vol. 2, edited by Vera Tiesler, Rafael Cobos, and Merle Greene Robertson, 275-314. Instituto Nacional de Antropología e Historia, Universidad Autónoma de Yucatán, Mexico City and Mérida. 
Lacadena, Alfonso, and Søren Wichmann. 2005. "The Dynamics of Language in the Western Lowland Maya Region.” In Art for Archaeology's Sake: Material Culture and Style across the Disciplines. Proceedings of the Thirty-Third Annual Conference of the Archaeological Association of the University of Calgary, edited by Andrea WatersRist, Christine Cluney, Calla McNamee, and Larry Steinbrenner, 32-48. University of Calgary, Calgary.

Law, Danny. 2009. "Pronominal Borrowing among the Maya." Diachronica 26(2):214-252. Law, Danny. 2014. Language Contact, Inherited Similarity and Social Difference: The Story of Linguistic Interaction in the Maya lowlands. John Benjamins, Amsterdam.

Luckenbach, Alvin H., and Richard S. Levy. 1980. “The Implications of Nahua (Aztecan) Lexical Diversity for Mesoamerican Culture-History." American Antiquity 45(3):455-46I.

Macri, Martha J. 2000. “T536 Xo from Nahuatl Xochitl 'Flower.” Glyphdwellers Report II. Electronic document, http://nas.ucdavis.edu/NALC/glyphdwellers.html, accessed November 6, 2015 .

Macri, Martha J. 2005. "Nahua Loan Words from the Early Classic Period: Words for Cacao Preparation on a Río Azul Ceramic Vessel.” Ancient Mesoamerica I6(2):321-326.

Macri, Martha J. 2010. "Scribal Interaction in Postclassic Mesoamerica." In Astronomers, Scribes, and Priests: Intellectual Interchange between the Northern Maya Lowlands and Highland Mexico in the Late Postclassic Period, edited by Gabrielle Vail and Christine L. Hernández, 186-215. Dumbarton Oaks, Washington, DC.

Macri, Martha J., and Matthew G. Looper. 2003. "Nahua in Ancient Mesoamerica: Evidence from Maya Inscriptions." Ancient Mesoamerica I4(2):285-297.

Mallory, J. P. 1976. “Time Perspective and Proto-Indo-European Culture.” World Archaeology 8(I):44-56.

Martin, Simon. 20I2. "Hieroglyphs from the Painted Pyramid: The Epigraphy of Chiik Nahb Structure Sub I-4, Calakmul, Mexico.” In Maya Archaeology 2, edited by Charles Golden, Stephen D. Houston, and Joel Skidmore, 60-8I. Precolumbian Art Research Institute Mesoweb Press, San Francisco.

Matras, Yaron. 2012. "An Activity-Oriented Approach to Contact-Induced Language Change." In Dynamics of Contact-Induced Language Change, edited by Claudine Chamoreau and Isabelle Léglise, 17-51. Mouton de Gruyter, Berlin.

McKillop, Heather I. 1995. "Underwater Archaeology, Salt Production, and Coastal Maya Trade at Stingray Lagoon, Belize." Latin American Antiquity 6(3):214-228.

McKillop, Heather I., and Paul Healy. 1989. Coastal Maya Trade. Occasional Papers in Anthropology No. 8. Department of Anthropology, Trent University, Peterborough, Canada.

McKusick, Charmion R. 1980. "Three Groups of Turkeys from Southwestern Archaeological Sites." In Papers in Avian Paleontology Honoring Hildegarde Howard, 
edited by Kenneth E. Campbell Jr., 225-235. Contributions in Science 330, Natural History Museum of Los Angeles County, Los Angeles.

Membreño, Alberto. 1897. Honduñerismos: Vocabulario de los provincialismos de Honduras. Tipografía Nacional, Tegucigalpa.

Morán, Fray. [1695] 1935. Arte y diccionario en lengua cholti. Edited by William Gates. Maya Society publ. 9. Gates Collection, Brigham Young University, Provo.

Real Academia Española, Asociación de Academias de la Lengua Española. 2014.

Diccionario de la Lengua Española, 23rd ed., Edición del Tricentenario. Real Academia Española, Madrid.

Reed, Erik K. 1951. “Turkeys in Southwestern Archaeology.” El Palacio 58:195-205.

Renfrew, Colin. 1987. Archaeology and Language: The Puzzle of Indo-European Origins. Jonathan Cape, London.

Robertson, John. S., and Danny Law. 2009. "From Valency to Aspect in the Ch'olanTzeltalan Family of Mayan." International Journal of American Linguistics 75(3):293-316.

Smith, Michael, and Francis F. Berdan. 2003. The Postclassic Mesoamerican World. University of Utah Press, Salt Lake City.

Speller, Camilla F., Brian M. Kemp, Scott D. Wyatt, Cara Monroe, William D. Lipe, Ursula M. Arndt, Dongya Y. Yang, and Kent V. Flannery. 2010. "Ancient Mitochondrial DNA Analysis Reveals Complexity of Indigenous North American Turkey

Domestication." Proceedings of the National Academy of Sciences of the United States of America $107(7): 2807-28 \mathrm{I} 2$.

Stuart, David. 1988. “The Río Azul Cacao Pot: Epigraphic Observations on the Function of a Maya Ceramic Vessel." Antiquity 62(234):153-I57.

Stuart, David. 2005. The Inscriptions from Temple XIX at Palenque: A Commentary. PreColumbian Art Research Institute, San Francisco.

Stross, Brian. 1982. "Maya Hieroglyphic Writing and Mixe-Zoquean." Anthropological Linguistics 24(I):73-134.

Suárez, Ruano Alberto. I892. "Idioma Chortí." Box 42, Folder 7, Gates Collection, Lee Library. Brigham Young University, Provo.

Taube, Karl. 2000. The Writing System of Ancient Teotihuacan. Ancient America No. I. Center for Ancient American Studies, Barnardsville, North Carolina.

Thompson, J. Eric S. 1990. Maya History and Religion. University of Oklahoma Press, Norman.

Tourtellot, Gair, and Jeremy A. Sabloff. 1972. "Exchange Systems among the Ancient Maya." American Antiquity 37(I):126-135. 
Wald, Robert. 2004. "The Languages of the Dresden Codex: Legacy of the Classic Maya." In The Linguistics of Maya Writing, edited by Søren Wichmann, 27-58. University of Utah Press, Salt Lake City.

Wharton, Jennifer. 1998. “Stone Dock Testing at Subop i4, Laguna de On Island.” In Belize Postclassic Project 1997: Laguna de On, Progresso Lagoon, Laguna Seca, edited by Robert M. Rosenwig and Marylin Masson, 67-70. Occasional Publication No. 2. Institute of Mesoamerican Studies, Albany.

Whittaker, Gordon. 1986. "The Mexican Names of Three Venus Gods in the Dresden Codex." Mexicon 8(3):56-60.

Wichmann, Søren. 1995. The Relationship among the Mixe-Zoquean Languages of Mexico. University of Utah Press, Salt Lake City.

Wichmann, Søren. 1998. “A Conservative Look at Diffusion Involving Mixe-Zoquean Languages." In Archaeology and Language II: Archaeological Data and Linguistic Hypotheses, edited by Roger Blench and Matthew Spriggs, 297-323. Routledge, London. Wichmann, Søren. 2002. Hieroglyphic Evidence for the Historical Configuration of Eastern Cholan. Research Reports on Ancient Maya Writing No. 51. Center for Maya Research. Washington, DC.

Wichmann, Søren. 2006. "A New Look at Linguistic Interaction in the Lowlands as a Background for the Study of Maya Codices." In Sacred Books, Sacred Languages: Two Thousand Years of Ritual and Religious Maya Literature, edited by Rogelio Valencia Rivera and Geneviève Le Fort, 45-64. Acta Mesoamericana I8. Verlag Anton Saurwein, Munich, Germany.

Wichmann, Søren, and Cecil H. Brown. 2003. "Contact among Some Mayan Languages: Inferences from Loanwords." Anthropological Linguistics 45(I):57-93.

Wichmann, Søren, and Kerry Hull. 2009. "Loanwords in Q'eqchi', a Mayan Language." In Loanwords in the World's Languages: A Comparative Handbook, edited by Martin Haspelmath and Uri Tadmor, 873-896. Mouton de Gruyter, Berlin.

Witkowski, Stanley R., and Cecil H. Brown. 1978. "Mesoamerican: A Proposed Language Phylum." American Anthropologist 80(4):942-944. 


\section{Chapter 5}

\section{Reframing the Tripod \\ A Foreign Form Adopted by the Early Classic Maya}

D. BRYAN SCHAEFFER

On the cover of the seminal volume The Maya and Teotihuacan: Reinterpreting Early Classic Interaction (Braswell 2003a), a tripod ceramic becomes the representative material, and therefore, cultural focus of this particular interregional interaction. The presentation of the complex interaction between the central Mexican metropolis of Teotihuacan and the Maya region is visually distilled into the singular object of the tripod. ${ }^{1}$ This specific form has become an index of Teotihuacan's influence on and interaction with the Maya region during the Early Classic period, particularly the fourth through sixth centuries AD (Ball 1983; Borhegyi 1951; Bove and Medrano Busto 2003; Clayton 2005; Conides 2001; Demarest and Foias 1993; Nielsen 2003; Stuart 2000; Taube 2003; see also Jesper Nielsen et al., chapter 6 in this volume). But such a unidirectional emphasis of influence negates Maya agency (see, e.g., Cash 2005; Englehardt 20I2). In this chapter, I argue that Early Classic Maya ceramicists appropriated and adapted the tripod form, creating an innovative fusion of artistic styles. This fusion clearly demonstrates that the Maya were aware of and appreciated the specific Teotihuacan tripod form, even as they translated and incorporated the tripod form into their own artistic canons.

Following this introductory section, I will briefly review the current scholarship on tripod ceramics from Teotihuacan. The subsequent section outlines the problem of the tripod's origin for the Maya area. Then I examine particular tripods excavated in the Maya region in order to reframe our understanding of the Maya tripod by adding a few germane observations and by exploring questions that unpack the 
central ideas of this chapter. In the final section, I argue that the tripod ceramic form is an index of travel. In other words, the tripod ceramic form in the Maya realm visually signifies interregional interaction because traveling human beings take from and bring to foreign regions their knowledge, experience, and visual cultures. Therefore, the act of travel can produce new and innovative fusions of local and extralocal visual programs. This, in turn, layers the tripod form with significant meaning. Viewing the tripod ceramic form through this lens of travel offers a novel perspective. My contention is that the tripod form in general, and its material manifestation in the Maya area during the Early Classic in particular, is ripe for further analysis.

The tripod ceramic vessel is a constitutive component of social agency whose shared form underscores the multidirectional nature of interregional interaction in ancient Mesoamerica. ${ }^{2}$ The Early Classic tripod vessels found in the Maya area have been analyzed within the contextual framework of material and cultural interactions and exchanges between Teotihuacan and disparate Maya cities. This framework includes talud-tablero architecture, ${ }^{3}$ written narratives, iconography, stelae, Fine Orange ceramics, incensarios, figurines, and other material evidence. However, the analytical angle of drawing out the implicit categorical designation of the tripod as associated with travel presents a fresh perspective, even if such a focused lens attempts to explicate only a fraction of this complex interregional interaction through the specificity of the tripod form. Many tripod vessels have been excavated from the tombs of elite Maya and therefore contain the culturally instructive particles of funerary practices, the material vestiges of the rulers' connection to not just Teotihuacan, but to various Mesoamerican regions, including other Maya cities.

Tripod ceramic vessels formed part of interregional interactions through gift exchange and ritual feasts, activities of a cultural and political nature often only implicitly connected to the act of travel (Ball 1983; Reents-Budet 1998; Shaw and Johnstone 2006; Stuart 1998). Some tripods retained lids, but we do not know if many or most tripods originally had lids as several presented in this chapter show no signs of having lids (although some do; see figure 5.I ). ${ }^{4}$ Scholars argue (e.g., Braswell 2003 b, c; Demarest and Foias 1993; Nielsen 2003) that through the accretion of all evidence — architectural, art historical, epigraphic, and archaeological—we are able to begin to comprehend the political, economic, diplomatic, and artistic spheres of interregional interaction between Teotihuacan and various Maya cities. I suggest that the tripod vessel itself elicits clues as to how the ancient Maya conceptualized, and therefore visualized, their connection to the foreign city of Teotihuacan. It is certain that not all Maya cities interacted with Teotihuacan on all political, economic, or cultural levels and that the modes of interaction were overwhelmingly 


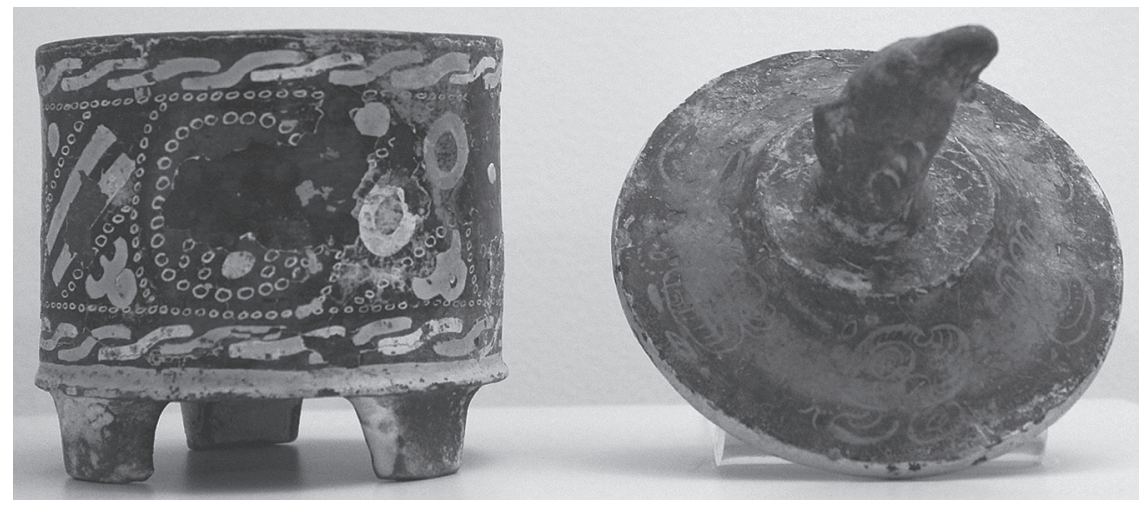

FIGURE 5.I. Early Classic tripod purportedly from the Maya lowlands, whose lid has a hieroglyphic script that describes this vase as containing the "cacao drink" of a king (photo by the author, Museo de Etnología y Arqueología de Guatemala, Guatemala City).

carried out at the elite level (Clayton 2005; Taube 2003; cf. Joyce Marcus, chapter $\mathrm{I} 2$ in this volume). ${ }^{5}$

Therefore, the practicality of noting and examining both specific details and general patterns will provide the frame with which tripod ceramics are discussed in this chapter. Most tripods excavated in the Maya area, with a few notable exceptions, were integrated into prominent funerary collections of ceramics from various Mesoamerican regions, materially tying the buried noble or ruler with other polities, peoples, deities, landscapes, and, therefore, other avenues of political and sacred power within a localized context. ${ }^{6}$ The foreign tripod form coupled with indigenous Maya iconography represents a Teotihuacan-Maya hybrid aesthetic that frames an autochthonizing process. Through the prism of travel, it also acknowledges foreign influence and localized adaptation.

\section{THE TEOTIHUACAN TRIPOD}

James Bennyhoff (1967) and Evelyn Rattray (1977) have proposed that the origin of the tripod vessel in Mesoamerica could possibly be the present-day Mexican state of Veracruz. Whatever its origin, Teotihuacanos certainly adapted the form to their own style and iconography as will be demonstrated in this chapter. Because a secure chronological sequence for tripod vessels in the Maya area is elusive, I now turn to the ceramic stratigraphy for Teotihuacan tripods in order to use it as a building block for understanding the tripod vessels from the Maya region (in the following sections). The chronology I am utilizing for Teotihuacan ceramics is that 

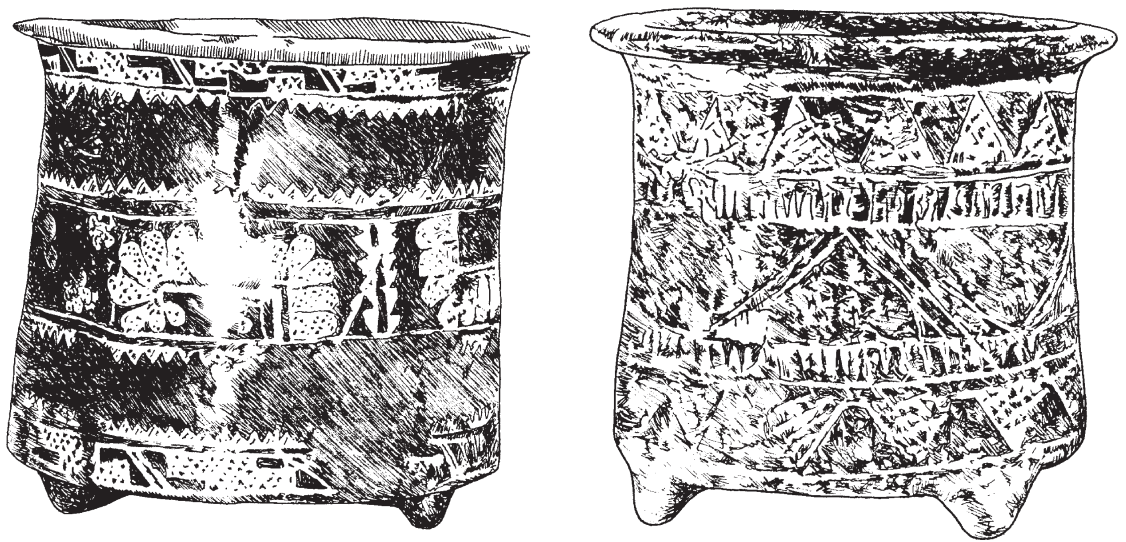

FIGURE 5.2. Two incised tripod vessels from Teotihuacan with large nubbin supports; Miccaotli phase AD 150-225/250 (drawings by Hannah Mason after Rattray 2001:485-486, figs. 47-48).

presented by George Cowgill (1997:I3I). According to Rattray (200I), who uses the same chronology, the tripod vessel is first formed as early as the Miccaotli phase. Tripod supports at Teotihuacan start as large nubbins that barely lift the vessel off the ground (figure 5.2). These initial tripods are crudely incised; some have postfire cross-hatch incising and others are prefired, cross-hatch incised (Rattray 2001:109). Their shape does not appear to be perfected, perhaps demonstrating an impetus for the newly conceived stylistic program of tripod vessels. The two incised vessels also portray a starting point for the decorative surface program on tripod ceramics manufactured at Teotihuacan.

In her volume on Teotihuacan ceramics, Rattray (2001; cf. Berlo 1980 and Conides 200I) identified over eleven different ceramic forms including plates, dishes, bowls, jars, amphoras, incensarios, copas (cups), and, of course, the tripod ceramic vase (figure 5.3). The form and structure for tripod supports created at Teotihuacan varied and were not limited solely to vases. Plates, bowls, and jars also have tripod supports. Large nubbin supports appear as early as the Miccaotli phase from $\mathrm{AD} 150-225 / 250$, and thus the tripod vessel begins to take form as its own category of a ceramic type at Teotihuacan. This date for the initial appearance of the tripod vessel at Teotihuacan contradicts, between 50-150 years, the later date of $\mathrm{AD} 300$ proposed by Braswell (2003b). However, it appears that Braswell's dating for the tripod vessel within the Maya area is correct. The Maya region produces and/or adopts the tripod vessel form, and its proliferation takes hold between AD 300 and 600 . 

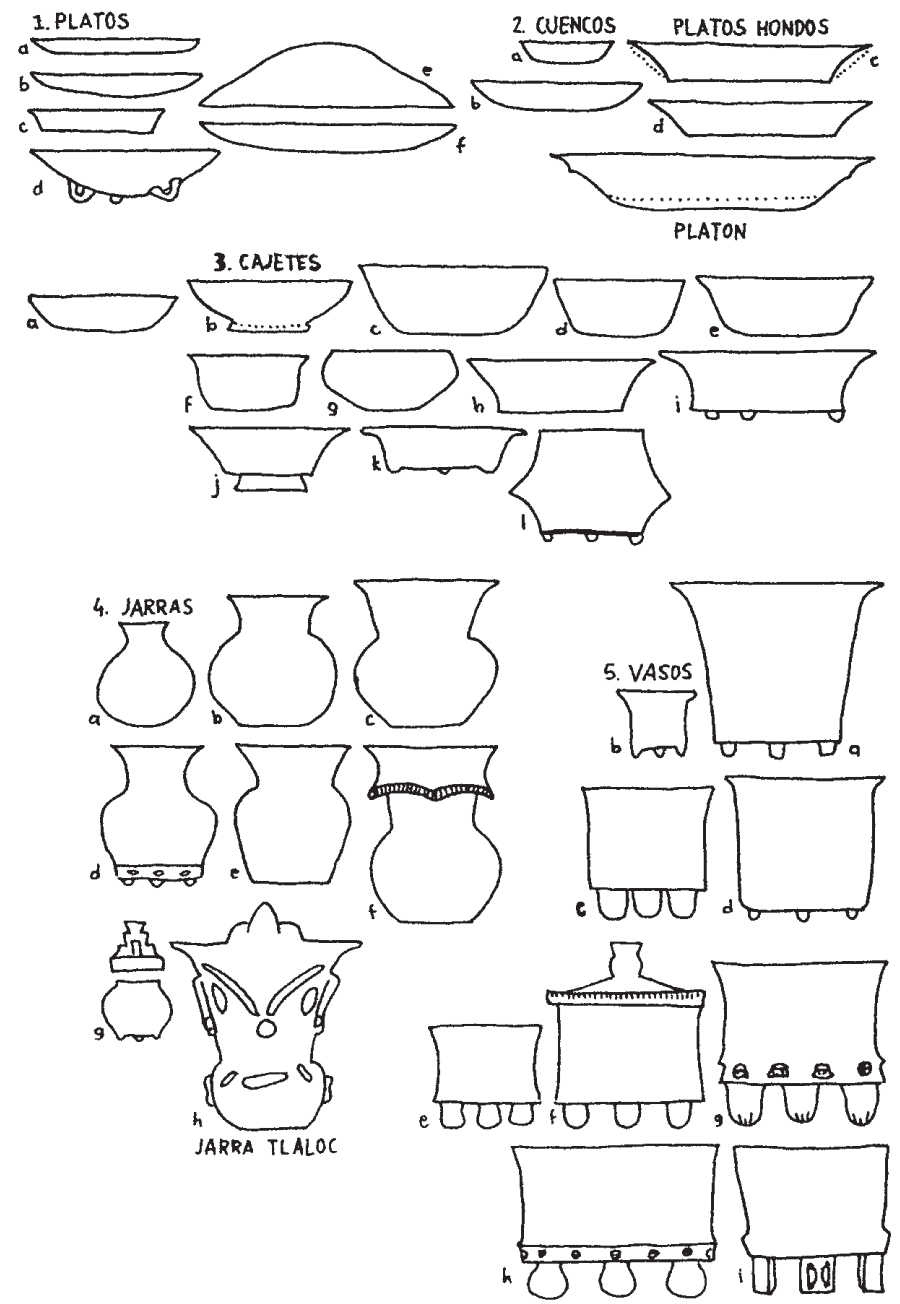

FIGURE 5.3. Drawing of various ceramic vessel forms from Teotihuacan. Differing tripod supports shown in lower right (drawing by Hannah Mason after Rattray 2001:460, fig. 20).

The next phase is referred to as the Early Tlamimilolpa phase from AD 225/250 to 350, during which tripod supports on certain vessels begin to change shapes, suggesting a play with form and style by Teotihuacan ceramicists. Ceramic vessels become cylindrical vases with knoblike supports that lift the vessel higher off the ground than those of the Miccaotli phase. This Early Tlamimilolpa phase also includes the 


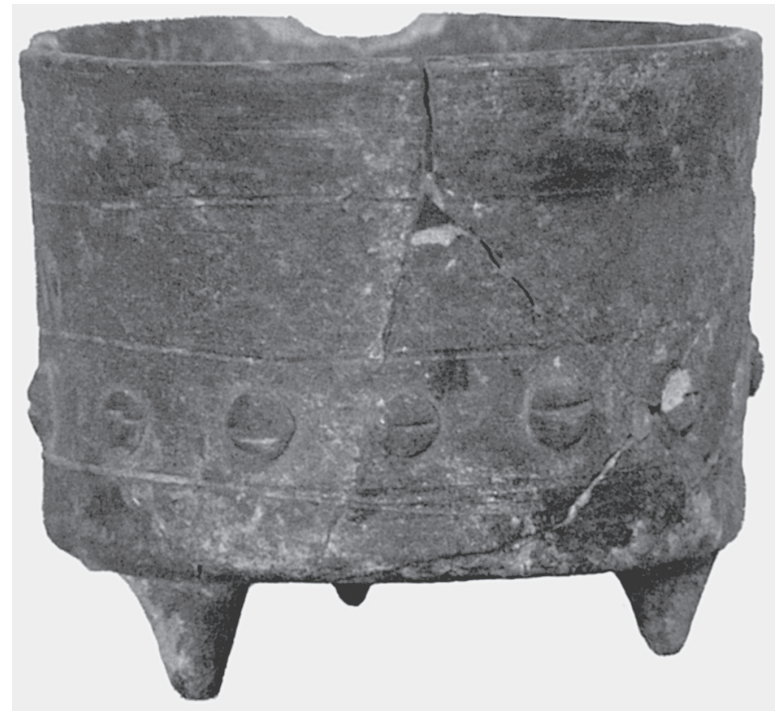

Figure 5.4. Conical tripod supports innovated during the Late Tlamimilolpa phase (digital image by Martha Soto, modified after Rattray $200 \mathrm{I}$, fig. 87 , p. 5II).

introduction of a basal flange with what appear to be cacao beans and a direct rim. Rattray (2001:493) writes that this particular vessel was found in Burial 2I at La Ventilla B in Teotihuacan. It presents an evolution, then, in tripod supports and also in the actual shape of the ceramic vessel itself. Lids for certain tripod vessels, though rare during this phase, have been found (Rattray 2001:109). Cowgill (2003:317) suggests that this phase and its transition into the Late Tlamimilolpa phase comprise the "most pronounced changes in the whole Teotihuacan ceramic sequence." He surmises that the evolution of flat-bottomed bowls with outcurving sides and nubbin supports suggests a "continuity of the local population." This assertion, if true, affirms the aforementioned idea that the Teotihuacan ceramicists were engaging with different forms and styles for the tripod vessel in order to enhance its aesthetic value and create new structural designs. The Late Tlamimilolpa phase, then, continues this variation of the vessel's form and the shape of the supports (figure 5.4). The conical tripod supports on the vessel in figure 5.4 underscore a fledgling design innovation that occurs during this phase, but its austere decoration is a visual persistence from previous time periods. It is also during the Late Tlamimilolpa phase that hollow slab rectangular supports begin to appear.

The subsequent Xolalpan phase from AD 400-550 is the time during which the Teotihuacan-style tripod vessel was at its influential zenith in the Maya area. The Xolalpan phase is subdivided into an early phase and a late phase. The Early Xolalpan phase is characterized by both rounded tripod supports and rounded 
Figure 5.5. Talud Tablero-style tripod supports, Late Xolalpan phase (digital image by Martha Soto, modified after Rattray 2001:556, fig. 154).

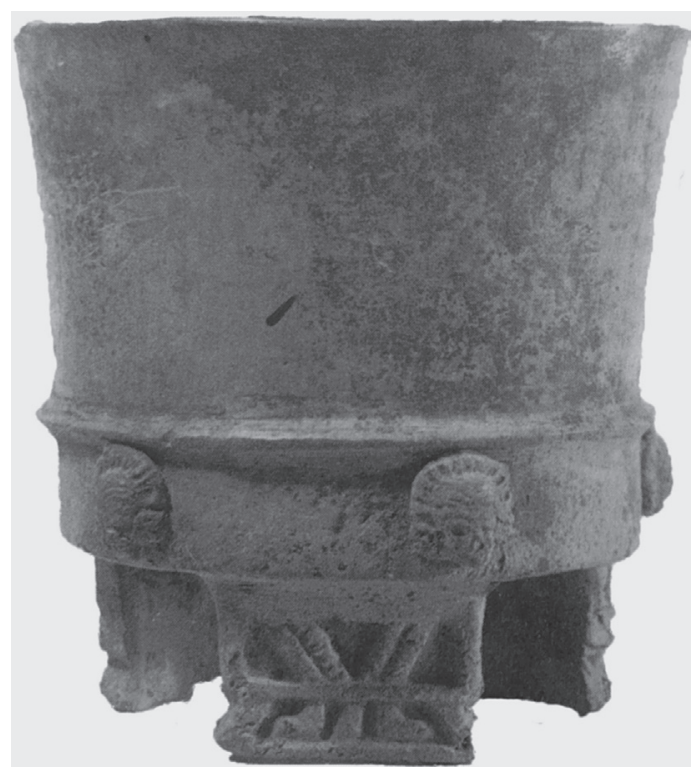

supports that appear more linear, almost rectangular, continuing to build upon the changes in form of the supports from the previous phase. Lids that accompany certain tripod vessels begin to have rounded knobs on their top that seemingly echo the shape of large polished ware jars from this same period that were excavated in the Tetitla complex burials at Teotihuacan. Stucco decoration on bowls also begins during the Early Xolalpan phase (Rattray 2001:Iro).

Late Xolalpan phase tripod vessels multiply and build upon the dynamic and varied forms of the ceramic vessel and supports. Certain tripods have pseudo plano-relief decoration with molded heads, instead of cacao beans, encircling the basal flange. This particular tripod form maintains the slab-footed rectangular supports with carved designs. Other tripods from this time period have the largest globular supports and much more intricate plano-relief decoration and design. However, other tripod ceramics continue the austere decoration from the Tlamimilolpa phase, but combine the lack of decoration with talud-tablero-style supports (figure 5.5). This is an interesting form for the supports because, as Esther Pasztory (1997:156) avers, the tripod supports contemporaneously appeared with talud-tablero architecture. However, she does not offer any specific evidence for such a claim. Another vessel from the Tetitla burials displays a Late Xolalpan stucco painted design on a dark background, demonstrating the appearance of stucco decoration specifically on tripods. 
A chronological ceramic stratigraphy for tripod ceramic vessels from Teotihuacan has been an apposite starting point for the examination of tripods from the Maya area. By analyzing the decoration and form of Teotihuacan tripods, I believe that I have only glimpsed the beginning of a more detailed and thorough study for the hybrid aesthetic of tripod vessels that are reportedly from the Maya area. I now turn to specific tripod ceramic vessels in order to examine their various shapes and decorative programs. It is the objective of this chapter to examine the hybrid aesthetic of tripod ceramics from the Maya area and determine what the combination of styles denotes for a Maya-Teotihuacan connection in the Early Classic.

\section{THE TRIPOD'S ORIGIN IN THE MAYA AREA}

Scholars have discussed the tripod ceramic vessel as a diagnostic trait of Teotihuacan's presence anywhere in Mesoamerica that the tripod is found (Ball 1983; Borhegyi 1951; Bove 1990; Bove and Medrano Busto 2003; Braswell 2003a, b; Cheek 1977; Cowgill 2003; Culbert 1993; Demarest and Foias 1993; Kidder et al. 1946; Pendergast 2003; Sanders 1977; cf. Jesper Nielsen et al., chapter 6 in this volume). Although Bennyhoff (1967) and Rattray (1977) argue that the tripod vessel may not have originated at Teotihuacan, they do suggest that the particular form is a pan-Mesoamerican characteristic that developed distinct local variations. In terms of the tripod vessel within the Maya area, Carmen Varela Torrecilla and Geoffrey Braswell (2003:259) argue that the basic tripod form without any Teotihuacan or central Mexican characteristics was first used in Preclassic Kaminaljuyú, but they do not cite any specific evidence for this claim. Braswell (2003b:IO2) also claims that at Teotihuacan "there is little evidence for the local production of cylindrical tripods before AD 300 or after AD 600 . All of the central Mexican-style ceramics found at Kaminaljuyú date to a period after AD 300." This assertion appears to be true of many Maya sites in both the lowlands and the highlands of the Maya area. At Tikal, however, Laporte and Fialko (1987) posit an earlier date than AD 300 for slab-footed tripod vessels, suggesting that the Maya artists drew upon not only the stylistic canons known at Teotihuacan but also other known ceramic traditions from the cultures of Veracruz, Tabasco, and the Pacific coast of Guatemala. This makes sense given the geographical proximity of the Maya to the visual cultures of the Mexican Gulf Coast and the Guatemalan Pacific coast.

Where, then, did the tripod vessel originate for the Maya region? Coggins (1983:55) suggests that Yax Nuun Ayiin, the man who became ruler of Tikal in AD 379, was from Kaminaljuyú and that with him came the connections to central Mexico that would have initiated stylistic or formal changes in visual culture such as ceramics. The fifth century Burial io of the Manik Complex at Tikal, believed 
to be the tomb of Yax Nuun Ayiin or his son, contained "stuccoed vessels with quadripartite designs painted in the style found at Teotihuacan and depicting the goggle-eyes, fangs, Kan crosses, year signs, chalchihuitls, and dart-throwers of the Teotihuacan patron rain deity Tlaloc" (Coggins 1983:50). Coggins does not mention that at least eight tripod vessels (and fragments), all with lids, were found in Burial to and that solely Maya hieroglyphs and iconography appear on them (Culbert 1993:figs.19-2I). Therefore, the eight tripods found in Burial Io demonstrate a localized Maya appropriation of an etic ceramic form but with emic writing and iconography. ${ }^{7}$ Her argument is problematic, however, because there is insufficient evidence to determine whether central Mexican-style ceramics first appeared at Kaminaljuyú or Tikal, whatever Yax Nuun Ayiin's origin. In addition, there is scant archaeological evidence at Tikal of material items from central Mexico (Iglesias Ponce de León 2003; Laporte 2003; cf. Joyce Marcus, chapter 12 in this volume). Braswell (2003b:I0I) observes that the chronological evidence for foreignstyle ceramics found in Mound A at Kaminaljuyú may precede, be contemporary with, or postdate Yax Nuun Ayiin's life, a chronological supposition that lacks temporal specificity and therefore fails to settle the origin of the tripod ceramic form in the Maya region.

Determining a particular center for the dissemination of the tripod vessel throughout the Maya area is a complicated task because of contradictory and elusive evidence. There is no common chronology for ceramic vessels in the Maya region, hence the difficulty in pinpointing any one city or region as the origin for the dissemination or appropriation of tripod vessels amongst Maya ceramicists. Citing available evidence of interaction between Kaminaljuyú, Copán, and Tikal, Braswell (2003b:IOI) reasons that the "temporal data do not allow us to propose any one of those sites as the point of origin from which central Mexican-style pottery spread throughout the Maya region." Whatever the origin for the tripod form may be, the overwhelming majority of scholars have pointed to the tripod vessel in the Early Classic as evidence of interaction between Teotihuacan and the Maya, if only at the elite level, and if only perceived by us through the tripod's singular physical form.

\section{THE MAYA ADOPT THE TRIPOD FORM: TEOTIHUACAN-MAYA HYBRIDITY}

Previous studies have attempted to understand the geopolitical implications of Teotihuacan presence in the Maya region by utilizing archaeological, epigraphic, and art historical evidence (Adams 1990; Ball 1983; Borhegyi 1971; Bove and Medrano Busto 2003; Braswell 2003a, b; Cheek 1977; Cowgill 2003; Culbert 1993; Demarest and Foias 1993; Fields and Reents-Budet 2005; Kidder et al. 1946; Marcus 2003; Pendergast 1975; Reents-Budet et al. 2004; Sanders 1977). Beginning with 

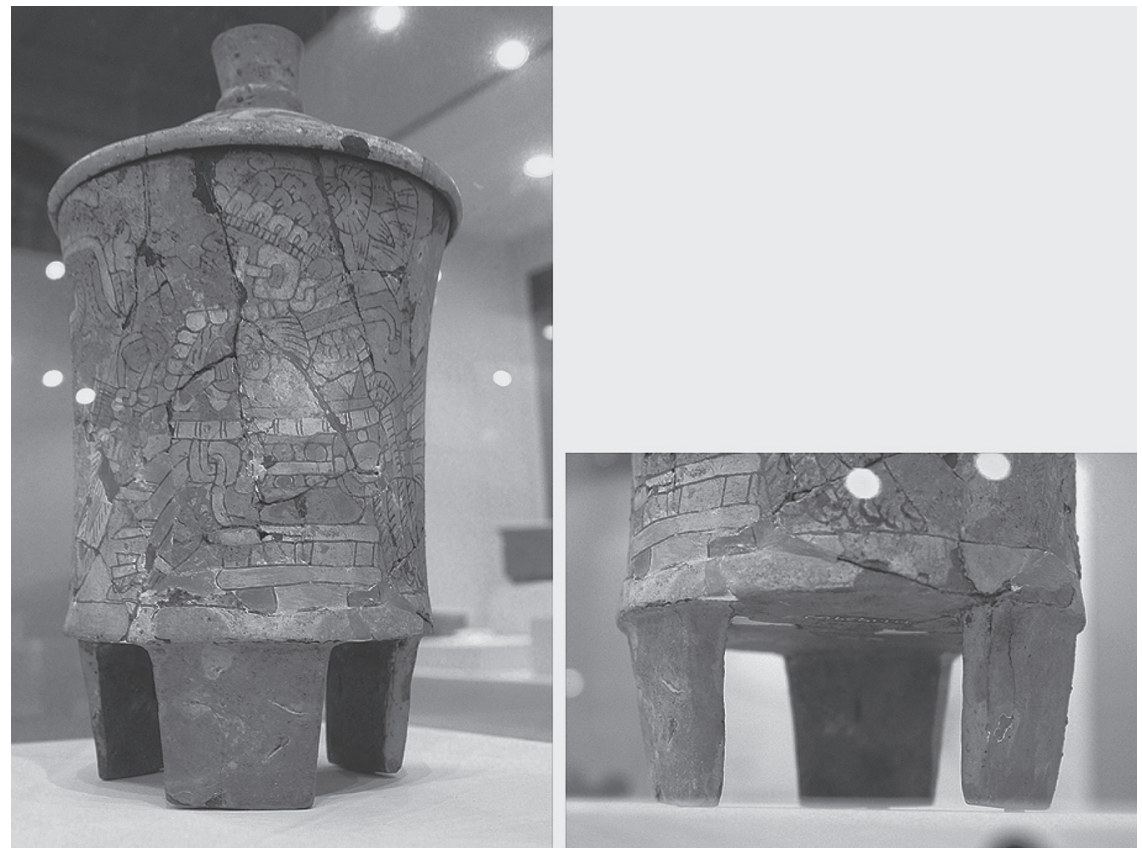

FIGURE 5.6. Tripod from Kaminaljuyú depicting a ruler with Maya jadeite jewelry and a central Mexican headdress. Ceramic with stucco and pigment. $20.3 \mathrm{~cm}, \mathrm{AD} 400-650$. Notice the tripod supports do not match any of those shown in Rattray's 200 I study of Teotihuacan ceramics (photos by the author, Museo de Etnología y Arqueología de Guatemala, Guatemala City).

Bennyhoff (1967), scholars have suggested that the Maya were simply appropriating the distinct Teotihuacan style, something they became familiar with through interregional trade with Teotihuacan, but then adapted to fit their own particular local variations (Bennyhoff 1967; Berlo 1989; Braswell 2003a; Demarest and Foias 1993; Hellmuth 1978; Laporte and Fialko 1987; Rattray 1977; Sanders 1977; Varela Torrecilla and Braswell 2003). Rather than attempting to understand the geopolitical territory of Maya-Teotihuacan interaction, it is my goal here to visually consider the hybrid aesthetic of tripod vessels in order to comprehend such a fusion of styles.

Dated between AD 400 and 500, a specific tripod vessel with lid (figure 5.6) was excavated from Mound B, Tomb B-II at the Maya city of Kaminaljuyú in presentday Guatemala (Fields and Reents-Budet 2005:225). Kaminaljuyú is over 1,100 km from Teotihuacan but has architectural features, such as talud-tablero, and ceramic forms and iconography that suggest interaction with central Mexico. This ceramic 
FIGURE 5.7. Tripod vessel with Teotihuacan iconography reportedly from the Maya area (drawing by Hannah Mason after Fields and Reents-Budet 2005:227, fig. 122).

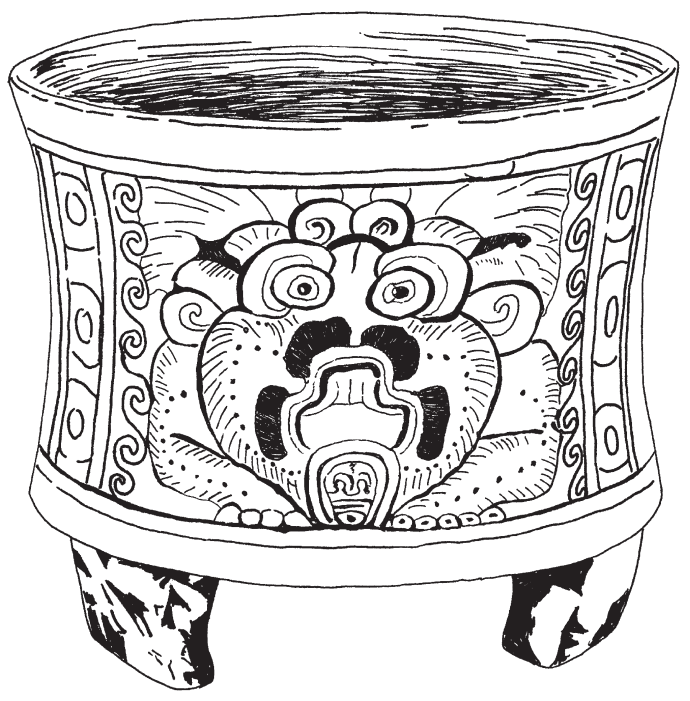

and stucco vessel depicts a figure, most likely a king or ruler, dressed in central Mexican garb and seated on a throne. He is dressed in Teotihuacan style with a spangled headdress, yet he wears Maya-style jadeite jewelry. Although this is a tripod vessel, the supports do not have a clear correlation in form to any of the tripod supports established by Rattray's ceramic study (cf. figure 5.3). One could refer to them as slab-footed but they are much thinner and more curvilinear than any of the typical slab-footed supports from Teotihuacan.

Another tripod vessel with stucco and Maya-innovated supports also depicts Teotihuacan iconography (figure 5.7). The supernatural plumed jaguar is devouring a human heart and is surrounded by water or blood. Virginia Fields and Dorie Reents-Budet (2005:225) suggest that this vessel was most likely made in the Maya area between AD 450 and 600, during the Xolalpan phase at Teotihuacan, because the vessel's shape and the form of the supports do not correspond to a Teotihuacan style.

On an incised tripod excavated in Tomb A-I of Mound A at Kaminaljuyú (figure 5.8), there is an inversion of the hybrid aesthetic observed on the vessel depicted in figure 5.7. This vase has Maya-style imagery as the scroll emanating from the central figure's nose and mouth is, according to Karl Taube (2003:308), reminiscent of the Maya serpent-breath element on Stela 5 from El Zapote and as seen in detail from a ceramic vessel found at Tikal. However, the supports' form clearly indicates Teotihuacan-inspired design. The protruding beads that encircle the basal flange 


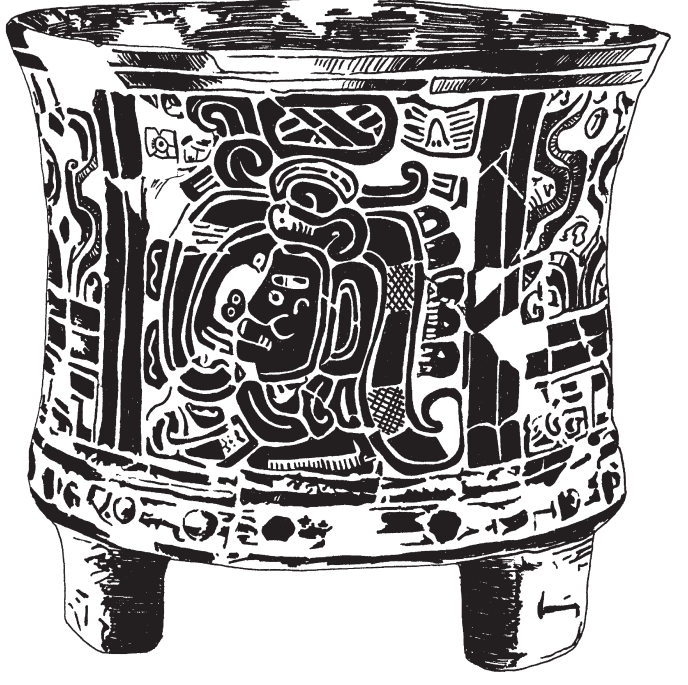

FIGURE 5.8. Tripod from Kaminaljuyú, Mound A, Tomb A-I. Ceramic with slip and red pigment, $19.5 \times$ $21 \mathrm{~cm}, \mathrm{AD}$ 400-500. This vessel has Maya imagery and Teotihuacan-inspired supports (drawing by Hannah Mason after Fields and Reents-Budet 2005:224, fig. II7).

of this tripod also point to a visual influence from Teotihuacan vessels. Whether or not this motif is a cacao bean, this specific decorative element clearly has a precedent from tripod vessels at Teotihuacan.

Found in the tomb believed to belong to Yax Nuun Ayiin, who ruled Tikal from $\mathrm{AD} 379$ to 404 , a lidded tripod with stucco and pigment dated to $\mathrm{AD} 404$ further demonstrates the fusion of Teotihuacan form and Maya imagery (figure 5.9a). The effigy head on top of the lid is a Maya figure, and a Mayan hieroglyphic text appears on the lid as well. Fields and Reents-Budet (2005:232) state that the chemical composition of this tripod implies that it was made in a Tikal workshop producing ceramics exclusively for the elite class, thereby denoting an autochthonous origin for this specific tripod. This vessel was among many other stuccoed-and-painted ceramics found in Yax Nuun Ayiin's tomb, perhaps to emphasize the copying of ceramics with a clear origin at Teotihuacan. Ceramic tripod vessels with lids have been found at Teotihuacan and have a starting point in the Early Xolalpan phase from circa AD 375 to 450 (figure $5.9 \mathrm{~b}$ ).

Two stucco-and-painted vessels excavated from the Sub-Jaguar Tomb at Copán and dated to AD 525 have nearly the exact same shape and tripod supports (see Fields and Reents-Budet 2005:233, figs. I28-I29). The only major difference between the two is the subject matter on the vessels. One contains four glyph-like images of a Maya-style saurian head. The other depicts a Teotihuacan-style image of a feather-encircled star with water issuing from its edge. Although these tripods are 


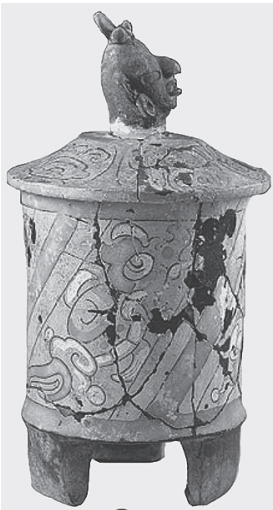

a.

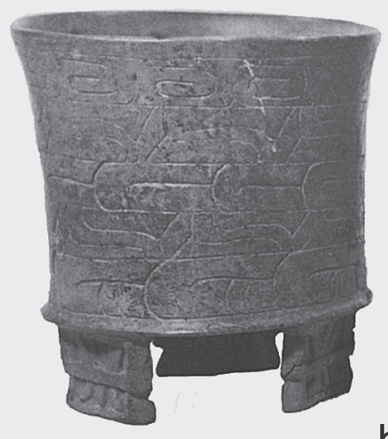

b.

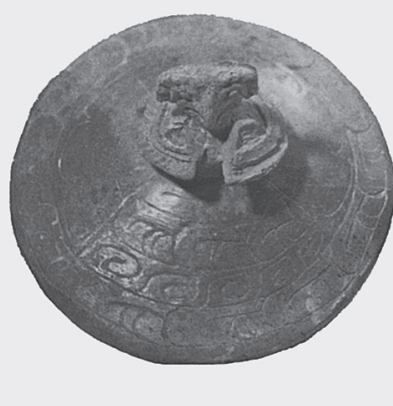

.

FIGURE 5.9. (a) Tripod vessel with Maya hieroglyphs on the lid. Tikal Structure $5 \mathrm{D}-34$, Burial Io. Ceramic with stucco and pigment, $24.4 \times 8.8 \mathrm{~cm}, \mathrm{AD} 456$ (digital image by Martha Soto, modified after Fields and Reents-Budet 2005:232, fig. 127); (b) example of tripod vessel with lid and bird's head from Teotihuacan (digital image by Martha Soto, modified after Rattray 2001:559, fig. 158).

nearly identical in form and appearance, each vessel utilizes distinct cultural imagery in order to become imbued with different meanings (Fields and Reents-Budet 2005:232). One ties the buried ruler to the local landscape and power, while the other visually connects the deceased to the extralocal, foreign realm of Teotihuacan. But these two vessels were found together with several other ceramics of varying shapes and sizes in the same tomb and therefore these fraternal twin tripods are contextualized within a larger collection of Mesoamerican ceramics (see Bell et al. 2004:plate 8).

Ten of the twelve stuccoed-and-painted vessels found in the Sub-Jaguar Tomb have been chemically sampled. According to Dorie Reents-Budet, Ellen E. Bell, Loa P. Traxler, and Ronald L. Bishop (2004:185), the analysis of paste ware chemistry indicates that six of them, and one lid, were most likely made in workshops at Quiriguá, a Maya site located in Guatemala, close to the border with Honduras. The uniformity in both form and decorative content of these vessels suggests the possibility that the other six could have been made within the general vicinity of Quiriguá and Copán, perhaps within the Motagua Valley. These six vessels with a secure chemical analysis of production in the Maya region clearly illustrate that Maya ceramicists appropriated and adapted the tripod form of Teotihuacan style. Maya ceramicists imbued the vessels with an indigenous design and visual vocabulary while simultaneously recognizing the physical tripod form as derived from and therefore connected to Teotihuacan. 
Two of the six lidded tripod vessels made at Quiriguá also demonstrate a fusion of Maya innovation in form with Teotihuacan iconography (see Fields and ReentsBudet 2005:230-231, figs. 125-126). Dated to AD 525, both have lids with Mayastyle effigy heads. The blue-green, red, and tan colors are consistent with the previous two vessels, as are the thin supports. These tripods are also infused with a hybrid Maya-Teotihuacan aesthetic, showing distinct elements of Maya form with Teotihuacan imagery. Originally carved-incised and slip-painted, these ceramics portray a feathered feline devouring a human heart, which recalls Teotihuacan iconography that we have already viewed on other vessels (Fields and Reents-Budet 2005:232). The supports mirror those mentioned above from the Sub-Jaguar Tomb at Copán, which appear to be a Maya-style form. The lids display a profile of saurian heads, a decorative motif from Maya artistic canons.

Combining Maya imagery and a Teotihuacan-style figure, another tripod vessel dated between AD 450 and 550 was excavated at Becan in the state of Campeche, Mexico (figure 5.10), by Joseph Ball (1974:2-9) in what he has termed a "dedication cache" that was deposited during the construction of a new building over an older one. When found, this tripod vessel contained a hollow figurine that had broken and spilled its contents, similar to hollow figurines from Teotihuacan. The ceramic figure held ten small solid figurines, six of which portrayed Teotihuacan warriors, two that were non-Teotihuacan men, and two that are decorated with what Fields and Reents-Budet (2005:222) refer to as "the mosaic headgear with chinstrap adopted by the Maya." Again, this vessel is emblematic of the stylistic and material interplay between Teotihuacan features such as the hollow figure, slab-footed supports, and beads that encircle the basal flange of the vase. Maya traits are also present on this tripod vessel, imbuing it with a hybrid aesthetic that denotes a mélange of the Teotihuacan-style figurine with Maya iconography. Found on this tripod is the depiction of the Maya rain god Chaak, who sits in front of the Jade Mountain, the origin of all precious things, including rain (Fields and Reents-Budet 2005:222).

Certain tripod vessels from the Maya area reveal a specific Maya innovation for the supports. A tripod from the Maya site of Oxkintok in northwest Yucatán illustrates such an innovation (figure 5.II). The modeled supports for this Maya vessel are bat effigies, which conceptually and visually signal a unique Maya-style decorative detail that stems from the local Maya cultural and ecological landscape. This particular tripod's main body has no iconography, but it does have a simplified repetition of vertical lines that form columns, perhaps representative of a graphic version of architectural columns at Oxkintok.

We have already observed this type of connection between an architectural feature and ceramics with the talud-tablero and its structural interpretation for ceramics, specifically the tripod. Incised Teotihuacan-style vessels with a plain decorative 


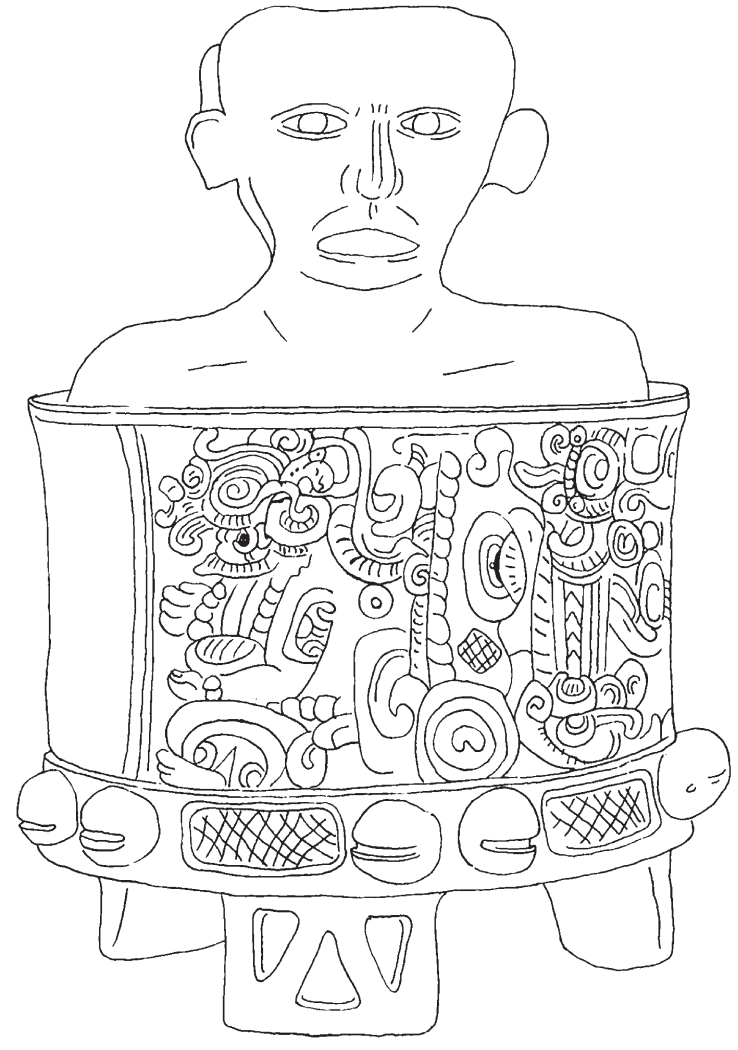

FIgURE 5.I0. Tripod from dedication cache at Becan, Campeche. Ceramic, $16.5 \times 18 \mathrm{~cm}$ (drawing by Pearl Lau).

program associate the austere Maya tripod from Oxkintok with similar ones from Teotihuacan. However, central Mexican vessels that have slab-footed open-work supports usually date from the Early Xolalpan phase at Teotihuacan (Rattray 2001:535). According to Varela Torrecilla and Braswell (2003:259-260), gougedincised, plano-relief, and stucco are all absent on tripod vessels from northwest Yucatán. Dated between AD 500 and 600, the Oxkintok tripod with bat-effigy supports illustrates that different regions within the Maya area developed distinct stylistic local adaptations not only for the supports, but also for the overall decorative program of the tripod vessel, adding to the ceramic canon of distinct tripod configurations.

The tripod vessels I have examined in this section were excavated at various Maya sites, including Copán, Kaminaljuyú, Tikal, Oxkintok, and Becan. They evidence specific local adaptation and innovation in the tripod supports as well as iconographic links to an indigenous artistic repertoire and to the foreign visual programs 
FIGURE 5.II. Tripod vessel from Oxkintok, Yucatán. Notice the bat-effigy supports, clearly a Maya innovation (Varela Torrecilla and Braswell 2003:260, fig. Io.2a, courtesy of the University of Texas Press).

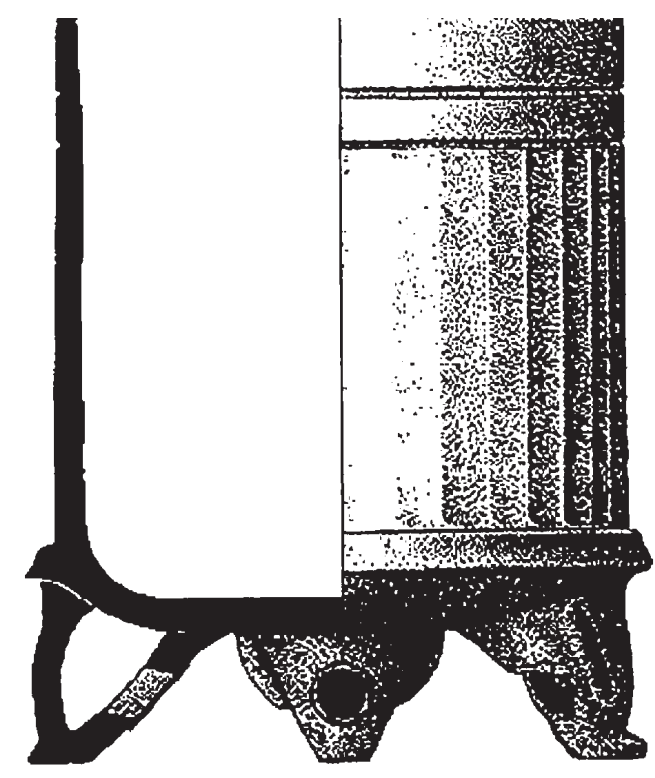

of Teotihuacan. The distinct coupling of two sets of tripod ceramics (see Fields and Reents-Budet 2005:230-23I, figs. I25-I26; 233, figs. I28-I29) from the Sub-Jaguar tomb at Copán underscores the visual parity between a local Copán ruler and the distant metropolis of Teotihuacan, thereby aligning the two realms, through the burial of the ruler, into a conceptual equivalence. The Teotihuacan-Maya hybrid aesthetic demonstrates the Maya ceramicists' fusion of physical, visual, and conceptual traits that linked them to their own artistic canons as well as to that of Teotihuacan.

\section{TRAVEL AND FOREIGN OBJECTS}

Found in the so-called Problematical Deposit 50 at Tikal (Culbert 1993:fig. 128), known as the "Arrival" vase, an engraved blackware tripod ceramic illustrates interaction between traveling Teotihuacanosand a Maya personage, most likely a ruler (figure 5.12). The horizontal image on this particular tripod depicts a group of Teotihuacan functionaries and warriors as they arrive at a central Mexican-style-inspired taludtablero platform with a Maya-style temple. Presumably, this structure is located in the Maya area because to the left of the central edifice, another pyramid structure clearly portrays the Maya style of monumental architecture. The main figures designated as warriors in this image display their central Mexican weapon, the atlatl or spear-thrower. Their headdresses, garb, and paraphernalia also suggest their central 
Mexican origin. Greeting these Teotihuacan functionaries is a figure who appears to have Maya characteristics such as his headdress and skirt.

An element often overlooked in this much-discussed image floats in front of the Teotihuacan officials: lidded-tripod ceramics viewed in profile that visually attach themselves to the space of the visiting delegates. Much like the atlat in the hands of the Teotihuacan vanguard, the tripod vessels, then, become a visual statement of Teotihuacan diplomacy, of travel from a foreign place, of possible economic trade or gift giving, and of an interregional interaction facilitated through these various groups representing Teotihuacan as they meet with an autochthonous Maya ruler. This simple iconographic depiction becomes a metaimage as it is inscribed onto the surface of a blackware tripod vessel, a secondary imagistic layering to the structural, physical body itself. Therefore, the ceramicist highlights the visual, cultural connotations of tripod vessels from Teotihuacan as imaged on a tripod vessel cached in the Maya kingdom of Tikal. Ceramics, and in this case specifically the tripod vessel, are material objects imbued with social agency in that they are physical extensions of not only the locus of production, but also the rulers, deities, rituals, geographic landscapes, and mythologies associated with the loci of manufacture. This particular tripod vessel's image visually captions the conceptual link between foreign objects (or as noted above, the appropriation of a foreign stylistic form such as the tripod) and travel, a bridge that will perhaps shed some light on how the Early Classic Maya elite conceptualized, visualized, and at times autochthonized the material culture that we categorize as indicative of interaction with Teotihuacan.

Why would the Maya elite and other ruling noble classes in ancient Mesoamerica look to foreign places, such as the mighty metropolis of Teotihuacan, as a necessary component for establishing their cultural, religious, and political identities, and their histories and power? Perhaps one answer is the idea of consecration. Foreign lands are often associated with the unknown, potentially dangerous supernatural realms that are manipulated by rulers, by the shaman-priests who position themselves as intermediaries (Helms 1979, 1988). Therefore, foreign territories and the material objects produced there are "naturally" consecrated, layered with visual significance and conceptual connections similar to those belonging to the power, divinity, and prestige of the supernatural realm.

A major element of foundational narratives from around the world, connection to the foreign, unknown spheres "disconnects" ruling factions from autochthonous populations, thereby lending a rarefied air to their sociopolitical, economic, and religious leadership (Stone 1989). Placement of absolute power in the hands of a small group must be justified by an association with the foreign, with realms, rituals, languages, and material objects or goods that are beyond the reach, knowledge, and experiences of the larger general population (Christensen 1996). As Andrea Stone 


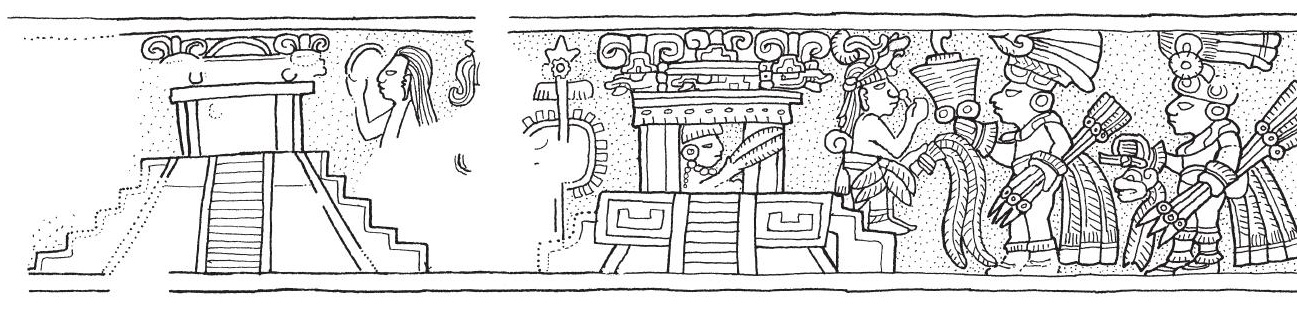

(1989) has observed, a delicate balance between "connection" to the local (through marriage, for example) and "disconnection" through ties with the foreign (through travel, symbols, knowledge, and associated objects) needs to be maintained by rulers. A distinct, constructed identity, often one tied to the foreign, is therefore an integral facet for obtaining and commanding power.

By traveling to foreign lands in order to receive their gods, the K'iche Maya establish their lineages through a connection to the foreign, naturally consecrated sphere of disconnection with the local. In the Popol Vuh, the founding dynasties-once they have received their gods at the foreign citadel of Tulan Zuyua - carry off the patron deities Tohil, Auilix, and Hacavitz and relocate them. Carried by Balam Acab, Auilix was the first to be inscribed into a local, known canyon "named Hidden Canyon, a great canyon in the forest" (Christenson 2003:223). Then Hacavitz was left on the "top of a great fire house," either a local mountain or temple. ${ }^{8}$ Tohil is then carried by Balam Quitze into the great forest: "Nearby was the god of the Tamub, along with the god of the Ilocab... The god of the Ilocab was there on a nearby mountain" (Christenson 2003:225). ${ }^{9}$ This narrative sequence of the Popol Vuh highlights an autochthonizing frame employed by the K'iche Maya when they came into contact with foreign objects. Indeed, the K'iche Maya narrative exemplifies how the lineage founders, therefore the rulers, conceptualized foreign objects that, though extralocal, could be inscribed into the local Maya landscape. Such objects, much like the Early Classic tripod ceramics excavated in the Maya region, were imbued with the dual identity of local and foreign, of the mundane realm and the supernatural one.

Similar to the concept of foreign realms as inherently sacred, the idea of natural consecration is evident in other symbols and objects. David Freedberg (1989:33-37) observes that objects such as black meteoric stones (known as baitulia) fallen from the sky were regarded by ancient Greek cults as imbued with divine presence. Images or objects that "naturally" have a resemblance to human figures, such as stones carved by water and time, have also been treated with reverence because of a perceived connection to the sacred (Freedberg 1989:33). There is a sense, then, that 


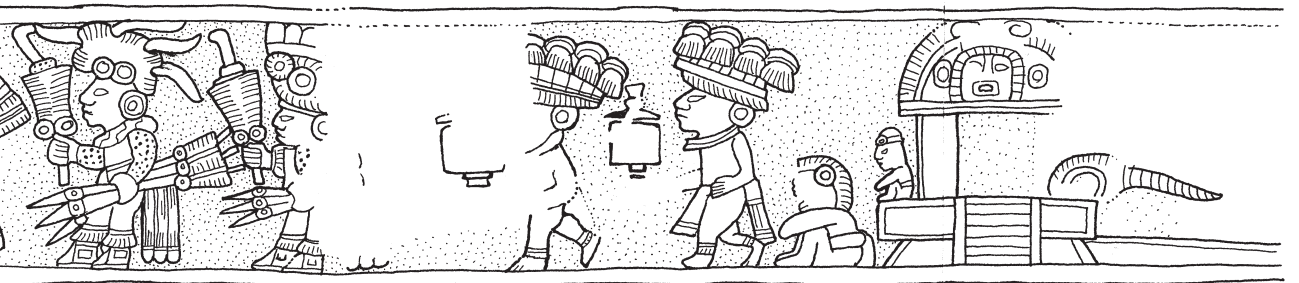

Figure 5.12. Scene incised on blackware tripod vessel located in Problematical Deposit 50 at Tikal. Notice the lidded tripods, in profile, floating in front of the last two standing figures to the right (drawing by Linda Schele, (c) David Schele, photo courtesy Ancient Americas at LACMA [ancientamericas.org]).

objects associated with foreignness are also imbued with a connection to the supernatural, the realm of inherent consecration that lends the presence and the owner of such objects a prestigious position. Objects that are layered with symbols and images of foreign creation represent a connection to divine creation, to an association with the numinous and powerful realm of the gods. But as the narrative from the Popol Vuh illustrates, the Maya engaged in an autochthonizing process for their very gods from a foreign Tulan (Stuart 2000) by physically integrating them into the local landscape, by "Mayanizing" their association with a recognized foreign realm. Many of the tripods I have visually analyzed above serve this same function, and the appropriated tripod form itself could have gone through a similar conceptual, physical, and visual autochthonizing process.

\section{CONCLUSIONS}

The tripod ceramic vessel is an object whose physical form could have originated in the Gulf Coast cultures of Veracruz, was then adopted by Teotihuacan, and was subsequently appropriated by the Early Classic Maya. Such a historical process would demonstrate that interregional interaction's material evidence in Mesoamerica surfaces in many ways, in this case through the specificity of a ceramic form. The Teotihuacan-Maya hybrid aesthetic integrated into the tripods discussed here highlights the representative nature of artistic appropriation and adaptation. Indeed, multiple tripod ceramic vessels excavated in the tombs of Maya rulers reinforce a fusion of the foreign with the actual local land through the physical act of being buried-much like the effigies of the K'iche patron deities in the Popol Vuh as they were inscribed or buried into the local geographic milieu. Moreover, I suggest that Maya ceramicists and artists understood that through an autochthonizing 
frame, the power and prestige of Teotihuacan's foreign symbols and forms could be employed to enhance the local ruler's identity. ${ }^{10}$ The tripod form's association with travel painted the local, known places and geographies with the extralocal and therefore supernatural colors of exotic experience, of recondite knowledge that specified and structured the encounters with the prestigious doctrines, rituals, and institutions associated with Teotihuacan. Teotihuacan could have been conceptualized as a foreign locale linked to the sacred, supernatural realms that rendered objects and their physical forms as a legitimizing material mechanism for local ritual and political governance.

In this chapter, I have argued that Maya ceramicists actively and intentionally appropriated and subsequently adapted the foreign tripod vessel form and localized it. The tripod form's obscure origin (possibly Veracruz) underscores the need to advance our current understanding of this particular ceramic form in the Maya area. We do know, however, that the Maya - among other multiple and varied cultures in Mesoamerica-subsequently employed the tripod form by incorporating it into their ceramic canons. Several tripods examined in this chapter highlight an ascendant ceramic form connected to Early Classic interregional interaction between Teotihuacan and disparate Maya cities. Maya ceramicists imbued the etic tripod form with emic iconography as well as innovated the tripod form itself.

The scene depicted on the engraved blackware tripod vessel from Problematical Deposit 50 of Tikal (figure 5.12) is, in a sense, emblematic of our current understanding of the Teotihuacan-Maya hybrid aesthetic. Perhaps this ceramic vessel, because of its representative scene portraying cultural and political interaction between the Maya and Teotihuacan, is intentionally self-reflective of its origin ${ }^{11}$ but also unknowingly self-reflexive, given our limitations in historical specificity: it is an ambiguous scene open for interpretation, depicted on a tripod vessel, badly burned, and located in a problematical deposit at Tikal. However, the apparently simple and singular cultural exchange as imaged on this tripod, forcefully and explicitly tether the visual scene and the ceramic onto which it was incised to interregional interaction through the human activity of travel. Could the tripod form be the calling card, as it were, of interregional diplomacy? Moreover, while the three supports serve a practical function by lifting the bottom of the vessel off the ground and by maintaining the equilibrium of the vessel when placed on the ground, one might ask what symbolic significance the three supports may have held for the Maya or for the residents of Teotihuacan $?^{12}$ As the blackware tripod was not located in an elite burial, this much-discussed ceramic scene reveals multiple potentialities for expanding our knowledge of not only the tripod vessel's physical form, but of the conceptual, visualized, and experiential intersection between interregional interaction and travel, between foreign domains and localizing aesthetic frameworks. 


\section{NOTES}

I. I understand that this could be the publisher's or editor's choice to use a single tripod for the front cover, as there are multiple possibilities of visual culture from which to choose. The point is that this specific tripod vessel is used to visually represent the complexity of Early Classic interaction between Teotihuacan and the Maya-and rightly so. The "Dazzler Vase" contains imagery of the talud-tablero architecture generally associated with Teotihuacan (or central Mexico) and an image of the "foreign" ruler and founder of the Copan dynasty Yax K'uk' Mo' with the goggle-eyes of Tlaloc, a central Mexican deity. It is possible that Yax K'uk' Mo' and some other Early Classic Maya rulers traveled to Teotihuacan in order to be invested in office for their Maya kingdoms (see Fash et al. 2009).

2. For a discussion of how artistic objects are imbued with social agency, see Alfred Gell (1998). Gell's discussion focuses on how artistic objects and images symbolically and conceptually function, emphasizing what they "do" rather than concentrating on what they aesthetically "are."

3. Juan Laporte (2003) argues that using the term "multilateral interaction" is more appropriate when discussing the appearance and use of Teotihuacan elements at Tikal. For instance, the talud-tablero architectural style develops at Tikal during the second half of the third century AD, two centuries before the Tikal elite adopt iconography and the common talud-tablero form in the Mundo Perdido complex. According to Laporte, of all the edifices at Tikal with the talud-tablero form, there is only one example that contains every stylistic element associated with the talud-tablero architectural form at Teotihuacan. Therefore, this particular characteristic employed as an identifying feature of interaction with Teotihuacan is, like much of the Teotihuacan-Maya debate, controversial.

4. I point out that only some of the tripod ceramics excavated at Maya sites had lids because this may have something to do with their ritual function as it signals a concern with the possible contents inside of the ceramics. Without additional chemical analyses of the interior of the specific tripods I discuss in this chapter, it is difficult to know what they contained. However, certain ceramic vessels have glyphs that phonetically spell "cacao," or chocolate. One was found at Río Azul, Guatemala, and then chemically tested, which demonstrated that chocolate was indeed put inside the vessel (See Hall et al. 1990). With more testing and epigraphic analysis, we could ascertain the contents of the tripod ceramics analyzed in this chapter.

5. The interaction was not unidirectional either. Many scholars (e.g., Braswell 2003b, c; Demarest and Foias 1993; Nielsen 2003) have noted that material evidence such as mural fragments and ceramic shards from Teotihuacan exhibit clear Maya characteristics, meaning that there were Maya living at Teotihuacan.

6. One could even say these tripods were "curated" by the dead ruler's funerary handlers, who intentionally surrounded the buried ruler with indices of foreign regions. According to 
Mary Helms (1988), many indigenous peoples around the world, including in Mesoamerica, associate foreign realms with supernatural forces and power. Objects such as the tripods would imbue the funerary chamber of kings, queens, and other nobles with the powerful, foreign presence of the supernatural, the realm to which these rulers were believed to have traveled.

7. According to Patrick Culbert (1993), these eight tripods with lids are "almost certainly a local Tikal type," meaning that they were sourced and produced locally. This observation, coupled with Maya hieroglyphic writing and iconography, means that Tikal ceramicists appropriated only the foreign tripod form itself but then materially and visually autochthonized the vessels through their production and the addition of Maya writing, and imagery.

8. Christenson notes that this phrase, hun nima cae ha 'a great fire/red house', is likely not a proper name and Dennis Tedlock proposes that this was an ancient pyramid-temple of the K'iche. While agreeing that it is a possibility because the Maya painted their pyramidtemples red, Christenson suggests that this could reference an actual mountain, or in this case, a volcano. Either way, the point here is that the K'iche take what is foreign and inscribe it into their local landscape.

9. The Tamub and the Ilocab are two of the K'iche lineages.

Io. And it was most likely not simply a case of a local ruler adopting foreign symbols and forms. Many Early Classic Maya rulers may have traveled to Teotihuacan to receive investiture of rulership through rituals performed at the Pyramid of the Sun, the architectural and ritual locus for such pilgrimages (see Fash et al. 2009).

II. Culbert (1993) states "this vessel was surely imported" because of its "large diameter and relatively short sides," qualities that fall outside of the physical dimensions for tripod ceramics produced by Early Classic Maya ceramicists, implying that it was produced at Teotihuacan or at least central Mexico.

I2. Annabeth Headrick (2007) has written about three sociopolitical groups who ruled at Teotihuacan, which could be visually represented by the three physical supports of the tripod (as well as the three main pyramidal structures there: the pyramid of the sun, the pyramid of the moon, and the Feathered Serpent pyramid). For the Maya, the Popol Vuh could again provide a conceptual link as there were three patron deities of the founding K'iche lineages (originally there are four, but when the K'iche return from their journey to Tulan Zuyua, there are only three). At the site of Palenque, the Temple of the Cross group consists of three temple-pyramids or symbolic witz (mountain), tying the number three to physical buildings associated with particular patron deities. There are many more connections to the number three, too many to enumerate here.

\section{REFERENCES}

Adams, Richard E. W. 1990. "Archaeological Research at the Lowland Maya City of Rio Azul." Latin American Antiquity I(I):23-4I. 
Ball, Joseph W. 1974. "A Teotihuacan Cache from the Maya Lowlands." Archaeology 27(I):2-9.

Ball, Joseph W. 1983. "Teotihuacan, the Maya, and Ceramic Interchange: A Contextual Perspective." In Highland-Lowland Interaction in Mesoamerica: Interdisciplinary Approaches, edited by Arthur G. Miller, I25-145. Dumbarton Oaks, Washington, DC.

Bell, Ellen E., Marcello A. Canuto, and Robert J. Sharer, eds. 2004. Understanding Early Classic Copan. University of Pennsylvania Museum of Archaeology and Anthropology, Philadelphia.

Bennyhoff, James A. 1967. "Chronology and Periodization: Continuity and Change in the Teotihuacan Ceramic Tradition.” In Teotihuacan: XI Mesa Redonda, edited by Alberto Ruz Lhuiller, 19-29. Sociedad Mexicana de Antropología, Mexico City.

Berlo, Janet C. 1980. Teotihuacan Art Abroad: A Study of the Metropolitan Style and Provincial Transformation in Incensario Workshops. BAR International Series 199. Archaeopress, Oxford.

Berlo, Janet C. 1989. "Art Historical Approaches to the Study of Teotihuacan-Related Ceramics from Escuintla, Guatemala." In New Frontiers in the Archaeology of the Pacific Coast of Southern Mesoamerica, edited by Frederick J. Bove and Lynette Heller, 147-165. Arizona State University, Tempe.

Borhegyi, Stephen F. 195I. "Further Notes on Three-pronged Incense Burners and Rimhead Vessels in Guatemala." Notes on Middle American Archaeology and Ethnohistory $4($ IOI $): 162-176$.

Bove, Frederick J. 1990. “The Teotihuacan-Kaminaljuyu-Tikal Connection: A View from the South Coast of Guatemala." In The Sixth Palenque Round Table 1986, edited by Merle G. Robertson and Virginia M. Fields, I35-142. University of Oklahoma Press, Norman.

Bove, Frederick J., and Sonia Medrano Busto. 2003. “Teotihuacan, Militarism, and Pacific Guatemala." In The Maya and Teotihuacan: Reinterpreting Early Classic Interaction, edited by Geoffrey E. Braswell, 45-80. University of Texas Press, Austin.

Braswell, Geoffrey E., ed. 2003a. The Maya and Teotihuacan: Reinterpreting Early Classic Interaction. University of Texas Press, Austin.

Braswell, Geoffrey E. 2003b. "Dating Early Classic Interaction between Kaminaljuyu and Central Mexico." In The Maya and Teotihuacan: Reinterpreting Early Classic Interaction, edited by Geoffrey E. Braswell, 8I-IO4. University of Texas Press, Austin.

Braswell, Geoffrey E. 2003c. "Understanding Early Classic Interaction between Kaminaljuyu and Central Mexico." In The Maya and Teotihuacan: Reinterpreting Early Classic Interaction, edited by Geoffrey E. Braswell, I05-142. University of Texas Press, Austin.

Cash, Cristen L. 2005. Locating the Place and Meaning of the Talud-Tablero Architectural Style in the Early Classic Maya Built Environment. Unpublished PhD dissertation. University of Texas, Austin. 
Cheek, Charles D. 1977. “Teotihuacan Influence at Kaminaljuyu.” In Teotibuacan and Kaminaljuyu, edited by William T. Sanders and Joseph W. Michels, 44I-452. Pennsylvania State University Press, State College.

Christensen, Alexander F. 1996. "History, Myth, and Migration in Mesoamerica." Paper presented at the annual meetings of American Society for Ethnohistory. Portland, Oregon. Electronic document, http://web.ku.edu/ hoopes/aztlan/History.htm, accessed September Io, 2015.

Christenson, Allen J. 2003. Popol Vuh: The Sacred Book of the Maya. University of Oklahoma Press, Norman.

Clayton, Sarah C. 2005. "Interregional Relationships in Mesoamerica: Interpreting Maya Ceramics at Teotihuacan." Latin American Antiquity 16(4):427-448.

Coggins, Clemency C. 1983. "An Instrument of Expansion: Monte Alban, Teotihuacan, and Tikal." In Highland-Lowland Interaction in Mesoameria: Interdisciplinary Approaches, edited by Arthur G. Miller, 49-68. Dumbarton Oaks, Washington, DC.

Conides, Cynthia Alexandria. 2001. The Stuccoed and Painted Ceramics from Teotihuacan, Mexico: A Study of Authorship and Function of Works of Art from an Ancient Mesoamerican City. Unpublished PhD dissertation. Columbia University, New York.

Cowgill, George L. 1997. "State and Society at Teotihuacan, Mexico." Annual Review of Anthropology 26:129-16I.

Cowgill, George L. 2003. “Teotihuacan and Early Classic Interaction: A Perspective from Outside the Maya Region." In The Maya and Teotihuacan: Reinterpreting Early Classic Interaction, edited by Geoffrey E. Braswell, 337-356. University of Texas Press, Austin.

Culbert, Patrick T. 1993. Tikal Report No. 25, Part A: The Ceramics of Tikal: Vessels from the Burials, Caches, and Problematical Deposits. University of Pennsylvania Museum of Archaeology and Anthropology, Philadelphia.

Demarest, Arthur A., and Antonia E. Foias. 1993. "Mesoamerican Horizons and the Cultural Transformations of Maya Civilization.” In Latin American Horizons, edited by Don S. Rice, I47-191. Dumbarton Oaks, Washington, DC.

Englehardt, Joshua D. 20I2. "Structuration of the Conjuncture: Agency in Classic Maya Iconography and Texts." In Early Writing and Agency in Archaeology, edited by Joshua D. Englehardt, 194-218. University Press of Colorado, Boulder.

Fash, William L., Alexandre Tokovinine, and Barbara Fash. 2009. "The House of New Fire at Teotihuacan and its Legacy in Mesoamerica." In The Art of Urbanism: How Mesoamericn Kingdoms Represented Themselves in Architecture and Imagery, edited by William L. Fash and Leonardo López Luján, 20I-229. Dumbarton Oaks, Washington, DC.

Fields, Virginia M., and Dorie Reents-Budet. 2005. Lords of Creation: the Origins of Sacred Maya Kingship. Scala Publishers Limited, London. 
Freedberg, David. 1989. The Power of Images: Studies in the History and Theory of Response. University of Chicago Press, Chicago.

Gell, Alfred. 1998. Art and Agency: An Anthropological Theory. Oxford University Press, Oxford.

Hall, Grant D., Stanley M. Tarka Jr., W. Jeffrey Hurst, David Stuart, and Richard E. W. Adams. 1990. "Cacao Residues in Ancient Maya Vessels from Río Azul, Guatemala." American Antiquity 55(I):138-143.

Headrick, Annabeth. 2007. The Teotihuacan Trinity: The Sociopolitical Structure of an Ancient Mesoamerican City. University of Texas Press, Austin.

Hellmuth, Nicholas. 1978. “Teotihuacan Art in the Escuintla, Guatemala, Region.” In Middle America: AD 400-700, edited by Esther Pasztory, 71-85. Columbia University Press, New York.

Helms, Mary W. 1979. Ancient Panama: Chiefs in Search of Power. University of Texas Press, Austin.

Helms, Mary W. 1988. Ulysses' Sail: An Ethnographic Odyssey of Power, Knowledge, and Geographical Distance. Princeton University Press, Princeton.

Iglesias Ponce de León, María Josefa. 2003. "Problematical Deposits and the Problem of Interaction: The Material Culture of Tikal during the Early Classic Period." In The Maya and Teotihuacan: Reinterpreting Early Classic Interaction, edited by Geoffrey E. Braswell, 167-198. University of Texas Press, Austin.

Kidder, Alfred V., Jesse D. Jennings, and Edwin M. Shook. 1946. Excavations at Kaminaljuyu, Guatemala. Washington, DC: Carnegie Institution of Washington Publication 56r. Carnegie Institution of Washington.

Laporte, Juan Pedro. 2003. "Architectural Aspects of Interaction between Tikal and Teotihuacan during the Early Classic Period.” In The Maya and Teotihuacan: Reinterpreting Early Classic Interaction, edited by Geoffrey E. Braswell, 199-216. University of Texas Press, Austin.

Laporte, Juan Pedro, and Vilma Fialko. 1987. "La cerámica del Clásico Temprano desde Mundo Perdido, Tikal: Una reevaluación.” In Maya Ceramics: Papers from the 1985 Maya Ceramic Conference, Vol. I, edited by Prudence M. Rice and Robert J. Sharer, I23-I8I. BAR International Series 345(i). Archaeopress, Oxford.

Marcus, Joyce. 2003. “The Maya and Teotihuacan.” In The Maya and Teotihuacan: Reinterpreting Early Classic Interaction, edited by Geoffrey E. Braswell, 337-356. University of Texas Press, Austin.

Nielsen, Jesper. 2003. Art of the Empire: Teotihuacan Iconography and Style in Early Classic Maya Society, AD 380-500. Unpublished PhD dissertation. University of Copenhagen, Copenhagen.

Pasztory, Esther. 1997. Teotihuacan: An Experiment in Living. University of Oklahoma Press, Norman. 
Pendergast, David M. 1975. "Evidence of Early Teotihuacan-Lowland Maya Contact at Altun Ha." American Antiquity 36(4):455-460.

Pendergast, David M. 2003. “Teotihuacan at Altun Ha: Did It Make a Difference?” In The Maya and Teotihuacan: Reinterpreting Early Classic Interaction, edited by Geoffrey E. Braswell, 235-247. University of Texas Press, Austin.

Rattray, Evelyn C. 1977. “Los contactos entre Teotihuacan y Veracruz." In $X V$ Mesa Redonda, Sociedad Mexicana de Antropología, Vol. 2, 30I-3II. Universidad de Guanajuato, Guanajuato.

Rattray, Evelyn C. 200I. Teotihuacan: Ceramics, Chronology, and Cultural Trends. Instituto Nacional de Antropología e Historia and the University of Pittsburgh, Mexico City and Pittsburgh.

Reents-Budet, Dorie. 1998. “Elite Maya Pottery and Artisans as Social Indicators.” In Craft and Social Identity: Archaeological Papers of the American Anthropological Association 8(I), edited by Cathy Lynne Costin and Rita P. Wright, 7I-89. American Anthropological Association, Washington, DC.

Reents-Budet, Dorie, Ellen E. Bell, Loa P. Traxler, and Ronald. L. Bishop. 2004. "Early Classic Ceramic Offerings at Copan: a Comparison of the Hunal, Margarita, and SubJaguar Tombs." In Understanding Early Classic Copan, edited by Ellen E. Bell, Marcello A. Canuto, and Robert J. Sharer, 159-190. University of Pennsylvania Museum of Archaeology and Anthropology, Philadelphia.

Sanders, William T. 1977. "Ethnographic Analogy and the Teotihuacan Horizon Style." In Teotihuacan and Kaminaljuyu, edited by William T. Sanders and Joseph W. Michels, 397-4IO. Pennsylvania State University Press, State College.

Schele, Linda, and David A. Freidel. 1990. A Forest of Kings: Untold Stories of the Ancient Maya. William Morrow, New York.

Shaw, Justine, and Dave Johnstone. 2006. "Classic Politics in the Northern Maya Lowlands." In Lifeways in the Northern Maya Lowlands: New Approaches to Archaeology in the Yucatán Peninsula, edited by Jennifer P. Mastthews and Bethany Morrison, 142-154. University of Arizona Press, Tucson.

Stone, Andrea. 1989. "Disconnection, Foreign Insignia, and Political Expression:

Teotihuacan and the Warrior Stelae of Piedras Negras." In Mesoamerica after the Decline of Teotihuacan, AD 700-9oo, edited by Richard A. Diehl and Janet C. Berlo, I53-172. Dumbarton Oaks, Washington, DC.

Stuart, David. 1998. “'The Fire Enters His House’: Architecture and Ritual in Classic Maya Texts." In Function and Meaning in Classic Maya Architecture, edited by Stephen D. Houston, 373-425. Dumbarton Oaks, Washington, DC.

Stuart, David. 2000. “'The Arrival of Strangers': Teotihuacan and Tollan in Classic Maya History." In Mesoamerica's Classic Heritage: From Teotihuacan to the Aztecs, edited 
by Davíd Carrasco, Lindsay Jones, and Scott Sessions, 465-513. University Press of Colorado, Boulder.

Taube, Karl A. 2003. “Tetitla and the Maya Presence at Teotihuacan.” In The Maya and Teotihuacan: Reinterpreting Early Classic Interaction, edited by Geoffrey E. Braswell, 273-3I4. University of Texas Press, Austin.

Varela Torrecilla, Carmen, and Geoffrey E. Braswell. 2003. "Teotihuacan and Oxkintok: New Perspectives from Yucatán." In The Maya and Teotibuacan: Reinterpreting Early Classic Interaction, edited by Geoffrey E. Braswell, 249-272. University of Texas Press, Austin. 


\section{Chapter 6}

\section{Across the Hills, toward the Ocean}

Teotibuacan-Style Monuments in Guerrero, Mexico

Jesper Nielsen, Elizabeth Jiménez García, And Iván Rivera

Cultural interaction between the central Mexican metropolis of Teotihuacan and the Maya region in the Early Classic has been the subject of intense debate in the past fifteen years (Braswell 2003a; Nielsen 2003; Stuart 2000), but Teotihuacan's possible presence, artistic influence, and economic and/or strategic interests in the region of Mesoamerica that today corresponds to the state of Guerrero has received scant scholarly attention. In the present chapter, we wish to provide an overview of archaeological finds in the region that may provide us with the evidence needed to address this lacuna. We focus on a series of carved stone monuments that display iconographic elements that belong to the same type of imperial iconography encountered on Teotihuacan-style monuments not only in the Maya area, but also in Veracruz, Oaxaca, and at the key site of El Rosario in Querétaro. Among the sites to be discussed are Acatempan, Cerro de los Monos, and Tepecoacuilco (figure 6.I). The majority of the monuments are executed in a style that is predominated by local traditions (see Paddock 1972:228), and although we believe that direct Teotihuacan takeovers of one or several sites in the region could in fact have occurred, based on current evidence, the main center(s) of Teotihuacan presence in Guerrero remains to be identified.

Thanks to contributions of scholars such as Rosa María Reyna Robles, Clara Luz Díaz Oyarzábal, Elizabeth Jiménez García, Paul Schmidt Schoenberg, and Karl Taube (Jiménez García et al. 1998; Reyna Robles 1990; 2002, 2013; Reyna Robles and Rodríguez Betancourt 1994; Schmidt Schoenberg 2006; Taube 2000a, 


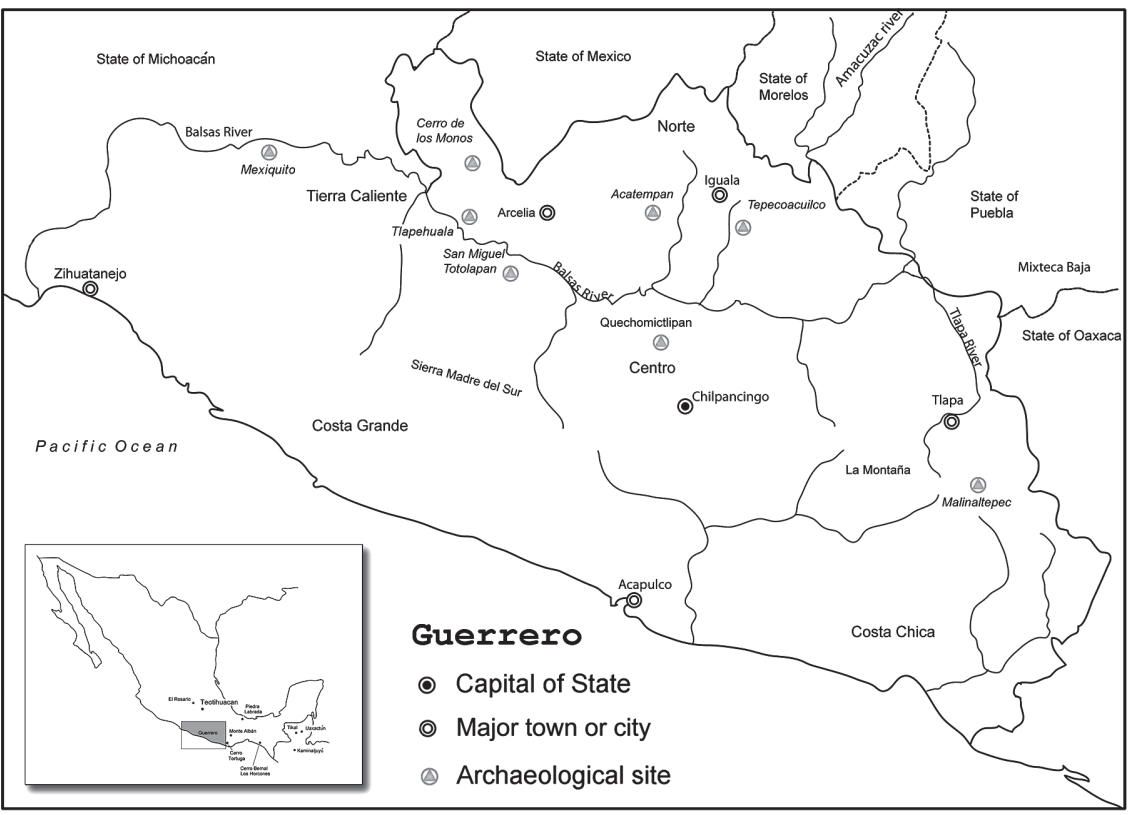

FIGURE 6.I. Maps showing (a) the state of Guerrero in the wider geographical context of Mesoamerica (top), and (b) the major rivers and modern towns and cities as well as archaeological sites mentioned in the text (maps by A. Iván Rivera G.).

2011:93-98), whose works we will draw upon here, we now have a sufficient database of carved monuments to approach the issue of Teotihuacan presence in Guerrero. Several of the same investigators have also commented on the relationship between Teotihuacan and Guerrero, and, apart from stone monuments, other categories of artifacts also point to an interaction between the two areas (Jiménez García et al. 1998:69).

According to Schmidt Schoenberg (2006), few indications of Teotihuacan influence have been encountered in the central part of the state, whereas carved stelae from sites such as Tepecoacuilco and Acatempan in the north and San Miguel Totolapan in the southern Tierra Caliente suggest some influence. We will reanalyze the iconography of these stelae in detail below. Teotihuacan-style ceramics, including Fine Thin Orange ware and cylindrical tripods, have been reported from different parts of the state, including the coastal region. ${ }^{1}$ In his 1972 discussion of Teotihuacan cultural traits in different areas of Mesoamerica, John Paddock noted a strong Teotihuacan influence in local material forms and expressions in Guerrero, and at the same time Jeffrey Parsons (1971:238) suggested that northeastern Guerrero had 
been controlled by Teotihuacan in much the same way as the Valley of Mexico had been. As we shall see, careful iconographic analyses of the carved stone monuments do not run counter to such interpretations, though the evidence for warfare-based incursions is not at all as clear as what we know from the Maya region. Thus, the strategies employed by a possible expansionist Teotihuacan empire in Guerrero may have been different from those used elsewhere; the region may have witnessed less intensive Teotihuacan involvement, or perhaps we are yet to locate the sites with most direct Teotihuacan presence, which may in turn be explained by the limited archaeological excavations and reconnaissance in large parts of the state and by the heavy looting of archaeological sites (Reyna Robles 2013). ${ }^{2}$

The tremendous importance of Teotihuacan culture in the central Mexican highlands during the Late Preclassic and Early Classic periods has long been recognized by scholars. Nonetheless, archaeologists, epigraphers, and art historians have only recently begun to map and understand the extent of the influence of this powerful state across Mesoamerica in the fourth and fifth centuries AD (see, e.g., Berlo 1984; Nielsen 2003; Santley 1989; Stuart 2000). Thus, numerous parts of Mesoamerica that may potentially reveal economic, political and cultural interactions, and exchanges with the ancient metropolis have not yet been adequately investigated (Cowgill 2003:324). Here we present iconographic analyses of imagery that strongly suggest Teotihuacan presence. We will refer to comparable iconographic and epigraphic evidence found elsewhere in Mesoamerica, where it has been suggested that the Teotihuacan empire had succeeded in taking power-presumably with the aim of controlling the flow of local resources and/or extracting tribute (e.g., Nielsen 2003, in press; Nielsen and Helmke 2015). In doing so, we exemplify what can be called an imperial iconography centered on the display of a relatively small, but well-defined group of Teotihuacan objects and elements of dress related to warfare. These include spear-throwers; darts; square shields; the so-called shell-platelet headdress; and a headdress with human hearts, back mirrors, and torches. Scholars have debated the interpretation of such images along with other possible material indicators of Teotihuacan culture, including talud-tablero architecture, green Pachuca obsidian, and stuccoed and painted tripods (see D. Bryan Schaeffer, chapter 5 in this volume). Are they evidence of Teotihuacan military-based takeovers or conquests? Or should they rather be seen as the result of local non-Teotihuacano elites who, for internal political reasons, emulated these foreign symbols as a means of strengthening their own power? (see Braswell 2003b; Cowgill 2003; Stone 1989; Stuart 2000; see also Nielsen 2003:I-8 for an overview of previous studies of Teotihuacan-Maya interaction). Studies of interaction in Mesoamerica, such as those collected in this volume, emphasize the complexity and multidirectionality of contacts between different regions. While the varied types of interaction between Teotihuacan and 
other parts of Mesoamerica, including Guerrero, must be stressed, the iconography, along with the epigraphic records from the Maya area, do suggest a military expansion and incursions into several regions. Together they indicate that for a relatively brief span of time, Teotihuacan controlled what may have been one of the greatest empires in the history of Mesoamerica. Presumably, based on what we know about Aztec imperial expansion, the choice of Teotihuacan's political leadership to invest itself in different regions of Mesoamerica was primarily a question of access to resources that were needed in the capital and its immediate hinterland (Cowgill 2003:316, 2015:50-52, 195-203; Nielsen 2003).

\section{TEOTIHUACAN AND ITS ROLE IN EARLY CLASSIC MESOAMERICA: A BRIEF OVERVIEW}

Archaeologists first discovered an unprecedented amount of Teotihuacan taludtablero architecture and artifacts outside of central Mexico during the excavations undertaken by the Carnegie Institution at the Late Preclassic and Early Classic Maya highland site of Kaminaljuyú in Guatemala (Kidder et al. 1946:218-240, 250-256). Since then, the findings in the burials of Mounds A and B southeast of the Acropolis have generated a continued debate over the links between Kaminaljuyú and Teotihuacan (Braswell 2003c; Cheek 1977; Nielsen 2003:16I-I88). Among the spectacular finds from the burials were stuccoed and painted tripods and vases with Teotihuacan-style motifs, Fine Thin Orange ceramics, and back mirrors with Teotihuacan iconography, as well as so-called Storm god jars. A few decades later, the excavations of the Tikal Project (1956-1970) at the Northern Acropolis provided further evidence of Teotihuacan influence. A series of inscribed monuments from the central Petén (e.g., Tikal Stela 31, the Tikal Ballcourt Marker, Uaxactún Stela 5, and mural paintings from La Sufricaya) have since enabled epigraphers to recount some of the central events, including the arrival of Teotihuacanos in the area in $\mathrm{AD} 378$, and the subsequent installment at Tikal of a Teotihuacan-affiliated ruler, Yax Nuun Ayiin, son of "Spearthrower Owl" (Jatz'o'm Kuy), who is believed to have ruled in Teotihuacan from AD 374 to AD 439 (Martin and Grube 2008:29-35; Stuart 2000:467-490; see also Estrada-Belli et al. 2009). In this case a possible Teotihuacan takeover is documented in historical texts and is implied via the spread of imperial iconography (Stuart 2017). In the r990s new evidence of strong links to Teotihuacan were discovered in a series of tombs in the Acropolis of Copán (see Bell et al. 2004; Sharer et al. 2005). Thus, several researchers now agree that Teotihuacan succeeded in conquering and controlling several important Maya cities in the late fourth century $\mathrm{AD}$. This incursion into the Maya region is commonly referred to as the Teotihuacan entrada. 
It has also been suggested that Teotihuacan had economic and political interests in Veracruz at sites such as Matacapan, Piedra Labrada, and Sayultepec (Nielsen 2003:78-79; Santley 1989; Yarborough 1992; see also Philip J. Arnold III and Lourdes Budar, chapter 7 in this volume). Based on archaeological surveys in the Río Amatzinac Valley in eastern Morelos, Hirth (1978) argued that Teotihuacan presence caused changes in settlement patterns and that the resource Teotihuacan specifically sought to control here was cotton. At Cinteopa in Morelos, Teotihuacanstyle almenas (stepped architectural elements decorating roofs) with goggle-eyed warrior-priests holding obsidian knives with bleeding hearts impaled on them testify further to Teotihuacan presence in the region (Cook de Leonard 1985; Nielsen and Helmke 20I4:I2I-I22). Looking toward north-central and western Mexico, researchers have noted Teotihuacan influence at a number of sites in the states of Hidalgo, Querétaro, Guanajuato, and Michoacán (e.g., Brambila Paz and Crespo 2002; Braniff 2000; Castañeda López 2008; Díaz Oyarzábal 1980; Ekholm 1945; Faugère 2007; Filini 2004; Nielsen in press). In Michoacán, Teotihuacan-style objects and murals have been found at several sites in the Cuitzeo Basin, at sites such as Huandacareo, Tres Cerritos, and Queréndaro (e.g., Filini 2004; Filini and Cárdenas García 2007; Hers 2013; Nielsen in press). Frequently, local stylistic features and chronological indicators suggest indirect influence or Epiclassic emulations of Teotihuacan architecture and iconography, as can be seen at sites such as Plazuelas and Peralta in Guanajuato and Tingambato in Michoacán. This, however, is not the case with the recently discovered murals at the archaeological site of El Rosario in the state of Querétaro, some $140 \mathrm{~km}$ northwest of Teotihuacan-a discovery that has completely changed our view of Teotihuacan imperial interests in the Bajío region. The murals constitute the first example of Teotihuacan-style murals and elaborate iconography discovered that far north of Teotihuacan (SaintCharles Zetina et al. 2010:26-34, 65-112). Parading goggle-eyed Teotihuacano warriors depicted in the murals carry shields; darts and flaming torches and their speech scrolls, affixed with darts and bleeding hearts, can be interpreted as references to war songs (Nielsen 2014). This strongly suggests a Teotihuacan military takeover in order to control the resources that could be gained from the San Juan del Río Valley and its surroundings (Nielsen and Helmke 2015).

Previous interpretations of the relationship between Teotihuacan and the Zapotec capital of Monte Albán as one based on diplomacy and trade have been challenged in recent years, and there is new evidence to suggest a significant Teotihuacan presence and perhaps even militarism at Monte Alban (Taube 20Ir:9I-93, figs. 5.IIc-e; Winter 1998; Winter et al. 1999). Clear traces of Teotihuacan influence are found further southward along the Pacific coast in Oaxaca (Joyce 2003; Rivera Guzmán 20II); in Chiapas at Cerro Bernal, Los Horcones, and Fracción Mujular (García 
des-Lauriers 2007; Navarrete 1986; Taube 2000a:40-44, fig. 33); and all the way into southern Guatemala, where Teotihuacan-style artifacts such as richly decorated tripods, so-called candeleros (small, twin-chambered incense burners), and theatrical incense burners have been found at Escuintla, Tiquisate, Lake Amatitlán, and Montana (Berlo 1984; Bove and Medrano Busto 2003; Hellmuth 1975; Nielsen 2003:189-199).

Comparing the spread and consistency of the imperial iconography of Teotihuacan with that of the Late Postclassic Mexica, we note a striking difference, since the latter is in fact quite rare, with the notable exception of Castillo de Teayo in Veracruz (Umberger 1996). The extent of the Mexica-headed empire of the Triple Alliance is documented mainly by written sixteenth-century sources and not by archaeological or iconographic evidence left by imperial representatives in the tribute-paying provinces (Smith and Montiel 200I; Umberger 1996). Currently, we seem to have better archaeological and iconographic evidence for the existence of a Teotihuacan empire than for the Triple Alliance empire (Nielsen 2003:6I-86). Based solely upon the iconographic and epigraphic records there is sufficient evidence to suggest the existence of a short-lived but widespread, hegemonic Teotihuacan empire. Thus, we are now able to identify a number of specific sites and areas that seem to have been under Teotihuacan control or imperial influence.

\section{DARTS AND SHIELDS: THE REPERTOIRE OF \\ TEOTIHUACAN IMPERIAL ICONOGRAPHY}

Before we turn to the relevant monuments from Guerrero, we will briefly discuss the Teotihuacan-related iconographic motifs that are most frequently encountered in the Maya area and elsewhere in Mesoamerica in the fourth and fifth centuries. It is important to emphasize the fact that there is a marked consistency in the selection of motifs depicted, which seem to be centered around martial and sacrificial themes, and thus warriors or warrior-priests with weaponry, burning torches, and Stormgod attributes constitute the dominant repertoire of images that as a whole we refer to here as Teotihuacan imperial iconography (Nielsen 2003:87-97, in press).

The majority of human figures represented are almost certainly warriors or otherwise related to armed conflict and sacrifice, as they appear equipped with standard Teotihuacan warrior outfit, including spear-thrower, darts, feather-rimmed square shields, and high-backed sandals. Headdresses include the shell-platelet headdress with War Serpent features (see Taube 1992) and in addition warriors often wear goggles, undoubtedly as a reference to the Teotihuacan Storm god whose role in warfare and as a symbol of Teotihuacan political authority has long been recognized (Anderson and Helmke 2012:186-187; Headrick 2007; Paulinyi 2001). Another 
recurring motif is the torch, most often held by warriors. Jesper Nielsen (2003:88-93, 2006) has suggested that these motifs are related to the concept of toma de posesion 'taking possession' and serve as references to the act of founding a new dynasty or settlement, as well as to the appropriation of new territory. Apart from this set of recurring war-related motifs, some geographical areas emphasized other aspects of Teotihuacan culture and ideology. The Escuintla region of Guatemala displays a high concentration of objects and images related to ideas about the afterlife, including butterflies and a floral world (Berlo 1984; Taube 200ob). In Guerrero there are some surprising examples of so-called ballcourt markers with Teotihuacan iconography and elements of Teotihuacan writing that are rarely seen elsewhere and provide important evidence of variation in the motifs represented. However, as we shall see, the ballcourt markers also appear to be associated with warfare and sacrifice, though in a less direct and obvious way.

While some of the monuments that we discuss below are close to being identical to representations from Teotihuacan itself, most of the examples in our corpus are not as clear evidence of direct Teotihuacan presence as several of the famous images from the central Petén or the murals from El Rosario. This leads to the obvious questions: by and for whom were these different sculptures produced? And what were their intended purposes? In a discussion of art styles in the Epiclassic period Debra Nagao (1989:100) noted: "The adoption of foreign stylistic or iconographic traits potentially served multiple functions and ends. It was a means of emulating or imitating one's cultural betters in order to become more closely identified with a superior authority. It was also a way of expressing far-flung ties-a visual form of namedropping. At the same time, the adoption of a nonlocal style could be interpreted as a symbol of supremacy and conquest." In the case of Teotihuacan-style iconography in Guerrero, all three functions were probably at play at specific times and at specific locations, but it is the examples of the latter category that will have our special attention here. Adoption may not, however, be the most precise term to use since the change in expression and in style, as well as in content, may well have been demanded and overseen by Teotihuacan representatives. ${ }^{3}$ In such cases we should perhaps rather be referring to forced adoptions. It is also in such historical contexts that we must expect the greatest degree of similarity between the iconography of the imperial capital and the province, since the iconography was designed and manufactured in a setting controlled by the imperial system. This, however, does not mean that there is no difference between the metropolitan style of the imperial capital and its provincial counterpart. In most cases differences are evident. As noted by Emily Umberger (1996:177-178) in her brilliant analysis of Aztec imperial art: "Provincial centers are inhabited principally by elites, administrators, and others from the center and have center-trained artists producing works close 
in style but with possible modifications in types, materials, and imagery according to local variables. Peripheral centers are inhabited by local peoples, and the locally produced works, which reveal awareness of the style of the center, are a step further removed from its artistic canons." In the case of Early Classic Guerrero, we suggest that the former is applicable only to a few sites known at present. In contrast, the latter would correspond to a number of sites where the use of Teotihuacan-derived motifs and iconographic elements appear in compositions that deviate from what we find at Teotihuacan. What we must emphasize once again, though, is the repetition and consistency in the iconographic motifs. These correspond to those found in the Maya area and elsewhere, and suggest a relatively well-controlled and concerted introduction of the motifs and the messages they carried.

\section{TEOTIHUACAN-STYLE MONUMENTS IN GUERRERO}

An increasing demand for natural resources such as shell, feather, greenstone, and cotton not found in the Basin of Mexico may have been the prime mover for Teotihuacan's presence in the region. Archaeological remains found in the various parts of Guerrero point to relationships between Teotihuacan groups and populations along the Pacific Coast, and in the central and northern parts of Guerrero, where greenstone and possibly also cotton could be acquired. The same products were sought in these areas by the expanding Aztec Empire some seven centuries later (Carrasco 1999:266-280; Litvak King 197I). Thus, we know from written documents that the province of Tepecoacuilco paid tribute to Tenochtitlan in the form of green stones and blankets (Matrícula de Tributos [1980], fol. 9r; Codex Mendoza [1992], fol. 37r). Spondylus shells, probably collected in the Costa Grande region during the Early Classic and transported back to Teotihuacan (see Kolb 1987), were a resource that was also valued by the Mexica, who charged it as tribute from the city of Cihuatlán (Matrícula de Tributos [1980], fol. 9v; Codex Mendoza [1992], fol. 38r). In the case of the Montaña region, Tlapan (Matrícula de Tributos [1980], fol. ror; Codex Mendoza [1992], fol. 39r) paid tribute mainly in the shape of cotton blankets and raw materials such as gourds. We thus can easily imagine that Teotihuacanos were interested in acquiring similar resources from the area.

In terms of identifying the most probable routes of interaction between Teotihuacan and Guerrero, the natural environment and topography offer several options depending on what particular part of Guerrero we are dealing with, but in practical terms the possibilities can be reduced to three. ${ }^{4}$ The first sets out in the southeastern part of the Mexico Basin, moves through the Chalco-Amecameca region, by the slopes of Popocatepetl, and continues down the Amatzinac River Valley in Morelos. Teotihuacan presence in this region has long been recognized 
(Hirth 1978). From there the route continues in a southeasterly direction and reaches the Mixteca Baja and Tlapaneca regions by the Río Tlapaneco, finally arriving at Las Minas-Alpoyeca and Tlapa in Guerrero. The second route follows the Río Amacuzac in western Morelos and enters into Guerrero between the presentday towns of Quetzalapa and Huitzuco. This area remains poorly studied, though some of the most fascinating Teotihuacan-style monuments in Guerrero come from this part of the state (e.g., Tepecoacuilco). The third route departs from the western part of the Basin of Mexico, passes through the Toluca Valley, where clear evidence of Teotihuacan occupation has been found (Sugiura 2009), and from here continues past the Nevado de Toluca Volcano, towards the south until reaching the Balsas River and nearby Arcelia and Tlapehuala. Before the construction of large dams in modern times, the Balsas River was navigable from the northern part of Guerrero to its mouth at the Pacific Ocean (Wicks and Harrison 1999:157-162). The importance of the Balsas River as a communication route is yet to be investigated in detail, but may have been comparable to the role played by the Usumacinta River in the Maya lowlands. Several Classic Maya political centers were situated on the banks of the river, which was fundamental not only for the trade and exchange of goods, but also for elite interaction (Golden et al. 20I2). There are many important Classic period settlements along the Balsas River, for example, Mexiquito, but these have only just begun to be the subject of careful archaeological studies (Armillas 1947; Meanwell 2007).

As noted above, we focus on sites with Teotihuacan-style stone monuments, and though practically all of these sculptures are currently in museum collections and no longer found in situ, most of them have a relatively secure provenance. Unfortunately, there have been very few controlled excavations at sites with monuments, and we lack even the most basic knowledge of the exact archaeological contexts of nearly all the monuments discussed here.

\section{EL NORTE}

In line with general practice we subdivide the large territory covered by the modern state of Guerrero into the five areas of Norte, Tierra Caliente, Centro, Las Costas (Chica and Grande) and the Montaña (Schmidt Schoenberg 2006:30-3I). We begin our survey in the northern part of the state, bordering on the modern states of Mexico, Morelos, and Puebla, and it is from here that we have some of the most fascinating examples of Teotihuacan-style monuments. They can all be described as stelae (i.e., freestanding rectangular stone monuments), and though small stela-like monuments are known from Teotihuacan (such as the tecalli monument from the Quetzalpapalotl Palace; see Acosta 1964:36, fig. 60), it was clearly not 
the preferred format of stone sculpture in the central Mexican metropolis (Jordan 2014:106-110). This is important to emphasize and may be explained as a result of local processes where foreign iconography is displayed according to existent local practices, just as was the case in the central Maya lowlands in the late fourth century, where Teotihuacan ideology was predominantly expressed to a local audience via the already well-known stela-like format. ${ }^{6}$

One of the most illustrative examples is the monument that reportedly comes from Acatempan (figure 6.2a; Jordan 2014:I4I; Piña Chan 1977:fig. 72; Reyna Robles 2002; Taube 2000a:9, 2011:93-94), and it displays Teotihuacan imperial iconography as well as writing. It shows a Teotihuacan warrior portrayed frontally, wearing a large raptorial bird headdress comparable to those often represented in Teotihuacan iconography, possibly suggesting a relation with a specific warrior order. In the beak of the bird is the lower part of the so-called year sign (or "trapeze and ray") which reappears in the toponym below (Nielsen and Helmke 2017). Other significant elements are the individual's goggles and the square, featherrimmed shield (and the two darts behind it), as well as the spear-thrower held in his left hand. The spiral wave-like design on the shield is interesting since this is also found on the shields of Teotihuacan warriors at El Rosario, as well as at Teotihuacan (Taube 20rI:93). Such degree of correspondence suggests a detailed and direct transference of knowledge of Teotihuacan military organization and emblems. The warrior's sandals, embellished by feather tassels or tufts, are also highly characteristic of Teotihuacan representations and indeed seem to have served as yet another standard marker of individuals associated with this place. As first pointed out by Taube (2000a:9), the warrior stands on top of a toponym that consists of the "trapeze and ray" sign and the "twisted root sign," which most likely functions as a locative suffix in Teotihuacan writing. From comparable examples in the Maya area, we know that depictions of warriors or triumphant kings standing on toponyms sometimes refer to their conquest of that particular site or some other affiliation with this place (see Nielsen 2006:4). On the Acatempan monument it is difficult to determine which of the two is the more plausible, but the fact that the "trapeze and ray" sign also shows up in the beak of the bird (thus substituting for the human hearts or backbones normally found in this position) in the headdress speaks in favor of this as a reference to a place conquered by Teotihuacan, and as such a possible toponymic reference to Acatempan. On either side of the glyph and the warrior figure flowers appear, and as Taube (2011:94) noted: "flowers were closely identified with warfare and a flowery paradise in Teotihuacan thought."

Several similar motifs can be observed on an unprovenanced stela, attributed to Guerrero, currently in the Rufino Tamayo collection in Oaxaca (figure 6.2b; Taube 2011:94-95). The front depicts the upper part of a Teotihuacan warrior wearing a 


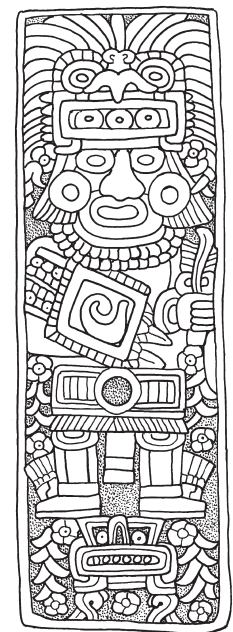

a)

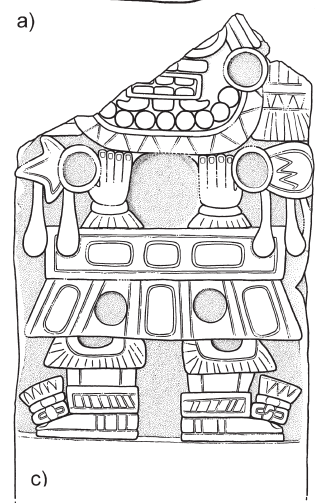

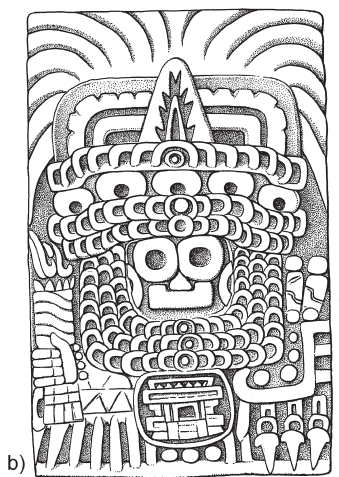

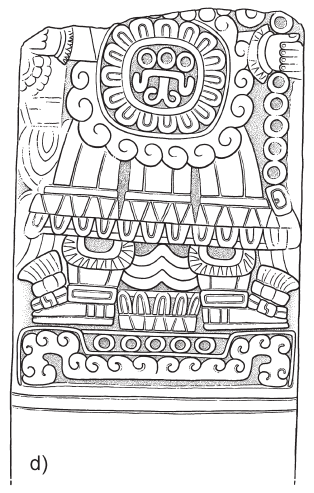

FigURE 6.2. Monuments from northern Guerrero: (a) Acatempan, unknown dimensions (drawing by Karl Taube); (b) Small stela-like monument in the Rufino Tamayo collection in Oaxaca, $70 \mathrm{~cm}$ tall (drawing by Nicolas Latsanopoulos); (c-d)

Tepecoacuilco Stelae I and 2, I.I $4 \mathrm{~m}$ and $\mathrm{I} .24 \mathrm{~m}$ tall (drawings by Nicolas Latsanopoulos).

huge shell-platelet headdress with a possible "year sign" and a large array of feathers, as well as goggles and a nose-bar, the two latter being characteristic of warriors associated with the Teotihuacan Storm god. In one arm he holds a burning torch, whereas the other is covered by a square shield with three darts behind it. The shield appears to have been marked by a wave-like emblem similar to that seen on the Acatempan stela. What is unusual is that the figure carries the calendrical date " 3 house" on his chest. This is a feature that is more common in the Epiclassic and Early Postclassic periods, but the rounded cartouche indicates that this is in fact a Classic period monument (see Helmke et al. 2013). The two most likely interpretations are that this is either the 260-day calendar name of the portrayed individual or that the date refers to the year in which an important event transpired, possibly 
a conquest. ${ }^{7}$ The emphasis on warfare and conquest is continued on the back of the stela, where a row of six darts penetrates an undulating ground line which we interpret as a stylized landscape, and hence an Early Classic forerunner of the wellknown late Postclassic Mixtec visual convention of expressing a military conquest by an atlatl dart penetrating the toponym of the vanquished city. The unusual spiral design with footprints surrounded by plant-like elements may specify the name of the locality, or may, as Taube suggested, be related to the previously mentioned spiral sign on Teotihuacan shields that sometimes occur with footprints (Taube 2011:94, fig. 5.14b). As with the Acatempan monument, we thus have a possible combined iconographic and epigraphic reference to a Teotihuacan conquest.

Clara Luz Díaz Oyarzábal first published a detailed description of the two monuments (known as Stela I and 2; figure 6.2c-d) from the vicinity of Tepecoacuilco (Díaz Oyarzábal 1986, 1990); ${ }^{8}$ she suggested that they represent Teotihuacan equivalents to Tlaloc and Chalchiuhtlicue, and other authors have followed this line of interpretation (Jordan 2014:138-141; Schmidt Schoenberg 2006:32). Recently, Taube (2011:95-98) provided excellent and detailed interpretations that offer a deeper understanding of these two important monuments. In spite of the damage that has occurred to both monuments, leaving them without the upper third, a number of crucial observations and identifications can be made. Thus, on Stela $\mathrm{I}$ an individual holds forth a dart, drops falling from its pointed blade, in front of the chest (figure 6.3a). Darts dripping with blood are known from the murals in Atetelco and Tetitla at Teotihuacan (figure 6.3b; cf. Taube 20r1:fig. 5.16d). Also, a stuccoed and painted Teotihuacan tripod vessel in the Brooklyn Museum (figure 6.3c) shows a goggle-eyed warrior holding a dart with two hands, and this example constitutes the closest parallel to the figure on Stela r. Enough survives of the figure's head to recognize an open mouth with teeth visible, goggles, and a possible nose-bar. The sandals are virtually identical to those worn by the Acatempan warrior as well as the person on Tepecoacuilco Stela 2. Rather than the Storm or Rain god himself, this is probably yet another Teotihuacan warrior figure affiliated with the martial aspect of the Storm god. Stela 2 (figure 6.2d) shows an individual with a large cloud-rimmed medallion or disk on the chest marked by a stylized Teotihuacan Storm god with a bifurcated tongue. The objects held by the individual can interpreted as a hanging strand of jade beads (left hand) and some other oblong object, and as Taube (2011:96; fig. 5.17d-e) notes: "In ancient Mesoamerica, jade and quetzal plumes were some of the treasured items of conquest and tribute, and figures were commonly shown holding bundles of quetzal plumes ${ }^{9}$ and strands of beads." As in the case of Acatempan, the figure stands on top of a combination of glyphic signs that probably allude to a specific location. Thus, rather than depicting two water deities, the Tepecoacuilco stelae appear to represent historical 


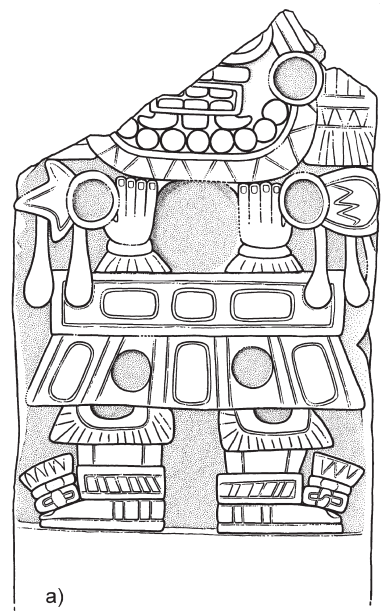

c)

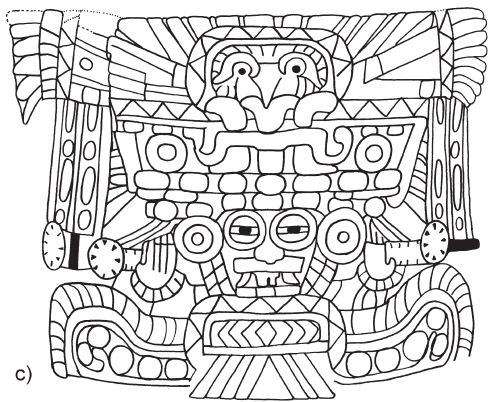

FIGURE 6.3. Examples of Teotihuacan Storm gods or Storm god impersonators holding darts or a lightning bolt dart in front of them: (a) Tepecoacuilco Stela I (drawing by Nicolas Latsanopoulos); (b) mural from Corridor 2I at Tetitla, Teotihuacan (reconstruction and drawing by Nicolas Latsanopoulos); (c) detail of stuccoed and painted Teotihuacan tripod vessel in the Brooklyn Museum in New York (drawing by Iván Rivera).

events, and possibly historical individuals, centered on military conquest and tribute collection.

Also in the collections of the Museo Nacional de Antropología is an unprovenanced stela fragment, said to come from Guerrero, ${ }^{10}$ which has several similarities to the Tepecoacuilco stelae (figure 6.4; cf. Taube 2011:97-99). This intriguing object shows the lower part of a human individual twice, and as Taube (2011:97) noted: "On close inspection, it is evident that there are two distinct carving styles present ... This stela was likely recarved from a larger broken monument." The feet of the latest carving stands on top a toponymic register composed of a "shallow basin" sign marked by jade disks and streams of water (represented according to Teotihuacan conventions by two bands of eyes), quite possibly the exact same place referred to on Tepecoacuilco Stela 2. Between the legs is a "year sign" and the stylized Storm god with a quincunx and blood droplets in his mouth. It has been suggested that cardinal aspects of the Teotihuacan Storm god existed, and in particular 
FIGURE 6.4. Unprovenanced stela (96 cm tall), reportedly from Guerrero and currently in the Sala Teotihuacan,

Museo Nacional de Antropología in Mexico City (drawing by Iván Rivera).

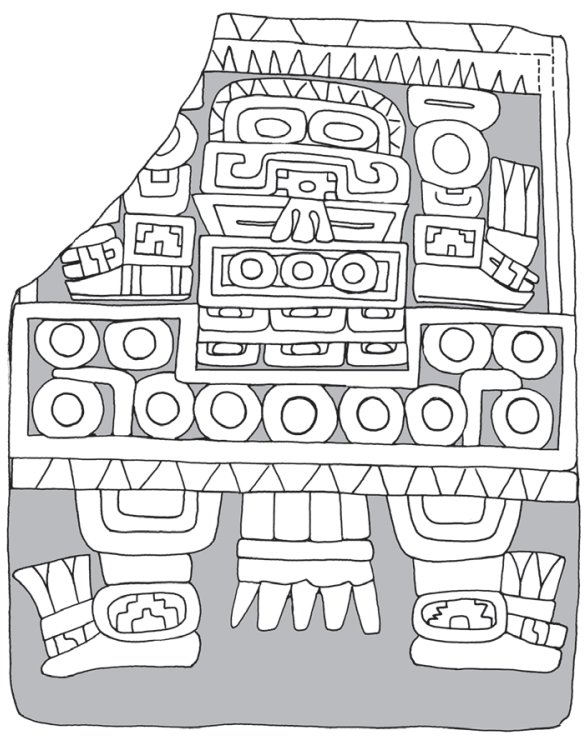

one appears to have been associated with warfare, and this is the "white" Storm god (Anderson and Helmke 2013:186-187). His identifying characteristic is a quincunx representing the cosmos, which Taube relates to an understanding of this particular deity as a "world devourer" since the stylized cosmogram often appears in the mouth of the god. In a political perspective, Taube (20II:IOI-IO3) sees this as an expression of "the Teotihuacan state as the taker of territory." Thus, this may be a reference to the "world devouring" Storm god, here also shown feeding on the "trapeze and ray" sign, as did the raptor in the headdress of the Acatempan Teotihuacan warrior. In conclusion, the monuments from this part of Guerrero display a great familiarity with the iconographic conventions of Teotihuacan in terms of both style and content, as well as Teotihuacan writing. The themes expressed center on warfare, conquest, and possibly tribute collection and as such form part of Teotihuacan imperial iconography.

\section{Tierra Caliente}

From the site of San Miguel Totolapan one stela, carved on both sides, is known, and it exhibits some likely influences from Classic central Mexican iconography (figure 6.5). The stela was originally part of a collection of archaeological artifacts that included other Teotihuacan-style objects, such as a fragment of a socalled Huehueteotl incense burner and a candelero (Reyna Robles and Rodríguez 

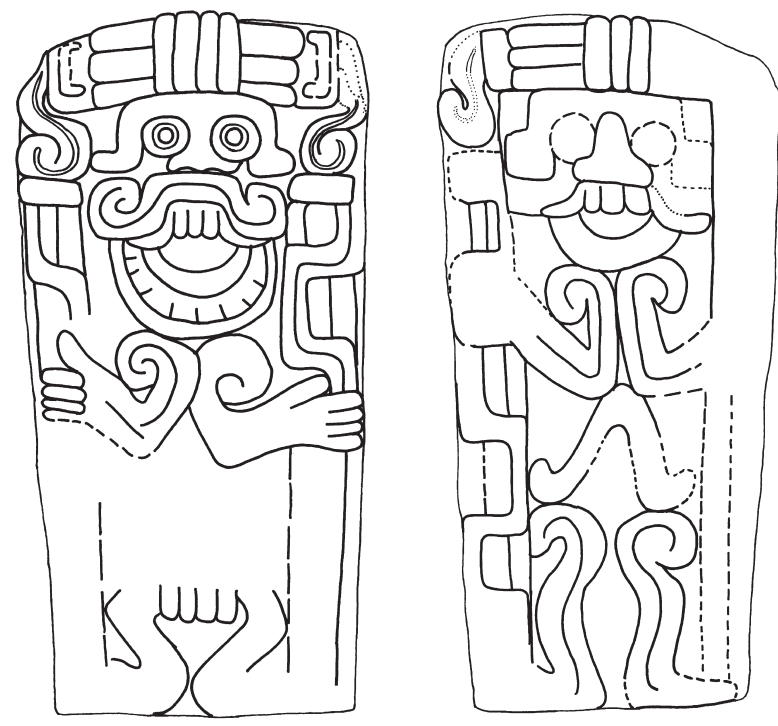

FIGURE 6.5. The stela from San Miguel Totolapan ( $\mathrm{I} .40 \mathrm{~m}$ tall), front and back (drawing by Iván Rivera).

Betancourt 1994:96; see also Jordan 2014:I4I-I43). The monument is $\mathrm{I} .40 \mathrm{~m}$ tall and although the one side suffers from weathering, it seems that originally a very similar design was found on the front and back of the stela: a standing individual with a Storm god mask, if not the Storm god himself. Reyna Robles and Rodríguez Betancourt (1994:98) interpret the objects held in both hands of the figure as related to clouds and conch shells, but based on comparisons with other representations from Teotihuacan and elsewhere these are in fact clearly bound torches with a single flame on top (von Winning 1979; Nielsen 2003[II]:12, fig. B7a-i, 2006), while a third torch serves as a headdress. Thus, this is probably a local interpretation of the aspect of the Teotihuacan Storm god qualified by one or several torches, and the face of the San Miguel Totolapan figure indeed has much in common with the "black" Storm god found in the murals from the Barrio San Sebastián, who is shown with torches (Anderson and Helmke 2013:186, fig. IOa-b). As for the overall style of the image, however, it is different from what we would expect to find at Teotihuacan, for example the "Charlie Chaplin" posture of the legs, as well as the way in which the arms and shoulders are represented (cf. Lomitola 2008). Based on the current evidence, we therefore suggest that Teotihuacan influence at San Miguel Totolapan was probably indirect and sporadic, and the Storm god imagery was adopted according to a regional style of expression.

Known since the middle of the last century, the archaeological site of Cerro de los Monos is located approximately $5.5 \mathrm{~km}$ east of Villa Madero, in the municipality of 

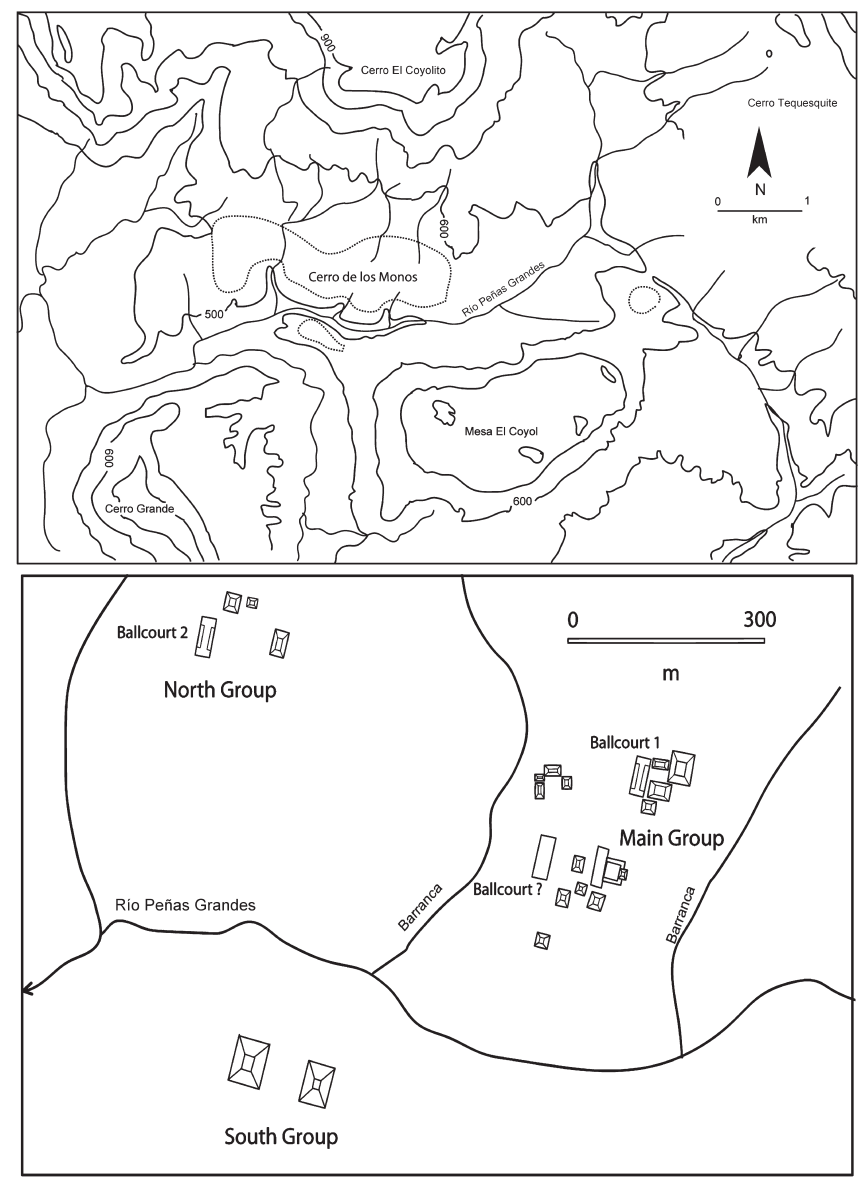

FIGURE 6.6. The archaeological site of Cerro de los Monos, Guerrero: the site's location close to the Río Peñas Grandes (top) and a schematic plan of the main architectural structures (drawings by Iván Rivera).

Tlalchapa (figure 6.6). In the archaeological literature it has been cited as an important place due to the presence of several sculptures (figure 6.7; cf. Armillas 1947; Cepeda Cárdenas 1970; Hendrichs 1945; Reyna Robles and Rodríguez Betancourt 1990; Schmidt Schoenberg and Litvak King 1986). The site has not, however, been thoroughly investigated, due in part to its relative remoteness and the social problems of the region. An unpublished archaeological report by Hugo Moedano Köer (195I) suggests that is was one of the largest and most complex sites reported in this part of Guerrero. It consists of several groups of mounds, plazas, and platforms 


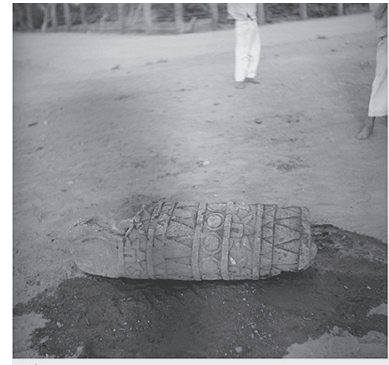

a)

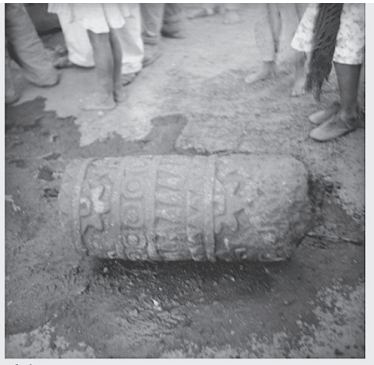

b)

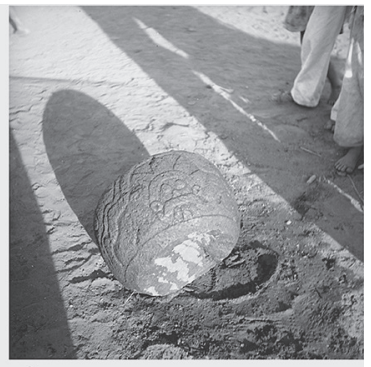

c)

FIGURE 6.7. Early photographs (before 1960) showing (a-b) Cerro de los Monos Column I and 2 and (c) Sculpture I on the plaza of the village of Villa Madero (photos courtesy of Archivos de INAH, Pachuca).

distributed on the southern slope of a hill named Cerro Coyolito, separated by small streams that flow down to join the Río Peñas Grandes (figure 6.6) Aerial photography allows for the identification of at least two ballgame courts with a northsouth orientation, and associated with multiple sets of mounds. It is possible that not all groups were contemporaneous (Moedano's report indicates that the site was occupied in the Classic and Postclassic), but the architecture and sculptures reveal that this was an important site with intense occupation and construction.

Before proceeding with an iconographic analysis of the sculptures, it is worth stressing that what we have here designated as "columns" may in fact be sections of so-called ballcourt markers. While no formal ballcourts have been identified at Teotihuacan itself (however, see Uriarte 2006), the famous mural paintings from the residential compound at Tepantitla show different ballgames being played. One of these appear to take place on an open field marked by two markers or standards, and one such object, a finely sculpted stone monument, was discovered at La Ventilla (figure 6.8a; cf. Arroyo de Anda 1963). The La Ventilla ballcourt marker is $2.13 \mathrm{~m}$ tall and composed of four distinct parts, namely, a columnar support, a conical, and a spherical or globular central part, and finally a disk- or medallionlike upper part. Other possible fragments have been found at Teotihuacan (Acosta 1964:29, figs. 34-35; Aveleyra Arroyo de Anda 1963:figs. 5, 7-8), but it is from outside of Teotihuacan that we have the best additional evidence of this type of monument. Most well known is the Tikal Ballcourt Marker, excavated in a small talud-tablero platform together with a Teotihuacan-style mask in Group 6C-XVI (figure 6.8c; see Laporte and Fialko 1995; Nielsen 2003:106-109). A rich burial (PNT-174) from the same architectural compound also contained a number of other Teotihuacan-style artifacts, including a slate mirror and cylindrical tripods 


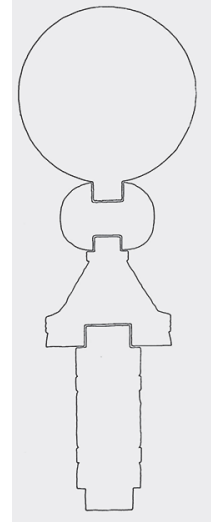

a)

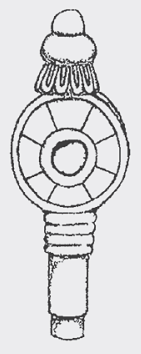

b)

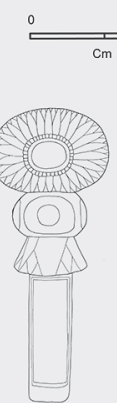

c)

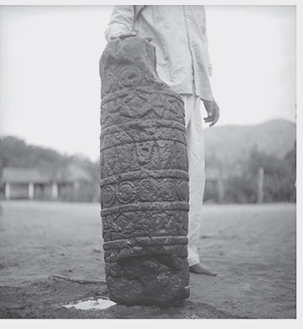

d)

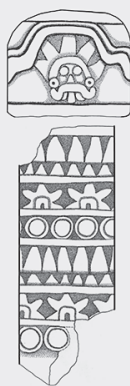

e)

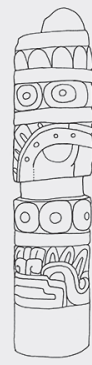

f)

FIGURE 6.8. Comparison of Teotihuacan-style ballcourt markers or battle standards:

(a) La Ventilla, Teotihuacan; (b) Chalcatzingo, Morelos, (c) Tikal, Petén (Guatemala);

(d) Cerro de los Monos Column i; (e) Cerro de los Monos Column I and spherical Sculpture I as they may have been originally assembled; (f) Unprovenanced stone column from Guerrero, possibly from Cerro de los Monos [drawings: (a) after Aveleyra Arroyo de Anda [1963]; (b) after Grove and Angulo 1987; (c) by Iván Rivera after Laporte 2003; (d) photo courtesy of Archivos de INAH, Pachuca; (e) by Elizabeth Jiménez García and Daniel Correa Baltazar; (f) by Iván Rivera after Franco Carrasco (1973)].

and what was probably a shell-platelet headdress (Laporte 1989:173-175; Nielsen 2003:IOI-IO5). The column of the ballcourt marker is inscribed with two Maya glyphic texts outlining the arrival of Teotihuacanos at Tikal in AD 378 (Martin and Grube 2008:30-31; Stuart 2000). The text has a direct reference to the object itself," and states that it belonged to "Spearthrower Owl," or Jatz'o'm Kuy, the assumed ruler at Teotihuacan between AD 374-439. His name reappears on in the center of the circular disk, surrounded by feathers. Thus, while the c. I m tall monument may have been related to the ballgame, it certainly also was a prestigious object that served to relate the conquest narrative and display the power of Teotihuacan, and as such it functioned akin to an effigy battle standard as first suggested by David Freidel and Linda Schele (Freidel et al. 1993:299-301; see also in Koontz 2009:22-23). A possible ballcourt marker was also found at Kaminaljuyú (Kidder et al. 1946; Parsons 1986:64, fig. 164), and yet another was found near Chalcatzingo in Morelos (figure 6.8b; cf. Cook de Leonard 1967:pl. 8; see also Hirth 1978). Of importance is that a Teotihuacan-style marcador is also known from Arcelia in the Tierra Caliente region of Guerrero (Cepeda Cárdenas 1970:16, figs. 21-22), and with these examples in mind, we can approach a group 

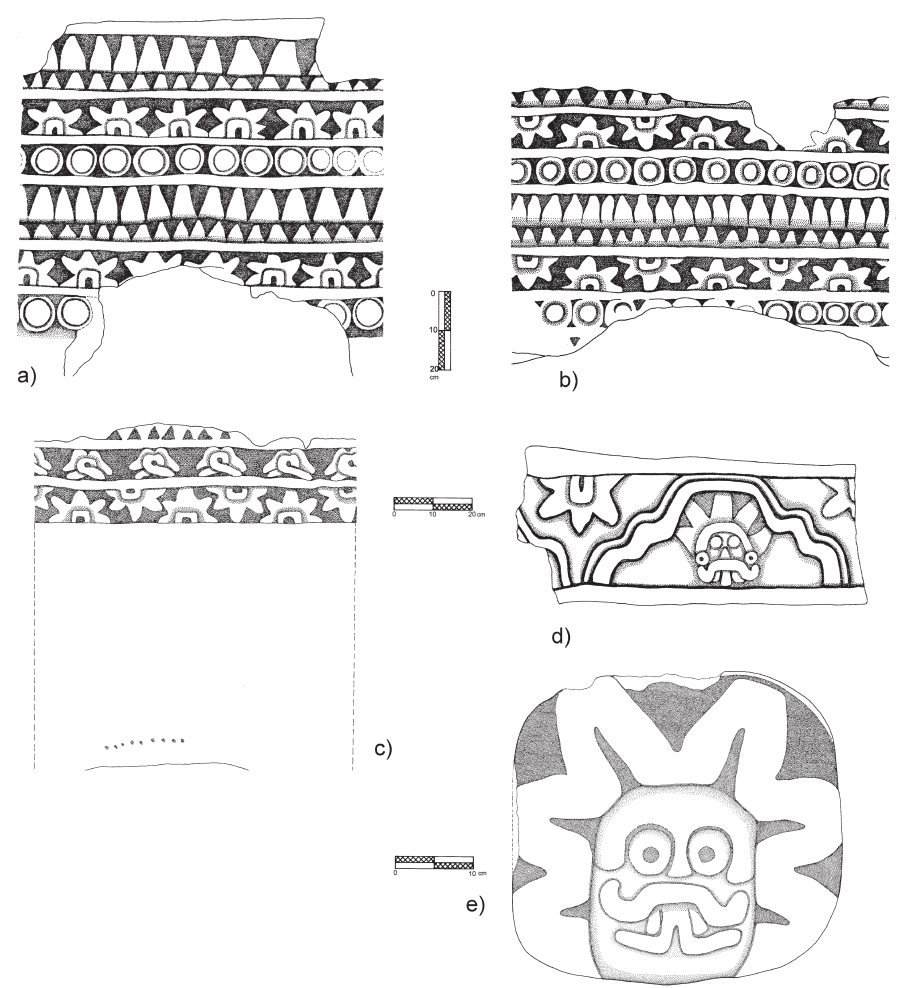

FIGURE 6.9. Roll-out drawings of the carved monuments from Cerro de los Monos (now in the Regional Museum in Chilpancingo, Guerrero): (a) Column I; (b) Column 2; (c) Column 3; (d) Sculpture I; (e) Relief panel from Pueblo Viejo, Iguala, Guerrero (drawings by Elizabeth Jiménez García and Daniel Correa Baltazar).

of sculptures from Cerro de los Monos and other sites in the region, which may all originally have been part of similar ballcourt markers or battle standards.

First, we concentrate on three columnar fragments that all share some iconographic features. Column I $(94 \times 27.5 \mathrm{~cm})$ (figure 6.9a) has a repeating design composed of rows of geometric triangular elements (perhaps imitating feathers), circular disks, possibly chalchibuites or jade disks, and bands with halved stars. The exact same elements appear on Column $2(72 \times 30 \mathrm{~cm})$ (figure $6.9 \mathrm{~b})$, the only difference being that the halved stars are here oriented both up- as well as downward. The half-star motif is common at Teotihuacan and served two different purposes, in some cases representing starfish in a watery environment, but frequently the halved stars are associated with 
warfare and death (and possibly Venus), as is also the case in Epiclassic iconography (Baird 1989; Brittenham 2015:99-110) and in Classic Maya writing, where the logogram for star EK' representing a half-star combined with streams of water is placed on top of the location that is subject to the act of aggression (Martin 200I). This observation becomes particularly interesting when we look at Column $3(86 \times 28 \mathrm{~cm}$; figure 6.9c), where halved stars occur in combination with a repeated hieroglyphic collocation that combines an unidentified leaf-like sign with the "twisted root" sign. ${ }^{12}$ As we have already seen, the latter probably functions as a locative suffix, and one possible interpretation would thus be that this is a toponymic reference to the place that war was waged against. The imagery of Cerro de los Monos Sculpture I, a globular stone object (ca. $32 \times 43 \mathrm{~cm}$; figure 6.9 d), speaks in favor of this being a reference to war. Thus, halved stars are shown in combination with the Teotihuacan logogram for "hill, mountain," which is frequently used in forming toponyms in Teotihuacan writing (see Helmke and Nielsen 2014; Taube 2000a:7-9, 25-26). Infixed in the sign for hill, thus qualifying it, is a stylized Storm god face paired with a half-star, and the sign would read something like the "Hill of the Star / War Storm god."

In 1973 José Luis Franco Carrasco published a photo of a fragment of another carved column that resembles those already discussed, and it too may originally have come from Cerro de los Monos (see figure 6.8f). The imagery includes circular disks, feather-like elements, and the head of a serpent-like creature that can be compared to that on the Arcelia marcador and that may be related to the Teotihuacan War Serpent mentioned in the text on the Tikal marcador (Stuart 2000). A carved relief (figure 6.9e) from Pueblo Viejo near the modern city of Iguala in northern Guerrero ${ }^{13}$ shows a stylized Storm god emerging from the center of a star. In this representation, the deity has a protruding bifurcated tongue similar to that seen on Tepecoacuilco Stela 2 (see figure 6.2d). Identical representations are found at Teotihuacan, for example, in the murals in the Conjunto de los Jaguares (de la Fuente 1995:119, fig. 12.4) and during excavations at the Quetzalpapalotl Palace, several almenas with similar "star-Tlalocs" were discovered (Acosta 1964:23, figs. 16-17). An exquisite alabaster almena depicts the same aspect of the Storm god but with water gushing from its open mouth, thus making a perfect parallel to the previously mentioned Maya logogram for war (Helmke and Nielsen 2014:89-9I, fig. se; cf. Somogny Éditions d'Art 2009:cat. no. 129). Assuming that Cerro de los Monos Sculpture I (see figure 6.8e) was once part of a marker or standard, it can be compared to the ballcourt markers mentioned above. Finally, we have already seen that ballcourt markers or battle standards were used to record and commemorate military actions, and viewed as a whole the sculptures from Cerro de los Monos thus again demonstrate the coherency of the motifs commissioned by what we argue were imperial representatives from Teotihuacan. 


\section{Centro}

A site of potential major importance in the central part of the state is Quechomictlipan (also referred to as Omitlán and Yerbabuena). Located approximately midway between Xochipala and Tlacotepec, it was visited and described by the Scottish mineralogist, amateur archaeologist, and collector William Niven in 1890 (see Wicks and Harrison 1999:31-38). Several large ruined mounds were spread out over several ridges, and at least one carved stone monument was discovered during Niven's visit. This is currently kept in the Museo Nacional de Antropología in Mexico City and is commonly referred to as "Estela de Acapulco" (e.g., Manzanilla López 2008:120) (figure 6.10). There can be little doubt, however, about its original provenance since a photograph from Niven's expedition shows the monument lying horizontally at the site of Quechomictlipan (see Reyna Robles 2008:60), and we thus rename it Quechomictlipan Monument I. The stela depicts a standing individual, with both arms and hands in front of the body, and wears a belt of shells or hearts. The face has the standard attributes of the Storm god-large, goggled eyes, ear spools, and open mouth displaying prominent fangs - and the headdress is composed of what appears to a highly stylized serpent creature emphasizing the upper jaw, fangs, and snout (see also Jordan 2014:137-138). Around the neck the figure wears a large necklace with a pendant in shape of what appears to be heart. The monument exhibits some close similarities with the stela from San Miguel Totolapan, in particular the unusual "Charlie Chaplin" position of the legs (which may point to influences from regions other than central Mexico and Teotihuacan; Lomitola 2008), and it is plausible that they belong to the same period and local style-yet emphasizing two different aspects of the Storm god. ${ }^{14}$ In terms of any direct Teotihuacan influence or presence at Quechomictlipan there is little available evidence pointing in this direction, but further investigations at site may eventually change this.

\section{Las Costas and the Montaña}

The extensive coastal region of Guerrero is further divided into the Costa Grande to the north and Costa Chica to the south. Rubén Manzanilla López (2008:110-I33; see also Suárez Díez 1977:82) discusses different kinds of Teotihuacan-influenced material culture from the Costa Grande-including ceramics, sculpture, and shell objects - though none of these would seem to indicate a marked Teotihuacan presence. Schmidt Schoenberg (2006:32) mentions a marcador from Acatolín near Tecpán, with some similarity to the one from La Ventilla, and a ballcourt ring from Tecpán adds to the corpus of carved sculptures from the site (Manzanilla López 2008:65, fig. 19). Between Zihuatanejo and Petatlán, Manzanilla and his 


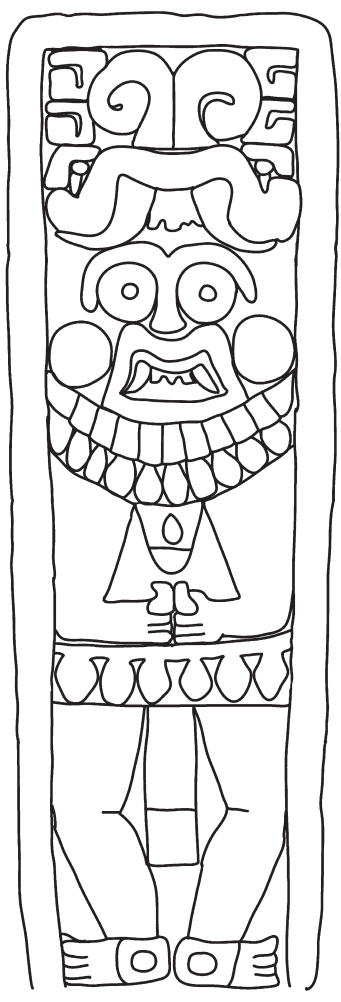

FIGURE 6.IO.

Quechomictlipan

Monument I (I.I4m tall)

(drawing by Iván Rivera). colleagues registered fifty-five sites, some of them with continuous occupation from the Middle Preclassic to the colonial period. The archaeological record is dominated by local forms, but also suggests cultural interaction with central Mexico, and molded human figurines show some affinities with Teotihuacan. La Soledad de Maciel stands out between the sites with Classic occupation; the ceremonial center covers approximately one square kilometer, and include plazas, platforms, and foundations made from adobe as well as a ballgame court. Three stone rings decorated with entwined serpents were also discovered, but the style does not suggest direct Teotihuacan influence (Manzanilla López and Moguel Cos 1990; Manzanilla López 2008:122-123, figs. 6I-62). Excavations by Gordon Ekholm at Tambuco (near Acapulco) on the Costa Chica revealed cylindrical tripods with hollow feet, but apart from this evidence pointing to Teotihuacan, contacts in this region remains scarce (Schmidt Schoenberg 2006:33).

Evidence suggesting interaction with Teotihuacan has been found in at least four sites in the Montaña region..$^{15}$ Las Minas-Alpoyeca, located north of Tlapa, is a ceremonial center with talud-tablero architecture and Teotihuacan-style ceramics, including Fine Orange ceramic vessels and bowls with nubbin supports, as well as incense burners with iconographic elements resembling Teotihuacan Storm god faces. Another site is Contlalco (Tlapa), which appears to have developed during the Early Classic period. Here Raúl Barrera and Carlos Parra excavated part of a fully stuccoed altar reminiscent of Teotihuacan patio altars, and found black-and-orange ceramics suggesting some Teotihuacan influence or local inspiration (Barrera and Parra 1992:13-15).

\section{CONCLUDING REMARKS}

In pre-Columbian times the vast area that today constitutes the state of Guerrero was inhabited by several different ethnic and linguistic groups (see Vélez Calvo 1998), which all, in varying degrees, were involved in socioeconomic and religious 
interactions, as well as military conflicts with neighboring regions and peoples. Such contacts continually caused changes in local communities and their cultural traditions, including language and symbolic and artistic expressions. Based on the available iconographic evidence, we suggest that many important changes that occurred in Guerrero during the Classic period were related to contacts with or the actual presence of Teotihuacanos at a number of select sites.

The carved monuments presented and discussed above are important in several ways; first, they are evidence of a vibrant sculptural tradition in Guerrero in the fourth-sixth centuries AD. Second, they add to the emergent picture of a time period in Mesoamerica in which the influence and power of Teotihuacan was felt in nearly every part of Mesoamerica. Furthermore, the monuments contribute to the ongoing discussion concerning how and to what degree Teotihuacan was involved in actual conquests and political maneuvering in these areas, or whether local dynasties merely mimicked the style and content of Teotihuacan iconography for their own ends and purposes. In our view, the stelae and other carved sculptures from Guerrero that we have analyzed in detail here all conform to the imperial iconography of Teotihuacan, and there can be no doubt that local elites and artists possessed a knowledge of its standards with regards to the basic repertoire of motifs.

In some cases, such as San Miguel Totolapan, the iconography points to local adaptations, indicating an indirect knowledge of the original source of inspiration. This would suggest a similar situation as observed in the Maya area where sites such as Tikal and Kaminaljuyú display Teotihuacan iconography that is almost identical to that of Teotihuacan, whereas smaller surrounding cities and communities produced less-precise and well-articulated imitations. It is in the north and the tierra caliente that we have found the clearest evidence of direct Teotihuacan influence, and at several sites we have also noted examples of Teotihuacan writing. In sum, stone monuments displaying Teotihuacan imperial iconography can be traced in a number of sites in Guerrero, most prominently at Acatempan, Cerro de los Monos, and Tepecoacuilco. In our view, they strongly suggest that some members of the Teotihuacan elite, possibly imperial representatives and/or merchants, settled in those areas. This is not to say that all examples of Teotihuacan-style monuments or ceramics encountered in the various regions of Guerrero reflect conquests and subsequent collection of tribute. Some can undoubtedly be understood as part of other modes of interaction and exchange, just as goods and luxury items may have been brought back to the metropolis through long-distance trade in the hands of merchants similar to Mexica pochteca.

We have detailed several resources that may have underlain Teotihuacan interest in Guerrero, but the routes through Guerrero that we suggest were used by Teotihuacan armies and merchants also need to be seen and understood in a wider perspective. 
These routes also provided access to the coastal regions of Oaxaca and Chiapas, where Teotihuacan-style monuments and other types of evidence showing links to central Mexico have been found (García des-Lauriers 2007; Navarrete 1986; Rivera Guzmán 20II), and farther south toward the Pacific coast and piedmont regions of Guatemala, where Teotihuacan presence is well documented. As such, Guerrero stands out as a region of major importance because its network of trade routes were crucial in terms of connecting the Basin of Mexico with eastern Mesoamerica and the exotic and prestigious resources that could be gained from those distant lands.

ACKNOWLedgments. We would like to express our gratitude to a number of colleagues who, in one way or the other, have been helpful and generous with their assistance, advice, and access to data and drawings, including Christophe Helmke, Nicolas Latsanopoulos, Karl Taube, Paul Schmidt, José Luís Ramírez, and Mayra Mendoza Avilés. Comments from two anonymous reviewers also improved the quality of or contribution considerably. We would also especially like to thank the director of the Museo Regional de Guerrero in Chilpancingo, Maura Liliana Ortíz, who kindly permitted our inspection and documentation of several of the monuments discussed here. Jesper Nielsen also wants to thank the late Toke Sellner Reunert for accompanying him on his first trip to Guerrero in 2008, where several of the Teotihuacan-style monuments from Cerro de los Monos first caught his attention. During the writing of this chapter, Iván Rivera was supported by an INAH Fellowship at the University of Leiden, the Netherlands. Finally, we want to thank the editors, Joshua D. Englehardt and Michael D. Carrasco, for the wonderful opportunity to present our ideas and research in the present volume.

\section{NOTES}

I. Figurines and stone masks from Guerrero are sometimes described as Teotihuacan style, but in fact these rarely conform to similar objects from Teotihuacan, and their direct association with Teotihuacanos is dubious (see, e.g., Rubín de la Borbolla and Spratling [1964:figs. 63-73, III-I24]).

2. The current political situation, the power of the carteles, and the scale of drug trafficking make archaeological investigations in most of Guerrero exceedingly difficult and dangerous (see Reyna Robles 2013).

3. See also Janet Berlo's (1984:211-217) useful concluding discussion of pronvincialism and eclecticism in the art of Teotihuacanos abroad.

4. Kolb (1987:118-I19) discusses two trade Teotihuacan routes that pass through Guerrero (southward into Morelos, the Río Nepaxa drainage, and the Balsas River) and notes that one of these (what he coins the Pacific Coast Route E), which provided access to Laguna 
Papagayo and Acapulco, would have been the shortest distance from Teotihuacan to "any Pacific coast Spondylus source.”

5. Prior to the appearance of Teotihuacan-style monuments in the region, there is little evidence of a local tradition of large stone sculptures. Thus, the Middle Preclassic monuments from San Miguel Amuco and Teopantecuanitlan are evidently executed in an Olmec style. In the Late Preclassic the famous Mezcala tradition begins to appear, but the dimensions of these characteristic stone figures and masks produced by this culture are far smaller than those encountered in the Early Classic (see Paradis 2002, 2010; Reyna Robles 2002).

6. The term stela should be used with some caution because we do not know whether all these monuments were in fact originally freestanding monuments, or rather embedded in architectural contexts as tablets, jambs, or pilasters. However, we have generally chosen to follow the designations assigned in previous publications.

7. Elsewhere it has been suggested that the year-bearer set that was in use in central Mexico in the Classic period was identical to that of the Late Postclassic, that is 'house, 'rabbit', 'reed', and 'flint' (see Helmke and Nielsen 2011:12-20; Helmke et al. 2013).

8. Both monuments are currently on display at the Museo Nacional de Antropología in Mexico City.

9. Based on a more recent drawing of the monument by Nicolas Latsanopoulos, Taube's identification of the object in the figure's right hand, as quetzal feathers must be questioned.

IO. In the 1960 s the monument was part of a private collection (Franco Carrasco 1973).

II. Remarkably, the marcador is referred to as "his 'Storm god," the latter glyph (F8) being undeciphered, but nearly identical to the stylized version of the Storm god that Taube characterized as a "world devourer." This further suggests that such markers or standards were intimately associated with the martial aspects of this deity.

I2. Halved stars also appear with skeletal figures on a stela from the site of Mexiquito in the Tierra Caliente region (Reyna Robles 2002:384, fig. Ioa), but the style of this and other monuments from the site does not suggest a direct influence from Teotihuacan.

13. Today the relief is housed in the regional museum in Chilpancingo.

I4. A stela fragment whose origin is attributed to Guerrero (though the exact location of its discovery is unknown), may be related to the Quechomictlipan monument as it displays the same type of frame and is almost of the same size (see Franco Carrasco 1973).

I5. See Campo Lanz (2010) for a comprehensive study of the famous Teotihuacan-style stone mask found at Malinaltepec.

\section{REFERENCES}

Acosta, Jorge R. 1964. El palacio de Quetzalpapalotl. INAH, Mexico City.

Anderson, Kasper W., and Christophe Helmke. 2013. "The Personification of Celestial

Water: The Many Guises of the Storm God in the Pantheon and Cosmology of

Teotihuacan." Contributions in New World Archaeology 5:165-196. 
Armillas, Pedro. 1947. “Arqueología del Occidente de Guerrero.” El Occidente de Guerrero. IVa Mesa Redonda, 74-76. Sociedad Mexicana de Antropología, Mexico City.

Aveleyra Arroyo de Anda, Luis. 1963. La estela teotihuacana de La Ventilla. Museo Nacional de Antropología / INAH, Mexico City.

Baird, Ellen T. 1989. "Stars and War at Cacaxtla." In Mesoamerica after the Decline of Teotihuacan AD 700-90o, edited by Richard A. Diehl and Janet C. Berlo, IO5-I22. Dumbarton Oaks, Washington, DC.

Barrera, Raúl, and Carlos Parra. 1992. "Hallazgo arqueológico en la región de la Montaña de Guerrero." Revista Gruta 2:13-16.

Bell, Ellen E., Marcello A. Canuto, and Robert J. Sharer, eds. 2004. Understanding Early Classic Copan. University of Pennsylvania Museum of Archaeology and Anthropology, Philadelphia.

Berlo, Janet C. 1984. Teotihuacan Art Abroad: A Study of the Metropolitan Style and Provincial Transformation in Incensario Workshops. BAR International Series 199. Archaeopress, Oxford.

Bove, Frederick J., and Sonia Medrano Busto. 2003. "Teotihuacan, Militarism, and Pacific Guatemala." In The Maya and Teotihuacan: Reinterpreting Early Classic Maya Interaction, edited by Geoffrey E. Braswell, 45-79. University of Texas Press, Austin.

Brambila Paz, Rosa, and Ana Ma. Crespo. 2002. "El Centro Norte de Mesoamérica: Su organización territorial en el Clásico." In Ideología y politica a través de materiales, imágenes y simbolos: Memoria de la Primera Mesa Redonda de Teotihuacan, edited by María Elena Ruiz Gallut, 547-562. CONACULTA/INAH, Mexico City.

Braniff, Beatriz. 2000. "A Summary of the Archaeology of North-Central Mesoamerica: Guanajuato, Querétaro, and San Luis Potosí.” In Greater Mesoamerica: The Archaeology of West and Northwest Mexico, edited by Michael S. Foster and Shirley Gorenstein, 35-42. University of Utah Press, Salt Lake City.

Braswell, Geoffrey E., ed. 2003a. The Maya and Teotibuacan: Reinterpreting Early Classic Maya Interaction. University of Texas Press, Austin.

Braswell, Geoffrey E. 2003b. "Introduction: Reinterpreting Early Classic Interaction." In The Maya and Teotihuacan: Reinterpreting Early Classic Maya Interaction, edited by Geoffrey E. Braswell, I-43. University of Texas Press, Austin.

Braswell, Geoffrey E. 2003c. "Understanding Early Classic Interaction between Kaminaljuyu and Central Mexico." In The Maya and Teotibuacan: Reinterpreting Early Classic Maya Interaction, edited by Geoffrey E. Braswell, I05-142. University of Texas Press, Austin.

Brittenham, Claudia. 2015. The Murals of Cacaxtla: The Power of Painting in Ancient Central Mexico. University of Texas Press, Austin.

Campo Lanz, Sofía Martínez del, ed. 20ro. La máscara de Malinaltepec. INAH, Mexico City. 
Carrasco, Pedro. 1999. The Tenoch a Empire of Ancient Mexico: The Triple Alliance of Tenochtiltan, Tetzcoco, and Tlacopan. University of Oklahoma Press, Norman.

Castañeda López, Carlos. 2008. "Plazuelas, Guanajuato." Arqueología Mexicana 92:44-47.

Cepeda Cárdenas, Gerardo. 1970. “Estela del Cerro de los Monos, Tlalchapa, Guerrero.” Boletin INAH 40:15-20.

Cheek, Charles D. 1977. “Teotihuacan Influence at Kaminaljuyu.” In Teotibuacan and Kaminaljuyu, edited by William T. Sanders and Joseph W. Michels, 44I-452. Pennsylvania State University Press, State College.

Codex Mendoza. 1992 [1542]. "A Facsimile Reproduction of Codex Mendoza." Vol. 3 in The Codex Mendoza (4 vols.), by Frances F. Berdan and Patricia Rieff Anawalt. University of California Press, Berkeley.

Cook de Leonard, Carmen. 1967. "Sculptures and Rock Carvings at Chalcatzingo." Contributions of the University of California Archaeological Research Facility, no. 3, 57-73.

Cook de Leonard, Carmen. 1985. "Las almenas de Cinteopa." Cuadernos de Arquitectura Mesoamericana 4:5I-56.

Cowgill, George L. 2003. "Teotihuacan and Early Classic Interaction: A Perspective from outside the Maya Region." In The Maya and Teotihuacan: Reinterpreting Early Classic Maya Interaction, edited by Geoffrey E. Braswell, 315-335. University of Texas Press, Austin.

Cowgill, George L. 2015. Ancient Teotihuacan: Early Urbanism in Central Mexico. Cambridge University Press, New York.

de la Fuente, Beatriz. 1995. "Zona 2: Conjunto de los Jaguares." In La pintura mural prehispánica en México: Teotihuacán (Catálogo), ist ed., edited by Beatriz de la Fuente, vol. I: II5-I2 I. UNAM, Instituto de Investigaciones Estéticas, Mexico City.

Díaz Oyarzábal, Clara Luz. 1980. Chingú: Un sitio clásico del área de Tula, Hdg. Colección científica, INAH/SEP, Mexico City.

Díaz Oyarzábal, Clara Luz. 1986. "La presencia Teotihuacana en las Estelas de Tepecuacuilco." In Primer Coloquio de Arqueología y Etnohistoria del Estado de Guerrero, 203-208. INAH / Gobierno del estado de Guerrero, Mexico City.

Díaz Oyarzábal, Clara Luz. 1990. Colección de objetos de piedra, obsidiana, conchas, metales y textiles del Estado de Guerrero. Museo Nacional de Antropología. Colección Catálogos de Museos, INAH, Mexico City.

Ekholm, Gordon. 1945. “A Pyrite Mirror from Querétaro, Mexico.” Notes on Middle American Archaeology and Ethnology 53(2):178-181.

Estrada-Belli, Francisco, Alexandre Tokovinine, Jennifer M. Foley, Heather Hurst, Gene A. Ware, David Stuart, and Nikolai Grube. 2009. "A Maya Palace at Holmul, Petén, Guatemala and the Teotihuacan 'Entrada': Evidence from Murals 7 and 9." Latin American Antiquity 20(I):228-259. 
Faugère, Brigitte, ed. 2007. Dinámicas culturales entre el Occidente, el Centro-Norte y la Cuenca de México, del Preclásico al Epiclásico. El Colegio de Michoacán, Zamora.

Filini, Agapi. 2004. The Presence of Teotihuacan in the Cuitzeo Basin, Michoacan, Mexico. A World-System Perspective. BAR International Series I279. Archaeopress, Oxford.

Filini, Agapi, and Efraín Cárdenas García. 2007. "El Bajío, la Cuenca de Cuitzeo y el Estado Teotihuacano." In Dinámicas culturales entre el Occidente, el Centro-Norte y la Cuenca de México, del Preclásico al Epiclásico, edited by Brigitte Faugère, 137-154. El Colegio de Michoacán, Zamora.

Franco Carrasco, José Luis. 1973. Arte precolombino de México: Cerámica, piedra, metal. Fotografía de Germán Carrasco Franco. Ediciones Lito Offset Fersa, Mexico City.

Freidel, David, Linda Schele, and Joy Parker. 1993. Maya Cosmos: Three Thousand Years on the Shaman's Path. Quill, William Morrow, New York.

García des-Lauriers, Claudia. 2007. Proyecto Arqueológico Los Horcones: Investigating the Teotihuacan Presence on the Pacific Coast of Chiapas, Mexico. Unpublished PhD dissertation, University of California, Riverside.

Golden, Charles, Andrew Scherer, A. René Muñoz, and Zachary Hruby. 20ı2. "Polities, Boundaries, and the Trade in the Classic Period Usumacinta River Basin." Mexicon 34(I):II-I9.

Grove, David C., and Jorge Angulo V. 1987. "A Catalog and Description of Chalcatzingo's Monuments." In Ancient Chalcatzingo, edited by David C. Grove, II4-I3I. University of Texas Press, Austin.

Headrick, Annabeth. 2007. The Teotihuacan Trinity: The Sociopolitical Structure of an Ancient Mesoamerican City. University of Texas Press, Austin.

Hellmuth, Nicholas. 1975. “The Escuintla Hoards: Teotihuacan Art in Guatemala.” Foundation for Latin American Anthropological Research Progress Reports I(2):5-58.

Helmke, Christophe, and Jesper Nielsen. 201. The Writing System of Cacaxtla, Tlaxcala, Mexico. Ancient America, Special Publication No. 2. Boundary End Archaeology Research Center, Barnardsville, NC.

Helmke, Christophe, and Jesper Nielsen. 20r4. "If Mountains Could Speak: Ancient Toponyms Recorded at Teotihuacan, Mexico." Contributions in New World Archaeology 7:73-II2.

Helmke, Christophe, Jesper Nielsen, Cecilia Leni, and Amasadaí Navarrete Campos. 2013. “The Carved Monuments of Cerro Xoconoch, Teotihuacan Valley, Mexico." Mexicon 35(4):90-95.

Hendrichs Pérez, Pedro. 1945. Por tierras ignotas: Viajes y observaciones en la Región del Río de las Balsas. Editorial Cultura, Mexico City. 
Hers, Marie-Areti. 2013. "Un nuevo lenguaje visual en tiempos de rupturas (600-900 d.C.)." In Miradas renovadas al Occidente Indígena de México, edited by Marie-Areti Hers, 215-27I. CONACULTA / INAH, Mexico City.

Hirth, Kenneth G. 1978. “Teotihuacan Regional Population Administration in Eastern Morelos." World Archaeology 9(3):320-333.

Jiménez García, Elizabeth, Guadalupe Martínez Donjuán, and Aarón Arboleyda Castro. 1998. “Arqueología." In Historia General de Guerrero, Vol. I: Época prehispánica, 23-140. Gobierno del Estado de Guerrero, JGH Editores, Chilpancingo, Mexico.

Jordan, Keith. 2014. Stone Trees Transplanted? Central Mexican Stelae of the Epiclassic and Early Postclassic and the Question of Maya "Influence." Archaeopress Pre-Columbian Archaeology No. 2. Archaeopress, Oxford.

Joyce, Arthur A. 2003. "Imperialism in Pre-Aztec Mesoamerica: Monte Albán, Teotihuacan, and the Lower Río Verde Valley." In Ancient Mesoamerican Warfare, edited by M. Kathryn Brown and Travis W. Stanton, 49-72. AltaMira Press, Walnut Creek, CA.

Kidder, Alfred V., Jesse D. Jennings, and Edwin M. Shook. 1946. Excavations at Kaminaljuyú, Guatemala. Carnegie Institution of Washington, Publication 56I, Washington, DC.

Koontz, Rex. 2009. Lightning Gods and Feathered Serpents: The Public Sculpture of El Tajin. University of Texas Press, Austin.

Kolb, Charles C. 1987. Marine Shell Trade and Classic Teotihuacan, Mexico. BAR International Series 364. Archaeopress, Oxford.

Laporte, Juan Pedro. 1989. Alternativas del Clásico Temprano en la relación TikalTeotihuacan: Grupo 6C-XVI, Tikal, Peten, Guatemala. Unpublished PhD dissertation, UNAM, Mexico City.

Laporte, Juan Pedro. 2003. "Architectural Aspects of Interaction between Tikal and Teotihuacan during the Early Classic Period." In The Maya and Teotihuacan: Reinterpreting Early Classic Interaction, edited by Geoffrey. E. Braswell, 199-216. University of Texas Press, Austin.

Laporte, Juan Pedro, and Vilma Fialko. 1995. "New Perspectives on Old Problems: Dynastic References for the Early Classic at Tikal." In Vision and Revision in Maya Studies, edited by Flora S. Clancy and Peter D. Harrison, 33-66. University of New Mexico Press, Albuquerque.

Litvak King, Jaime. 1971. Cihuatlán y Tepecoacuilco: Provincias tributarias de México en el Siglo XVI. UNAM, Mexico City.

Lomitola, Lisa. 2008. Ritual Use of the Human Form: A Contextual Analysis of the "Charlie Chaplin" Figure of the Maya Lowlands. Unpublished MA thesis, University of Central Florida, Orlando. 
Manzanilla López, Rubén. 2008. La región arqueológica de la Costa Grande de Guerrero: Su definición a través de la organización social y territorialidad prehispánicas. Colección Científica, Serie Arqueología, INAH, Mexico City.

Manzanilla López, Rubén, and Ma. Antonieta Moguel Cos. 1990. "El Periodo Clásico en la Región Costera de Zihuatanejo y Petatlán, Estado de Guerrero.” In La Época Clásica: Nuevos hallazgos, nuevas ideas, edited by Amalia Cardos de Méndez, 237-265. INAH, Mexico City.

Martin, Simon. 200I. “Under a Deadly Star: Warfare among the Classic Maya.” In Maya: Divine Kings of the Rainforest, edited by Nikolai Grube, Eva Eggebrecht, and Matthias Seidel, 174-185. Könemann, Cologne, Germany.

Martin, Simon, and Nikolai Grube. 2008. Chronicle of the Maya Kings and Queens. Thames and Hudson, London.

Matrícula de Tributos. 1980 [1520-1530]. Facsimile edition with commentaries by Frances F. Berdan and Jacqueline de Durand-Forest, Akademische Druck- u. Verlagsanstalt, Graz, Austria.

Meanwell, Jennifer. 2007. Middle Balsas Project: An Investigation of Pottery Functionality and Chronology. Foundation for the Advancement of Mesoamerican Studies, Inc., Crystal River, FL.

Moedano Köer, Hugo. 195I. "Informe sobre la existencia de la zona arqueológica de El Coyol, Guerrero." Unpublished report, vol. LVII: 408-413. Guerrero. Archive of the Coordinación Nacional de Arqueología, INAH, Mexico City.

Nagao, Debra. 1989. "Public Proclamation in the Art of Cacaxtla and Xochicalco." In Mesoamerica after the Decline of Teotihuacan, AD 700-900, edited by Richard A. Diehl and Janet C. Berlo, 83-104. Dumbarton Oaks, Washington, DC.

Navarrete, Carlos. 1986. "The Sculptural Complex at Cerro Bernal on the Coast of Chiapas." Notes of the New World Archaeological Foundation 1:3-28.

Nielsen, Jesper. 2003. Art of the Empire: Teotihuacan Iconography and Style in Early Classic Maya Society ( $A D$ 380-500). 2 vols. Unpublished PhD dissertation, University of Copenhagen, Copenhagen.

Nielsen, Jesper. 2006. “The Queen's Mirrors: Interpreting the Iconography of Two Teotihuacan Style Mirrors from the Early Classic Margarita Tomb at Copan.” PARI Journal 6(4):I-8.

Nielsen, Jesper. 2014. “'To Sing Arrows': Observations on the Representations of Sound in the Writing and Iconography of Teotihuacan." In A Celebration of the Life and Work of Pierre Robert Colas, edited by Christophe Helmke and Frauke Sachse, 175-191. Acta Mesoamericana 27, Verlag Anton Saurwein, Munich, Germany.

Nielsen, Jesper. In press. "Hearts and Torches: Possible Teotihuacan Military Entradas in North-Central and Western Mesoamerica." In Seeking Conflict: Understanding Ancient 
Hostilities in Mesoamerica, edited by Shawn G. Morton and Meaghan M. PeuramakiBrown. University Press of Colorado, Boulder.

Nielsen, Jesper, and Christophe Helmke. 20r4. "House of the Serpent Mat, House of Fire: The Names of Buildings in Teotihuacan Writing." Contributions in New World Archaeology 7:113-140.

Nielsen, Jesper, and Christophe Helmke. 2015. "Estudio preliminar de la iconografía de los murales de El Rosario, Querétaro, México." In El Valle de San Juan del Rio: Un palimpsesto arqueológico, edited by Juan Carlos Saint-Charles Zetina, 75-83. Archivo Histórico Municipal / Fondo Editorial de Querétaro, Querétaro, México.

Nielsen, Jesper, and Christophe Helmke. 2017. "Feathers, Year-Signs and Big Wigs: The Burdens of Office and Sociopolitical Significance of Headdresses at Teotihuacan." Paper presented January 29 at the International Symposium on the Sociopolitical Organization of Teotihuacan. San Juan Teotihuacán.

Paddock, John. 1972. "Distribución de rasgos teotihuacanos en Mesoamérica." In Teotihuacán-XI Mesa Redonda, 223-239. Sociedad Mexicana de Antropología, Mexico City.

Paradis, Louise I. 2002. "Ahuináhuac, una aglomeración urbana al final del Preclásico y principio del Clásico en la región Mezcala-Balsas, Guerrero.” In El pasado arqueológico de guerrero, edited by Christine Niederberger and Rosa María Reyna Robles, 77-97. CONACULTA / INAH, Gobierno del Estado de Guerrero, Chilpancingo and Mexico City.

Paradis, Louise I. 2010. "Guerrero Region.” In Archaeology of Ancient Mexico and Central America: An Encyclopedia, edited by Susan Toby Evans and David L. Webster, 311-321. Routledge, New York.

Parsons, Jeffrey. 1971. Prehistoric Settlement Patterns in the Texcoco Region, Mexico. Anthropological Papers, Museum of Anthropology, No. 3. University of Michigan, Ann Arbor.

Parsons, Lee A. 1986. The Origins of Maya Art: Monumental Stone Sculpture of Kaminaljuyú, Guatemala, and the Southern Pacific Coast. Dumbarton Oaks, Washington, DC.

Paulinyi, Zoltán. 200I. "Los señores con tocado de borlas: Un estudio sobre el Estado teotihuacano." Ancient Mesoamérica I2(I):I-30.

Piña Chan, Román. 1977. Quetzalcoatl, serpiente emplumada. Fondo de Cultura Económica, Mexico City.

Reyna Robles, Rosa María. 1990. “La Época Clásica en el Estado de Guerrero.” In La Época Clásica: Nuevos hallazgos, nuevas ideas, edited by Amalia Cardos de Mendez, 221-236. INAH, Mexico City.

Reyna Robles, Rosa María. 2002. Esculturas, estelas y lápidas de la Región del Balsas: Acercamiento a su cronología e interpretación. In El pasado arqueológico de Guerrero, edited 
by Christine Niederberger and Rosa María Reyna Robles, 359-386. CONACULTA/ INAH, Gobierno del Estado de Guerrero, Chilpancingo and Mexico City.

Reyna Robles, Rosa María. 2008. "William Niven: Descubriendo el pasado arqueológico de Guerrero.” Diario de Campo. Suplemento No. 49:5I-65.

Reyna Robles, Rosa María. 2013. "Inspección arqueológica en la Alta Sierra Madre del Sur de Guerrero." Arqueología 46:137-152.

Reyna Robles, Rosa María, and Felipe Rodríguez Betancourt. 1994. "Elementos teotihuacanos en el Estado de Guerrero: Nuevas evidencias." In Matices y alcances: Investigaciones recientes en salvamento arqueológico, 95-106. Subdirección de Salvamento Arqueológico, INAH, Mexico City.

Rivera Guzmán, Ángel Iván. 20II. "Cerro de la Tortuga: Un sitio arqueológico con iconografía teotihuacana en la Región Chatina, Costa de Oaxaca." In Monte Albán en la Encrucijada Regional y Disciplinaria: Memoria de la Quinta Mesa Redonda de Monte Albán, edited by Nelly M. Robles García and Ángel Iván Rivera Guzmán, 429-443. INAH, Mexico City.

Rubín de la Borbolla, Daniel F., and William Spratling. 1964. Escultura precolombina de Guerrero. UNAM, Mexico City.

Saint-Charles Zetina, Juan Carlos, Carlos Viramontes, and Fiorella Fenoglio Limón. 2010. El Rosario, Querétaro: Un enclave teotihuacano en el Centro Norte. Tiempo y Región. Estudios Históricos y Sociales, col. IV. Municipio de Querétaro, INAH and Universidad Autónoma de Querétaro, Mexico.

Santley, Robert S. 1989. "Obsidian Working, Long-Distance Exchange, and the Teotihuacan Presence on the South Golf Coast." In Mesoamerica after the Decline of Teotihuacan AD 700-9oo, edited by Richard A. Diehl and Janet C. Berlo, I3I-I5I. Dumbarton Oaks, Washington, DC.

Schmidt Schoenberg, Paul. 2006. "La Época Prehispanica en Guerrero." Arqueología Mexicana 82:28-37.

Schmidt Schoenberg, Paul, and Jaime Litvak King. 1986. "Problemas y perspectivas de la arqueología en Guerrero." In Primer coloquio de arqueología y etnobistoria del Estado de Guerrero, 27-5I. INAH and Gobierno del estado de Guerrero, Mexico.

Sharer, Robert J., David W. Sedat, Loa P. Traxler, Julia C. Miller, and Ellen E. Bell. 2005. "Early Classic Royal Power in Copan: The Origins and Development of the Acropolis (ca. AD 250-600)." In Copán: The History of a Kingdom, edited by E. Wyllys Andrews V and William L. Fash, 139-199. School of American Research Press, Santa Fe / James Currey, Oxford.

Smith, Michael E., and Lisa Montiel. 200I. "The Archaeological Study of Empires and Imperialism in Pre-Hispanic Central Mexico.” Journal of Anthropological Archaeology $20(3): 245-284$. 
Somogny Éditions D’Art. 2009. Teotihuacan: Cité des Dieux. Musée du Quai Branly, Paris. Stone, Andrea. 1989. "Disconnection, Foreign Insignia, and Political Expansion:

Teotihuacan and the Warrior Stelae of Piedras Negras." In Mesoamerica after the Decline of Teotihuacan AD 700-9oo, edited by Richard A. Diehl and Janet C. Berlo, 153-172. Dumbarton Oaks, Washington, DC.

Stuart, David. 2000. “The Arrival of Strangers': Teotihuacan and Tollan in Classic Maya History." In Mesoamerica's Classic Heritage: From Teotihuacan to the Aztecs, edited by Davíd Carrasco, Lindsay Jones, and Scott Sessions, 465-513. University Press of Colorado, Boulder.

Stuart, David. 2017. “The Historical Record of Teotihuacan-Maya Relations.” Paper presented January 29 at the International Symposium on the Sociopolitical Organization of Teotihuacan. San Juan Teotihuacán.

Suárez Díez, Lourdes. 1977. Tipología de los objetos prehispánicos de Concha. Colección Científica. INAH, Mexico City.

Sugiura Yamamoto, Yoko. 2009. "Caminando el Valle de Toluca: Arqueología regional, el legado de William T. Sanders.” Cuicuilco I6(47):87-III.

Taube, Karl. 1992. "The Iconography of Mirrors at Teotihuacan." In Art, Polity, and the City of Teotihuacan, edited by Janet C. Berlo, 169-204. Dumbarton Oaks, Washington, DC.

Taube, Karl. 2000a. The Writing System of Ancient Teotihuacan. Ancient America No. I. Center for Ancient American Studies, Barnardsville, NC.

Taube, Karl. 200ob. “The Turquoise Hearth: Fire, Self-Sacrifice, and the Central Mexican Cult of War." In Mesoamerica's Heritage: From Teotihuacan to the Aztecs, edited by Davíd Carrasco, Lindsay Jones, and Scott Sessions, 269-340. University Press of Colorado, Boulder.

Taube, Karl. 20I . "Teotihuacan and the Development of Writing in Early Classic Central Mexico." In Their Way of Writing: Scripts, Signs, and Pictographies in Pre-Columbian America, edited by Elizabeth H. Boone and Gary Urton, 77-109. Dumbarton Oaks, Washington, DC.

Umberger, Emily. 1996. "Aztec Presence and Material Remains in the Outer Provinces." In Aztec Imperial Strategies, edited by Frances F. Berdan, Richard E. Blanton, Elizabeth Hill Boone, Mary G. Hodge, Michael E. Smith, and Emily Umberger, I5I-179. Dumbarton Oaks, Washington, DC.

Uriarte, María Teresa. 2006. "The Teotihuacan Ballgame and the Beginning of Time." Ancient Mesoamerica 17(I):17-38.

Vélez Calvo, Raúl. 1998. “Etnohistoria.” In Historia general de Guerrero, Vol. ı: Época prehispánica, I4I-478 Gobierno del Estado de Guerrero, JGH Editores, Chilpancingo, México. 
von Winning, Hasso. 1979. “The 'Binding of the Years' and the 'New Fire' in Teotihuacan." Indiana 5:15-26.

Wicks, Robert S., and Roland H. Harrison. 1999. Buried Cities, Forgotten Gods: William Niven's Life of Discovery and Revolution in Mexico and the American Southwest. Texas Tech University Press, Lubbock.

Winter, Marcus. 1998. “Monte Albán and Teotihuacan." In Rutas de intercambio en Mesoamérica, edited by Evelyn C. Rattray, I53-184. UNAM, Mexico City.

Winter, Marcus, Cira Martínez López, and Alicia Herrera Muzgo T. 1999. "Monte Albán y Teotihuacan: Política e ideología." In Ideologá y política a través de materiales, imágenes y simbolos: Memoria de la Primera Mesa Redonda de Teotihuacan, edited by María Elena Ruiz Gallut, 627-644. Conaculta / INAH, Mexico City.

Yarborough, Clare McJimsey. 1992. Teotihuacan and the Gulf Coast: Ceramic Evidence for Contact and Interactional Relationships. PhD dissertation, University of Arizona. University Microfilms, Ann Arbor. 


\section{Chapter 7}

\section{A Sprinkling of Culture}

Contact and Connections between the Tuxtlas Region and the Coastal Maya

Philip J. Arnold III And Lourdes Budar

En este pequeño estudio no pienso hacer más que reseñar brevemente lo que la arqueología nos dice de las relaciones entre Veracruz y la región maya, notando época por época los vínculos más sobresalientes, en una palabra los chipechipes [sic] culturales que han bañado las dos regiones.

\section{J. Eric S. Thompson (1953:447)}

When J.E.S. Thompson offered his brief summary of Veracruz-Maya interaction, archaeological research in both areas was still in its infancy. Investigators struggled to place the newly defined "La Venta" culture in proper context, and the results of early fieldwork at Uaxactún and Chichén Itzá were still coming to light. And yet, despite the relative scarcity of data, it was already clear that a sprinkling of cultural contacts had washed over, and perhaps fertilized, Gulf lowlands development.

Here we offer an update to Thompson's (1953) synopsis. Improved chronologies, better-established stylistic sequences, and new analyses allow us to identify linkages that were unknown more than six decades ago. These recent data underscore important connections, likely facilitated by maritime travel between coastal communities (e.g., Budar 2014). Such connections offer a stark contrast to the overland routes that linked the Gulf lowlands with highland Mexico (e.g., Santley 1989; Smith and Berdan 2003). The characteristics of such maritime interaction may have promoted particular opportunities and restrictions not apparent when considering contact primarily with inland cultures. 
We begin our discussion with a historical review that contextualizes early understanding of interregional interaction in southern Veracruz. This overview underscores the early, Mayan-flavored orientation of early investigations. We then explore evidence for these connections using three data sets, each one emphasizing a particular time frame. First, we consider the development of the Stela-Base-Throne complex, a bundled phenomenon that appears to have originated during the Formative period and continued into the Classic period. We then turn our attention toward fine paste (i.e., untempered) pottery. This ware has played a particularly strong role in evaluating connections between the coastal Maya and other groups. Finally, we present information regarding hollow, mold-made figurines; their use spans the Classic and Postclassic periods. These figurine data especially emphasize coastal connections, revealing interaction between sites in Campeche, Tabasco, and Veracruz.

\section{BACKGROUND}

The Sierra de los Tuxtlas is an isolated volcanic uplift that interrupts the low, continuous coastal plain of southern Veracruz, Mexico (figure 7.I). It is a region long recognized for its fertile land, lush tropical flora, and teeming fauna. Cotton, cacao, and tropical bird feathers were among the region's products highly prized throughout prehispanic Mesoamerica. Moreover, the basalt stone that constitutes a large portion of the sierra provided excellent, accessible material for producing ground stone tools such as manos, metates, celts and, on occasion, larger stone monuments.

The Tuxtlas has also been characterized as a region whose cultural development owes much to outside influence. Several cultural forces, including Teotihuacan and the Aztec Triple Alliance, have been identified as affecting settlement in the Tuxtlas. On one hand, the magnitude of such influence has likely been overstated and recent studies seek to correct it (e.g., Arnold 2014; Budar and Arnold 2014; Stoner and Pool 20I5; Venter 2012). On the other hand, treating the Tuxtlas as a cultural isolate would be an unfortunate and unnecessary overcorrection. It is clear that throughout the prehispanic era, the Tuxtlas affected, and was affected by, various pulses of cultural expression. One important line of investigation, therefore, is to identify the ebb, flow, and directionality of these interactions (e.g., Arnold and Pool 2008; Stark 1990; Stoner and Pool 2015).

For example, scholars have proposed that during the region's Classic period (AD 300-900), the highland Mexican metropolis of Teotihuacan exerted considerable sway over settlements in the sierra (e.g., Coe 1965; Parsons 1978; Santley 2007). Researchers pointed to the Teotihuacan-associated talud-tablero architecture at Matacapan; the presence of green obsidian from the Sierra de las Navajas source in Pachuca, Hidalgo; and the presence of the "Reptile Eye Glyph" on stone 


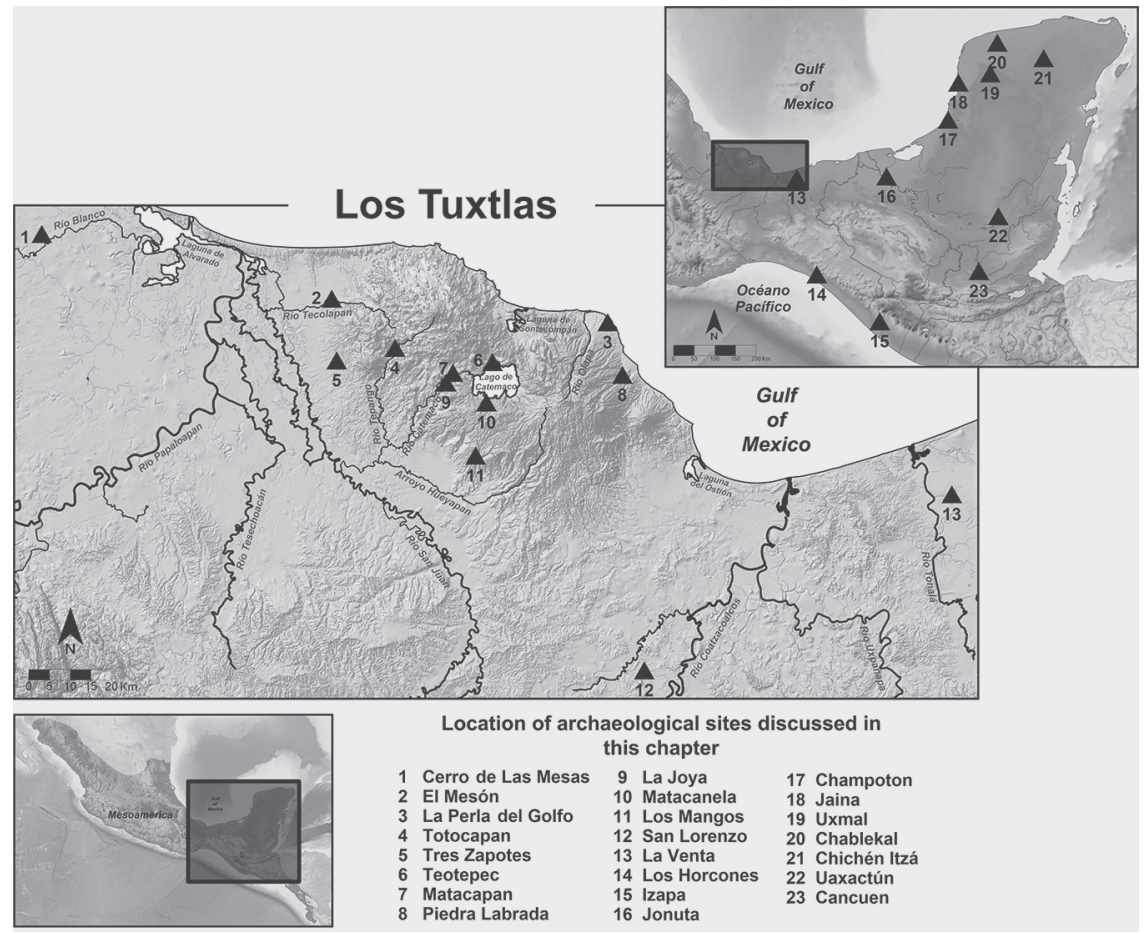

FIGURE 7.I. Regional map detailing locations of sites mentioned in the text (adapted from Budar and Becerra Álvarez 2015).

monuments at Piedra Labrada. Several studies have treated the nature of this highland presence and have offered increasingly nuanced treatments of those contact (e.g., Arnold and Santley 2008; Budar and Arnold 2014; Pool 1992; Santley et al. 1987; Stoner and Pool 2015).

Occupation during the Late Postclassic (ca. AD 1300-1500) was viewed as influenced by the Aztec Triple Alliance. Geopolitical reconstructions based on ethnohistoric documents place at least a portion of the Tuxtlas under the thumb of the Triple Alliance (e.g., Barlow 1949; Gerhard 1993). Regional archaeological research at Totogal and Agaltepec has recovered material culture, such as Texcoco Molded pottery, that replicates external Aztec conventions (Arnold and Venter 2004; Venter 2008). Additional surveying has documented inscribed monuments that suggest an affiliation with the Triple Alliance (e.g., Urcid and Killion 2008).

Thus, much of the research attention given to occupation within the Tuxtlas has been directed toward connections with the Mexican highlands. It is noteworthy, 


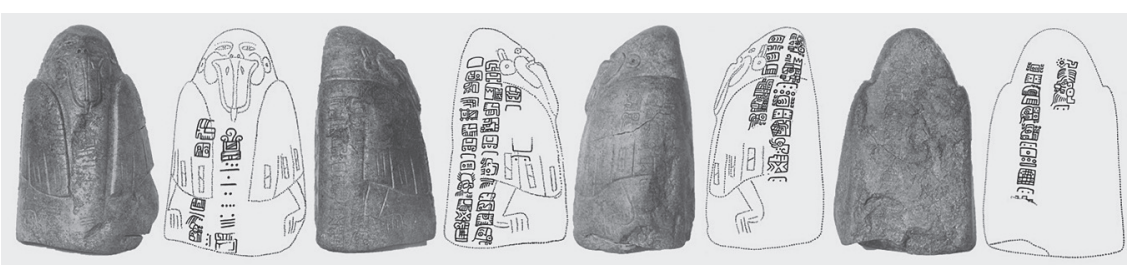

FIGURE 7.2. The Tuxtla Statuette (illustration by Lourdes Budar).

however, that the lowland Maya (particularly as perceived in the 1920s-1940s) were generally recognized as providing the major impetus for Tuxtlas cultural development.

The early discovery of the Tuxtla Statuette (figure 7.2), with its inscriptions and long-count calendric notation, suggested to researchers that Mayan influence had reached-or actually commenced-in southern Veracruz. The Tuxtla Statuette is a portable greenstone sculpture that depicts a human wearing what appears to be an avian costume, including a waterfowl buccal mask and sporting a possible cape representing wings. More important, it includes several columns of inscribed glyphs and a long-count date. When the Tuxtla Statuette was first reported, Holmes (1907:70I) concluded that "the inscribed figurine may be regarded as a probable relic of the former Maya occupancy of the region about San Andres Tuxtla." Doubling down, other scholars, such as Sylvanus G. Morley, suggested that the glyphs and long-count calendrics were of a later date, but purposefully executed in a more archaic style (Diehl 2004:I84; Morley 1946:4I-42). ${ }^{1}$ The possibility that the writing was something other than Mayan was scarcely considered.

The discovery of the Tuxtla Statuette, in turn, provided an important impetus for the 1925 Tulane Expedition to Middle America. Frans Blom and Oliver La Farge undertook a journey that covered a considerable portion of southern Veracruz, including the Tuxtla Mountains. The expedition was designed to obtain information on "the history of the ancient Maya, the Maya country, the daily life of the Maya descendants, and the methods used in modern archaeological research" (Blom and La Farge 1926:4). The Sierra de los Tuxtlas was specifically targeted:

The great Maya cultural centers lay east of the Isthmus of Tehuantepec. An outlying branch of Indians speaking a dialect of the Maya language is still found in the Huasteca, south of Tampico. Little is known about the link between these two, and it has long been desirable to investigate the region between the Maya proper and the Huasteca. The lack of information on the area between these two groups of the same language, and the existence of the Tuxtla Statuette was enough to warrant an 
expedition to the Tuxtla Mountains. To add to this, a photograph of a monolith had recently been received at Tulane University-a stone monument carved with figures that looked somewhat like Maya glyphs. This photograph was sent by a Mexican engineer, Sr. Rafael de la Cerda, of Mexico City, who had made some explorations in the region in question in search of petroleum. At a place called Piedra Labrada he had seen some other stone monuments. (Blom and La Farge 1926:17)

Blom and La Farge made their way through the Tuxtla Mountains documenting sites and sculpture where present. When the expedition arrived at Tabasco, they identified Maya influence on several of the La Venta sculptures. Notably, they also began to differentiate between the art style at La Venta and the sculpture noted during their travels through the Tuxtlas: "It might be well to summarize the discoveries at La Venta. We have here a collection of huge stone monuments, and at least one large pyramid. Some features of these monuments are similar to things seen by us in the Tuxtla region; other features are under strong influence of the Maya culture to the east" (Blom and La Farge 1926:90). In fact, La Venta's perceived similarities with Maya style were considered so strong that the researchers were "inclined to ascribe these ruins to the Maya culture" (Blom and La Farge 1926:90).

Continued interest in establishing the extent of the ancient Maya throughout southern Veracruz also fueled part of the multiseason activities (1938-1946) directed by Matthew Stirling and funded by the National Geographic Society. Of course, these activities would ultimately revolutionize our understanding of the Olmec culture along the southern Mexican Gulf lowlands (e.g., Diehl 2004; Pool 2007). Nonetheless, when the project started, it was oriented toward investigating Maya civilization (Lyon 1997:8-9).

The fortuitous discovery of Stela C during Stirling's first season at Tres Zapotes (Stirling 1939, 1943) promoted additional interest, as well as confusion, regarding a possible Mayan connection. The monument's reconstructed long-count sequence placed it several centuries prior to anything dated from the Maya lowlands at that time. Moreover, Stela $\mathrm{C}$ was recovered on its side and had apparently been reset by a group unfamiliar with its original message. Thus, the cultural arena under question expanded to include chronological issues as well as geographical coverage. "Did the ancestor of both the Maya and the Huastec formerly live in southern Vera Cruz [sic]?" wrote Stirling (1939:135) following the first year of fieldwork. One year later, Stirling (1940:312,333) jettisoned the attribution "Maya" and began to use the newly coined term "Olmec" to describe the prehispanic occupation at Tres Zapotes. At the same time that Stirling (1939) started his research, Mexican archaeologist Juan Valenzuela, accompanied by Karl Ruppert of the Carnegie Institute, and topographer Agustín García Vega, began two seasons of fieldwork throughout the 
Tuxtlas. Valenzuela (1945a:83) noted that an important thrust of the project was to establish potential connection between the Tuxtlas and the known prehispanic cultures of Oaxaca and the Basin of Mexico. Moreover, the project was particularly interested in recovering information relevant to "the florescence of the great Maya culture" (Valenzuela 1945a:83).

Valenzuela's (1945a) work at the site of Matacapan, with its evidence of potential Teotihuacan affiliation, set the stage for much later intensive investigations within the site and the surrounding region (e.g., Santley 2007). Nonetheless, Valenzuela (1945a:107) concluded his report of the first season with the observation that there also "existed a strong influence of the Maya culture, representing various time periods." In fact, reporting on the results of his project's second season, Valenzuela (1945b:93) confidently asserts: "It is undoubtable, moreover, that the most abundant and characteristic elements are from the great Maya culture."

One final discussion of the southern Veracruz-Tabasco region is in order. Michael Coe's (1965) influential overview for the Handbook of Middle American Indians covered the zone's entire prehistory and provided a synthesis that is still useful over fifty years later. Coe was involved in his San Lorenzo Tenochtitlán research (Coe and Diehl 1980) when the Handbook piece was written, and his synthesis quickly dispelled any connection between the earlier Olmec occupation and a later Maya presence. Coe (1965) notes two Classic period waves of external influence in the region: an Early Classic (AD 300-600) expression that owes much to Teotihuacan, and a Late Classic (AD 600-900) "macrostyle" that "is highly Mayoid, under the cultural shadow of Late Classic Maya culture in Yucatan" (Coe 1965:705). In particular, he notes similarities in the figurine style between Mixtequilla examples and Jaina figurines. Coe (1965:707) also calls attention to similarities in the ceramics, especially as related to Z Fine Orange from Uxmal and Y Fine Orange at Uaxactún. Nonetheless, in Coe's (1965:715) opinion, "the Late Classic of southern VeracruzTabasco strikes one as a peasant phenomenon, with no great art but with some amusing clay figurines."

Thus, early investigations in the Tuxtlas and throughout southern Veracruz were directly tied to revealing the origins of the lowland Maya civilization. Evidence of early long-count dates, on both portable and installed sculpture, suggested that the "Mayan" calendar may have developed in southern Veracruz.

\section{SPRINKLES OF CULTURAL CONTACT}

As researchers undertook additional studies, they uncovered multiple lines of evidence that suggested cultural contact throughout the Gulf Coast lowlands. Below we consider aspects of three data sets, noting relationships through time and across 
space. The first, the Stela-Base-Throne complex, is the oldest of these phenomena and links the Tuxtlas to Pacific coast groups across the Isthmus of Tehuantepec. The second example involves fine paste ceramics, whose Late Classic distribution has been especially noted among lowland Maya scholars. Finally, we consider hollow, mold-made figurines. Also produced from an untempered paste, these portable images enjoyed widespread popularity starting at the end of the Classic period and continuing into the Postclassic.

Of importance is that this presentation underscores that such contacts are rarely unidirectional or all encompassing. Rather, segments of ideologies and material culture may be appropriated, reconfigured, and reintroduced. Cultural traits often move in multiple directions and are manipulated differently by active participants who are donors as well as recipients (see, e.g., Budar and Arnold 2014; Stoner and Pool 2015; Venter and Pool 2014).

\section{The Stela, Base, and Throne Complex}

The Stela, Base, and Throne Complex (SBTC) illustrates nicely how a consistent grouping of items characterized and linked the southern Gulf lowlands and portions of the Maya region. The SBTC is also an example of a sculptural corpus that appeared very early along the Gulf Coast, perhaps earlier than in the Maya zone. Without realizing it, Blom and La Farge (1926) initiated the study of the SBTC by recording individual pieces of sculpture over the course of their expedition. Their data allow us to reconstruct thirty-four possible examples of the SBTC (table 7.I). These documented cases range from Piedra Labrada to Chiapas, but in reality the SBTC easily extends into south-central Veracruz (e.g., at Tres Zapotes and Cerro de las Mesas; cf. Stirling 1943) (figure 7.3).

A sculptural complex is more than a work of art; it is also a representational code. Various elements create a visual discourse and can be understood when taken together. In this sense, the stela and base along with its throne and/or altar component appear to be one of those devices born in the Terminal Formative, possibly in the Soconusco region (Budar and Becerra Álvarez 2015). Specialists such as Guernsey (2006:3I-32) suggest that the prototypes of the sculptural concept of "stela-base" can be traced back to earlier times when smooth basalt columns constituted an initial stela preform. Nonetheless, at La Venta, where the majority of studies situate the beginning of stela installation, the stela constitutes a radical innovation within the discursive model, combining the high relief of the central figure and the low relief of the secondary adjacent figures in a vertical position. Beginning with the Middle Formative, stelae were included in the public architectural program, giving them constant visual access. In Tres Zapotes, the installation 
TABLE 7.I. Number of Stela-Base-Throne Complexes (SBTCs) at Selected Sites.

\begin{tabular}{lc}
\hline Sites & No. of SBTCs \\
\hline Piedra Labrada & I \\
La Venta & 3 \\
Tortuguero & 3 \\
Palenque & I \\
Chuctiepá & I \\
Yoxihá & Io \\
Tonina & 6 \\
San José Reforma & I \\
Comitan & I \\
Tenam & I \\
Chinkultik & 6 \\
Total & 34 \\
\hline
\end{tabular}
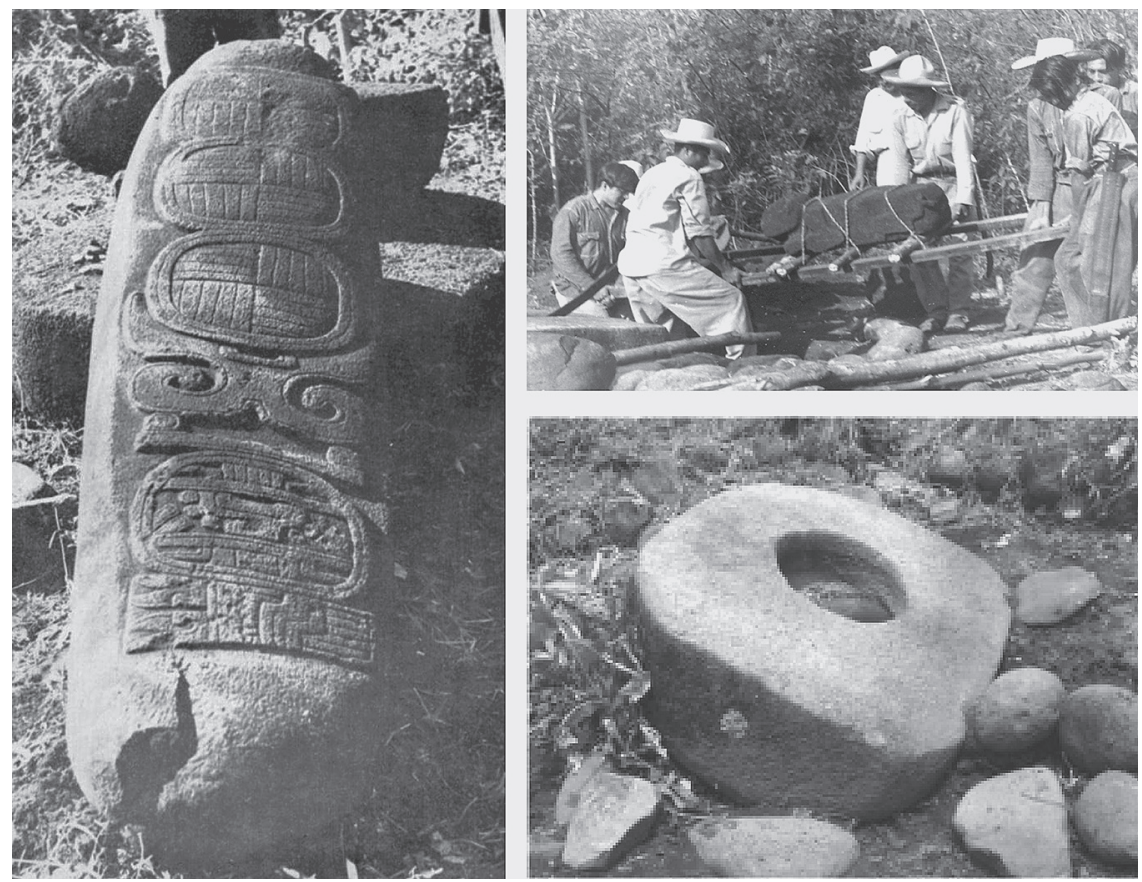

Fig URE 7.3. Stela-Base-Throne Complex in situ at Piedra Labrada (I960) (photographs by Eraclio Zepeda, from archives of Lourdes Budar). 
of these monuments includes a component that would be fundamental to the later SBTC tradition: the insertion of long-count calendar dates.

The pattern of erecting stela in combination with other sculptural elements, whether bases or thrones, appears to be an innovation that is commonly installed in patios or plazas surrounded by mounds and platforms (Budar and Becerra Álvarez 20I5). Unfortunately, when the individual elements of the SBTC are separated, it can be difficult to establish the discursive function of the whole; nonetheless, the case of Izapa is relevant, because here the majority of the monuments-especially the stelae, their bases, and altars—were found in situ (see, e.g., Norman 1976).

The stela of Izapa were arranged around different plazas and were found in approximately the same stratigraphic level (Lowe et al. 1982:159). This association suggests that that these monuments were all sculpted during the Guillén phase (350-50 BC; Lowe et al. 1982:23, 133). Similarly, Norman (1976:324) indicates that the monument grouping at Izapa exhibits a reduced stylistic evolution, which makes it likely that they are intended to be viewed as a unit. This unit integrates the space to produce images and messages from a singular sculptural and architectural program that demarcated the site's sacred space (Guernsey 2006:30).

Following Reilly (1994), the installation in the centers of the site's public architecture suggests that local elite adopted, manipulated, and implemented the SBTC. Such elite control is an essential and effective method to mark the political ideology, cosmology, and ritual actions of these leaders in a more permanent manner (Budar and Becerra Álvarez 2015). Guernsey (2006) has suggested that the SBTC personifies the central rituals of the fundamental authority, being analogs to the specialists that participated in the festivals and rituals.

We know that stelae had a commemorative function; their installation validated and legitimated important successes in time and space, integrating them into the historical development of the society (Budar 2010). The majority of these monuments alludes to political or religious events, or makes reference to individuals. However, one cannot discard the idea that these monuments could have served as a medium of political propaganda, highlighting the claim even more than the event. Stelae constituted the most effective means to create enduring discourse via a system of writing: births, marriage alliances, royal views, battles, conquests, captive taking, and leader's enthronement, as well as astronomical events and religious observations. Early examples of stela with inscriptions are found in sites such as Tres Zapotes, Los Mangos, Cerro de las Mesas, and Izapa. Nonetheless, the apex of erecting monuments occurred during the Classic period with the greatest number found in the Maya region.

In the Tuxtlas, both Piedra Labrada and Matacanela offer documented cases in which elements of the SBTC contribute to discursive programs. Piedra Labrada is 
FIGURE 7.4. Piedra Labrada Stela I (illustration by Lourdes Budar).

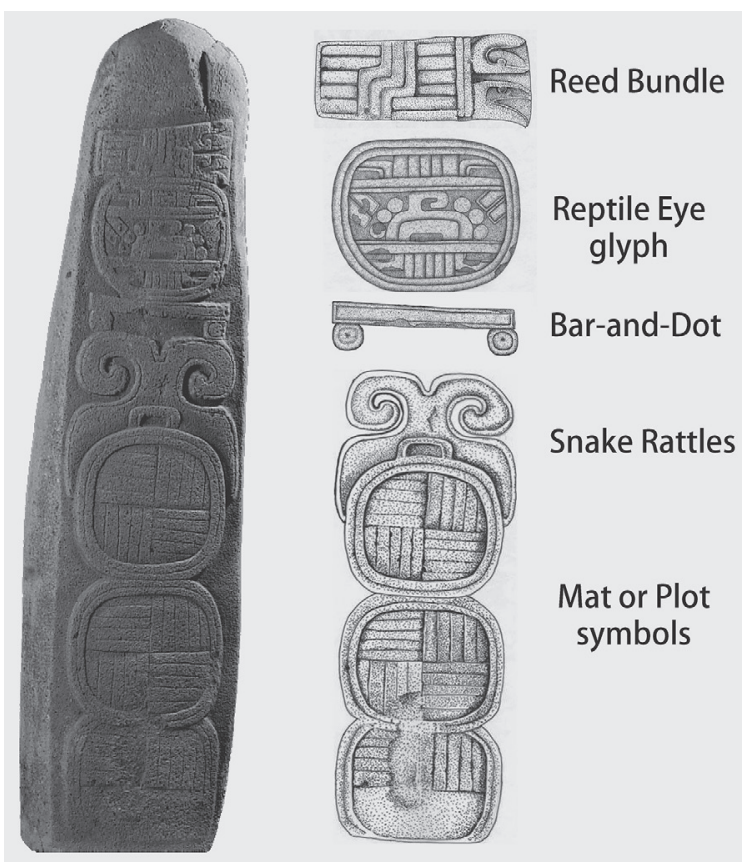

located in the coastal zone east of the Tuxtlas and includes occupation from the Middle Formative (Budar 2008). The case of Stela I at Piedra Labrada puts in perspective a complicated historical trajectory for the region. This SBTC involves a sculpture reminiscent of the columnar basalt common in the Middle Formative of southern Veracruz; however, the iconographic elements engraved on the stela are associated with the Middle Classic, particularly the emblems of Teotihuacan style, as well as the bar-and-dot numbering system.

Piedra Labrada Stela I (figure 7.4) contains a series of inscriptions that do not make much sense together, in that there is no other monument with the same iconographic pattern. The stela, carved on only one side, exhibits a reed bundle, the Reptile Eye glyph, the bar-and-dot number seven (although upside down, with the dots below the $\mathrm{bar}^{2}$ ), snake rattles, and two complete mat or plot symbols with a third that represents only the middle of the same symbol (Budar 2013).

The inscriptions on Piedra Labrada Stela I are, according to many scholars, an irrefutable marker of Teotihuacan influence (e.g., von Winning 196I). But the truth is that the majority of elements associated with Teotihuacan "writing" did not originate at Teotihuacan but rather they derived from other regions (Budar 20I0; Taube 200I). For example, the "four-way hatching" glyph, the same that Blom 


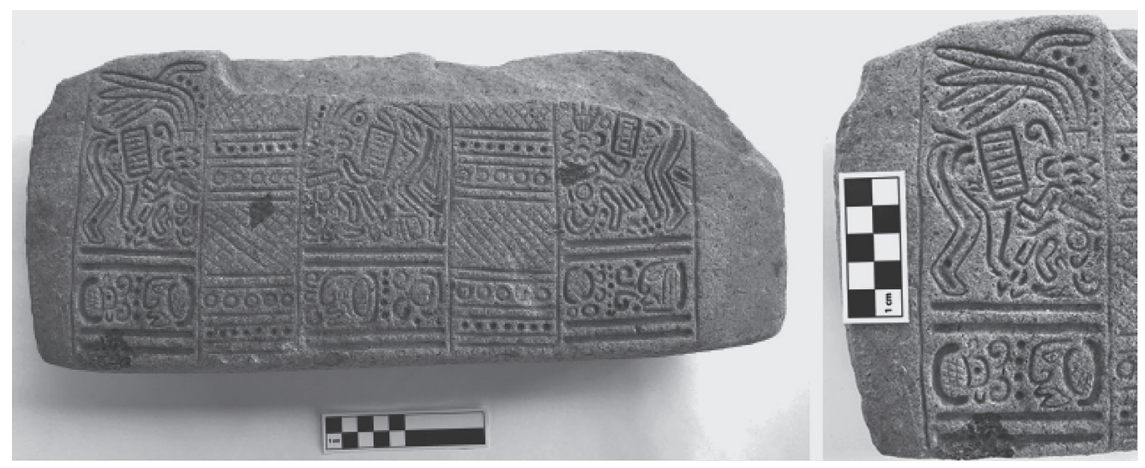

FiguRE 7.5. La Perla del Golfo carved stone block (photographs by Lourdes Budar).

and La Farge (1926:40-4I) associated with the Maya "Pax" glyph, appears repeatedly on the monuments that Carlos Navarrete located during his investigations at Los Horcones in Cerro de Bernal, Chiapas (Garcia-Des Lauriers 2007; Navarrete Cáceres 1976). Like the Piedra Labrada stela, the Los Horcones monuments are associated with central highland glyphs as well as Mayan glyphs.

Three stela bases and an unworked stela also occur in other architectural complexes in Piedra Labrada. Unlike Piedra Labrada Stela I, these monuments are not distributed across the central plaza but rather are located in a courtyard near the site's Central Plaza 2. Moreover, the stela that remains on the site is undecorated; it contains no inscriptions nor details that could indicate that it was engraved, though, as has been proposed by other scholars, smooth stelae could have been stuccoed or painted, and this decorative material may have since eroded (Guernsey 2006:36; Parsons 1986:63). The important thing about this evidence is that, as seen in other sites in the Gulf Coast region, the SBTC is integrated into the central programs of public architecture.

The Reptile Eye glyph and the reed bundle have long been recognized by investigators as originating in the highlands, while the "four-way hatching" symbol has been attributed to the Maya (Budar 2013). Thus, Stela I at Piedra Labrada offers a combination of two traditions fused in a very particular way that also appears as a common trait in the Tuxtlas. This same combination of traditions is visible in Tuxtlas Polychrome (Arnold 2014; Coe 1965), in the local figurine tradition (see below), and in a carved stone block recently uncovered near La Perla del Golfo on the Santa Marta coast (figure 7.5).

The sandstone block measures $15 \mathrm{~cm}$ wide $\times 40 \mathrm{~cm}$ long and presents an iconographic combination that speaks to two traditions. It is divided into five vertical 

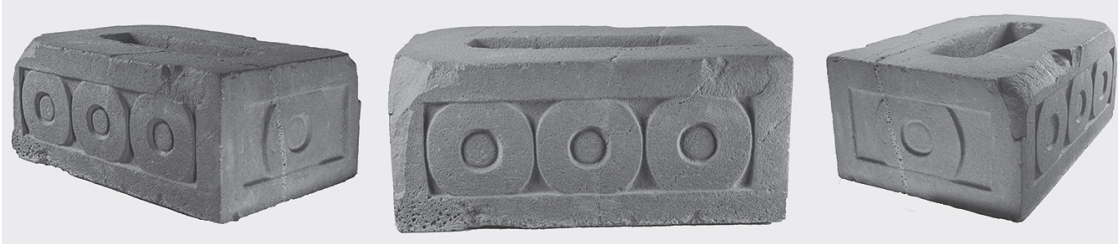

FIGURE 7.6. One of the three boxes of Matacanela, currently in the Museo de Antropología de Xalapa-Universidad Veracruzana (photographs by Lourdes Budar).

sections: three of which include figures that could be interpreted as ballplayers who wear belts in the form of yokes, an elaborate feather headdress, and ear spools. These figures correspond most closely to the style of south-central Gulf Coast; however, at the bottom portion of each of the three columns are divisions marked by two upper and lower lines. Between these lines is a small inscription rendered in a Mayan style that is repeated in the three sections. Alejandro Sheseña and Rogelio Valencia (personal communication, 2016) have identified the inscription as the logogram K'AY, or "singer," which is composed of a human head accompanied by a virgule. Nonetheless, additional analysis is still required.

Matacanela, in the south central Tuxtlas, is the only other site that contains a group of monuments that can be considered to represent a SBTC. Blom and La Farge (1926:23) identified three "boxes" as elements of the sculptural complex, and that designation has remained (figure 7.6). Unfortunately, we lack the information that pertains to the early twentieth-century work of Seler and Sachs, who excavated these monuments at Matacanela, so we do not know how many sculptures made up this complex (Hanffstengel and Tercero 2003; Seler-Sachs [1922] 1996). Nonetheless, neither Blom and La Farge in 1925 (Blom and La Farge 1926) nor Juan Valenzuela and Ruppert in 1937 (Valenzuela 1945a) were able to identify any lids for these "boxes," and none of these three sculptures are consistent in shape or size. Stone boxes had their heyday during the Postclassic period in highland Mexico.

We propose that these rectangular sculptures are not "boxes"; rather, the characteristics of these pieces better conform to a particular type of stela bases. In fact, Seler-Sachs ([1922] 1996:xi) noted that these sculptures included "squared incisions with a mortise hole, as if they had been pedestals for figures."

We also recognize that neither group of investigators documented stela among the six other sculptures that they mention from Matacanela. Nonetheless, three possible scenarios (and not necessarily mutually exclusive) may account for this lack of mention: (I) between 1907 and 1925 the stela at Matacanela were moved, stolen, or destroyed; (2) the stelae may have been made of wood and decayed before they 

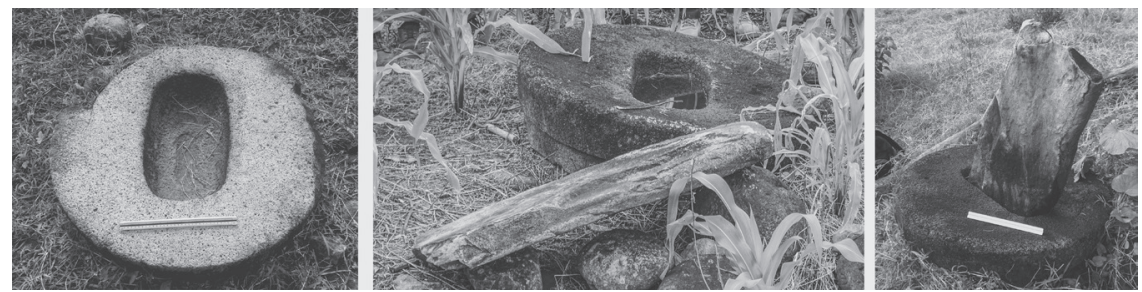

FIGURE 7.7. Stelae Bases in situ, Complex 2 of Piedra Labrada (photographs by Lourdes Budar).

could be documented; or (3) the stelae were undecorated and did not attract the attention of the researchers. This latter possibility is not that surprising, given that several areas within Matacanela contain prismatic basalt blocks of different thicknesses and sizes on the site's surface.

This case is not isolated, however, since Complex 2 at Piedra Labrada exhibits similar characteristic. Bases of stelae, similar in form to the sculpture from Matacanela, have been registered, but the stelae themselves were not recovered (figure 7.7). This makes Matacanela and Piedra Labrada the only two sites in the Tuxtlas known to contain the SBTC.

Tres Zapotes is probably the closet site to Matacanela that exhibits monuments that are associated with this sculptural complex. The celebrated Monument $C$ from Tres Zapotes is an elaborately carved stone "box" excavated by the Selers in the early 1900 s (Seler-Sachs [1922] 1996:X; see also Stirling 1943:18-2I). A second, undecorated "box" (Monument B) was also recovered from Tres Zapotes (Stirling 1943:17-18).

As noted above, Stela $\mathrm{C}$ is a basalt monolith that on one side displays a large mask rendered with human traits and is associated with the Olmec style. The other side, however, provides a bar-and-dot calendar date of 7.16.6.16.18 (32 BC) making it the oldest, most complete long-count date recovered to date. This date also makes Stela $\mathrm{C}$ at Tres Zapotes a contemporary of the Guillén phase monuments installed at Izapa. According to Stirling's data, the majority of these monuments was recovered from the flat areas of Mound Group 3 in the northern portion of Tres Zapotes and, at least in the case of Stela C, was associated with an "altar" (Stirling 1943:14).

Cerro de las Mesas is another site relatively close to the Tuxtlas that contains interesting characteristics in terms of the SBTC. Between 1939 and 1940, Stirling (1943) registered at least eighteen sculpted monuments, several of which were found in the so-called Monument Plaza, along with at least twelve stelae. These stelae include images of individuals accompanied by columnar glyphic inscriptions. It is worth noting that the time span recorded on the monuments is restricted to the period between AD 300 and AD 600, ${ }^{3}$ that is, the Early/Middle Classic in the Tuxtlas. 
Cerro de las Mesas was one of the influential regional sites of central southern Veracruz and has demonstrated connections to the site of Totocapan, located in the northwestern portion of the Tuxtlas (Stoner 20II). Paradoxically, Totocapan has not produced evidence for the SBTC in its discursive devices. Similarly, the central portion of the Tuxtlas has not produced monuments that conform to this sculptural complex. Thus, it would appear that the SBTC configuration was only utilized on the eastern edge of the Tuxtlas and possibly extended into the low, inundated zone of central south Veracruz by a coastal route.

\section{Fine Paste Pottery}

Fine paste pottery (i.e., pottery lacking visible temper) is one of the more diagnostic ceramic wares in lowland Mesoamerica. By the 1930s, researchers within the Maya lowlands, particularly the Yucatán, identified fine paste pottery as a particular ceramic type that could be useful in identifying relationships between highland and lowland regions (Brainerd 194I). Subsequent studies provided finer-grained classifications of the ware and continued to emphasize fine paste pottery (especially what became called Fine Orange) as a useful reference for chronological placement and interregional contact (e.g., Berlin 1956; Bishop 2003; Bishop and Rands 1982; Jiménez Alvarez 2015; Smith 1956, 1958). Most of these studies suggest that fine paste pottery in their respective regions dates primarily to Late/Terminal Classic (ca. AD 800-900) and Postclassic (> ca. AD 900) periods. Moreover, most researchers seem to agree that the major production/consumption zone for this ware includes the coastal region of the Gulf of Campeche, stretching from central Veracruz through Tabasco and moving northward along the coast of the Yucatán (e.g., Brainerd 1941; Jiménez Alvarez 2015).

Readers could be forgiven, therefore, for thinking that the adoption of fine paste ceramics is primarily an "end-of-the-Classic" phenomenon. And while this characterization may be valid for the Maya region, it does not hold for the lowlands of southern Veracruz. According to Annick Daneels (2006:479) the use of untempered, kaolinite clays distinguishes Classic period southern Veracruz from the pottery assemblages that characterize the remainder of the state at this time. Excavated contexts in and around the Tuxtlas (e.g., Esquivias 2002; Ortiz and Santley 1988; Pool 1990), as well as to the north (Stark 200I) and south (Symonds 1995) of the uplift, reveal the presence of untempered pottery by the first half of the Classic period. Additional research across the coastal zone also implicates the Classic period adoption of this ware (e.g., Loughlin 2012; Sisson 1976; von Nagy 2003). Pool and Britt (2000) suggest that the Classic period appearance of untempered pottery in the Tuxtlas is associated with updraft kiln firing 
and the additional visual and tactile performance characteristics afforded by that pyrotechnology. Specifically, they suggest that a volcanic eruption at ca. AD 250 disrupted ceramic consumption and, in combination with new ceramic attributes informed by external influence, promoted selection for oxidized, fine paste wares (Pool and Britt: 2000:158).

Researchers have noted both temporal and spatial trends in the adoption of these fine paste wares along the southern Gulf lowlands and across the Bay of Campeche. For example, throughout southern Veracruz, pottery made from Fine Orange/Buff pastes generally precedes Fine Gray fabrics (e.g., Daneels 2006; Pool 1995). The Maya lowland sequences that depart from this pattern usually begin with a version of fine paste gray wares sometime after AD 750 (see, e.g., Bishop 2003; Bishop et al. 2005; Jiménez Álvarez 2015). As noted below, there is tendency for the ceramic sequence of southern Veracruz to move from Fine Orange to Fine Gray and then back to Fine Orange. Thus, the gray-to-orange transition within the Maya region simply captures the latter portion of a longer, oscillating sequence in play along the southern coastal lowlands.

At Matacapan, the beginning of the Classic period is marked by Fine Buff and Fine Orange pottery. Fine Buff (Matacapan Bayo Fino, Type 30 ) is considered to be a reproduction of a ware associated with Teotihuacan and often occurs as cylindrical tripod vessels (Ortiz and Santley 1988:100-114). Pool (1990:230-237) excavated a ceramic production area at Matacapan dated to Phase C, or the beginnings of the Classic period (ca. AD 300). This production context included the remains of a simple updraft kiln and produced a ceramic rim assemblage that exhibited almost 30 percent of Fine Buff sherds.

Additional research by the Matacapan Project (Arnold et al. 1993; Pool 1990; Santley et al. 1989) demonstrates that Fine Orange pottery (Matacapan Type 6) became increasingly common during the site's Middle Classic occupation (ca. AD 450-650). Excavated production contexts, in addition to physicochemical analyses, clearly indicate that ceramics with Fine Orange paste were produced at multiple locales throughout the Tuxtlas (Arnold 2014; Pool and Santley 1992; Stoner and Glascock 2011).

Recent investigations at the site of Teotepec (Arnold and VanDerwarker 2008; Thompson et al. 2009) reveal that polychrome images rendered upon a fine orange paste also characterize occupation within the Tuxtlas by approximately AD 550 . This type, known as Tuxtlas Polychrome (Matacapan Types II and I2; Arnold 2014; Coe 1965; Ortiz and Santley 1988), has been documented in deposits stretching from the western Lower Papaloapan Basin (Pool and Santley 1992; Stark 200I) to the Hueyapan region along the southern foothills of the Tuxtlas (Esquivias 2002). This ceramic is frequently associated with a Late Classic date (Coe 1965; Daneels 


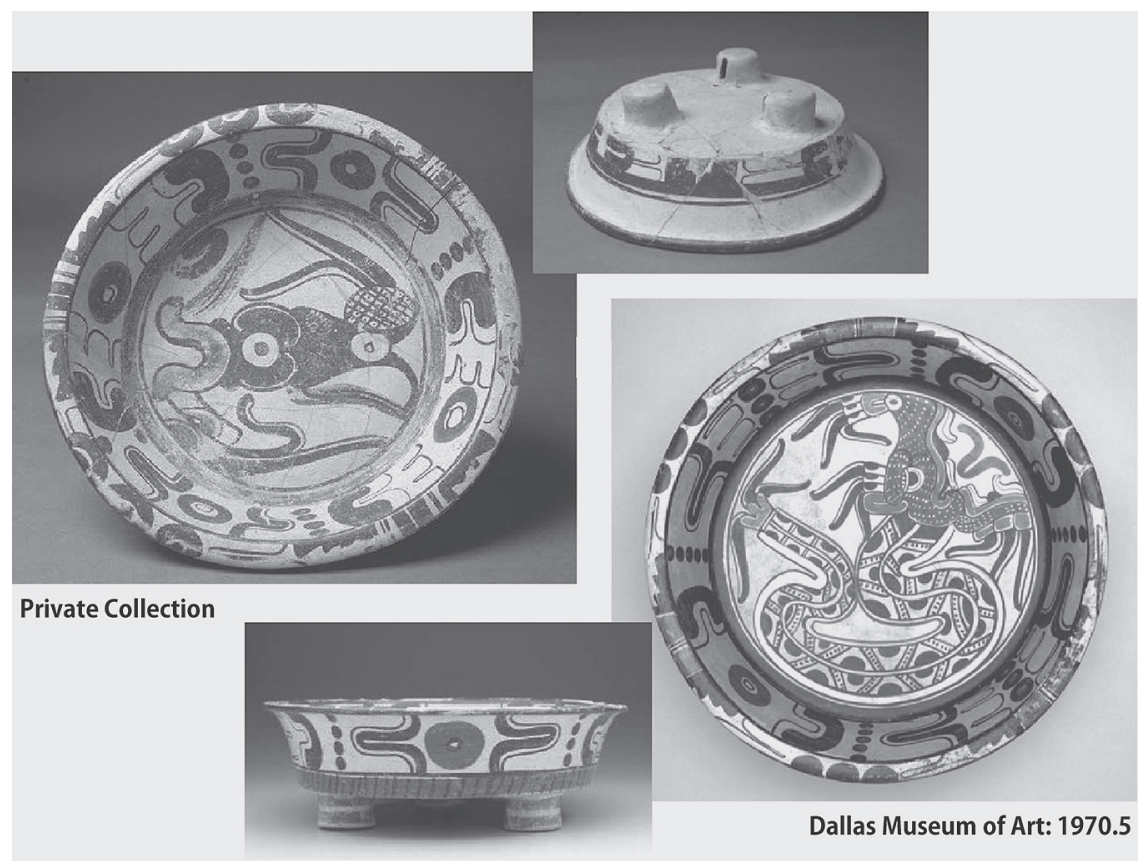

FigURE 7.8. Some examples of Tuxtlas Polychrome.

2006; Pool 1995), but excavations at Teotepec now indicate an earlier appearance for Tuxtlas Polychrome (Arnold 2014; see figure 7.8).

During the Late Classic in the Tuxtlas (ca. AD 650-900), Fine Gray pottery (Matacapan Type I) achieves its maximum popularity and appears throughout southern Veracruz. Pool (1990:324-325) excavated a Fine Gray production context at Matacapan; these data suggest that Fine Gray manufacture may have exceeded that of Fine Orange at this time. A gray, fine paste pottery also appears in the Coatzacoalcos basin during this time period (Zapote Fine Orange to Gray, Coe and Diehl 1980:218; Type 25, Symonds 1995:299-300).

Nonetheless, Late Classic contexts from other portions of southern Veracruz indicate that pottery made from a fine orange paste continued to be popular. For example, the end of the Classic period in and around San Lorenzo (e.g., Coe and Diehl's [1980] Villa Alta phase) is marked by the appearance of Campamento Fine Orange (Coe and Diehl 1980:214-217). Coe and Diehl (1980:216) recognized that Campamento Fine Orange "is somewhat different from all Fine Orange types described thus far for the Maya area and Tabasco" and also noted that it may have antecedents in the earlier types recovered from Tres Zapotes (Coe and Diehl 
1980:213). Despite these observations, they concluded that Campamento Fine Orange "was ultimately derived from the Maya area" (Coe and Diehl 1980:216).

Stacey Symonds (1995) subsequently excavated Late Classic deposits near San Lorenzo in an attempt to clarify the character of the Villa Alta phase. As did Coe and Diehl (1980), Symonds (1995:329) concluded that Campamento Fine Orange (Symond's Type I) was not a product of local inspiration. Unlike prior assessments, however, Symonds emphasized the connections between Campamento Fine Orange and the Middle Classic Fine Orange from the Tuxtlas, as well as formal similarities with vessels from the Mixtequilla region to the northwest.

The region's Postclassic pattern indicates a reversal (in the Tuxtlas) or a continuation (in other areas) to an emphasis on fine orange ceramics. Early Postclassic (ca. AD I000) occupation at Isla Agaltepec is marked by Fine Orange ceramics (Arnold and Venter 2004), as is the contemporary presence in the Coatzacoalcos drainage (Coe and Diehl 1980; Symonds 1995:663-665). The resurgence of orange, fine paste pottery during the Postclassic is consistent with the patterns reported in other portions of the coastal lowlands (e.g., Jiménez Álvarez 2015; Smith 1958).

Finally, there appears to be a general north-to-south temporal trend along the Gulf lowlands reflecting the adoption and distribution of fine paste wares. As noted above, the earliest fine paste pottery within southern Veracruz marks the beginning of the Classic period. The timing of this association is well documented from excavation and survey from the Mixtequilla (Stark 200I) through the El Mesón region (Loughlin 2012:137) and Tres Zapotes (Pool 2003), and into the sierra as represented in its Río Tepango Valley (Stoner 20Ir:26I) and the Río/Lake Catemaco regions (Arnold and McCormack 2002; Arnold and VanDerwarker 2008; Ortiz and Santley 1988; Pool and Santley 1992; Pool and Britt 2000; Santley and Arnold 1996).

Speaking from her vantage within the Coatzacoalcos drainage, Symonds (1995: 329) notes: "The regional settlement pattern and ceramic sequence appears to indicate that fine orange appeared first to the north and west of the lower Coatzacoalcos drainage, moving into this region in the late stages of the Middle Classic, developing into a full blown diagnostic of the Terminal Classic period as the population increased to its greatest density."

It is also worth remembering that areas to the southeast of the Tuxtlas, such as the Río San Juan and Coatzacoalcos drainages, were largely depopulated during the middle portion of the Classic period (Arnold 1997; Borstein 2001, 2005; Symonds et al. 2002). Nonetheless, occupation along the Santa Marta coastline remained strong at this same time (Becerra Álvarez 20I2; Budar 2014). This difference suggests that coastal movement, rather than overland interaction, was an important force during the middle centuries of the Classic period. 
Research within the area of Champoton, coastal Campeche underscores this transition. Jerald $\mathrm{Ek}$ (2OI2) argues that fine paste ceramics first appear during the Champoton 5 period, starting approximately AD 700. According to his analysis: "The Champoton 5 phase reflects a radical reorientation to the Gulf Coast in terms of demography, direction of cultural influence, norms of ceramic production, trade networks, and economic organization ... Fine paste groups produced in the lower Usumacinta region of Tabasco and as far as southern Veracruz are found in high frequencies and within a wide range of contexts, indicating increasing long distance exchange of ceramics" (Ek 2012:154). This transition is also associated with an overall change toward the occupation of coastal settlements and a subsistence strategy that moves away from agrarian pursuits and becomes increasingly marine focused (Ek 20I2).

Finally, ceramics of fine orange paste that appear to have been produced in the Coatzacoalcos region have been identified at Cuncuén in Guatemala (Forné et al. 20ro). This elemental identification comes from a sealed context that also included pottery from the Chablekal Group, a ceramic complex well dated to AD 700-800. This fine paste orange ceramic is tentatively classified as an example of Campamento Fine Orange (Forné et al. 2010:1157, 2013:54).

\section{Mold-Made Figurines}

Along with fine paste pottery, figurines produced using a nontempered clay fabric have also come to characterize connection across the Gulf coastal lowlands. These figurines are usually mold made and manufactured using the orange spectrum of the fine paste ceramics. On occasion, these figurines are also decorated with black chapopote or a distinctive blue paint, often referred to as Maya Blue (e.g., D. Arnold 2005; Coe 1965:705). Like their pottery counterparts, these distinctive figurines have long been recognized as possible chronological and/or cultural markers. Unlike the fine paste pottery, however, the main distribution of these figurines usually dates to the very end of the Classic and into the Postclassic periods.

Mary Butler (1935) was one of the first researchers to attempt a large-scale regional and temporal comparison of Maya figurines. Her analysis separated forms into a hand-modeled "Archaic" form that contrasted with presumably later "Mouldmade" $[$ sic $]$ examples. These latter examples, often rendered as whistles, were identified from collections that stretched from coastal Veracruz through Tabasco, into Campeche and the Yucatán (Butler 1935:64I). Her initial assessment placed these mold-made specimens in the latter centuries of the first millennium AD.

Among the mold-made examples, Butler (1935:654-657) also identified three "Gulf Coast styles," consisting of "Campeche," "Tabasco," and "Vera Cruz" [sic] 
respectively. Common among these three subgroups is a standing figure whose hands are either raised at shoulder level or held down by its side. Of note for the present discussion, Butler (1935:664) cites Lago de Catemaco, San Andrés Tuxtla, and Cerro de las Mesas as source locations for material in her comparison. Based on the data available, Butler (1935:659-663) concludes that Campeche, and particularly the Island of Jaina, may have been the origin for figurine styles later represented in Tabasco (especially Jonuta) and Veracruz.

Of course, Jaina Island, Campeche, is perhaps the most celebrated context for Classic- to Postclassic-period figurines along the Gulf lowlands (e.g., McVicker 20I2:215). Corson (1976) presents an analysis of this material, including excavated specimens recovered by INAH projects spanning the decades of the 1940 os through I96os. Among the mold-made figurines that he identifies, the Campeche group (and its multiple variations) stands out as an especially widespread phenomenon across the Gulf lowlands. The Campeche group is in part distinguished by the appearance of a quechquemitl (often rounded with depicted embroidery), frequent use of a white slip, and a pose in which the female individuals stand with hands raised to the shoulders and palms facing outward while males are standing with hands down at their sides (Corson 1976:130, 139, table 4). This pose is first exhibited in an earlier Jonuta category (Corson 1976:table I).

Corson (1976:157-160) specifically discusses possible connections between the Tuxtlas/southern Veracruz and Jaina as reflected in the figurines. He suggests that Campeche-style figurines reported from the southern Veracruz (e.g., Drucker 1943a, 1943b; Valenzuela 1945a, 1945b; Weiant 1943) likely originated along the northern Campeche coast (Corson 1976:159). In contrast, he also notes that the female pose with hands raised at shoulder level may have "originated in Veracruz and spread rapidly to the south and west, through the Tuxtlas and across the Tabascan plain, taking on a number of local expressions as it expanded" (Corson 1976:159). This observation underscores the multidirectionality that likely characterized interactions across the Gulf lowlands.

Marilyn Goldstein (1979:40) analyzed over 1,300 figurines from sites along the Gulf lowlands and private collections, using stylistic and technological criteria. She also conducted Neutron Activation Analysis (NAA) on a small sample of these figurines. This analysis identified eight distinct clays used in figurine manufacture, potentially indicating seven discrete production areas (Goldstein 1979:52).

Among the specimens, Goldstein (1979:71-73) identified a "Style YV or 'Veracruziano" figurine style. As the name implies, these figurines are thought to have stylistic traits that relate them to southern Veracruz. Included among these traits are the use of molds, orange fine paste clay, and postures that include a standing 
"orant" stance (arms bent at the elbow, hands at should height with palms forward) and decorative huipils. Goldstein identified 120 "Veracruziano" figurines; unfortunately, over one-third of the sample was derived from unprovenienced private collections. The stylistic analysis suggests that a locus of manufacture might be identified "along the Campeche coast, between Jaina and Champoton," though, due to the strong Veracruz influence, "the possibility of a more westerly site of origin cannot be overlooked" (Goldstein 1979:7I). Based on their mold-made character, Goldstein (1979:I05, II2) also suggests that these "Veracruziano" figurines likely postdate $\mathrm{AD} 750$.

Goldstein's (1979) neutron activation analysis failed to identify clearly a Veracruz provenience for any of the thirty-five sampled figurines. This result, however, is not overly surprising given the relatively small sample size for NAA coupled with the absence of provenienced Veracruz figurines from the original analysis. It is worth noting, nonetheless, that the lone YV figurine within the NAA sample appears as a single, extreme outlier within the generated dendrogram (Goldstein 1979:table VI). Goldstein (1979:70-7I) refers to this specimen as "an untempered orange clay of distinctive chemical composition, grouping with no other tested samples."

Figurines that correspond to the systems proposed by Butler (1935), Corson (1976), and Goldstein (1979) have been recovered from excavated contexts across southern Veracruz. In fact, Weiant (1943) used the term "Mayoid" to describe figurines recovered from the first season of excavation at Tres Zapotes. Several of his illustrated examples (Weiant 1943:pl. 4I, p. 42) would fit comfortably within Butler's (1935) Cr group, Corson's (1976) Jonuta-Campeche Intergrading Series and Campeche A groups, or Goldstein's (1979) YV stylistic group. Coe (1965:705) also noted a "macro style" across southern Veracruz that included many of the characteristics identified as "Mayoid," although as mentioned earlier, he ultimately regarded these products as little more than "amusing clay figurines" (Coe 1965:715).

It is worth mentioning that hollow, mold-made figurines, produced with an untempered Orange-Buff paste and decorated with a white slip, have an early appearance within the Tuxtlas. One example was recovered as part of the La Joya archaeological project (figure 7.9) and dates to the Middle Classic period (ca. AD 450) (Arnold and McCormack 2002; Vásquez Zárate 2007). This figurine is very similar to a specimen excavated by Valenzuela (1945b:fig. 26) at the neighborhood of Belén Chico, just north of San Andrés Tuxtla. Moreover, San Marcos figurines from Tres Zapotes also conform to the suite of traits mentioned above and are estimated to span the Middle and Late Classic periods. Finally, the well-known Nopiloa and Sonriente figurine styles from south central Veracruz also date primarily to ca. AD 400-800 (see, e.g., Coe 1965; Medellín Zenil 1960). 


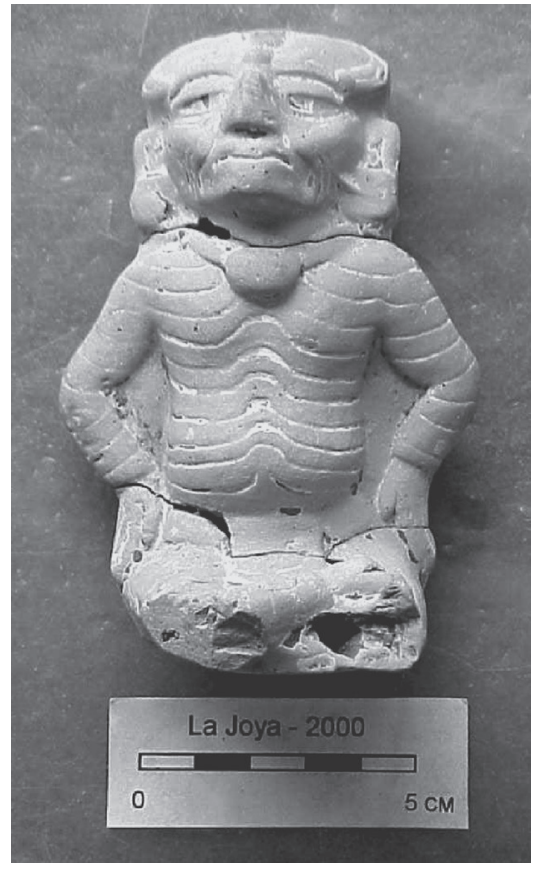

FigURE 7.9. Hollow figurine from La Joya (photograph by Philip J. Arnold III).

\section{SUMMARY AND CONCLUSIONS}

These three examples of southern Veracruz connections with the Maya region span the Formative through Postclassic periods and incorporate two distinct pathways. The earlier, Formative period expression of the SBTC appears to extend across the Isthmus of Tehuantepec, uniting occupations on both the Gulf lowlands and the Pacific coast. This route follows the pathway that Lee Parsons has dubbed the "Peripheral Coastal Lowlands" (Parsons 1978). Parsons (1978:25-26) used this terminology to underscore the region's autonomy relative to both the Mexican highlands and the Maya lowlands; nonetheless, the unfortunate choice of terminology has done little to highlight the important, in situ cultural developments that characterized this region's prehistory.

The Classic period along southern Veracruz is characterized by the early adoption of Fine Buff and Fine Orange pottery in and around the Tuxtla Mountains. This ceramic tradition also includes an appearance of the elaborate Tuxtlas Polychrome by early in the second half of the first millennium. The use of fine paste pottery, first for elite consumption and later for more popular use, spread along the Gulf lowlands by the latter part of the Classic period. Of course, we are not claiming that 
the Tuxtlas was responsible for exporting finished pottery across the adjacent Gulf lowlands; compositional analysis clearly demonstrates that fine paste ceramics from different Gulf lowlands regions were often manufactured from local clay deposits. Nonetheless, we do suggest that some of the inspiration for the appearance and popularity of this particular ware may have its origins within southern Veracruz.

Figurines, produced using molds and made from an Orange or Buff fine paste fabric, mark the end of the Classic period and spill into the Postclassic. The origin of these figurines is still murky; they may have become popular in the area around Campeche and been distributed westward to southern Veracruz, or they may have originated in southern Veracruz and moved eastward along the coast. Reports of figurine molds fragments come from sites in both areas, so the evidence for actual production remains ambiguous (e.g., Sanders 1963; Weiant 1943:106, pl. 43). Regardless, the distribution of this material clearly demonstrates a continued connection among the different ethnic groups that occupied the southern Gulf lowlands.

It should be clear, therefore, that myriad connections, through time and across space, united the southern Gulf lowlands with the coastal Maya region. While early work within the Tuxtlas may have overemphasized such interactions, it would be equally problematic to negate them entirely. Groups within the Tuxtlas obviously participated in far-flung interactions, both inland toward highland Mexico and seaward toward the lowland Maya. More than sixty years ago, Thompson identified a sprinkling of culture that linked groups across the Gulf lowlands. Ongoing research not only affirms that observation, but suggests that Thompson's (1953:447) "chipechipes $[s i c]$ culturales" (cultural sprinklings) may have, on occasion, become a cultural aguacero—a downpour.

\section{NOTES}

I. Ironically, Morley's (1946) statements are in direct opposition to his earlier observations published by Holmes (1907). Holmes asked several individuals to comment on the Tuxtla Statuette, and Morley, at that time a graduate student at Harvard (Brunhouse 1971:158-159), observed that "finally, the question arises, that if this statuette may be safely regarded as having been found in situ in the region of San Andres Tuxtla, and if the Initial Series is correct as rendered above, may not this be the region to look for the earlier forms, at least, of the Maya glyphs, if not for their actual beginnings?" (S. Morley, cited in Holmes 1907:700).

2. Scholars generally interpret the "bar and dot" notation on the Piedra Labrada Stela I as reflecting an inverted version of the number seven. We suspect, however, that this graphic element actually represents a throne, rather than a number. Our reading is supported by the 
interpretation of glyph \#II2 on the La Mojarra Stela (another Gulf lowlands monument) that is also read as "throne" (Kaufman and Justeson 2001:2.45).

3. The inscriptions of Stela 6 at Cerro de las Mesas correspond to AD 468; Stela 8, which has similar characteristics, has a calendar date of AD 533 (see, e.g., Miller 1991:30).

\section{REFERENCES}

Arnold, Dean E. 2005. "Maya Blue and Palygorskite: A Second Possible Pre-Columbian Source." Ancient Mesoamerica I6(I):51-62.

Arnold, Philip J., III. 1997. "Introduction to Part 2: Regional Scales." In Olmec to Aztec:

Settlement Patterns in the Ancient Gulf Lowlands, edited by Barbara L. Stark and Philip J. Arnold III, I39-I43. University of Arizona Press, Tucson.

Arnold, Philip J., III. 20I4. "Of Polychromes and Politics in Southern Veracruz, Mexico." In Social Dynamics of Ceramic Analysis: New Techniques and Interpretations; Papers in Honour of Charles C. Kolb, edited by Sandra L. López Varela, 64-74. British Archaeological Reports International Series 2683. Archaeopress, Oxford.

Arnold, Philip J., III, and Valerie M. McCormack. 2002. En la Sombra del San Martín: Final Field Report of the La Joya Archaeological Project. Report submitted to the Instituto Nacional de Antropología e Historia, Mexico City.

Arnold, Philip J., III, and Christopher A. Pool, eds. 2008. Classic Period Cultural Currents in Southern and Central Veracruz. Dumbarton Oaks, Washington, DC.

Arnold, Philip J., III, Christopher A. Pool, Ronald R. Kneebone, and Robert S. Santley. 1993. "Intensive Ceramic Production and Classic-Period Political Economy in the Sierra de los Tuxtlas, Veracruz, Mexico.” Ancient Mesoamerica 4(2):175-I9I.

Arnold, Philip J., III, and Robert S. Santley. 2008. "Classic Currents in the West-Central Tuxtlas." In Classic Period Cultural Currents in Southern and Central Veracruz, edited by Philip J. Arnold III and Christopher A. Pool, 293-32r. Dumbarton Oaks, Washington, DC.

Arnold, Philip J., III, and Amber VanDerwarker. 2008. Informe técnico del Proyecto Arqueológico Teotepec: La segunda temporada (2008). Report on file, INAH Technical Archives, Mexico City.

Arnold, Philip J., III, and Marcie L. Venter. 2004. "Postclassic Occupation at Isla Agaltepec, Southern Veracruz, Mexico." Mexicon 25(6):I2I-I26.

Barlow, Robert H. 1949. The Extent of the Empire of the Culhua-Mexica. University of California Press, Berkeley.

Becerra Álvarez, Gibránn. 20I2. El patrón de asentamiento durante el Clásico Tardio en el sitio arqueológico de Piedra Labrada. Unpublished BA thesis. Universidad Veracruzana, Xalapa. 
Berlin, Heinrich. 1956. Late Pottery Horizons of Tabasco, Mexico. Carnegie Institution of Washington, Publication 606. Washington, DC.

Bishop, Ronald L. 2003. "Five Decades of Maya Fine Orange Ceramic Investigation by INAA." In Patterns and Process: A Festschrift in Honor of Dr. Edward V. Sayre, edited by Lambertus van Zelst, 8I-9I. Smithsonian Center for Materials Research and Education, Suitland, MD.

Bishop, Ronald L., and Robert L. Rands. 1982. "Maya Fine Paste Ceramics: A Compositional Perspective." In Excavations at Seibal: Analyses of Fine Paste Ceramics, edited by Gordon R. Willey and Jeremy A. Sabloff, 283-314. Memoirs of the Peabody Museum of Archaeology and Ethnology, vol. I5, no. 2. Harvard University, Cambridge.

Bishop, Ronald L., Erin L. Sears, and James M. Blackman. 2005. "A través del río del cambio." Estudios de Cultura Maya 26:17-40.

Blom, Frans, and Oliver La Farge. 1926. Tribes and Temples: A Record of the Expedition to Middle America, Conducted by the Tulane University of Louisiana in Ig25. Middle American Research Institute Report r. Tulane University, New Orleans.

Borstein, Joshua. 200I. Tripping over Colossal Heads: Settlement Patterns and Population Development in the Upland Olmec Heartland. Unpublished PhD dissertation, Department of Anthropology, Pennsylvania State University.

Borstein, Joshua. 2005. "Epiclassic Political Organization in Southern Veracruz, Mexico: Segmentary versus Centralized Integration." Ancient Mesoamerica I6(I):II-2I.

Brainerd, George W. 194I. "Fine Orange Pottery in Yucatan." Revista Mexicana de Estudios Antropológicos 5(2-3):163-183.

Brunhouse, Robert L. 1971. Sylvanus G. Morely and the World of the Ancient Maya. University of Oklahoma Press, Norman.

Budar, Lourdes. 2008. "Detrás de los cerros, en el último rincón de Los Tuxtlas: Piedra Labrada." In Arqueología, paisaje y cosmovisión en Los Tuxtlas, coordinated by Lourdes Budar and Sara Ladrón de Guevara, I05-116. Museo de Antropología Xalapa and la Universidad Veracruzana, Xalapa.

Budar, Lourdes. 2010. "Si las piedras hablaran ... Elementos para la interpretación de la Estela i de Piedra Labrada.” In Piedra Labrada, edited by Sara Ladrón de Guevara, Eraclio Zepeda, and Lourdes Budar, 39-76. Universidad Veracruzana, Xalapa.

Budar, Lourdes. 2013. "Líneas verticales, líneas horizontales: El símbolo de la trama como elemento simbólico del paisaje." In Haciendo arqueología: Teoría, método y práctica, coordinated by Sara Ladrón de Guevara, Lourdes Budar, and Roberto Lunagómez, 193-213. Colección La Ciencia en Veracruz. UV, FOMIX y CONACYT, Xalapa.

Budar, Lourdes. 2014. Proyecto Arqueológico Piedra Labrada-Sierra de Santa Marta, Los Tuxtlas, Ver. Informe técnico de la temporada de investigación 2014. Technical Archives of the Instituto Nacional de Antropología e Historia, Mexico. 
Budar, Lourdes, and Philip J. Arnold III. 20I4. "Los Tuxtlas y Teotihuacan: Nuevas perspectivas en la retrospectiva de una relación." Paper presented at the VIII Coloquio Bosch-Gimpera, Universidad Nacional Autónoma de México, Mexico City.

Budar, Lourdes, and Gibránn Becerra Álvarez. 2015. "El complejo escultórico de Matacanela." Paper presented at the 8 oth annual meeting of the Society for American Archaeology, San Francisco.

Butler, Mary. 1935. “A Study of Maya Mouldmade Figurines.” American Anthropologist (n.s.) $37(4): 636-672$.

Coe, Michael D. 1965. "Archaeological Synthesis of Veracruz and Tabasco." In Archaeology of Southern Mesoamerica, part 2, edited by Gordon R. Willey, 679-715. Handbook of Middle American Indians 3. University of Texas Press, Austin.

Coe, Michael D., and Richard A. Diehl. 1980. In the Land of the Olmec, Vol. I: The Archaeology of San Lorenzo Tenochtitlán. University of Texas Press, Austin.

Corson, Christopher. 1976. Maya Anthropomorphic Figurines from Jaina Island, Campeche. Ballena Press Studies in Mesoamerican Art, Archaeology, and Ethnohistory No. I. Ballena Press, Ramona CA.

Daneels, Annick. 2006. "La cerámica del Clásico Veracruz (o-1000 d.C.)." In La producción alfarera en el México antiguo II, coordinated by Beatriz Leonor Merino Carrión and Ángel García Cook, 393-504. Instituto Nacional de Antropología e Historia, Mexico City.

Diehl, Richard A. 2004. The Olmecs: America's First Civilization. Thames and Hudson, London.

Drucker, Philip. 1943a. Ceramic Sequences at Tres Zapotes, Veracruz, Mexico. Bureau of American Ethnology Bulletin I40. Smithsonian Institution, Washington, DC.

Drucker, Philip. 1943b. Ceramic Stratigraphy at Cerro de las Mesas, Veracruz, Mexico. Bureau of American Ethnology Bulletin I4I. Smithsonian Institution, Washington, DC.

Ek, Jerald. 2012. "The Political and Economic Organization of Late Classic States in the Peninsular Gulf Coast: The View from Champoton, Campeche." In The Ancient Maya of Mexico: Reinterpreting the Past of the Northern Maya Lowlands, edited by Geoffrey E. Braswell, I4I-167. Equinox, London.

Esquivias, Chantal. 2002. On the Edge of Empire? Settlement Changes in Chacalapan, Southern Veracruz, Mexico, during the Classic and Postclassic Periods. Unpublished PhD dissertation, Department of Archaeology, Boston University.

Forné, Mélanie, Chloé Andrieu, Arthur A. Demarest, Paola Torres, Claudia Quintanilla, Ronald L. Bishop, and Olaf Jaime-Riverón. 2013. "Crisis y cambios en el Clásico Tardío: Los retos económicos de una ciudad entre las Tierras Altas y las Tierras Bajas mayas." In Millenary Maya Societies: Past Crises and Resilience, edited by M.-Charlotte Arnauld and Alain Breton, 49-6r. Electronic document, www.mesoweb.com/publications /MMS/3_Forne_etal.pdf, accessed December 7, 2018. 
Forné, Mélanie, Ronald L. Bishop, Arthur A. Demarest, M. James Blackman, and Erin L. Sears. 2010. "Gris fino, naranja fino: Presencia temprana y fuentes de producción, el caso de Cancuén.” In XXIII Simposio de Investigaciones Arqueológicas en Guatemala, 2009, edited by Bárbara Arroyo, Lorena Paiz Aragón, Adriana Linares Palma, and Ana Lucía Arroyave, iI50-I169. Museo Nacional de Arqueología y Etnología, Guatemala.

Garcia-Des Lauriers, Claudia. 2007. Proyecto Arqueológico Los Horcones: Investigating the Teotihuacan Presence on the Pacific Coast of Chiapas, Mexico. Unpublished PhD dissertation, Department of Anthropology, University of California at Riverside.

Gerhard, Peter. 1993. A Guide to the Historical Geography of New Spain. Rev. ed. University of Oklahoma Press, Norman.

Goldstein, Marilyn M. 1979. Maya Figurines from Campeche, Mexico: Classification on the Basis of Clay Chemistry, Style, and Iconography. Unpublished PhD dissertation, Columbia University.

Guernsey, Julia. 2006. Ritual and Power in Stone: The Performance of Rulership in Mesoamerican Izapan Style Art. University of Texas Press, Austin.

Hanffstengel, Renata von, and Cecilia Tercero Vasconcelos. 2003. Eduard y Caecilie Seler: Sistematización de los estudios americanistas y sus repercusiones, UNAM, CONACULTA, INAH, Mexico City.

Holmes, W. H. 1907. "On a Nephrite Statuette from San Andrés, Tuxtla, Vera Cruz, Mexico.” American Anthropologist (n.s.) 9(4):69I-70I.

Jiménez Álvarez, Socorro del Pilar. 2015. "Cultural Interchange Regarding the Distribution of Fine Paste Ceramics within Riverine Societies along the Usamacinta's Mid to Low Basin and Various Gulf Coast Communities." In Archaeology and Bioarchaeology of Population Movement among the Prehispanic Maya, edited by Andrea Cucina, 25-36. Springer, New York.

Kaufman, Terrence, and John Justeson. 200I. "Epi-Olmec Writing and Texts.” Electronic document, http://www.albany.edu/pdlma/EOTEXTS.pdf, accessed May 25, 2017.

Loughlin, Michael L. 2012. El Mesón Regional Survey: Settlement Patterns and Political Economy in the Eastern Papaloapan Basin, Veracruz, Mexico. Unpublished PhD dissertation, Department of Anthropology, University of Kentucky.

Lowe, Gareth W., Thomas A. Lee Jr., and Eduardo Martínez Espinoza. 1982. Izapa: An Introduction to the Ruins and Monuments. Papers of the New World Archaeological Foundation, No. 31. Brigham Young University, Provo.

Lyon, Rosemary Durkin. 1997. (Re)Discovering the Olmec: National Geographic Society-Smithsonian Institution Archaeological Expeditions to Veracruz/Tabasco, 1949-1946. Unpublished MA thesis, American University, Washington, DC.

McVicker, Donald. 2012. "Figurines Are Us? The Social Organization of Jaina Island, Campeche, Mexico." Ancient Mesoamerica 23(2):21I-234. 
Medellín Zenil, Alfonso. 1960. Cerámicas del Totonacapan. Universidad Veracruzana, Xalapa.

Miller, Mary Ellen. 1991. "Rethinking the Classic Sculptures of Cerro de las Mesas, Veracruz." In Settlement Archaeology of Cerro de las Mesas, Veracruz, Mexico, edited by Barbara L. Stark, 26-38. Cotsen Institute of Archaeology, University of California Los Angeles, Los Angeles.

Morley, Sylvanus Griswold. 1946. The Ancient Maya. Stanford University Press, Stanford, CA.

Navarrete Cáceres, Carlos. 1976. "El complejo escultórico del Cerro Bernal, en la Costa de Chiapas, México." Anales de Antropología (UNAM) i 4:23-45.

Norman, V. Garth. 1976. Izapa Sculpture: Part 2, Text. Papers of the New World Archaeological Foundation No. 30. Brigham Young University, Provo.

Parsons, Lee A. 1978. "The Peripheral Coastal Lowlands and the Middle Classic Period.” In Middle Classic Mesoamerica: AD 400-700, edited by Esther Pasztory, 25-34. Columbia University Press, New York.

Parsons, Lee A. 1986. "The Origins of Maya Art: Monumental Stone Sculpture of Kaminaljuyu, Guatemala, and the Southern Pacific Coast." Studies in Pre-Columbian Art and Archaeology 28. Dumbarton Oaks, Washington, DC.

Ortiz Ceballos, Ponciano, and Robert S. Santley. 1988. La cerámica de Matacapan . Unpublished manuscript. University of New Mexico, Albuquerque.

Pool, Christopher A. 1990. Ceramic Production, Distribution, and Resource Procurement at Matacapan, Veracruz, Mexico. Unpublished PhD dissertation, Department of Anthropology, Tulane University.

Pool, Christopher A. 1992. "Strangers in a Strange Land." In Ancient Images, Ancient Thought: The Archaeology of Ideology, edited by A. S. Goldsmith, 43-55. Archaeological Association, University of Calgary, Alberta.

Pool, Christopher A. 1995. "La cerámica del Clásico Tardío y el Posclásico en la Sierra de los Tuxtlas." Arqueología 2(13-I4):35-48.

Pool, Christopher A. 2003. "Ceramic Production at Terminal Formative and Classic Period Tres Zapotes." In Settlement Archaeology and Political Economy at Tres Zapotes, Veracruz, Mexico, edited by Christopher A. Pool. Cotsen Institute of Archaeology Monograph 50. University of California Los Angeles, Los Angeles.

Pool, Christopher A. 2007. Olmec Archaeology and Early Mesoamerica. Cambridge University Press, Cambridge.

Pool, Christopher A., and Georgia Mudd Britt. 2000. "A Ceramic Perspective on the Formative to Classic Transition in Southern Veracruz, Mexico." Latin American Antiquity II(2):139-I6I.

Pool, Christopher A., and Robert S. Santley. 1992. "Middle Classic Pottery Economics in the Tuxtla Mountains, Southern Veracruz, Mexico." In Ceramic Production and 
Distribution: An Integrated Approach, edited by George J. Bey III and Christopher A. Pool, 205-234. Westview Press, Boulder.

Reilly, F. Kent, III. 1994. Visions to Another World: Art, Shamanism and Political Power in Middle Formative Mesoamerica. Unpublished PhD dissertation, University of Texas, Austin. Sanders, William T. 1963. "Cultural Ecology of the Maya Lowlands." Estudios de cultura maya 3:203-24I.

Santley, Robert S. 1989. “Obsidian Working, Long-Distance Exchange, and the Teotihuacan Presence on the South Gulf Coast." In Mesoamerican after the Decline of Teotihuacan AD 700-9oo, edited by Richard A. Diehl and Janet C. Berlo, I3I-I5I. Dumbarton Oaks, Washington, DC.

Santley, Robert S. 2007. The Prehistory of the Tuxtlas. University of New Mexico Press, Albuquerque.

Santley, Robert S., and Philip J. Arnold III. 1996. "Prehispanic Settlement Patterns in the Tuxtla Mountains, Southern Veracruz, Mexico.” Journal of Field Archaeology $23(2): 225-249$.

Santley, Robert S., Philip J. Arnold III, and Christopher A. Pool. 1989. “The Ceramics Production System at Matacapan, Veracruz, Mexico." Journal of Field Archaeology I6(I):107-132.

Santley, Robert S., Clare Yarborough, and Barbara A. Hall. 1987. "Enclaves, Ethnicity, and the Archaeological Record at Matacapan." In Ethnicity and Culture, edited by Reginald Auger, Margaret F. Glass, Scott MacEachern, and Peter H. McCartney, 85-100. Archaeological Association, University of Calgary, Alberta.

Seler-Sachs, Caecilie. [1922] 1996. "The Antiquities of Canton Tuxtla in the State of Veracruz." In Eduard Seler: Collected Works in Mesoamerican Linguistics and Archaeology, 2nd ed., Vol. 5, edited by J. Eric S. Thompson and Francis B. Richardson, ix-xxi. Labyrinthos, Culver City, CA.

Sisson, Edward B. 1976. Survey and Excavation in the Northwestern Chontalpa, Tabasco, Mexico. Unpublished PhD dissertation, Department of Anthropology, Harvard University, Cambridge.

Smith, Michael E., and Francis F. Berdan, eds. 2003. The Postclassic Mesoamerican World. University of Utah Press, Salt Lake City.

Smith, Robert E. 1956. Ceramic Sequence at Uaxactun, Guatemala. Middle American Research Institute Publication 20. Tulane University, New Orleans.

Smith, Robert E. 1958. "The Place of Fine Orange Pottery in Mesoamerica Archaeology." American Antiquity 24(2):151-160.

Stark, Barbara L. 1990. "Gulf Coast and the Central Highlands of Mexico: Alternative Models for Interaction." In Research in Economic Anthropology, edited by Barry L. Isaac, 243-285. JAI Press, Greenwich, CT. 
Stark, Barbara L., ed. 200I. Classic Period Mixtequilla, Veracruz, Mexico: Diachronic Inferences from Residential Investigations. Institute for Mesoamerican Studies Monograph I2. State University of New York, Albany.

Stirling, Matthew W. 1939. "Discover the New World's Oldest Dated Work of Man." National Geographic Magazine 66(2):183-218.

Stirling, Matthew W. 1940. “Great Stone Faces of the Mexican Jungle.” National Geographic Magazine 68(3):309-334.

Stirling, Matthew W. 1943. Stone Monuments of Southern Mexico. Bureau of American Ethnology Bulletin I38. Smithsonian Institution, Washington, DC.

Stoner, Wesley D. 201r. Disjuncture among Classic Period Cultural Landscapes in the Tuxtla Mountains, Southern Veracruz, Mexico. Unpublished PhD dissertation. Department of Anthropology, University of Kentucky, Lexington.

Stoner, Wesley D., and Michael D. Glascock. 20II. "Neutron Activation Analysis of Ceramic Samples from the Teotepec, Southern Veracruz, Mexico." Unpublished report prepared by the Archaeometry Laboratory, Research Reactor Center, University of Missouri, Columbia.

Stoner, Wesley D., and Christopher A. Pool. 2015. “The Archaeology of Disjuncture: Classic Period Disruption and Cultural Divergence in the Tuxtla Mountains of Mexico." Current Anthropology 56(3):385-420.

Symonds, Stacey C. 1995. Settlement Distribution and the Development of Cultural Complexity in the Lower Coatzacoalcos Drainage, Veracruz, Mexico: An Archaeological Survey at San Lorenzo Tenochtitlán. Unpublished PhD dissertation. Vanderbilt University.

Symonds, Stacey C., Ann Cyphers, and Roberto Lunagomez. 2002. Asentamiento prehispánico en San Lorenzo Tenochtitlán. Serie San Lorenzo, vol. 2. Instituto de Investigaciones Antropológicos, UNAM/INAH, Mexico City.

Taube, Karl A. 200I. “La escritura teotihuacana." Arqueología Mexicana 48:58-63

Thompson, J. Eric S. 1953. “Relaciones entre Veracruz y la zona Maya.” In Huastecos, totonacos y sus vecinos, 447-454. Revista Mexicana de Estudios Antropológicos I3, parts 2 and 3.

Thompson, Victor, Philip J. Arnold III, and Amber M. VanDerwarker. 2009. "Geophysical Investigations at Teotepec (I000 B C-1000 A D), Mexico.” Journal of Field Archaeology $34(4): 439-455$.

Urcid, Javier, and Thomas W. Killion. 2008. "Social Landscapes and Political Dynamics in the Southern Gulf-Coast Lowlands (AD 500-1000)." In Classic Period Cultural Currents in Southern and Central Veracruz, edited by Philip J. Arnold III and Christopher A. Pool, 259-291. Dumbarton Oaks, Washington, DC.

Valenzuela, Juan. 1945a. “Las exploraciones efectuadas en Los Tuxtlas, Veracruz, México." Anales del Museo Nacional de Arqueología, Historia y Etnografía 5:83-107. 
Valenzuela, Juan. 1945b. "La segunda temporada de exploraciones en la región de los Tuxtlas, estado de Veracruz." Anales del Instituto Nacional de Antropología e Historia I:8I-106.

Vásquez Zárate, Sergio Rafael. 2007. Las figurillas cerámicas del horizonte formative en La Joya-Comoapan, Región de Los Tuxtlas. Unpublished MA thesis, Escuela Nacional de Antropología e Historia, Mexico City.

Venter, Marcie L. 2008. Community Strategies in the Aztec Imperial Frontier: Perspectives from Totogal, Veracruz, Mexico. Unpublished PhD dissertation, Department of Anthropology, University of Kentucky, Lexington.

Venter, Marcie L. 2012. "A Reassessment of the Extent of the Eastern Aztec Empire in the Mesoamerican Gulf Lowlands." Ancient Mesoamerica 23(2):235-250.

Venter, Marcie L., and Christopher A. Pool. 2014. "Late Classic Boundary Interactions in the Southern Gulf Lowlands." Paper presented at the 79 th annual meeting of the Society for American Archaeology, Austin.

von Nagy, Christopher L. 2003. Of Meandering Rivers and Shifting Towns: Landscape Evolution and Community within the Grijalva Delta. Unpublished PhD dissertation, Department of Anthropology, Tulane University, New Orleans.

von Winning, Hasso. 196r. “Teotihuacan Symbols: The Reptile’s Eye Glyph.” Ethnos: Journal of Anthropology 26(3):121-166.

Weiant, C. W. 1943. An Introduction to the Ceramics of Tres Zapotes Veracruz, Mexico. Bureau of American Ethnology Bulletin 139. Smithsonian Institution, Washington, DC. 


\section{Chapter 8}

\section{Zaragoza-Oyameles Obsidian Projectile Points \\ Cantona's Place in Early Classic Period Long-Distance Gift Exchange and Interaction}

Charles L. F. Knight

The adage "no one remembers who came in second place" has a special applicability to archaeology of the central Mexican highlands during the Classic period. By the end of the Early Classic period around AD 550 Teotihuacan was the most prominent and populous urban settlement in the Americas, with an estimated population from 100,000-200,000 and a site size covering 2,000 ha (Millon 1976:212, but see Cowgill [2015:143] for a revised estimate). Its direct and indirect influence throughout Mesoamerica has received intensive archaeological attention for more than half a century (Braswell 2003a; see Braswell 2003c for an overview of the subject), reflecting the wide array and nature of long-distance exchange, interaction, and influence between people of many disparate regions. At the same time, the second-most-populous city in the Classic period central highlands, which for more than twenty-five years has received intensive archaeological investigation, has typically been overlooked in discussions on central Mexican archaeology of the Early Classic period. This city is Cantona, located in the Cuenca Oriental of eastern Puebla, $37 \mathrm{~km}$ northwest of the Cofre de Perote at the edge of the central Mexican highlands (figure 8.I). Although these two cities are located less than $145 \mathrm{~km}$ apart and are separated by the easily traversable Tlaxcala Corridor land route, the nature and degree of interaction between them are not well understood. Little in the literature has considered the political, economic, or ideological role or impact of Cantona in the Mexican highlands during the Early Classic period. Publications in English and Spanish on the archaeology of the site (Ferriz 1985; García Cook 2003, 


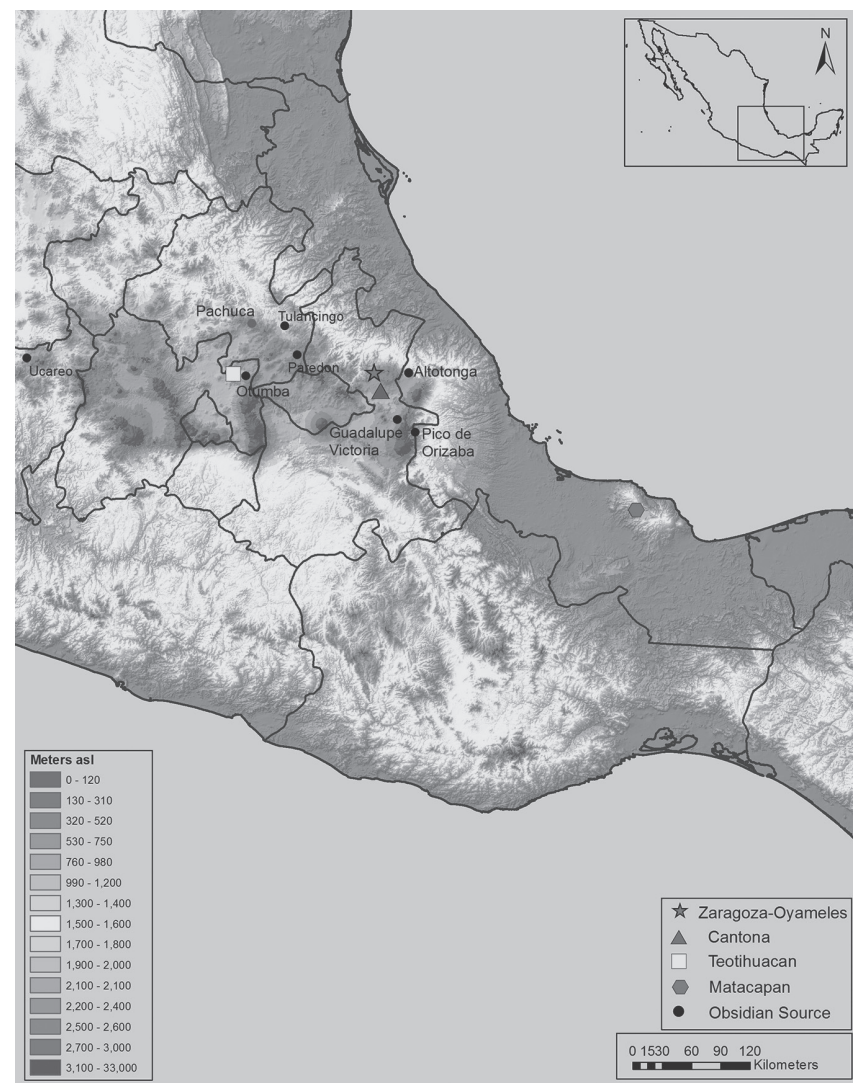

FIGURE 8.I. Location of Cantona in relation to Teotihuacan and obsidian sources in central Mexico.

2014; García Cook and Merino Carrión 1998; García Cook et al. 20ıо; Merino Carrión and García Cook 2007; Rojas Chávez 200I) paint a picture of a major center participating in exchange and communication networks both parallel to and separate from those of Teotihuacan.

Like Teotihuacan, the economic basis of Cantona is argued to have been the control over the extraction and initial reduction of obsidian, and the subsequent long-distance exchange of obsidian polyhedral cores and prismatic blades (García Cook and Carrión 1998:210; García Cook 2003, 2014; García Cook and Merino Carrión 2005; García Cook et al. 2010). The source area Cantona is believed to have controlled is Zaragoza-Oyameles, located $\mathrm{I} 3 \mathrm{~km}$ to the north. Using recent data on the bifacial technologies recovered from the Zaragoza-Oyameles source area and 
published data on excavations undertaken at Cantona itself, this chapter attempts to flesh out the nature of interregional interaction between the two most populous urban centers in the Early Classic period highlands. From a Cantona-based perspective, the occupation of the central Mexican highlands during the Early Classic period becomes more nuanced, recognizing political, economic, and ideological exceptions and pockets of resistance to the gravitational pull of Teotihuacan on the occupation of the region.

\section{BACKGROUND}

The city of Cantona was built on the Tepeyahualco lava flow, or malpais, the uppermost of a series of andesite lava flows that emanated from the Caldera Humeros during a series of eruptions 40,000-60,000 years ago (Ferriz 1985:363-364; figure 8.2). The site has been divided into three zones by archaeologists-a northern, middle, and southern zone-based on the distribution of architecture and the natural extent of the lava flow. Archaeological attention has been concentrated in the southern zone, where the level of preservation is best, and that also contains the civic-ceremonial core of the site (García Cook 2003:317). All architecture at Cantona is constructed from the porous tezontle (a volcanic lava rock) found throughout the area. Site architecture was made without the aid of mortar or plaster. Rather, buildings were made from dry-laid tezontle of different colors to produce visual contrasts: black-gray for roads, stairs and buildings, temples, and so on; and red for some building facades. Site layout utilized the natural topography of the overlapping, $13-75 \mathrm{~m}$ thick lava flows. For instance, the highest points of the terraces formed by the terminal edge of the upper flow in the southern zone produced a naturally elevated terrace upon which the civic-ceremonial core was constructed. This also provided sweeping views of the older, basal flows below, where much domestic, nonelite habitation exists.

Unlike the astronomically aligned grid pattern of Teotihuacan's layout, the internal layout of Cantona is asymmetrical, defined by a series of walled compounds connected by walled streets that follow the natural topography of the lava flows. There are an estimated 7,500 of these elite and nonelite walled compounds (or patios) throughout Cantona; more than 1,500 streets connect the compounds, and seventeen broader causeways exit the city and lead to other destinations (García Cook 2003:319-325; García Cook and Zamora Rivera 2010:34).

The contrast in the physicality of the contemporaneous cities of Cantona and Teotihuacan is considerable and may represent more than just pragmatic responses to environmental constraints. For instance, in his discussion on the Early Classic period construction at Cholula, McCafferty (2007:454) has suggested that the lack 


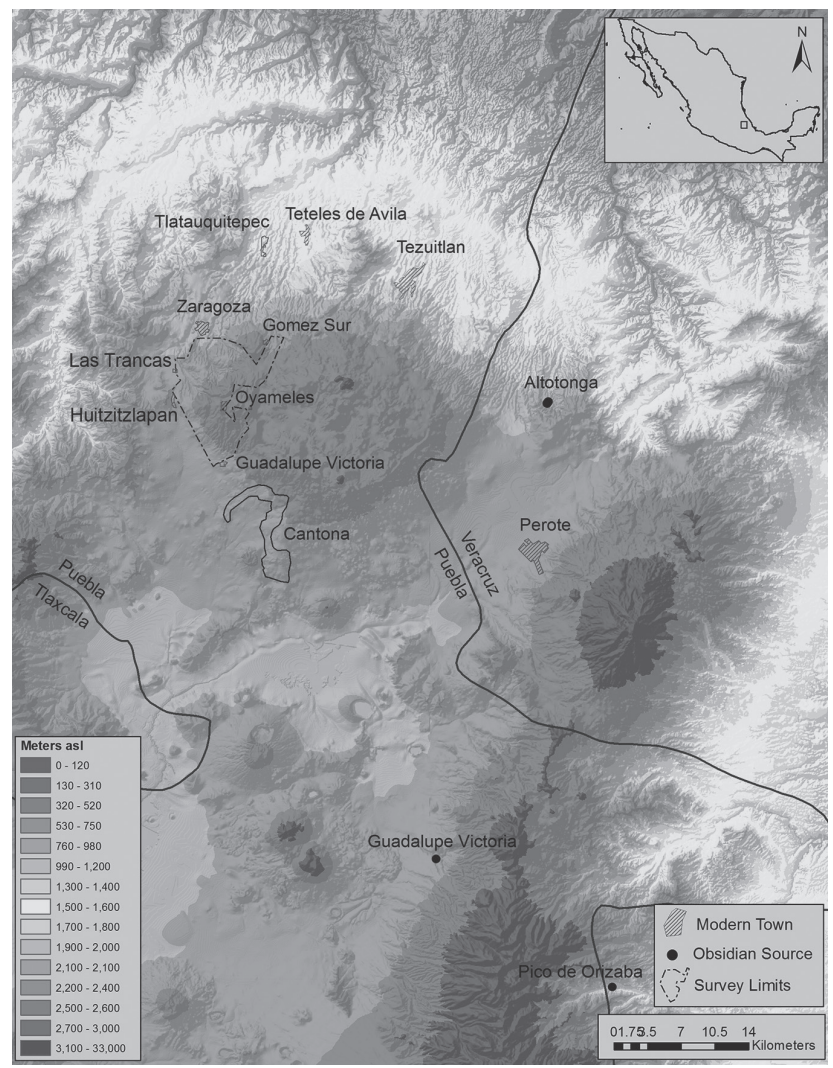

FIGURE 8.2. Limits of Cantona in relation to the general area of the Zaragoza-Oyameles Obsidian Survey, Puebla, Mexico.

of similarities with the contemporaneous Teotihuacan architectural canon may represent an "intentional public rejection of its ideological 'empire' and an expression of separate identity." While the natural topography of Cantona would have created sizable physiographic limitations on how the city could have been constructed, a conscious rejection of Teotihuacan's identity also may underlie the city's layout and architectural style.

From 1992-2016, Dr. Ángel García Cook directed a program of survey and excavation at Cantona, with excavations focused on the civic-ceremonial site core and in the adjacent "suburbs" (García Cook 2003; García Cook and Merino Carrión 1998; García Cook and Vackimes Serret 2014:220-222). More than Ioo radiocarbon dates have been produced from excavated contexts within the civic-ceremonial 
core of the city (García Cook and Zamora Rivera 2010:33), dating the original settlement to the Middle Formative period (ca. 600 BC), when it was a small hamlet. By 300 в the site occupation grew to a population of 10,000 and covered 200 ha. In the late Early Classic period around AD 400, the population is estimated at 50,000 covering $670 \mathrm{ha}$, and then reaches its apogee of 90,000 inhabitants, covering 1430 ha, in the Late Classic period around AD 750 (García Cook 2003:339). In comparison, the Epiclassic occupation of Xochicalco during the Gobernador phase (AD 650-900) was a time when Xochicalco grew and floresced "into a major administrative center in Central Mexico" covering 400 ha, with an estimated population of 9,000-15,000 people (Hirth 2000:68-69). Cholula, one of the longest-occupied urban centers in Mesoamerica, had a population that covered approximately $4 \mathrm{~km}^{2}$ during its Stage 2 construction phase (AD 200-600) during the Early Classic period (McCafferty and Peuramaki-Brown 2007:107). Although population estimates have not been made for this Early Classic period occupation, the size covered by its population at this time is similar to that of Xochicalco. Cholula's Early Classic occupation does not appear to have been influenced, at least in terms of style or site orientation, by Teotihuacan (McCafferty 2007:454). Both Xochicalco and Cholula grew substantially in the later Epiclassic period after the fall of Teotihuacan (Hirth 2000:68; McCafferty and Peuramaki-Brown 2007:107), but neither of these sites witnessed the degree of growth that occurred at Cantona during the same period, when its population and size more than doubled from the earlier Early Classic period. In short, there is nothing in the central Mexican highlands outside of Teotihuacan itself during the Early Classic period that compares to Cantona in estimated size and population.

One result of twenty years of excavation at Cantona has been the identification of over 350 obsidian reduction activity areas in a 19 ha zone adjacent to the civicceremonial core of the city (García Cook 2014:107; García Cook et al. 2010:219). The proximity of these workshops to the civic-ceremonial core and their physical location directly in, yet below the line-of-sight from, the core has resulted in their interpretation as "state workshops" (García Cook 2003:337, 2014:107-IIO). The excavations of four of these state workshops indicate that prismatic cores and blades were primarily produced for local elite consumption and export beyond Cantona (García Cook et al. 20I0:219; García Cook 20I4). Broad site survey also suggests that widespread domestic production of utilitarian obsidian implements occurred throughout the site (Rojas Chávez 200I). Green Pachuca obsidian, closely associated with the Teotihuacan polity during the Early Classic period, is not entirely absent from Cantona, but is quite rare. García Cook (2014:139) states that a "mínima expresión" of the material was recovered from site excavations in Cantona's core and it was found typically in blade form. Of 51,677 obsidian artifacts analyzed 
from the site survey, only four were made from green obsidian, the same amount as made from chert (Rojas Chávez 200I:322, table 26). In addition, a single green projectile point in the Shumla A style (either Stemmed-A or Stemmed-B, following the Teotihuacan classification [Spence 1996], see below) was recovered from the broader site survey (Rojas Chávez 2001:223).

The ceramic record at Cantona (García Cook and Merino Carrión 1998; Gómez Santiago 20Io) reveals little interaction with Teotihuacan, either directly through ceramic trade wares, or indirectly via local ware emulation. Thin orange wares, figurines, or vessels supports in the Teotihuacan tradition are almost nonexistent at Cantona. Rather, the city's ceramic tradition demonstrates a strong local flavor, with a standardized and hyperconservative range of vessel shapes, pastes, and decoration appearing throughout the site's long occupation. At the same time, some form of connectivity with far-off Mesoamerican polities is evident through the recovery of vessels in styles representative of southern Veracruz, Oaxaca, the Mixteca Poblana, the Bajío, and Campeche (García Cook and Merino Carrión 1998). In addition, a variety of whole and partial shells and shell ornaments were recovered from the civic-ceremonial core, the majority of which date to the late Cantona I to Cantona II period occupations, or 350 BC-AD 600 (García Cook and Vackimes Serret 2014:227). These shell artifacts reflect the involvement of the Cantona elite in trade networks with the Gulf lowlands, the Caribbean, and the Pacific coast (García Cook and Vackimes Serret 2014:239-240). Thus the ceramic and shell data suggest Cantona's independent involvement in pan-Mesoamerican exchange networks. On the other hand, the obsidian industry, which played such an important part in the economies of both cities, may reveal connectivity not otherwise seen.

\section{ZARAGOZA-OYAMELES OBSIDIAN SOURCE AREA SURVEY}

In the winters of 2012-2014, I directed an intensive surface survey and surface collection program of the Zaragoza-Oyameles source area (Knight 2012, 2013, 2015; Knight et al. 2017; figure 8.3). The survey consisted of seven archaeologists walking along parallel transects spaced $5 \mathrm{~m}$ apart in plowed and unplowed fields. The locations of all surface tools-such as projectile points, cores, bifaces, and scrapers, as well as all ground stone and ceramics-were marked with a handheld GPS and then collected. Once identified, sites were either roo percent surface collected or with a proportional random sample of $5 \times 5 \mathrm{~m}$ surface units, depending on site size. In total, 1,534 ha ( 3,790 acres) were surveyed in this manner, resulting in the identification of 48 primary reduction sites, three habitation sites, 50 nonquarry reduction sites, 117 obsidian exposures, 77 surface extraction pits, and one extraction trench. 


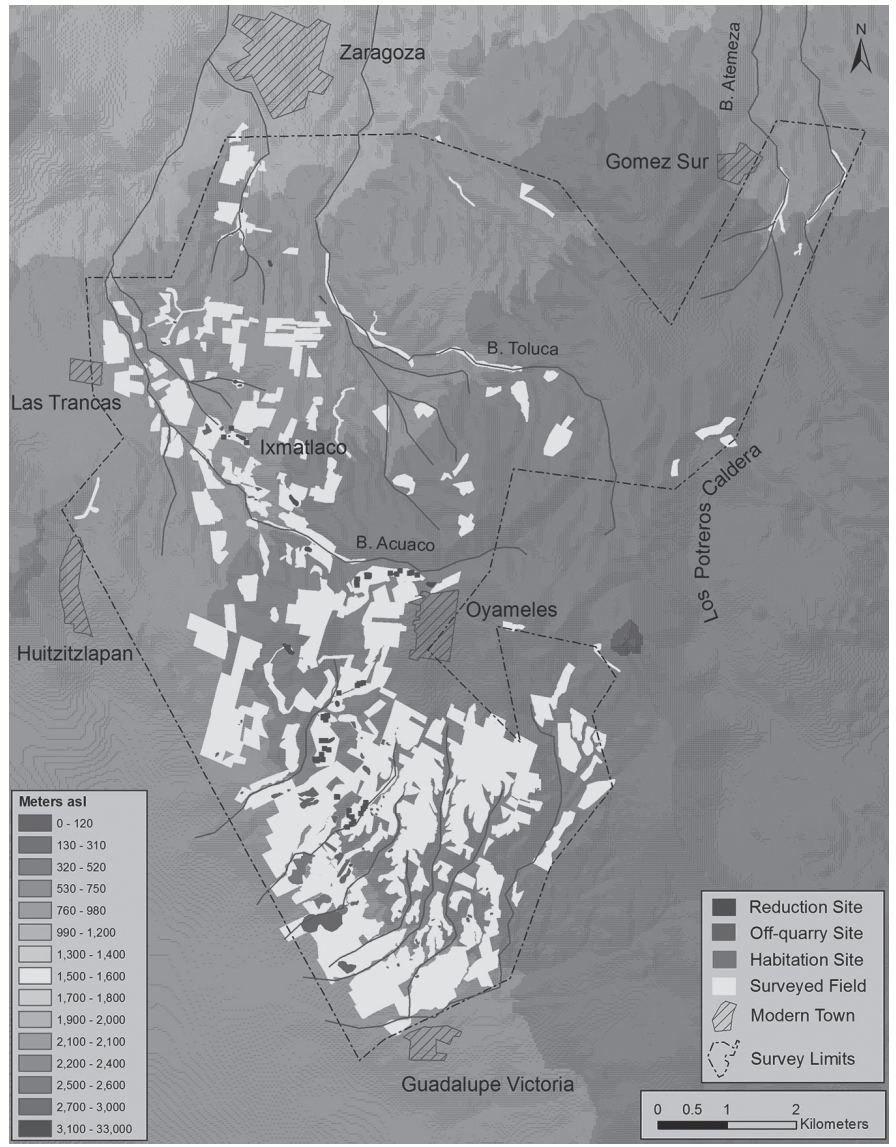

FIGURE 8.3. Specific limits of the 20I2-20I4 seasons of the Zaragoza-Oyameles Obsidian Survey.

The surface survey also resulted in the collection of eighty-five complete and partial obsidian projectile points. Following García Cook's (1967) typology, several types of projectile points, likely arrow points, were identified. These include Hidalgo (Early Classic), Pedernales (Late Classic), Santa Clara (Early-Late Classic), Tecolote (Early-Late Classic), and Texcoco A (Late Classic-Postclassic) projectile points. Additionally, fifteen are similar in outline to the Early Classic, central Mexican points identified at Teotihuacan as Stemmed-A and Stemmed-B by Spence (1996:fig. 2) or, using Tolstoy's (1971:fig. 2) typology, as Shumla A and Gary (figure 8.4). Tolstoy identified the Stemmed-B (Shumla A) style as most common 


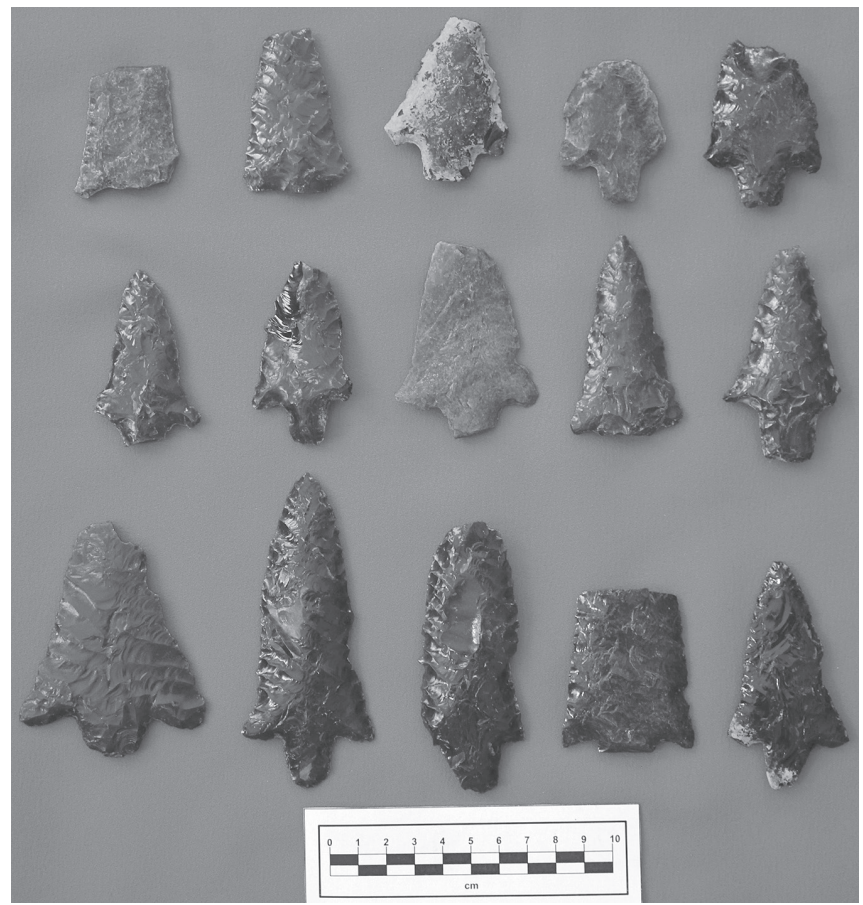

FIGURE 8.4. Zaragoza-Oyameles projectile points in the central Mexican Stemmed-A and Stemmed-B style.

in the Teotihuacan II period. In García Cook's (1967:138, plate II, tables I0, 29-33) comparative analysis of projectile points, he found that the Stemmed-B (Shumla A) point style was most common in the Basin of Mexico throughout the Classic period, AD 350-1100. Finally, in the point typology developed by Sarabia (1996, referenced in Gazzola [2014:227]) for Teotihuacan projectile points, these two point styles are categorized as within the Family C style (Gazzola 2014:fig. 9).

For the discussion here, I use Spence's original, typologically neutral terms of Stemmed-A and B.

At Teotihuacan, finely made points of the Stemmed-A and Stemmed-B variety are closely associated with the military and elite (Carballo 2011:133-145, 159-163; Parry 2014:292; Sugiyama 1989), as several caches containing many examples of these point styles have been recovered from the Moon and Feathered Serpent Pyramids. In addition, points in these styles made from central Mexican obsidian have been recovered from burials and caches at several Mayan centers, such as Tikal (Moholy-Nagy et al. 1984), Altun Ha (Pendergast 2003:238, fig. 9.2, 1990:fig. I2I), 
Caracol (Chase and Chase 2011:10), Uxmal (Braswell 2013:164), and Calakmul (Braswell and Glascock 2011:129, note I), as well as at Balberta on the Pacific coast of Guatemala (Bove and Medrano Busto 2003:50), and Mirador Mound 20 in Chiapas, Mexico (Agrinier 1970:39, 67, figs. 52, 86). At the same time, less finely made versions of these point styles have also been found in domestic contexts at Teotihuacan, such as gray specimens recovered in the Oztoyahualco compound (Hernández 1993:409, fig. 292).

Obsidian evidence for interaction between Teotihuacan and Cantona is not overwhelming. At Cantona, a single Stemmed-A point made from green obsidian was recovered during site excavations, but no description of those excavations is provided (Rojas Chávez 200r:223), while obsidian from the Zaragoza-Oyameles source was found in the Moon Pyramid dart point workshop materials analyzed by David Carballo (Carballo et al. 2007:40). Thus, there appears to have been some degree of obsidian exchange occurring between Teotihuacan and Cantona, but how this apparent interaction relates to the production of the central Mexican style dart points is unclear.

\section{CHEMICAL CHARACTERIZATION AND FLAKING PATTERNS}

In a small number of cases in which chemical characterization of gray obsidian projectile points (Stemmed-A and/or Stemmed-B, and undescribed styles) found along with green Pachuca points in Early Classic ritual/elite contexts in eastern Mesoamerica have been carried out, several were found to have been made from Zaragoza-Oyameles obsidian (Bove and Medrano Busto 2003:53; Moholy-Nagy et al. 1984). All surface points collected during the Zaragoza-Oyameles Regional Obsidian Survey were chemically characterized using portable-XRF by the Missouri University Research Reactor (Knight et al. 2017). The results show that all were made from Zaragoza-Oyameles obsidian, thus were locally produced. Surface artifacts systematically collected at the Zaragoza-Oyameles source area included all stages of bifacial reduction, from large blades and flakes to preforms and finished products, as well as the debitage resulting from their production (Knight 2012, 2013, 2015). Evidence from the Cantona survey and excavation indicates that both Stemmed-A and Stemmed-B varieties in gray obsidian were consumed there (Rojas Chávez 200r:223). As a result, the data suggest several scenarios for the introduction of gray Stemmed-A or Stemmed-B points into elite and ritual contexts in eastern Mesoamerica. The first is that Stemmed-A and Stemmed-B points could have been produced at the source area, under the auspices of the Cantona elite or independently by local producers. These could have been exchanged with Teotihuacanos who, in turn, gifted them to the Maya. However, ceramic data from 
Cantona indicates that the Cantona elite actively participated in long-distance exchanges with eastern Mesoamerica and, therefore, could have exchanged such points with them directly and independently of Teotihuacan.

Another scenario envisions that Zaragoza-Oyameles material made its way into Teotihuacano workshops, where the points would have been produced by Teotihuacano artisans. As mentioned above, at least two examples of ZaragozaOyameles obsidian were recovered from the Teotihuacan dart point workshop (Carballo et al. 2007:40). On the other hand, data on obsidian exchange networks during the Early Classic period from areas immediately adjacent to the Basin of Mexico suggest that little, if any, Zaragoza-Oyameles obsidian was brought into the Basin of Mexico. At several sites located within the Tlaxcala corridor, Carballo and colleagues (2007) found that Zaragoza-Oyameles obsidian was common in Formative period occupations, but beginning in the Classic period was replaced by obsidians associated with Teotihuacan, such as Otumba and Pachuca. Outside of the Basin of Mexico and adjacent areas, the proportion of Zaragoza-Oyameles obsidian increases substantially in Early Classic assemblages, such as in the Tehuacán Valley (Drennan et al. 1990:188-189), in the Valley of Oaxaca (Elam 1993; PiresFerreira 1975), in the Lower Rio Verde Valley of Oaxaca (Joyce et al. 1995), and in the Isthmus of Tehuantepec (Zeitlin 1982). In the southern Gulf lowlands, Zaragoza-Oyameles obsidian completely dominates the chipped stone assemblages of consumption sites at this time (Knight and Glascock 2009; Stark et al. 1992, Santley et al. 200I).

William Parry (2014:292) has observed that many of the points cached at Teotihuacan were more finely made than similar point styles used in domestic contexts. Attributes that indicate such fine finishing include biface symmetry, thinness, and parallel pressure flaking on both faces. Hirth and colleagues (2003:147) have noted that the vast majority of central Mexican fine points exhibit diagonal pressure flaking from the lower left to upper right on each face (figure 8.5). This pressure flaking pattern is the result of the way in which the point is held during flake removal and the angle of the pressure tool, assuming the knapper was right-handed (Hirth et al. 2003:I48-I50). The lower-left to upper-right patterning seems to be typical of the Early Classic period projectile points recovered from the Moon Pyramid (Carballo 20II:figs. 5.20, 7.I) and those from the Feathered Serpent Pyramid burials (Sugiyama 1989). In addition, the illustrated Stemmed-A green obsidian points recovered from elite caches at the Classic period Mayan site of Caracol all have the lower-left to upper-right patterning (Chase and Chase 201r:Io, fig. 5).

In the examples recovered from Zaragoza-Oyameles, all points in the central Mexican Stemmed-A and Stemmed-B styles exhibit the attributes of fine flaking, but they differ in the direction of pressure flake removal. The points recovered from 

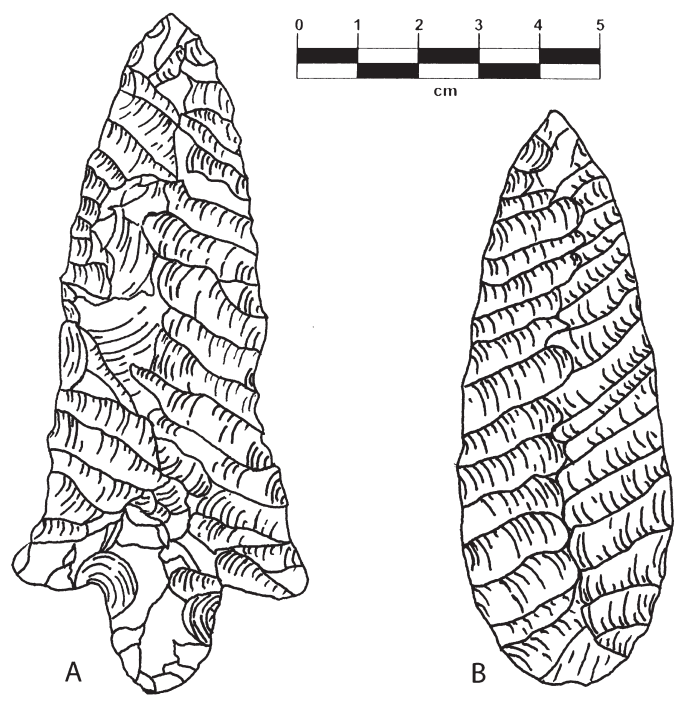

FigURE 8.5. (a) ZaragozaOyameles stemmed-A style point exhibiting upper-left to lower-right diagonal flaking pattern; (b) ovate-shaped point exhibiting lower-left to upperright diagonal flaking pattern (redrawn from Hirth et al. 2003:fig. 10.4).

the Zaragoza-Oyameles source area are marked by an upper-left to lower-right diagonal flaking pattern. The predominance of the upper-left to lower-right diagonal flaking pattern in the Zaragoza-Oyameles examples suggests local variation in the method of pressure flake removal, assuming the knappers were right-handed. Thus, even if local knappers were emulating a central Mexican projectile point style, the local tradition of pressure flake removal differed for this point style. Of the other seventy projectile points recovered, most did not exhibit fine pressure flaking. Where it occurs, however, a variety of pressure flaking styles existed, often on the same point. These included the upper-left to lower-right diagonal flaking pattern, lower-left to upper-right diagonal, and perpendicular to the edge.

\section{DISCUSSION}

One avenue to investigate whether the gray obsidian points found in contexts outside of central Mexico were made by Zaragoza-Oyameles artisans would be to determine whether they exhibit the upper-left to lower-right diagonal flaking pattern. Thus far, the published data are not conclusive. For instance, the base of a gray obsidian projectile point in the Stemmed-A style was recovered at Tres Zapotes from Classic period contexts (Hester et al. 1971:pl. I-a; Weiant 1943:121, pl. 78-72). Since the vast majority of Classic period obsidian consumed at Tres Zapotes and elsewhere in the Gulf lowlands was from Zaragoza-Oyameles (Knight 
and Glascock 2009; Stark et al. 1992; Santley et al. 200I), it may be assumed that this point also is from that source. The flaking pattern shows removals perpendicular to the edge along the left margin and indeterminate on the right margin; perhaps the opposite face would show greater detail, but there is no published image of it that I am aware of.

Farther afield, the only published image of a chemically characterized ZaragozaOyameles point is from Tikal (Moholy-Nagy et al. I984:fig. 3c, or see Moholy-Nagy 2003:fig. 65s for a slightly cleaner version), which exhibits a flaking pattern unlike either attributed to central Mexican points. While several of the pressure flake scars along the right margin of the illustrated example are oriented upper-left to lowerright, they are insufficient to characterize the entire point as exhibiting this flaking pattern. Of the four illustrated gray obsidian points in Tikal problematic deposit PNT-2I (Iglesias Ponce de León 2003:fig. 6.5a-d), two (a, b) illustrate the lowerleft to upper-right flaking pattern of central Mexico, as do three of the four green points $(\mathrm{e}-\mathrm{g})$. None exhibit the upper-left to lower-right diagonal flaking pattern.

At Balberta, on Guatemala's Pacific coast, Bove and Medrano Busto (2003:53) mention that three gray Zaragoza-Oyameles points were recovered in association with other gray points and a green point/effigy cacao cache in the site core, and separately in other elite contexts dating to the Early Classic period. The green points were made in the quintessential central Mexican style associated with Teotihuacan (Bove and Medrano Busto 2003:50), but no information is given on the general style or flaking pattern of the gray obsidian points. They (Bove and Medrano Bust 2003:52) add that fine paste wares also were recovered from the same contexts, which, according to the NAA characterization conducted on six samples, likely were produced in the Gulf lowlands.

While the green Pachuca points recovered at Balberta reflect some type of relationship with Teotihuacan or Teotihuacanos, the fine paste wares and ZaragozaOyameles obsidian points can be interpreted as reflecting connections with the Gulf lowlands and, perhaps, indirectly with Cantona. Another perspective is offered by Bove and Meddrano Busto (2003:52) who interpret the presence of the fine paste wares as evidence for possible indirect ties to Teotihuacan, via the Gulf lowlands centers related to Teotihuacan, such as Matacapan. However, our interpretations of the strength of Teotihuacan's influence in the Gulf lowlands, and beyond, via Matacapan have undergone considerable revisions since first proposed by Santley $(1983,1989)$. For instance, data from the last twenty years in the Sierra de los Tuxtlas, and beyond, indicate that the distribution of Teotihuacanrelated obsidian and ceramics was strongest within Matacapan's regional hinterland (Braswell 2003b:III; Pool and Stoner 2004:94-97; Santley and Arnold 1996, 2005:190; Stoner 20I2; cf. Philip J. Arnold III and Lourdes Budar, chapter 7 in this 
volume). While Santley and his colleagues (200I) have argued that Matacapan was a major node in the regional distribution of highland obsidians, there is little evidence from consumer sites beyond Matacapan's hinterland of that role (Pool and Stoner 2004:82-86; Stark et al. 1992; Stoner 2012). Zeitlin (1982:268-269) pointed out a massive increase in the use of Zaragoza-Oyameles and, neighboring, Altotonga obsidians beginning in the Early Classic period in data from the southern Isthmus of Tehuantepec. This increase in Zaragoza-Oyameles and Altotonga obsidians corresponded to a virtual disappearance of El Chayal and Guadalupe Victoria obsidians that were so prevalent in the region previously. He posited that these two sources could have been controlled by the central Veracruz center of El Tajín and thus represented a parallel and contemporaneous distribution network to that of Teotihuacan. At the time, Zeitlin (1982:269) suggested that Teotihuacan may have had some indirect control over the distribution of these obsidians into the Isthmus region via El Tajín, thus creating a situation of "dual-administration." We now recognize that it was Cantona, independent of Teotihuacan, and not El Tajín that was the real powerhouse behind the distribution of Zaragoza-Oyameles obsidian throughout Mesoamerica from at least the Early Classic through early Post-Classic periods (Braswell 2003d; García Cook 2003, 2014; García Cook et al. 2010).

At Kaminaljuyú, numerous gray obsidian points were recovered from a context that included fine central Mexican style points made of green obsidian (Kidder et al. 1946:137-138). The green points all exhibited the lower-left to upper-right flaking pattern, while the gray points exhibited either the upper-left to lower-right diagonal flaking pattern or a pressure flake removal pattern different from either of these. The only problem is that the gray points illustrated are not good examples of either Stemmed-A or Stemmed-B point styles, looking much cruder than those found at the Zaragoza-Oyameles source area. The gray Kaminaljuyú points may not represent any connection with central Mexico at all, but rather may have been made of gray El Chayal obsidian, the source closest to Kaminaljuyú. Geoffrey Braswell (2003b:130) suggests something similar, adding that he believes the gray Kaminaljuyú points to be poorly crafted homologies of Teotihuacan-style points made from local obsidian. The same can be said for the illustrated, unsourced gray points from Tikal (Moholy-Nagy 2003:figs. 64-67). Moholy-Nagy and her colleagues (1984:III) note that these gray points also could represent local emulation of central Mexican styles, which might explain the variation in patterns of pressure flake removals. This issue could easily be clarified with chemical characterization using a nondestructive, portable-XRF machine.

Nonetheless, in eastern Mesoamerica projectile points made from ZaragozaOyameles obsidian were being included in ritually and politically significant clustering of exotic materials, often associated with Teotihuacan. However, the idea 
that it was the Teotihuacan elite that were incorporating projectile points made from Zaragoza-Oyameles obsidian seems unlikely for several reasons. First, all evidence indicates that Cantona was independent from Teotihuacan and, as a result, would not have fallen under its political and ideological influence and/or control. Considering the significant symbolic importance of the gifted items associated with Teotihuacan (Spence 1996), and Teotihuacan's control over the nearby black-gray, Otumba obsidian, there is no reason for black-gray Zaragoza-Oyameles obsidian points to have been included in the gifts that represented Teotihuacan in longdistance gift exchange. In fact, if Teotihuacan was the only highland Mexican polity involved in long-distance gifting, then we would expect Teotihuacanos to actively discourage other independent highland Mexican polities from doing the same. As a result, we would not expect to find points made from Zaragoza-Oyameles obsidian in Early Classic elite and ritual contexts in eastern Mesoamerica at all.

Second, any artisan responsible for creating the official projectile points representing Teotihuacan in long-distance gift exchange would have been able to distinguish the local Teotihuacan-sanctioned black-gray Otumba obsidian from nonlocal, foreign-controlled Zaragoza-Oyameles black-gray obsidian. Therefore, the presence of Zaragoza-Oyameles debitage in the Moon Pyramid workshop was not an accident or happenstance resulting from the artisans acquiring whatever obsidian was available. It was there on purpose. While the nature of the Cantona elite's control over the extraction and early-stage production of tools at the Zaragoza-Oyameles source area is still being investigated, it is safe to say that Cantona's elite would have been aware of material from the source making its way to Teotihuacan and would have controlled such exchange. Therefore, its presence in the Moon Pyramid workshop likely represents some form of limited gifting between Cantona and Teotihuacan and was meant for specific, possibly ritual or elite use at Teotihuacan, not as part of Teotihuacan's program of long-distance gift exchange. That only a single Stemmed-A point in green obsidian has thus far been recovered at Cantona suggests that whatever the nature of interaction between Cantona and Teotihuacan was, at least in regards to obsidian, it was either fleeting, strained, or considerably limited.

Finally, the evidence of ceramics from across Mesoamerica at Cantona underlines the fact that the Cantona elite were well established in long-distance exchange networks, especially via the Gulf lowlands (Braswell 2003d), and thus powerful enough to independently cultivate their own relationships with foreign polities outside of the central Mexican highlands. How Maya, and other eastern Mesoamerican elites chose to arrange the gifts they received-such as in burials or caches, and so forth-is another issue. But it is very possible that they combined gifts from several exotic, central Mexican polities into one tableau of greatest significance to themselves. This concept is emphasized by Demarest and Foias (1993:170-17I) in 
discussions of the nature of central Mexican and Maya interaction during the Early Classic, from an "internalist" perspective (Stuart 2000).

After the demise of Teotihuacan around AD 550 (Cowgill 2015:233), the central Mexican Stemmed-A and Stemmed-B point styles ceased to be dominant in the Basin of Mexico and elsewhere. Rather, sites from the Basin demonstrate the use of the Ramec point style (the San Marcos point style in the Texas typology and in García Cook's [1967] typology), throughout the Epi-Classic period. At the Metepec biface workshop in Teotihuacan (Nelson 2009), the Ramec point was the principal point style produced. This point style also has been recovered at Xochicalco in EpiClassic contexts (Andrews 2002: fig. 7). In the illustrated examples of Ramec points from Teotihuacan, the lower-left to upper-right flaking pattern is present (Nelson 2009:fig. 5). However, at Xochicalco, the lower-left to upper-right pattern as well as the upper-left to lower-right flaking pattern were evident on Ramec points (Andrews 2002:fig. 7). While this point style appears to have become a chronological marker in certain areas within central Mexico, not a single point in this style was recovered during the survey of the Zaragoza-Oyameles obsidian source area (Knight 2012, 2013, 2015), or at Cantona during its zenith (Rojas Chávez 2001).

In the Epiclassic period, Zaragoza-Oyameles obsidian becomes one of the earliest central Mexican obsidians to appear in the northern Maya lowlands in large quantities (Braswell 2003d:I40). The quick introduction of relatively large quantities of Zaragoza-Oyameles obsidian into the northern lowlands occurred during Cantona's post-Teotihuacan florescence, when it achieved its maximum size and population and when it could capitalize on the interaction and exchange relations it had cultivated in the previous Early Classic period. I interpret both of these postTeotihuacan patterns as reflecting a continuation of Cantona's independence from polities in the Basin of Mexico and its focus on long-distance interactions with the Gulf lowlands, isthmus, Pacific coast, and all points further east.

\section{CLOSING STATEMENTS}

While the current data cannot answer the question of whether the projectile points made of Zaragoza-Oyameles obsidian received by foreign elites came from Cantona or Teotihuacan, the concept that long-distance gift exchange during the Classic period between the central Mexican highlands and eastern Mesoamerica may reflect something other than just Teotihuacan-based gift exchange is an important point (see Demarest and Foias 1993:171; Marcus 2003:355). Much has been made of the green Pachuca points found in ritual contexts outside of central Mexico. Perhaps because of Pachuca's distinctive green color and the close association with gray Otumba obsidian and Teotihuacan, archaeologists outside central 
Mexico have not been as rigorous in identifying the variety of gray obsidians that they have encountered in similar ritual contexts as the Pachuca materials. Central Mexican-style projectile points were being produced at the Zaragoza-Oyameles source area and consumed at Cantona. They were produced through a local tradition that resulted in a pressure flaking pattern different from that found in the Basin of Mexico, and one that is easily recognized and that may turn out to be a diagnostic attribute. It appears that they also were part of the long-distance gift exchange that the Cantona elite were actively participating in with the rest of Mesoamerica. As the web of Early Classic interaction and exchange in Mesoamerica becomes better understood (Braswell 20036:14-19), we may find that the Maya, and others, were utilizing a much broader suite of exotic materials than previously considered in their political, economic, and ideological constructions. In the case of interactions with Cantona, this may have meant projectile points and prismatic blades made from Zaragoza-Oyameles obsidian. But it is not just the presence of Zaragoza-Oyameles obsidian in these far-off locales that needs to be addressed. A broader questions is what mechanism(s) resulted in obsidian from west Mexico, such as Ucareo and Zacualtipan (Braswell 2013:164; Moholy-Nagy et al. 1984:table 2; Moholy-Nagy 20I3:table 6), for example, entering eastern Mesoamerica during the Early Classic? Should we reasonably expect that Teotihuacan was responsible for the movement of every type of highland Mexican obsidian into eastern Mesoamerica during its florescence? We know that numerous obsidian exchange networks were in place before Teotihuacan existed (Boksenbaum et al. 1987; Cobean et al. 1971; Pires-Ferreira 1975, 1976; Pool et al. 2014), as well as after (Braswell 2003d). Therefore, as several authors have observed (Demarest and Foias 1993:162-164; Marcus 2003:355), numerous exchange networks independent of Teotihuacan were likely at play during the Early Classic period provisioning eastern Mesoamerica with obsidian.

My aim in this chapter has been to present data from the Zaragoza-Oyameles obsidian source area, which suggests the involvement of Cantona in the "web of interaction" with contemporaneous polities in the Maya lowlands, independently of Teotihuacan. I am confident that with more rigorous analysis and recording of highly portable artifacts, such as obsidian projectile points in all contexts, that Early Classic interaction between eastern and western Mesoamerica will be shown to have involved numerous independent polities beyond the umbra of Teotihuacan.

\section{REFERENCES}

Agrinier, Pierre. 1970. Mound 20, Mirador, Chiapas, Mexico. Papers of the New World Archaeological Foundation 28. Brigham Young University, Provo, UT. 
Andrews, Bradford. 2002. "Stone Tools and the Elite Political Economy at Epiclassic (AD 650-900) Xochicalco." Electronic document, http://www.famsi.org/reports/oro29 /o1029Andrewsor.pdf, accessed September I5, 2015.

Boksenbaum, Martin W., Paul Tolstoy, Garman Harbottle, Jerome Kimberlin, and Mary Neivens. 1987. "Obsidian Industries and Cultural Evolution in the Basin of Mexico before 500 B C." Journal of Field Archaeology I4(I):65-75.

Bove, Frederick J., and Sonia Medrano Busto. 2003. "Teotihuacan, Militarism, and Pacific, Guatemala." In The Maya and Teotihuacan: Reinterpreting Early Classic Interaction, edited by Geoffrey E. Braswell, 45-79. University of Texas Press, Austin.

Braswell, Geoffrey, ed. 2003a. The Maya and Teotihuacan: Reinterpreting Early Classic Interaction. University of Texas Press, Austin.

Braswell, Geoffrey E. 2003b. "Understanding Early Classic Interaction between Kaminaljuyú and Central Mexico." In The Maya and Teotihuacan: Reinterpreting Early Classic Interaction, edited by Geoffrey E. Braswell, I05-I42. University of Texas Press, Austin.

Braswell, Geoffrey E. 2003c. "Introduction: Reinterpreting Early Classic Interaction.” In The Maya and Teotihuacan: Reinterpreting Early Classic Interaction, edited by Geoffrey E. Braswell, I-43. University of Texas Press, Austin.

Braswell, Geoffrey E. 2003d. “Obsidian Exchange Spheres.” In The Postclassic Mesoamerican World, edited by Michael E. Smith and Francis F. Berdan, I3I-I59. University of Utah Press, Salt Lake City.

Braswell, Geoffrey E. 2013. "Ancient Obsidian Procurement and Production in the Peten Campechano: Uxul and Calakmul during the Early Classic to Terminal Classic Periods." Indiana 30:149-171.

Braswell, Geoffrey E., and Michael D. Glascock. 20II. "Procurement and Production of Obsidian Artifacts at Calakmul." In The Technology of Maya Civilization: Political Economy and beyond in Lithic Studies, edited by Zachary X. Hruby, Geoffrey E. Braswell, and Oswaldo C. Mazariegos, I19-I29. Equinox Publishing Ltd., Sheffield, UK.

Carballo, David M. 20I. Obsidian and the Teotihuacan State: Weaponry and Ritual Production at the Moon Pyramid. University of Pittsburgh and UNAM, Pittsburgh and Mexico City.

Carballo, David M., Jennifer Carballo, and Hector Neff. 2007. "Formative and Classic Period Obsidian Procurement in Central Mexico: A Compositional Study Using Laser AblationInductively Coupled Plasma-Mass Spectrometry." Latin American Antiquity I8(I):27-43.

Chase Arlen F., and Diane Z. Chase. 20ri. "Status and Power: Caracol, Teotihuacan, and the Early Classic Maya World." Research Reports in Belizean Archaeology 8:3-18.

Cobean, Robert H., Michael D. Coe, Edward A. Perry Jr., Karl K. Turekian, and Dinkar P. Kharkar. 1971. "Obsidian Trade at San Lorenzo Tenochtitlan, Mexico." Science I74(4010):666-67I. 
Cowgill, George L. 2015. Ancient Teotihuacan Cambridge University Press, New York.

Demarest, Arthur A., and Antonia E. Foias. 1993. "Mesoamerican Horizons and the Cultural Transformations of Maya Civilization.” In Latin American Horizons, edited by Don S. Rice, I47-191. Dumbarton Oaks, Washington, DC.

Drennan, Robert D., Philip T. Fitzgibbons, and Heinz Dehn. 1990. "Imports and Exports in Classic Mesoamerican Political Economy: The Tehuacan Valley and Teotihuacan Obsidian Industry." In Research in Economic Anthropology, vol. I2, edited by Barry Isaac, 177-200. JAI Press, Greenwich, CT.

Elam, J. Michael. 1993. Obsidian Exchange in the Valley of Oaxaca, Mexico. PhD dissertation, University of Missouri, Columbia. University Microfilms international, Ann Arbor, MI.

Ferriz, Horacio. 1985. "Caltonac: A Prehispanic Obsidian-Mining Center in Eastern Mexico? A Preliminary Report.” Journal of Field Archaeology I2(3):363-370.

García Cook, Ángel. 1967. Análisis tipologico de artefactos, Investigaciones I2, Instituto Nacional de Antropología e Historia, Mexico.

García Cook, Ángel. 2003. “Cantona: The City.” In Urbanism in Mesoamerica, edited by William T. Sanders, Alba Guadalupe Mastache, and Robert H. Cobean, 31I-343. Instituto Nacional de Antropología e Historia and Pennsylvania State University, Mexico City and State Park.

García Cook, Ángel. 20I4. “Los 'Talleres Estatales' de Cantona, Puebla.” In Estudio de la lítica arqueológica en Mesoamérica, edited by Lorena Mirambell and Leticia González Arratia, 105-166. Instituto Nacional de Antropología e Historia, Mexico City.

García Cook, Ángel, and Beatriz Leonor Merino Carrión. 1998. “Cantona: Urbe prehispánica en el Altiplano Central de México." Latin American Antiquity 9(3):191-216.

García Cook, Ángel, and Beatriz Leonor Merino Carrión. 2005. “Sobre tres elementos líticas con carácter ritual: Navajas de autosacrificio, navajas con cresta, y cortadores o tranchet." In Reflexiones sobre la industria litica, edited by Letica González Arratia and Lorena Mirambell, 299-323. Instituto Nacional de Antropología e Historia, Mexico City.

García Cook, Ángel, and Katina Vackimes Serret. 20r4. "Elementos de concha presentes en Cantona, Puebla." Arqueología: Segunda Época 47:216-245.

García Cook, Ángel, and Mónica Zamora Rivera. 20ıо. "Sobre una laja grabada de Cantona: Ubicación temporal y ambiental.” Arqueología: Segunda Época 45:33-52.

García Cook, Ángel, Dolores Tenorio, Melania Jiménez-Reyes, Fabiola Monroy-Guzmán, and Carmen López-Reyes. 2010. "Estudio de procedencia de obsidiana arqueológica de Cantona, Puebla." Arqueología: Segunda Época 43:217-229.

Gazzola, Julie. 2014. "Estudio y resultados preliminares de los artefactos de obsidiana localizados en un conjunto de fases tempranas en Teotihuacan." In Estudio de la litica 
arqueológico en Mesoamérica, edited by Lorena Mirambell and Letica González Arratia, 213-245. Instituto Nacional de Antropología e Historia, Mexico City.

Gómez Santiago, Denisse. 20ı. “Las primeras expresiones alfareras de Cantona.” Arqueología: Segunda Época 44:159-178.

Hernández, Cynthia. 1993. "La lítica." In Anatomia de un conjunto residencial teotihuacano en Oztoyahualco, Vol. I: Las excavaciones, edited by Linda Manzanilla, 388-467. UNAM Instituto de Investigaciones Antropológicas, Mexico City.

Hester, Thomas R., Robert N. Jack, and Robert F. Heizer. 1971. "The Obsidian of Tres Zapotes." In Papers on Olmec and Maya Archaeology, 65-132. Contributions of the University of California Archaeological Research Facility 13. University of California Archaeological Research Facility, Berkeley.

Hirth, Kenneth G. 2000. Archaeological Research at Xochicalco, Vol. I: Ancient Urbanism at Xochicalco: The Evolution and Organization of a Pre-Hispanic Society. University of Utah Press, Salt Lake City.

Hirth, Kenneth G., Gene L. Titmus, J. Jeffrey Flenniken, and Jacques Tixier. 2003. "Alternative Techniques for Producing Mesoamerican Pressure Flaking Patterns on Obsidian Bifaces." In Mesoamerican Lithic Technology: Experimentation and Interpretation, edited by Kenneth G. Hirth, I47-I52. University of Utah Press, Salt Lake City.

Iglesias Ponce de León, María Josefa. 2003. "Problematical Deposits and the Problem of Interaction: The Material Culture of Tikal during the Early Classic Period." In The Maya and Teotihuacan: Reinterpreting Early Classic Interaction, edited by Geoffrey E. Braswell, 167-198. University of Texas Press, Austin.

Joyce, Arthur A., J. Michael Elam, Michael D. Glascock, Hector Neff, and Marcus Winter. 1995. "Exchange Implications of Obsidian Source Analysis from the Lower Verde Valley." Latin American Antiquity 6(I):3-15

Kidder, Alfred V., Jesse D. Jennings, and Edwin M. Shook. 1946. Excavations at Kaminaljuyú, Guatemala. Carnegie Institution of Washington Publication 56I. Carnegie Institution of Washington, Washington, DC.

Knight, Charles L. F. 20I2. Reconocimiento regional de la obsidiana en ZaragozaOyameles, Puebla, México, Informe de la Temporada de 2012. Submitted to the Instituto Nacional de Antropología e Historia, Mexico City.

Knight, Charles L. F. 20I3. Reconocimiento regional de la obsidiana en ZaragozaOyameles, Puebla, México, Informe de la Temporada de 2013. Submitted to the Instituto Nacional de Antropología e Historia, Mexico City.

Knight, Charles L. F. 20I5. Reconocimiento regional de la obsidiana en ZaragozaOyameles, Puebla, México, Informe de la Temporada de 2014. Submitted to the Instituto Nacional de Antropología e Historia, Mexico City. 
Knight, Charles L. F., and Michael D. Glascock. 2009. “The Terminal Formative to Classic Period Obsidian Assemblage at Palo Errado, Veracruz, Mexico." Latin American Antiquity 20(4):507-524.

Knight, Charles L. F., Heng Hu, Michael D. Glascock, and Stephen A. Nelson. 2017. "Obsidian Sub-Sources at the Zaragoza-Oyameles Quarry in Puebla, Mexico: Similarities with Altotonga and Distribution throughout Mexico." Latin American Antiquity 28(I):I-20.

Marcus, Joyce. 2003. “The Maya and Teotihuacan." In Obsidian Reflections: Symbolic Dimensions of Obsidian in Mesoamerica, edited by Marc N. Levine and David M. Carballo, 337-356. University Press of Colorado, Boulder.

McCafferty, Geoffery G. 2007. "What Else Is New? A Cholula-Centric Perspective on Lowland/Highland Interaction during the Classic/Postclassic Transition." In Twin Tollans: Chichen Itza, Tula and the Epiclassic to Early Postclassic Mesoamerican World, edited by Jeff Karl Kowalewski and Cynthia Kristan-Graham, 449-48I. Dumbarton Oaks, Washington, DC.

McCafferty, Geoffrey G., and Meaghan Peuramaki-Brown. 2007. "Ancient Cities of Mesoamerica." Western Humanities Review 6I(3):I00-III.

Merino Carrión, Beatriz Leonor, and Ángel Garcia Cook. 2007. "La alfarería en Cantona del 500 al 1000 de Nuestra Era." In La producción alfarera en el México Antiguo, edited by Leonor Marino Carrión and Ángel Garcia Cook, II3-164. Colección Científica no. 505. Instituto Nacional de Antropología e Historia, Mexico City.

Millon, René. 1976. "Social Relations in Ancient Teotihuacán." In The Valley of Mexico: Studies in Pre-Hispanic Ecology and Society, edited by Eric R. Wolf, 205-248. University of New Mexico Press, Albuquerque.

Moholy-Nagy, Hattula. 2003. The Artifacts of Tikal: Utilitarian Artifacts and Unworked Materials. Tikal Report No. 27, Part B. University of Pennsylvania Museum of Archaeology and Anthropology, Philadelphia.

Moholy-Nagy, Hattula. 2013. "An Analysis of pXRF Source Attributions from Tikal, Guatemala." Latin American Antiquity 24(I):72-97.

Moholy-Nagy, Hattula, Frank Asaro, and Fred H. Stross. 1984. “Tikal Obsidians: Sources and Typology." American Antiquity 49(I):104-117

Nelson, Zachary. 2009. "Obsidian Biface Production at Teotihuacan: Reexamining a Coyotlatelco Phase Workshop from Hacienda Metepec." Ancient Mesoamerica 20(I):I49-162.

Parry, William J. 2014. “Reflections on Reflections.” In Obsidian Reflections: Symbolic Dimensions of Obsidian in Mesoamerica, edited by Marc N. Levine and David M. Carballo, 279-318. University Press of Colorado, Boulder. 
Pendergast, David M. 1990. Excavations at Altun Ha, Belize, 1964-1970, Vol. 3. Royal Ontario Museum, Toronto.

Pendergast, David M. 2003. “Teotihuacan at Altun Ha: Did It Make a Difference?” In The Maya and Teotihuacan: Reinterpreting Early Classic Interaction, edited by Geoffrey E. Braswell, 235-247. University of Texas Press, Austin.

Pires-Ferreira, Jane W. 1975. Formative Mesoamerican Exchange Networks and Special Reference to the Valley of Oaxaca. Prehistoric and Human Ecology of the Valley of Oaxaca, Memoirs of the Museum of Anthropology. Vol. 3. University of Michigan, Ann Arbor.

Pires-Ferreira, Jane W. 1976. "Obsidian Exchange in Formative Mesoamerica." In The Early Mesoamerican Village, edited by Kent V. Flannery, 292-306. Academic Press, New York.

Pool, Christopher A., and Wesley Stoner. 2004. "El fenómeno teotihuacano en tres Zapotes y Matacapan: Una discusión comparativa." In La Costa del Golfo en tiempos teotihuacanos: Propuestas y perspectivas, edited by María Elena Ruiz Gallut and Arturo Pascual Soto, 77-ıoo. Instituto Nacional de Antropología e Historia, Mexico City.

Pool, Christopher A., Charles L. F. Knight, and Michael D. Glascock. 2014. "Formative Obsidian Procurement at Tres Zapotes, Veracruz, Mexico: Implications for Olmec and Epi-Olmec Political Economy." Ancient Mesoamerica 25(I):271-293.

Rojas Chávez, Juan Martín. 200I. La litica de Cantona, Puebla: Análisis, tecnológico y morfológico. Unpublished BA thesis, Escuela Nacional de Antropología e Historia, Mexico City.

Santley, Robert S. 1983. "Obsidian Trade and Teotihuacan Influence in Mesoamerica." In Highland-Lowland Interaction in Mesoamerica: Interdisciplinary Approaches, edited by Arthur G. Miller, 69-I24. Dumbarton Oaks, Washington, DC.

Santley, Robert S. 1989. "Obsidian Working, Long-Distance Exchange, and the Teotihuacan Presence on the South Gulf Coast." In Mesoamerica after the Decline of Teotihuacan AD 700-9oo, edited by Richard A. Diehl and Janet C. Berlo, I3I-I5I. Dumbarton Oaks, Washington, DC.

Santley, Robert S., and Philip J. Arnold III. 1996. "Prehispanic Settlement Patterns in the Tuxtla Mountains, Southern Veracruz, Mexico." Journal of Field Archaeology $23(2): 225-249$.

Santley, Robert S., and Philip J. Arnold III. 2005. "The Obsidian Trade to the Tuxtlas Region and Its Implications for the Prehistory of Southern Veracruz, Mexico." Ancient Mesoamerica 16(2):179-194.

Santley, Robert S., Thomas P. Barrett, Michael D. Glascock, and Hector Neff. 200I. "PreHispanic Obsidian Extraction in the Tuxtla Mountains, Southern Veracruz, Mexico.” Ancient Mesoamerica I2(I):49-63. 
Sarabia, Alejandro G. 1996. "Lítica tallada de la Pirámide de la Serpientes Emplumadas, Informe del Proyecto Templo de Quetzalcoatl.” Archivo ZAR, Instituto Nacional de Antropología e Historia, Mexico City.

Spence, Michael W. 1996. "Commodity or Gift: Teotihuacan Obsidian in the Maya Region." Latin American Antiquity 7(I):2I-39.

Stark, Barbara L., Lynette Heller, Michael D. Glascock, J. Michael Elam, and Hector Neff. 1992. "Obsidian-Artifact Source Analysis for the Mixtequilla Region, South-Central Veracruz, Mexico." Latin American Antiquity 3(3):221-239.

Stoner, Wesley D. 20I2. "Modeling and Testing Polity Boundaries in the Classic Tuxtla Mountains, Southern Veracruz, Mexico.” Journal of Anthropological Archaeology $3 \mathrm{I}(3): 38 \mathrm{I}-402$.

Stuart, David. 2000. “'The Arrival of Strangers': Teotihuacan and Tollan in Classic Mayan History." In Mesoamerica's Classic Heritage: From Teotihuacan to the Aztecs, edited by Davíd Carrasco, Lindsey Jones, and Scott Sessions, 465-513. University Press of Colorado, Boulder.

Sugiyama, Saburo. 1989. "Burials Dedicated to the Old Temple of Quetzalcoatl at Teotihuacan, Mexico." American Antiquity 54(I):85-106.

Tolstoy, Paul. 197 I. "Utilitarian Artifacts of Central Mexico." In Archaeology of Northern Mesoamerica, Handbook of Middle American Indians, edited by Robert Wauchope, G. Ekholm, and Ignacio Bernal, 270-296. University of Texas Press, Austin.

Weiant, Clarence. W. 1943. An Introduction to the Ceramics of Tres Zapotes, Veracruz, Mexico. Bureau of American Ethnology Bulletin 139. Smithsonian Institution, Washington, DC.

Zeitlin, Robert N. 1982. “Toward a More Comprehensive Model of Interregional Commodity Distribution: Political Variables and Prehistoric Obsidian Extraction in Mesoamerica." American Antiquity 47(2):260-275. 


\title{
Chapter 9
}

\section{Interregional Interaction of the Chalchihuites Culture in Northwest Mesoamerica during the Classic and Postclassic Periods}

\author{
José Luis Punzo Díaz
}

The northwest section of Mesoamerica is one of the most dynamic and culturally diverse areas of Mexico. This region is ecologically varied, spanning the Pacific coast and coastal plains, to the mountains of the Sierra Madre Occidental, across the grasslands of the eastern slopes to the mostly desertic areas in the central part of northern Mexico. A variety of people lived throughout this diverse landscape over time. There is evidence for human occupation beginning in the Archaic period (prior to 2000 BC), especially in some parts of the Sierra Madre and on the eastern slopes in the grasslands (Kelley 1952). The direct dating of maize made by MacWilliams et al. (2006) in the Sierra Tarahumara, slightly to the north of the area that forms the focus of this contribution, provided dates between 3,4002,300 years BP. This indicates a long tradition of agriculture before the influence of other Mesoamerican cultures appears. Prior to the emergence of the Chalchihuites culture, the region was inhabited by a cultural group generally known as "Loma San Gabriel," both in Zacatecas and in Durango (Foster 1978; Kelley 2002). To the north and east were hunter-gatherer groups that we know very little about.

In this chapter, I review processes of regional transformation in the northwest-shaped through interaction with various other Mesoamerican cultural traditions-that began in AD 200 and lasted over 1,300 years. Such interaction underpins archaeologically observed patterns in regional data, such as the existence of multiple cultural elements in the northwest that appear to have roots in neighboring regions, and serves to define the northwest frontier of Mesoamerica itself. These 
interactions impacted the southern core areas of Mesoamerica, northern Mexico, and even the American Southwest. Patterns of interaction across northwestern Mesoamerica-and between the northwest and other regions-have received much attention from archaeologists working in the area, and several descriptive and explanatory models have been proposed. Most of these are variations of World Systems Theory proposed by Wallerstein (1974), especially those presented in the last three decades of the twentieth century (see, e.g., Braniff 1992; Kelley 1986; Pailes and Whitecotton 1979; Pulb 1986). The most important and well known of these "core-periphery" models applied to northwestern Mesoamerica is that proposed by Kelley (1986). He postulated the concept of the "Aztatlán mercantile system" as an explanation for the presence of what he considered Mesoamerican traits in the US Southwest. Following and building on this model, there are more recent perspectives such as the Aztatlán expansion proposed by Mountjoy (2000), or the recent works of Carpenter (e.g., Carpenter et al. 20Io), in what he calls "the road to Paquimé." Other models that attempt to explain interaction across the northwest are based on ethnolinguistics, such as that proposed by Wilcox (1986; Wilcox et al. 2008) arguing a Tepehuán-Pima connection.

In my research, I employ a model based on a prestige goods economy that has been applied to long-distance trade relationships (Bradley 1999; Foster 1986; McGuire 1980, 1987; Nelson 1986). This model posits that "exotic" goods were used by local elites as a sign of power. I prefer this model because I think that it is not possible to explain sociocultural development in northwestern Mesoamerica-especially with regards to the Chalchihuites culture in Zacatecas and Durango-through simplified reductions of social processes stemming from interaction with an "active" center in core areas of Mesoamerica (such as Teotihuacan), whose influence was transmitted to a "passive" receptor along (or beyond) the northern frontier. Rather, I hold that the northwest region was a buffer zone (cf. McCarthy 2008) or a transitional area between the Mesoamerican world and other societies, some agricultural and some not, with different traditions. Thus, I maintain that the Chalchihuites phenomenon should be viewed as a mixture of groups with diverse adaptations to their particular environment that occurred in the context of cultural exchange stimulated by Mesoamerican relationships. Consistency in the types of goods encountered in the region-especially those ostensibly acquired from Mesoamerican sources to the south (e.g., ceramic iconography or lapidary technologies)—-makes it very difficult to archaeologically detect differences between neighboring groups throughout the northwest. This is why I hold that there are some earlier sites such as Cerro Moctehuma and Alta Vista in Zacatecas-as well as La Ferrería (Formerly known as the Schroeder site) and Cañón de Molino in Durango in later periods-that reflect the northward movement of prestige goods used by local elites in the region. 


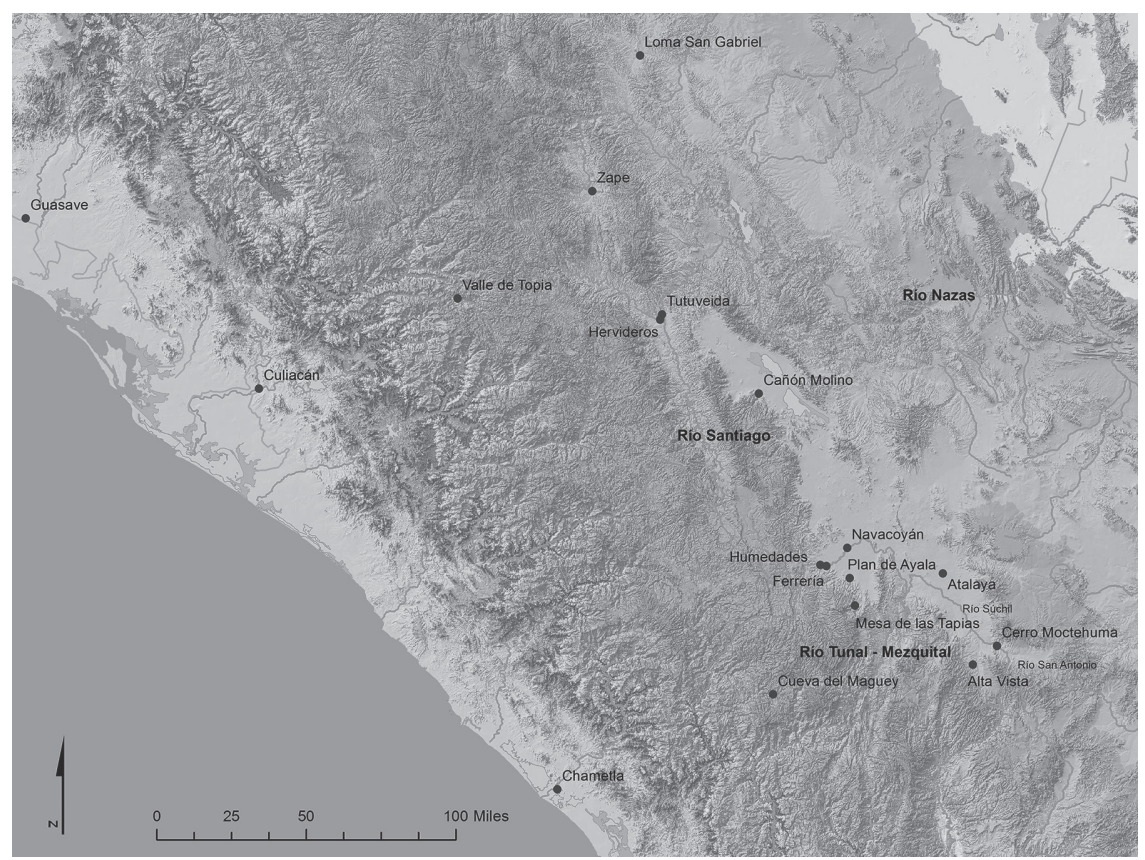

FIGURE 9.I. Map of the principal sites associated with the Chalchihuites culture.

\section{THE FIRST 400 YEARS: THE FRONTIER IN NORTHWESTERN ZACATECAS}

The Chalchihuites culture in northwest Zacatecas began developing around AD 200 , especially along the Suchil River. Kelley named this phenomenon the Canutillo phase (Kelley 1985, 1990). These groups were the first inhabitants in the northwest to have some Mesoamerican traditions (expressed primarily in ceramic iconography), and were also the first to establish settlements northwest of the Mesoamerican frontier (figure 9.I). During the early Canutillo phase, small hamlets were built along rivers. They were laid out as a series of quadrangular rooms surrounding patios with small central altars. The houses were built with perishable materials, such as jacales (thatch-roofed, wattle-and-daub huts). In those hamlets, especially along the San Antonio River, more traditional Mesoamerican features are evident (cf. Córdova and Martínez 2006), including Canutillo red filled ceramics, which displays an incised pattern filled with red pigment. Throughout this early period, the site of Cerro Moctehuma was the most significant. This site is on an eastern branch of the Suchil River, eight kilometers from the junction of the Suchil and Colorado Rivers. Like many Chalchihuites sites, it sits atop a large mesa that bounds the Suchil River. The site layout is a pattern of courtyards with a central altar, which, in some cases, 
was surrounded by platforms and rooms, with a small pyramidal structure on one end. The site also has a larger pyramid, with some courtyards at its foot, very similar to those present at La Ferrería in Durango, as we will see.

Alta Vista, on the Colorado River in northwestern Zacatecas, and La Quemada, IOO mi. southeast, emerged as regional centers around AD 400. During the next two archaeological phases subsequent to Canutillo (Vesuvio AD 650-750 and Alta Vista AD 750-850), a number of traditionally Mesoamerican characteristics appear in the region, particularly in terms of architecture. These characteristics stand out at La Quemada, for example, architectural elements such as closed plazas with central altars, pyramids, ballcourts, and columned rooms (Jiménez-Betts 1994:140). At this time, Alta Vista became the northernmost point of the Mesoamerican tradition, having features related to Teotihuacan in central Mexico (e.g., formalized pyramidal architecture, pecked-cross petroglyphs with astronomical connotations). In this sense, the most accepted interpretation today is that Alta Vista was an older hamlet later controlled by Teotihuacan ritual specialists, looking for the point where "the sun turns back" - the Tropic of Cancer (Aveni et al. 1982; Medina and García 2010). Studies of the pecked cross-like petroglyphs at Cerro Chapín, Zacatecas, by Kelley and Aveni (Aveni et al. 1982), those at Tuitán, Durango, by Hers and Flores (2013; see also Flores 2013), and ongoing work by myself and others appear to corroborate this astronomical hypothesis. Of course, it is significant that recent work at Teotihuacan indicates that by AD 575 it was experiencing social, political, and religious crises that resulted in the destruction of important portions of the city and the dispersion of part of its population (cf. López-Luján 2003; Manzanilla 2003). How such upheavals in central Mexico affected the northwest frontier, however, remains obscure.

At Alta Vista, the Hall of Columns (figure 9.2) and the southeast plaza are the oldest constructions at the site, dating to circa AD 400-450. The corners of the southeast plaza are oriented to the cardinal points-a rarity in Mesoamerica. The plaza is sunken and had a central altar. On the northeast side is the Hall of Columns. In this square structure are four parallel rows with seven columns each, made of adobe, possibly used to support an expansive roof. This important site had other sectors such as the Serpent Wall; the Astronomer's Complex, built around AD 500-550; the Southeast Plaza; and the Labyrinth or the Three Temples Complex. One temple, the Sun Pyramid, built around AD 835, is an adobe structure with a top decorated with sun-related motifs and crenellated elements. An interior crypt contained rich offerings that included a set of pseudo-cloisonné cups. Also in the complex is the Temple of the Skulls. It housed a great amount of human bones, including a striking assemblage of perforated skulls, and femurs with traces of tied ropes used for hanging them from the ceiling as trophies (García and Medina 2008). 


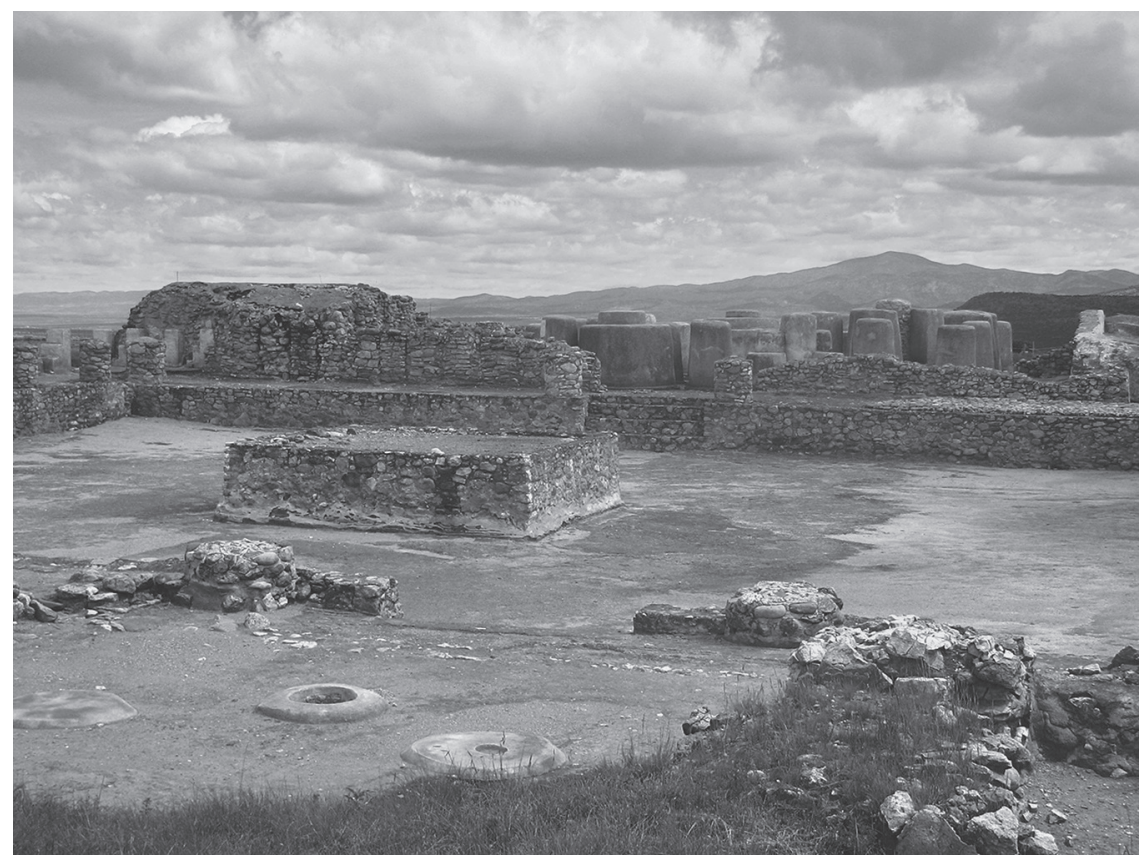

FIGURE 9.2. The Hall of Columns at Alta Vista.

One of the most characteristic elements of the Chalchihuites in northern Zacatecas is the situation of sites adjacent to abundant mines, including several surrounding Alta Vista. Weigand (1968, 1982, 1995) posited that the mines and their rare minerals or gemstones provided the main motivation behind Teotihuacan's interest and presence in the area (see also Jesper Nielsen et al., chapter 6 in this volume). Research over the last twenty years has refined our understanding of this scenario. First, dating objects from the mines, Schiavitti (1996) concluded that the mining in the area dates to the late Alta Vista phase, well after the decline of Teotihuacan. Regarding the resources that were mined, different green stones, such as malachite, have been recovered; however, no turquoise has been found (Fenoglio 2011; Schiavitti 1996). Nevertheless, Kelley reports more than 17,000 turquoise items in northern Zacatecas but very few in Durango. Recently, UV and X-ray fluorescence studies have been applied to samples from sites in northern Zacatecas investigated by Córdova and Martínez (2006). They confirmed the presence of a great amount of chemical turquoise and a smaller proportion of amazonite (Melgar et al. 20I4), but without positive provenience.

Since the Classic period Vesuvio and Alta Vista phases have usually been considered to be the time when the majority of Mesoamerican characteristics appear in 
the region, we may perhaps infer that this influence was a result of the dispersion of part of the Teotihuacan population, and that Mesoamerican ideas thus impacted local developments during these phases. At this time in the northwest there is clear social stratification, a developed astronomical knowledge, rich Mesoamerican-style iconography, and the development of complex architecture throughout the region. The iconography presented on examples of Suchil ceramics is indicative of this Mesoamerican link. First, the quadrangular division of the plates and many of the motives were very close to the Chupicuaro tradition of Guanajuato-Michoacán and the Loma Alta tradition of central Michoacán (Carot and Hers 20II). For example, the representation of pairs of double-headed "priests," the use of the Mesoamerican speech scroll, and humanized serpents, among other motifs, are suggestive of interaction-or at the least suggest that Suchil ceramic artisans were conversant with contemporaneous representational conventions in other areas of Mesoamerica "proper." Further, at the end of the preceding Canutillo phase and the beginning of the Vesuvio phases, the movement of people or Mesoamerican traits to the north is suggested at sites such as La Atalaya in southeastern Durango. There, materials associated mainly with the Alta Vista and Ayala phases have been found, but with a very solid presence of earlier Canutillo ceramics (Kelley 1962). Recent research at the community museum in Villa Union, Durango, confirms the presence of those kinds of materials.

\section{A 200-MI. SHIFT IN THE NORTHWEST FRONTIER OF MESOAMERICA}

\section{CA. AD 600: THE VESUVIO-ALTA VISTA PHASES (AD 650-850) IN \\ ZACATECAS AND THE AYALA PHASE (AD 600-850) IN DURANGO}

Around $\mathrm{AD} 600$ the Mesoamerican frontier shifted to its most northern extent, in the vicinity of Zape, near the border of the states of Durango and Chihuahua (Brand 197I; see figure 9.I). It is important to question whether such a "frontier" was perceived by the cultural groups inhabiting this region, as this category was created by modern-day scholars, and there are no obvious natural boundaries separating groups that adopted some Mesoamerican traditions and those who did not. Thus, the northwestern frontier comprises a large territory of interaction and cultural contact among different groups that produced and consumed, in different proportions, the archaeological items that are related to broader, pan-Mesoamerican traditions. In this sense, sites south of this frontier region in Durango-such as those in the Guadiana Valley (for instance, La Ferrería) or Cañón de Molino in the Guatimapé Valley_are evidence of more abundant materials that display clearer links to Mesoamerican cultural traditions further south. Such parallels are evident in ceramics with rich iconography, such as the representation of plumed serpents, 
horned serpents, big felines such as jaguars and mountain lions; and architectural features such as sunken patios, pyramids, colonnaded halls, and ballcourts, among others. On the other hand, sites in the north, such as Hervideros in the Santiago River Valley (Hers 2006; Hers and Polaco 2005) or Zape (Brand 197I) in the northwest part of the state of Durango - and closer to the frontier itself-evidence fewer material parallels. Nonetheless, at these northern sites, Mesoamerican influence is noted in architectural features such as colonnaded halls, ballcourts, or ceramic types with rich Mesoamerican iconography such as Michililla red fill engraved or Mercado Red-on-Buff, but these are in minor proportion compared to southern assemblages.

The reasons behind this phenomenon of expanding Mesoamerican influence in the Chalchihuites region during the Classic period continue to elude adequate explanation. It could be due to any number of factors, or combination thereof, including ( $\mathrm{I}$ ) an influx of people from the south who were abandoning certain central Mexico sites and/or Teotihuacan; (2) the imposition by force of Mesoamerican ideas upon the Chalchihuites; and/or (3) climactic shifts that increased rainfall in the north, thereby augmenting the amount of arable land suitable for intensive agricultural cultivation. This issue is beyond the scope of the present chapter and therefore must be treated in future investigations. For the moment, however, I will explore the proposition that the florescence of the Chalchihuites culture, the expansion of the northwestern frontier of Mesoamerica, and the consolidation of major sites in the northwest were a result of internal factors and changes within the region, rather than an effect of Teotihuacan hegemony or direct imposition from central Mexico (cf. Jesper Nielsen et al., chapter 6 in this volume).

The Ayala phase in the Guadiana Valley begins about AD 600 (figures 9.3 and 9.4), during which time Chalchihuites groups first consolidated their settlements. Based on its size and the presence of architectural futures such as pyramids, large, sunken patio complexes, and ballcourts, it is evident that La Ferrería was the most complex site constructed at the beginning of the Ayala phase, and is therefore perhaps most representative of the burgeoning Chalchihuites consolidation, at least in some aspects. In general, however, Chalchihuites builders in the Guadiana Valley used almost every elevation above the valley floor to construct their settlements. They selected hills near rivers or creeks and with good surrounding agricultural land. No evidence of canal irrigation has been found, and it is presumed that crops were planted in areas with a high water table or that received sufficient rain from constant summer showers. On hilltops, Chalchihuites groups built diverse structures, even on the small hills. One constant element is the use of small plazas surrounded by mostly square habitation rooms as the nuclei of the sites. Typically, only a single room was built, but in some cases double or triple rooms are found. However, there does not appear to have been 


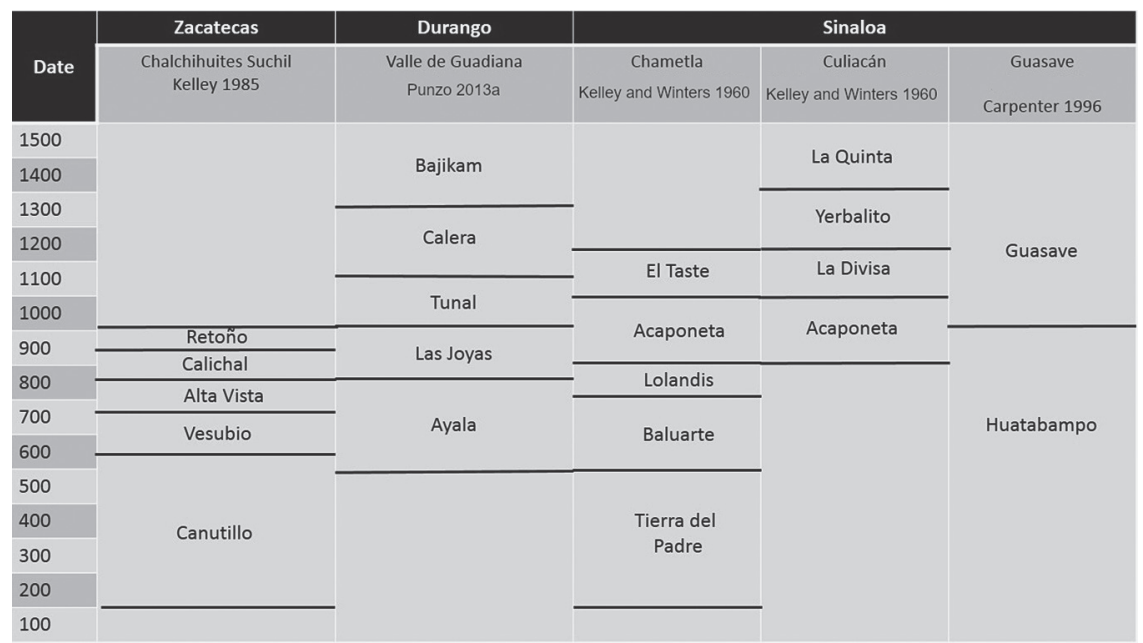

FIGURE 9.3. Comparative chronologies from Zacatecas, Durango, and Sinaloa.

any internal communication between rooms. Isolated structures-some of them circular in form-are also frequently found in the patios (Punzo 2016).

One of the clearest indicators of interaction between the northwest and broader, pan-Mesoamerican traditions is the presence of ballcourts. The courts are simple constructions having two parallel walls 10 to $\mathrm{I} 5 \mathrm{~m}$ in length and less than $\mathrm{I} \mathrm{m}$ in height. There is usually a 4 to $6 \mathrm{~m}$ separation between walls, with no walls across the postulated terminus. The orientation of the ballcourts is generally north-south (Kelley 1997). In the Guadiana Valley, there are examples of ballcourts in sites such as La Ferrería and Mesa del Encinal, but there are also sites that have double ballcourts, including Mesa de las Tapias in the southern Guadiana Valley and La Tutuveida in northwestern Durango near Santiago Papasquiaro (Berrojalbiz 20I2). Ballcourts are thus spread throughout the Chalchihuites territory in Durango.

Archaeologists working in the region generally agree that the apogee of Alta Vista in northern Zacatecas is contemporary with the beginning of the Ayala phase in the Guadiana Valley of Durango, circa AD 600. In numerous surveys over the past decade in the Guadiana Valley, we have established the presence of ceramic types associated with this phase at roughly 35 percent of the sites in the valley that evidence Chalchihuites decorated wares (Punzo 2013a). In this sense, the Nayar site could be the best example of developments at the beginning of the Ayala phase. The site was built atop a small mesa with some terraced slopes, but the primary construction was at the top of the hill. It is noteworthy that the mesa is surrounded by cliffs, although 


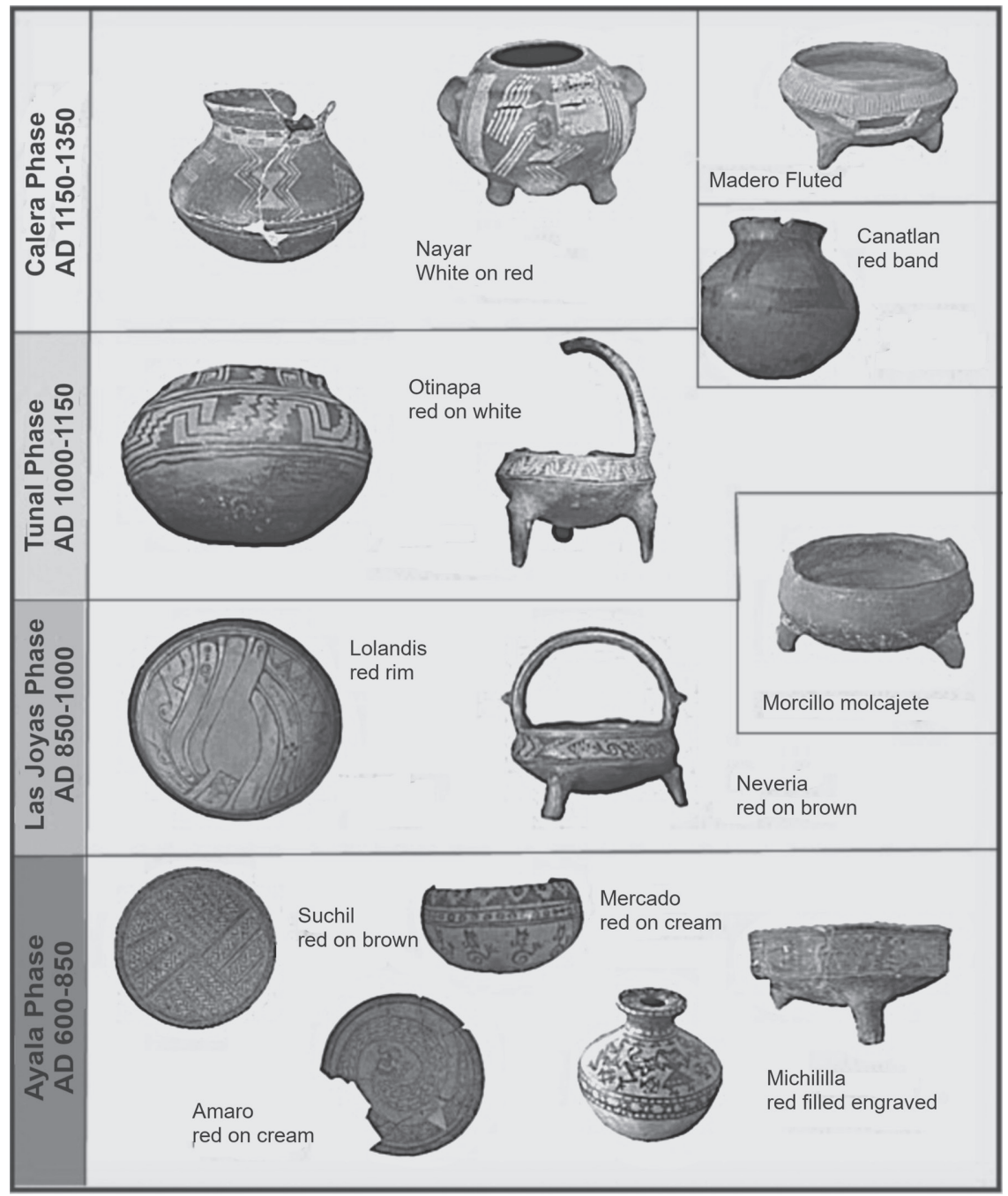

FIGURE 9.4. The Chalchihuites chronology in Durango with associated ceramic types.

a narrow stairway and path provided a single, easy access to the summit. We excavated the site in $201 \mathrm{I}$ and found a structure from a pre-Chalchihuites context at the bottom of the excavation, on which was superimposed a typical Chalchihuites compound of a sunken patio surrounded by square rooms. At this site, a pair of complete Suchil Red-on-Buff plates in burial contexts was unfortunately recovered by looters, but we also recovered similar sherds in more secure archaeological contexts 
(Punzo et al. 20II). The same ceramic type has been found at La Ferrería and at the site of Navacoyan - also in the Guadiana Valley—and is generally considered an important marker of contemporaneity with the Alta Vista phase at Alta Vista, since it is found in abundance at that site. Two other significant Ayala phase ceramic types are Mercado and Amaro Red-on-Buff/Cream (see figure 9.4). Iconography found on this ceramic ware was shared throughout the Chalchihuites territory and was related to established Mesoamerican artistic traditions, as noted first in studies by Kelley and Abbott (197I). They link the Chalchihuites ceramic iconography to beliefs associated with the path of the sun, the representation of plumed serpents (or bird-serpents), and earth monsters. These, among other elements, are indicative of relations and dialogues with other traditions in Mesoamerica proper. More recent studies support these findings and further consolidate links to pan-Mesoamerican iconography in the Chalchihuites tradition (Ambríz 2013; Hers 2005; Medina and García 2010; Rodríguez 2009).

In 20II, our petrographic analysis of the ceramics of the Guadiana Valley Chalchihuites types concluded that almost all the Chalchihuites ceramic types were made with local clays (Sandoval 20ri). The only one with a clearly extralocal origin was Suchil Red-on-Buff, made with clays that likely came from the San Antonio River near Alta Vista. In addition, the presence of four vessels at Alta Vista manufactured with the pseudo-cloisonné technique is significant, since pseudo-cloisonné ceramics have also been encountered at sites in western Mesoamerica-such as Los Guachimontones (Englehardt and Heredia in press) and Cerro del Huistle in Jalisco (see Hers 1983) - that are possibly related to the Chalchihuites culture. Further, possible pseudo-cloisonné sherds have been reported in similar temporal contexts at some sites in northern Zacatecas (e.g., Cerro Moctehuma, Portero del Calichal, Vesuvio, and Cerrito de la Cofradía; Kelley and Abbott 197I). In an important study, Sue Ward (1970) analyzed twenty-one pseudo-cloisonné sherds, mostly from sites in the northwest such as La Cofradía, Vesuvio, Moctehuma, Calichal, Totoate, Cerro Blanco, and La Ferrería. Ward identified different groups that suggested common manufacturing sources at distant sites, indicating nonlocal production.

It is also noteworthy that there are some complete vessels decorated with the pseudo-cloisonné technique. At Alta Vista, the most impressive examples are high annular-based cups or goblets, an uncommon vessel form in the rest of the Alta Vista phase ceramics (Kelley and Abbott 197I). On the other hand, at La Ferrería, the only one found with this decoration is a globular vessel, a form frequently used in Ayala phase wares. The iconography of these vessels is very significant. The goblets at Alta Vista are highly decorated, possessing more than thirty colors or hues (Kelley and Abbott 197I). The most important visual element is usually located on 
the vessel interior and depicts a complex life form-a bird holding a snake in a couple of cases and a human with a feather headdress, earplugs, mask, and a shield in another instance (Rodríguez 2009). The La Ferrería globular vessel is completely decorated. In the center is a human with a serpent body that surrounds the vessel, holding some white flowers or possibly paper rolls. The central figure is surrounded by elements that resemble maguey leaves. Other decorated ware found in the Guadiana Valley and at Alta Vista uses a negative design technique. Currently, no complete vessels and only a very few fragments have been found. Investigations at sites in Durango and Zacatecas have only yielded sherds from shallow bowls or plates. The decorative motif includes only dots and a few lines. Unfortunately, the small number and size of the sherds do not allow for substantive inferences regarding the meaning or sociocultural significance of the design.

In terms of interaction within and involving the northwest, however, the ceramic design techniques are very relevant. During the Alta Vista and Ayala phases, design elements with a Mesoamerican origin appear in the north along with techniques (e.g., pseudo-cloisonné) that probably originated in western Mesoamerica. Ceramics with similar designs have been reported at many west Mexican sites (Aronson 1993; Pomedio 2009), for example, at El Otero in Jiquilpán in northwestern Michoacán (Hers 2013; Noguera 1944) or in the lake basins of Jalisco (Lumholtz 1945). This suggests the presence of interaction networks that linked western Mesoamerica northward to Zacatecas and Durango, and possibly even further north into the US Southwest. Another important marker of interregional interaction during the Classic period is the presence of "foreign" ceramics from the Pacific coast in the inland northwest, especially at the site of La Ferrería in Durango. ${ }^{1}$ With the thorough reanalysis of the ceramics recovered by Kelley in the 1950 and the survey and excavations conducted in last decade, we now can conclude that 39 percent of the pottery from the Pacific coast found at La Ferrería is related to the Ayala phase (Punzo 2013a). The fact that 15.8 percent of the ceramics found by Kelley at the site are coastal types suggests a significant degree of interaction between La Ferrería and the coastal areas of Sinaloa and Nayarit at this time.

The coastal ceramics associated with the Ayala phase of AD 600-850 are concentrated in two of the most important structures at La Ferrería, Structure 7 ( La Pirámide; figure 9.5) and Structure I (La Casa de los Dirigentes; figure 9.6). During recent excavations at La Ferrería we stratigraphically correlated Ayala phase pottery types such as Michililla red-filled engraved, Mercado and Amaro Red-on-Buff/ Cream with coastal types like Middle Chametla Polychrome and Middle Chametla Polychrome Engraved. These types date to between AD 500 and AD 700, during the Baluarte phase on the coast (Foster 1995:70; Kelly 2008; Kelley and Winters 1960). In addition to the utilitarian red band and late black band incised, both types are 


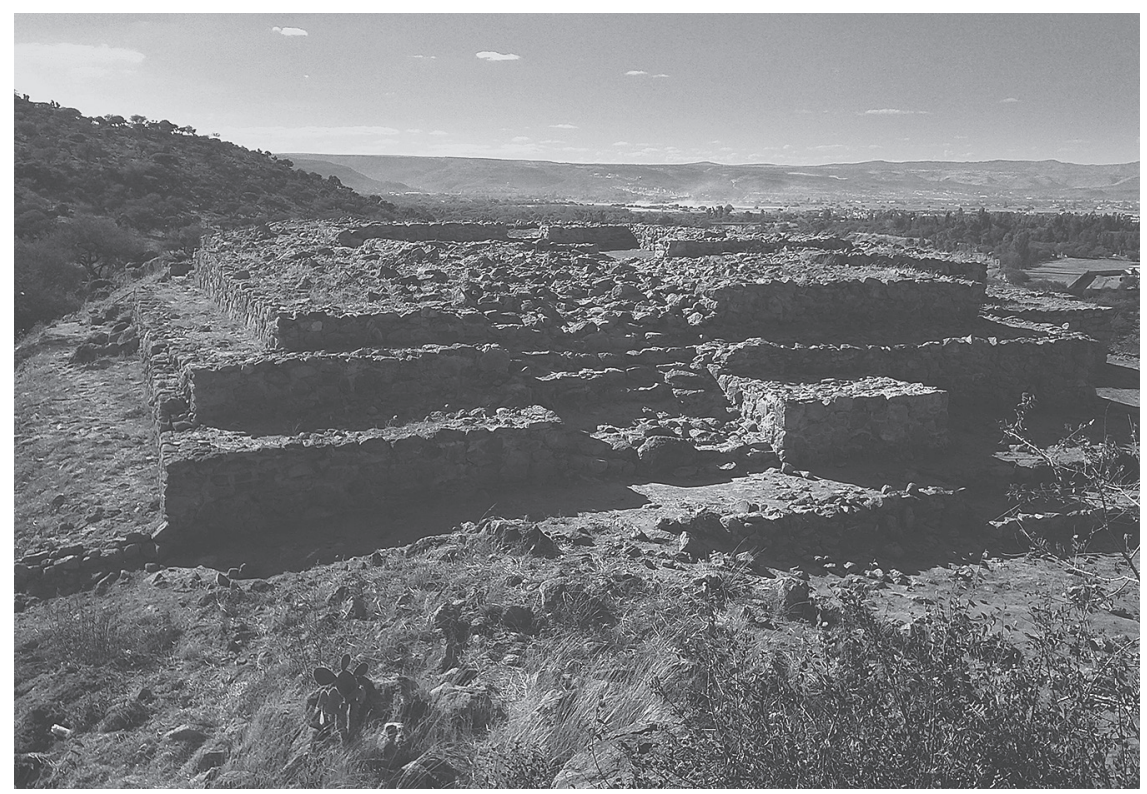

FiguRE 9.5. La Ferrería Structure 7 (La Pirámide).

also present throughout the subsequent Chametla phases. Through petrographic study of the coastal sherds from La Ferrería (Vidal 20rI), we have learned that at least the Middle Chametla Polychrome Engraved was manufactured in southern Sinaloa, specifically in the Baluarte River basin and perhaps at the Chametla site itself. Kelley (1986) recognized this area as a precedent in the Aztatlán Mercantile System. These new data, however, suggest that a reevaluation of Kelley's original model is in order. In contrast to Kelley's idea of restricted interaction due to the lack of population in the Guadiana Valley during the Ayala phase, I propose instead that this period was one of intensive interregional interaction. La Ferrería likely served as a regional center for the distribution of ceramics and exotic goods such as marine shell into the Chalchihuites culture.

Another significant item found in northwestern Mesoamerica, and suggestive of interaction with broader Mesoamerican traditions, is the iron pyrite mirror. Such mirrors have been found at both Alta Vista and La Ferrería (figure 9.7). At Alta Vista a ceramic disc with a wood ring with indications of turquoise tesserae and pseudo-cloisonné decoration was found under the Hall of Columns, thus dating prior to AD 450 (Hers 2013). At La Ferrería, Kelley found two mirrors associated with burials under Structure 2 (La Casa Colorada), which he dated to an early stage 


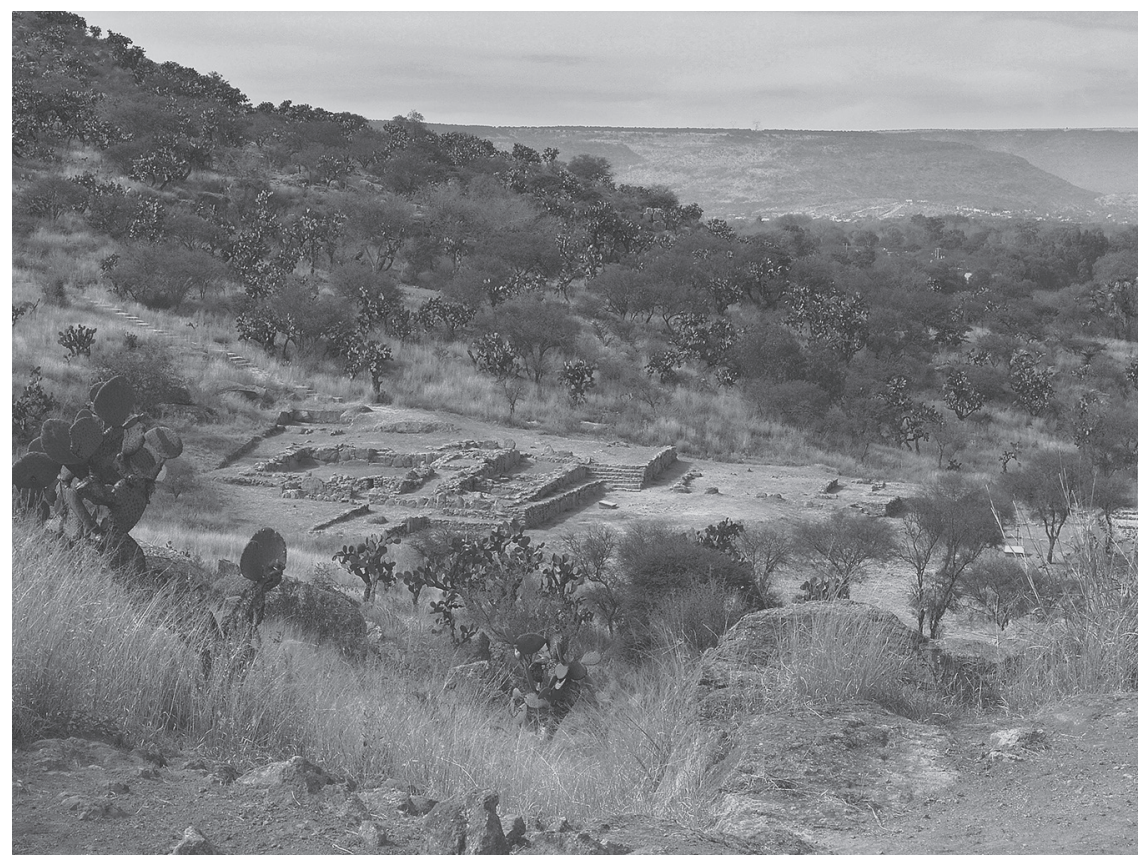

Figure 9.6. La Ferrería Structure I (La Casa de los Dirigentes).

of occupation of the structure during the Ayala phase. Iron pyrite mirrors have a long history in Mesoamerica, and appear to have been important ritual objects since the Formative period. For example, Taube (1992) has identified several representations of and images that depict mirrors with significant meanings at Teotihuacan, which he argues held important roles in diverse rituals. Such mirrors have also been encountered at many western Mesoamerican sites in Michoacán, Jalisco, and Nayarit (Hers 2013), and in the US Southwest iron pyrite mirrors are common in contemporaneous Hohokam contexts (McGuire and Villalpando 2008).

\section{THE LAS JOYAS PHASE (AD 850-1000): THE APOGEE OF THE GUADIANA VALLEY CHALCHIHUITES AND LA FERRERÍA}

By AD 850 all of the Chalchihuites sites that we have identified in the Guadiana Valley were occupied. The appearance of a great variety of sites probably reflects an increase in population size. Around this time "Mesoamerican" influences appear to have intensified on regional Chalchihuites groups, which simultaneously strengthened their ties with outlying regions, especially the Pacific coast, probably reflecting the 


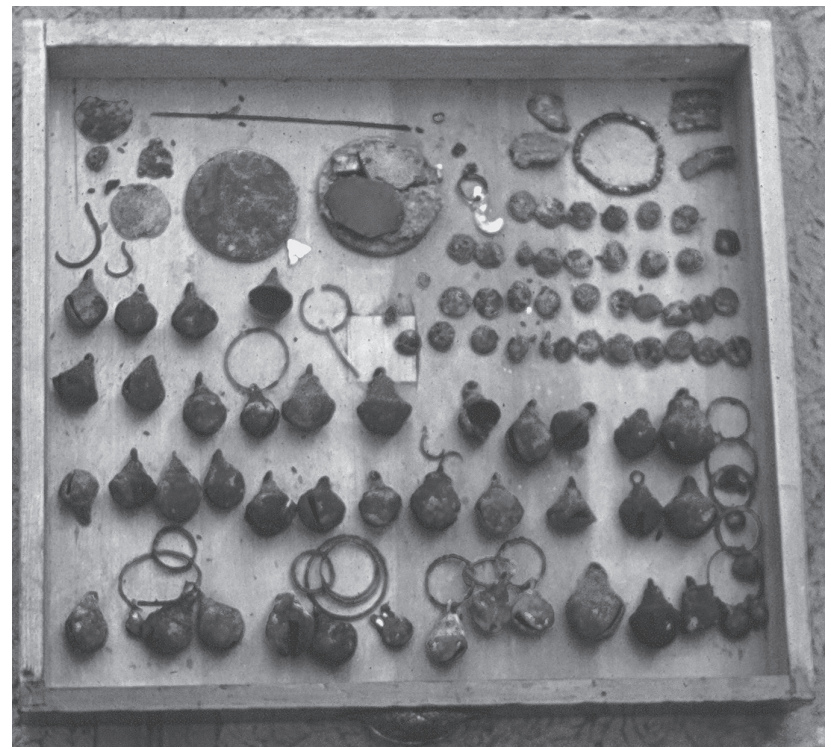

FIGURE 9.7. La Ferrería iron pyrite mirrors and other items from Kelley's excavations in the I950s.

start of the Acaponeta phases in the Chametla and Culiacán areas. But this Las Joyas phase also sees increasing independence for the Chalchihuites culture in Durango. During the preceding Ayala phase, iconography and architecture appear related to major sites in Zacatecas. In the Las Joyas phase, however, the iconography painted on ceramic vessels appears connected to broader pan-Mesoamerican traditions, traceable in the previous phase, but using more abstract motifs that appear locally inspired (cf. Englehardt and Heredia in press). This could indicate the selective incorporation of ideas by local ceramists. This is particularly seen in Nevería Red-on-Buff ceramics, which use abstract Mesoamerican elements such as deer, squirrels, and the representation of the earth monster, along with handles that display sun or star motifs.

Also at this time, La Ferrería became the largest settlement in the Guadiana Valley and the only site that combines the "typical" pattern of patios surrounded by residences with structures that likely had ritual significance, such as pyramids, ballcourts, circular structures, and square-roomed compounds. I suggest that during the Terminal Classic or Epiclassic Las Joyas phase, La Ferrería functioned as the northernmost ritual center in Mesoamerica, and the biggest in the Guadiana Valley, serving as a focal point and node of interaction for sites throughout the valley and perhaps more distant communities. Thus, by AD 800 there were three major 
regional centers in northwestern Mesoamerica: Alta Vista and Cerro Moctehuma in Zacatecas, and La Ferrería roo kilometers northwest in Durango.

As detailed above, construction of the main buildings at La Ferrería started during the preceding Ayala phase ( $\mathrm{AD} 600-850$ ). In Las Joyas times, in addition to the building of Structure 5 (La Casa Grande), there is evidence of efforts to renew features such as Structure I (La Casa de los Dirigentes) and the circular structures mentioned by Kelley (1958). These two phases thus witnessed the florescence of the Chalchihuites occupation in the Guadiana Valley and saw major construction efforts. There are some parallels to these renewed construction episodes in regions such as the Bajío, which some scholars point to as evidence of a Teotihuacan presence, although others insist that this is a local phenomenon (see, e.g., Kristan-Graham 2011).

The north slope of La Ferrería contains small rectangular structures built over more than fifty terraces. This sector of the site has paths that connect the different terraces and facilitated access to and communication between the site summit, the abundant agricultural lands along the Tunal River, and ritual areas within the site. La Ferrería had two ceremonial precincts, located on the summit and the eastern flank of the main hill, respectively. On the summit itself are a small square pyramid and a circular structure of $\mathrm{I} 4 \mathrm{~m}$ in diameter and almost $\mathrm{I} \mathrm{m}$ in height. A small sunken patio with a square room is attached. The east sector of La Ferrería was home to key buildings such as the pyramid, the ballcourt, and the sunken patio compounds-themselves one of the defining features of the site. Although also found in other contexts throughout the valley, the compounds at La Ferrería are the largest in the region.

Probably the prominent feature at La Ferrería is the northernmost square, stepped pyramid in Mesoamerica, Structure 7 (see figure 9.5). Construction of this pyramid made use of a natural rock mass as a core and was then covered with additional layers of stones and earth. The northeast corner of the pyramid presents a remarkable characteristic, making a zigzag form (to the right of the image in figure 9.5). The crest of the pyramid is flat with a big sunken patio aligned to the cardinal directions and at least one square room in the west portion, which we excavated in 2012. At that patio, we made some archaeoastronomical observations and determined that the sunken patio marks the solstice and the equinox points where the sun rises behind the Sierra del Registro, thus creating a horizon calendar. The pyramid thus materializes a dynamic relationship between the sun, architecture, and landscape markers (Punzo 2012). From the center of the patio it is possible to observe the sunrise from the vertex or the northeast corner of the east entrance during the summer solstice, from the southeast corner of the patio vertex on the winter solstice, and during the spring and fall equinox from the south edge of the east entrance. The equinox points aligned with the stairway, as well as a petroglyph at the foot of 
the natural hill that depicts a hunter with arms and legs extended holding a lance or darts in his left hand and another object, too deteriorated for positive identification, in his right hand, and next to whom appear a series of quadrupeds that have been interpreted as deer. These alignments perhaps suggest that important rituals were to have occurred on these astronomically significant days (Punzo 2012). This type of solar observation has also been suggested to have occurred at other sites such as Alta Vista, Cerro Chapin, and Cerro Pedregoso in Zacatecas (Aveni et al. 1982). These relationships likely permitted the Chalchihuites people to associate the movement of the sun with agricultural cycles and a ritual calendar. The presence of a solar calendar related to ritual cycles and agriculture is another significant pan-Mesoamerican trait, albeit in this case with the incorporation of local elements.

Above, I briefly mentioned a potential relationship between La Ferrería and the Chametla area of Sinaloa during the Ayala phase. This relationship appears to have strengthened during the Las Joyas phase. Such strengthening of interaction is reflected in the abundance of Lolandis red rim pottery at La Ferrería-a pottery type that Isabel Kelly (2008) argued is among the most important at northwestern coastal sites. At La Ferrería, the Lolandis sherds comprise 44 percent of the ceramics from Structure 5 (La Casa Grande) and 22 percent of the types found in Structure I (La Casa de los Dirigentes). Another twelve structures had a minor percentage of coastal pottery Kelley and Abbott (197I) argue that during the Las Joyas phase, a colony of coastal people in residence at La Ferrería produced such pottery. A recent petrographic analysis (Vidal 20II) indicates that the Lolandis ceramic type was made in both the Durango and Chametla areas and was traded along the Sierra Madre in both directions. Lolandis pottery is abundant in the Guadiana Valley, present not only at La Ferrería, but also at the sites of Navacoyan, Plan de Ayala, Las Humedades, and Nayar.

That fact notwithstanding, the amount of material from the coast in the Guadiana Valley actually decreased at this time. The percentage of coastal types to the total Las Joyas phase ceramic assemblage is only 8 percent, lower than in the preceding Ayala phase (as detailed above). Nonetheless, it is significant that the diversity of coastal ceramic types present in regional assemblages increased at this time. During Las Joyas, La Ferrería apparently received a wider variety of pottery from the coast of Sinaloa, such as Aguaruto engraved, from the central region of Sinaloa among the Aztatlán; and Botadero engraved, Cocoyolitos Polychrome, Chametla red rim decorated (AD 750-1050; Foster 1995:70), Tuxpan engraved, and Lolandis (AD 750-900; Kelley and Winters 1960) from southern Sinaloa. These types are also present in sites such as Plan de Ayala and Navacoyan in the Guadiana Valley and the site of Cañón de Molino in the Guatimapé basin. Thus, interaction with the coast is not suggested through the sheer amount of material encountered 
in inland Durango, but rather through the diversity of the materials present. It is also potentially significant that during this phase the Gomelia site along the Santiago River began to have important interactions with the Pacific coast, channeled through the central part of Sinaloa, and through the northern site of Zape-a conclusion supported by the ceramic types found at these sites. The conclusion of the Las Joyas phase around AD I000 also marks the end of relations between the Chalchihuites sites of Zacatecas and those in Durango. Around that time, the major Chalchihuites sites in Zacatecas, such as Alta Vista, were abandoned. These changes in the southern frontier impacted the Durango area as many sites were diminished or abandoned in the Guadiana Valley.

\section{THE ABANDONMENT OF CHALCHIHUITES IN ZACATECAS AND THE APPEARANCE OF THE AZTATLÁN TRADITION IN THE EARLY POSTCLASSIC (CA. AD 1000)}

The end of Las Joyas and the beginning of the Tunal phase at approximately AD I000 was a gradual transition and not an abrupt change. In the early Tunal phase the number of settlements in the Guadiana Valley diminished as smaller groups coalesced into larger villages. Almost one-half of the sites occupied during the Las Joyas phase were abandoned, and major construction ceased at La Ferrería. Other sites in the Guadiana Valley, however, increased in size, as occurred at Navacoyan, Cerro de las Casitas, Mesa de las Tapias, and Plan de Ayala, as well as at Cañón de Molino in the Guatimapé Valley (Punzo 2013a). This pattern of population change in the Guadiana Valley was roughly contemporaneous with the abandonment of Chalchihuites sites in Zacatecas around AD 950, especially Alta Vista (Kelley 1985:269-287). This phenomenon had a great impact on sites in Durango, as any intimate relations between Zacatecas and Durango ended with the abandonment of Alta Vista. At the same time, the Pacific coast experienced changes at the beginning of the Acaponeta phase in southern and central Sinaloa and around Guasave to the north. The northern frontier of Mesoamerica along the Sinaloa coastal areas seems to have shifted north to around 26 degrees north latitude, the parallel on which the site of Zape in Durango was approximately situated.

During the Tunal phase, ceramic vessel forms and decoration changed considerably. The manufacture of tripod vessels, first seen in the Ayala and Las Joyas phases (see figure 9.4), continued, and ollas began to be decorated. A white slip and red paint were common, while the use of Brown and Buff slips and pseudoslips with red paint were abandoned. Iconography also changed-zoomorphic and anthropomorphic motifs were replaced by geometric patterns and abstract motifs. Kelley called this ceramic type Otinapa red-on-white, and it has many similarities with 
the ceramics from the coast of Nayarit and Sinaloa, and even with Hohokam in the US Southwest (Carot and Hers 20II). As Guadiana Valley sites grew in size at this time, more coastal ceramics appeared. In 1954, a very early Otinapa tripod vessel was found in La Ferrería Structure I (La Casa de los Dirigentes) along with an Aztatlán Polychrome vase. This association helps date the end of the Las Joyas and the beginning of the Tunal phases. In addition, the finding is very significant because the local Otinapa vessel was encountered in the same ritual context as the imported Aztatlán codex-style vase. Another significant change observed in the ceramic materials during this transition is the presence of coastal globular spindle whorls associated with the Lolandis and Acaponeta phases in Chametla (Kelly 2008) as opposed to the engraved button spindle whorls characteristic of the Chalchihuites culture. The presence of globular spindle whorls in the Guadiana Valley has been documented at La Ferrería, Navacoyan, and Cerro de las Casitas. It is also worth mentioning that six engraved button spindle whorls were found at Paquimé in northern Chihuahua in a Medio period context (AD I200-I450). These finds suggest sporadic contact between this final manifestation of the Chalchihuites culture with the Casas Grandes region in Chihuahua (Punzo and Villalpando 20I5).

The second half of the Tunal phase witnessed the appearance of a very important trade ceramic from the coast in Durango: Guasave Red-on-Buff, which dates to AD IIo0-I450 (Carpenter 1996). At La Ferrería, this ceramic type constitutes 9 percent of the total of the ceramics from the coast encountered during the Tunal phase. This is significant because the building activity at La Ferrería wanes at this point, though occupation and activities continue at least to the year AD I200, as we found during our excavations in 201 ( (Punzo et al. 20II). In the Guadiana Valley, the Navacoyan site seems to have been fortified at this time, increasing in size and importance. At this site, the Guasave ceramic type is the most abundant of the coastal wares. The other important site in the Guadiana Valley at which Guasave Red-on-Buff ceramics have been found is Plan de Ayala. The presence of this pottery type in the northern site of Cañón de Molino is also significant, and suggests that interaction networks between inland Durango and coastal Sinaloa continued to operate throughout the Tunal and subsequent Calera phases.

Along with the appearance of ceramics from the Pacific coast, metallic items are more frequently encountered beginning in the Tunal phase. The proposed beginning date for copper production in Mesoamerica is $\mathrm{AD} 600$, based on findings at the Tomatlán site in Jalisco and Cerro del Huistle on the Jalisco and Zacatecas border (Hosler 1994). Many archaeologists, including myself, are uncertain of this date and suggest that metallurgical production may not have commenced until at least 300 years later (Maldonado 2006; see also Niklas Schulze and Blanca E. Maldonado, 
chapter II in this volume). In any case, metal objects are very rare in the northwest prior to AD 900. In Alta Vista, a single copper bell was reported in a late burial in Pyramid I (Aveni et al. 1982). At post-AD 900 sites in Durango, numerous copper bells and other metal objects have been recovered including chains, rings, plaques, pins, hooks, earplugs, and zoomorphic figures (figure 9.8). The majority of bell shapes in Durango are conical (type $\mathrm{IC}$ in Pendergast's [1962] classification) and have been recovered at sites in the Guadiana Valley (La Ferrería and Navacoyan) and in northern Durango at Corral de Piedra (Bridget Zavala, personal communication, 20I5). During excavations at Navacoyan site, we found a $\mathrm{ICra}$ copper bell in a context related to the Las Joyas phase, confirming a date between AD 900 and rooo like the ones proposed in Amapa in Nayarit, one of the most important Aztatlán sites. In the US Southwest, this type of bell was found in Pueblo Alto in New Mexico's Chaco Canyon dating to AD IO40-1100 and at Gila Pueblo, Arizona, dating to AD I345-I385 (Vargas 1995:29-38).

Other types of relevant bells present in Durango are the IAsa bells (Tlaloc type) of Cañón de Molino. This type is also present at numerous sites in west Mexico, such as Amapa; Tuxcacuesco in Jalisco; and Apatzingán, Coahuayana, and Tepalcatepec in Michoacán. Further north this type is present at Paquimé in Chihuahua (Di Peso 1974), at Black Falls Ruin and in Wupatki in northern Arizona, which in both locations dates to AD 1100-1250 (Vargas 1995). Recently in Trincheras, Sonora, four copper bells of type IAsa and one of an unidentified style were encountered during surface collection, all in a context in which pottery associated with Paquimé was also recovered (Punzo and Villalpando 2015). These data confirm the presence of this material in a temporal context contemporaneous with the Tunal and Calera phases, suggesting that interregional interaction between the northern frontier of Mesoamerica in Durango and both northern Mexico and the American Southwest was continuing at this time.

The beginning of the Calera phase in Durango was marked by another change in ceramic styles. The use of White and Buff slips decorated with red paint, employed since the Ayala phase, was abandoned. A red polished slip appeared, decorated with abstract elements in white paint. This pottery type, known as Nayar white-on-red (Kelley and Abbott 197I) shows the influence of motifs from the coast, such as the checkerboard decoration of the Gusave Red-on-Buff. This use of elements and colors is very similar to other pottery styles found across west Mexico, for example, in Santiago white-on-red pottery from Nayarit (Foster 1995) or other types from Jalisco. However, the iconography and the designs expressed in those ceramics vary across regions.

During the Calera phase at La Ferrería there was very little activity, and portions of the site were likely abandoned. Few ceramics from the coast are present, although 


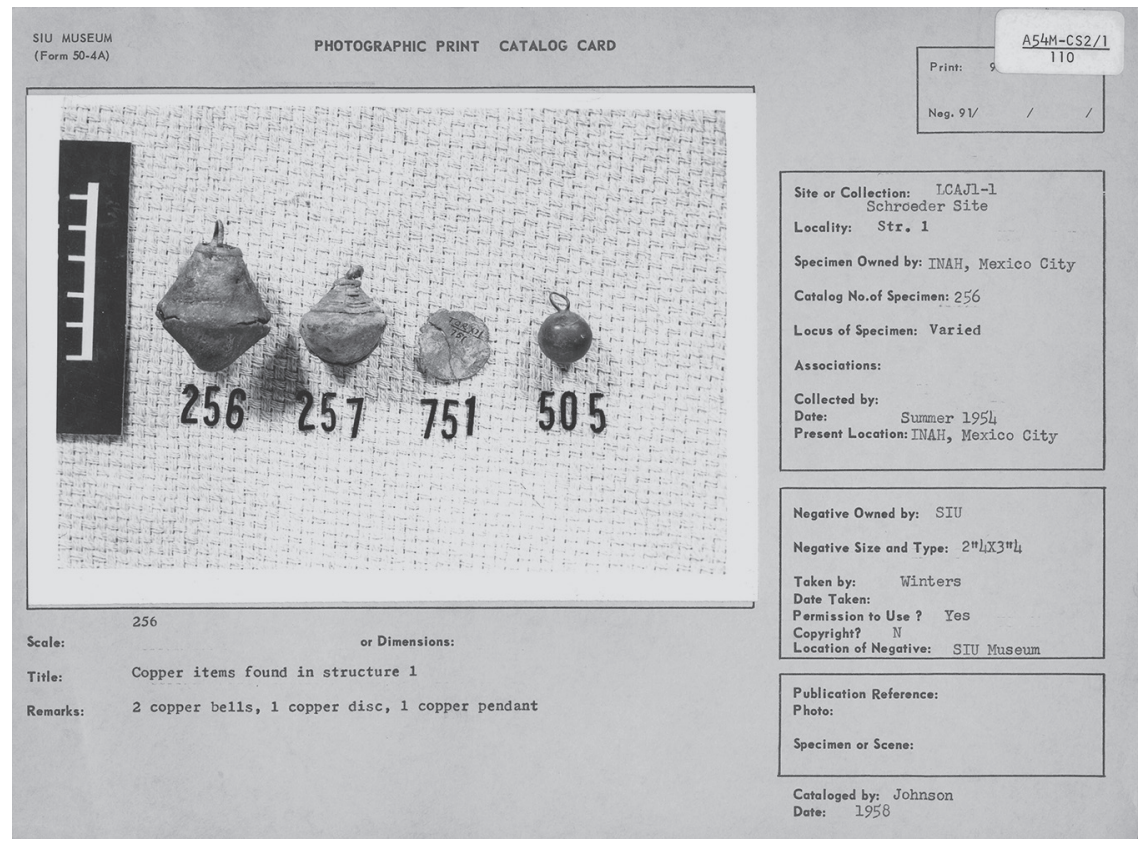

FIGURE 9.8. Copper objects found by Kelley in la Ferrería.

a couple of Dun-fluted (AD I250-I400) ceramic fragments from the Culiacán region were found at La Ferrería. Nevertheless, during the Tunal and Calera phases, relations between the coast and inland Durango did intensify. A close relation between the Chalchihuites and the Aztatlán Tradition (Kelley 1986) is suggested through the presence of traded prestige goods such as globular spindle whorls, metal objects, and ceramic pipes. It likely that these trade relationships began during the Ayala phase, escalated during the Las Joyas phase, and reached their apogee during the latter part of the Tunal phase, in which the Guadiana Valley became an important link between regional Chalchihuites sites, west Mexico, and greater Mesoamerica. Further, the strengthened nature of the relationship between the cultures of the Pacific coast and inland Durango during the late Tunal phase created a new phenomenon in the highlands of the Sierra Madre that separated the coast and inland. Beginning around AD ro5o cliff dwellings were constructed and occupied (figure 9.9), creating small communities residing in rock shelters along the cliffs lining the rivers and creeks of the region (Punzo 2013b). Inhabitants were related to the Chalchihuites communities to the east and produced the same pottery types, though these were manufactured with local materials (Sandoval and Punzo 2015). 


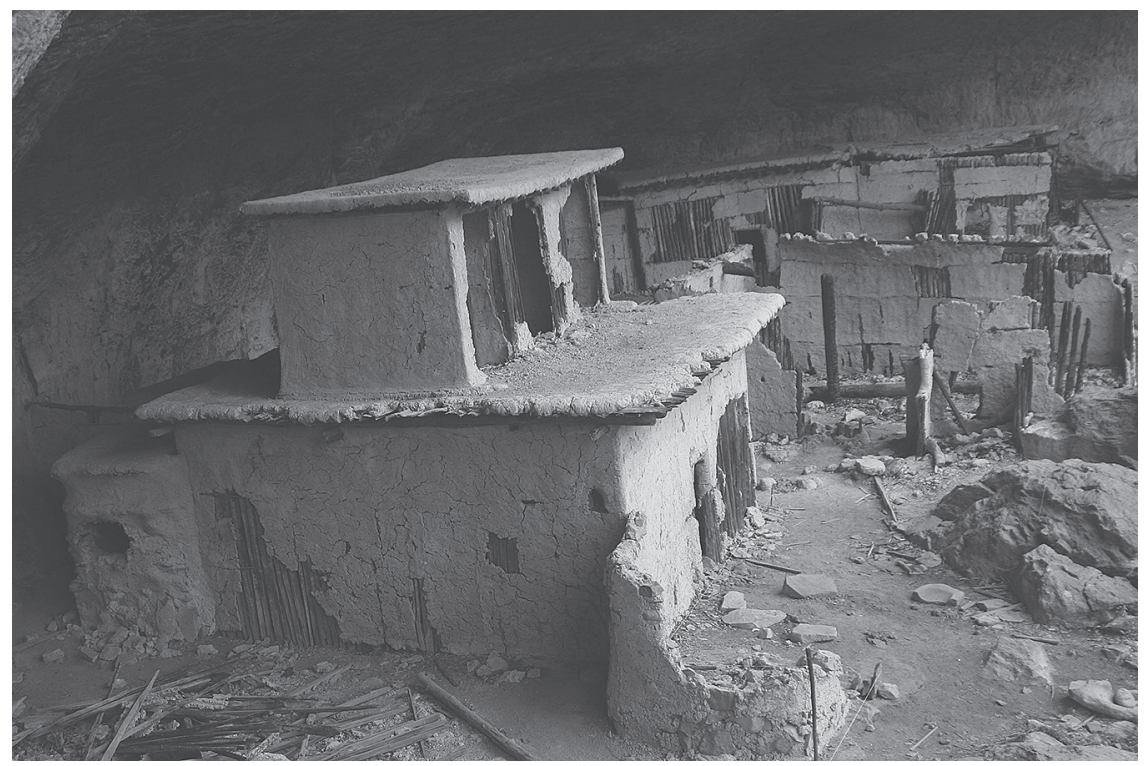

Figure 9.9. Cliff dwelling, Cueva del Maguey, Durango.

\section{THE TOTAL ABANDONMENT OF CHALCHIHUITES SITES AND THE CONTRACTION OF THE NORTHWESTERN FRONTIER OF MESOAMERICA TO THE WEST CA. AD 1350}

The occupation of the Valleys of Durango by the Chalchihuites culture ended around $\mathrm{AD}$ 1350. Presumably, people from further northwest migrated into the region (Berrojalbiz 2012; Berrojalbiz and Hers 2013; Hers 200I) and mixed with a diminished Chalchihuites population, transforming into an altered social group without a strong Mesoamerican heritage. However, the inhabitants of the highlands in the Sierra Madre maintained a solid Mesoamerican tradition for another 250 years, enduring until the conquest of the area by the Spaniards at the end of the sixteenth century and beginning of the seventeenth (Punzo 2013b). The inhabitants of the highlands, named Acaxees and Xiximes by the Spaniards, also used important elements related to Mesoamerican traditions in their rituals, such as the ballgame. Archaeologically, we find some architectural evidence of ballcourts, and in the historical sources there are ample descriptions of the game and the ritual (Punzo 1999, 2013b).

The principal adornments of those Acaxee and Xixime warriors were necklaces of marine shells, copper earrings, jaguar or mountain lion leather bracelets and quivers, and a disk carried on the back (Punzo 2013b). These ornaments are known from 
historical descriptions, but only copper elements have been found in archaeological contexts. In the 1970s, Charles Di Peso reported the presence of a conical copper bell at the Topia site, the most important Acaxee site (Obregón 1988). Also at the site was a copper earplug. At the nearby Canelas sites some metal rings were found. The Jesuits, who evangelized in the Sierra Madre at the end of the sixteenth century, noted the Acaxee emphasis on the acquisition of metal objects and their importance. This site of Topia is on an old route between the coastal Culiacán area and central Durango. The route was used by the Spaniards during the conquest and then to access the mines developed in the area of Topia and San Andrés (Punzo 2013b).

The Mesoamerican elements discussed above, as well as parrot and macaw breeding by these groups, were key to integrating this region in interregional interactions that included Mesoamerica, northern Mexico, and the US Southwest until the late Postclassic period, when ties were broken and the region was abandoned not long after the arrival of the Spanish in the mid-sixteenth century.

\section{FINAL THOUGHTS}

The northern frontier of Mesoamerica during the Classic and Postclassic period is marked by two major cultural developments. The first was the appearance of the Chalchihuites culture in northern Zacatecas, a region whose prior occupation and population did not exhibit a great degree of social complexity, and the second was the emergence of the Aztatlán tradition on the coast of Nayarit and Sinaloa-a tradition with deep roots in western Mesoamerica.

Regional developments in northwestern Mesoamerica have traditionally been viewed only as the result of migrations of people from central Mexico, especially from Teotihuacan, that imposed their way of life on a passive local population-in other words, a colonialist scheme. In this chapter, I have presented data to argue that regional developments were also driven by internal factors unique to the region, with a great degree of local agency. Although local populations did receive influence from Mesoamerica, including traditional prestige goods, these were incorporated into localized cultural systems, and groups in the northwest deployed and interpreted such items within their own cultural canons, using them in regionally specific contexts. In this way, such groups played an active role in the spread of many panMesoamerican ideas, objects, and symbols throughout the northwest-categories and artifacts that are traceable archaeologically.

The apogee of Alta Vista in northern Zacatecas and the emergence of the Chalchihuites culture in Durango, $200 \mathrm{mi}$. to the north, corresponded generally to the decline of Teotihuacan in central Mexico around the year AD 600. During this time, northwestern Mesoamerica witnessed the proliferation of pan-Mesoamerican 
symbolism, perhaps most evident in ceramic iconography and architectural forms (e.g., pyramids, colonnaded halls, ballcourts, etc.). The spread of such forms and motifs is generally indicative of interaction between the northwest and broader Mesoamerican culture areas and traditions. Nonetheless, recent research in the region suggests that the development of the Chalchihuites culture did not merely stem from a process of colonization by central Mexican interlopers. Rather, the evidence indicates the selective appropriation and differential use of this corpus of pan-Mesoamerican ideas to variable degrees across the northwest. For example, at La Ferrería the presence of pan-Mesoamerican iconographic motifs is common on ceramics at the site, and such elements are formally quite similar to central Mexican iterations of the same motifs. Further to the north, however, at sites such as Zape or Hervideros, such motifs, although present, are less common and exhibit greater formal variability. That said, both inter- and intraregional interaction are suggested by the presence and similar use of certain ceramic types and architectural features across the northwest.

Regional patterns of settlement and interaction underwent profound changes around AD I000. At this time the Chalchihuites sites in Zacatecas were abandoned, but there was an explosion of Mesoamerican presence in the coast, moving from Chametla in southern Sinaloa to Guasave $250 \mathrm{mi}$. to the north. As detailed above, relations between the Chalchihuites in the Guadiana Valley and Chametla on the Sinaloan coast existed and were important prior to AD I000, but after this date interaction between the coast and inland areas became stronger and even more pronounced. Not only did interaction between the coast and the Guadiana Valley increase at this time, but there was also a spike in interaction and interconnectivity between the coast and all Chalchihuites populations in Durango, evidenced through the appearance of "coastal" artifacts throughout Durango, along the eastern slopes of the Sierra Madre, and at regional cliff-dwelling sites such as Cueva del Maguey.

These general patterns continued for the next 350 years. But there is also evidence for an increase in interaction between the northwest and areas further afield at this time (e.g., the presence of cranial deformation at the site of Cañón de Molino in Durango [Lazalde 1987], an activity not typically practiced by Chalchihuites people previously). Nonetheless, again it would appear that local groups in Durango selectively employed these "new" pan-Mesoamerican ideas within their own cultural contexts and expressed them in locally specific ways, from ceramic iconography to the use of copper items in rituals. By AD 1350, however, interaction within and across the northwest appears to have tapered off significantly. When the Spaniards arrived in the region some 200 years later, they encountered among the indigenous groups who inhabited the Sierra Madre few surviving relics of the intense interaction-between Chalchihuites, Aztatlán, and broader pan-Mesoamerican cultural traditions - that had characterized the northwest for nearly a millennium. 


\section{NOTE}

I. Notably, there are no such "coastal" pottery types reported at any site in Zacatecas during this period.

\section{REFERENCES}

Ambríz, Emmanuel. 2013. La iconografía cerámica chalchibuiteña: Análisis de las imágenes centrales en espiral. Unpublished BA thesis, Escuela Nacional de Antropología e Historia.

Aronson, Meredith A. 1993. Technological Change: West Mexican Mortuary Ceramics. Unpublished PhD dissertation, Department of Materials Science and Engineering, University of Arizona, Tucson.

Aveni, Anthony, Horst Hartung, and Charles Kelley. 1982. "Alta Vista (Chalchihuites): Astronomical Implications of a Mesoamerican Ceremonial Outpost at the Tropic of Cancer." American Antiquity 47(2):316-335.

Berrojalbiz, Fernando. 20I2. Paisajes y fronteras del Durango prehispánico. UNAM, Mexico City.

Berrojalbiz, Fernando, and Hers Marie-Areti. 2013. "El Alto Nazas: La Comarca del Venado." In Historia de Durango: Época antigua, edited by José Luis Punzo and Hers Marie-Areti, 272-317. IIH-UJED, Durango.

Bradley, Ronna. 1999. "Shell Exchange within the Southwest: The Casas Grandes Interaction Sphere." In The Casas Grandes World, edited by Curtis F. Schaafsma and Carroll L. Riley, 213-228. University of Utah Press, Salt Lake City.

Brand, Donald. 1971. "Geography and Archaeology of Zape, Durango." In The North Mexican Frontier, edited by Charles Kelley, 2I-49. Southern Illinois University Press, Carbondale.

Braniff, Beatriz. 1992. La frontera prehistórica pima-ópata en Sonora, México, Proposiciones arqueológicas preliminares. INAH, Mexico City.

Carot, Patricia, and Hers Marie-Areti. 20Ir. "De Teotihuacan al Cañón de Chaco: Nueva perspectiva sobre las relaciones entre Mesoamérica y el Suroeste de los Estados Unidos.” Anales del Instituto de Investigaciones Estéticas UNAM XXXIII(98):5-53.

Carpenter, John. 1996. El Ombligo de la Labor: Differentiation, Interaction, and Integration in Prehispanic Sinaloa, Mexico. Unpublished PhD dissertation, Anthropology Department, University of Arizona, Tucson.

Carpenter, John, Guadalupe Sánchez, and Ismael Sánchez. 2010. Proyecto arqueológico Norte de Sinaloa: Rutas de intercambio. Investigaciones en Mochicabui, Sinaloa. Informe técnico de la temporada 2009. INAH-Consejo de Arqueología, Mexico City. 
Córdova, Guillermo, and Estela Martínez. 2006. Proyecto arqueológico Valle del Río Súchil, Zacatecas y Durango, Informe de la tercera de campo, julio-agosto del 2006-octubre de 2006. Archivo Técnico de la Coordinación Nacional de Arqueología-INAH, Mexico City.

Di Peso, Charles. 1974. Casas Grandes: A Fallen Trading Center of the Gran Chichimeca. Amerind Foundation Norland Press, Flagstaff.

Englehardt, Joshua D., and Verenice Y. Heredia Espinoza. In press. "Process and Meaning in Late Formative and Early Classic Period Ceramics of the Western Mesoamerican Teuchitlán Tradition." In Mesoamerican Ceramics: Form, Meaning, and Function, edited by Michael D. Carrasco and Maline Werness-Rude. University Press of Florida, Gainesville.

Fenoglio, Fiorella. 20Ir. Minería en la cultura chalchihuites: Un modelo para armar. Colección Científica. INAH, Mexico City.

Flores, Daniel. 2013. "Astronomía prehispánica en Durango." In Historia de Durango: Época antigua, edited by José Luis Punzo and Marie-Areti Hers, 372-397. IIH-UJED, Durango.

Foster, Michael. 1978. Loma San Gabriel: A Prehistoric Culture of Northwest Mexico. Unpublished PhD dissertation, Department of Anthropology, University of Colorado, Boulder.

Foster, Michael. 1986. “The Mesoamerican Connection: A View from the South.” In Ripples in the Chichimec Sea, edited by Frances J. Mathien and Randall H. McGuire, 55-69. Southern Illinois University, Carbondale.

Foster, Michael. 1995. "The Chalchihuites Chronological Sequences: A View from the West Coast of Mexico." In Arqueología del Norte y Occidente de México: Homenaje al Dr. J. Charles Kelley, edited by Barbro Dahlgren and M. Dolores Soto, 67-92. UNAM, Mexico City.

García, Baudelina, and José Humberto Medina. 2008. Alta Vista, Chalchibuites, Zacatecas. Diálogos con el pasado. INAH, Mexico City.

Hers, Marie-Areti. 1983. "La pintura pseudocloisonné: Una manifestación temprana en la cultura chalchihuites." Anales del Instituto de Investigaciones Estéticas UNAM $\mathrm{XV}(83): 25-39$.

Hers, Marie-Areti. 200I. “Zacatecas y Durango: Los confines tolteca-chichimecas." In La Gran Chichimeca: El lugar de las rocas secas, edited by Beatriz Braniff, II3-I54. Jaca Book, Milan.

Hers, Marie-Areti. 2005. "Imágenes norteñas de los guerreros chichimecas." In Reacomodos demográficos del Clásico al Posclásico en el Centro de México, edited by Linda Manzanilla, II-44. UNAM, Mexico City.

Hers, Marie-Areti. 2006. "La cultura chalchihuiteña: Un antiguo camino de tierra adentro." In Las rutas de la Nueva España, edited by Chantal Cramaussel, 277-298. El Colegio de Michoacán, Zamora. 
Hers, Marie-Areti. 2013. "Un nuevo lenguaje visual en tiempos de rupturas (600-900 d.C.)." In Miradas renovadas al Occidente de México, edited by Marie-Areti Hers, 215-252. UNAM, INAH, CEMCA, Mexico City.

Hers, Marie-Areti, and Oscar Polaco. 2005. "Le Project Hervideros: Un regard sur le passé préhispanique de la Sierra Madre Occidentale du Durango, Mexique.” In La Sierra Madre Occidentale: Un Château d'eau Menacé, edited by Luc Descroix, Juan Estrada, José Luis González Barrios, and David Viramontes, 93-105. IRD Editions, Paris.

Hers, Marie-Areti, and Oscar Polaco. 2013. "Bajo el signo del astro solar: Migración, astronomía y arte rupestre en la Sierra Madre Occidental, México." Revista Digital Universitario I4(6). Electronic document, http://www.revista.unam.mx/vol.i4/num6/ arti3/index.html.

Hosler, Dorothy. 1994. The Sounds and Colors of Power: The Sacred Metallurgical Technology of Ancient West Mexico. MIT Press, Cambridge.

Jiménez-Betts, Peter. 1994. “El Noroeste: La periferia septentrional de Mesoamérica." In México en el mundo de las colecciones de arte: Mesoamérica 2, edited by M. L. Sabu, 137-177. UCOL, Mexico City.

Kelley, Charles. 1952. Archaeological Survey Blank: Form 5I-IA: Site: Los Caracoles TOR G6-2 (LSQK2-5). Archivo Centro INAH, Durango.

Kelley, Charles. 1958. Schroeder Site, Durango, Mexico. Structure I, Season 1954. Archivo Técnico de la Coordinación Nacional de Arqueología-INAH, Mexico City.

Kelley, Charles. 1962. Northern Frontier of Mesoamerica: First Annual Report: August Is 196I-August I5 1962. National Science Foundation, University Museum and Mesoamerican Cooperative Research of the Southern Illinois University, Carbondale.

Kelley, Charles. 1985. "The Chronology of the Chalchihuites Culture." In The Archaeology of West and Northwest Mesoamerica, edited by Michael S. Foster and Phil C. Weigand, 269-287. Westview Press, Boulder.

Kelley, Charles. 1986. “The Mobile Merchants of Molino." In Ripples in the Chichimec Sea, edited by Frances J. Mathien and Randall H. McGuire, 8I-IO4. Southern Illinois University, Carbondale.

Kelley, Charles. 1990. "The Classic Epoch in the Chalchihuites Culture of the State of Zacatecas.” In La Época Clásica: Nuevos hallazgos, Nuevas ideas: Seminario de arqueología, edited by Amalia Cardós, II-I4. Museo Nacional de Antropología e Historia-INAH, Mexico City.

Kelley, Charles. 1997. "The Known Archaeological Ballcourts of Durango and Zacatecas, Mexico." Boletin Biblioteca Juan Comas 13 (40):2-40.

Kelley, Charles. 2002. "A Mesoamerican Colonization of Zacatecas-Durango: The Loma San Gabriel and Chalchihuites Cultures." In Homenaje al Dr. John Charles Kelley, edited by María Teresa Cabrero, Jaime Litvak, and Peter Jiménez, 83-98. IIA-UNAM, Mexico City. 
Kelley, Charles, and Ellen Abbott. 1971. An Introduction to the Ceramics of the Chalchibuites Culture of Zacatecas and Durango, Pt. I: The Decorated Wares. Mesoamerican Studies 5. Southern Illinois University Press, Carbondale.

Kelley, Charles, and Howard Winters. 1960. "A Revision of the Archaeological Sequence in Sinaloa, Mexico." American Antiquity 25(4):547-56I.

Kelly, Isabel. 2008. Excavaciones en Chametla, Sinaloa. Siglo XXI, Mexico City.

Kristan-Graham, Cynthia. 201. "Structuring Identity at Tula: The Design and Symbolism of Colonnaded Halls and Sunken Spaces.” In Twin Tollans: Chichén Itzá, Tula and the Epiclassic to Early Postclassic Mesoamerican World, edited by Jeff Karl Kowalski and Cynthia Kristan-Graham, 428-467. Dumbarton Oaks, Washington, DC.

Lazalde, Jesús. 1987. Durango indígena. Museo de Historia-UJED, Durango.

López-Luján, Leonardo. 2003. “La destrucción del cuerpo: El Cautivo de Mármol de Teotihuacan." Arqueología Mexicana iI (65):55-59.

Lumholtz, Carl. 1945. El México desconocido. 2 vols. Publicaciones Herrerías, Mexico City.

MacWilliams, Art, Robert Hard, Ron Roney, Karen Adams, and William Merrill. 2006. Investigaciones de los sitios de cultivo de maiz temprano en Chibuahua: Informe de la temporada 2003. Centro INAH Chihuahua, Chihuahua.

Maldonado, Blanca. 2006. Preindustrial Copper Production at the Archaeological Site of Itziparatzico, a Tarascan location in Michoacán, Mexico. PhD dissertation, Pennsylvania State University. University Microfilms, Ann Arbor.

Manzanilla, Linda. 2003. "Teopancazco: Un conjunto residencial teotihuacano." Arqueología Mexicana II (64):50-53.

McCarthy, Mike. 2008. "Boundaries and the Archaeology of Frontier Zones." In Handbook of Landscape Archaeology, edited by Bruno David and Julian Thomas, 202-209. Left Coast Press, Walnut Creek, CA.

McGuire, Randall. 1980. "The Mesoamerican Connection in the Southwest." Kiva $46(\mathrm{I}-2): 3-38$.

McGuire, Randall. 1987. “The Greater Southwest as Periphery of Mesoamerica." In Center and Periphery: Comparative Studies in Archaeology, edited by Tim Champion, 40-66. Unwin Hyman, London.

McGuire, Randall, and Elisa Villalpando. 2008. "The Hohokam and Mesoamerica." In The Hohokam Millennium, edited by Suzanne K. Fish and Paul R. Fish, 57-64. School for Advance Research Press, Santa Fe.

Medina, José Humberto, and Baudelina García. 2010. A Ioo años de su descubrimiento, Alta Vista. Gobierno del Estado de Zacatecas / CONACULTA / INAH, Zacatecas and Mexico City. 
Melgar, Emiliano, José Luis Ruvalcaba, Kilian Lactlavetine, Guillermo Córdova, and Estela Martínez. 2014. "Procedencia y manufactura de las turquesas de pajones, El Bajío, y Cerro Moctehuma, Chalchihuites, Zacatecas." Tiempo y Región 7:191-222.

Mountjoy, Joseph. 2000. "Pre-Hispanic Cultural Development along the Southern Coast of West Mexico." In Greater Mesoamerica: The Archaeology of West and Northwest Mexico, edited by Michael S. Foster and Shirley Gorenstein, 8I-I06. University of Utah Press, Salt Lake City.

Nelson, Richard. 1986. "Pochtecas and Prestige: Mesoamerican Artifacts in Hohokam Sites." In Ripples in the Chichimec Sea, edited by Frances J. Mathien and Randall H. McGuire, 154-184. Southern Illinois University, Carbondale.

Noguera, Eduardo. 1944. “Exploraciones en Jiquilpan.” Anales del Museo Michoacano 3:37-52. Obregón, Baltasar. 1988. Historia de los descubrimientos antiguos y modernos de la Nueva España. Porrúa, Mexico City.

Pailes, Richard, and Joseph Whitecotton. 1979. "The Greater Southwest and the Mesoamerican 'World System': An Exploratory Model of Frontier Relationships.” In Frontier Comparative Studies, edited by William W. Savage Jr. and Stephen I. Thompson, I05-I2I. University of Oklahoma Press, Norman.

Pendergast, David. 1962. "Metal Artifacts from Amapa, Nayarit, México." American Antiquity 27(3):370-379.

Pomedio, Chloé. 2009. La céramique du Bajío, Guanajuato, Mexique: Étude technostylistique de la céramique incisée du Cerro Barajas. 2 vols. Unpublished doctoral dissertation, U.F.R. Art et Archéologie, Université Paris I Panthéon-Sorbonne.

Pulb, Helmut. 1986. Prehispanic Exchange Networks and the Development of Social Complexity in Western Mexico: The Aztatlan Interaction Sphere. Unpublished PhD dissertation, Department of Anthropology, Southern Illinois University.

Punzo, José Luis. 1999. Arqueología de la Mesa de Tlabuitoles: Apuntes para la historia xixime. Unpublished BA thesis, Escuela Nacional de Antropología e Historia, Mexico City.

Punzo, José Luis. 2012. "Paisaje y petrograbados del Sitio de la Ferrería, Durango, México." In Rock Art in the Americas: Mythology, Cosmogony and Rituals, edited by Francoise Fauconier and Serge Lemetier, 6I-72. BAR International Series 2448. Archaeopress, Oxford.

Punzo, José Luis. 20Iza. "La población chalchihuiteña del Valle de Guadiana." In Historia de Durango: Época antigua, edited by José Luis Punzo and Hers Marie-Areti, 190-207. IIH-UJED, Durango.

Punzo, José Luis. 2013b. Los moradores de las Casas en Acantilado de Durango: Rememorando el mundo de la vida de los Grupos Serranos en el Siglo XVII. Unpublished doctoral dissertation, Escuela Nacional de Antropología e Historia, Mexico City. 
Punzo, José Luis. 20ı6. "Revisando la arquitectura chalchihuiteña en el valle de Guadiana, Durango: El caso del sitio arqueológico de la Ferrería." Cuicuilco 23(67):317-332.

Punzo, José Luis, Emmanuel Ambríz, Cinthya Isabel Vidal, and Cindy Sandoval. 20 I. Proyecto de Investigaciones Arqueológicas del Área Centro Oeste de Durango: Informe técnico parcial de la Temporada 2oII. INAH, Mexico City.

Punzo, José Luis, and Elisa Villalpando. 2015. "Paquimé: A Revision of Its Relations to the South and West." In Ancient Paquimé and the Casas Grandes World, edited by Paul E. Minnis and Michael E. Whalen, 172-191. University of Arizona Press, Tucson.

Rodríguez, Nora. 2009. El conjunto iconográfico águila-rombo-serpiente en chalchibuites zacatecas: Un acercamiento a través de la analogía wixarika (Huichola). Unpublished BA thesis, Escuela Nacional de Antropología e Historia, Mexico City.

Sandoval, Cindy. 2011. La aplicación de la petrografía en la caracterización y proveniencia de las cerámicas chalchihuiteñas de las ramas guadiana y súchil del Sitio Arqueológico La Ferrería en Durango, Dgo. Unpublished BA thesis, Universidad Autónoma de Zacatecas, Zacatecas.

Sandoval, Cindy, and José Luis Punzo. 2015. "A Petrographic Analysis of the Ceramics of the Dwellers in the Sierra Madre Occidental and the Ferrería Site of the Guadiana Valley." Paper presented at the 8oth Annual Meeting of the Society for American Archaeology, San Francisco.

Schiavitti, Vincent. 1996. Organization of the Prehispanic Suchil Mining District of Chalchibuites, Mexico AD 400-950. Unpublished PhD dissertation, Department of Anthropology, State University of New York, Buffalo.

Taube, Karl. 1992. “The Iconography of Mirrors at Teotihuacan." In Art, Ideology, and the City of Teotihuacan: A Symposium al Dumbarton Oaks, edited by Janet Berlo, 169-204. Dumbarton Oaks, Washington, DC.

Vargas, Victoria. 1995. Copper Bell Trade Patterns in the Prehispanic U.S. Southwest and Northwest Mexico. Archeological Series i87. Arizona State Museum, University of Arizona, Tucson.

Vidal, Cinthya Isabel. 201. El Intercambio en el Noroccidente Prehispánico: El intercambio entre la rama guadiana de la tradición arqueológica chalchibuites y la tradición Aztatlán, entre 60o-I30o d.C. Unpublished BA thesis, Escuela Nacional de Antropología e Historia.

Wallerstein, Immanuel. 1974. The Modern World-System I: Capitalist Agriculture and the Origins of the European World-Economy in the Sixteen Century. Academic Press, Berkeley. Ward, Sue. 1970. Chalchibuites Analysis Report 2. Southern Illinois University, Carbondale. Weigand, Phillip C. 1968. "The Mines and Mining Techniques of the Chalchihuites Culture." American Antiquity 33(I):35-6I. 
Weigand, Phillip C. 1982. "Mining and Mineral trade in Prehispanic Zacatecas." Mining and Mineral Trade in Prehispanic Zacatecas: Special Issue of Anthropology 6:87-134.

Weigand, Phillip C. 1995. "Minería Prehispánica en las Regiones Noroccidentales de Mesoamérica con Énfasis en la Turquesa.” In Arqueología del Occidente y Norte de México, edited by Eduardo Williams and Phil C. Weigand, II5-I38. El Colegio de Michoacán, Zamora.

Wilcox, David. 1986. “The Tepiman Connection: A Model of Mesoamerican-Southwestern Interaction." In Ripples in the Chichimec Sea, edited by Frances J. Mathien and Randall H. McGuire, 135-154. Southern Illinois University, Carbondale.

Wilcox, David, Phil Weigand, Scott Wood, and Jerry Howard. 2008. "Ancient Cultural Interplay of the American Southwest in the Mexican Northwest." Journal of the Southwest 50(2):103-206. 


\section{Chapter 10}

\section{Round and Round We Go \\ Cholula, Rotating Power Structures, Social Stability, and Trade in Mesoamerica}

Timothy J. Knab and John M.D. Pohl

Cholula has always presented a paradox in Mesoamerican Studies, both synchronically and diachronically. It is, and has been, a major Mesoamerican urban entity, which does not follow the patterns and processes many researchers have taken for granted. Perhaps researchers have viewed Mesoamerica through not rose-colored glasses, but Aztec-colored glasses for too long. Here we will present a model of the rotating power structures that we believe are, and always were, far more common in Mesoamerica than the Aztec imperial model of a single hierarchical power structure stretching from the emperor to the calpultin, lineage-based territorial units.

Rotating power structures are probably more common in Mesoamerica than the Aztec imperial model, as they are far more stable and far more resilient in the face of radical change. The Pochteca, the merchants, of the Cholula barrio of San Miguel Tianguisnahuac (see figure IO.I) in the sixteenth century, and the presentday residents of the barrio of San Miguel Tianguisnahuac all require stable and resilient systems to carry out their activities, be they long-distance trade, or the complex fiesta cycle of Cholula. Diego Durán's ([1546] 1971:137) comments on fiestas in the barrio of San Miguel Tianguisnahuac clearly indicate the role of the merchants in rotating power systems. Rotating power systems concentrate social capital at each level within the system guaranteeing at each level that individuals with sufficient resources and social capital are available to take on complex tasks such as organizing long-distance trade or orchestrating the fiesta of the Virgin of the Remedies, which brings over a hundred thousand people into Cholula every 


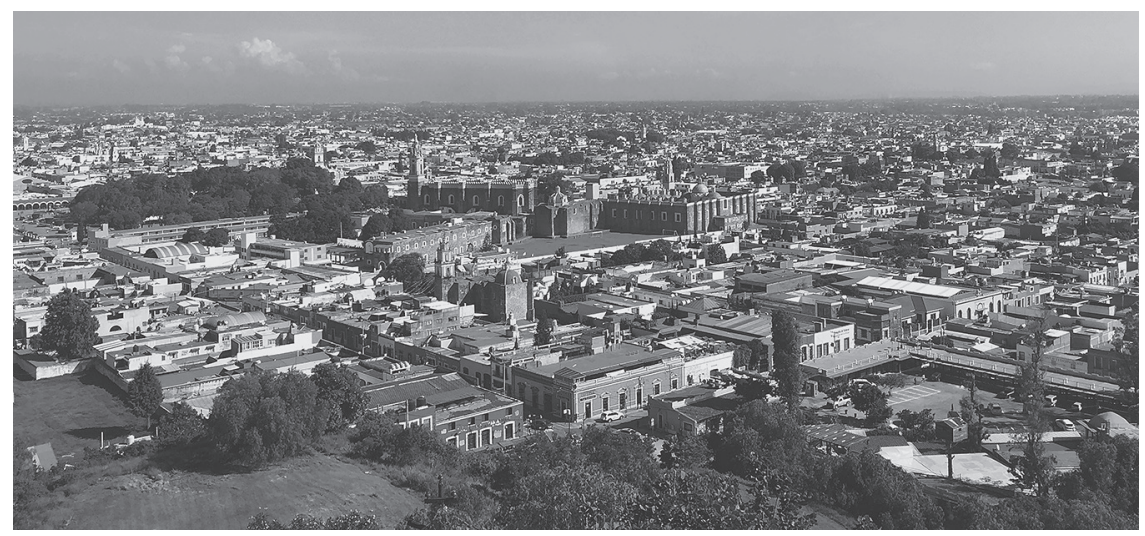

FIGURE IO.I. A view of the city of Cholula, Puebla, to the east as seen from the summit of the Great Pyramid. In the upper center of the photo is the Church of San Gabriel and the Franciscan complex. At the center of the photo below in the foreground is the smaller barrio church dedicated to San Miguel Tianguisnahuac. Sixteenth-century maps confirm that the these barrios were maintained through the colonial period and continue to the present day, contributing physical continuity to the city's social and political structures that extend back to the fourteenth century (photo by John M. D. Pohl).

year (Knab 2013). This is no different now than it was in the sixteenth century, or the Late Postclassic period.

Cholula offers a more sophisticated understanding of the diversity of social, political, and economic strategies in Mesoamerica and challenges the idea that indigenous traditions associated with governance by urban states had ceased with the fall of the Aztec empire in I52 I. Recent scholarship demonstrates that a confederacy of city-states throughout southern Mexico successfully resisted both Aztec and Spanish subjugation. A ruling class of nobles commonly referred to as caciques resurrected themselves on a new colonial foundation and continued to play an important role in cultural developments in Mesoamerica. This dramatic period of social transformation is better characterized in terms of a "Late Antiquity" as it is understood in other parts of the world that experienced comparable developments (Brown 1971). Essential characteristics include governance through decentralized political systems, the maintenance of a field of common values through an investment in pilgrimage and commercial centers such as Rome and Cholula; the initiation of a pagan nobility through the missionizing efforts of orders of mendicant friars; and the development of international styles, Nahua-Mixtec and Gothic-Renaissance, that bridged differences in ethnicity and language (Pohl et al. 2012). 
Late Antiquity recognizes the fact that many of the agendas that powered indigenous agency during the sixteenth century had already been introduced in the Late Postclassic period and continued through the colonial period to the present day. The appeal of the cult of Quetzalcoatl centered at Cholula and the cult ceremonies associated with becoming a tecuhtli, or lineage head-essentially a king-transcended all local religious customs and bound ethnically diverse peoples together into similar social and political units, facilitating elite alliances and economic exchange throughout the central and southern Mexican highlands. As the "Rome" of New Spain, Cholula then continued to fulfill its role in supplying a centralizing ideology without the military dominance of an imperial capital as Tenochtitlán had been.

We will start with the contemporary system, which is quite clearly not simply an extension of earlier systems (Knab 2013), though it does share specific and fundamental structural features with past systems, which makes it a far better model for Mesoamerican urban social organization than the Aztec imperial model. What we propose to show is rather astounding. Despite the fact that social systems have changed radically through time and have virtually no direct links to the preColumbian, or colonial, meanings and symbols, structurally they have remained quite constant through time. Rotating power structures achieve this remarkable stability because large amounts of social capital are invested in such systems and all stakeholders share potential power within the system.

Cholula is arguably the oldest living city in the Americas, but that is not why its rotating power structures are so important (Kobayashi 2013). Rotating power structures have a far greater inherent stability than simple linear hierarchies. They involve far greater numbers of individuals in the power structure and each individual has far more social capital (Putnam 1995) invested in maintaining such power structures. Making multiple individuals into stakeholders, each with the potential for increased position and power, means that few will abandon their position and that all will actively promote the maintenance of such a system (figure I0.2).

Both ethnohistorical and archeological evidence support the rotating model of power structures in Mesoamerica. We will argue that such structures are, and were, far more common in Mesoamerica than the imperial model. Despite the imposition of Spanish rule and Spanish systems of governance nearly 500 years ago, rotating power structures are still well represented today in traditional Mesoamerican cargo systems. Based on evidence from Cholula's baroquely complex ritual system (Bonfil 1973), we will build our model pointing out basic features that distinguish it from other models of urban power structures in Mesoamerica. Given our focus on the barrio of the merchants, San Miguel Tianguisnahuac, we will also show how such rotating power systems support individuals in carrying out complex tasks (figure io.3). 


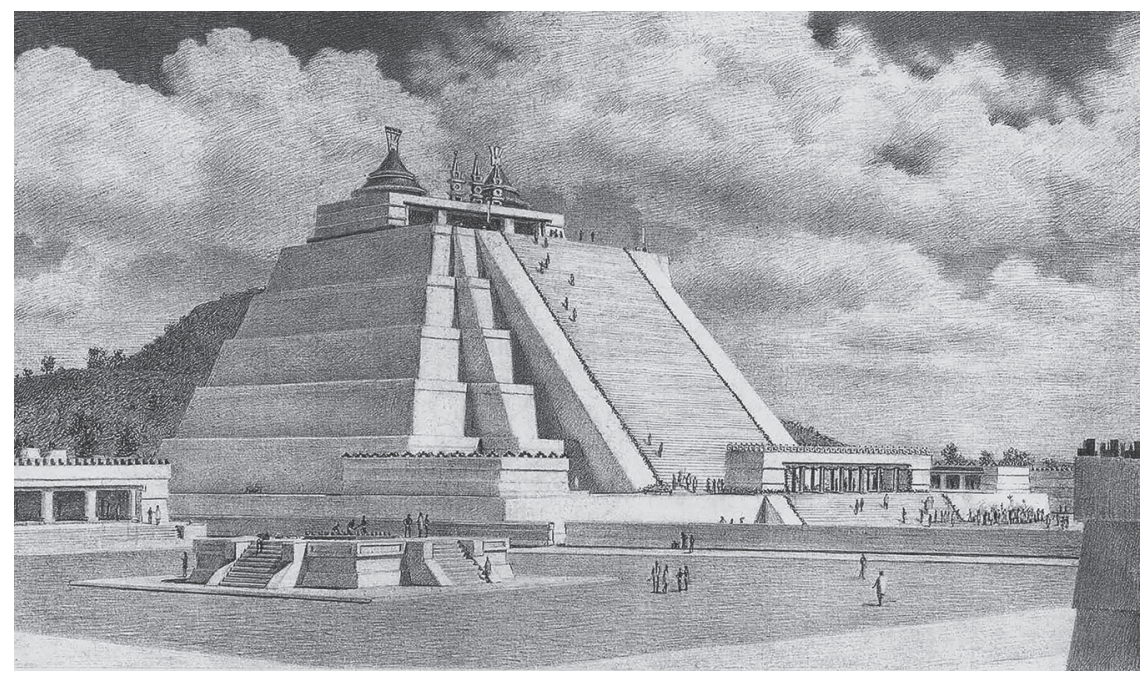

FIGURE I0.2. Artistic interpretation of the Temple of Quetzalcoatl. Behind the temple can be seen the silhouette of the earlier Great Pyramid (Scott Gentling and Stuart Gentling, Collection of John M. D. Pohl).

\section{CHOLULA}

Cholula is a tale of two cities, San Pedro and San Andrés, which both have similar, yet different, rotating power structures. The two Cholulas have not probably seen eye to eye since the twelfth century when the Toltecs arrived, and to this day the two Cholulas cannot agree on the direction of one-way streets or to which municipality the Great Cholula Pyramid belongs. The systems of social organization in San Pedro Cholula are far better documented (Bonfil 1973; Knab 2012, 2013; Kobayashi 2013; Reyes 2000) than those of San Andrés, thus we will rely on them for our model far more heavily. Both Cholulas, though, have complicated ritual systems that are becoming even more complex as the two municipalities are rapidly becoming a part of the Puebla suburbs. It is in fact the complex system of ritual activity that distinguishes traditional members of cholanteco society from both outsiders and secular cholantecos.

There are today over 500 organized ritual celebrations in San Pedro Cholula alone, and the number increases as Cholula becomes more prosperous. This is the paradox that Guillermo Bonfil Batalla (1973:250-290) meditated upon, with help from Paul Kirchhoff (see Bonfil 1973:22), his professor, in the groundbreaking ethnography Cholula: La ciudad sagrada en la era industrial. Traditional celebrations, rather than disappearing as Cholula becomes part of the industrial age and 


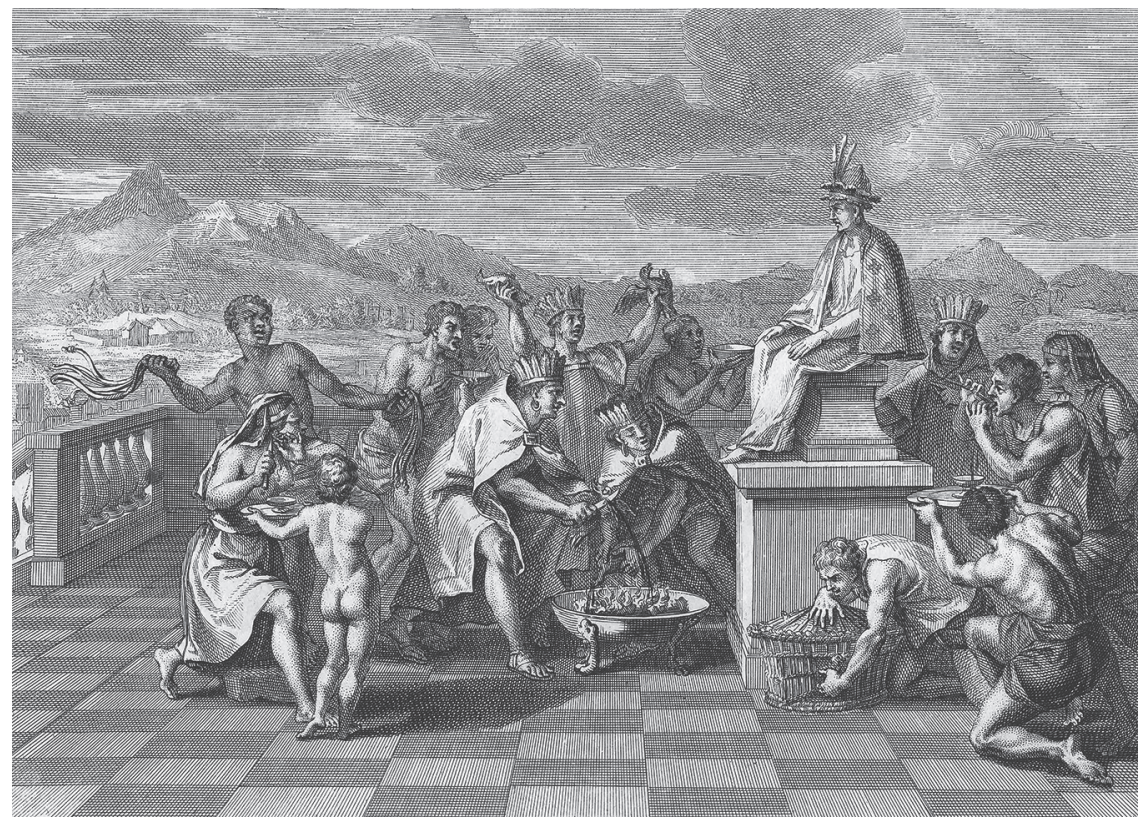

FIGURE I0.3. A print by Bernard Picart portrays Quetzalcoatl at Cholula being venerated as the "Mercury" of the Mexicans because both gods were credited with being the patrons of merchants. The comparison to Mercury is significant. In Medieval Europe, the Roman deity was intentionally connected with the archangels Gabriel and Michael (Pohl and Lyons 2016:13). Since the church of San Gabriel was actually constructed from the masonry of the Temple of Quetzalcoatl, it seems likely that the selection of the archangels as patrons at Cholula was rooted in a comparable sixteenth-century classical dialogue between the Franciscans and the indigenous nobles of the city (collection of John M. D. Pohl).

is consumed by the suburbs of Puebla, are becoming ever more complex and ubiquitous. The bells and exploding fireworks of Cholula's churches never seem to quit (Knab 20I2).

If we were to follow the standard Mesoamerican literature on cargo systems (Cancian 1972; DeWalt 1975; Magazine 2012; Redfield 1956; Sandstrom 1991; Wasserstrom 1978, 1983), we would assume to find traditionalists in Cholula desperately impoverished but with very high status. That is not the case. Many are quite well off, pillars of bourgeois society and active in dozens of community organizations.

Unfortunately, much of the literature in the last century on cargo systems never took into account the changing political and legal landscape of Mexican municipalities, an absence that seriously distorted the way in which cargo systems function in Mesoamerica. The picture we have in the anthropological literature based on 
twentieth-century studies is seriously skewed. When civil and religious administrations were divorced from each other in the radically anticlerical period shortly after the Mexican Revolution, religious hierarchies were separated from some of their basic financing. Individuals were forced to take on the devastating expense of traditional fiestas on their own.

Cholula had established systems of rotating mayordomias, which meant that each cargo holder, as he ascended in the system, developed an ever-larger network of individuals to assist in defraying the expenses of vast festivities. These systems tend to concentrate social capital in the hands of such individuals and qualify them for ever more prestigious cargos. Some cargo holders actually make money on their cargos, or at least have enough ritual goods left over that they can donate to other cargo holders in stark contrast to the impoverishment reported in most studies of cargo systems.

There are ten barrios in San Pedro Cholula and eight in San Andrés. In addition to the barrio celebrations, there are innumerable comisiones, cofradias, hermandades, and Catholic Associations, which also sponsor celebrations, pilgrimages, and processions throughout the ritual year in Cholula. As Chance and Taylor (1985) have noted, hierarchical organizations were well established under canon law in the colonial period, but in Cholula they were part of an ongoing dialogue among members of the crown's government: the church and the nobles of Cholula. It is far beyond the scope of this chapter to discuss the whole range of ritual activity in Cholula, but there is one particular system that is fundamental to understanding ritual activity in Cholula and rotating power systems in general. This is the system that sponsors the circulares, the three major city-wide celebrations every year: the celebration of the Virgin of the Remedies, the celebration of the Virgin of Guadalupe, and the celebration of Saint Peter of the Souls, the patron Saint of San Pedro Cholula (figure 10.4).

Each of the circulares is the responsibility of a different barrio each year (Kobayashi 2013). The way the system works is that once an individual has served as the mayordomo of his or her own barrio's patron saint, which may well take serving the barrio in dozens of other positions, the individual is then a potential candidate for one of the circulares. Given that there are ten barrios, each barrio is responsible for the same celebration only once every ten years; thus there are ten candidates to choose from each time a barrio must take on one of the circulares.

Once an individual has served as the mayordomo of his or her own barrio, that individual becomes a principal or teachca, elder brother, or official, of the barrio. The principales are in charge of selecting future officials within the system and are authorities within the barrio. Once a principal has successfully fulfilled the role of mayordomo, she or he then has the power to select, with the other principals, the next candidate for mayordomo within her or his own barrio and to be selected as the mayordomo in charge of one of the circulares. 


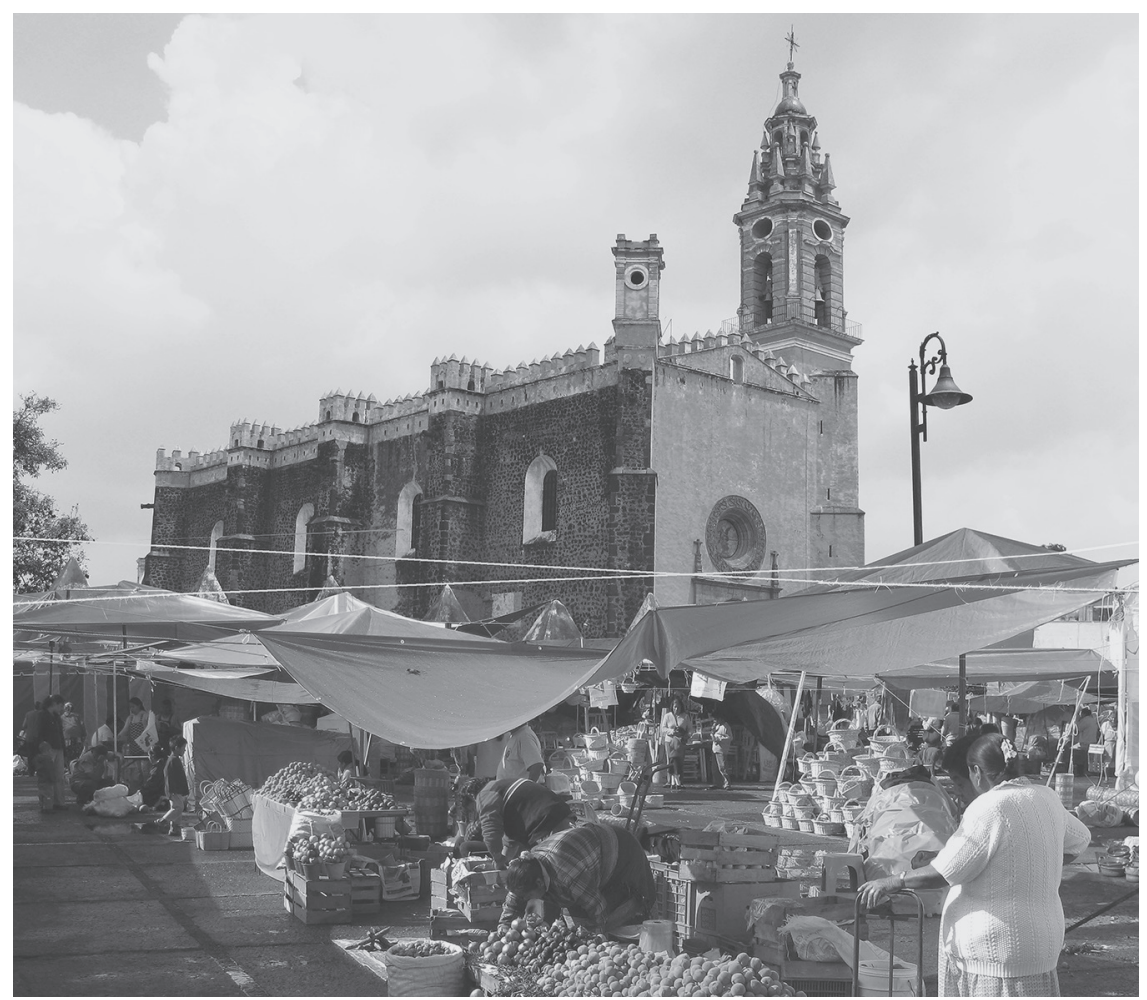

FIGURE I0.4. The annual market held in the main plaza of San Pedro Cholula in front of the Franciscan church of San Gabriel in conjunction with the feast of the Virgin of the Remedies. Each year over a Ioo, o o people representing a broad diversity of indigenous populations from all over southern Mexico journey to the city to trade in the market as well as attend the festival of the Virgin of the Remedies (photo by John M. D. Pohl.)

Once an individual has served as mayordomo for one of the circulares, he or she then becomes a principal or teachca for the city of Cholula. The principales then have the responsibility of selecting from the candidates of each barrio the next mayordomo from each barrio. This system guarantees that candidates have sufficient experience in organizing the immense and complicated celebrations first of all at the level of the barrio and then citywide. The system also guarantees a stable transition among qualified candidates capable of administering and carrying out the duties of office on the basis of carefully nurtured social capital.

The notion of social capital is essential to understanding this system. Social capital is the set of relationships that an individual or organization can rely on in 
carrying out the tasks of everyday life. The system itself builds social capital at each distinct level. Within the barrio system, the role of the principales is to guarantee that individuals selected as mayordomos are capable of carrying out that duty, that they have sufficient social capital as well as the financial means to take on the cargo. The role of the mayordomo is not simply the celebration of the patron saint but to assure that all of the hijos del barrio, or barrio members, can participate fully in the annual celebration. The mayordomias function as a social safety net for the bijos del barrio. The fundamental reason for participating in the traditional system is that it acts as a type of social security, which Mexico does not provide its population. Each organization in which a potential mayordomo participates adds to his or her reserves of social capital, which can be called on in times of hardship. Most traditionalists in Cholula participate in at least six, and sometimes up to a dozen, traditional organizations before being selected as mayordomos. Once they have become principales, they may well participate in twenty or more organizations before being appointed to one of the rotating circulares. The sheer number of traditional organizations in Cholula is rather astounding. By our count, there are more than a hundred different organizations and over 500 traditional celebrations per year in San Pedro Cholula alone.

The circular nature of this system also guarantees that both individuals and organizations are imbued with enough social capital that the system works and that it grows as an individual passes from one level to the next. Not only are individuals part of multiple organizations as they pass from one level to the next in circular power arrangements, but at each level the individual must consolidate social networks necessary to the success at the next level. In this way the social organizations that an individual becomes part of increase his, or her, attractiveness as a candidate for the next level of the hierarchy. In this way circular systems build up large amounts of social capital, both for the individual and for the community as a whole. With large amounts of social capital invested in the system, the system becomes extremely stable and in a very real sense is a self-perpetuating entity. All stakeholders have an interest in the perpetuation of the system.

In the case of San Pedro Cholula, the rotating power structure produces each year ten potential leadership candidates for the rotating mayordomías, and since each barrio only takes charge of a rotating mayordomía once every ten years each barrio can offer ten potential candidates for the principales to select among when the barrio becomes responsible for the celebration. Candidates are weighed on the basis of many factors such as kinship, past performance, social networks, and organizational ability. Because of the investment of such large amounts of social capital in terms of individual qualifications in a rotating power system, the system itself becomes extremely stable, selecting by consensus individuals who can carry out the 
goals of the system. Everyone involved in the system has a clear stake in seeing that the system functions efficiently.

For individuals who participate in this traditional system, the networks that they develop along the way through the system provide a solid basis for support in case of hard times in a nation with virtually no social safety net for the poor. This is social capital (Baron et al. 2000) in Bourdieu's (1985:724) sense of the term. But it is not just the support that the system provides individuals; it is the network of individuals that each person builds up who can be trusted to reciprocate when called upon (Magazine 2012) in arranging the lavish celebrations of the saints, which are necessary for advancement, and the network of organizations that an individual can call on when arranging such a celebration. This is also a solid form of social capital (Putnam et al. 1993:35-36) that is built into circular rotating power systems. These systems build the social capital that benefits all participants. They also build the trust that is essential for such systems to function smoothly in what has been until very recently an impoverished peasant society where trust was at a premium.

Structurally, rotating power systems are extremely stable, as individuals invest great amounts of social capital in them and reap concrete benefits from that investment of social capital. In Cholula, at least, this implies that the baroque system of celebrations for the saints will not disappear with modernization. Now the important question to ask is just how long have such power systems existed in Cholula? It is safe to say that they have existed at least since the construction of the present sanctuary on top of the Great Pyramid of Cholula in the latter part of the nineteenth century. There is also evidence that such rotating power systems have existed since the time of the conquest and probably back through the Postclassic.

According to legend, Cholula was founded by Topiltzin Quetzalcoatl (Nicholson 200I). This culture hero had come to the Plain of Puebla from Tula, Hidalgo, where he was credited with founding the original Toltec capital administered by a dual priesthood, much like that documented for Cholula at the time of the conquest. The priesthood in Cholula sponsored the cult and thereby the international trade by the city's merchant elite. Although bound through mutual social, political, religious, and economic obligations, Tula's governing authorities were clearly subject to violent expressions of internal political factionalism, and by II5O the city had been destroyed, ostensibly a conflict between Quetzalcoatl and a rival named Tezcatlipoca. There is considerable evidence for historicity in the recorded events (Kristan-Graham 1999). Carved pillar reliefs at Temple B not only depict portraits of warriors named for the rival priests, but ofrendas and mesas built into the columned hallways of the associated Palacio Quemado depict the titles of Quetzalcoatl and his father Mixcoatl (Cobean et al. 2012:162). Processions of ranking lords, on the other hand, bear the accoutrements of long-distance merchants (Kristan-Graham 
1999). Considering that Temple B in turn is believed to be inspired by the great Temple of the Plumed Serpent at Teotihuacan, it is likely that at some level the Cholula model we present here had its roots in the great Classic period metropolis itself, especially when we consider the obvious evidence for a corporate elite at that metropolis that used these structures to convey the essential symbolic context for their political and economic agendas (Cowgill 2015; Sugiyama 2003).

\section{CHOLULA THROUGH TIME}

Excavations at Cholula together with colonial historical sources confirm that between 1100 and 1200 the Tolteca-Chichimeca, the Toltecs coming from the north, established a new cult center dedicated to Quetzalcoatl at what is today the Convent of San Gabriel in Cholula's main plaza (Lind 2012:89; Uruñela and Plunkett 2012:164-165). Using descriptions of the pre-Columbian city and colonial maps, and field-checking the sources, one can reconstruct the complex nature of the city's pre-Columbian administration. The veneration of Quetzalcoatl, Cholula's merchant god and patron of the city's largest religious festival, reveals a path to power (Durán [1546] 1971:138) in Postclassic society through competitive feast sponsorship by groups of merchant-lords, who invested vast resources from trading ventures as far south as Guatemala in return for royal titles, insignia, and positions of power as civic administrators (Pohl 2003). A buey tlatoani, together with the tetecubtin (lineage heads-kings), administered the lands of the city as a polity regionally, but confederations of kingdoms throughout the Mexican highlands submitted to the authority of two high priests in matters of alliance and factional dispute. The Spaniards compared Cholula to Rome in this regard and considering how much of the ecclesiastical authority in the Vatican was dominated by Roman families at this time, one can envision a system in which hegemony over much of southern Mexico could have been managed through the same Cholula families, noble houses or lineages, generation after generation.

By the mid-sixteenth century, the Cholula's administration had formed a close relationship with the Franciscan order headquartered there while continuing to dominate trade in textiles and cacao among other high-value goods with Central America. In fact Viceroy Mendoza revived the native order of tecuhtli so that the indigenous nobility could hold titles as "knights" that would be equivalent to those of Spanish administrators (Bancroft 1883:755). The Dominican chronicler Durán ([1546] 1971:129, 139) expressed much concern about Cholula. His qualms were not just based in the rivalry among different orders, but a sincere distrust of the Franciscan's syncretic acceptance of native traditions. He maintained that the city's merchants continued to compete with one another over the sponsorship of a major 
feast, but that it was held on the day that it had been traditionally celebrated in honor of Quetzalcoatl and that they profited greatly from the feast's patronage.

I wish to give warning that there is a diabolical custom among the natives, especially in Cholula, where the god [Quetzalcoatl] was worshiped; peddlers will traffic for ten twelve and even twenty years, earning and saving up two or three hundred pesos. And after their toil, wretched eating and sleeping-they offer a most lavish banquet. There they spend all their savings. What I most regret is that they follow the ancient custom of holding that memorial feast in order to celebrate their [ancient] titles and set themselves on high. This would not be wrong except that for their celebration they await the day on which the god [Quetzalcoatl] was honored. (Durán [1546] 1971:139)

Durán had much to be concerned about, for the feast of Quetzalcoatl was the largest for the Plain of Puebla and held annually in the plaza before the Cholula's main temple. Forty days prior to the celebration, a slave was purchased by the merchants and dressed to impersonate Quetzalcoatl (Durán [1546] 1971:I29). The slave sang and danced through the streets daily collecting contributions for the feast from the homes of people throughout the city. Then, at the appointed time, he was sacrificed to the god he represented. The feast itself featured many days of dances, singing, dramas, and farces in and around a $30 \mathrm{ft}^{2}{ }^{2}$ central platform that was adorned with arbors of flowers. The general populace who attended contributed vast quantities of food. After dining on specially prepared dishes of bird and rabbit, the merchants then danced in their finest ritual dress together with actors pretending to be victims of disease and blindness performing at the same time that solemn prayers were sung to Quetzalcoatl imploring him to protect the Cholula people from disease.

Durán's ([1546] 1971:138-140) description of a rotating system of power among Cholula's dominant merchant families through an investment in feast sponsorship is in fact the basis for a continuing system of rotational power in Cholula today. Although we recognize that Cholula has undergone significant social and political transformations from the late colonial period through independence, the reform period, and the revolution, much of its basic political and religious hierarchical structures appear to have remained intact, or have been intentionally revitalized by successive generations of the city's population to the present day.

\section{SAN MIGUEL TIANGUISNAHUAC}

The present-day barrio of San Miguel Tianguisnahuac is generally recognized as the oldest barrio in San Pedro Cholula (Reyes 2000). It was the barrio of the merchants, and there are families who today maintain kinship ties through marriage with families in El Salvador, Guatemala, Nicaragua, and Honduras. Long-distance 
FIGURE 10.5. The image of San

Miguel de Tianguisnahuac is dressed in his green-plumed finery in preparation for the procession of the barrio saints throughout the city before they are presented at the sanctuary of the Virgin of the Remedies. In pre-Columbian times, both statues and living deity impersonators were addressed as an ixptla, or divine representative of a god. The ritual dress was the means by which the teotl, or spirit force of the god, was invited to take possession of its earthly representation (photo by John M. D. Pohl)

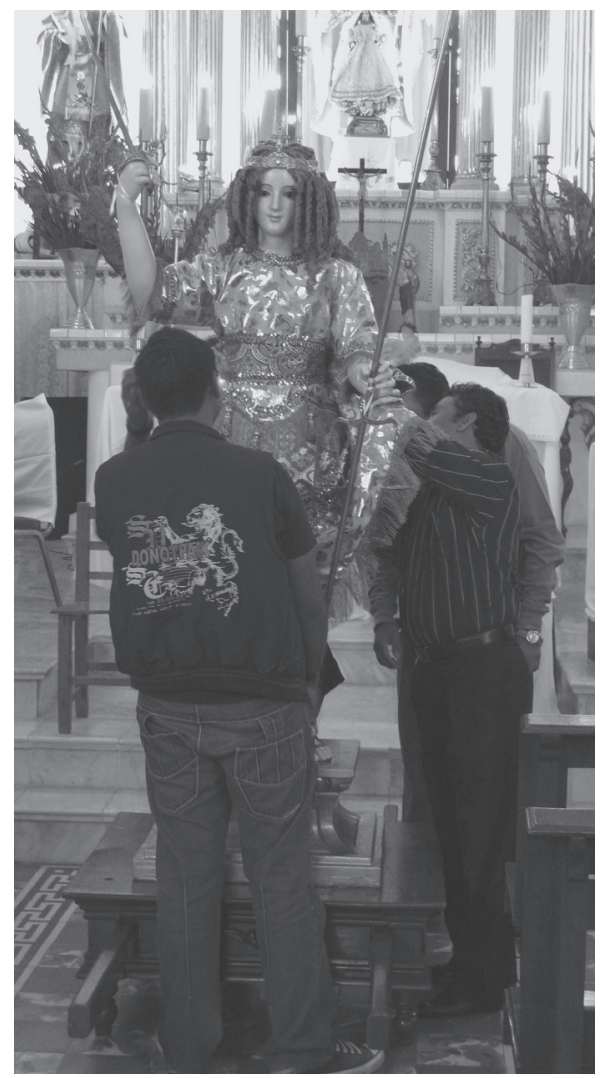

trade has been a mainstay of the barrio probably up to the postrevolutionary period. Although trade is no longer a significant activity in the barrio, the status of the barrio as the first barrio in the rotational system of the circular mayordomías maintains its position in the system (figure I0.5).

Bonfil Batalla (1973:183) lists only six mayordomías and two ritual organizations within the barrio. The most important of the mayordomías is that of San Miguel the patron saint of the barrio. There are also mayordomías of the Santísima Cruz, Virgin of the Rosary, Virgin of Guadalupe, Niño Dios, and San Rafael. Today there many more organized fiestas in the barrio than there were in the time of Bonfil. There are ritual observations for San Francisco, the Santo Entierro, San Gabriel, San Luís, and many others. In 2015, the barrio of San Miguel was in charge of the commission for the Holy Week festivities. San Miguel also coordinates the participation of the town of Tlaxcalantzingo in the fiestas of the Virgin of the Remedies, serves on the commission 


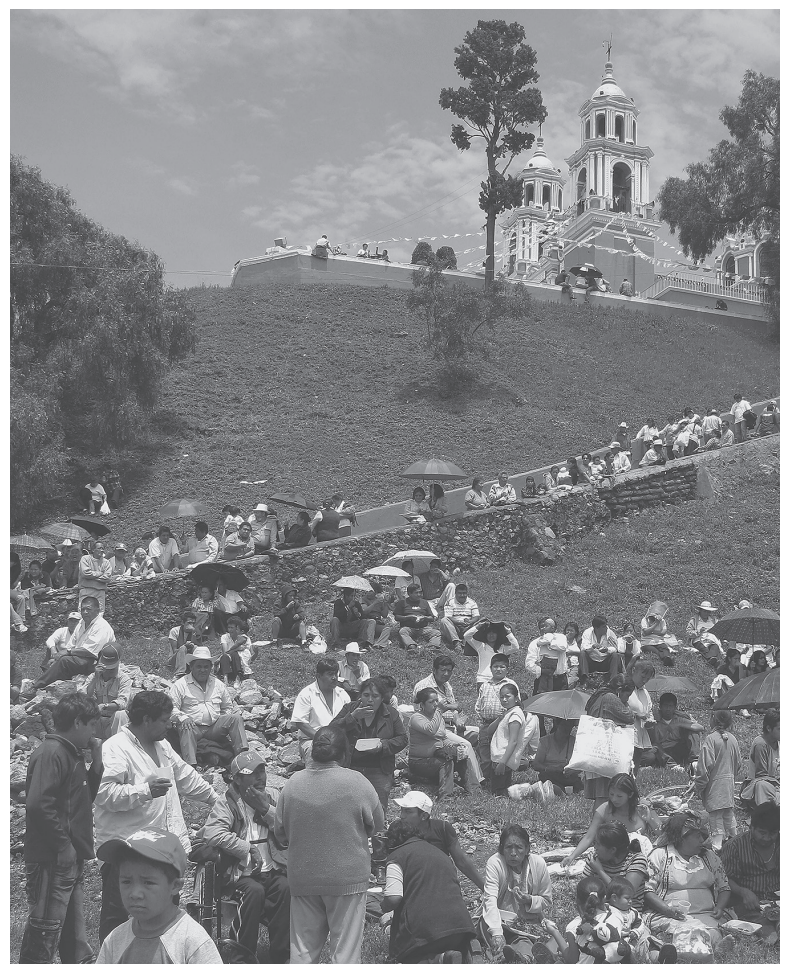

FIGURE 10.6. At the close of the celebration for the Virgin of the Remedies, thousands of participants in the festivities descend from the Virgin's shrine at the summit of Cholula's Great Pyramid to participate in a feast sponsored by the mayordomo. (photo by John M. D. Pohl.)

for the festival of the Ploughmen and the Poor, Labradores y Pobres. In addition to serving on the Hermandad de Cargadores and the Asociación de la Vela Perpetua, members of the barrio serve on the commission del Santo Entierro, the Pro María Asociación, and dozens of other organizations. Ritual activity in the barrio is constant. Generally, individuals must serve in the barrio on the minor mayordomías before taking over the most important cargo, which is that of San Miguel. This system allows the individual to build a network of associates both within the barrio and outside who will help defray the costs and organize the events of ritual celebrations. With each cargo the individual is building the social capital necessary to coordinate major ritual observances. These systems are hierarchically organized and very important in testing the ability of an individual to coordinate complex rituals. The more people an individual can coordinate to assist in these celebrations, the greater the social capital that is available for these individuals. These people can be counted on to assist in further cargos (figure Io.6).

In early cargos for the barrio, individuals will first use kinship-based networks, but as the cargos become more important and complex people begin to rely on members 
of other organizations they belong to, people they work with, migrants, and many others. Thus, by the time an individual becomes the mayordomo of the patron saint, he or she has already accumulated considerable social capital, and once someone has served as the mayordomo of the patron saint the individual will continue with an active participation in ritual organizations to increase his or her possibility of being selected for one of the circulares, thus continuing to build social capital.

Once an individual has served as the mayordomo of one of the circulares of the community, he or she becomes a principal for all the barrios of San Pedro Cholula with power over selection future candidates. Within the ritual system of Cholula, such individuals command great respect and status. The constant participation of people with increasing responsibility, and the people they rely upon to help, contributes to the stability of a rotating system. They are all stakeholders in the system and have invested great amounts of social capital. Although they may not be selected for cargos, stakeholders have the ability to serve and know that in stressful times their social capital will assist them.

\section{TRADE AND TRADERS}

One of the fundamental requirements of long-distance trade is stability. For long-distance traders to embark on multiyear-long trading expeditions, they have to know that the goods acquired can be disposed of at a profit and their position within the community will be recognized. Individual traders and families of traders in this sense are not unlike the mayordomos of the barrio of San Miguel building social capital, alongside economic capital, with ever more extensive trading expeditions. The extensive banquets sponsored by traders build social capital in the same way that mayordomos build social capital. This social capital in a rotating power structure maintains and augments social capital. The system itself is thus maintained as the elimination of one or more elements of the system will not eliminate the system. In a simple hierarchical system, the elimination of the head or a significant number of the members of the hierarchy results in the dissolution of the system. Traders especially are thus assured that no matter how long their journeys, are they will return to the same functioning system (figure 10.7).

There is a fundamental relationship between long-distance trade and rotating systems of power. This relationship is to be found not merely in the extreme stability of such systems, but in the relationships between trade, traders, and their communities. The social capital that is essential for long-distance trade goes far beyond supply and demand, profit and loss. In an era before the commoditization of goods, the relationships between traders and suppliers and the relationships between traders and clients were essential elements in the process of trading. 


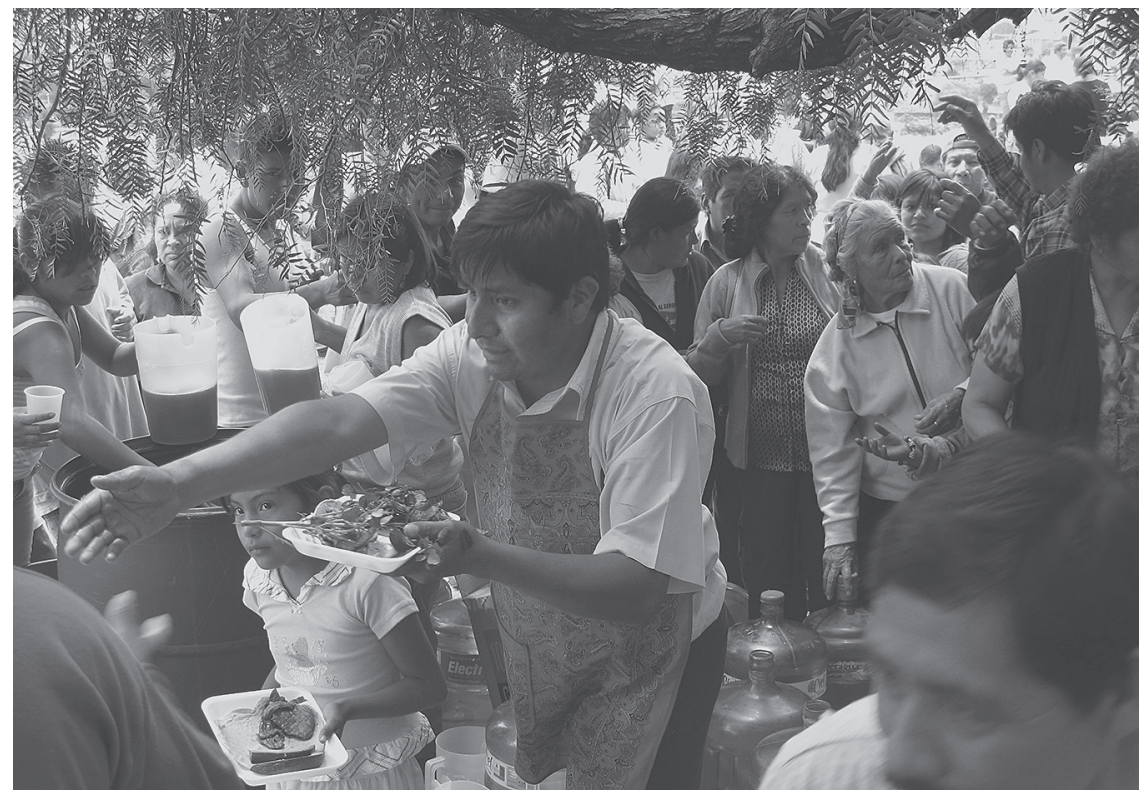

FIGURE I0.7. Celebrants share in platters of cecina, salt beef, grilled on an open fire; rajas, grilled peeled strips of poblano peppers; and white cheese with toasted handmade tortillas while consuming fruit drinks as well as the more traditional atole and aguardiente. The mayordomo's feast takes weeks to prepare and draws upon vast amounts of capital that the mayordomo had amassed in the years before his election (photo by John M. D. Pohl).

The social networks necessary for long-distance trade, just as the social networks necessary for carrying out complex celebrations typical of Cholula's baroquely complicated ritual system, are fundamental for success. With each cargo the social networks of the mayordomo are expanded, just as with each trading expedition the trader's social networks are expanded. These relationships are the social capital necessary for the system to function. In building social capital, both mayordomos and traders have a major investment in the organizations in their communities. Once they have reached the point at which they begin to participate in the rotating power structures that organize the most complex and highly valued celebrations, individuals have an investment in social capital that is so great that they are the most highly valued individuals in the community. The traders of the barrio of San Miguel Tianguisnahuac continued to play a major role in long-distance trade throughout the colonial period, and their networks are as important today as they were in the Postclassic. Today migrants play an essential role in maintaining the complex ritual system of Cholula. 


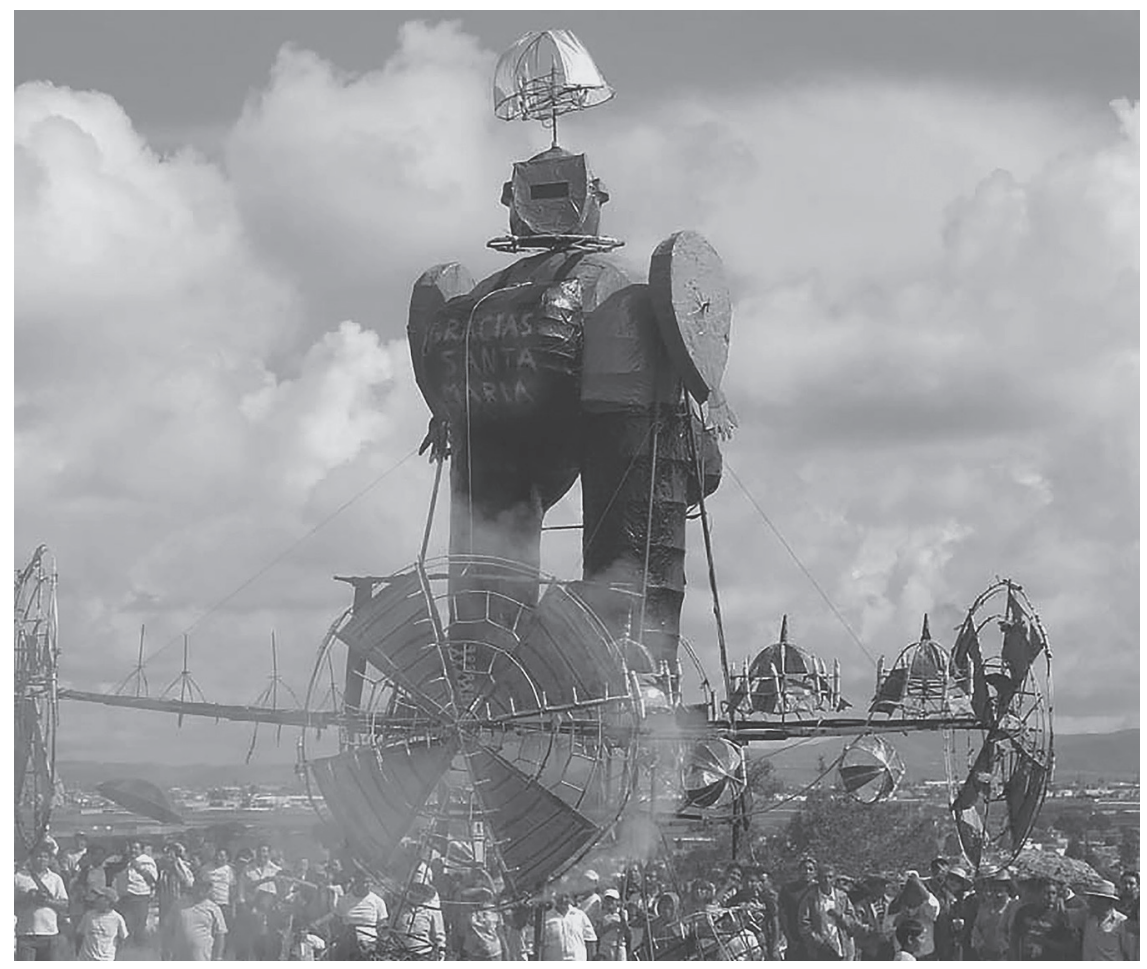

FIGURE I0.8. The climax of the feast of the Virgin of the Remedies is a massive fireworks display. Here a fifteen-foot-tall image representing the mayordomo festooned with whirling fireworks spins and spits dangerously. Finally, a panel mounted on the chest will suddenly explode open, showering the crowd with a rain of fruits and candies (photo by John M. D. Pohl).

Rotating systems of power over long periods of time will maintain the stability of social networks that are necessary for long-distance trade in Mesoamerica. Such rotating systems have been perhaps much more important in maintaining coherent social structure than we have given them credit for. The elders of the Pochteca had vast social networks spanning great distances that allowed them to build up extensive expertise in locating transporting and disposing of elite goods within the system. The mayordomos of San Miguel who become principales of the barrio, and then the city, control vast networks necessary for coordinating massive rituals and feasts. These networks constitute the social capital, which maintains such systems. Trade and traders in Mesoamerica relied on the same types of rotating power structures to maintain stable systems over time (figure Io.8). 
The accumulation of social capital (Putnam 1995), in addition to creating social stability, functions as a type of social safety net for individual in hard times. In Cholula mayordomos assure that the welfare of their members, the hijos del barrio, in a very concrete way. This is especially important in rural Mexico, where the government does not provide a social safety net. Here it should be noted that the same situation applied to the Pochteca at the time of the conquest and that the social capital accumulated along with the economic capital, in the process of long-distance trade, made such endeavors viable. In fact, social and economic capital go hand in hand for traders, each augmenting the other for a successful trader.

Thus, not only do rotating power systems provide the stability necessary for longdistance trade, but the social capital invested in rotating systems in hard times will pay off for individuals who have made that investment. These systems train and incorporate effective and competent individuals into a system making them stakeholders for the perpetuation of that system. The system is thus greater than any one individual and more stable that the life and death of any one individual.

\section{CONCLUSION}

While we tend to view Tenochtitlán's Templo Mayor as a testament to the ideology of military dominance by a class of elites who made their war god Huitzilopochtli the primary focus of veneration (Brumfiel 1987), the cult of Quetzalcoatl at Cholula shows us an alternative path to power in Postclassic society through the competitive manipulation of temple and feast sponsorship by a ruling merchant elite. The rotating power systems typified by Cholula's complex ritual system were a major factor in Mesoamerican social organization. They build social capital into a circulating system that makes all participants stakeholders in the perpetuation of that system. Rotating power systems also show extreme stability over time, funneling competent effective individuals into the system in which they become stakeholders. Such systems are inherently more stable than hierarchically organized systems such as the Aztec system, where eliminating the head of the system effectively cripples the system. Although the nobility of Cholula was decimated by Cortés, and the city lost 90 percent of its population, Cholula remained a cohesive urban entity through the colonial period and into the twenty-first century. Rotating power systems played a big role in this. Rotating power systems in Cholula were never a single continuous system. They were reconstituted over and over due to their inherent stability and their ability to incorporate great amounts of social capital for stakeholders while offering potentially great social benefits. We therefore recognize that there were major breaks in social, political, and economic continuity in Cholula over the course of the last five centuries. But it is clear that shared memory, 


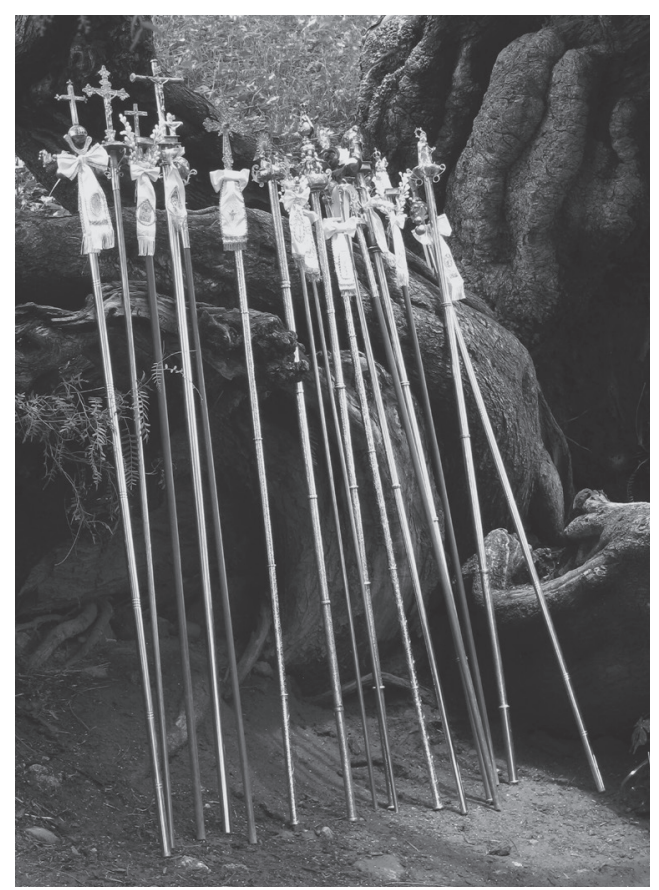

FIGURE 10.9. As the mayordomos of San Bernardino Tlaxcalantzingo arrive to participate in the feast, they set aside their silver staffs of office. At the conclusion of the festivities, they take their Cetros (scepters) and Patron Saint back to Tlaxcalantzingo.

traditional knowledge of barrio identity, and continuity from of Late Antiquity have empowered Cholula's population to transcend calamitous setbacks and to continually rebuild their fundamental institutions.

Rotating power systems at the same time provide stability to social institutions and maintain the social capital built up over time. For this reason they were probably far more ubiquitous in Mesoamerica than the hierarchical Aztec model that fell so quickly to the onslaught of a marauding band of Spaniards. Rotating power systems have features that are fundamental to maintaining stability over time in carrying out complex endeavors, be they long-distance trade, or maintaining a complex ritual system.

Such systems were probably far more common in Mesoamerica than the Aztec or Maya hierarchical lineage systems, which were easily and effectively eliminated by 
decapitating, sometimes literally, the head of the power structure. Rotating power structures can suffer major losses without paralyzing the system. In specific cases in which no lineage-based hierarchical system is clearly indicated, rotating power systems should be taken into account. We propose that the specific examples of Tula and Teotihuacan should be reexamined in terms of rotating power systems, which maintained a complex multiethnic multicultural city of traders and artisans through generation after generation. Rotating power structures are at the heart of many urban systems throughout Mesoamerica (figure I0.9).

\section{REFERENCES}

Bancroft, Hubert Howe. 1883. History of Mexico, Vol. in: The Works of Hugh Hubert Bancroft. A. L. Bancroft and Company, San Francisco.

Baron, Stephen, John Field, and John Schuller. 2000. Social Capital: Critical Perspectives. Oxford University Press, Oxford.

Bonfil Batalla, Guillermo. 1973. Cholula: La ciudad sagrada en la era industrial. IIH-UNAM, Mexico City.

Bourdieu, Pierre. 1985. "The Social Space and the Genesis of Groups." Theory and Society I4(6): $723-744$.

Brown, Peter. 1971. The World of Late Antiquity. Harcourt, Brace, and Jovanovich, New York.

Brumfiel, Elizabeth M. 1987. "Elite and Utilitarian Crafts in the Aztec State." In Specialization, Exchange, and Complex Societies, edited by Elizabeth M. Brumfiel and Timothy K. Earle, IO2-II8. Cambridge University Press, Cambridge.

Cancian Frank. 1972. Change and Uncertainty in a Peasant Economy: The Mayan Corn Farmers of Zinacantan. Stanford University Press, Stanford.

Chance, John K., and William B. Taylor. 1985. "Cofradías and Cargos: An Historical Perspective on the Mesoamerican Civil-Religious Hierarchy." American Ethnologist I2(I):I-26.

Cobean, Robert H., Elizabeth Jiménez, and Alba Guadalupe Mastache. 2012. Tula, México: Fidecomiso historia de las Américas. El Colegio de México and the Fondo de Cultura Económica, Mexico City.

Cowgill, George L. 2015. Ancient Teotihuacan: Early Urbanism in Central Mexico. Cambridge University Press, Cambridge.

DeWalt, Billie. 1975. "Changes in the Cargo Systems of Mesoamerica." Anthropological Quarterly 48(2):87-105.

Durán, Diego. [1546] 1971. Book of the Gods and Rites and Ancient Calendar. Translated and edited by Fernando Horcasitas and Doris Heyden, University of Oklahoma Press, Norman. 
Durán, Diego. [1546] 1994. "History of the Indies of New Spain." Translated, annotated, and with an introduction by Doris Heyden University of Oklahoma Press, Norman.

Knab, Timothy J. 2012. "Bells, Bombs, Music, and Madness: Mayordomías and Social Cohesion in Cholula." In Children of the Plumed Serpent: The Legacy of Quetzalcoatl in Ancient Mexico, edited by Virginia M. Fields, 134-I46. Los Angeles County Museum of Art in association with Scala Publishers Limited, Los Angeles.

Knab, Timothy J. 2013. "Reinventing the Millennial Myth: The Great Pyramid of Cholula and the Virgin of the Remedies." In Constructing, Deconstructing and Reconstructing Social Identity: 2000 Years of Monumentality in Teotihuacan and Cholula Mexico, edited by Saburo Sugiyama, Shigeru Kabata, Tomoko Taniguchi, and Etsuko Niwa, 107-118. CSRI Achi Prefectural University, Achi, Japan.

Kobayashi, Takanori. 2013. "A History Engraved in the Urban Landscape: Formation of the Sacred City and Construction of Traditional Festivals in Cholula, México." In Constructing, Deconstructing and Reconstructing Social Identity: 2000 Years of Monumentality in Teotihuacan and Cholula Mexico, edited by Saburo Sugiyama, Shigeru Kabata, Tomoko Taniguchi, and Etsuko Niwa, II9-132. CSRI Achi Prefectural University, Achi Japan.

Kristan-Graham, Cynthia. 1999. “The Architecture of the Tula Body Politic.” In Mesoamerican Architecture as a Cultural Symbol, edited by Jeffrey Kowalski, 162-175. Oxford University Press, Oxford.

Lind, Michael. 2012. "The Kingdom and Pilgrimage Center of Cholula." In Children of the Plumed Serpent: The Legacy of Quetzalcoatl in Ancient Mexico, edited by Virginia M. Fields, 89-93. Los Angeles County Museum of Art in association with Scala Publishers Limited, Los Angeles.

Magazine, Roger. 2012. The Village Is Like a Wheel: Rethinking Cargos, Family, and Ethnicity in Highland Mexico. University of Arizona Press, Tucson.

Nicholson, Henry B. 200I. Topiltzin Quetzalcoatl: The Once and Future Lord of the Toltecs. University Press of Colorado, Boulder.

Pohl, John M. D. 2003. "Ritual Ideology and Commerce in the Southern Mexican Highlands." In The Postclassic Mesoamerican World, edited by Michael Smith and Frances Berdan, 172-177. University of Utah Press, Salt Lake City.

Pohl, John M. D., and Claire L. Lyons. 2016. "Introduction." In Altera Roma: Art and Empire from Mérida to Mexico, edited by John M. D. Pohl and Claire L. Lyons, I-I9. UCLA Cotsen Institute of Archaeology Press, Los Angeles.

Pohl, John M. D., Virginia M. Fields, and Victoria L. Lyall. 2012. "Introduction.” In Children of the Plumed Serpent: The Legacy of Quetzalcoatl in Ancient Mexico, edited by Virginia M. Fields, John M. D. Pohl, and Victoria L. Lyall, I5-49. Scala, London. 
Putnam, Robert D. 1995. “Bowling Alone: America's Declining Social Capital.” Journal of Democracy 6(I):65-78.

Putnam Robert D., with Robert Leonardi and Raffaella Y. Nanetti. 1993. Making Democracy Work: Civic Traditions in Modern Italy. Princeton University Press, Princeton.

Redfield, Robert. 1956. The Little Community and Peasant Society and Culture. University of Chicago Press, Chicago.

Reyes García, Cayetano. 2000. El Altépetl, origen y desarrollo: Construcción de la identidad regional nábuatl. El Colegio de Michoacán, Zamora.

Sandstrom, Alan R. 1991. Corn Is Our Blood: Culture and Ethnic Identity in a Contemporary Aztec Indian Village. Civilization of the American Indian Series, vol. 206. University of Oklahoma Press, Norman.

Sugiyama, Saburo. 2003. "Governance and Polity at Classic Teotihuacan.” Mesoamerican Archaeology: Theory and Practice, edited by Julia A. Hendon and Rosemary A. Joyce, 97-ıı. Wiley-Blackwell, Malden, MA.

Uruñela, Gabriela, and Patricia Plunkett. 2012. “The Franciscans in Cholula." In Children of the Plumed Serpent: The Legacy of Quetzalcoatl in Ancient Mexico, edited by Virginia M. Fields, I64-167. Los Angeles County Museum of Art in association with Scala Publishers Limited, Los Angeles.

Wasserstrom, Robert. 1978. "The Exchange of Saints in Zinacantan: The Socioeconomic Bases of Religious Change in Southern Mexico.” Ethnology I7(2):197-210.

Wasserstrom, Robert. 1983. Class and Society in Central Chiapas. University of California Press, Berkeley. 


\title{
Chapter 11
}

\section{The Movement of Metal Goods in the Mesoamerican Late Postclassic Period}

\author{
A Case Study from the Templo Mayor in Tenochtitlan
}

Niklas Schulze and Blanca E. Maldonado

At the time of the Spanish Conquest, three main centers of metallurgical production coexisted in the New World: the Andean area, the Colombian-Lower Central American region, and Mesoamerica (Cardós de Méndez et al. 1988; Hosler 1994; Schulze 2008a; Torres Montes and Franco Velázquez 1996; West 1994; see figure II.I). Native American metal craftsmen from these centers rivaled their European counterparts in the sophistication of their technical skills. The ideological and social constructs in which they worked, however, were very different. The Spanish were in the early stages of modern capitalism, and metals, especially gold and silver, were coveted for their economic value. For Native Americans, on the other hand, metals were more than a simple commodity. For some pre-Columbian peoples, gold, for instance, was considered the "feces of the gods" (see, e.g., Sahagún [1590] 1969-1982 [book II]:233), of economic and aesthetic value to humans (e.g., tribute and ornaments) but, ultimately, deriving its importance from its symbolic value and divine origin. This ideological importance probably influenced not only the perception of metal objects, but also their production (Lleras 2005:14).

Furthermore, in Mesoamerica, precious metals did not have the exceptional value that set them apart from other materials, as was the case in Europe, but rather shared their high status with materials such as jade. Snarskis (2003) sees this as part of a process of substitution that would have eventually led to the decline of the importance of jade as a high-status material that culminated in the dominance of precious metals, following a pattern he described for Costa Rica. 


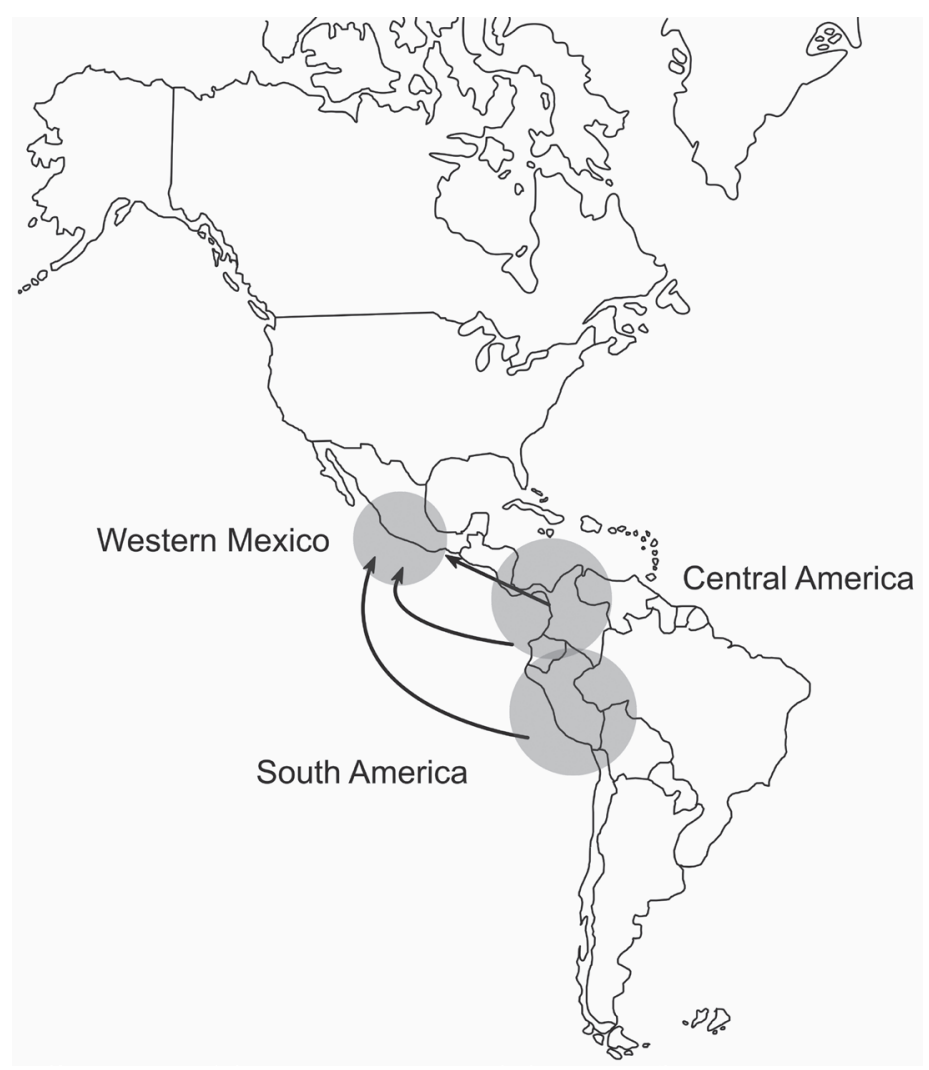

FIGURE II.I. The northward diffusion of metallurgy from regions in Central or South America via maritime and/or terrestrial trade routes. The circles indicate metallurgical production regions in the New World mentioned in the text.

While many aspects of prehispanic metallurgical production are difficult to study directly due to a lack of archaeological evidence, the movement of imported and specially crafted goods is perhaps the most easily detectable aspect of ancient political economies and the constitution of materially based social practices. The present chapter examines the different mechanisms of distribution of metal items in Mesoamerica. Emphasis is placed on the geographical movement of raw materials and products, as well as on the value and significance of metal in the Mesoamerican world. Metal is considered as an indicator of both economic activity and symbolic action. A case study of metal bells deposited as offerings in the Templo Mayor of Tenochtitlán is presented.

New World metallurgy emerged in the Andean region of South America between the Initial period ( 1800 to 900 BC) and the Early Horizon (900 to 
200 B C; Lechtman 1980). In Mesoamerica, some early finds suggest the presence of imported metal items (e.g., Cardós de Méndez et al. 1988). The earliest metal objects that were most likely produced locally are found at archaeological sites located in the west Mexican states of Jalisco, Colima, Nayarit, Michoacán, and Guerrero, with the earliest estimates at AD 600-700 (Hosler 1994). The late date of appearance of metals and the similarity of the techniques employed by the native metalsmiths to those developed in South America have led many scholars to suggest that metal objects and metallurgical techniques were introduced into west Mexico from Peru and Ecuador by traders using watercraft capable of long-distance voyages along the Pacific coast of South and Central America (Edwards 1969; Hosler 1994; Meighan 1969; Mountjoy 1969). Whether this is an accurate assumption, and what role the land route through Central America played, is still a matter of debate.

The territory of modern west Mexico is an area where copper and other metallic minerals are present in relative abundance. A distinctive metallurgical tradition flourished in this region for nearly a millennium before Spanish Contact. Throughout Mesoamerica, a wide range of metal artifacts were fashioned from the Late Classic through the Late Postclassic. During this time, metallurgy became a part of the social fabric of ancient Mesoamerican life (Hosler 1994; Simmons and Shugar 2013). Copper and copper-based artifacts (mainly those made of copper alloyed with tin, arsenic, or lead) are found throughout much of Mesoamerica by the Early Postclassic, having been distributed via a well-developed trade and tribute network.

The value that metal objects held in this part of the Americas was firmly grounded on the particular social realities that shaped ancient Mesoamerica for centuries. One of the ways Mesoamerican rulers, nobles, and other elites displayed their wealth, power, and social status was through a variety of symbolically charged, highly valued materials, including green stones, feathers, Spondylus shell, and metal objects, among others. Rulers and religious specialists had access to and manipulated a range of complex symbols that functioned as material expressions of group ideology (Evans 2008). The production of bells, tweezers, finger rings, and elaborate clothing ornaments (with shimmering metal) was not only an economic act, but it was also political and ideological in nature, often embedded in specific publically significant and value-laden acts or events (Hosler 1994; Lleras 2005). Thus, by their own acts of creation and transformation, smiths and their patrons actively maintained the vital links believed to connect the community and its people with the supernatural energies of the universe (see Helms 1993).

Objects made of metal had powerful sacred connotations for Mesoamerican peoples; they were often associated with the creation of human kind, certain deity cults, or distant, exotic realms (Hosler 1994; Schulze 2008a). The Aztecs, for example, 

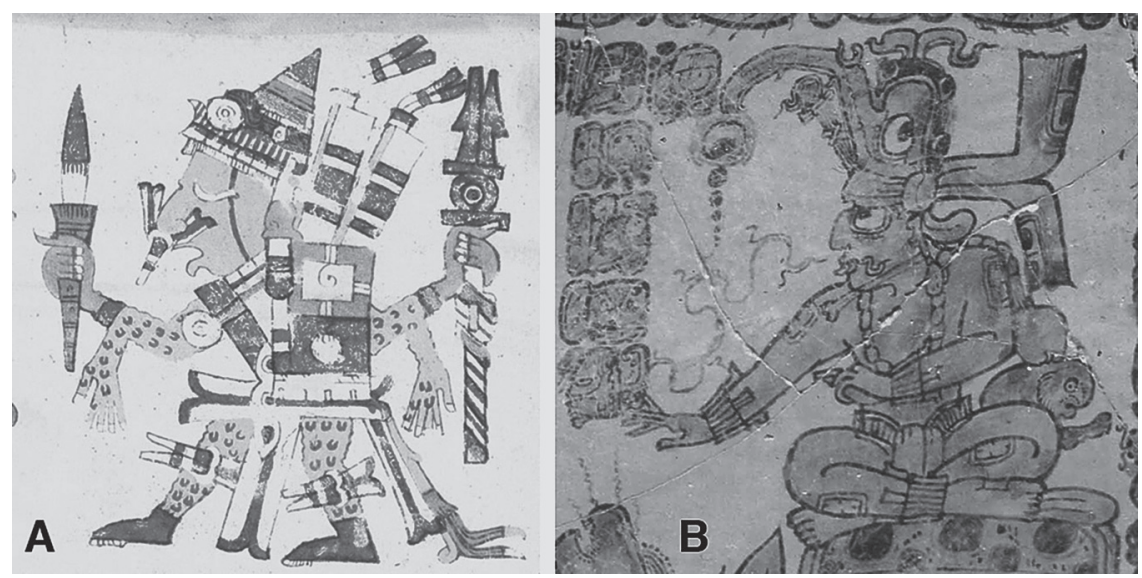

FIGURE II.2. Mesoamerican deities associated with metal: (a) Xipe Totec, the Aztec patron god of metalsmiths and other luxury arts and crafts, on p. 6I of the (Codex Borgia); (b) K'inich Ajaw as a ruler, Classic period Maya (detail of KI398).

considered one of their most powerful deities, Xipe Totec, to be the patron of metalsmiths and other luxury arts and crafts (Barba y Piña Chan 1989:139; see figure II.2a). Among the Maya, the strong connection of metal with the gleaming rays of the sun, represented by a deity known as K'inich Ajaw or God G (Miller and Taube 1993; figure II.2b), suggests they believed metal possessed animate characteristics and had divine associations.

The ability to transform minerals into beautifully crafted metal objects-with their unique sounds, lustrous colors, and divine associations-might have been considered an astounding, perhaps even magical, transformation by ancient Mesoamericans. Cast bells of different shapes and sizes are considered to be the most ubiquitous metal artifacts produced in ancient Mesoamerica (Hosler 1994). Due to their unique sonority, tones, and resonance, copper and bronze bells were used extensively by religious practitioners in a variety of ritual performances, often involving dance or battle.

Pohl (2003:176) notes that "the value of wealth acquired from distant lands was amplified through artistic transformation." The value of bells and other metallic objects was probably augmented by the sometimes great distances involved in their acquisition and the technical challenges required for their production. Mesoamerican elites and religious specialists who possessed such highly valued objects were able to effectively manipulate them as potent material expressions of ideology and social power, through their connection to distant places and spiritual realms (Helms 1993; Hosler 1994; Simmons and Shugar 2013). 


\section{THE TASKSCAPE OF METAL PRODUCTION}

The production of metal objects required the collection or extraction, processing, and transportation of raw materials from their points of origin. In the case of copper alloy lost-wax cast bells, the main materials needed would include metal ore (mainly copper, but also lead, arsenic, and/or tin for alloying), beeswax, refractory clay, and wood for charcoal. Most of these materials are not present in the final product (wax, clay, and charcoal) and tracing their origins would be difficult, even if a metal workshop had been located, which, sadly, is not the case in Mesoamerica. Sourcing the metal is also difficult, since the mines are heterogeneous, not permitting a consistent trace element fingerprint. Furthermore, trace elements are affected by the production process (refining, alloying, recycling etc.) and oxidation (see Budd et al. 1996:168; Henderson 2000:254; Palmer et al. 1998:374; Root I949b:206).

The provenance of metallic raw materials is therefore still hypothetical. Nevertheless, it is possible to at least (a) acknowledge that the different raw materials used during the production process should be taken into account; and (b) keep in mind that the origins of the material(s) (natural distribution and extraction site) on the one hand, and the origin of the object (workshop) on the other, do not need to be (and normally probably were not) identical. This means that the metal objects are not only the physical evidence of an economic relationship between a producer and a user, but also of a number of economic transactions and technological activities that take place previous to the production of the artifact itself. The distribution of the different points of origin on the map naturally depends on the availability of raw materials. However, the mere existence of a raw material-a copper ore, for example-does not imply that it was actually exploited. While identifying a mine might indicate the extraction of the material, only the location of a smelting site proves the production of metal. The workshop, finally, might tell us about the different metals used (e.g., prills, or drops of spilled alloy), or about the artifacts produced (waste material and molds). In the end it is the artifact and its archaeological context that remain as detailed evidence of where and how the product of this process was used and/or discarded.

In sum, the process described above could be represented spatially as follows:

a. areas of natural raw material distribution

b. multiple raw material extraction locations (raw materials for the elaboration of the

object and the functioning of the process)

c. processing and raw material transformation sites (e.g., smelting)

d. production sites (workshops)

e. artifact find-spots. 
The concept of "taskscape" (Ingold 1993:158) is used here as a spatial expression of the operational sequence model (Cresswell 1976:6; Leroi-Gourhan 1964:16) and the life history (Schiffer 1972, 2004:580) of an object. While the operational sequence focuses on the production processes and the material transformation, the life history includes the economic movements and use-life of the artifacts. The configuration of the taskscape depends to a large degree on raw materials distribution, combined with technological knowledge, as well as with the social and economic relations of the actors. Thus, the study of the taskscape will tell us a story of a technological production process and economic relations, the interregional interaction and dynamic cultural processes on which this volume focuses. In Mesoamerica, the main difficulty in the study of metal production is that the available information is based almost exclusively on the above-mentioned points (a) and (e), which, due to the provenancing problems also outlined above, are very difficult to match up. This means that, at least at the moment, our main objects of investigation are the artifacts and the spatiotemporal relations that associate them with their context. This chapter will concentrate on the economic (life) history of an important collection of cast copper bells, which were found as part of the offerings of the Templo Mayor of Tenochtitlán.

\section{A Case Study: Cast Copper Bells in the Offerings of the Templo Mayor of Tenochtitlán}

Throughout the Postclassic period in Mesoamerica, copper and copper alloy bells were highly valued objects (Smith 2003a; figure ir.3). They were frequently found in funerary contexts as jewelry placed around the neck, wrists, or ankles of the dead. According to the Florentine Codex and other sources written in the decades after the conquest, as well as in Mexica sculptures (e.g., the Coyolxauhqui monolith), bells appear represented attached to the garments of elites and deities. They were also found as part of ritual offerings throughout Mesoamerica.

The Templo Mayor was the main temple of the Aztecs, located in the capital of Tenochtitlán. The different building phases of the temple pyramid contained offerings of different materials that were deposited on various occasions (e.g., López Luján 1994). The study presented here focuses on the copper and alloy bells found before 2003-a total of 3,389 bells from 48 offerings-that were analyzed in the framework of an archaeometallurgical investigation (Schulze 2008a). The majority of these artifacts are globular or pear-shaped and measure between $\mathrm{I}$ and $4 \mathrm{~cm}$ in height (figure II.4). They were made of nearly pure copper $(\mathrm{Cu})$ as well as of copper alloyed with tin $(\mathrm{Sn})$, arsenic (As), and/or lead (Pb).

While many Mesoamerican bells do not come from controlled excavations, the Templo Mayor collection allows studying the contexts of the bells, and even shows 


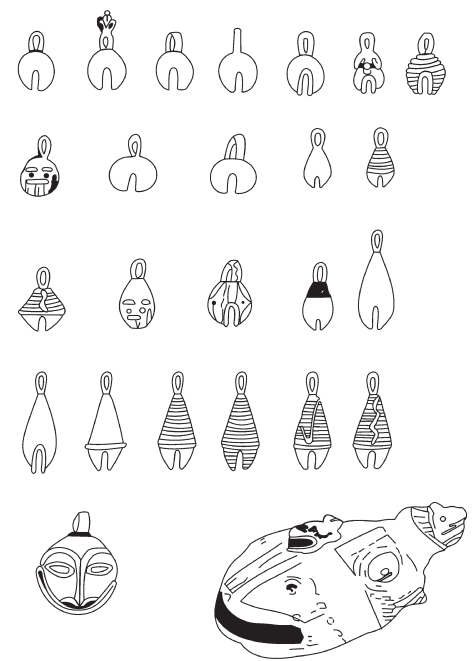

a.

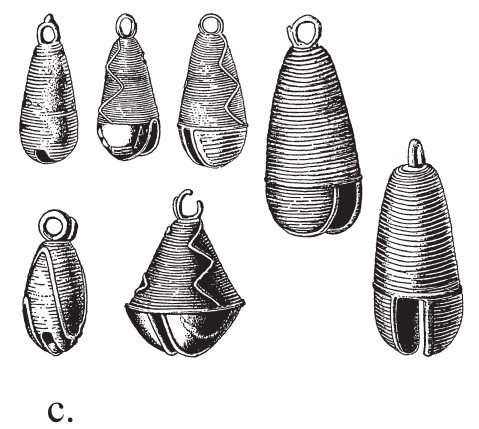

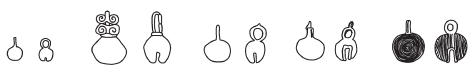

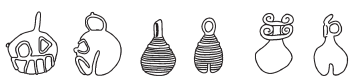

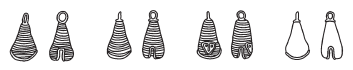
11010
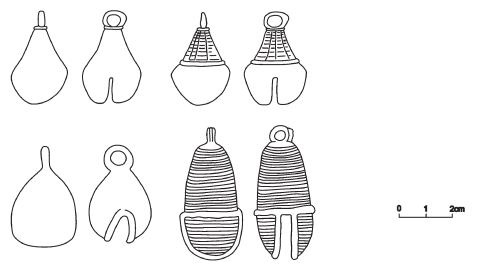

b.

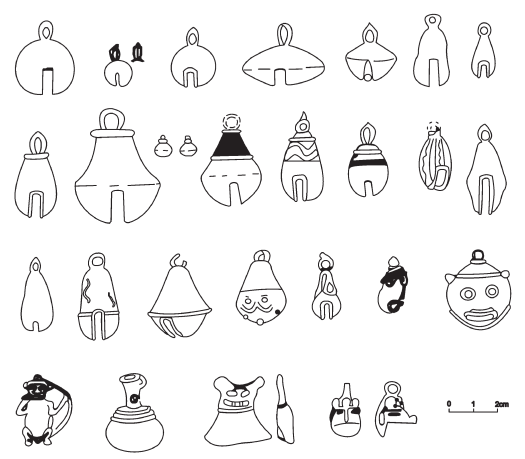

d.

FIGURE II.3. Examples of different Mesoamerican bell typologies (from Schulze 2008a): (a) Mesoamerican bells (figure redrawn by Mario Retiz, based on Pendergast 1962:526); (b) bells from the Regional Museum of Guadalajara (figure redrawn by Mario Retiz, based on Hosler 1994:27I); (c) Type F bells from the Cenote de Chichen Itza (figure redrawn by Mario Retiz, based on Lothrop 1952:91); (d) bells from the Maya region (figure redrawn by Mario Retiz, based on Bray 1977:370).

a clear relative and absolute chronology. The investigation revealed information about-among other subjects-the production process of the bells, their symbolism, and the economic implications of supplying the temple with the necessary copper items (Schulze 2008a, 2008b, 2010a, 2010b, 2013; Schulze and Ruvalcaba 2008). 


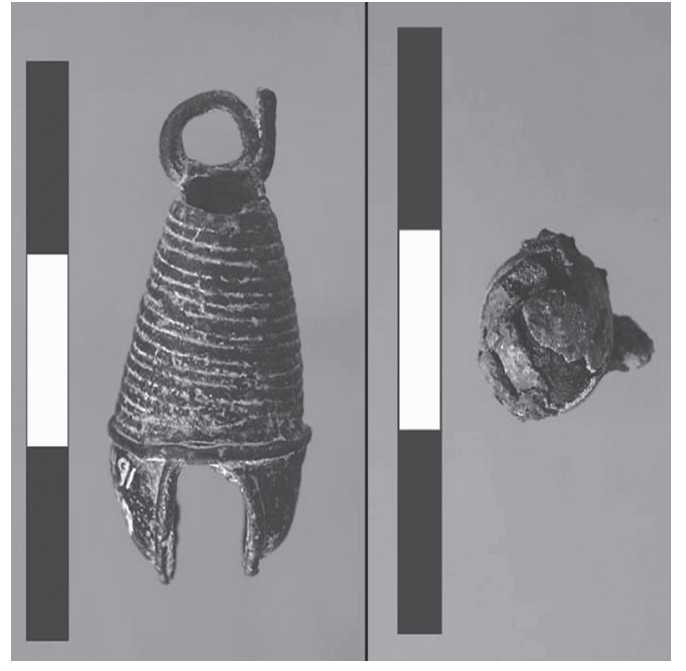

FIGURE II.4. Examples of the most common bell forms from the offerings of the Templo Mayor, pear-shaped and globular (Photo by Niklas Schulze, used with permission of INAH).

The following description attempts to retrace the path of copper bells through the economic system of the Late Postclassic Aztec empire, from the raw material sources to the offerings of the Templo Mayor. The economic movement of the materials and objects on the map are structured by the operational sequences of copper bell production, as well as by their use-life. However, rather than a detailed step-by-step description of this process, we seek to delimitate noticeably large blank areas on the taskscape map of bell production and use. We will start by looking at the available information on bells and metal trade, mainly from archaeology and documentary sources.

As already mentioned, cast bells have been largely described as luxury objects or ritual paraphernalia. From this perspective, bells would fall in the category of key commodities, defined by Smith (2003a:I18) as those whose production and exchange were particularly important for the functioning of the Postclassic Mesoamerican system. The value of such goods is based on a number of attributes:

Raw materials restricted to certain major environmental zones

Raw materials limited to a small number of locations

Complex technology required

Lengthy and/or complex production process

Requirement of highly skilled craftsmanship

High value in relation to weight 
To differing degrees, all of these attributes apply to bells and qualify them as objects of considerable economic value, a status shared with other metal items also regarded as luxury goods. In the case of copper bells, however, their classification as pure luxury goods is problematic due to the wide range of contexts in which they occur (e.g., Bray 1977:370). An example of elite and commoner access to exotic goods is the presence of bronze objects, amongst other kinds of materials, in almost all residential middens at Cuexcomate, Morelos, during Late Postclassic-A (Smith 2003b:249-250). This nonexclusive distribution of elite goods was interpreted as an indication of the development of a higher degree of commercialization, with marketplace economy and little control of production and distribution of prestige goods by elites (Hirth 1998; see also Berdan et al. 2003:102; Smith 2003a:123; Smith and Berdan 2003:7). This allows a connection of the bells with both ritual and elite contexts, as well as with those of domestic type and common access. The range of spheres in which bells appear, indicates different meanings and uses, and suggests their circulation through different economic channels.

Smith and Berdan (2003:3) regard Mesoamerica as a single economic and cultural area, defined by trade and a variety of other types of social interactions. Discussing the Aztec case, however, Michael Ohnersorgen (2006:29) emphasizes the diversity in the administration of the different provinces of the empire, influenced not only by the character of the provinces under control themselves, but also by imperial objectives. Both particular relationships with the provinces and imperial objectives had a direct impact on the economic channels through which various goods may have been mobilized in Mesoamerica. These channels can be categorized into five groups (see, e.g., Chang 1975:214; Dalton 1975:104-109; Olmedo y González 1986:83-91; Schulze 1997:37, 2008a:403-404), all of which may have contributed to a greater or lesser degree to supplying the Templo Mayor offerings with copper alloy bells:

Spoils of war

Tribute (both recurring or sporadic events)

Gifts

Trade (local, regional, or long distance)

Direct extraction

SPOILS OF WAR

The following quote from fray Diego Durán shows clearly that war booty was brought back from the conquered provinces and offered in the temple: 
Llegados los mexicanos a la ciudad de México fueron de toda la ciudad muy bien recibidos, con muchos regocijos y fiestas de los sacerdotes, que salieron con sus braseros en las manos o incensarios, e incensándoles y diciéndoles muchas palabras de loor y cantares de alabanza los festejaron y llevaron al templo, donde ofrecieron grandes ofrendas de los despojos y de las cosas que de la guerra traían...

(When the Mexicans arrived in the city of Mexico [after defeating Tepeaca] they were very well received by all the city, with much rejoicing and festivities of the priests, who came out with braziers or incense burners in their hands, and lighting them and offering many words and songs of praise they celebrated them and took them into the temple, where they made great offerings of the booty and the things that they brought from war...). (Durán 1984:2:153, translation ours)

The type and quantity of offered objects depended to a large degree on the region that was conquered. However, the importance these events had remains unclear, and it would be difficult to identify spoils of war in the archaeological record.

Nevertheless, the expansion of the Aztec empire and the conquest of the provinces of Anahuac had an impact on the supply of the empire with exotic goods beyond those that were brought back from battle. Fray Bernardino de Sahagún ([1590] 1989:582) points out that the conquests during the rulership of tlatoani Ahuítzotl directly affected the supply of exotic products and craft production. The conquests would enlarge the tribute system, open new markets for trade, and give access to more raw materials through direct extraction. The expansion toward the Pacific, for example, opened access to regions rich in minerals. This might have promoted a change in the alloys used in bell production (Schulze 2008a). Bray (1989:255) notes that Ahuítzotl was also the tlatoani under whom the state control over trade and exchange increased.

\section{TRIBUTE}

Copper and copper alloys in the form of hatchets (Torres and Franco 1996:97) - apparently also used as ingots - as well as of cast bells, often appear as both regular and sporadic tribute in different documentary sources. The province of Tepecoacuilco (Matrícula de Tributos, lámina 17; Codex Mendoza, folio 39r; see Galvany 1991), for example, delivered roo copper hatchets to Tenochtitlan every eighty days. Quiauhteopan (Matrícula de Tributos, lámina 20; Codex Mendoza, folio 42r; see Galvany 1991) paid a tribute of eighty copper hatchets and forty copper bells. Both provinces are located north of the modern state of Guerrero (figure II.5). Although the schedule of the tribute from Quiauhteopan is not mentioned in the Matrícula de Tributos, the Codex Mendoza states that such delivery was made every six months. 


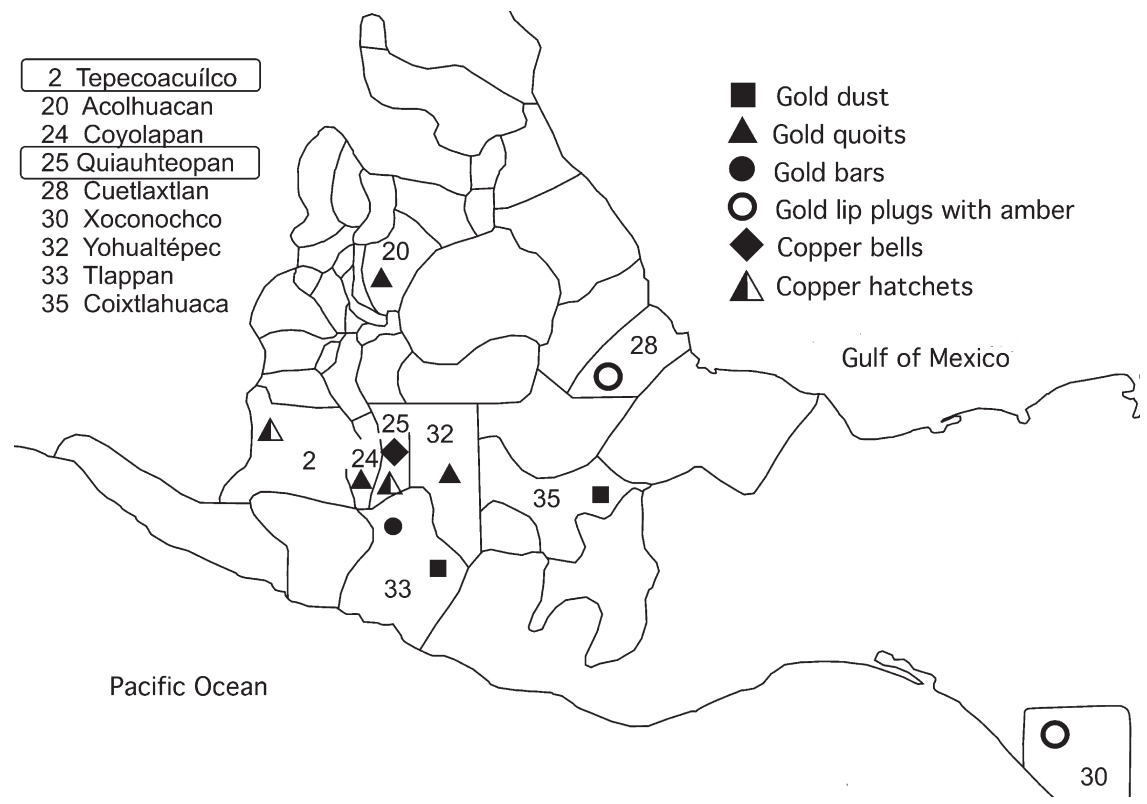

FigURE II.5. Metal tributes mentioned in the Matrícula de Tributos (adapted from Schulze 2008a:408, fig. 11.27, after Castillo Ferreras 1991:map 4).

There are cases that indicate that there was not always a good correlation between the local raw materials and production and the levied tribute (e.g., Barlow 1992:154, 176; Berdan 1975:168, 1977:93-94), a fact that can be explained by the priorities of the empire (Berdan et al. 1996:129). The most common or ephemeral materials (clay and charcoal in the former case and beeswax in the latter) used in the process of bell making are difficult to trace to a definite origin and/or have low archaeological visibility. Charcoal, for instance, is used in the furnaces for metallurgical processes, but does not necessarily appear associated with the final objects. Clay and wax are directly involved in the shaping of the bells, but are normally eliminated from the final product. The wax, for example, is usually burnt in the course of the process. There is, however, information concerning the tribute payments of beeswax and copal resin (both used in the making of wax molds for bell casting) from prehispanic and colonial times (Anderson y Dibble 1950-1982:11:93-94; Sahagún [1590] 1989:189; Codex Mendoza, folio 36r y 37r; Matrícula de Tributos lámina 16 y 17; PNE 1905-1906:1:163, 255). Two provinces mentioned in this context are Tlachco and Tepecoacuilco (Berdan and Anawalt 1992:76-82), located in northern Guerrero. Junius Bird (1979) highlights the importance of wax in the lost-wax 
casting process, and suggests that the use of this technique was directly linked to the presence of the stingless Meliponidae bees. This opinion is shared by other investigators (Northover 1989:218; see also Patiño 1992:127).

\section{GIFTS}

Gift giving was closely related to tribute. It was reciprocal and less formally organized but, as the quote by fray Diego Durán shows, clearly not optional:

... pues jamás, cuando van a saludar o a visitar a alguna persona saben llevar las manos vacías y el llevarlas vacías tienen por afrenta, así los que saludan, como los saludados

(... for when [the Indians] go to welcome someone or to visit a person it is not their custom to go empty-handed because this would be considered offensive, and this is customary with the hosts as well as with the guests). (Durán 1984:2:526, translation ours)

As with the spoils of war, it is difficult to estimate the volume of goods that were moved by gift giving. But, as Berdan et al. (2003:106) point out, this practice allowed for the movement of luxury goods throughout Mesoamerica without markets or traders. Furthermore, it is important to note the impact of gift giving on the production of luxury goods. Berdan et al. (2003:106) propose a patron relationship of the ruler or member of the elite with the artisans in order to ensure a constant raw material supply.

\section{TRADE}

A number of authors (see, e.g., Berdan et al. 2003:104; Schulze 1997:230; Spence 1981:I84) have argued that imperial tribute alone was not enough to satisfy the demands of the nobles, even if many of the objects and materials required for their manufacture appeared on lists of delivered goods. Tribute, though certainly a very important mechanism for the movement of goods throughout Mesoamerica, appears to be overestimated due to bias of the ethnohistorical sources, which in many cases, are a reflection of the interests of Aztec and Spanish elites in urban centers. It is likely that less centralized, local tribute systems, as well as trade in its various forms, played a more important role than the sources may suggest (Berdan et al. 2003:104; Schulze 1997; Spence 1981:184).

In favor of this idea is the fact that metal goods (including bells) were also moved through the pochteca-long-distance merchants supported by the state-as described in the following excerpt from a farewell discourse given by one of the long-distance traders during a feast before travel:

... antes que dexe este barrio y este pueblo, porque ya tengo compradas las cosas con que tengo de rescatar por los pueblos por donde fuere. Tengo compradas 

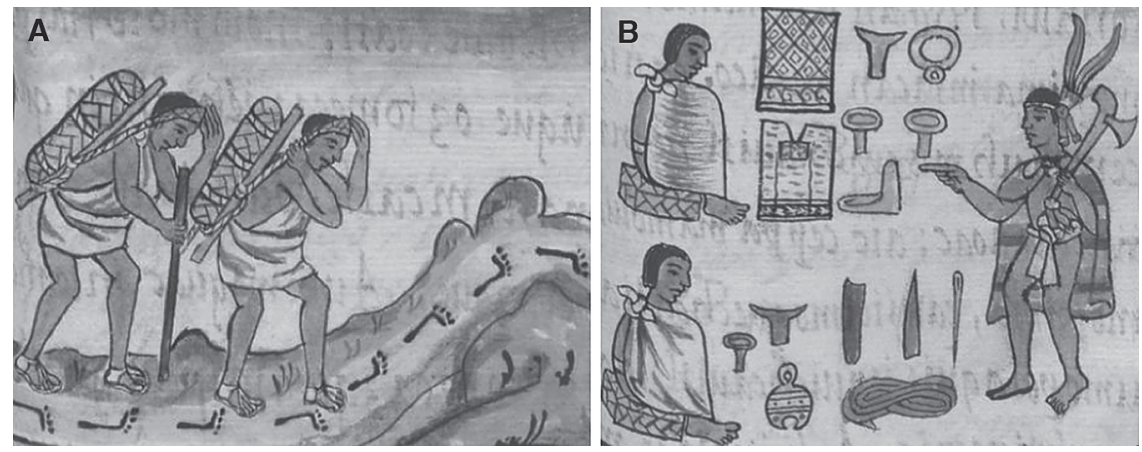

FIGURE II.6. (a) Traders transporting and (b) selling goods, including copper bells, needles, textiles, and personal ornaments of gold and obsidian (Códice Florentino [1979 Book 9, fol. 8]).

muchas navajas de piedra, y muchos cascabeles, y muchas agujas, y grana, y piedra lumbre

(... before I leave this neighborhood and this town, because I have already bought the things that I have to bring to the villages where I shall go. I have bought many knives of stone, and many bells and many needles, and cochineal, and flint stone). (Sahagún [1590] 1989:546, translation ours)

Sahagún ([1590] 1989:550-55I) describes the items that merchants carried longdistance to places such as Xicalanco, which include gold products for rulers and copper bells for the common people (figure ir.6). Berdan (1988:639; see also Berdan et al. 2003:102), however, has pointed out that trade conducted by the pochteca was only one aspect of the Mesoamerican economy, and traders acting at the intraimperial, regional, or local level were probably responsible for the movement of a large volume of goods. Such goods would still travel long distances, passing from merchant to merchant ("down-the-line trade," Berdan et al. 2003:103).

Sahagún ([1590] 1989:609) also mentions several places were gold and copper were sold, suggesting that metallurgists themselves brought their products to sell in the market:

El que vende cuentas de oro, plata o cobre, o trata en cadenas o collares de oro, y en sartales de las muñecas de las manos, el que es deste oficio suele ser platero.

(The one who sells gold, silver or copper, or trades gold chains or necklaces, and strings for the hand-wrists, is usually a silversmith by trade). (Sahagún [I590] 1989:609, translation ours) 
El que trata en agujas fúndelas y las limpia, acicalándolas muy bien. Hace también cascabeles y aguixillos, punzones, clavos, hachas y destrales, azuelas y escoplos.

(The one who trades needles casts them and cleanses them, brushing them well. [He] makes also bells, awls, nails, axes, hatchets, copper adzes, and chisels). (Sahagún [1590] 1989:622, translation ours)

Bernal Díaz del Castillo ([1576] 1979:1:188) describes the sale of metal artifacts on the Tlatelolco market: "y vendían [en el mercado de Tlatelolco] hachas de latón y cobre y estaño" (and they sold [on the Tlatelolco market] hatchets made of brass and copper and tin; translation ours). Cortés ([I524] 1989:7I) makes similar remarks.

Hirth and Pillsbury (2013:4) highlight the importance of the marketplace: "In the marketplace, economic motives blended with social interactions, and all economic institutions - from the household to the palace-converged." No mention is made in ethnohistoric sources of any restrictions or different marketplaces that would result in the separation of the sales of high-status materials from those of the commoners. For that reason, Berdan et al. (2003:IOI) call Tlatelolco a "multipurpose" market. This makes it feasible that the only restriction that regulated the sales of elite materials and objects was their price.

\section{DIRECT EXTRACTION}

Langenscheidt (1985:56) indicates that apart from obsidian, no direct exploitation of mines by the Mexica is known. He stresses that they procured minerals and metals through trade and tribute. This argument is reinforced by a point made by fray Diego Durán, who describes how Motecuhzoma I sent his messengers to Guazacualco "para pedir a los señores le hiciesen la merced de enviarles algún polvo de oro" (to ask the lords to do him the favor of sending some gold dust) (Durán 1984:2:225, translation ours). This "request" was obviously backed by the tacit threat of repression through the Mexica army. Nevertheless, the control of the mines stayed with the local population. Berdan (2003:94-95) highlights the lack of direct control of extraction by larger polities in Mesoamerica: "An interesting aspect of the Postclassic Mesoamerican economy is the apparent lack of direct political control of certain key resource-extraction zones. This is the case with mines in western Mexico (Hosler 2003), obsidian throughout Mesoamerica (Braswell 2003), and high quality salt in northern Yucatán (Kepecs 2003). While local polities may have exercised some control over production arrangements, larger polities do not seem to have made major efforts to gain control over these resource areas."

One possible exception mentioned by Berdan et al. (2003:106) is the control the Tarascan empire had over copper mines in west Mexico. 


\section{AREAS OF NATURAL RAW MATERIAL DISTRIBUTION}

The problem of identifying the origin of the raw material of an object might sometimes relate in great part to the material itself. While in north and middle America, certain materials may originate from very few or even a single possible source (e.g., jade, turquoise, amber; see Harbottle and Weigand 1992:96; Velázquez Castro and Melgar Tísoc 2014:297-298; Vivanco Bonilla 1992), others are nearly ubiquitous (e.g., clay, wood, or certain types of stone). Distinguishing between different possible points of extraction of the raw material also depends on the possibility of analytically linking the object material to the mine, bank, quarry or point of extraction. This is possible with materials such as obsidian (Cobean et al. 199I), where the different extraction points have unique trace element "fingerprints." Other materials, for example, metals, do not offer this possibility (see, e.g., Palmer et al. 1998:374).

While it is important to highlight that the lost wax casting process involves multiple raw materials, the only visible ones in the finished product are the metals. Dorothy Hosler (1994) stresses the importance of the West Mexican Metalworking Zone as perhaps not the sole but the most important source of metals for prehispanic metallurgy. This would reduce the area of possible extraction of metals for the copper bells and would make it necessary to investigate the relationship between the Aztec and the Tarascan empires and their possible competition for the resource.

Metallogenetic studies, however, indicate that mineral wealth is more widely distributed in Mexico than that. The accumulated production of copper, lead, and tin for the years 1942, 1953, and 1954 indicates that west Mexico is an important, but by no means the only metal producer (see table II.I).

Important differences between prehispanic and modern possibilities in terms of mining technology and transport, as well as different needs, have to be taken into account when considering this information. Nevertheless, the table shows that copper and lead ores are widely distributed in the Mexican territory. Whether these resources were exploited in prehispanic times is a different question. The challenge archaeometallurgical investigations face is that the indications of clearly prehispanic mineral mining and metal production sites (smelting) in Mesoamerica are scarce (see, e.g., Aguilar 1946:64-66; Grinberg 1996; Hendrichs 1940; Hosler 1998, 2004; Hosler and Macfarlane 1996; Langenscheidt 1970, 1985, 1997; León-Portilla 1978, 1980; Patterson 1971), and no metalworking workshops have yet been identified in Mesoamerica.

No equivalents to large mining sites such as Buriticá, Colombia (Bray 1978:25; Plazas and Falchetti 1978:12), for example, have been found in Mexico. This may be due to low archaeological visibility of the production processes, or to a possible misidentification of existing archaeological vestiges (e.g., mold fragments, crucibles, slag, furnaces, etc.). Another explanation would be the absence of great mining and 
TABLE II.I. Mexican copper, lead, and tin production from the years 1942, 1953, and 1954.

\begin{tabular}{|c|c|c|c|c|}
\hline Region & States & Copper $(\mathrm{kg})$ & Lead $(\mathrm{kg})$ & $\operatorname{Tin}(\mathrm{kg})$ \\
\hline Highland & Hidalgo, México, Morelos, Puebla, & $I, 136,621$ & $10,970,994$ & $\circ$ \\
\hline $\begin{array}{l}\text { Central } \\
\text { Mesa }\end{array}$ & $\begin{array}{l}\text { Aguascalientes, Durango, Guanajuato, } \\
\text { Querétaro, San Luis Potosí, Zacatecas }\end{array}$ & $28,968,667$ & $168,625,139$ & 352,202 \\
\hline North & $\begin{array}{l}\text { Baja California Norte, Baja California } \\
\text { Sur, Chihuahua, Coahuila, Nuevo } \\
\text { León, Sinaloa, Sonora, }\end{array}$ & $136,845,236$ & $394,033,556$ & ○ \\
\hline South & Chiapas, Oaxaca & $\mathrm{I}, 548, \mathrm{I} 86$ & $I, 297,970$ & $\circ$ \\
\hline West & Guerrero, Jalisco, Michoacán, Nayarit & $4,137,522$ & $20,534,582$ & 7 \\
\hline Gulf Coast & Tamaulipas, Veracruz & 78,048 & $4,584,621$ & o \\
\hline
\end{tabular}

All states provide at least one of the three metals. States that are not represented in the table do not produce any of these three metals (data from González Reyna 1956).

production centers, with production taking place at small sites with rather ephemeral installations, many of which probably were obliterated by later extraction activities (Schulze 2008a:440).

\section{THE TEMPLO MAYOR OFFERING}

This brief review of economic movements of metal and metal offerings, with special emphasis on copper bells, has shown the complexity and diversity of the Late Postclassic economic organization. The tribute system, as well as different combinations of trade and market exchange moved goods toward the center of the Aztec empire and supplied the Templo Mayor with the materials needed. Ethnohistorical sources indicate that the priests in some cases had the responsibility to obtain bells for the attire of sacrificial victims that represented Xiuhtecutli:

El Sacerdote de Tecanman. El Sacerdote de Tecanman tenía a su cargo la madera de pino que se convertirá en teas. Y era también su oficio reunir la pintura roja, la negra, y las sandalias de hule, el chalequillo y las campanillas que necesitaba el que representaba a Xiuhtecutli, el dios viejo, cuando moría.

(The priest of Tecanman saw to the pine wood to be used as torches, and his duties also were to gather together the red and black paint, and also the rubber sandals, the sleeveless shirt, the bells that were needed for [the impersonator of] Xiuhtecutli, the old god, when he died). (León-Portilla 1992:93; Códice Matritense del Real Palacio [1560-I565] 1906; translation ours) 
In his description of the celebrations of etzalcualiztli, the sixth month of the Aztec calendar, Sahagún ([1590] 1989:128-129) mentions that the priests bought some of the supplies needed on the market. The chronicler Torquemada also refers to priests obtaining supplies needed for the funeral of Tezozomoc on the market:

y que en confirmación de esto [la muerte de Tezozomoc] habían visto algunos mayordomos suyos que estaban en el dicho mercado, comprando cosas, que ellos gastaban y habían menester en semejantes entierros

(and in confirmation of this [the death of Tezozomoc] they had seen some of his stewards who were in the market, buying things that they used and required in such burials). (Torquemada 1975:167, translation ours)

However, tribute also played an important role in supplying the temple, as Durán's description of the special tributes paid at the inauguration of a new building phase of the Templo Mayor under tlatoani Motecuhzoma I shows:

Viendo el rey Motecuhzoma la prisa con que su templo se hacía, mandó a todos los señores de la tierra que, para que su dios fuese más honrado y reverenciado, que se recogiesen por todas las ciudades mucho número de piedras preciosas, de piedras de hijada verdes-que ellos llaman chalchihuites-, y viriles, y piedras de sangre, esmeraldas, rubíes y cornerinas. En fin, de todo género de piedras ricas y preciadas joyas, y muchas riquezas y que a cada braza que el edificio creciese, fuesen echadas, entre la mezcla, de aquellas piedras preciosas y ricas joyas. Y así, echando por cabezas aquel tributo, cada ciudad acudía con sus joyas y piedras a echar su lecho de ellas.

(Motecuhzoma, seeing how fast his temple was being constructed, ordered all the nobles of the land, in order for his gods to be more honored and revered, to gather in all the cities a great number of precious stones, green jades, the ones they call chalchihuites-, and beryls, blood stones, emeralds, rubies and cornelians. In short [to gather] every kind of rich stone and precious jewel and treasure, to throw those precious stones and rich jewels into the fill at each new stage of the building's growth. And so, giving tribute, each city came with the jewels and precious stones to cast into the layer, each in its turn). (Durán 1984:2:228, translation ours)

The preparation of Ahuítzotl's coronation ( $\mathrm{AD}$ I486) was another occasion when tribute was demanded. However, this tribute was not offered directly, but it was passed on to the artisans, for them to produce the needed objects of stone, metal, feathers, clay, and other materials. All of those involved in the process were threatened to be exiled and deprived of their posts, if something did not go according to plan:

Y así, convidados todos los grandes y avisados de que hubiese cuenta con la provisión, especialmente daban este aviso a los prepósitos, mayordomos, factores y tesoreros 
que había en todas las ciudades, amenazándoles que si en alguna cosa hiciesen falta, que serían privados de sus oficios, desterrados de la tierra, ellos y sus deudos y parientes. Juntamente a los lapidarios que se diesen prisa a labrar las piedras preciosas que para la fiesta eran necesarias; a los plateros para los joyas [sic], a los oficiales de componer pluma, para los plumajes galanos y para los bailes; a los olleros para la loza necesaria; a los oficiales de hacer humazos, a los componedores de rosas, a todos apercibían y amenazaban, si en algo ellos faltasen, de les castigar y desterrar de la ciudad a ellos y a su generación, y que de todo hubiese gran abundancia. Andaban sobre ellos muchos mandoncillos, que no los dejaban descansar ni parar, tan solícitos y diligentes, que parecía irles la vida en ello, y causábalo el gran temor que tenían a sus señores y reverencia.

(And so, all the great ones [were] invited and warned that they should bring the provision, they especially gave this warning to the superiors, butlers, stewards, and treasurers from all the cities, threatening them that if anything should go lacking, they would be deprived of their trades, banished from the earth, they and their families and relatives. In the same way the lapidary should hurry the carving of the precious stones that were required for the party; the metalworkers for the jewelry, the feather workers, for the gala ensembles and dances; the potters for the necessary crockery; the smoke-makers, the flower arrangers, all of them were warned and threatened that if they missed anything, they and their generation would be punished and banished from the city, and that everything had to be in great abundance. Many demanding taskmasters who would not let them rest or stop were over them, so solicitous and diligent, as if their lives depended on it, and this was because of the great fear and reverence they had for their masters). (Durán 19842:323, translation ours)

During the inauguration of another new building phase of the Templo Mayor, once again during the times of Ahuítzotl, the special tribute was redistributed to the artisans for them to make whatever was needed for the celebration:

Todo lo cual fue entregado al tesorero real o mayordomo mayor, para que él lo repartiese, conforme a la orden que le estaba dada; especialmente, proveyese de todo lo que los sacerdotes pidiesen para el culto de los dioses y solemnidad presente. Y segundo, a los oficiales de plateros y lapidarios y a los componedores de plumas, que se les diese todo lo necesario para las joyas, plumajes, coronas y cosas preciosas que a los reyes y grandes señores se habían de dar y presentar, para que con ello no solamente mostrasen la grandeza y suntuosidad de México, pero también para que solemnizasen la gran fiesta de la renovación y fin del templo.

(All of which was delivered to the royal treasurer or chief steward, for him to allocate it, according to the order that was given; especially, to provide all that the priests 
required for the worship of the gods and the present solemnity. And secondly, to the silversmiths and lapidary and feather workers, to whom was given everything for the jewels, feathers, crowns, and precious things that kings and great lords had to give and present, so that they could not only show the grandeur and magnificence of Mexico, but also give solemnity to the great feast of renewal, and the termination of the temple). (Durán 1984:2:341, translation ours)

This information highlights the existence of at least four different modalities of supplying the Templo Mayor with offerings:

a. Spoils of war that are directly offered upon return from the battlefield (see above; Durán 1984:2:153).

b. Priests obtaining the offerings on the market.

c. Tributes being offered directly.

d. Tribute being redistributed and reworked by local artisans before being offered.

While options (a) and (c) would result in rather heterogeneous offerings (objects from different regions and different workshops), options (b) and especially (d) would ensure more homogeneous collections of objects, since it is less likely that a large number of different workshops were involved in their production.

It is this latter organization that might have been responsible for the rather surprising homogeneity of the Templo Mayor bell collection (forms as well as elemental compositions), which even augments in the latest building phases, starting with the reign of Ahuítzotl. This homogeneity contrasts with other Mesoamerican collections of bells that display considerably more variability (Schulze 2008a, 2013, Schulze and Ruvalcaba in press).

Similar observations have been made by Velázquez Castro and Melgar Tísoc (2014), who also detected a remarkable homogeneity and a particular production style for lapidary work and mollusk shell objects in the Templo Mayor offerings, starting in this case with the reign of Axayacatl (AD I469-I48I). The explanation here is also the movement of raw materials from long distances with a local production established in Tenochtitlán, which led to the development of the "Tenochca imperial style."

\section{CONCLUDING REMARKS}

As J. C. Arnold (1988:101) has stated, "the exchange of raw materials and finished products in a society is an activity that is inextricably bound up with economic, social and political life. The nature of the movement of goods can only be understood if it is seen in relation to the complex and changing framework of society." Taking the production process and the economic movements of metal objects, particularly 
copper alloy bells, as an example, we have tried to show some of the mechanisms of interregional interaction and dynamic cultural processes in Mesoamerica. Metal production implies the use of different raw materials, which have to be collected or extracted in different locations and transported to the production site(s). Hirth and Pillsbury (2013:II) refer to this type of manufacture, with different tasks carried out by different actors, as a "segmented operation."

The above means that the metal and/or metal artifact, in different stages and moments of production and use, has passed through many hands and was transported large distances before it comes to form part of the archaeological context. In sum, it can be stated that the raw materials and artifacts connected different regions of Mesoamerica in one complex economic operation. The lacunae in the archaeological record and the complex nature of the principal material used (metal) make it difficult to reach specific conclusions concerning the spatial distribution of the locations of extraction and production.

The example we chose to present, the copper (alloy) bells found in the offerings of the Templo Mayor of Tenochtitlán, is special for several reasons: the power of the Mexica ruler, backed by the threat of retribution delivered by the army, created a very particular economic situation that allowed for materials and artifacts to "flow" toward the center, Tenochtitlán, through a number of different economic channels - mainly tribute, gifts, trade, and spoils of war. Furthermore, at the Templo Mayor, functioning as the stage for constant ritual activities, the Mexicas gathered the largest-known collection of copper alloy bells in Mesoamerica (more than 3,000 objects). This means that a constant supply of materials and artifacts had to be maintained.

The ethnohistoric sources mention a variety of economic channels, but especially one mechanism would have allowed for close control of production deadlines and quality. The materials were delivered from the provinces and handed to the artisans by the officials for production of the necessary objects. The concentration of the production close to the temple allowed for very tight control and explains the use of alloys not common in the rest of Mesoamerica and the great morphological and compositional homogeneity of the copper bells of the Templo Mayor. However, it cannot be stressed enough that the economic situation of the Templo Mayor was very particular.

Hirth and Pillsbury (2013:7) point out that the institutional economy, though better documented, is not to be taken as the model for the entire economic system. At other sites (e.g., Tamtoc; see Schulze and Ruvalcaba in press) and in Mesoamerica in general, a relative heterogeneity of the bells can be observed (see figure II.3). This means that the production and supply processes were not as closely controlled outside the Templo Mayor. It means, furthermore, that an as-yet-unknown number of 
different workshops in different locations produced bells with sometimes important morphological and compositional differences. In order to understand this complex and diverse taskscape it will be necessary in the future to locate and study extraction and production sites of metal objects in Mesoamerica.

\section{REFERENCES}

Aguilar Piedra, Carlos H. 1946. La orfebrería en el México precortesiano. Acta Antropológica 2(2). Editorial Acta Antropológica, Mexico City.

Anderson, Arthur J. O., and Charles E. Dibble, eds. and trans. 1950-1982. Florentine Codex: General History of the Things of New Spain. 13 vols. School of American Research and University of Utah Press, Santa Fe and Salt Lake City.

Arnold, C. J. 1988. An Archaeology of the Early Anglo-Saxon Kingdoms. Routledge, London. Barba, Beatriz, and Román Piña Chan. 1989. "La metalurgia mesoamericana: Purépechas, mixtecas y mayas." In Orfebrería prehispánica, edited by Carlos H. Aguilar, Beatriz Barba, Román Piña Chan, Luis Torres Montes, Francisca Franco Velázquez, and Guillermo Ahuja, 105-216. Corporación Industrial, San Luis Potosí.

Barlow, Robert H. 1992. La extensión del imperio de los Culhua Mexica. Instituto Nacional de Antropología e Historia, Mexico City.

Berdan, Frances F. 1975. Trade, Tribute, and Market in the Aztec Empire. Unpublished PhD dissertation, Department of Anthropology, University of Texas, Austin.

Berdan, Frances F. 1977. "Distributive Mechanisms in the Aztec Economy." In Peasant Livelihood, edited by Rhoda Halperin and James Dow, 9I-Ior. St. Martin’s Press, New York.

Berdan, Frances F. 1988. "Principles of Regional and Long-Distance Trade in the Aztec Empire." In Smoke and Mist: Mesoamerican Studies in Memory of Thelma D. Sullivan, Pt. 2, edited by J. Kathryn Josserand and Karen Dakin, 639-656. BAR International Series 402(ii). Archaeopress, Oxford.

Berdan, Frances F. 2003. “The Economy of Postclassic Mesoamerica." In The Postclassic Mesoamerican World, edited by Michael E. Smith and Francis F. Berdan, 93-95. University of Utah Press, Salt Lake City.

Berdan, Frances F., and Patricia Rieff Anawalt, eds. 1992. The Codex Mendoza. 4 vols. University of California Press, Berkeley.

Berdan, Frances F., Richard E. Blanton, Elizabeth Hill Boone, Mary G. Hodge, Michael E. Smith, and Emily Umberger. 1996. Aztec Imperial Strategies. Dumbarton Oaks, Washington, DC. 
Berdan, Frances F., Marilyn A. Masson, Janine Gasco, and Michael A. Smith. 2003. "An International Economy." In The Postclassic Mesoamerican World, edited by Michael E. Smith and Francis F. Berdan, 96-108. University of Utah Press, Salt Lake City.

Bird, Junius. 1979. "Legacy of the Stingless Bee." Natural History 88(9):49-51.

Braswell, Geoffrey E. 2003. “Obsidian Exchange Spheres.” In The Postclassic Mesoamerican World, edited by Michael E. Smith and Francis F. Berdan, I3I-I58. University of Utah Press, Salt Lake City.

Bray, Warwick. 1977. "Maya Metalwork and Its External Connections.” In Social Process in Mayan Prehistory, edited by Norman Hammond, 365-403. Academic Press, London.

Bray, Warwick, 1978. “The Gold of El Dorado: Catálogo de la Exposición.” Royal Academy, London, edición española en Editorial La Rosa, Bogotá.

Bray, Warwick. 1989. "Fine Metal Jewelry from Southern Mexico." In Homenaje a José Luis Lorenzo, edited by Lorena Mirambell, 243-276. Instituto Nacional de Antropología e Historia, Mexico City.

Budd, Paul, R. Haggerty, A. M. Pollard, B. Scaife, and R. G. Thomas. 1996. "Rethinking the Quest for Provenance." Antiquity 70(267):168-174.

Cardós de Méndez, Amalia, Ernesto González Licón, Angelina Macías Goytia, and Perla Valle de Revueltas. 1988. "El análisis de la metalurgia mesoamericana prehispánica." In La antropología en México VI, panorama histórico: El desarrollo técnico, edited by Carlos García Mora and Ma. de la Luz del Valle Berrocal, 367-394. Instituto Nacional de Antropología e Historia, Mexico City.

Castillo Ferreras, Víctor M. 1991. “La matrícula de tributos.” In Matrícula de tributos: Nuevos estudios, edited by Julio Galvany Llorente. Secretaría de Hacienda y Crédito Público, Mexico City.

Chang, Kwang-Chih. 1975. "Ancient Trade as Economics or as Ecology.” In Ancient Civilization and Trade, edited by Jeremy Sabloff and C. C. Lamberg-Karlovsky, 21 I-224. University of New Mexico Press, Albuquerque.

Cobean, Robert H., James R. Vogt, Michael D. Glascock, and Terrance L. Stocker. I99I. "High-Precision Trace-Element Characterization of Major Mesoamerican Obsidian Sources and Further Analysis of Artifacts from San Lorenzo Tenochtitlan, Mexico.” Latin American Antiquity 2(1):69-91.

Códice Florentino. 1979. Manuscrito 218-20 de la Colección Palatina de la Biblioteca Medicea Laurenciana edición facsímile. 3 vols. Secretaría de Gobernación / Archivo General de la Nación, Mexico City.

Códice Matritense del Real Palacio. [1560-1565] 1906. Edición facsímile, edited by Francisco del Paso y Troncoso. Hauser y Menet, Madrid. 
Cortés, Hernán. [1524] 1989. Cartas de relación de la conquista de México. Colección Austral, Espasa-Calpe Mexicana, S.A., Mexico City.

Cresswell, Robert. 1976. "Avant-propos." Techniques et culture 1:5-6.

Dalton, George. 1975. "Karl Polanyi's Analysis of Long-Distance Trade and His Wider Paradigm." In Ancient Civilization and Trade, edited by Jeremy Sabloff and C. C. Lamberg-Karlovsky, 63-132. University of New Mexico Press, Albuquerque.

Díaz del Castillo, Bernal. [1576] 1979. Historia verdadera de la conquista de la Nueva España. 2 vols. Edited and with an introduction by Claudia Parodi. Promexa Editores, Mexico City.

Durán, Diego. 1984. Historia de las indias de la Nueva España e Islas de la Tierra Firme. 2 vols. Edited and with an introduction by Ángel Ma. Garibay. Porrúa, Mexico City.

Edwards, Clinton R. 1969. "Possibilities of Pre-Columbian Maritime Contacts among New World Civilizations." In Precolumbian Contact within Nuclear America, edited by J. Charles Kelley and Carroll L. Riley, 3-10. Mesoamerican Studies, vol. 4. Southern Illinois University Press, Carbondale.

Evans, Susan Toby. 2008. Ancient Mexico and Central America: Archaeology and Culture History. 2nd ed. Thames and Hudson, New York.

Galvany Llorente, Julio, ed. 1991. Matrícula de tributos: Nuevos estudios. Secretaría de Hacienda y Crédito Público, Mexico City.

González Reyna, Jenaro. 1956. "Riqueza minera y yacimientos minerales de México." Congreso Geológico International, XX Sesión, Banco de México, Departamento de Investigaciones Industriales, Mexico City.

Grinberg, Dora M. K. de. 1996. “Técnicas minero-metalúrgicas en Mesoamérica.” In Mesoamérica y los Andes, edited by Mayán Cervantes, 427-471. Centro de Investigaciones y Estudios Superiores de Antropología Social, Mexico City.

Harbottle, Garman, and Phil C. Weigand. 1992. "Türkishandel in Altamerika." Spektrum der Wissenschaft 4:96-102.

Helms, Mary W. 1993. Craft and the Kingly Ideal: Art, Trade, and Power. University of Texas Press, Austin.

Henderson, Julian. 2000. The Science and Archaeology of Materials: An Investigation of Inorganic Materials. Routledge, London.

Hendrichs, Pedro R. 1940. "Datos sobre la técnica minera prehispánica." México Antiguo $5: 148-160$ and $179-194$.

Hirth, Kenneth. 1998. “The Distributional Approach: A New Way to Identify Marketplace Exchange in the Archaeological Record." Current Anthropology $39(4): 45 I-476$. 
Hirth, Kenneth G., and Joanne Pillsbury. 2013. "Merchants, Markets, and Exchange in the Pre-Columbian World." In Merchants, Markets, and Exchange in the Pre-Columbian World, edited by Kenneth G. Hirth and Joanne Pillsbury, I-22. Dumbarton Oaks, Washington, DC.

Hosler, Dorothy. 1994. The Sounds and Colors of Power. MIT Press, Cambridge.

Hosler, Dorothy. 1998. "Artefactos de cobre en el periodo posclásico tardío mesoamericano: Yacimientos minerales, Regiones productivas y uso." In El Occidente de México: Arqueología, historia y medio ambiente, Actas del IV Coloquio Internacional de Occidente Ig96, edited by Ricardo Ávila, Jean P. Emphoux, Luis G. Gastélum, Susana Ramírez, Otto Schöndube, and Francisco Valdez, 319-330. Universidad de Guadalajara, Guadalajara.

Hosler, Dorothy. 2003. "Metal Production." In The Postclassic Mesoamerican World, edited by Michael E. Smith and Francis F. Berdan, 159-171. University of Utah Press, Salt Lake City.

Hosler, Dorothy. 2004. "Nuevos datos sobre la producción de metal en el Occidente de la época prehispánica." In Bienes estratégicos del Antiguo Occidente de México, edited by Eduardo Williams, 335-355. El Colegio de Michoacán, Zamora.

Hosler, Dorothy, and Andrew Macfarlane. 1996. "Copper Sources, Metal Production, and Metals Trade in Late Postclassic Mesoamerica." Science 273 (5283):1819-1824.

Ingold, Tim. 1993. “The Temporality of the Landscape.” World Archaeology 25(2):152-174.

Kepecs, Susan. 2003. "Salt Sources and Production." In The Postclassic Mesoamerican World, edited by Michael E. Smith and Francis F. Berdan, I26-130. University of Utah Press, Salt Lake City.

Langenscheidt, Adolphus. 1970. “Las Minas y la Minería Prehispánica.” In Minería prehispánica en la Sierra de Queretaro, 45-47, Secretaría del Patrimonio Nacional, Mexico City.

Langenscheidt, Adolphus. 1985. "Bosquejo de la minería prehispánica de México." Quipu 2(I):37-58.

Langenscheidt, Adolphus. 1997. "La minería en el área mesoamericana." Arqueología Mexicana 5(27):6-9.

Lechtman, Heather N. 1980. "The Central Andes: Metallurgy without Iron.” In The Coming of the Age of Iron, edited by Theodore A. Wertime and James D. Muhly, 267-334. Yale University Press, New Haven.

León-Portilla, Miguel. 1978. "Minería y metalurgia en el México antiguo." In La minería en México: Estudios sobre su desarrollo histórico, edited by Miguel León-Portilla, Jorge Gurría Lacroix, Roberto Moreno, and Enrique Madero Bracho, 7-36. Universidad Nacional Autónoma de México, Mexico City. 
León-Portilla, Miguel. 1980. Toltecayotl: Aspectos de la cultura náhuatl. Fondo de Cultura Económica, Mexico City.

León-Portilla, Miguel. 1992. Ritos, Sacerdotes, y Atavios de los Dioses: Fuentes Indígenas de la Cultura Náhuatl, Textos de los Informantes de Sahagún I. Universidad Nacional Autónoma de México, Mexico City.

Leroi-Gourhan, André. 1964. Le geste et la parole I: Technique et langage. Albin Michel, Paris.

Lleras, Roberto. 2005. "Metales preciosos: Oro y plata de nuestros ancestros." In Joyas de los Andes: Metales para los hombres, metales para los dioses, edited by Gema Swinburn Puelma, II-53. Museo de Arte Precolombino, Santiago de Chile.

López Luján, Leonardo. 1994. The Offerings of the Templo Mayor of Tenochtitlan. University Press of Colorado, Boulder.

Lothrop, Samuel Kirkland. 1952. Metals from the Cenote of Sacrifice in Chichén Itza, Yucatán. Memoirs of the Peabody Museum of Archaeology and Ethnology, Harvard University, vol. ı, no. 2. Peabody Museum, Cambridge.

Matrícula de Tributos. 1980 [1520-1530]. Facsimile edition with commentaries by Frances F. Berdan and Jacqueline de Durand-Forest. Akademische Druck- u. Verlagsanstalt, Graz, Austria.

Meighan, Clement W. 1969. "Cultural Similarities between Western Mexico and Andean Regions." In Precolumbian Contact within Nuclear America, edited by J. Charles Kelley and Carroll L. Riley, II-25. Mesoamerican Studies, vol. 4. Southern Illinois University Press, Carbondale.

Miller, Mary Ellen, and Karl A. Taube. 1993. The Gods and Symbols of Ancient Mexico and the Maya: An Illustrated Dictionary of Mesoamerican Religion. Thames and Hudson, New York.

Mountjoy, Joseph B. 1969. "On the Origin of West Mexican Metallurgy." In Precolumbian Contact within Nuclear America, edited by J. Charles Kelley and Carroll L. Riley, 26-42. Mesoamerican Studies, vol. 4. Southern Illinois University Press, Carbondale.

Northover, J. Peter. 1989. “Non-Ferrous Metallurgy in British Archaeology." In Scientific Analysis in Archaeology and Its Interpretation, edited by Julian Henderson, 213-236. Oxford University Press, Oxford.

Ohnersorgen, Michael A. 2006. "Aztec Provincial Administration at Cuetlaxtlan, Veracruz." Journal of Anthropological Archaeology 25(I):I-32.

Olmedo, Bertina, and Carlos J. González. 1986. Presencia del estilo mezcala en el Templo Mayor: Una clasificación de piezas antropomorfas. Unpublished BA thesis, Escuela Nacional de Antropología e Historia, Mexico City.

Palmer, J. W., M. G. Hollander, P. S. Z. Rogers, T. M. Benjamin, C. J. Duffy, J. B. Lambert, and J. A. Brown. 1998. "Pre-Columbian Metallurgy: Technology, Manufacture, and 
Microprobe Analysis of Copper Bells from the Greater Southwest." Archaeometry $40(2): 36 I-382$.

Patiño, Víctor M. 1992. Historia de la cultura material en la América equinoccial, Vol. 5: Tecnología. Biblioteca Ezequiel Uricoechea, Instituto Caro y Cuervo, Santafé de Bogotá.

Patterson, Clair C. 1971. "Native Copper, Silver, and Gold Accessible to Early Metallurgists." American Antiquity 36(3):286-321.

Pendergast, David M. 1962. "Metal Artifacts in Prehispanic Mesoamerica." American Antiquity $27(4): 520-545$.

Plazas, Clemencia, and Ana María Falchetti. 1978. "El Dorado: Colombian Gold." Catálogo de exposición. Australian Art Exhibitions Corporation Limited.

PNE. 1905-1906. Papeles de Nueva España, edited by Francisco del Paso y Troncoso, 2. Serie, Geografía y Estadística. 7 vols. Tipográfico Sucesores de Rivandeneyra, Madrid.

Pohl, John M. D. 2003. "Ritual Ideology and Commerce in the Southern Mexican Highlands." In The Postclassic Mesoamerican World, edited by Michael E. Smith and Francis F. Berdan, 172-177. University of Utah Press, Salt Lake City.

Root, William C. 1949. "Metallurgy." In Handbook of South American Indians, Vol. 5: The Comparative Ethnology of South American Indians, edited by Julian H. Steward, 205-225. Bureau of American Ethnology, Bulletin I43. Smithsonian Institution, Washington, DC.

Sahagún, Fray Bernardino de. 1969-1982. Florentine Codex: General History of the Things of New Spain, I590. I2 books. Translated and edited by Arthur J. O. Anderson and Charles E. Dibble. School of American Research and the University of Utah Press, Santa Fe and Salt Lake City.

Sahagún, Fray Bernardino de. [1590] 1989. Historia general de las cosas de Nueva España. 2 vols. Edited, glossary, paleography, and notes by Alfredo López Austin and Jorge García Quintana. Consejo Nacional para la Cultura y las Artes, Mexico City.

Schiffer, Michael B. 1972. "Archaeological Context and Systemic Context." American Antiquity 37(2):156-165.

Schiffer, Michael B. 2004. "Studying Technological Change: A Behavioral Perspective." World Archaeology 36(4):579-585.

Schulze, Niklas. 1997. Die Materialien der ofrenda 20 des Templo Mayor in Tenochtitlan: Der ökonomische Aspekt. Unpublished MA thesis, Universität Hamburg, Hamburg. Schulze, Niklas. 2008a. El proceso de producción metalúrgica en su contexto cultural: Los cascabeles de cobre del Templo Mayor de Tenochtitlan. Unpublished doctoral thesis. Universidad Nacional Autónoma de México, Mexico City.

Schulze, Niklas. 2008b. “'For Whom the Bell Tolls': Mexican Copper Bells from the Templo Mayor Offerings: Analysis of the Production Process and Its Cultural Context." In Materials Issues in Art and Archaeology VIII, Material Research Society Symposium 
Proceedings, Vol. I047, edited by Pamela B. Vandiver, Blythe McCarthy, Robert H. Tykot, Jose Luis Ruvalcaba, and Francesca Casadio, I047-Y02-02. Materials Research Society Proceedings, Warrendale, PA.

Schulze, Niklas. 20roa. "El proceso de producción metalúrgica en su contexto cultural y socio-económico: Los cascabeles de cobre del Templo Mayor de Tenochtitlan.” In Memoria, Ier Seminario Taller Internacional sobre Patrimonio Geológico, Minero y Metalúrgico, edited by Ximena Díaz, II4-II9. Ministerio de Recursos Naturales No Renovables y el INIGEMM, Loja, Ecuador.

Schulze, Niklas. 20ı b. “¿Cobre para los dioses y oro para los españoles? Las propiedades sociales y simbólicas de un metal sin importancia." In Producción de bienes de prestigio ornamentales y votivos de la América antigua, edited by Emiliano Melgar, Reyna Solís, and E. González, 71-83. Syllaba Press, Bogotá.

Schulze, Niklas. 2013. “¿How 'Real’ Does It Get? Portable XRF Analysis of ThinWalled Copper Bells from the Aztec Templo Mayor, Tenochtitlán, Mexico." In Archaeometallurgy in Mesoamerica: Current Approaches and New Perspectives, edited by Aaron N. Shugar and Scott E. Simmons, 203-226. University Press of Colorado, Boulder.

Schulze, Niklas, and José L. Ruvalcaba. 2008. "Portable XRF Analysis of Corroded Copper Bells from the Templo Mayor (Mexico): Metal Composition, Technological Choices and Cultural Influences." In La ciencia de materiales y su impacto en la arqueología, Vol. I, Academia Mexicana de Ciencia de Materiales, A.C., edited by Jesús Arenas, Demetrio Mendoza, José Luis Ruvalcaba, and Verónica Pérez Rodríguez, Io I-ıı. Ediciones Lagares, Mexico City.

Schulze, Niklas, and José L. Ruvalcaba. In press. "Metales de Tamtoc." In Tamtoc: Esbozo de una antigua sociedad urbana, Vol. 2, edited by Estella Martínez Mora and Guillermo Córdova Tello. Instituto Nacional de Antropología e Historia, Mexico City.

Simmons, Scott E., and Aaron Shugar. 2013. "Archaeometallurgy in Ancient Mesoamerica." In Archaeometallurgy in Mesoamerica: Current Approaches and New Perspectives, edited by Scott E. Simmons and Aaron N. Shugar, I-28. University Press of Colorado, Boulder.

Smith, Michael E. 2003a. "Key Commodities." In The Postclassic Mesoamerican World, edited by Michael E. Smith and Francis F. Berdan, I17-I25. University of Utah Press, Salt Lake City.

Smith, Michael E. 2003b. "Economic Change in Morelos Households." In The Postclassic Mesoamerican World, edited by Michael E. Smith and Francis F. Berdan, 249-258. University of Utah Press, Salt Lake City.

Smith, Michael E., and Frances F. Berdan. 2003. "Postclassic Mesoamerica." In The Postclassic Mesoamerican World, edited by Michael E. Smith and Francis F. Berdan, 3-13. University of Utah Press, Salt Lake City. 
Snarskis, Michael J. 2003. "From Jade to Gold in Costa Rica: How, Why, and When." In Gold and Power in Ancient Costa Rica, Panama, and Colombia, Symposium at Dumbarton Oaks, g and Io October I9g9, edited by Jeffrey Quilter and John W. Hoopes, 159-204. Dumbarton Oaks, Washington, DC.

Spence, Michael W. 1981. “On Aztec Specialization and Exchange." Current Anthropology 22(2):I83-I84.

Torquemada, Fray Juan de. 1975. Monarquía indiana, edited and introduction of studies by Miguel León-Portilla. Universidad Nacional Autónoma de México, Instituto de Investigaciones Históricas, Mexico City.

Torres Montes, Luis, and Francisca Franco Velázquez. 1996. "La metalurgia tarasca: Producción y uso de los metales en Mesoamérica.” In Temas mesoamericanas, edited by Sonia Lombardo and Enrique Nalda, 7I-IIo. Instituto Nacional de Antropología e Historia, Mexico City.

Velázquez Castro, Adrián, and Emiliano Ricardo Melgar Tísoc. 2014. "Producciones palaciegas tenochcas en objetos de concha y lapidaria." Ancient Mesoamerica 25(I):295-308.

Vivanco Bonilla, Maria Elena. 1992. El ámbar en Mesoamérica. Unpublished BA thesis, Escuela Nacional de Antropología e Historia, Mexico City.

West, Robert C. 1994. "Aboriginal Metallurgy and Metalworking in Spanish America." In Quest of Mineral Wealth: Aboriginal and Colonial Mining and Metallurgy in Spanish America, edited by Alan K. Craig and Robert C. West, 5-20. Louisiana State University, Baton Rouge. 


\section{Chapter 12}

\section{Competitive versus Peaceful Interaction}

JOYCE MARCUS

Interaction comes in many forms: long-distance versus local, peaceful versus hostile, direct versus indirect, long-term versus short-term, multidirectional versus unidirectional, and transformative versus nontransformative. Long-distance exchange and unidirectional interaction have so far attracted most of our attention. Some archaeologists regard long-distance exchange as the key ingredient in their models of state formation (e.g., Kidder et al. 1946; Rathje 1971, 1972; Sanders 1974, 1977). Others think that the impact of long-distance exchange has been overstated, usually at the expense of local exchange (Braswell 2003; Demarest and Foias 1993; Drennan 1984a, 1984b, 1985; Foias 1987; Iglesias Ponce de León 2003; Johnson 1973, 1975; Marcus 1983, 2003; Pendergast 2003; Sharer 2003). And as we shall see in this chapter, competitive interaction on a local level can be more transformative than peaceful long-distance interaction.

\section{LOCAL EXCHANGE}

The Yucatán Peninsula (figure I2.I) provides abundant evidence for the importance of local exchange. When the Spaniards arrived in the Yucatán, they encountered more than sixteen autonomous polities (cuchcabaloob) actively moving a wide array of local products by barter and tribute. Exchange occurred within and between polities (Roys 1957, 1965, 1972). Perishable items included cotton cloth, henequen fiber, salt, fish, cuttlefish, cuttlefish eggs, turtles, turtle eggs, crabs, honey, beeswax, 


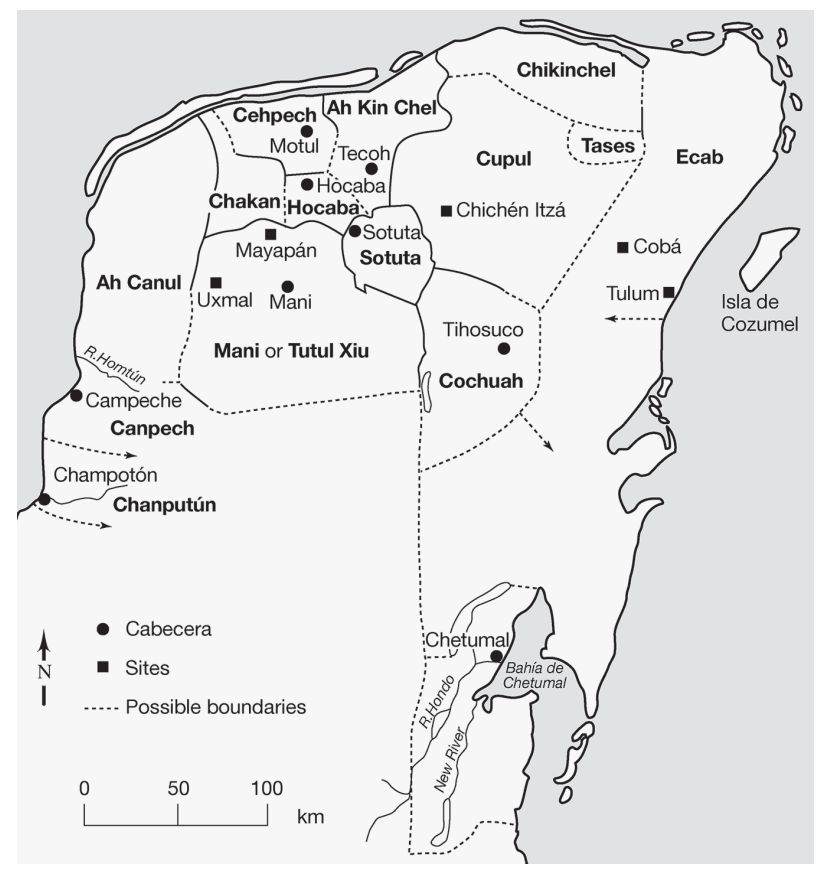

Fig URE 12.1. The Yucatán Peninsula, divided into sixteen autonomous provinces, at AD 1550-1580 (drawing by Kay Clahassey).

maize, beans, squash, cacao, chiles, copal, mats, and wood (Andrews 1984; Andrews and Mock 2002; Relaciones de Yucatán 1898, 1900; Roys 1972; Tozzer 194I). Nonperishable items such as flint and pottery were also exchanged.

From 1549 to $156 \mathrm{I}$ the principal tribute item was the cotton manta, which consisted of Io $\mathrm{yd}^{2}$ of cloth divided into four piernas, or "breadths" (Roys et al. 1959:206). Every man was required to pay one manta a year. In 156I, tribute demands were adjusted so that every four months each married couple was expected to deliver one pierna of cloth, I lb. of beeswax, one turkey hen, and half a fanega of maize. (I fanega $=1.6$ bus.; Roys [1972:196] gives I fanega $=\mathrm{I} .6$ or 2 bus. in Spain and 2.56 bus. in Mexico. Cooper Clark [1938:1:64] and Roys [1957:170] indicate that I fanega $=1.6$ bus.)

The volume of perishable items moving within and between polities was impressive in the sixteenth century and probably equally impressive in the prehispanic era, even though it is impossible to specify the amount of each perishable item (Drennan 1984a:28). Cloth and food were particularly important in prehispanic exchanges, as shown by scenes painted on Maya vessels of local lords receiving cloth 
bundles and food such as tamales and cacao beverages (Marcus 2000:fig. 7; ReentsBudet 1994:26, 76, 120, 131, 258, 262).

Trade between polities on the Yucatán Peninsula, however, could be interrupted by war (Roys 1972:53). Sixteenth-century documents reveal that such wars were usually motivated by a desire to acquire slaves and gain access to scarce or highly valued goods such as salt, shells, or cacao. When high-status individuals were captured, they were sacrificed. In contrast, commoners were spared and became the slaves of their captors (Relaciones de Yucatán 1898, 1900:11:149).

Given that coastal polities had a near monopoly over the salt beds, people from interior provinces often tried to gather salt on their own. Roys (1972:47) says that these interior peoples often had to be driven away from the salt beds. Some provinces, in fact, refused to exchange salt and fish: "The Chels would not sell salt and fish to the people of Sotuta, and in retaliation the latter refused to sell fruit and game to Ah Kin Chel" (Roys 1972:53).

Such interpolity refusal to maintain the flow of goods could lead to conflict unless a centralized government emerged. While Mayapán (ca. AD I200-1450) was the capital of the peninsula, much of this interpolity conflict was suppressed and the lords from each polity were required to reside in the capital (Chi 1941:230-231; López de Cogolludo [1688] 1867-I868; Means 1917; Pollock et al. 1962; Roys 1962; Tozzer 194I).

What, then, were the respective roles of local exchange and long-distance exchange? Was the state more affected by local exchange, as Johnson (1973, 1975) argued for southwestern Iran, or by long-distance exchange, as Rathje (1971) and Sanders (1974) argued for the Maya?

\section{OVERRELIANCE ON UNIDIRECTIONAL MODELS}

Historically, we have given greater weight to long-distance exchange than to local exchange. Two prominent examples involve Teotihuacan and its presumed unidirectional impact on two Maya cities: Kaminaljuyú and Tikal. Those who argue (based on hieroglyphic texts) that Teotihuacan took over Tikal's government (see, e.g., Stuart 2000) are forced to ignore an archaeological record showing very few items at Tikal that were actually of central Mexican origin (Borowicz 2003; Iglesias Ponce de León 2003; Laporte 1989, 2003). As one anonymous reviewer noted, "the crucial point that hieroglyphic inscriptions are not always reliable records of "what happened' appears too rarely in discussions about the Classic Maya, especially regarding Teotihuacan and Tikal."

For the very century during which a "new Teotihuacan world order" was allegedly imposed on the Tikal region (AD 378-478), María Josefa Iglesias Ponce de León 
(2003:180) has shown that Tikal's burials and ritual deposits reveal no evidence of Teotihuacan impact, neither ceramic nor architectural. In one Tikal deposit (PNT2I) she found only four sherds out of 167,338 that could have been imported from central Mexico (and all four were Thin Orange, manufactured in Puebla).

In a similar vein, only 16 of the 340 vessels from the elite burials in Mounds A and B of Kaminaljuyú were imported from central Mexico and they, too, were of Thin Orange. In fact, at this time sites all over Mesoamerica (including Teotihuacan itself) were importing Thin Orange from Puebla (Rattray 1990a, 1990b; Rattray and Harbottle 1992). Thin Orange ware and Pachuca obsidian reached Guatemala's Pacific piedmont, but the excavators there say: "We concluded that the Teotihuacan presence, at least in the Balberta zone, was minimal. As a result, we became increasingly skeptical of claims of military conquest or colonization on the Pacific Coast" (Bove and Medrano Busto 2003:53).

Today we know that the iconic tombs in Mounds A and B at Kaminaljuyú-once thought to contain Teotihuacanos-actually contain more items from the Gulf Coast, northern Guatemala, and Chiapas than from Teotihuacan (Braswell 2003; Demarest and Foias 1993). In addition, isotopic data from the skeletons of the principal seated occupants of each tomb have proven that they were not Teotihuacanos (White et al. 2000). The exotic tomb offerings might have reached Kaminaljuyú either through an extensive network of multiple trading partners, or via mourners from diverse regions who left behind vessels after attending the funerals (Marcus 2003).

Foreign offerings at Altun $\mathrm{Ha}$ and Becan provide additional examples of interaction that is no longer thought to explain the rise and development of Maya civilization (Pendergast 2003:236). Inside Tomb F-8/ I at Altun Ha, there were no central Mexican items. To be sure, left above the roof of that tomb were more than 248 pieces of Pachuca obsidian; the daggers and prismatic blades (some of which were reworked into human figures) date to AD I50-250.

Along with the Pachuca obsidian above the roof there were twenty-three nonlocal pottery vessels, some of which do suggest highland Mexican styles. Pendergast (2003:246), however, asked himself two questions: "What lasting impact did the Teotihuacan-Altun Ha link have at the site, and what conclusions can we draw from the material regarding the importance of Teotihuacan in early southern Maya lowlands development?" His answer to both questions was "none."

My own view is that these imports may either have been brought to Altun $\mathrm{Ha}$ as gifts from those attending the funeral, or obtained through middlemen and stored until needed to celebrate the interment of a ruler. The Altun Ha Maya maintained their cultural substrate and local traditions while exchanging items with other societies throughout the Maya region and well beyond. The Maya imported, borrowed, 
copied, adapted, and manipulated nonlocal items to meet their needs (Schele and Freidel 1990), but such items explain little about the rise of Maya kingship and state institutions.

All exchanges are worth documenting. It continues to be a challenge, however, to assess the importance of local, regional, and interregional exchanges of ideas, objects, and styles. It is not foreign political systems that are borrowed, only selected sumptuary goods and exotic products. The most we can say is that such exchange can be considered a form of social relations.

\section{COMPETITIVE INTERACTION CAN BE TRANSFORMATIVE}

We now have a number of cases in which hostile interaction was more politically transformative than friendly long-distance trade. In both the Valley of Oaxaca and the El Mirador region, intense political and military competition seems to have been one of the engines that drove state formation to completion. We will now look at two case studies that show how competitive interaction can transform society.

\section{A Case Study from the Valley of Oaxaca}

Between 1800 and $1300 \mathrm{BC}$, egalitarian village societies emerged throughout central and southern Mexico. From I500 to I200 B C the villages of highland Oaxaca tended to be small (usually $\mathrm{I}-3$ ha in size), with only a few villages reaching to ha. Houses were rectangular, built of wattle and daub, and sometimes whitewashed with lime. No true temples were known at this time, but at the large village of San José Mogote there were small public buildings that served as men's houses (Marcus and Flannery 1996). These men's houses were plastered with lime and oriented 8 degrees north of east, perhaps to face the rising sun at the equinox. No convincing evidence of social inequality exists at this early time, but Oaxaca as well as much of Mesoamerica would soon reveal disparities in political hierarchy and village size.

By 1 го BC these egalitarian societies were changing. Two of the larger villages were San José Mogote in the Valley of Oaxaca (Flannery and Marcus 2003, 2005, 2015; Marcus and Flannery 1996) and Santa Cruz Tayata in the Valley of Huamelulpan (Kowalewski et al. 2009:174-177, 287-289). Both San José Mogote and Santa Cruz Tayata became chiefly centers for multivillage societies with hereditary inequality. In the Basin of Mexico, Tlapacoya and Tlatilco also became large chiefly centers. In contrast to the Valley of Oaxaca and the Basin of Mexico, the Tehuacán Valley had only small villages.

At 1000 B C San José Mogote was divided into wards or barrios. Each ward had its own men's house that served as a meeting place for the barrio's initiated men. In 


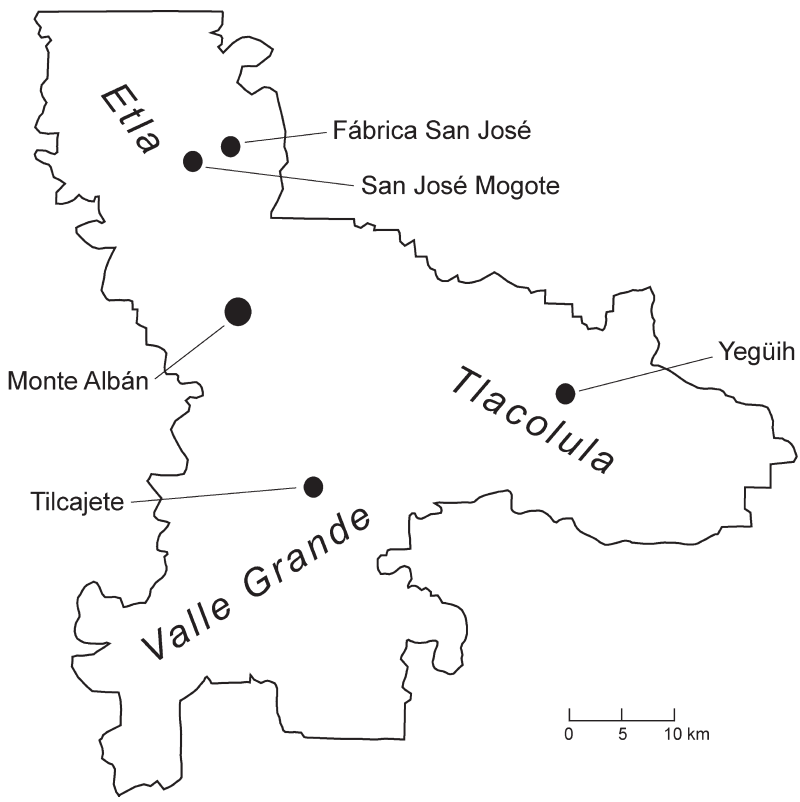

FIG URE 12.2. The Valley of Oaxaca, showing three competing centers-San José Mogote, Yegüih, and Tilcajete-one in each subvalley (drawing by Kay Clahassey).

addition to barrio-level ritual buildings, San José Mogote began to build larger public buildings to serve the whole community. The platforms for these larger buildings were built of circular plano-convex adobes, for which broken jars served as molds (Flannery and Marcus 2005, 2015). Set in the walls of one stone platform were carved stones representing a feline and a raptorial bird. Some stones used to build these platforms were brought from $5 \mathrm{~km}$ away, even though tons of volcanic tuff were readily available right at San José Mogote. Heavy blocks of limestone were brought from Rancho Matadamas, $5 \mathrm{~km}$ to the west. From the east came travertine, also $5 \mathrm{~km}$ away (Marcus and Flannery 1996:125).

The construction of large public buildings utilizing limestone and travertine suggests that San José Mogote was now the head of a chiefly society, whose chief had the power to require satellite villages to contribute stone for public constructions at his chiefly center (figure I2.2). Requiring building material from subordinate villages was a form of corvée labor or service to a higher-order site. In addition to commanding the delivery of stones from satellite villages, the chief might send high-status women from his paramount center to marry men at those satellites. 
Evidence for this marriage strategy occurs at the satellite village of Fábrica San José, where the most elite burials were those of women whose cranial deformation (Burial 25) and sumptuary goods (Burial 39) suggested that they were hypogamous brides from the chiefly center of San José Mogote (Drennan 1976; Marcus and Flannery 1996:113). The woman in Burial 39, for example, was associated with four vessels, one of which was a Delia White cylinder she was grasping in both hands; she had more than fifty beads in her mouth (Drennan 1976:248). Burial 54 was associated with seven vessels, a shell, and a clay hollow doll near her right shoulder.

The elite at higher-order centers wanted to display prestige goods, so they had their craftsmen polish greenstone (serpentinite or jadeite), magnetite, and hematite; cut mica plates of various shapes; and convert marine shells from the Pacific Ocean and freshwater mussels from the Gulf of Mexico into necklaces and ear ornaments. San José Mogote and many other highland societies developed a keen interest in importing products that could be imbued with ritual and prestige value.

Exchange-much of it between elites-characterized the period from 1200 to 900 BC. Elite trade items of this period include mirrors made of magnetite and ilmeno-magnetite. Artisans at San José Mogote obtained these ores from sources six to $33 \mathrm{~km}$ away—near Tenango, San Jerónimo Tititlán, Arrazola, and Cacaotepec. Two mirrors from the Cacaotepec source were traded to San Lorenzo in Veracruz. A mirror from the Tititlán source was traded to Etlatongo in the Mixteca. An unworked lump from the Tenango source was traded to La Juana-San Pablo in Morelos.

The emergence of hereditary rank was a crucial turning point in social evolution. Egalitarian societies (in which prestige was based on achievement) were replaced by societies with hereditary rank (in which status and privileges were inherited). One line of archaeological evidence for hereditary rank is the production of ornaments whose use was manipulated by the elite. Unfortunately for archaeologists, egalitarian societies can also accumulate exotic goods through bride-price. Given that fact, archaeologists interested in showing that rank was inherited have had to pay special attention to items buried with infants or children. Since those children were too young to have achieved the right to possess such things, they probably inherited their rank.

Archaeologists working in Oaxaca have assembled ten lines of evidence to infer the emergence of rank (Marcus and Flannery 1996:93-110), and among those are deliberate cranial deformation of elite children, differential access to jade ornaments and iron-ore mirrors, differential access to venison, use of mother-of-pearl and Spondylus shell ornaments, a dichotomy between seated (elite) burials and prone (lower-status) burials, clay figurines depicting individuals in contrasting positions of authority and obeisance, and four-legged stools resembling those carried by chiefly attendants in rank societies. 
From 850 to 500 B C political changes were occurring in both the highlands and lowlands. In the Valley of Oaxaca, rival centers rose to challenge the authority of San José Mogote. Evidence for competitive interaction can be documented in a variety of ways - in the burning of houses and temples, in the construction of defensive palisades, in the taking of human crania as trophies, and in the presence of skeletons showing healed fractures from multiple violent encounters (Flannery and Marcus 2003, 2012). This kind of competitive interaction was the social engine that led to the loss of community autonomy and the emergence of administrative hierarchies (Flannery and Marcus 2012; Marcus 2006, 2012; Redmond and Spencer 2012; Spencer and Redmond 2003, 2006).

The Zapotec state emerged in the context of fierce intravalley competition. From 700 to 500 BC one polity of 2,000 people occupied the Etla subvalley, with its chiefly center at San José Mogote. Another polity of I,000 persons occupied the Tlacolula subvalley, with its chiefly center at Yegüih. A third polity of I,00o persons lay in the Valle Grande, with its chiefly center at San Martín Tilcajete. For centuries these three societies competed with each other for followers, land, and resources (see figure 12.2). San José Mogote was attacked and its major temple deliberately burned; it built a new temple and carved a monument depicting the sacrificed corpse of an elite enemy (figure 12.3; Marcus and Flannery 1996:129).

By 500 B C the leaders of San José Mogote realized that their valley-floor location was indefensible. With 2,000 of their followers, they moved to a defensible location-the summit of a 400-m-high mountain-where they began to build $3 \mathrm{~km}$ of defensive wall. This fortified center became Monte Albán.

The early residents at Monte Albán had the support of the northern and central valleys, the region from which their founders had come. A few hours' walk to the south lay Tilcajete, an unyielding rival. Tilcajete's response to the founding of Monte Albán was to get bigger. Tilcajete's elite laid out a plaza with an astronomical orientation deliberately chosen to contrast with Monte Albán's. At 330 B C Monte Albán attacked Tilcajete, burning some of its major buildings. Tilcajete refused to capitulate; instead, it drew in more supporters and doubled its population. Tilcajete's leaders moved their public buildings to a more defensible ridge, defiantly retaining the same astronomical orientation and erecting defensive walls (Spencer and Redmond 2003, 2006).

Monte Albán readied itself for a long campaign by concentrating thousands of farmers, artisans, and warriors in 155 nearby villages. At 30 B C Monte Albán attacked Tilcajete again, burning the ruler's palace and a nearby temple. Tilcajete did not recover from this attack and was abandoned. On a mountaintop nearby, the victorious rulers of Monte Albán created a new administrative center (Elson 2007).

What resulted from this act of subjugation-as well as many other military victories-was a unified Zapotec state with a $2150 \mathrm{~km}^{2}$ heartland. Monte Albán 


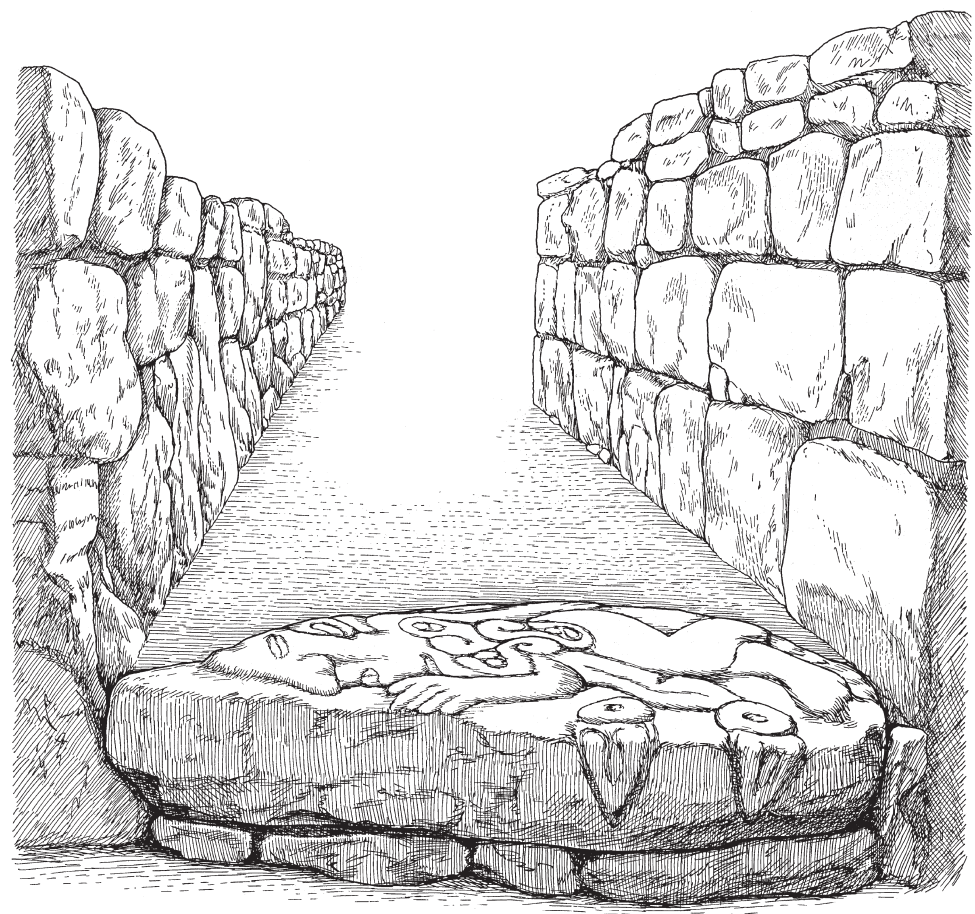

FIG URE I 2.3. The position of San José Mogote's Monument 3, a carved stone that served as the threshold for the corridor, ensured that anyone entering the corridor would have stepped on the body of a sacrificial victim (drawing by John Klausmeyer).

came to be a central place with palaces, royal tombs, standardized two-room temples, and hieroglyphic references to places over which Monte Albán claimed hegemony (Marcus and Flannery 1996:198).

The emergence of a new higher-order capital, occupying the top of the political hierarchy, was the outcome of five centuries of intense political competition. The Valley of Oaxaca did not develop a state as the result of trade with some distant area it longed to emulate. Competition drove a number of rival polities to grow, defend themselves, consolidate power, and attempt to subdue each other, until one of their number emerged victorious. The victors' leaders then controlled so large an area that it required new political institutions to administer.

The Oaxaca case shows how competition with one's neighbors can lead to the emergence of additional hierarchical levels, and new institutions such as monarchy. Unable to reach the boundaries of their new polity in a day's travel, they divided it 


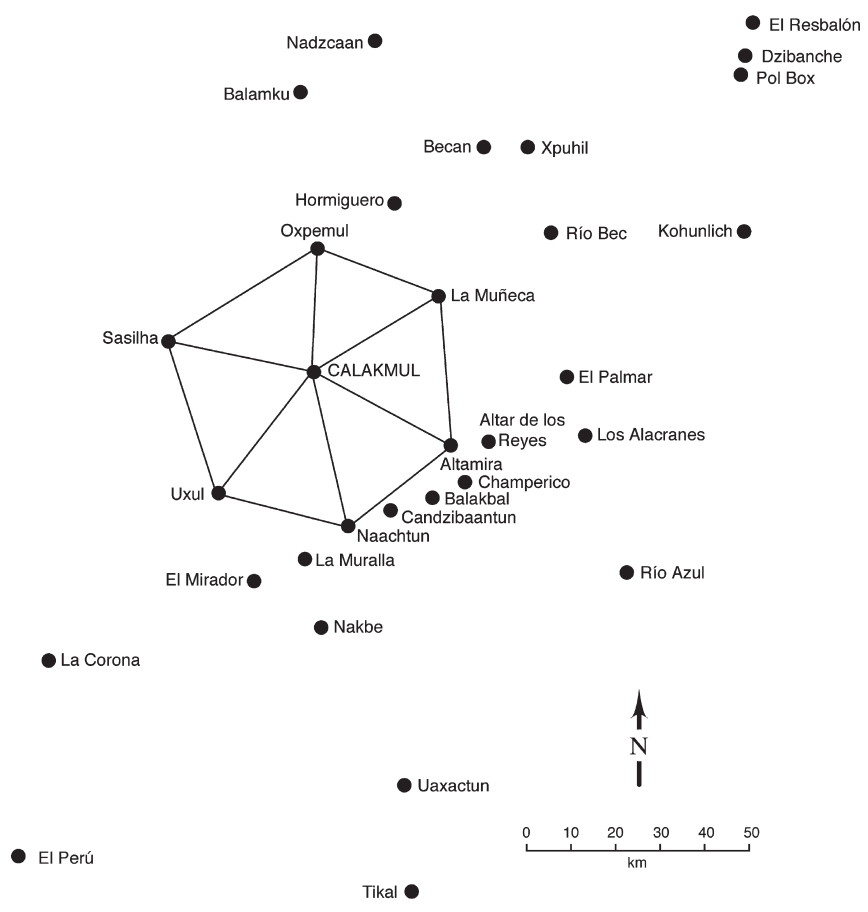

FIGURE I2.4. Calakmul's core area (its hexagonal lattice of subjects) and its many neighbors and subordinate sites (drawing by Kay Clahassey).

into provinces ruled by secondary centers. These secondary centers lay equidistant from Monte Albán (Marcus and Flannery 1996:175).

\section{A Maya Case Study}

Another region that affords us the opportunity to study competitive interaction and the rise of complexity straddles the border separating northern Guatemala from Mexico. That region witnessed a series of oscillations in which four rival centers (Nakbe, El Mirador, Dzibanche, and Calakmul) competed for positions in the political and administrative hierarchy (figure 12.4). The result could be vertical moves in the site hierarchy (from village to town to capital city) or horizontal moves (from an ally of Site A to an ally of Site B).

Our Maya evidence suggests that local competition was a catalyst for the emergence of complexity. Without multiple leaders vying for control, certain political 
strategies might never have emerged. Perhaps the most intriguing unanswered question is how the El Mirador region managed to achieve such a head start on monumentality and political complexity, compared to other lowland Maya regions. Was that head start related to the unusual density of sites, the proximity of rival cities, or the ability of competing actors to find new ways to attract more followers?

We have learned how to use Maya hieroglyphic texts to identify primary, secondary, and tertiary centers in a political hierarchy, but we certainly need follow-up excavation to confirm that lower-order centers were required to deliver goods and labor to higher-order centers (Flannery and Marcus 2012; Marcus 1973, 1992, 1993). Hieroglyphic texts alone do not provide evidence that a particular higher-order center was calling up men from its subordinate sites to defend it when attacked, nor do they provide the date when the first royal palace appeared at each center.

Some of the key Maya sites in northern Guatemala and southern Yucatán were Balakbal, Calakmul, Naachtun, El Mirador, La Corona, La Muralla, Nakbe, Oxpemul, Uxul, Los Alacranes, Altar de los Reyes, and Altamira. Among the largest were Nakbe, El Mirador, and Calakmul, and their importance is evident both in the extent of each site and the monumentality of its individual structures. Nakbe was a day's walk from El Mirador. El Mirador was a day's walk from Calakmul. The clustering of three huge sites-Nakbe, El Mirador, and Calakmul-created a competitive situation, because each site wanted to attract more followers than the others.

While there were many sites of this period in Belize, they tended to lack the enormous pyramids known from northern Guatemala. The monumental sites of the Mirador region can be seen as the centers of flamboyant chiefdoms, both because they invested so much labor in creating monumental structures and because they had administrative hierarchies of at least three levels. We suspect that each paramount chief lived at the largest and best-defended site. The second-level sites were medium-sized communities, each probably led by a subchief who might be a relative of the paramount. At the third level were villages whose leaders were probably under the command of subchiefs at second-tier sites.

Given the current state of our knowledge, we can suggest that two-level chiefdoms characterized parts of Belize while three-level chiefdoms characterized the El Mirador region. By the Late Preclassic, the chiefly centers were building triadic temples, intrasite roads linking plaza groups, and intersite roads that linked firsttier centers to each other and to their respective second-tier centers (Folan et al. I995a, 200I). Each huge site took its turn being the dominant center-first Nakbe (ca. 800-400 BC), then El Mirador (200 BC-AD I50), Dzibanche (AD 400-600), and finally Calakmul (AD 600-700). 
Nakbe's history began rather modestly during the Middle Preclassic. Its earliest buildings ( $1000-800 \mathrm{BC}$ ) had earthen floors with postholes intruding into bedrock (Hansen 1998). Nakbe likely featured an egalitarian society at this time, but by $800 \mathrm{BC}$ the site had grown to cover 50 ha, with three-m-high stone platforms supporting perishable structures. Thick plaster floors appeared by $600 \mathrm{BC}$, and sometime between 600 and 400 B C Nakbe's platforms reached $8 \mathrm{~m}$ in height.

At this time Nakbe's first ballcourt was constructed, and in the site's East Group, some structures reached more than $16 \mathrm{~m}$ in height. Nakbe also built an intrasite causeway that linked its West Group and East Group. It appears that the site's labor force was used both to intensify agriculture and to build pyramids, temples, and roads. Arlen and Diane Chase (1995) have found artificial garden plots at Nakbe, delimited by stone walls and containing soil laboriously transported from nearby marshy areas. We also see water storage facilities constructed at this time, since both the garden plots and the site's growing population would have needed water during the dry season. These investments in large-scale transport of soils, along with the development of monumental architecture, imply new strategies for organizing labor. Not surprisingly, we see many of the symbols of rulership used by later Maya kings - the headband and mat motifs — on Middle and Late Preclassic figurines at Nakbe, suggesting that these symbols of political authority were already present.

By Late Preclassic times an intersite causeway had been built, linking Nakbe's West Group to the site of El Mirador. Nakbe's Stela I, found in the main plaza of the West Group, bears no hieroglyphs but does show two Maya lords facing each other (figure 12.5).

Another innovation at Nakbe was an architectural complex called an "E Group." This complex takes its name from a similar set of buildings found in Group E at Uaxactún (Chase and Chase 1995; Ricketson and Ricketson 1937). An E Group is made up of a large pyramid constructed on the west side of a plaza so as to face a long platform on the east side that supports three structures. Blom (1924) suggested that these E Groups had astronomical significance, and that interpretation continues to find support (Chase and Chase 1995). To an observer standing on the west pyramid, the sun rises directly behind the middle temple of the three on the east side during an equinox, behind the north temple on the east side during the summer solstice, and behind the south temple on the east side during the winter solstice. Preclassic E Group plazas are currently known from Nakbe, El Mirador, Uaxactún, Wakna, Tikal, and a number of other sites (Sharer and Traxler 2006). 
FIGURE 12.5. Stela I of Nakbe, which shows two lords facing each other, once reached $3.4 \mathrm{~m}$ in height (redrawn by Kay Clahassey from Sharer and Traxler 2006:fig. 5.17).

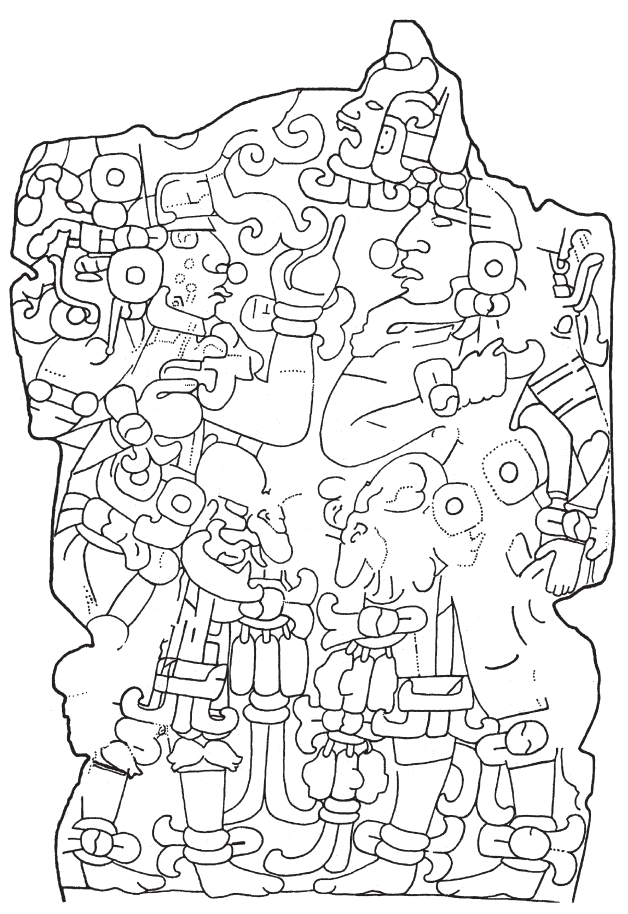

EL MIRADOR

The massive site of El Mirador, which lies northwest of Nakbe, has a series of roads radiating out from it (Folan et al. 1995a). One, as mentioned, leads from Nakbe to El Mirador. Another road leads north from El Mirador to Calakmul. Our current evidence suggests that as Nakbe declined in power, El Mirador became the largest and most powerful Late Preclassic site in the region, reducing Nakbe to one of its satellites. El Mirador's monumental architecture demonstrates that its rulers were able to attract more laborers than its rivals did and that it chose to invest its workforce in creating roads, plazas, and temples on a huge scale.

Like Nakbe, the site of El Mirador was laid out on an east-west axis. The West Group at El Mirador-linked by a causeway to the East Group-was built on a natural hill. Sharer and Traxler (2006:252) have suggested that one of the site's monumental buildings at this time was an actual palace. We await details, since this would be the oldest Maya palace known so far.

Was El Mirador the capital of the first Maya state, or simply the final developmental stage before statehood? To answer this question, we need to determine whether 
El Mirador had a three-tiered or four-tiered administrative hierarchy (Wright and Johnson 1975), a genuine palace (Spencer and Redmond 2004), standardized state temples (Marcus and Flannery 1996), and genuine royal tombs such as those of Tikal and Calakmul (Folan et al. 1995b:321-22). Unfortunately, El Mirador is too early to have hieroglyphic texts that provide rulers' names, emblem glyphs, and phrases such as "divine king." Whatever level of complexity El Mirador achieved, it was short lived.

\section{CALAKMUL}

The history of Calakmul began in the Middle Preclassic, when it was still a village. By the Late Preclassic, Calakmul was using its labor force to build enormous buildings, one of which was Structure II. Calakmul's Structure II is similar to El Tigre at El Mirador; both are huge pyramids that feature triadic temples (Folan et al. 1995b:316-317).

At this same time, Calakmul and El Mirador were already linked by a road. Once El Mirador collapsed, Calakmul went on to construct a series of additional roads that linked it to subordinate centers such as Naachtun, Oxpemul, Balakbal, and Uxul (Marcus 1973, 2004b; Robichaux and Pruett 2005; Ruppert and Denison 1943; Šprajc 2008). There appears to be a good fit between the actual location of Calakmul's secondary centers and the predictions of Central Place Theory (Christaller 1933; Haggett 1966, 1972; Lösch 1954), which suggest that the most efficient way to administer subordinate sites is to have them spaced equidistantly from each other. Most efficient of all is when secondary centers are spaced one day's travel from the capital (ca. $30 \mathrm{~km}$ ), which appears to have been the case with Calakmul.

It appears that Calakmul learned something from the collapse of El Mirador, because Calakmul was able to create a first-generation state that not only endured but added more and more satellite communities over time (Marcus and Folan 1994). Calakmul came to control a large part of Campeche, from El Mirador in the southwest to Dzibanche in the northeast, and to administer a realm the hieroglyphic texts call the Kaan (or snake) Polity (figure i2.6).

The first appearance of the Kaan polity name occurs on monuments at three sites (Dzibanche, El Resbalón, and Pol Box) that lie northeast of Calakmul (Carrasco Vargas and Boucher 1987; Esparza Olguín and Pérez Gutiérrez 2009; Nalda 2004; Velásquez García 2004). Those monuments suggest that the rulers of the Kaan Polity were attempting to consolidate the core of their territory by force. One Kaan king-Yuknoom Ch'een I, who reigned from AD 500 to 520-is mentioned on a prisoner stairway at Dzibanche (figure 12.7). Another Kaan king-K'altuun Hix (AD 520-546) - was responsible for taking the prisoners depicted on the steps at El Resbalón (Carrasco Vargas and Boucher 1987). 
FIGURE 12.6. Top: the Snake head, or Kaan, sign; bottom: the Snake Head Polity emblem glyph can be translated as "Divine Lord of the Snake Polity" (drawing by Kay Clahassey).
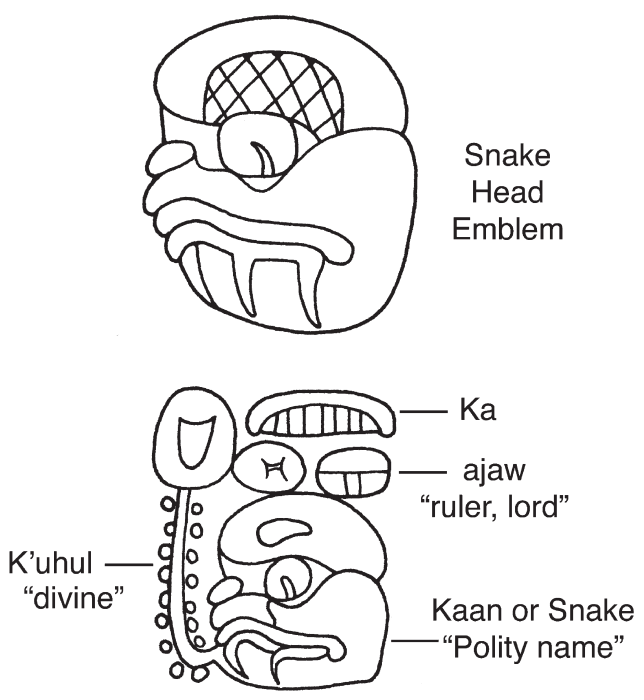

The next Kaan king was victorious in a battle that led both to his control of Caracol and to the sacrifice of a Tikal ruler (Martin 2005b). By defeating the Tikal ruler in AD 562, Calakmul was able to expand its territory and increase the influence of the Kaan dynasty.

Although Calakmul produced the most stone monuments of any Maya site (II7), all but two were commissioned by kings who ruled after AD 500. During the sixth century $\mathrm{AD}$, the rulers of the Kaan polity used military conquest to extend the radius of their state. The court of the Kaan polity moved from Dzibanche to Calakmul by AD 636 (Helmke and Awe 2016; Marcus 2004b, 2012; Martin 2005a; Stuart 2012; Tokovinine 2007). Calakmul's enormous increase in influence on farflung polities had its roots in local conflicts within the Kaan polity (Marcus $2004 \mathrm{~b}$, 2012; Tokovinine 2007).

From AD 600 to 700 Calakmul maintained its ties with far-flung allies while successfully holding on to its neighboring subjects. Calakmul's political network of allies was a mosaic, rather than a continuous bloc, with intervening gaps either where Tikal held sway, or where it was simply not worth trying to incorporate new land (Grube 2004; Marcus and Folan 1994; Martin and Grube 1995, 2008).

So extensive were Calakmul's alliances that the Kaan emblem was mentioned more widely than the Tikal emblem glyph. This extensive distribution, combined with the fact that so many subordinate centers mentioned the Kaan emblem, was what originally led me to suggest that Calakmul might be one of the most important Maya capitals, administering a state with a multitiered hierarchy of sublords 


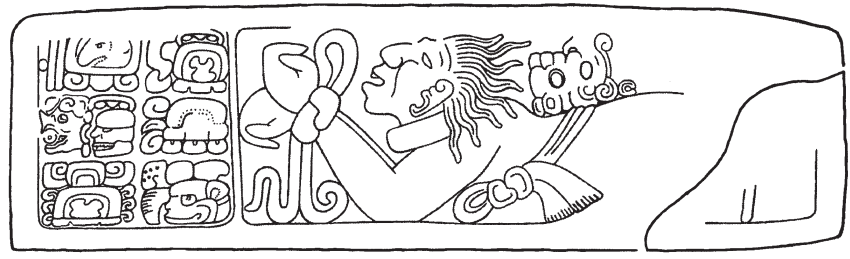

Monument 5

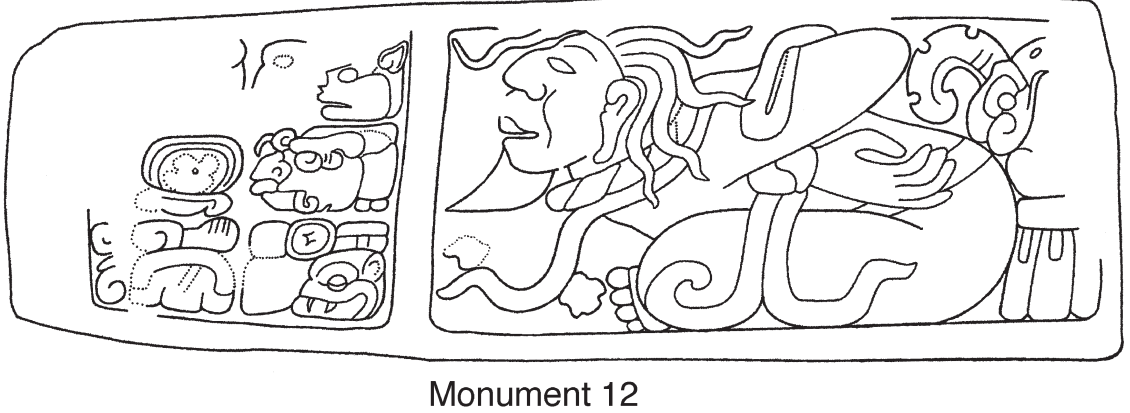

FIGURE 12.7. Carved steps from a Dzibanche stairway, showing prisoners defeated by a divine lord of the Snake Polity (redrawn by Kay Clahassey from Velásquez García 2004). Monument s's text refers to the prisoner of Yuknoom Ch'een I, divine lord of the Snake Polity. Monument I2's text refers to the prisoner of the divine lord of the Snake Polity.

(Marcus 1973, 1993, 2004b, 2012). In retrospect, it looks as if the supremacy of a city such as Calakmul or Tikal was determined not just by its intrinsic strength but also by its ability to draw allies away from its rivals (Marcus 2004b, 20I2; Martin 200I, 2005a; Martin and Grube 1995, 2000). At its peak, each city had perhaps 50,000 inhabitants and could draw on thousands of men as laborers and warriors (Folan et al. 1995b:310).

While Calakmul had the upper hand in this competition for 132 years, in AD 695 the Tikal ruler Jasaw Chan K'awiil I scored a major victory over Calakmul (Marcus $2004 \mathrm{~b}$; Martin and Grube 2008). The son of this victorious Tikal ruler later invested in major new constructions, one of which was Tikal's Temple I (Trik 1963). On the wooden lintel of that temple, the son commissioned a text that recorded the victory his father had achieved over Calakmul, plus the fact that his father had captured a battle trophy - a huge effigy of one of Calakmul's patron deities (Coe et al. 196I). Such effigies were carried onto the battlefield as sacred protectors, and the capture of Calakmul's patron deity would have been a major coup for Tikal. At the base of Temple I the son placed Burial II6, the tomb of his father Jasaw Chan K'awiil I (Trik 1963:4). 
Many of the strategies employed by the Kaan Polity were shared with early states elsewhere in the ancient world (Feinman and Marcus 1998; Marcus 1976, 1992, 1993, 2000). These strategies include the incorporation of sites by military force, the installation of allies as rulers at subordinate sites, the sending out of princesses from the capital to marry subordinate lords, and requiring rulers from subordinate sites to attend the inaugurations of rulers at the capital.

\section{SYNTHESIS}

The political and military competition among Nakbe, El Mirador, Dzibanche, and Calakmul was the engine driving the creation of the first Maya state. Secondary states could form in even more ways (e.g., Flannery and Marcus 2012; Marcus 2004a).

Nakbe could be seen as a prototype for later Maya cities, given its causeways, stela, altar, E group plaza, ballcourt, and other impressive investments in monumentality. Nakbe collapsed without achieving statehood, however, and its population moved to El Mirador, Dzibanche, and Calakmul. I have no doubt that much of the greatness of Calakmul and Tikal resulted from the competition for more land, more allies, and more followers.

\section{CONCLUSIONS}

The engine of history is competition - especially competition among neighbors. To be sure, rulers eager for sumptuary goods engaged in long-distance trade for exotic items displaying foreign styles. But we should not use the presence of trade wares or foreign costumes as an excuse to fantasize about Teotihuacanos taking the thrones of Zapotec or Maya cities. In both Oaxaca and in the El Mirador region, state formation was the outcome of centuries of competition among local elites and does not need to be explained as the result of long-distance trade with foreign peoples.

ACKNOWLEDGMENTs. I thank Joshua D. Englehardt for inviting me to participate in this volume and I thank Kay Clahassey and John Klausmeyer for their outstanding illustrations that add so much to every article. This chapter has benefited from the constructive comments from three anonymous reviewers; I very much appreciate the insights they offered.

\section{REFERENCES}

Andrews, Anthony P. 1984. "The Political Geography of the Sixteenth Century Yucatan Maya: Comments and Revisions." Journal of Anthropological Research 40(4):589-596. Andrews, Anthony P., and Shirley B. Mock. 2002. "New Perspectives on the Prehispanic Maya Salt Trade." In Ancient Maya Political Economies, edited by Marilyn A. Masson and David A. Freidel, 307-334. AltaMira Press, Walnut Creek, CA. 
Blom, Frans. 1924. "Report on the Preliminary Work at Uaxactun, Guatemala." In Carnegie Institution of Washington Year Book, no. 23, 217-219. Washington, DC.

Borowicz, James. 2003. "Images of Power and the Power of Images: Early Classic Iconographic Programs of the Carved Monuments of Tikal." In The Maya and Teotihuacan: Reinterpreting Early Classic Interaction, edited by Geoffrey E. Braswell, 217-234. University of Texas Press, Austin.

Bove, Frederick J., and Sonia Medrano Busto. 2003. "Teotihuacan, Militarism, and Pacific Guatemala." In The Maya and Teotihuacan: Reinterpreting Early Classic Interaction, edited by Geoffrey E. Braswell, 45-79. University of Texas Press, Austin.

Braswell, Geoffrey E. 2003. "Understanding Early Classic Interaction between Kaminaljuyú and Central Mexico." In The Maya and Teotibuacan: Reinterpreting Early Classic Interaction, I05-142. University of Texas Press, Austin.

Carrasco Vargas, Ramón, and Sylviane Boucher. 1987. "Las escaleras jeroglíficas del Resbalón, Quintana Roo.” In Primer Simposio Mundial sobre Epigrafía Maya I986, I-21. Ministerio de Cultura y Deportes, Instituto de Antropología e Historia y Asociación Tikal, Guatemala.

Chase, Arlen F., and Diane Z. Chase. 1995. "External Impetus, Internal Synthesis, and Standardization: E-Group Assemblages and the Crystallization of Classic Maya Society in the Southern Lowlands." In The Emergence of Lowland Maya Civilization: The Transition from the Preclassic to Early Classic, A Conference at Hildesheim, Germany, November 1992, edited by Nikolai Grube, 87-IOI. Acta Mesoamericana, No. 8. Anton Saurwein, Markt Schwaben.

Chi, Gaspar Antonio. 1941. "Relación sobre las costumbres de los indios (1982)." In Landa's Relación de las cosas de Yucatán, edited by Alfred Marston Tozzer, 230-232. Papers of the Peabody Museum of Archaeology and Ethnology, Harvard University, Volume i8. Cambridge.

Christaller, Walter. 1933. Die zentralen Orte in Süddeutschland: Eine ökonomischgeographische Untersuchung über die Gesetzmässigkeit der Verbreitung und Entwicklung der Siedlungen mit städtischen Funktionen. Gustav Fischer, Jena, Germany.

Coe, William R., Edwin M. Shook, and Linton Satterthwaite. 1961. The Carved Wooden Lintels of Tikal. Museum Monographs, Tikal Report No. 6. University of Pennsylvania, University Museum, Philadelphia.

Cooper Clark, James. 1938. Codex Mendoza: The Mexican Manuscript Known as the Collection of Mendoza and Preserved in the Bodleian Library, Oxford. 3 vols. Waterlow and Sons, London.

Demarest, Arthur A., and Antonia E. Foias. 1993. "Mesoamerican Horizons and the Cultural Transformations of Maya Civilization." In Latin American Horizons, edited by Don S. Rice, I47-191. Dumbarton Oaks, Washington, DC. 
Drennan, Robert D. 1976. Fábrica San José and Middle Formative Society in the Valley of Oaxaca. University of Michigan Museum of Anthropology Memoir 8. Ann Arbor, MI.

Drennan, Robert D. 1984a. "Long-Distance Movement of Goods in the Mesoamerican Formative and Classic." American Antiquity 49(I):27-43.

Drennan, Robert D. 1984b. "Long-Distance Transport Costs in Pre-Hispanic Mesoamerica." American Anthropologist 86(I):105-II2.

Drennan, Robert D. 1985. "Porters, Pots, and Profit: The Economics of Long-Distance Exchange in Mesoamerica." American Anthropologist 87(4):891-893.

Elson, Christina M. 2007. Excavations at Cerro Tilcajete: A Monte Albán II Administrative Center in the Valley of Oaxaca. University of Michigan Museum of Anthropology Memoir 42. Ann Arbor, MI.

Esparza Olguín, Octavio Q., and Vania E. Pérez Gutiérrez. 2009. "Archaeological and Epigraphic Studies in Pol Box, Quintana Roo.” PARI Journal 9(3):I-16.

Feinman, Gary M., and Joyce Marcus, eds. 1998. Archaic States. School of American Research, Santa Fe.

Flannery, Kent V., and Joyce Marcus. 2003. "The Origin of War: New ${ }^{14} \mathrm{C}$ Dates from Ancient Mexico." Proceedings of the National Academy of Sciences 100(20):11801-11805.

Flannery, Kent V., and Joyce Marcus. 2005. Excavations at San José Mogote I: The Household Archaeology. University of Michigan Museum of Anthropology Memoir 40. Ann Arbor, MI.

Flannery, Kent V., and Joyce Marcus. 20I2. The Creation of Inequality. Harvard University Press, Cambridge.

Flannery, Kent V., and Joyce Marcus. 2015. Excavations at San José Mogote 2: The Cognitive Archaeology. University of Michigan Museum of Anthropology Memoir 58. Ann Arbor, MI.

Foias, Antonia E. 1987. The Influence of Teotihuacan in the Maya Culture during the Middle Classic: A Reconsideration of the Ceramic Evidence from Kaminaljuyu, Uaxactun, and Copan. BA honors thesis, Department of Anthropology, Harvard University, Cambridge.

Folan, William J., Joyce Marcus, and W. Frank Miller. 1995a. "Verification of a Maya Settlement Model through Remote Sensing." Cambridge Archaeological Journal $5(2): 277-283$.

Folan, William J., Joyce Marcus, Sophia Pincemin, María del Rosario Domínguez Carrasco, Laraine Fletcher, and Abel Morales López. 1995b. "Calakmul: New Data from an Ancient Maya Capital in Campeche, Mexico." Latin American Antiquity 6(4):310-334.

Folan, William J., Jacinto May Hau, Joyce Marcus, W. Frank Miller, and Raymundo González Heredia. 200ı. "Los caminos de Calakmul, Campeche." Ancient Mesoamerica I2(2):293-298. 
Grube, Nikolai. 2004. "El origen de la dinastía Kaan." In Los cautivos de Dzibanché, edited by Enrique Nalda, II4-I3r. Instituto Nacional de Antropología e Historia, Mexico City.

Haggett, Peter. 1966. Locational Analysis in Human Geography. St. Martin's Press, New York.

Haggett, Peter. 1972. Geography: A Modern Synthesis. Harper and Row, New York.

Hansen, Richard D. 1998. "Continuity and Disjunction: The Pre-Classic Antecedents of Classic Maya Architecture." In Function and Meaning in Classic Maya Architecture, edited by Stephen Houston, 49-122. Dumbarton Oaks, Washington, DC.

Helmke, Christophe, and Jaime Awe. 2016. "Death Becomes Her: An Analysis of Panel 3 , Xunantunich, Belize." PARI Journal I6(4):I-I4.

Iglesias Ponce de León, María Josefa. 2003. "Problematical Deposits and the Problem of Interaction: The Material Culture of Tikal during the Early Classic Period." In The Maya and Teotihuacan: Reinterpreting Early Classic Interaction, edited by Geoffrey E. Braswell, 167-198. University of Texas Press, Austin.

Johnson, Gregory A. 1973. Local Exchange and Early State Development in Southwestern Iran. University of Michigan Museum of Anthropology Anthropological Paper 5I. Ann Arbor, MI.

Johnson, Gregory A. 1975. "Locational Analysis and the Investigation of Uruk Local Exchange Systems." In Ancient Civilization and Trade, edited by Jeremy A. Sabloff and C. C. Lamberg-Karlovsky, 285-339. University of New Mexico Press, Albuquerque.

Kidder, Alfred V., Jesse D. Jennings, and Edwin M. Shook. 1946. Excavations at Kaminaljuyu, Guatemala. Carnegie Institution of Washington Publication 56I. Carnegie Institution, Washington, DC.

Kowalewski, Stephen A., Andrew K. Balkansky, Laura R. Stiver Walsh, Thomas J. Pluckhahn, John F. Chamblee, Verónica Pérez Rodríguez, Verenice Y. Heredia Espinoza, and Charlotte A. Smith. 2009. Origins of the Nuu: Archaeology in the Mixteca Alta, Mexico. University Press of Colorado, Boulder.

Laporte, Juan Pedro. 1989. "Alternativas del Clásico Temprano en la Relación TikalTeotihuacan: El Grupo 6C-XVI, Tikal, Petén.” PhD dissertation, Universidad Nacional Autónoma de México, Mexico.

Laporte, Juan Pedro. 2003. "Architectural Aspects of Interaction between Tikal and Teotihuacan during the Early Classic Period." In The Maya and Teotihuacan: Reinterpreting Early Classic Interaction, edited by Geoffrey E. Braswell, 199-216. University of Texas Press, Austin.

López de Cogolludo, Diego. [1688] 1867-1868. Historia de Yucatán. 2 vols. 3rd ed. Mérida, Yucatán, Mexico.

Lösch, August. 1954. The Economics of Location. Translated by William H. Woglom. Yale University Press, New Haven. 
Marcus, Joyce. 1973. “Territorial Organization of the Lowland Classic Maya.” Science I80(4089):911-916.

Marcus, Joyce. 1976. Emblem and State in the Classic Maya Lowlands: An Epigraphic Approach to Territorial Organization. Dumbarton Oaks, Washington, DC.

Marcus, Joyce. 1983. "Lowland Maya Archaeology at the Crossroads." American Antiquity $48(3): 454-488$.

Marcus, Joyce. 1992. "Dynamic Cycles of Mesoamerican States." National Geographic Research and Exploration 8:392-4II.

Marcus, Joyce. 1993. “Ancient Maya Political Organization.” In Lowland Maya Civilization in the Eighth Century AD, edited by Jeremy A. Sabloff and John S. Henderson, III-I83. Dumbarton Oaks, Washington, DC.

Marcus, Joyce. 2000. “Cinco mitos sobre La Guerra Maya.” In La Guerra entre los Antiguos Mayas, edited by Silvia Trejo, 225-247. Instituto Nacional de Antropología e Historia, Mexico City.

Marcus, Joyce. 2003. “The Maya and Teotihuacan.” In The Maya and Teotihuacan: Reinterpreting Early Classic Interaction, edited by Geoffrey E. Braswell, 337-356. University of Texas Press, Austin.

Marcus, Joyce. 2004a. "Primary and Secondary State Formation in Southern Mesoamerica." In Understanding Early Classic Copan, edited by Ellen E. Bell, Marcello A. Canuto, and Robert J. Sharer, 357-373. University Museum Press, University of Pennsylvania, Philadelphia.

Marcus, Joyce. 2004b. “Calakmul y su papel en el origen del estado maya." In Los Investigadores de la Cultura Maya I2(I):I4-3I. Universidad Autónoma de Campeche, Campeche, Mexico.

Marcus, Joyce. 2006. "Identifying Elites and Their Strategies." In Intermediate Elites in Pre-Columbian States and Empires, edited by Christina M. Elson and R. Alan Covey, 212-246. University of Arizona Press, Tucson.

Marcus, Joyce. 2012. "Maya Political Cycling and the Story of the Kaan Polity." In The Ancient Maya of Mexico: Reinterpreting the Past of the Northern Maya Lowlands, edited by Geoffrey E. Braswell, 88-ir6. Equinox Press, London.

Marcus, Joyce, and Kent V. Flannery. 1996. Zapotec Civilization: How Urban Society Evolved in Mexico's Oaxaca Valley. Thames and Hudson, London.

Marcus, Joyce, and William J. Folan. 1994. "Una estela más del Siglo V y nueva información sobre Pata de Jaguar, gobernante de Calakmul, Campeche en el Siglo VII." Gaceta Universitaria $4(15-16): 2 \mathrm{I}-26$.

Martin, Simon. 200I. "Court and Realm: Architectural Signatures in the Classic Maya Southern Lowlands." In Royal Courts of the Ancient Maya. Vol. I, edited by Takeshi Inomata and Stephen Houston, I68-194. Westview Press, Boulder, CO. 
Martin, Simon. 2005a. "Of Snakes and Bats: Shifting Identities at Calakmul." PARI Journal 6(2):5-15.

Martin, Simon. 2005b. "Caracol Altar 2r Revisited: More Data on Double Bird and Tikal's Wars of the Mid-Sixth Century." PARI Journal 6(I):I-9.

Martin, Simon, and Nikolai Grube. 1995. "Maya Superstates." Archaeology 48(6):4I-45.

Martin, Simon, and Nikolai Grube. 2000. Chronicle of the Maya Kings and Queens. Thames and Hudson, London.

Martin, Simon, and Nikolai Grube. 2008. Chronicle of the Maya Kings and Queens: Deciphering the Dynasties of the Ancient Maya. 2nd ed. Thames and Hudson, London.

Means, Philip Ainsworth. 1917. History of the Spanish Conquest of Yucatan and of the Itzas. Papers of the Peabody Museum of Archaeology and Ethnology 7. Harvard University, Cambridge.

Nalda, Enrique, ed. 2004. Los cautivos de Dzibanché. Instituto Nacional de Antropología e Historia, Mexico City.

Pendergast, David M. 2003. “Teotihuacan at Altun Ha: Did It Make a Difference?” In The Maya and Teotihuacan: Reinterpreting Early Classic Interaction, edited by Geoffrey E. Braswell, 235-247. University of Texas Press, Austin.

Pollock, Harry E. D., Ralph L. Roys, Tatiana Proskouriakoff, and A. Ledyard Smith. 1962. Mayapan, Yucatan, Mexico. Carnegie Institution of Washington Publication 619. Carnegie Institution, Washington, DC.

Rathje, William L. I97I. "The Origin and Development of Lowland Classic Maya Civilization." American Antiquity 36(3):275-285.

Rathje, William L. 1972. "Praise the Gods and Pass the Metates: A Hypothesis of the Development of Lowland Rainforest Civilizations in Mesoamerica." In Contemporary Archaeology: A Guide to Theory and Contributions, edited by Mark P. Leone, 365-392. Southern Illinois University Press, Carbondale.

Rattray, Evelyn C. 1990a. "New Findings on the Origins of Thin Orange Ceramics." Ancient Mesoamerica I(2):181-195.

Rattray, Evelyn C. 1990b. "Nuevos hallazgos sobre los orígenes de la cerámica anaranjada delgado." In La época Clásica: Nuevos hallazgos, nuevas ideas, edited by A. Cardoso, 89-106. Instituto Nacional de Antropología e Historia, Mexico City.

Rattray, Evelyn C., and Garman Harbottle. 1992. "Neutron Activation Analysis and Numerical Taxonomy of Thin Orange Ceramics from the Manufacturing Sites of Río Carnero, Puebla, Mexico." In Chemical Characterizations of Ceramic Pastes in Archaeology, edited by Hector Neff, 221-23I. Prehistory Press, Madison, WI.

Redmond, Elsa M., and Charles S. Spencer. 2012. "Chiefdoms at the Threshold: The Competitive Origins of the Primary State." Journal of Anthropological Archaeology $3 \mathrm{I}(\mathrm{I}): 22-37$. 
Reents-Budet, Dorie. 1994. Painting the Maya Universe: Royal Ceramics of the Classic Period. Duke University Press, Durham, NC.

Relaciones de Yucatán. 1898, 1900. In Colección de documentos inéditos relativos al descubrimiento, conquista y organización de las antiguas posesiones españolas de ultramar. Segunda serie, tomos I and 2 (vols. I and I3). Real Academia de la Historia, Madrid. Ricketson, Oliver G., Jr., and Edith Bayles Ricketson. 1937. Uaxactun, Guatemala, Group E-I926-I93I. Carnegie Institution of Washington Publication 477. Carnegie Institution, Washington, DC.

Robichaux, Hubert R., and Candace Pruett. 2005. "Las inscripciones de Oxpemul." In Los Investigadores de la Cultura Maya I3 (I):29-43. Universidad Autónoma de Campeche, Mexico.

Roys, Ralph L. 1957. The Political Geography of the Yucatan Maya. Carnegie Institution of Washington Publication 613. Carnegie Institution, Washington, DC.

Roys, Ralph L. 1962. “Literary Sources for the History of Mayapan.” In Mayapan, Yucatan, Mexico, by Harry E. D. Pollock, Ralph L. Roys, Tatiana Proskouriakoff, and A. Ledyard Smith, 25-86. Carnegie Institution of Washington Publication 619. Carnegie Institution, Washington, DC.

Roys, Ralph L. 1965. "Lowland Maya Native Society at Spanish Contact.” In Handbook of Middle American Indians, Vol. 3, edited by Robert Wauchope and Gordon R. Willey, 659-678. University of Texas Press, Austin.

Roys, Ralph L. 1972. The Indian Background of Colonial Yucatan. University of Oklahoma Press, Norman.

Roys, Ralph L., France V. Scholes, and Eleanor B. Adams. 1959. "Census and Inspection of the Town of Pencuyut, Yucatan, in 1583 by Diego García de Palacio, Oidor of the Audiencia of Guatemala." Ethnohistory 6(3):195-225.

Ruppert, Karl, and John H. Denison Jr. 1943. Archaeological Reconnaissance in Campeche, Quintana Roo, and Peten. Carnegie Institution of Washington Publication 543. Carnegie Institution, Washington, DC.

Sanders, William T. 1974. "Chiefdom to State: Political Evolution at Kaminaljuyú, Guatemala." In Reconstructing Complex Societies: An Archaeological Colloquium, edited by Charlotte B. Moore, 97-II6. Supplement to the Bulletin of the American Schools of Oriental Research 20. American Schools of Oriental Research, Cambridge.

Sanders, William T. 1977. "Ethnographic Analogy and the Teotihuacán Horizon Style.” In Teotihuacán and Kaminaljuyu: A Study in Prehistoric Culture Contact, edited by William T. Sanders and Joseph W. Michels, 397-4IO. Pennsylvania State University Press, University Park.

Schele, Linda, and David A. Freidel, 1990. A Forest of Kings: Untold Stories of the Ancient Maya. William Morrow, New York. 
Sharer, Robert J. 2003. "Founding Events and Teotihuacan Connections at Copan, Honduras." In The Maya and Teotihuacan: Reinterpreting Early Classic Interaction, edited by Geoffrey E. Braswell, I 43-165. University of Texas Press, Austin.

Sharer, Robert J., with Loa Traxler. 2006. The Ancient Maya. 6th ed. Stanford University Press, Stanford.

Spencer, Charles S., and Elsa M. Redmond. 2003. "Militarism, Resistance, and Early State Development in Oaxaca, Mexico." Social Evolution and History 2(I):25-70. Uchitel, Moscow.

Spencer, Charles S., and Elsa M. Redmond. 2004. "A Late Monte Albán I Phase (300-100 в C) Palace in the Valley of Oaxaca." Latin American Antiquity I5 (4):44I-455. Spencer, Charles S., and Elsa M. Redmond. 2006. "Resistance Strategies and Early State Formation in Oaxaca, Mexico." In Intermediate Elites in Pre-Columbian States and Empires, edited by Christina M. Elson and R. Alan Covey, 21-43. University of Arizona Press, Tucson.

Šprajc, Ivan. 2008. Reconocimiento arqueológico en el sureste del estado de Campeche, México: 1996-2005. BAR International Series 1742. Paris Monographs in American Archaeology 19. British Archaeological Reports, Oxford.

Stuart, David. 2000. “'The Arrival of Strangers': Teotihuacan and Tollan in Classic Maya History." In Mesoamerica's Classic Heritage: From Teotihuacan to the Aztecs, edited by Davíd Carrasco, Lindsay Jones, and Scott Sessions, 465-513. University Press of Colorado, Boulder.

Stuart, David. 2012. "Notes on a New Text from La Corona." Electronic document, https:// decipherment. wordpress.com/2012/06/30/notes-on-a-new-text-from-la-corona/.

Tokovinine, Alexandre. 2007. "Of Snake Kings and Cannibals: A Fresh Look at the Naranjo Hieroglyphic Stairway." PARI Journal 7 (4):15-22.

Tozzer, Alfred M. 1941. Landa's Relación de las cosas de Yucatán. A translation edited with notes by Alfred M. Tozzer. Papers of the Peabody Museum of Archaeology and Ethnology, Harvard University, Volume i8. Cambridge.

Trik, Aubrey S. 1963. "The Splendid Tomb of Temple I at Tikal, Guatemala." Expedition 6(I):2-18. University of Pennsylvania, University Museum, Philadelphia.

Velásquez García, Erik. 2004. "Los escalones jeroglíficos de Dzibanché.” In Los Cautivos de Dzibanché, edited by Enrique Nalda, 79-103. Instituto Nacional de Antropología e Historia, Mexico City.

White, Christine D., Fred J. Longstaffe, Michael W. Spence, and Kimberley R. Law. 2000. "Testing the Nature of Teotihuacan Imperialism at Kaminaljuyú Using Phosphate Oxygen-Isotope Ratios." Journal of Anthropological Research 56(4):535-558.

Wright, Henry T., and Gregory A. Johnson. 1975. "Population, Exchange, and Early State Formation in Southwestern Iran." American Anthropologist 77(2):267-289. 


\section{Conclusion}

\section{The World as They Knew It \\ The Interaction Sphere Concept in Current Mesoamerican Archaeology}

DAVID FREIDEL

Before European explorers of the late fifteen and early sixteenth centuries launched the imperial and mercantilist projects of their rulers (Wallerstein 1974; Wolf 1982), congeries of complex societies had for thousands of years defined themselves as worlds without the sense of globe. This was not an accident of history but rather a human propensity, for the complex societies of the Western Hemisphere independently arrived at this cultural conclusion long before they encountered Europeans. The chapters in this book elucidate a range of possible social dynamics and empirical entailments of interaction that generated and sustained the institutional framework of the ancient Mesoamerican world. For it was a world, and not one predicated on a particular list of cultural traits or necessarily on impositions from dominant regimes but rather one largely built over generations on the needs and desires of people, to identify with others who spoke different languages, wore different clothes, worshipped different gods, and made different things. The practical consequences of such successful efforts to overcome the propensities of xenophobia were trade and emulation, and these register in the archaeological record as reviewed in this book. But trade can extend beyond such ancient worlds and emulation can be sporadic and selective in such frontier areas (McGuire 1989; Urban and Schortman 1986), so it is fair to say that the ancient Mesoamerican world was populated by peoples who defined themselves as "in" more than "out," particularly in the frontier regions. I am here positing that while all such decisions were no doubt economic and political in the sense reviewed by Gary M. Feinman (chapter I), they were also 
social and cultural ones. However parochial their views, and local their adaptations to environmental and material constraints, participants in the Mesoamerican world knew that it existed and that, friend or foe, their neighbors were their partners in it.

After Joseph Caldwell's (1964) seminal introduction of the interaction sphere concept in the context of the Hopewell phenomenon in North America, this approach proved a productive theoretical challenge to culture area explanations. I later applied it to the case of lowland Maya Preclassic civilization in the context of a critique of culture area diffusionary schemes there (Freidel 1979). Some of its most famous variants in archaeology are derived from the World Systems model of Immanuel Wallerstein (1964) as alluded to by Gary M. Feinman at the beginning of this book. Recently in the arena of Neolithic and Bronze Age Eurasia, Michael Frachetti (2008, 20I2) has challenged both basic expressions of the culture area migration-diffusion approach (Anthony 2010) and the World Systems core-periphery approach (Kohl 1987, but see also Kohl 2008 for a more recent perspective) to the dissemination of key innovations such as plant and animal domestication and metallurgy across the vast steppe terrain and the advent of social and cultural complexity among its peoples. Frachetti (2012:19) proposes that interaction in his case expressed "nonuniform institutional complexity" whereby "organizational structures-such as shared trade parameters, building conventions, ideological symbolism, or even the value or signification of particular technological innovations-demonstrate periodic institutional alignments among participant communities without demanding they be subsumed under a coherent political structure or social identity." Several cases for interaction presented in this book illustrate nuanced patterns of production and distribution of things and distributions of technologies and material symbols that appear to reflect such nonuniformity: dynamic, selective and agent-driven interaction through space and time. These thoughts on nonuniform institutional complexity as an approach in important ways echo Feinman's apt commentary at the opening of this book, and one can generally conclude that the editors and the contributors are striving to expand the scope of the concept of interaction.

Guy David Hepp's chapter, 2, with its focus on new discoveries and analyses from the site of La Consentida on the west coast of Oaxaca introduces several of the key themes of the book. First of all, it is one of several refreshing forays into important new research outside the main traditional foci of Mesoamerican archaeology. Second, Hepp discusses interaction at several different and ultimately contingent geographic scales, including the famous prospect of Pacific coastal trade and migration between Mesoamerica and South America. In looking at the origins and development of ceramic containers in light of La Consentida's Early Formative Tlacuache phase assemblage, Hepp provides a closely argued comparison with other Early Formative ceramics that have been well researched and published-the 
Barra assemblages of coastal Chiapas and the Tierras Largas assemblage of the Valley of Oaxaca-and concludes that the Tlacuache phase assemblage is distinctive from Barra in forms, functions, and decoration. He suggests that the patterns in evidence point to the existence of a western Mexican Red-on-Buff horizon, or interaction sphere, distinct from an interaction sphere exemplified by Barra and related assemblages to the east on the Pacific coast of Guatemala. He is open to the prospect that the La Consentida ceramic tradition might be linked to South American ceramic traditions, though he is careful to point out that more research would be needed to pursue this matter. This inquiry touches on central issues perennially addressed in interaction sphere studies, namely, stylistic and technological innovation and diffusion.

As in the case of several other chapters, Hepp reviews the evidence for interaction derived from a series of data sets-including obsidian, material symbol systems-particularly as expressed in ceramic figurines and musical instruments, and greenstone artifacts. He notes that the patterns sometimes evidently contradict or deviate from the patterns seen in the ceramic spheres, but that nevertheless the people he studies certainly participated in regional interaction spheres evinced in these materials. This conclusion resonates with Frachetti's nonuniform institutional complexity model introduced above, as it points to the prospect that the La Consentida community participated in several distinct exchange institutions at any given time and that its members had choices and agency regarding their participation in any one of them. Among the choices Mesoamericans could make were whether or not to adopt the social and cultural contextual baggage of materials that they brought into their communities through interaction. The book editors Joshua D. Englehardt and Michael D. Carrasco address this matter squarely in their chapter. Ancient Mesoamericans were the only peoples in the Western Hemisphere to innovate writing systems that encoded spoken language (even while the Quipu systems of the Andean region remain under consideration). Following leads in the study of early writing elsewhere in the world, Joshua D. Englehardt and Michael D. Carrasco (chapter 3 ) propose that such innovation was enabled and facilitated through the regional interaction of sages using what they term iconographic systems. They propose that the people adept in such systems, what I call sages, with their learned and specialized skills in reading and relating visual iconographic configurations in terms of word symbols (storytelling, curing, and other performances of ritual involving declamation and singing, for example), were able to extract particular icons from exotic and borrowed contexts and situated them in novel ones. This process of decontextualizing and then recontextualizing an icon is well documented in the study of canons of art over time (Panofsky 1939) and makes good sense in the case at hand. It is a premise that also raises the issue of 
disjunction and continuity over time in the symbolic meanings linked to a given icon. Englehardt and Carrasco address this matter by looking at the variable compositional contexts of particular icons. For example, they observe that the Lazy-S scroll proposed by Reilly (1996) to have the meaning of cloud associated with rain in Middle Formative reliefs of Chalcatzingo and also to mean cloud in the Classic Maya script and Postclassic Dresden Codex, may have meant something related but different in the context of Classic Zapotec funerary imagery or Mixtec codices. Here the pervasiveness of the association with cloud and rain is strong enough for the authors to propose a secondary value to these contexts.

Still, it seems likely that the processes of recontextualizing icons in ways that attached them to words would have proceeded in the presence of a broad command of both the donor and receptor iconographic systems among the cosmopolitan sages doing this work. Surely such manipulation in ignorance of one of those systems would have generated arbitrary repurposing and not the enduring and continuous development of icons into word-based symbols that the authors illustrate, for example, in their intriguing "mat-throne" collocation. In sum, the authors agree that the kind of borrowing and resituating they describe actually implies a high degree of common-language-based conversation about the religious and ritual precepts informing the iconographic systems. Whether such linguistic interaction involved lingua franca, facility in several languages, or more likely both references the strong traditions in linguistic anthropology focused on these matters and referenced by the authors.

A core issue in this inquiry, and one that really extends into the authors' recent article in the Cambridge Archaeological Journal (Carrasco and Englehardt 2015), focusing on the Early Formative style Cascajal Block, is the innovation of linear arrangement of icons in ways that suggest their recontextualization and transformation into word symbols. In this chapter the authors imply that the CB pattern is an example of column arrangement, but a perplexing fact of the matter is that the icons appear to be arranged in horizontal lines in basic violation of virtually all uncontested examples of early Mesoamerican texts. That said, their brief for the juxtaposition of a throne and a mat icon as expressing a kenning, royal power, is pretty persuasive. Kent Reilly and I (20I0) proposed that the icons on the CB commemorate the laying out of iconic tokens in an act of divination, and Englehardt and Carrasco do not take issue with this possibility. In our reading, Reilly and I proposed that in fact the horizontal linear reading worked in "boustrophedon" fashion, that is, reading from left to right and then right to left from top to bottom. What if the pervasive shared cultural condition for the recontextualization of icons into word symbols was the perception of casting and arranging of divining tokens as what Scott Ortman (2OI2) calls a "conceptual metaphor" in this case representing 
the primordial act of creation, one through which the oracular divine speaks to the sage? While many diving tokens in Mesoamerica are simple and neutral forms, such as seeds or maize kernels, many others arranged on diving tables are iconic objects (Brown 20I4).

Columnar arrangement of tokens is actually the likely basis for numeracy prior to its use in literacy in Mesoamerica. Bar and dot notation, with dots representing the number $\mathrm{I}$ and bars the number 5 , most likely derived from the manipulation of actual artifacts on smooth surfaces (Freidel et al. 2017; Freidel et al. 2015). In the Mesoamerican vigesimal system of place notation, which must have had its origins in the Middle Formative period and which certainly was in place by the Late Formative, the bars and dots are arranged in columns. In this perspective the Cascajal Block may represent the first step toward word-based reading of icons, before the horizontal linear arrangement of divining tokens was effectively integrated into columnar calendar calculations based in numbers. When writing systems do emerge, they generally include elements of human beings, particularly heads but also hands, and these are already present in the iconographic depictions that presage true writing (Carrasco and Englehardt 2015). Prudence Rice (2017) suggests that these elements reference "disindividuated" fragments of votive ceramic figurines, an artifact category well represented in Middle Formative Mesoamerica. I would add that they also likely represent the appropriation by sages and rulers of the oracular voice represented in the inscriptions as they emerge as human declarations from supernaturally inspired divination patterns.

The sages highlighted here must have been familiar with several languages in order to interact in ways that eventually generated written scripts, and Kerry M. Hull in chapter 4 programmatically reviews several features of linguistic interaction that affirm this premise. Surely many Mesoamericans were multilingual in the deep past as they were at the time of the Spanish arrival, especially in frontier areas. Experts in ancient Mesoamerican languages have their differences, but generally ascribe to methodologies that can identify loanwords and developmental dynamics affected by these traditions, and these strands of argument support other evidence for long-term regional interaction between neighboring peoples. As a Mayanist focused in part on the relationship between Teotihuacan and the lowlands in the Early Classic period (Freidel et al. 2007), I am particularly curious about how that social and cultural interaction bears on this issue of linguistic interaction. Hull, in chapter 4 , defers to other experts who see the impact of Nawa on Mayan lowland languages as occurring after the fall of Teotihuacan, now placed around AD 550. David Stuart (2000), on the other hand, is confident that the lowland Maya called Teotihuacan Puh, "place of cattail reeds," and the Nawa term for "place of cattail reeds" is Tollan. It seems unlikely to me that the Maya 
were retrospectively imposing this famous name on Teotihuacan. Hull (2006) has written on Classic Maya political history, and the relationships between Cholan and Yucatecan as he reviews them in this chapter are, in my view, highly relevant to such history. He makes a good case for intensive interaction between these languages in the Classic period and even proposes the possibility of a lingua franca based on them. I am pursuing the prospect (Freidel 2012, 2018) that the Kaanul kings and queens he identifies with Calakmul, but which earlier in the Classic were evidently seated at Dzibanche, presided over a realm that was predominantly central peninsular and northern lowland Maya and Yucatecan speaking. The prolonged conflicts between Kaanul and the kings of Tikal, ancient Mutal, may have been based on an ethnic division as Tikal, and its southern lowland allies were likely Cholan speakers. In the last analysis, Hull makes clear that linguistic interaction can be usefully coordinated with other kinds of interaction in the elucidation of Mesoamerican ancient history.

The slab-footed tripod vase or cup, along with its often-accompanying knobbed lid, is a leitmotif of Early Classic regional interaction emanating from Teotihuacan. D. Bryan Schaeffer proposes (chapter 5) that this ceramic form exemplifies the consecration of foreign origin, lending objects prestige and power. This is a wellsustained principle expressed in many styles and fashions that have moved with trade, diplomacy, and war in worlds, ancient and modern. But the notion of the sacred implied by the term "consecration" is expressed in the movement of religious ideas, and certainly universalizing religions are distributed in the context of consecrated artifacts. While Schaeffer alludes to the possibility, citing Annabeth Headrick, that the tripod pattern itself may have had sacred connotations, in actuality it is the symbolism found on tripod cylinders that might support the notion of religious and political significance. The "dazzler" vessel from the Copán tomb that most posit to be that of the queen founder of the dynasty is particularly expressive of this reality. According to David Stuart (2004), Karl Taube (2004), and others, it depicts the personification of a fire shrine "origin house," in ancient Mayan a Wite' Naah. As Schaeffer observes, the goggle-ornamented eyes in the doorway are likely those of the king founder of the Copán dynasty K'inich Yak K'uk' Mo'. The Wite' Naah cult introduced into the Maya lowlands by Kaloomte' Sihyaj K'ahk' in AD 378 was the most important religious interaction between Teotihuacan and the Maya lowlands. The Huunal tomb, which likely held the remains of this king, had a second tripod cylinder ornamented with insignia framed by feathers such as banners. These are the "in-line triad" and "bigote" (Langley 1993) that most scholars see as a variant of the Storm God. However, I argue (Freidel 2012, 2018), following Susan Milbrath (2000), that this is the name of the Teotihuacan Moon Goddess. If I am right, then the king carried a ceramic gift declaring the feminine divine from 
Teotihuacan, while his wife had a representation of him as the male divine. Together they were "mother-fathers," founding ancestors. However this argument ends, the vessels were clearly very sacred. If Schaeffer is right that the vessel form itself was consecrated as exotic among the Maya, I would suggest that this status might have derived over time from the symbolism placed on such vessels. In any case, I quite agree with him and with Joseph Ball (1983) that the distribution of this exotic form in the Maya lowlands registers emulation and political interaction more than trade in ceramic containers or even the widespread gifting of such containers from highland Mexico to the Maya area. But if exotic containers themselves were rare and prestigious evidence of cosmopolitan aesthetic, it remains the case that Early Classic Mesoamericans exchanged other more tangible materials over distance and that such trade remains a source of potential practical economic and political interaction over distance.

The material stakes in question register in posited military interaction. At Yaxuna in the northern Yucatán, I participated in a project that discovered a remarkable Early Classic ceramic effigy of a female deity (Ardren 2002; Stanton et al. 2010; Suhler 1996; Suhler and Freidel 1998; Tiesler et al. 2017) that I identify as the Maya version of the Teotihuacan Moon Goddess. What I take to be carved stone versions of this young female were discovered in offerings in the Pyramid of the Moon (Sugiyama and López Austin 2007) and as in the case of such massive ritual offerings, Yaxuna Burial 24 evidently contained an aggregation of sacrifices. The Yaxuna context contained royal insignia jewels, and hence the sacrifices were probably of high elite status (Freidel 2014). Furthermore, Yaxuna project staff have posited that this tomb is evidence of a military takeover in the era of the Entrada of Sihyaj K'ahk'. Jesper Nielsen and his colleagues, in chapter 6, clearly favor the projection of military power by the government of Teotihuacan during the Early Classic period based on their research in Guerrero.

Nielsen (2003) has been an advocate for Teotihuacan militarism and imperialism for a long time, and the first third of this chapter is devoted to reviewing arguments favoring this position. So I take the opportunity to briefly state some of my own views on this vital kind of interaction. I concur with Sugiyama (2005) that the iconography and complex ritual deposits at Teotihuacan affirm that its government had long-term military programs. However, Teotihuacan's iconographic programs also express religious and cosmological principles that appeal to the practical agrarian concerns of the majority of people governed by Teotihuacan's elusive rulers. This is hardly contradictory in Mesoamerican history: the Templo Mayor was dedicated to Tlaloc, essential rain-bringer, and Huitzilopochtli, exemplary warrior. The complex relationship between economic, and foundationally agricultural, prosperity, and military power should be expanded and elaborated in our pursuit 
of good-fit models of regional interaction. So while the Classic period Feathered Serpent, the Storm God, the Moon Goddess, the Sun God (a Maya deity incorporated in the Wite' Naah Fire Shrine cult, see Taube 2004) certainly perform as war gods (among several others), they also perform as rain bringers and crop sustainers. As the great One Rabbit famine showed in the case of the Mexica, military power can prove necessary when food security by means of rain magic and trade or tribute prove insufficient.

Nielsen and colleagues (chapter 6) review the case for a Teotihuacan military presence in Guerrero primarily through the iconography of carved stone monuments. These monuments certainly display Teotihuacan style symbolism, including bleeding hearts and weaponry that imply warfare and sacrifice. But the sustained resistance to the notion of direct military intervention among many Maya archaeologists should give caution to deducing major imperial projection based on such data. In the Maya case there is clear textual evidence to support the Entrada of Sihyaj K'ahk' in AD 378, and archaeological evidence suggestive of the deposal and sacrifice of royalty at Tikal in the context of that Entrada. I think that the Entrada also registers in sacrificial interments at El Peru-Waka' in northwestern Petén and at Yaxuna in the Yucatán. That said, a case for imperial conquest analogous to ancient conquests discerned archaeologically elsewhere in the world has not been established through a range of artifact categories beginning with pervasive imposition of architectural designs replete with imperial propaganda and continuing through quotidian categories such as ceramics. As Schaeffer proposes in chapter 5, the slabfooted tripod vessels of the Maya lowlands are overwhelmingly local and likely express emulation rather than imperial subjugation. And the Teotihuacan inspired symbolism in the Maya lowlands is rapidly and quite thoroughly syncretized with long-established Maya symbolism yielding an innovative and cosmopolitan elite culture that is quite distinct from art in the Mexican city. The relationship between Teotihuacan and the Early Classic lowland Maya is real and transformative of those kingdoms that embraced it, but it does not appear to be an imperial imposition. I believe it will turn out to be a major political and commercial alliance, with the military component being one of support for one faction against another in an internecine lowland Maya struggle (Freidel 2014). Nielsen and his colleagues are certainly correct that Teotihuacan-inspired monuments in Guerrero invite more archaeological investigation of trade routes linking southeastern Mesoamerica to that capital.

Speaking of trade, López de Gómara (Simpson 1964), biographer of Hernán Cortés, describes a foray inland of Spanish on the coast of Veracruz in which they encountered communities storing large quantities of bulk trade goods shipped by coastal canoe headed inland to the heart of the Mexica empire. While 
Mesoamerican archaeologists pay lip service to the role of contact period coastal trade on the Gulf of Mexico, Philip J. Arnold III and Lourdes Budar, chapter 7 , underscore the antiquity of this form of regional interaction as registered in ceramics and figurines. I have suggested (2014) that Middle Formative Olmec shipped salt from the coast of the Yucatán through La Venta by means of canoes, an idea favored by Richard Diehl (2006). Arnold and Budar's systematic and informative review of select expressions of interaction and with its focus on the Tuxtla Mountains begins with a consideration of the Stela-Base-Throne (SBT) complex of monuments that links the southern Gulf Coast lowlands to part of the Maya area to the east. Stelae as such occur in the Middle Formative at La Venta, and these are candidates for at least one independent innovation of the idea. As Reilly (1994, 2002; see also Freidel and Reilly 2010; González Lauck 2010) observes, the iconographic program on the majority of the La Venta stelae ranged along the southern base of the pyramid is resonant with incised pictographic programs on greenstone celts of the time. It is quite possible that these original stelae were commemorative of such celts, which were widely distributed between the southern Gulf Coast lowlands and the Maya area in Early into Middle Formative times. But the SBT complex is a distinct complex of monuments with a different distribution. While this chapter elucidates that distribution, it also points to the usefulness of considering the dynamics of selective participation in interaction as expressed through particular artifact categories, a matter of agency that I brought up in the context of Frachetti's nonuniform institutional complexity model. Particularly with regard to the fine paste ceramics, which Arnold and Budar show have likely origins in the southern Gulf Coast lowlands, interaction between this region and the Maya lowlands, particularly along the coast, was two-way and important not just in the Postclassic and contact periods but much deeper in time.

Charles L. F. Knight's cogent discussion, chapter 8, of the enormous Early Classic city of Cantona in eastern Puebla challenges the notion that Teotihuacan completely dominated Mesoamerican regional interaction in that era. More than a decade of research at the site shows that it lacks the architectural or artifactual signatures of Teotihuacan influence touted in other studies of Early Classic interaction. While it is of a scale to rival Teotihuacan, it lacks prodigious pyramids and its residents built a sprawling nucleated community rather than an orthogonal grid plan. Clearly their organizational model-however conceived politically, socially, and religiously-was distinct and autochthonous despite being less than $150 \mathrm{~km}$ away and situated near highly desirable obsidian sources. Knight's careful analysis of obsidian artifacts and available sourcing information suggests that Teotihuacan received prestigious gifts form Cantona but did not regularly trade with this city. Moreover, the distribution of projectile point types, particularly with regard to 
what appear to be deliberately distinctive crafting techniques, suggestively links Cantona in independent trade networks with other parts of Mesoamerica. While more work needs to be done on the sourcing side of this inquiry, this is a very useful reality check on the notion that Teotihuacan uniformly dominated interaction spheres in Mexico during its apogee.

The northern frontier of Mesoamerica is one of the key areas in which to test the hypothesis posed at the beginning of this essay that Mesoamerica constituted a selfdefining world. José Luis Punzo Díaz, in this theoretically stimulating and programmatic review, chapter 9, proposes that this northwestern section of Mesoamerica was not a passive recipient of innovations and ideas as might be construed in a World Systems approach, but rather a dynamic and agentive zone in which elites participated in the exchange of prestigious commodities. His notion of the Chalchihuites phenomenon as a buffer zone comprised of a diverse mixture of groups with varying subsistence regimes and participating in relations stimulated by encounters with Core-area Mesoamericans resonates with the nonuniform institutional complexity model proposed by Frachetti for the Eurasian steppe in relation to southwestern Asia. This is especially clear in Punzo's declaration that the florescence of the northwestern area was not the product of colonization but of "selective appropriation and differential use of this corpus of pan-Mesoamerican ideas to variable degrees." His careful assessment of the data suggests that the Chalchihuites phenomenon arose not as a stimulus response to Teotihuacan but rather after the decline and fall of that metropolis. This substantial review and synthesis contain many more valuable aspects, but for my purposes I can conclude that Punzo Díaz persuasively shows that the self-defining dynamic I propose was in the capable hands of local people interested in enhancing their local status and power and not the product of imposition from the core area.

Timothy J. Knab and John M. D. Pohl (chapter Io) offer a bold vision of local people shaping their interaction within regions in their model of rotating power, social capital, and trade in the context of Pre-Columbian and postcontact Cholula. While they are careful to insist that the conquest dramatically changed the religion and social institutions of this preeminent Mesoamerican city, they also provide reasons for their view that deep structures persisted across this divide in the collective organization and maintenance of social capital. They suggest that the political economics of Cholula's very complex Catholic festival cycles register the perpetuation of cults focusing on Quetzalcoatl for which the Pre-Columbian city was justly famous. Those cults were managed by the city's traders, glossed as Pochteca along with many other trader sodalities of highland Mexico, including those of the Aztec empire. They make the persuasive argument that just as the enduring and evolving Catholic festival sodalities of Cholula require long-term accumulation of 
social capital extending across large groups of people, so the accumulation, transport, exchange, and disbursement of trade commodities required such social capital to finance the expeditions and absorb the risk. This is a quite different scenario than the one most Mesoamerican archaeologists are familiar with in the case of the Aztecs. The Aztec Pochteca evidently received financing for expeditions from wealthy aristocrats as well as from the state and gave profitable returns on such investments. In light of the arguments favoring some form of collective governance in the case of Teotihuacan, this model would seem to have significant potential for elucidating the interface of social institutions and regional exchange interaction deeper in time.

The Templo Mayor excavations have revealed a startling abundance of cached offerings deposited with successive expansions of the pyramid. Niklas Schulze and Blanca E. Maldonado, chapter in, situate their sample of over 3,000 copper bells from the offerings within a clear and substantial consideration of the present state of metallurgical studies in Mesoamerica. Despite a frustrating lack of archaeological information on the location and organization of workshops, mines, and other aspects of the operative chain of metal ore to finished artifacts, their contextual control of the Templo Mayor sample and their close analysis of this sample yield some very intriguing possibilities. They conclude, based on the remarkable internal stylistic consistency of the sample and comparable metallurgical coherency, that the copper bell offerings were most likely the product of institutional production organized by the Aztec state. They speculate that the workshops may well have been located in the capital nearby. A second likely source for bells was acquisition by the state from markets, where traders would have brought them from other crafting localities. Placed within the larger context of imperishable offerings going into the repeated expansions of the Templo Mayor, jades, and other preciosities, I am reminded of anthropologist David Graeber's (20II) proposition that currencies are first and foremost tokens of debt, backed by states and demanded by them as taxes and tribute. Copper bells in the Late Postclassic and contact periods were indeed currency, along with copper axes in some areas. The wide array of materials incorporated into the Templo Mayor offerings express a ranging interest in the precious and exotic, no doubt for good religious and ritual reasons. But the pattern these authors see in the bells suggests to me that this state had identified an emerging currency token and was stimulating its manufacture and use as such within Mesoamerica's larger political and economic interaction sphere. This kind of deliberate stimulating of currency production to facilitate state control was something colleagues and I identified with Spondylus in the Late Preclassic period of the Maya lowlands (Freidel et al. 2002).

Before Schulz and Maldonado focus on the Templo Mayor deposits, they situate their discussion in a broad review of the state of metallurgy studies in Mesoamerican 
archaeology today. The intriguing possibility that lower Central American and South American metallurgy predates Mesoamerican metallurgy by centuries if not millennia leaves open the prospect of long-distance trade, exchange, and diffusion between the continents. They then show how interaction within Mesoamerica linked craftspeople over distances and gradually expanded the distribution of metals as sacred media analogous to the much earlier and more pervasive jade and other greenstones. As with Hepp's opening chapter in this book on early interaction spheres in coastal Oaxaca and adjacent areas, these authors show how this concept comfortably and productively operates at varying geographic scales, from the continental to the local.

The scale of interaction in Mesoamerica is a focus of Joyce Marcus's chapter I2, and she argues that competition among polities within the Valley of Oaxaca and within the Mirador zone of northern Petén are more likely drivers of increased scalar integration than are any outside sources of stimulation. In this context she particularly voices skepticism for the idea that Teotihuacan might have projected conquest power into the Early Classic Maya lowlands. Marcus is exceptionally well prepared, through long-term research and prolific publication, to advocate for the role of competition and warfare in the consolidation of a large state in the Valley of Oaxaca. But in the case of the Preclassic Maya lowlands, there are a number of new discoveries and research programs that make that situation rather different. We now know that the earliest documented solar commemorative architectural complex, E Group in the parlance of southeastern Mesoamerica, dates to the transition between the Early and Middle Preclassic periods (Iо०о B C) at the site of Ceibal. This is in the Petexbatún area on the Pasión River, far south of the Mirador area (Inomata et al. 2013). As James Doyle (2012) argues, E Groups characterize the first ceremonial centers throughout the core area of Petén, not just in the Mirador area. They are distributed in a pattern that appears to be cooperative more than competitive, with closely adjacent but distinct "viewsheds." The Mirador area itself contains a number of large sites with massive central architecture dating to the Preclassic, not just El Mirador and Nakbe. Preclassic Calakmul, while home to an impressive main pyramid, pales in comparison to Yaxnohcah to the southeast (Reese-Taylor 2017), and more and more large Preclassic sites are being discovered every year in the central interior of the peninsula. This landscape, more densely populated with large communities in the Preclassic period, will have to be much better understood archaeologically before we can address the kinds of interaction that its inhabitants undertook that moved them in the direction of increased scalar complexity. Personally I believe that El Mirador will prove to have held hegemonic sway over a large portion of the lowlands during the Late Preclassic period. I do not think that this polity could have accomplished such a feat primarily through warfare, though 
not doubt people fought wars in this period. Rather I predict that the evidence will eventually support El Mirador as a polity coordinating trade and commerce within the lowlands and beyond. It may well presage Knab and Pohl's Cholula model, presented in chapter Io, of collective rule and social capital in this regard. While this is speculation, it is certain that we are just at the beginning of our investigation of Preclassic lowland Maya civilization.

The rich and varied applications of the idea of interaction in this book demonstrate that it remains highly useful in the creation of archaeological models for Mesoamerica. It is a relatively neutral term for comparing complicated sets of data, and in that regard it starts to really show its value when it can be used as an armature for models of social institutions and cultural realities of the kind that people experience and experienced in the past. All of the contributors have this goal in mind, even as they are operating at different stages on the path toward it. The book moves us effectively along that path.

\section{REFERENCES}

Anthony, David W. 2010. The Horse, the Wheel, and Language: How Bronze-Age Riders from the Eurasian Steppes Shaped the Modern World. Princeton University Press, Princeton.

Ardren, Traci. 2002. "Death Becomes Her: Images of Female Power from Yaxuna Burials." In Ancient Maya Women, edited by Traci Ardren, 68-88. Altamira Press, Walnut Creek, CA.

Ball, Joseph W. 1983. “Teotihuacan, the Maya, and Ceramic Interchange: A Contextual Perspective." In Highland-Lowland Interaction in Mesoamerica: Interdisciplinary Approaches, edited by Arthur G. Miller, 125-145. Dumbarton Oaks, Washington, DC.

Brown, Linda. 2014. "When Pre-Sunrise Beings Inhabit a Post-Sunrise World: Time, Animate Objects and Contemporary Tz'utujil Maya Ritual Practitioners." In The Measure and Meaning of Time in Mesoamerica and the Andes, edited by Anthony F. Aveni, 53-77. Dumbarton Oaks Research, Washington, DC.

Caldwell, Joseph. 1964. "Interaction Spheres in Prehistory." Hopewellian Studies, Scientific Papers $12(6): 133-143$.

Carrasco, Michael D., and Joshua D. Englehardt. 2015. "Diphrastic Kennings on the Cascajal Block and the Emergence of Mesoamerican Writing." Cambridge Archaeological Journal 25(3):635-656.

Diehl, Richard A. 2006. The Olmecs: America's First Civilization. Thames and Hudson, New York.

Doyle, James. 2012. "Re-Group on 'E-Groups': Monumentality and Early Centers in the Middle Preclassic Maya Lowlands." Latin American Antiquity 23(4):355-379. 
Frachetti, Michael D. 2008. Pastoral Landscapes and Social Interaction in Bronze Age Eurasia. University of California Press, Berkeley.

Frachetti, Michael D. 20I2. "Multiregional Emergence of Mobile Pastoralism and Nonuniform Institutional Complexity across Eurasia." Current Anthropology 53(I):2-38.

Freidel, David A. 1979. "Culture Areas and Interaction Spheres: Contrasting Approaches to the Emergence of Civilization in the Maya Lowlands." American Antiquity 44(I):36-54.

Freidel, David A. 2012. "Maya and the Idea of Empire: A View from the Field.” Gordon R. Willey Lecture, Peabody Museum of Archaeology and Ethnology at Harvard University. https://www.peabody.harvard.edu/node/764, accessed December 7, 2018.

Freidel, David A. 2014. “The Origins and Development of Lowland Maya Civilization.” In The Cambridge World Prehistory, Vol. 2: East Asia and the Americas, edited by Colin Renfrew and Paul Bahn, 1043-1057. Cambridge University Press, New York.

Freidel, David A. 2018. "Maya and the Idea of Empire." In Pathways to Complexity: A View from the Maya Lowlands, edited by M. Kathryn Brown and George Bey, 363-386. University Press of Florida, Gainesville.

Freidel, David A., Hector L. Escobedo, and Stanley P. Guenter. 2007. "A Crossroads of Conquerors: Waka' and Gordon Willey's 'Rehearsal for the Collapse Hypothesis.” In Gordon R. Willey and American Archaeology: Contemporary Perspectives, edited by Jeremy A. Sabloff and William Fash, I28-208. University of Oklahoma Press, Norman.

Freidel, David A., Marilyn A. Masson, and Michelle E. Rich. 2017. "Imagining a Complex Maya Political Economy: Tokens and Currencies in Images, Texts, and the Archaeological Record." Cambridge Archaeological Journal 27(I):29-54.

Freidel, David A., and F. Kent Reilly III. 20I0. "The Flesh of God: Cosmology, Food, and the Origins of Political Power in Southeastern Mesoamerica." In Pre-Columbian Foodways: Interdisciplinary Approaches to Food, Culture, and Markets in Mesoamerica, edited by John E. Staller and Michael D. Carrasco, 636-679. Springer, New York.

Freidel, David A., Kathryn Reese-Taylor, and David Mora-Marín. 2002. "The Old Shell Game, Commodity, Treasure and Kingship in the Origins of Maya Civilization.” In Ancient Maya Political Economies, edited by Marilyn A. Masson and David A. Freidel, 4I-87. Altamira Press, Walnut Creek, CA.

Freidel, David A., Michelle E. Rich, and Marilyn A. Masson. 2015. "Pecked Circles and Divining Boards, Calculating Instruments in Ancient Mesoamerica." In Cosmology, Calendars, and Horizon-based Astronomy in Ancient Mesoamerica, edited by Anne Dowd and Susan Milbrath, 249-264. University Press of Colorado, Boulder.

Graeber, David. 20Ir. Debt: The First sooo Years. Melville House, Brooklyn and London. González Lauck, Rebecca B. 2010. "The Architectural Setting of Olmec Sculpture Clusters at La Venta, Tabasco." In The Place of Stone Monuments: Context, Use and Meaning in 
Mesoamerica's Preclassic Transitions, edited by Julia Guernsey, John Clark, and Barbara Arroyo, 130-I48. Dumbarton Oaks, Washington, DC.

Hull, Kerry M. 2006. "Politics by a Different Means: Ancient Maya Warfare and Alliance Strategies." Journal for the Comparative Study of Civilizations I1:81-98.

Inomata, Takeshi, Daniela Triadan, Kazuo Aoyama, Victor Castillo, and Hitoshi Yonenobu. 2013. "Early Ceremonial Constructions at Ceibal, Guatemala, and the Origins of Lowland Maya Civilization.” Science 340(613I):467-47I.

Kohl, Phillip L. 1987. "The Use and Abuse of World Systems Theory: The Case of the Pristine West Asian State." Advances in Archaeological Method and Theory II: I-35.

Langley, James C. 1993. “Symbols, Signs and Writing Systems." In Teotihuacan: Art from the City of the Gods, edited by Kathleen Berrin and Esther Pazstory, I28-139. Thames and Hudson and the Fine Arts Museums of San Francisco, New York and San Francisco.

McGuire, Randall. 1989. “The Greater Southwest as a Periphery of Mesoamerica.” In Centre and Periphery, edited by T. C. Champion, 40-6r. Allen and Unwin, London.

Milbrath, Susan. 2000. "Xochiquetzal and the Lunar Cult of Central Mexico." In In Chalchihuitl in Quetzalli: Precious Greenstone, Precious Quetzal Feather, Essays in Honor of Doris Heyden, edited by Eloise Quiñones Keber, 31-54. Labyrintos, Lancaster.

Nielsen, Jesper. 2003. Art of the Empire: Teotibuacan Iconography and Style in Early Classic Maya Society, AD 380-500. Unpublished PhD dissertation. University of Copenhagen, Copenhagen.

Ortman, Scott. 2012. "Bowls to Gardens: A History of Tewa Community Metaphors." In Religious Transformation in the Late Prehispanic Pueblo World, edited by Donna M. Glowacki and Scott Van Keuren, 84-107. University of Arizona Press, Tucson.

Panofsky, Erwin. 1939. Studies in Iconology: Humanistic Themes in the Art of the Renaissance. Oxford University Press, Oxford.

Reese-Taylor, Kathryn. 2017. "Founding Landscapes in the Central Karstic Uplands." In Maya E Groups: Calendars, Astronomy, and Urbanism in the Early Lowlands, edited by David A. Freidel, Arlen F. Chase, Anne S. Dowd, and Jerry Murdock, 480-515. University Press of Florida, Gainesville.

Reilly, F. Kent, III. 1994. "Enclosed Ritual Spaces and the Watery Underworld in Formative Period Architecture: New Observations on the Function of La Venta Complex A." In The Seventh Palenque Round Table, Ig89, edited by Merle Green Roberston and Virginia M. Fields, I25-135. Pre-Columbian Art Research Institute, San Francisco.

Reilly, F. Kent, III. 1996. “The Lazy-S: A Formative Period Iconographic Loan to Maya Hieroglyphic Writing." In Eighth Palenque Round Table, 1993, edited by Merle Green Robertson, Martha J. Macri, and Janet McHargue, 413-424. Pre-Colombian Art Research Institute, San Francisco. 
Reilly, F. Kent, III. 2002. "The Landscape of Creation: Architecture, Tomb and Monument Placement at the Olmec Site of La Venta." In Heart of Creation: Issues in Mesoamerican Iconography and Art History: Essays in Honor of Linda Schele, edited by Andrea Stone, 34-65. University of Alabama Press, Tuscaloosa.

Rice, Prudence. 2017. "The E Group as Timescape: Early E Groups, Figurines and the Sacred Almanac." In Maya E Groups: Calendars, Astronomy, and Urbanism in the Early Lowlands, edited by David A. Freidel, Arlen F. Chase, Anne S. Dowd, and Jerry Murdock, 135-176. University Press of Florida, Gainesville.

Simpson, Lesley B. 1964. Cortés: The Life of the Conqueror by His Secretary Francisco Lopez de Gomara. University of California Press, Berkeley.

Stanton, Travis W., David A. Freidel, Charles K. Suhler, Traci Ardren, James N. Ambrosino, Justine M. Shaw, and Sharon Bennett. 2010. Excavations at Yaxuná, Yucatán, Mexico. BAR International Series 2056. Archaeopress, Oxford.

Stuart, David. 2000. “'The Arrival of Strangers': Teotihuacan and Tollan in Classic Maya History." In Mesoamerica's Classic Heritage: From Teotihuacan to the Aztecs, edited by Davíd Carrasco, Lindsay Jones, and Scott Sessions, 465-513. University Press of Colorado, Boulder.

Stuart, David. 2004. "The Beginnings of the Copan Dynasty: A Review of the Hieroglyphic and Historical Evidence." In Understanding Early Classic Copan, edited by Ellen E. Bell, Marcello A. Canuto, and Robert J. Sharer, 215-248. University of Pennsylvania Museum of Archaeology and Anthropology, Philadelphia.

Sugiyama, Saburo. 2005. Human Sacrifice, Militarism, and Rulership: Materialization of State Ideology at the Feathered Serpent Pyramid, Teotihuacan. Cambridge University Press, Cambridge.

Sugiyama, Saburo, and Leonardo López Austin. 2007. “Dedicatory Burial / Offering Complexes at the Moon Pyramid, Teotihuacan: A Preliminary Report of 1998-2004 Explorations." Ancient Mesoamerica I8(I):127-I46.

Suhler, Charles K. 1996. Excavations at the North Acropolis, Yaxuná, Yucatán, México. Unpublished PhD dissertation. Southern Methodist University, Dallas.

Suhler, Charles K., and David A. Freidel. 1998. "Life and Death in a Maya War Zone." Archaeology 5I(3):28-34.

Taube, Karl. 2004. "Structure IoL-16 and Its Early Classic Antecedents: Fire and the Evocation of Resurrection of K'inich Yax K'uk' Mo.' In Understanding Early Classic Copan, edited by Ellen E. Bell, Marcello A. Canuto, and Robert J. Sharer, 265-295. University of Pennsylvania Museum of Archaeology and Anthropology, Philadelphia.

Tiesler, Vera, Andrea Cucina, Travis Stanton, and David Freidel. 2017. Before Kukulcan, Life, Death and Identity at Classic Period Yaxuna, Yucatan, Mexico. University of Arizona Press, Tucson. 
Urban, Patricia A., and Edward M. Schortman. 1986. The Southeast Maya Periphery. University of Texas Press, Austin.

Wallerstein, Immanuel. 1974. The Modern World-System I: Capitalist Agriculture and the Origins of the European World-Economy in the Sixteenth Century. Academic Press, New York.

Wolf, Eric R. 1982. Europe and the People without History. University of California Press, Berkeley. 



\section{Contributors}

PHILIP J. ARNOLD III received his PhD from the University of New Mexico and is currently professor of anthropology at Loyola University Chicago. His research interests include the origins of complex society, ancient technological systems, and economic behavior in pre-Columbian Mexico. These developments are assessed against a backdrop of approximately 3000 years of prehistory along Mexico's southern Gulf lowlands. His most recent project at Teotepec explores the impact of foreign incursions and influence on the in situ cultural development in the Tuxtla Mountains. He is the author and editor of numerous publications; his most recent volume, coedited with Lourdes Budar, is Arqueologia de Los Tuxtlas: Antiguos Paisajes, Nuevas Miradas (Universidad Veracruzana, 2016).

LOURDES BUDAR was trained as an archaeologist at the Universidad Veracruzana (UV). She earned a doctoral degree in Ciencias Humanas with a specialization in Estudios de la Tradición at El Colegio de Michoacán, A.C. She is a full-time professor in the UV Department of Anthropology. She is a member of the Sistema Nacional de Investigadores of the Consejo Nacional de Ciencia y Tecnología, as well as a board member of the Los Tuxtlas Biosphere Reserve of the National Comission of Protected Natural Areas. She is chair of the Landscape Archaeology and Cosmovision academic group, where her research focuses on landscape archaeology, Mesoamerican cosmovision and representational systems, and crisis, collapse, and processes of social reorganization in the Gulf coast area of southern Veracruz. 
She is director of the Proyecto Arqueológico Piedra Labrada-Sierra de Santa Marta, as well as the Proyecto Arqueológico San Martín Pajapan, Los Tuxtlas. She has over fifty national and international publications, including Piedra Labrada, with Sara Ladrón de Guevara; Arqueología de Los Tuxtlas, with Philip J. Arnold III; and Arqueología de la Costa del Golfo, dinámicas de la interacción politica, económica e ideológica, with Marcie L. Venter and Sara Ladrón de Guevara. She is currently the director of the UV Intercultural program.

MICHAEL D. CARRASCO (PhD art history, University of Texas, Austin, 2005) serves as associate professor of visual cultures of the Americas and cultural heritage studies in the Department of Art History. Drawing on a broad range of subjectsincluding poetics, iconography, image theory, and ecology-his principal areas of research include the origins of writing and indigenous aesthetics, theology, and epistemologies in Mesoamerica. The other main area of his scholarship lies in cultural heritage, particularly in digital humanities and the juncture between folk traditions and global art systems. His recent work has been supported by internal funding from FSU, an NEH Digital Humanities Level II Start-up Grant; an NEH Fellowship; the Consejo Nacional de Ciencia y Tecnología (CONACYT); and a Japan Council of Local Authorities for International Relations (CLAIR) Furusato Vision Project (for the project Oita's Bamboo Art and Heritage). His publications include the edited volumes Parallel Worlds: Genre, Discourse, and Poetics in Contemporary, Colonial, and Classic Maya Literature (University Press of Colorado, 2012) and Pre-Columbian Foodways: Interdisciplinary Approaches to Food, Culture, and Markets in Ancient Mesoamerica (Springer, 2010), and the exhibition catalogue Decolonizing Refinement: Contemporary Pursuits in the Art of Edouard Duval-Carrié. His articles have appeared in the Cambridge Archaeological Journal, Mexicon, and The World Religious Cultures, among others.

JOSHUA D. ENGLEHARDT (PhD anthropology, Florida State University, 20II) is a profesor-investigador (research professor) at the Centro de Estudios Arqueológicos of El Colegio de Michoacán, Mexico, and a Level I National Investigator of the Mexican National Council on Science and Technology (CONACYT). He specializes in Mesoamerican archaeology and visual culture, with a research focus on the development of Mesoamerican writing systems in the Formative period and the correlation of emerging scripts with diachronic changes in material culture. He is the codirector of the Mesoamerican Corpus of Formative Period Art and Writing, an $\mathrm{NEH}$-funded interdisciplinary project that is developing an online database and digital tools for the investigation and presentation of early Mesoamerican visual cultures. Developing out of his work on this project, he has a growing interest in 
the application of digital technologies in the humanities and the impact of new media on archaeological, art historical, and heritage studies. He is also currently a member of a multidisciplinary team currently exploring the cultural uses and significance of cycads and maize as part of the CONACYT-funded project Cícadas y la Domesticación de Maíz en el Paisaje Mesoamericano. Recent publications include Archaeological Paleography (Archaeopress, 2016), and the edited volumes Agency in Ancient Writing (University Press of Colorado, 2012), Diálogos sobre la relación entre arqueologia, antropologia, e historia (El Colegio de Michoacán, 2017), and These Thin Partitions: Bridging the Growing Divide between Cultural Anthropology and Archaeology (University Press of Colorado, 2017), as well as over twenty articles and book chapters that stem from his fieldwork throughout Mexico and twenty years of living, working, or studying in the Global South.

GARY M. FEINMAN is the MacArthur Curator of Anthropology at the Field Museum of Natural History, Chicago. His research interests include the archaeology of urban societies and preindustrial economics. He has codirected long-term archaeological research programs for decades in both Oaxaca, Mexico and Shandong, China. His publications include Images of the Past, 7 th edition (McGraw-Hill, 2012); coauthored with T. Douglas Price, Archaeological Perspectives on Political Economies (University of Utah Press, 2004), edited with Linda M. Nicholas; Ancient Oaxaca (Cambridge University Press, 1999), coauthored with Richard Blanton, Stephen Kowalewski, and Linda Nicholas; and Archaic States (School of American Research Press, 1998), coedited with Joyce Marcus. Feinman is a Fellow of the American Association for the Advancement of Science and received the Presidential Recognition Award from the Society for American Archaeology. He is the coeditor of the Journal of Archaeological Research.

DAVID FREIDEL is professor of anthropology at Washington University in St. Louis. He was principal investigator of three long-term archaeological research projects: the Cerros Project in Belize, the Selz Foundation Yaxuna Project in Mexico, and the El Peru-Waka' Project in Guatemala. He coauthored A Forest of Kings and Maya Cosmos with Linda Schele. He recently coedited a book on Maya E Groups and coauthored a book on the human remains of Yaxuna.

GUY DAVID HEPP is an assistant professor of anthropology at California State University, San Bernardino. He holds a BA and a PhD from the University of Colorado at Boulder and an MA from Florida State University. His research is focused on the early complex societies of Mesoamerica and his recent studies have considered the archaeology of La Consentida, an Early Formative period (2000-1000 cal 
BC) village in Oaxaca, Mexico. This project, funded by the NSF and the Fulbright Program, was awarded the Society for American Archaeology's 2016 Dissertation Award. In related work, he has published several papers regarding the iconography, depositional context, technological characteristics, and cosmological implications of ancient ceramic figurines and musical instruments.

KERRY M. HULL is a professor in the Department of Ancient Scripture at Brigham Young University and formerly a professor at Reitaku University, Japan, and a lecturer at Tokyo University of Foreign Studies and Hosei University, Japan. He earned a BA in Spanish and BA in French in 1992 from Utah State University. He received an MS in applied linguistics from Georgetown University in 1993. He completed a PhD in linguistic anthropology at the University of Texas at Austin in 2003. His research interests include Mesoamerican epigraphy, Mesoamerican languages, Maya oral traditions and narratives, sociolinguistics, ethnoornithology, ceremonialism, and Polynesian linguistics. He has conducted linguistic, ethnographic, and archaeological fieldwork in Mexico, Belize, Guatemala, and Honduras. He specializes in the language and culture of the Ch'orti' Maya of southern Guatemala. He has also carried out linguistic fieldwork on the Ua Pou dialect of Northern Marquesan and on the dialect used on the island of Raivavae in the Austral chain in French Polynesia. He most recently is the author of A Dictionary of Chorti' Mayan-Spanish-English (2016), a coeditor of Parallel Worlds: Genre, Discourse, and Poetics in Contemporary, Colonial, and Classic Maya Literature (2012), and a coeditor of The Ch'orti' Maya Area: Past and Present (2009).

ELIZABETH JIMÉNEZ GARCíA is an investigadora (investigator) at the Instituto Nacional de Antropología e Historia. She received an undergraduate degree in archaeology at the Escuela Nacional de Antropología e Historia and a doctoral degree in Mesoamerican Studies from the Universidad Nacional Autónoma de México. Her investigations and publications have centered on the archaeology and ethnohistory of the La Montaña region of eastern Guerrero, as well as on the sculptural iconography of Tula, Hidalgo. Her more recent interests are focused on the codices and colonial documents, housed in the Archivo General de la Nación, that speak to the history and lifeways of La Montaña cultural groups.

TIMOTHY J. KNAB is a full-time professor of anthropology, linguistics, and environmental studies at the Universidad de las Américas, Puebla, in Cholula, Puebla, Mexico. Dr. Knab has worked extensively with over a half dozen Mesoamerican languages and literatures. He is the author of numerous books and also a professional chef who works closely with the Slow Food movement. His students have achieved success in business, government, academia, and professional kitchens throughout the world. 
CHARLES L. F. KNIGHT, PhD in anthropology from the University of Pittsburgh, has investigated issues relating to the production, distribution and consumption of Mesoamerican chipped-stone tools, especially those made from obsidian for twenty-five years. Initially, he focused on researching consumer-site economics in the southern Gulf lowlands at the Olmec center of Tres Zapotes, Veracruz, and its environs. In order to better understand the processes responsible for the obsidian consumed in the southern Gulf lowlands, and, quite frankly, just tired of the garrapatas, he moved his research focus to the Highlands in 2012. Since then, he has investigated the extraction and early stage production of obsidian commodities at the Zaragoza-Oyameles obsidian source area in Cuenca Oriental of Puebla, Mexico. Here his primary interests include the degree of technological variation across space and through time, the concept of resource control, and the intergenerational transfer of crafting knowledge. He is the assistant director of the Consulting Archaeology Program at the University of Vermont.

BLANCA E. MALDONADO is an archaeologist specializing in ancient metallurgy and production processes. Specific areas of interest include pre-Columbian copper metallurgy in the New World, preindustrial nonferrous metallurgy, and the cultural dynamics of technological practices. Her research has focused mainly on Mesoamerica and the South Central Andes. Maldonado holds a PhD in anthropology from the Pennsylvania State University, with a specialization in archaeology. Her doctoral studies included training in archaeological science and archaeometallurgy at the University of Oxford and University College London. She has received several research grants and awards, including a DAAD Research Grant (for an Academic Stay at the University of Bonn, Germany) and a Postdoctoral Research Fellowship from the Alexander von Humboldt Foundation, also in Germany (Curt-Engelhorn-Zentrum Archäometrie Mannheim). She is currently professor and researcher in the Centre for Archaeological Studies at El Colegio de Michoacán, AC, in Mexico.

JOYCE MARCUS is the Robert L. Carneiro Distinguished University Professor of Social Evolution at the University of Michigan, Ann Arbor. Marcus's research includes the origins of the village, the origins of writing, comparative chiefdoms and states, the emergence of social and political inequality, and the political economy of states and empires. Marcus has carried out fieldwork and excavations in Nevada (Lovelock Cave), southern California (the La Brea Tar Pit), Mexico (San José Mogote), Guatemala (El Mirador, Tres Islas, Naranjo, Tintal, Chunhuitz), and Peru (Cerro Azul). Her books include Emblem and State in the Classic Maya Lowlands: An Epigraphic Approach to Territorial Organization (Harvard University 
Press, 1976); Mesoamerican Writing Systems: Propaganda, Myth, and History in Four Ancient Civilizations (Princeton University Press, 1992); Archaic States (School for Advanced Research, 1998), with Gary M. Feinman; Women's Ritual in Formative Oaxaca (University of Michigan Museum of Anthropology, 1998); Excavations at San José Mogote I: The Household Archaeology (University of Michigan Museum of Anthropology, 2005), with Kent Flannery; Excavations at Cerro Azul, Peru (The Cotsen Institute of Archaeology Press, 2008); The Ancient City (School for Advanced Research, 2008), with Jeremy A. Sabloff; Monte Albán (El Colegio de México, 2008); Andean Civilization (The Cotsen Institute of Archaeology Press, 2009), with P. Ryan Williams; The Creation of Inequality (Harvard University Press, 2012), with Kent Flannery; Excavations at San José Mogote 2: The Cognitive Archaeology (University of Michigan Museum of Anthropology, 2015), with Kent Flannery; and Coastal Ecosystems and Economic Strategies at Cerro Azul, Peru (University of Michigan Museum of Anthropology, 2016).

JeSPER NIELSEN is associate professor in the Section of American Indian Languages and Cultures at the University of Copenhagen. He received his MA (1998) and $\mathrm{PhD}$ (2003) from the Department of American Indian Languages and Cultures from the University of Copenhagen. His research focuses on Mesoamerican iconography, epigraphy, and religion, in particular in Teotihuacan, Maya, and Epiclassic cultures. He also has a strong interest in early colonial studies in central Mexico and the Maya region, as well as research history. Currently, he is co-directing the research project The Origins and Development of Calendars and Writing in Central Mexico together with Christophe Helmke. Jesper is also a member of the Proyecto La Pintura Mural Prehispánica en México at the Universidad Nacional Autónoma de México (UNAM) and a member of the consejo de asesores of the journal Arqueologia Mexicana. He has published numerous books, chapters, and articles in international peer-reviewed journals (including Ancient Mesoamerica, Antiquity, Latin American Antiquity, Mexicon, the PARI Journal, and Ancient America). Recent publications include Restless Blood: Frans Blom, Explorer and Maya Archaeologist, coauthored with Tore Leifer and Toke Reunert Sellner (2017) and "The Early Classic Murals of El Rosario, Mexico: Description and Iconographic Analysis," Ancient America I4:I-74 (with Christope Helmke, Fiorella Fenoglio, and Juan Carlos Saint-Charles, 2019).

JOHN M. D. POHL is both adjunct professor in art history at UCLA and Lecturer in Anthropology at Cal State, LA. He has received numerous fellowships and grants for his research on the Nahua, Mixtec, Zapotec, and Aztec civilizations of southern Mexico. In addition to academic pursuits, Dr. Pohl has had a prolific career as a 
writer, designer, and curator for major museums and exhibitions around the country including the Museum of the Cherokee Indian in Cherokee, North Carolina; "Sorcerers of the Fifth Heaven: Art and Ritual in Ancient Southern Mexico," for Princeton University; "The Aztec Pantheon and the Art of Empire," for the Getty Villa Museum; and "The Children of Plumed Serpent, the Legacy of Quetzalcoatl in Ancient Mexico," for the Los Angeles County Museum of Art and the Dallas Museum of Art.

José LUis PUnzo DíAz holds a PhD in archaeology from the Escuela Nacional de Antropología e Historia in Mexico City. He is a member of the National Research System (SNI) level I and has been a researcher for the Instituto Nacional de Antropología e Historia since 2004. Previously, he served as director of the Museo de las Culturas del Norte in Paquimé, Chihuahua. His principal research interests are the relations between the US Southwest, Northern Mexico, and Mesoamerica; archeometallurgy; the Chalchihuites culture of northern Mexico; and the archaeology of Michoacán. His extensive archaeological fieldwork has focused on Durango and Michoacán, and he has been the director of the Ferrería archeological zone in Durango, as well as Tzintzuntzan and Tingambato in Michoacán. He has published more than thirty archeological research papers and five books.

ÁNGEL IVÁN RIVERA GUZMÁN is an archaeologist of the Instituto Nacional de Antropología e Historia (INAH). He has realized archaeological investigations in the states of Oaxaca and Guerrero, Mexico. He is a specialist in the iconography and writing systems of southeastern Mesoamerica. His recent fieldwork focuses on the study of the engraved monuments of western Oaxaca and eastern Guerrero.

D. BRYAN SCHAEFfer received his PhD in art history from Florida State University. He is currently a visiting assistant professor at Thomas More University.

NIKLAS SCHULZE has studied prehistory and prehispanic languages and cultures (Hamburg, Germany) and holds an MA in scientific methods in archaeology (Bradford, England) and a PhD in anthropology (Mexico City, Mexico). Currently he is professor-researcher in archaeology at the Autonomous University of San Luis Potosí, Mexico. His research focus is on material culture (especially archaeometallurgy) and cultural heritage conservation. 



\section{Index}

a-k'a-cha, I32

Abbott, Ellen, 271, 277

abstraction, 86-88

Acab, 166

Acalan, 120

Acaponeta phase, 275, 278, 279

Acapulco, 197, 200n 4

Acatempan monument, 176, 177, 185, I86, 186

(fig.), $187,189,198$

Acatolín, 196

Acaxee, 282, 283

Acropolis, 179

aesthetics, 88, 104, I5I, I56, I58; Japanese, 90 ;

Korean, 90; Teotihuacan-Maya, 167, 168

Agaltepec, 2 I2

agriculture, 262, 277, 352

aguardiente, 306

Aguaruto, 277

Ah Kin Chel, 343

Ahuítzotl, 322, 329, 330, 33I

ajaw, 88, 92, 94, 97 (fig.), 98 (fig.); glyph variants,

$$
83,95-97
$$

almenas, 180,195

Alta Verapaz, 134

Alta Vista, 263, 265, 273, 276, 277, 280; abandonment of, 278
Alta Vista phase, 266, 267, 269, 271, 272; apogee of, 283

Altamira, 35I

Altar de los Reyes, 351

altars, 197, 218, 265

Altun Ha, 247, 344

Amapa, 280

Amaro Red-on-Buff/Cream, 271, 272

Amatzinac River Valley, 183

amazonite, 266

Anahuac, 322

Anasazi-Mogollon, 132

Anatolian hypothesis, I25

Anawalt, 68

Andean region, 313, 314-15

anthropomorphs, 7I, 7I (fig.), 278

Apatzingán, 280

Arcelia, I84, 193, I95

"Archaeological and Linguistic Correlations in Mayaland and Associated Areas of Meso-

America" (Kaufman), I25

archaeological approaches, I6, I8, 19, 20

archaeological records, 8, 10, 35

archaeology, 3, 16, 17, 240, 265; anthropological, 23n6; linguistics and, 98-100

archaeometrics, 17, 19 
Archaic-Formative period, sociocultural changes during, $5 \mathrm{I}$

Archaic period, 282

architecture, 6, 276, 284; Ayala phase, 275; earthen, 63; public, 220; talud-tablero, 150, 155, I62, I69ni, I69n3, I78, 179, 2 II

Arnold, J. C., 331

Arnold, Philip J., III, 7, 2I, 373

Arrazola, 347

arsenic, 317, 318

art, 18, 108n7, 197; Aztec imperial, I82; Maya, 94; scripts and, I07n 4 ; Zapotec, 94

art history, 16, 19, 21, 23n9, 86, 107n2

artifacts, 317; metal, 316, 326, 332; Teotihuacanstyle, I8I, 192-93

Asociación de la Vela Perpetua, 304

Atetelco, I87

Atkinson, Quentin D., phylogenic studies by, I25 atlatl, 164, 187

atole, 126,306

atz'aam, 137

Auilix, 166

Aveni, Anthony, 265

Axayacatl, reign of, 331

axes, copper, 375

Ayala phase, 267, 268, 269, 271, 272, 274, 275, 276, $277,278,280,281$

Aztatlán, 263, 277, 284; tradition, 278-8I

Aztatlán Mercantile System, 263, 273

Aztec empire, 183, 293, 320, 322, 327, 328, 374

Aztec Triple Alliance, 2II, 212

Aztecs, 14, 275, 315-16, 318, 375

Baja Verapaz, 134

Bajío phase, 61, 62, 75n6, 180, 245

Balakbal, 351, 354

Balam Quitze, 166

Balberta, 248, 251, 344

Ball, Joseph, I62, 371

ballcourt markers, 179, 192, 193, 193 (fig.), 194, 195

ballcourts, I82, I92, 197, 265, 268, 269, 275, 276, $282,284,352,357$

Balsas River, I84, 199n4

Baluarte phase, 272

Baluarte River, 273

bar and dot notation, 219, 23In2, 369

Barabas, Alicia M., 75ns

Barra phase, 72, 74, 75n3, 367; ceramic assemblages of, 54-58, 60-64; pottery, 54, 73, 74n2; vessel types/percentage, 56 (fig.); wares, 67

Barrera, Raúl, 197

Barrio San Sebastián, 190

barrios, 292, 297, 298, 299, 302, 303, 304, 307, $309,345-46$

Bartolomé, Miguel A., 75ns

basalt, 70, 2 II

Basin of Mexico, 183, 184, 199, 215, 247, 249, 254, 255,345

battle standards, 194; Teotihuacan-style, 193 (fig.)

Bay of Campeche, 224

Becan, 344; tripods from, 163, I63 (fig.)

Beekman, Christopher S., I2

beeswax, 317, 323, 324, 34I

Belén Chico, 229

Bell, Ellen E., I6I

bells, 324; IA5a, 280; ICra, 280; bronze, 316; collection of, 331; common forms of, 320 (fig.); copper, 280, 283, 316, 317, 318-22, 325, 325 (fig.), 327, 328, 332, 375; elite, 321; heterogeneity of, 332; Maya, 319 (fig.); Mesoamerican, 319 (fig.); metal, 314; production of, 316, 319, 320, 322, 323, 333; ritual, 321; Type F, 319 (fig.); typologies of, 319 (fig.)

Bennyhoff, James, I5I, I58

Berdan, Frances F., 321, 324, 325, 326

Berlo, Janet, 199n3

beryls, 329

bifaces, 24I, 245, 248, 249

billiard-ball model, 3, 8-II, 39

biodistance, 40

Bird, Junius, 323-24

bird ocarina, 7I (fig.)

Bishop, Ronald L., I6I

Black-and-White-on-Red pottery, 134

Black Falls Ruin, 280

blackware, 164, 167

blades, 244; obsidian, 34; prismatic, 24I, 255

Blom, Frans, 213, 214, 216, 219-20, 221, 352

Blomster, Jeffrey P., 68, 69

Blue Creek, 137

Boas, Franz, 9

Bonfil Batalla, Guillermo, 295, 303

Boot, Erik, 126

Botadero engraved, 277

bottles, 55, 62-63; long-necked, 61, 62 (fig.); stirrup, 64 
Bourdieu, Pierre, 300

Bove, Frederick J., 25I

bowls, I52, 197; conical, 58; decorated, 58, I55; flat-bottomed, I54; grater, 55, 58, 60-6I, 6I (fig.), 75n5; interior-incised, 74; kidneyshaped, 56,74 ; open, 62 ; semispherical, 57,58 (fig.), 60, 6I (fig.); square, 58, 6I (fig.)

boxes: funerary, 100 (fig.); stone, 22I, 22I (fig.), 222

Braswell, Geoffrey, 152, I56, 163, 252

Bray, Warwick, 322

Breitburg, Emmanuel, 132

bronze, 316, 321

Bronze Age, 22n 4, 366

Brooklyn Museum, 187

Brown and Buff slips, 278

Brown, Cecil, I22, I2 4, I25, I34, I35, I36, I39n3

Budar, Lourdes, 7, 21, 373

Buff fine paste, 231

Burial Io, 156-57

Burial 21, I54

Burial 25, 347

Burial 39, 347

Burial II6, 356

burials, 58, 62-63, 64, 155, 192, 344; adult male, 62; child, 61, 67; elite, 347; lower-status, 347

Buriticá, mining sites in, 327

Burmeister, Stefan, II, I2

Butler, Mary, 227, 228, 229

cacao, 62, I25, I69n 4, 211, 342, 343; beans, I37, I54, I55; drink, I5I

Cacaotepec, 347

caciques, 293

Calakmul, 137, 248, 350, 351, 353, 354-57, 370, 376 ; core area of, 350 (fig.); patron deities of 356; political network of, 355

Caldera Humeros, 242

Caldwell, Joseph, 366

calendar, 123; Aztec, 329; long-count, 213, 218; Mayan, 215; ritual, 277; solar, 277; Zapotec, Iogni3

Calera phase, I82, 279, 280

Calichal, 27I

Cambridge Archaeological Journal, 368

Campamento Fine Orange, 225, 226, 227

Campbell, Lyle R., I23, I2 4, I3I, I32, I38, I39n7, I39n9, I4In 24, I 4 In 25

Campeche, 162, I63, 211, 227, 228, 229, 231, 245, 354
Campo Lanz, 20onis

Cancuén, 137

candeleros, $\mathrm{I} 8 \mathrm{I}, \mathrm{I} 89$

Canelas sites, 283

Cañon de Molino, 263, 267, 277, 278, 279, 280, 284

Cantón Corralito, 60

Cantona, 244, 251, 252, 253, 254, 373; building, 242; ceramic data from, 245, 248-49; excavation at, 243; interaction with, 255 ; limits of, 243 (fig.); location of, 24I (fig.); population of, 244; Teotihuacan and, 24I, 24I (fig.), 242, 248; trade networks and, 374

Cantona I period, 245

Cantona II period, 245

Canutillo phase, 264, 265, 267

Canutillo red filled, 264

Capacha phase, 60, 72, 73; bottles, 64; vessels, $64,65,65$ (fig.); wares, 66

capitalism, I3, I4, 4I, 313

capitals, Maya, 355

Caracol, 248, 249, 355

Carballo, David, 248, 249

cargos, 296-97, 299, 304

Carnegie Institution, 179, 214

Carpenter, John, 263

Carrasco, José Luis Franco, 195

Carrasco, Michael D., 7, 367, 368

carved stone block, 220 (fig.)

Casas Grandes region, 279

Cascajal Block, 96, IOI, I02, 368, 369; 'thronemat' kenning on, 98 (fig.)

Castillo de Teayo, I8I

Catholic Associations, 297

causal-functional treatment, 9, II, 23n 5

Ceibal, 376

celebrations, 295-96, 329, 330; baroque system of, 300; complex, 306

celts, 92 (fig.), 93, 373

Cenote de Chichén Itzá, 319

centers: cultural, 213; higher-order, 347,351; political, I84; second-tier, 350, 35I

Central Place Theory, 354

Central Plaza 2, 220

Centro, 184,196

ceramicists, I70n7, 275; Maya, I57, 161, 164, I67, I68, I70nII

ceramics, I9, 56, 6I, 68, 70, 100, I37, I49, I68, 196, $224,245,267,268,270,273,275,284,366,367$, 
371; architectural, 162; Central American, 63-64; comparing, 69; distribution of, 251; exchange of, 227; fine paste, 231; foreign, 157, 272; funerary, I5I; Mesoamerican, 72, 16I; Mexican-style, 156; Mixteca-Puebla "international style," 5; movement of, I08n8; Oaxacan, 58, 60; production of, 227; pseudo-cloisonné, 271; Teotihuacan, I5I-52, I53, 158, 177, 197; trade, 279; tripod, I50, I5I, I52, I57, I64, I67, I69n4; west Mexican, 67

Cerrito de la Cofradía, 27I

Cerro Bernal, I8o

Cerro Blanco, 27I

Cerro Chapín, 265, 277

Cerro Coyolito, 192

Cerro de Bernal, 220

Cerro de las Casitas, 278, 279

Cerro de las Mesas, 222, 223, 228; Stela 6/Stela 8 at, $232 n_{3}$

Cerro de los Monos, 176, 190, 194, 195, 198; Column I and 2, 192 (fig.), 193 (fig.), 194, 194 (fig.); Column 2, 194, 194 (fig.); Column 3, 194, 195 (fig.); monuments from, 194 (fig.); Sculpture I, I95; site of, I9I (fig.)

Cerro del Huistle, 271, 279

Cerro Moctehuma, 263, 264, 271, 276

Cerro Pedregoso, 277

Chaak, 97, IIonI5, 162

Chablekal Group, 227

Chaco Canyon, 280

Chak Ak'Paat Yuk, 132, 133 (fig.)

CHAK-xi-wi-te-i, 126, I28 (fig.)

chak xiwitei, 126, 128 (fig.)

Chalcatzingo, 98, I09nI4, 193; bowls and, 60; reliefs from, 368

Chalcatzingo Monument 31, 99 (fig.)

Chalchihuites, 263, 266, 270, 284, 329, 374; abandonment of, 278-8I; apogee of, 274-78; chronology for, 270 (fig.); decorated wares, 269; Mesoamerican influence in, 268; population of, 282; sites, 264, 278, 281, 282-83; tradition, 271

chalchibuites, 194

Chalchiuhtlicue, 187

Chalco-Amecameca, 183

Chametla, 273, 275, 277, 279, 284

Champoton, 227, 229

Chance, John K., 297

charcoal, 317,323
Chase, Arlen, 352

Chase, Diane, 352

chemical characterization, 229, 248-50

Chiapas, 51, 63, 120, 137, I40n17, 180, 199, 216, $248,344,367$

Chica, 184

Chichén Itzá, 5, 34, 210

Chihuahua, 267, 279, 280

Childe, V. Gordon, 9

Chilpancingo, 200nı2

Chinese language, transference to/from, Io8-9n9

Chinkultik, I20

Ch'ol-Chontal, I2O

Ch'olan, II8-I9, I23, I24, I26, I28, I38, I39n3, I39n 4, I4OnII, 370; Ch'orti and, I2O; Ixil and, 136; Q'eqchi' and, 134-36; Yukatekan and, I20-22

Ch'olan-Tzeltalan, I19, I2I

Ch'olti', II9, I2O, I33, I35, I38, I40nI3; Classic, I22; linguistic interaction with, 129-30; Q'eqchi' and, 136

Cholula, 20, 242-43, 244, 292-93, 294, 295-30I, 304 (fig.), 377; celebrations in, 295-96; disease in, 302; excavations at, 301 ; fiesta cycle of, 292; population of, 309; postcontact, 374; Pre-Columbian, 374; ritual system of, 297 , 305, 306, 308; Rome and, 301; strategies for, 293; through time, 30I-2

Cholula: La ciudad sagrada en la era industrial (Bonfil Batalla and Kirchhoff), 295

Chontal, I2O, I40nII

Chorote, 123

Ch'orti', I19, I28, I31, I32, I33, I34, I36, I38, I4In22, I4In24, I 4In25; Ch'olan and, I2O; hieroglyphics and, I35; lexical contributions to, 130 ; linguistic interaction with, $129-30$

Christensen, Alexander F., I2

Christenson, Allen J., I7on8

Chuj, I3I

Chupicauaro tradition, 267

Church of San Gabriel, 296, 298 (fig.)

Cihuatlan, 183

Cinteopa, 180

Cival Structure I-sub I, 93 (fig.)

civic-ceremonial core, 242, 243-44, 245

civilization: Maya, I20, I34, I38, I39, 214, 215, 344, 366, 377; Mesoamerican, 34; Teotihuacan, 127 
Clark, John, Io, 34

Clarke, David L., II

Classic Maya, I22, I23, 167, 179, 215, 343; ceramic vase, 102; glyph T60 HUUN, huun, 'paper headband', 93 (fig.); political centers, I84; political history, 370 ; Teotihuacan and, I69nI, i7onio

Classic period, 4, I9, 97, IIOnI9, I2O, I2I, I22, I23, I36, I37, I38, I40nII, I86, I92, I98, 200n7, 2II, $216,223,224,225,226,227,230,231,240,247$, 249, 250, 254, 266, 268, 272, 283, 301, 316, 370, 372; influence during, 215; occupation, 197; ruling culture of, 124

clay, 231, 317, 323, 327

cliff dwelling, 282 (fig.)

Coahuayana, 280

Coatzacoalcos basin, 225, 226, 227

Cocoyolitos Polychrome, 377

Codex Borgia, 316

Codex Mendoza, 93 (fig.), 322

Coe, Michael, 132, 215, 226

cofradias, 297

Cofre de Perote, 248

Coggins, Clemency C., 156, 157

Colima, 64, 315

colonization, $3,43,284,323$

colonnaded halls, 268,284

Colorado River, 264, 265

Columbian-Lower Central American region, 313

columns, 193, 194, 195, 265

communication, 8, 37, 241, 276; broad-scale, 34 ; internal, 269; long-distance, 4; visual, 99, 107 competition: local, 350; military, 345; political, 345, 349; power, 2 I

complexity, II, 20, 350, 365; institutional, 366 ; political, 54, 351; sociocultural, 4

Conchas phase, grater bowls, 60

Conjunto de los Jaguares, 195

connection, disconnection and, 165-66

conquest, 3, 7, 41, 187; studies of, 13; symbol of, I 82

Contlalco, 197

Convent of San Gabriel, 301

conventions, IOI, IO4; adoption of, 87; iconicity of, 87 ; interpretive, 87 ; linear, 87 ; recombinatory, 87

copal, 323,342

Copán, I19, I40ni1, 157, 160, 161, 162, I69ni, 179; tomb at, 370 ; tripods from, 163,164 copper, 315, 316, 317, 319, 322, 325, 326, 327, 332, 375; production of, 279, 328 (fig.); objects, 28I (fig.); pure, 318

Córdova, Guillermo, 266

cores, 3, 245; prismatic, 244

Corral de Piedra, 280

Corson, Christopher, 228, 229

Cortés, Hernán, 308, 372

cosmology, 51, 218, 37I

Costa Chica, 196, 197

Costa Grande, 183, 184, 196

cotton, I37, I83, 21I, 34I

Covarrubias celt, 92 (fig.)

Cowgill, George, I52, I54

cross-cultural comparison, $15,22,23 \mathrm{n} 6$

Cruz A, 68, 70

Cruz B, 68

Cuenca Oriental, 248

Cueva del Maguey, 282, 284

Cuexcomate, $32 \mathrm{I}$

Cuitzeo Basin, I80

Culbert, Patrick, I70n7, I70nII

Culiacán region, 275, 281, 283

cults, $166,294,315,374$

cultural contexts, 42, 88, 106, 284

cultural groups, I0, 88, 262

cultural processes, $6,13,20,332$; interaction and, $8-$ II

culture, 7, 18, 23n8, 39, 40, 108n7, I50, 198, 227; archaeological, 108n7, I25; Chalchihuites, 262, 263, 264 (fig.), 271, 273, 275, 279, 282, 284; core, I4; culinary, 135 ; defining, 38 ; donor, 84 ; Formative, 67; high, 123; history, 12, 15, 35; Indo-European, I25; inland, 210; material, 3, 6, 8-9, IO, II, I5, 40, 84, I35, I96; Maya, I22, I23, 214, 215; Mesoamerican, 6, 284; mother, 3; Olmec, Io; pan-Mesoamerican, 284; regional, 4; Spanish, I23; Teotihuacan, I82; visual, 3, 96, I50, I56, I69nI, I87; Western, I35

Cuncuén, 227

cups, I52; pseudo-cloissoné, 265; tripod, 370 cuttlefish eggs, 34I

Dakin, Karin, I29, I3I, I39n9

Daneels, Annick, 223

darts, I57, I8I-83, I87, I88, 248, 249, 277 data, 6, 19, 38, 211, 215, 367; anthropological understanding of, 23n6; archaeological, 16, I25; ceramic, 245, 248-49; comparative, 22; 
epigraphic, II9, I2O; focusing on, 20; isotopic, 344; linguistic, 99-100, 125; methodology and, 8; overdetermining, I5; shell, 245; stylistic, 40; visual, 104

dazzler vessel, I69ni, 370

de la Cerda, Rafael, 214

decoration, 54, 58, 61, 64, 66, 69, I56, I81, 278; austere, I54; ceramic, 67, 73; Maya, I62; plastic/painted, 55; stucco, 155

deities, I5 I, 315, 372; female, 371; metal, 316 (fig.); rain, 97; del Santo Entierro, 304

Delia White cylinder, 347

Demarest, Arthur A., 253-54

development, 19, 87, 106, 369; cultural, 5, 7, 21I, 213, 283, 293; formal, 84-85; regional, 283

Di Peso, Charles, 283

Díaz del Castillo, Bernal, 326

Díaz Oyarzábal, Clara Luz, 176, I87

Diehl, Richard, 226, 373

diffusion, 3, 7, 15, 38-39; long-distance, 376; stylistic, 367 ; technological, 367

diplomacy, 180, 370; interregional, 168; Teotihuacan, 165

directionality, I5, 21, 37, 38, 104, I09, I23, 2II disconnection, connection and, $165-66$

disks, 6I, 194, 282

Divine Lord of the Snake Polity, 355

donor system, 84, 89, 90, 9I, IO5

Doyle, James, 376

Dresden Codex, 97, 99, I21, I22, I26, 132, I40ni6, 368

Durán, Diego, 292, 301, 321, 324, 326; rotating system of power and, 302 ; tributes and, 329

Durango, 262, 263, 265, 267, 268, 269, 270, 272, 275-8I, 283, 284; comparative chronology for, 269 (fig.)

dynamics, I5, 366, 374; cultural, 6, 8, I8, 20, 2I-22; developmental, 369 ; higher-order, IO, II, 22n5; regional, 7; social, 365 ; sociocultural, I0, 17

Dzibanche, 350, 35I, 354, 355, 357, 370, 375; stairway/carved steps from, 356 (fig.)

\section{E Group, 352, 357, 376}

Early Classic period, 22n 4, 92, 93, 94, II 8, I23, I29, 130, 138, 150, 156, I57, 167, 176, 178, 183, I87, 197, 215, 222, 240, 242, 244, 246, 248, 252, 253, 254, 255; assemblages, 249; ceramics, 166 , 37I; Teotihuacan and, 179-8I; tripods, I5I (fig.); vase, 93 (fig.)
Early Formative period, I8, 21, 52, 54, 62, 64, 68, $72-73,74,368,373$; archaeology of, 51; ceramics, 366 ; iconography of, 86; scripts of, 85; sites of, 52 (map); wares, 57

Early Horizon, 314-I5

Early Postclassic period, 186, 226, 278, 315

Early Preclassic period, I19, 376

Early Tlamimilolpa phase, $153-54$

Early Xolalpan phase, I54, I55, 163

earplugs, copper, 283

earrings, copper, 28

East Group, 352, 353

East Panel, I28, I29

economic activity, 35, 37, 41, 301, 314, 317, 365-66 economic relations, $36,317,318,321$

effigies, 62, 63 (fig.); bat, 162, 163, I64 (fig.)

EK', 195

Ek, Jerald, 227

ek' muyal construction, 99 (fig.)

Ekholm, Gordon, 197

El Chayal, 68, 252

El Mesón region, 226

El Mirador, 350, 351, 352, 357, 376, 377; collapse of, 354; development of, 353-54; trade and, 345

El Norte, $184-89$

El Otero, 272

El Peru-Waka', 372

El Quiche, I34

El Resbalón, 354

El Rosario, 176, I82, I85

El Sacerdote de Tecanman, 328

El Tajín, 252

El Tigre, 354

El Varal, 73

El Zapote, Stela 5 from, 159

elites, 230, 294, 316; Aztec, 324; bilingual, 106; corporate, 301; enemy, 348; Maya, 165; merchant, 308; non-Teotihuacano, 178 ; pagan, 293; Spanish, 324; tombs of, 150

emblems, I85, I86, 219, 354, 355

emulation, 3, 180, 245, 252, 365, 371, 372

"end-of-the-Classic" phenomenon, 223

Englehardt, Joshua D., 7, 367, 368

Entrada of Sihyaj K'ahk, 371, 372

Epiclassic period, 186, 244, 254, 275

epigraphy, 86, I08n8, I21, I37, I8I

Escuintla region, I3I, I8I, I82

Espiridión, 54, 57, 72, 74n 
Estela de Acapulco, 196

ethnicity, 39, I25, 231; construction/negotiation/ transformation of, 20; languages and, 293; material culture and, 40

ethnohistoric resources, 212, 324, 332

Etla subvalley, 348

etzalcualiztli, celebrations of, 329

evidence, 3; ancillary, 7, I2, 100, 294; archaeological, I00, I8I; ceramic, 64-68; diversity of, 39-40; epigraphic, 178 ; iconographic, I78, I8I; multiple lines of, 40 ; exchange, 40 , 64, 69, 24I; cultural, 4, 7, 10, 1I, 21, 103, 263; economic, 18, 294; factors of, 7; gift, 253, 254, 255; iconographic, I03; information, 4I, 43; intercultural, 16,20 ; interregional, $5,8,20$, 54, I05, 345; linguistic, 89; local, 34I-43, 345; long-distance, 4, 240, 241, 249, 253, 254, 255, 341, 343, 376; market, 13; material, 3, 18, 43; mechanisms of, 104; modes of, 12, 13, 37, 198, 249; networks of, I2, 13, 37, 51, 249; obsidian, 4, 2I, 37, 248; prehispanic, 342; regional, 345; social, 138 ; symbolic, 18

explanation, IO, II, 263

extraction, 245, 317, 328; direct, 321, 326; location of, 327,332

Fábrica San José, 347

feasts, 54, 150, 298, 301, 302, 304, 306, 307, 308, 309, 324, 331

Feathered Serpent Pyramid, I70nI2, 247, 249, 372

feathers, I37, I60, I62, I81, I83, I85, I86, I93, I94, 200n9, 21I, 221, 272, 315, 329, 330, 331, 370, 372

Feinman, Gary M., 5, 14-15, 19, 365-66

Fergus, Rob, 129

Fialko, Vilma, 156

Fields, Virginia, 91, 159, 160, 162

fiestas, 218, 297

figurines, 57, 71, 150, 197, 220, 352; anthropomorphic, 7 I (fig.); Campeche-style, 228; ceramic, 367, 369; hollow, 230 (fig.); Jaina, 215; Maya, 160, 227; mold-made, 216, 227-29; Postclassic, 228; San Marcos, 229; Style YV, 228, 229; Teotihuacan-style, 162, I99nI; Veracruziano, 228, 229

Fine Buff pottery, 224, 230

Fine Gray pottery, 224, 225

Fine Orange paste, 224, 225, 226, 227, 228, 231

Fine Orange pottery, 24, 150, 197, 223, 224, 225, $226,227,230$ fine paste pottery, 216, 223, 224, 225, 227, 230, 231 flaking patterns, 248-50, 250 (fig.), 251, 252, 254, 255

Flannery, Kent V., 92, 104

flint, 200n 7, 325, 342

Florentine Codex, 318

Flores, Daniel, 265

Foias, Antonia E., 253-54

Ford, James, 67, 73

foreign objects, 167 ; travel and, $157-64$

Formative period, 4, 10, 19, 21, 64, 69, 70, 89, 91, 92, 93, 99-100, 104, 230, 274; exchange during, I05

Fox, James W., I2O, I22

Fracción Mujular, I8०-8I

frameworks: compositional, 88 ; interpretiveorganizational, Iron 21; linguistic, 86 ; organizational, 91, I04

Franchetti, Michael D., 366, 367, 373, 374

Franciscans, 296, 301

Freedberg, David, 166

Freidel, David, 19, 193

funerary practices, I50, 151, 170n6, 344; Classic Zapotec, 368

Garía Cook, Ángel, 243-44, 246, 247, 254

García Vega, Águstin, 214

Gell, Alfred, i69n2

geographic regions, I0, 20, 88

gifts, I65, 32I, 324

Gila Pueblo, 280

Glascock, Michael D., 68, 69

glottochronology, 124

glyphs, 83, 93 (fig.), 95-97, 100, IIonI5, I39n6, 160, 187, 193, 200nII, 211-I2, 213, 222, 354, 355;

"four-way hatching," 219, 220; Maya, 214, 220, 23InI; "Pax," 220; "Reptile Eye," 21I-I2, 219, 220; Teotihuacan, I27; "winal," I2O

God G, 316

gold, $313,325,326$

Goldstein, Marilyn, 228, 229

Gomelia site, 278

goods, IO, 138; crafted, 314; elite, 307; exotic, 42, $43,263,273,322,345,347,357$; interregional exchange of, 8; luxury, 324; material, I08n6; metal, 324; movement of, 314, 331; prestige, 4-5, 13, 23n7, 263-64, 281; ritual, 297; selling, 325 (fig.); sumptuary, 345, 347; transfer of, 43

Gorbernador phase, 244 
Gothic-Renaissance style, 293

governance: collective, 375; Spanish systems of, 294; state level of, 35

Graeber, David, 375

grammar, 9I, I0I, I05, I06; Yukatekan, I2I

Gray, Russell D., I25

Great Pyramid, 295, 300, 304 (fig.)

Greater Q'anjob'alan, II9

Greater Tzeltalan, II

greenstones, 69, 70, 183, 266, 347, 367, 373, 376

Grondona, Verónica, 123

Grove, David C., 60, 90

Guadalupe phase, 60, 68

Guadalupe Victoria, obsidian from, 68-69, 252

Guadiana Valley, 267, 268, 269, 271, 272, 273, 279, 280, 281, 284; abandonment in, 278; apogee of, $274-78$

Guanajuato, 98, 180, 267

Guasave, 279, 284

Guasave Red-on-Buff, 279

Guatimapé Valley, 267, 277, 278

Guazacualco, 326

Guerrero, 64, 72, 188, 189, 191, 193, 195, 196, 199, 315, 322, 323, 371; ethnic/linguistic groups in, 197; iconography in, I82; map of, 177 (fig.); military presence in, 372; monuments in, I81, I83-84, I86 (fig.); sculpture in, 198 ; Teotihuacan and, 176, 177, 178, 179, 198

Guillén phase, 218, 222

Gulf Coast, 51, 52, 70, 84, 156, 167, 216, 220, 221, 344 ; archaeological culture of, Io $8 \mathrm{n} 7$; ceramics of, 6I; styles, 227

Gulf lowlands, 214, 216, 224, 226, 227, 228, 230, 245, 249, 251, 253, 373; cultural contact in, 215; development of, 210; pottery for, $23 \mathrm{I}$

Gulf of Campeche, 223

Gulf of Mexico, 347, 373

Gusave Red-on-Buff, 279, 280

Hacavitz, 166

Hall of Columns, 265, 266 (fig.), 273

halved stars, 194-95, 200nI2

Handbook of Middle American Indians (Coe), 215

Han'gŭl, 84

Härke, Heinrich, I2

Harpy Eagle, I29

Haspelmath, Martin, 89, 90, 108-9n9

hatchets, copper, 322

headbands, Maya royal, 9I, 93 (fig.) headdresses, I64; feather, 221, 272; Mexican, I58 (fig.); shell-platelet, I8I, 193; Teotihuacanstyle, I59; tri-lobed maize, 95,97 (fig.); vegetal, 88-89, 91-94, 92 (fig.), 93 (fig.), 95, 95 (fig.), 96

Headrick, Annabeth, I70nI2, 370

Helmke, Christophe, ironi8

Helms, Mary, I70n6

Hepp, Guy David, 21, 366, 367, 376

Hermandad de Cargadores, 304

hermandades, 297

Hers, Marie-Areti, 265

Hervideros, 268, 284

Hidalgo, I8O, 2II, 246

Hidden Canyon, 166

hierarchy, I3; lineage-based, 310 ; linear, 294; political, 345, 349, 35I

Hieroglyphic Ch'olan, II8-20, I19-20, I21, I35, 137, 138; linguistic interactions with, $123-25$; loanwords and, I26-29, I27 (table); status of, 122

hieroglyphs, 84, I32, I35, I5I, I57, 195, 343, 349, 354; Classical Ch'olti, I22; Maya, II8, I19-20, I26-29, I40nio, 16I (fig.), I70n7, 35I

hijos del barrio, 299, 308

Hill of the Star, 195

Hirth, Kenneth, I80, 249, 326, 332

Hodder, Ian, 9, Io

Hohokam, 274, 279

holistic approach, I8, 20

Holmes, W. H., 213, 23InI

Holy Week festivities, 303

Hopewell phenomenon, 366

Hopkins, Nicholas A., 120

Hosler, Dorothy, 327

Houston, Stephen, I2O, I22, 132

Huandacareo, I80

Huasteca, 213, 214

Huave, I3I

Huehueteotl, I89

Hueyapan region, 224

Huitzilopochtli, 308, 37I

Huitzuco, I 84

Hull, Kerry M., 7, 16, 21, I09nio, I29, I35, 369 , 370

Humboldt celt, 92 (fig.), 93

Hume, David, II

Husatec, Maya and, 214

Huunal tomb, 370 
iconographic systems, 90, 103, 106, 107-8n 5, 368,373

iconography, 19, 83, 84, 87, 88-89, 102, 106, I50, I57, I58, 163, 194, 197, 219, 278, 280, 369, 37I; analysis of, 192; Ayala phase, 275; celt, 92; central American, 189; ceramic, 27I, 284; diversity of, 86; Epiclassic, 195; Formative period, 99-100; imperial, 176, 179, I8I-83, I85, I89, I98; interaction and, 91-IOI; Maya, I62, I70n7; Mesoamerican, 85, 91-IOI, 93 (fig.), 267, 268, 271, 284; Olmec, 4, 89; style and, 89, 90; Teotihuacan, I27, I59, I59 (fig.), I62, I60n3, I79, I82, I83, I85, I98; understanding, 104; visual, 367; writing and, 86; Zapotec, 94

icons: ancestral, I04; decontextualizing/recontextualizing, 367 ; reading of, 369 ; recontextualizing, 368

identity, 40, 243; cultural, 20, 40; social, 366 ideology, 43, 255, 316; political, 218; Teotihuacan, I82, I85

ilmeno-magnetite, 347

Ilocab, 166, 170nio

imagery: Maya, 160, 162, 170n7; Teotihuacan, I6I, I62

INAH, 228

incensarios, 150,152

incense burners, 181,189 , 197

inequality, social, 70,345

information, 37 ; exchange, 41, 43; flows of, 36 ; syllabic, 126

Initial period, 314

innovation, 83, 103, 107, 122, 163, 216, 218, 352, 368, 373, 374; cultural, 4, 6; design, I54; diffused, 103; Maya, 162, 164; script, 84, 85; stylistic, 367 ; technological, 366, 367

interaction, $10,18,86,103,107,211,255,275,284$, 341, 367, 370, 371, 373; archaeological study of, II, I6, 38; artistic, Ioo; causal-functional treatments of, II; ceramic evidence for, 64-68; Ch'olan/Q'eqchi', 134-36; competitive, 2I, 34I, 345-57; complex societies and, 4, 19; concept of, 3, 2I, 42; cultural, 5, 8-1I, 21-22, 124, 176, 178, 197; direct, 341; economic, I4, 178; examining, $38-42$; factors of, 7; historical, 39; hostile, 34I; iconographic, 69-72, 9I-IOI, 104, IO5; identification of, 8-9; indirect, 341; interpretations of, 3 ; interregional, 4, 5, 6, 18, 20, 21, 54, 69-72, 86,
I04, I5O, I68, 242, 272, 283, 332; investigating, 35-36, 40; linguistic, 100, 105, II 8-19, I22-23, I23-25, I29-30, 369; local, 35, 34I; long-distance, 35, 36-38, 68, 248, 254, 34I; long-term, 341; macroregional, 35-36, 42; maritime, 210; material, I3, I8, 69-72, 100, I05; modeling, II-I5, 4I; modes of, 2I, 39, 40, 4I, 198; multidirectional, 34I; networks of, 37, 39, 42, 51, 272; nontransformative, 34I; patterns of, $20,38,39,40,41,284$; peripheral sites of, I4; political, 43, 178, 371; regional, 254, 284; relationships of, 17; religious, 197-98; role of, 20, 88-9I; scripts and, 88-9I, 9I-IOI, IOI-6; short-term, 34I; social, 7, II8-19, I24, I30, 326; socioeconomic, 197-98; spheres of, 20; studies of, 22, 23n9, 178; symbolic, I4; Teotihuacan and, 178-79; thinking about, 35, 36; transformative, 341, 345-57; understanding episodes of, iI; unidirectional, 34I; Veracruz-Maya, 210; Yukatekan/Ch'olan, I2O-22

interconnections, 43, 51, 284; interpersonal, 35; long-distance, 34

interpretation, 3, II, I5, 86, 87, 88; Mayan, I39n9; recontextualized, 106

iron pyrite, 273, 274, 275 (fig.)

Isla Agaltepec, 226

Isthmus of Tehuantepec, 64, 66, 68, 72, 213, 216, 230, 252

Ixil, I34, 136

Ixtepeque, 68

Izapa, 216

Izapa Stela 5, 97 (fig.)

Izapa Stela 25, 93 (fig.)

Izapan, 97

jade, 40, $187,194,313,327,329,376$

Jade Mountain, 162

jade plaque, detail from, 99 (fig.)

jadeite, 69 , 158 (fig.), 159, 347

jaguars, 268

Jaina Island, 215, 228, 229

Jakaltek, I24, I3I

Jakobson, Roman, 85

Jalisco, 65, 97, 271, 272, 274, 279, 280, 315

Japanese language, 84 ; transference to/from, I08-9n9

jars, 56, 63, 152; belted, 65 (fig.); broken, 346; cooking, 52, 57; double, 65 (fig.); globular, 56, 
61; necked, 62; remnants of, 57 (fig.); stirrup, 65 (fig.); Storm god, 179

Jasaw Chan K'awiil I, 356

Jatz'o'm Kuy, 179, 193

jester god, 96, 107

Jester God Headdress, 95

Jesuits, 283

jewelry, 330; jadeite, I58 (fig.), I59

jewels, 329

Jicaque, I3I

Jije Sokean, I32

Jiménez García, Elizabeth, 176

Jiquilpán, 272

Johnson, Gregory A., 343

Joloniel, I20

Jonuta, 228, 229

Jonuta-Campeche Intergrading Series, 229

Josserand, J. Kathryn, II

Joyce, Rosemary, $5 \mathrm{I}$

Justeson, John S., I08n5, I20, I22, 134; on interpretive conventions, 87

ka-ka-tu-na-la, ${ }_{2} 6$

Kaan, 355, 355 (fig.)

Kaan Polity, 354, 355, 357

Kaanul, 370

Kaktonal, I26

Kaloomte' Sihyaj K'ahk', 370

K'altuun Hix, 354

Kaminaljuyú, 156, 198; ballcourt markers at, 193; excavations at, 179; Mound A at, 157, 179, 344; Mound B at, 158, 179, 344; points, 252, 343, 344; Tomb A-I at, I59; Tomb B-II at, I58; tripods from, I58 (fig.), 160 (fig.), 163

Kan crosses, 157

Kaqchikel, I29

Kaufman, Terrence, I19, I20, I23, I24, I25, I26, I3I, I32, I35, I38, I39n7, I39n9, I 4In25; Nawa and, 127

K'AY, 22I

Kelley, Charles, 264, 265, 266, 271, 273, 276, 277, 278 ; ceramics found by, 272; copper objects found by, 28I (fig.); iron pyrite mirrors found by, 275 (fig.)

Kelly, Isabel, 58, 60, 65, 68; Capacha phase and, 73 ; interaction and, 64

K'iche Maya, I29, I35, I4In25, I67, I70nI2; lineages of, 166, 170n9; pyramid temple of, I70n 8 kiln firing, 223-24

K'inich Ajaw, 316, 316 (fig.)

K'inich Yak K'uk Mo', 378

Kirchhoff, Paul, 4, 51, 295

Knab, Timothy J., 20, 374, 377

knappers, 249, 250

Knight, Charles L. F., 2I, 373

knives, 325; obsidian, I80

ko2-mu-ti, ${ }_{2} 29,130$

kok muut, I29, 130

Kolb, Charles C., I99n4

Korean language, writing of, 84

Kristiansen, Kristian, 39, 42

ku-tzu, 132

La Atalaya, 267

La Casa Colorada, 273

La Casa de los Dirigentes, 274 (fig.), 276, 277, 279

La Casa Grande, 276, 277

La Consentida, 21, 52, 55, 63, 70, 366; anthropomorphs from, 71; bottles from, 62; burials at, 61, 67; ceramics from, 56, 58, 62, 72, 74, 367 ; decorative elements of, 64 ; fieldwork at, 68; figurines from, 71; grater bowls from, 60, 75n5; interaction/exchange and, 54, 64, 69; interregional relationships in, 72 ; manos from, 70 ; map of, 70 (fig.); obsidian from, 68 , 69, 69 (fig.), 72; occupational history of, 73; radiocarbon dates from, 53 (table); sunburst motif, 66 (fig.); trade network and, 68; utilitarian wares from, 58 ; vessels from, $65,66,68$; west Mexico and, 54

La Corona, 132, 351

La Corona Element 56, I33

La Farge, Oliver, 213, 214, 216, 220, 221

La Ferrería, 263, 265, 267, 268, 269, 271, 273, 279, 280, 281; apogee of, 274-78; copper objects in, 28 I (fig.); excavations at, 272; globular vessel, 272; Structure I, 274 (fig.), 279; Structure 7, 273 (fig.)

La Juana-San Pablo, 347

La Mojarra Stella, 93 (fig.), $232 \mathrm{n} 2$

La Muralla, 35I

La Perla del Golfo, 220; carved stone block from, 220 (fig.)

La Quemada, IIoni6, 265

La Soledad de Macel, 197

La Sufricaya, 179 
La Venta, 210, 214, 216, 373

La Ventilla, 192, 193, 196; Burial 21 at, I54 labor: divisions of, 4 I; organizing, 352

Laboradores y Pobres, 304

Labyrinth, 265

Lacadena, I05, I20, I2I-22

Lady 9 Grass, 100

Lago de Catemaco, 228

Laguna de On, 137

Lake Amatitlán, I8I

Landa, Maya alphabet of, I39n6

landscapes, 36, I51; cultural, 162; ecological, 162; geographic, 38 ; linguistic, ${ }_{13} 8$; social, ${ }_{13} 8$

Langenscheidt, Adolphus, 326

languages, I25, I37, I98; adjacent, 108n8, I23; donor, 90 , 122; ethnicity and, 293; literary, I2I; map of, I2I (fig.); Mesoamerican, I19, I23, I24, 132, 134, 369; non-Mayan, I19, I30, 132, 134, I38, I39n5; prestige, I22; sequential nature of, 87

lapidary, 263, 330, 33I

Laporte, Juan, 156, 169n3

Las Costas, 184 , $196-97$

Las Humedades, 277

Las Joyas phase, 274-78, 279, 281; figurine from, 230 (fig.)

Las Minas-Alpoyeca, 184, 197

Late Antiquity, 293, 294, 309

Late Classic period, 93, 120, 122, 137, 215, 216, 223, $224-25,226,229,244,246,315$

Late Formative period, 93, 94, 97, 98, 369; imagery of, 106; jade pectoral, 93 (fig.); scripts/ iconographies of, 83,86

Late Postclassic period, 36, 37, 42, 43, I81, 212 , 246, 293, 294, 315, 320, 321, 328, 375

Late Preclassic period, I19, 178, 179, 351, 352, 353, $354,375,376$

Late Tlamimilolpa phase, 154

Late Tutuveida, 269

Late Xolalpan phase, I55

Latsanopoulos, Nicolas, 20ong

Law, Danny, I21, I22, I23, I39ns

Laxtunich, I35

Lazy-S, 83, 97-98, 99 (fig.), I0० (fig.), Io9nir, IO9nI 4,368

lead, $317,318,327$; production of, 328 (fig.)

Leiden plaque, 97 (fig.)

Lesure, Richard G., 89, 90

Levy, Richard, I40nI8

lexemes, 90, II9 lineage systems, Aztec/Maya, 309-10

linguistic diversification, script development and, 102

linguistics, 16, I8, 19, 20, 21, 40, 64, 83, 84, 86, 87, IO4, I22, I25, I37; archaeology and, 98-100; historical, iI 8

loanwords, 90, 91, IIOnI8, I3I, I32, I33-34, I35, I36, I38, I39n 8, I39n9, I4OnI7, I4In2 4, 369; Hieroglyphic Ch'olan and, I26-29, I27 (table); Mije-Sokean, I08n8; Nawa, I27, 128

Locona phase, 64, 70, 73, 74

logograms, 87, 89, 94, 138n62, 195, 221

logographs, I26, 132

Lolandis phase, 277,279

Loma Alta tradition, 267

Loma San Gabriel, 262

Long Count, I09n13, 213, 218

Looper, Matthew G., I26, I40nII, I4OnI7

López de Gómara, Francisco, 372

lords, 342, 352, 357

Los Alacranes, 35I

Los Guachimontones, $27 \mathrm{I}$

Los Horcones, 180,220

Lower Papaloapan Basin, 224

Luckenbach, Alvin, I 40nı 8

Machalilla, 67, 68, 73

Macri, Martha, I26, I38ni, I40nio, I40niI, I40nI7

macroregions, $18,34,35,36,37,41,42,43,74$

Madrid Codex, I2I, I22

magnetite, 347

maize, 95, 97, 139n7, 262, 342, 369, 385

malachite, 266

Maldonado, Blanca F., Templo Mayor and, 375

Malinaltepec, 20onis

Mallory, J. P., I25

Manantial phase, 63

Manche Chol, 136

Manik Complex, Burial Io of, 156-57

manos, 70, 211

Manzanilla López, Rubén, 196

marcador, 193, 195, 196, 200 II

Marcus, Joyce, 19, 21, 35, 376

market system, I2, 23n 6, 37

marketplaces, 37, 298 (fig.), 321, 326

marriage alliances, I2, 37

Martínez, Estela, 266

Mascota Valley, 65 
masks, I90; greenstone, I30 (fig.); stone, I99nI, 2oon5; Teotihuacan-style, 192, I99nI; waterfowl buccal, 213

mat-throne collection, 368

Matacanela, 218, 221, 222; boxes of, 221 (fig.)

Matacapan, I8O, 2II, 215, 25I, 252; ceramic production at, 224

Matacapan Bayo Fino, Type 30, 224

Matacapan Project, 224, 225

materials, 6, 16, 39, 69, 168, 324, 366; building, 346; decorative, 220; ephemeral, 323; exotic, 252; high-status, 326; lexical, 138 ; linguistic, I23; transmission of, 36, 37. See also raw materials

Matras, 89 , IOI, I22

Matrícula de Tributos, 322; metal tributes mentioned in, 323 (fig.)

Maya, 97, 105, I36, I37, I49, I50, I51, I54, I66, I67, 198, 220, 223, 224, 225, 226, 248, 253, 255; case study, 350-5I; connections with, 2II; Husatec and, 214; imports by, 344-45; influence of, 213; region, 37, 157, 178, 179, 230, 231; society, I23; Teotihuacan and, 5, 156, 157-64, 168, 169ni, 169n3, 169n5, 176, 179; Veracruz and, 210, 2II; vessels and, 37I

Maya and Teotihuacan: Reinterpreting Early Classic Interaction (Braswell), I49

Maya Blue, 227

Maya lowlands, 7, 21, I20, I22, I34, I51, I85, 214, 216, 223, 224, 230, 231, 255, 351, 371, 375; development of, 344; Early Classic, 372, 376

Mayan language, II8-19, II9-20, I23-26, I30, I32-38, I39n3, I 40 nII, 369

Mayapán, 343

mayordomías, 297, 299, 303, 304

mayordomos, 297, 298, 299, 305, 306, 307, 308

mayuy, I35

Mazanilla, 196-97

McCafferty, Geoffrey G., 242-43

Medio period, 279

Medrano Busto, 251

Melgar Tísoc, Ricardo, 33I

Membreño, Alberto, I3I, I32, I33

Mendoza, Viceroy, 301

Mercado, 268, 271, 272

Mercado Red-on-Buff, 268

Mercaso, 272

merchants, 296, 325; long-distance, 5, 300-30I,
Mesa de las Tapias, 269, 278

Mesa del Encinal, 269

Mesoamerica, 13, 178, 198, 199, 272, 280, 309, $313,365,366,374$; archaeological attention for, 240,377 ; core areas of, 263 ; cultural mapping of, 20; defining, 5I; Early Formative period sites in, 52 (fig.); geographical/temporal extent of, I8; influence of, 274-75, 283; map of, 5 (fig.), 52 (fig.), I2I (fig.); northern frontier of, 262, 283; pre-Columbian, 22, 35; prehispanic, 35, 36-38, 4I-42, 43

metal, 19, 40, 314, 316, 326, 327, 332; economic movement of, 328; economic value of, 313 ; imported, 315; precious, 313; sourcing of, 317 metal objects, 280, 281, 283, 315, 317, 333; movement of, 328, 331; transforming, 316 metal production, 313, 327, 332; raw materials and, 317; taskscape of, 317-18

metallurgy, 34, 279, 314, 327, 366; Central/South American, 376; northward diffusion of, 314 (fig.); prehispanic, 327; studies, 375-76

metates, 2 II

Metepec, 254

methodologies, 3, I5, 18; data and, 8; interdisciplinary, 6

Mexica, I8I, 326, 372

Mexican Red-on-Buff, 367

Mexican Revolution, 297

Miccaotli phase, 152, 153

Michael, archangel, 296

Michililla red fill, 268

Michoacán, 37, 98, 180, 267, 272, 274, 280, 315

middens, 52, 58, 68, 321

Middle Chametla Polychrome, 272, 273

Middle Classic period, 219, 222, 224, 226, 229

Middle Formative Conchas phase, 60

Middle Formative period, 52, 84, 91, 92, 94, 98, 100, 104, 106, 219, 244, 368, 369, 372, 373; ceramics, 65; headdress, 92 (fig.); iconography of, 83, 85, 86, I07n5; maize god, 95; material-symbolic-linguistic complex of, 88 , 89; motifs, 97 , 105; scripts of, 83,85

Middle Preclassic period, 197, 200n5, 352, 354, 376

migration, 7, 9, 15, 17, 18, 37, 119, 283, 366; archaeological proof of, I2; Indo-European, I25; models of, II-I2, I3

Mije-Sokean, 21, 72, 74, 84, 85, 99, I05, II9, I23, I24, I25, I26, I27 
Milbrath, Susan, 370

militarism, Teotihuacan, I85, 371, 372

military force, 40, 42, 185, 326, 357

minerals, 327; metallic, 315; rare, 266; transforming, 316

Mirador Mound 20, 248

Mirador zone, 376

mirrors, iron pyrite, 273, 274, 275 (fig.)

Missouri University Research Reactor, 248

Mixcoatl, 300

Mixe-Zoquean, I39ns

Mixtec, 5, 98, I87, 368

Mixtec Codex Bodley, 98

Mixteca Alta, 68, 70

Mixteca Baja, 184

Mixteca Poblana, 245

Mixtequilla, 215, 226

models: archaeological, 15-17; assessing, 40-42; billiard-ball, 3, 8-1I, 39; "core-periphery," 15, 263; migration, II-I2, I3; problems with, I6; state formation, 341; theoretical, $16,17,22$; top-down, 40; trade-based, I2, I3-I4; unidirectional, 3, 21, 343-45

Moedano Köer, Hugo, I9I

Moholy-Nagy, Hattula, 252

monkeys, 7I-72, 7I (fig.)

Montaña, I8I, I83, I84, I96-97

Monte Albán, 43, 92, 180, 348-49, 350

Monte Albán Building J, 92, 93 (fig.)

Monte Albán Building L-sub façade, 95 (fig.)

Monte Albán Stelae I2-I3, 95 (fig.)

Monument 5, 356 (fig.)

Monument Plaza, 222

monuments, 185, 216, 218; carved, 194 (fig.), 198 , 372; Classic period, 186; freestanding, 200n6; Maya, 164; stone, 184, 196, 211, 220n5, 372;

Teotihuacan-style, 176, I84, 198, 199, 200ns

Moon Goddess, 370, 371, 372

Moon Pyramid, 247, 248, 249, 253

Mopan, I28, I40nis

Mora-Marin, David, IIon 23

Morelos, I80, I83, I84, 193, 199n 4, 32I

Morley, Sylvanus G., 213, $23 \mathrm{InI}$

Motecuhzoma, 326, 329

mother-fathers, $37 \mathrm{I}$

motifs, 97, 105, 107, IIOnI5, IIonI7, 181; Buddhist, 90; iconographic, 181, 183; sunburst, 64, 65, 66, 66 (fig.), 73; war-related, 182

Motozintlek, 132
Mound Group 3, 222

mounds, I91, 192

Mountjoy, 65, 263

murals, 180, 182, 187, 190, 195; San Bartolo west wall mural, 93 (fig.), 96, 102 (fig.)

Museo Nacional de Antropología, ironı6, I88, I96, 200 n8

musical instruments, 367 ; fragments of, $7 \mathrm{I}$ (fig.)

Mutal, 370

Naachtun, 35I, 354

Nagao, Debra, 182

Nahua, I2, I40nI7

Nahua-Mixtec style, 293

Nahuatl, 5, 84, I26, I27, I3I, I34, I38ni, I39n8, I4OnIo, I4OnII, I 4 OnI2, I4OnI4

Nakbe, 350, 351, 353, 357, 376; Stela I of, 352, 353 (fig.)

National Geographic Society, 214

Navacoyan, 271, 277, 278, 279, 280

Navarrete, Carlos, 220

Nawa, I23, I24, I26, I27, I29, I30, I37, I38, I39n5, I39n8, I39n9, I 40 n9, I $40 n 17,349,369$

Nayar, 269, 277

Nayar white-on-red, 280

Nayarit, 272, 274, 279, 280, 283, 315

Nebaj, 136

necklaces, 282, 325

needles, 325,325 (fig.), 326

networks, 297, 300; economic, 40; exchange, I2, I3, 37, 51, 249; human socioeconomic, 38 ; interaction, 37, 39, 42, 51, 272; interregional, 54; kinship-based, 304-5; long-distance, 35; political, 355; social, 35, 36, 299, 306, 307; socioeconomic, 43 ; trade, $12,13,68,137,227$, 374

Neutron Activation Analysis (NAA), 228, 229, $25 \mathrm{I}$

Nevada de Toluca Volcano, I84

Neveria Red-on-Buff, 275

Niederberger, Christine, 70

Nielsen, Jesper, 21, 182, 266, 371, 372

Nim Li Punit Stela I5, I32

Niño Dios, 303

Nisa phase, 60

Nivaclé, I23

Niven, William, 196

Nochixtlán Valley, 68, 69

Norman, V. Garth, 218 
Northern Acropolis, 179

Northwestern Frontier, 267-74, 282-83

Northwestern Zacatecas, frontier in, 264-67 nose-bar, 187

nubbin supporters, I52, I52 (fig.)

Oaxaca, 21, 52, 58, 64, 66, 68, 69, 70, 72, 125, $176,180,185,186,199,245,345,347,349-50$, 357, 366, 376; Tlacuache and, 54; objects, 88, 324, 345; offered, 322; signs and, ro 8n6; Teotihuacan-style, 189

obsidian, 4, I9, 21, 37, 40, 100, 104, 137, I80, 2II, 244-45, 248, 249, 255, 325, 344, 367, 373; Altotonga, 252; distribution of, 251; El Chayal, 252; extraction of, 326, 327; highland, 252; importation of, 68-69, 72; local, 252; low-quality, 68-69; Otumba, 249, 253, 254; Pachuca, 178, 244, 249, 255, 344; reduction of, 24I; sources of, 37, 68, 69, 70 (fig.), $24 \mathrm{I}$ (fig.); utilitarian, 244; XRF of, 69 (fig.)

obsidian points, 250-51, 250 (fig.); Stemmed-A style, 245, 246, 247 (fig.), 248, 249, 250, 252, 253, 254; Stemmed-B style, 245, 246, 247, 247 (fig.), 248, 249, 252, 254

Ocotillo phase, 62

OHL, I26; example of, 128 (fig.)

Ohnersorgen, Michael, 321

Ojochi phase, 6I, 62, 75n6

Olmec, 4, I0, I4, 88, 89, II , I26, 214, 222; as donor culture, 84; forms, 92; Gulf Coast, I05; influence of, 21; Middle Formative, 373; occupation by, 215; regional status of, 137

Olmec Horizon, 34, 42

Olmec language, 105, I23, I24, I37

Omitlán, 196

One Rabbit famine, 372

Opeño phase, 60, 66, 72

Orange-Buff paste, 229

organizations, 102 (fig.), 299, 366; columnar, 369; community, 296; hierarchical, 297; network of, 300; ritual, 303, 305; social, 52 , 294, 299, 308

ornaments, 282-83, 313, 325 (fig.); clothing, 315; shell, 245

Ortman, Scott, 368-69

Otinapa red-on-white, 278

Otinapa tripod vessel, 279

Otomanguean language, 21, 72, 74, I39ns

Otumba, 68, 69
Oxkintok, 162; tripods from, 163,164 (fig.)

Oxpemul, 35I, 354

Oztoyahualco, 248

Pachuca, 2II, 248

Pacific Coast, I56; interaction on, 64-68

Pacific Coast Route E, I99n 4

Paddock, John, 177

palaces, I3I, 215, 348, 349, 35I, 353, 354

Palacio Quemado, 300

Palenque, 97 (fig.), I28, I70nI2

Paquimé, 263, 279, 280, 389

Paredón, 68, 69

Parra, Carlos, 197

Parry, William, 249

Parson, Jeffrey, $177-78$

Parsons, Lee, 230

Pasión River, 137,376

Pasztory, Esther, 107n2, I55

patios, 197, 218, 268, 269, 276

patterns: borrowing, IOI; cultural, 74; divination, 369; flaking, 248-50, 250 (fig.), 25I, 252, 254, 255; iconographic, 219; interaction, $20,38,39$, 40, 4I, 284; interregional, 6; long-distance, 40-4I; phonological, I24; settlement, I9, I8O, 284; sociopolitical, 6

Pe phase, 60

Peche phase, 93

Pedernales, 246

Peralta, 180

Peripheral Coastal Lowlands, 230

Petatlán, 196

Petén, I37, 179, I82, 193, 372, 376

Petexbatún area, 376

petrographic analysis, 271, 273

phonology, I2I, I24, I25

phytomorphs, 55, 62

Picart, Bernard, print by, 296 (fig.)

pictorial systems, $86,87,88$, I07nI, I07n 4

Piedra Labrada, 180, 212, 214, 216, 218-19, 220, 222; SBTC at, 217 (fig.)

Piedra Labrada Complex 2, 222, 222 (fig.)

Piedra Labrada Stela I, 219, 219 (fig.), 220, 23In2

PIK, 129 (fig.)

pik, I28, I29 (fig.), I40nI4, I4OnI6

Pillsbury, Joanne, 326, 332

Piña Chan, Roman, 62

Pipil, I30, I3I, I40nII

Plain of Puebla, 302 
Plan de Ayala, 277, 278, 279

platforms, 52, 164, 192, 197, 218, 265, 302, 346, 352

plazas, 191, 218, 265, 268, 353, 375

Plazuelas, I80

Ploughmen and the Poor, 304

poblano peppers, 306 (fig.)

Pochteca, 292, 307, 308, 325, 374, 375

pochteca, 5, 198, 324

Pohl, John M. D., 20, 316, 374, 377

points, 252, 343, 344; arrow, 246; fine, 249;

Pachuca, 251, 254; projectile, 245, 246, 247,

249, 250, 253, 255, 373; solstice, 276; styles of, 247, 254. See also obsidian points

Pol Box, 354

political structure, 90, 255, 365-66

politics, II9, I50, I5I, I8I, 265, 293, 30I; central Mexican, 253; Mesoamerican, 245

polities, 326, 34I; Classic Maya, 34; rival, 349; trade between, 343

Pomoná, 120

Pool, Christopher, 223, 224, 225

Popocatepetl, 183

Popol Vuh, I66, 167, 170ni2

Portico 2, detail from, 102 (fig.)

Postclassic period, 5, I2, 19, 21, 43, 68, 84, 92, 98, I22, I87, 192, 21I, 216, 221, 226, 227, 230, 23I, $252,283,300,306,318,320,326$

power, 21, 302; absolute, 165; balances of, 36 ; economic, 371; explanatory, 17; head of, 310; military, 371; political, 36 , 91; position and, 294; rotating, 302, 374; royal, 368 ; social, 316 ; sociopolitical, 13

power structures, 306; rotating, 292, 294, 297, 299, 300, 302, 305, 307, 308, 309, 310, 374: urban, 294

Powis, Terry G., 62

pre-Columbian societies, 6, 301, 313

pressure flaking, 250, 252

prestige goods, 23n7, 263-64, 28I; exchange of, $4-5,13$

Pro María Asociación, 304

Problematical Deposit 50, 164, 167, 168

processes: conceptual, 167 ; cultural, 6, 8-II, I3, 20, 332; developmental, I06; economic, I2; interconnected, 35; internal, I2; local, I85; physical, 167; political, I2; production, 317, 318, 320, 327, 331; social, 4, 263; sociocultural, 3, 8, IO-II, I7, I9; supply, 332 production, 318, 323, 332; craft, 322; local, 36; location of, 332; metallurgical, 314; sites, 317 projectile points, 245, 247, 249, 250, 253, 373;

Central Mexican-style, 255; typology of, 246

promise ceremony, I3I

Protero del Calichal, 271

Proto-Indo-Europeans, 125

proto-Mayan, I19, I24, I25, I35

Proto-Mije-Sokean, I26, I32, I37, I39n7, I39n9

Proto-Uto-Aztecan, I29, I3I, I 4 InI23

Puebla, 184, 249, 295, 296, 344, 373

Pueblo Alto, bell from, 280

Pueblo Viejo, 195; relief panel from, 194 (fig.)

Puerto Hormiga, pottery from, 73

Puma/Jaguar, 88

Punta Ycacos Lagoon, 137

Punzo Díaz, José Luis, 7, 374

purity, concept of, 90

Purrón phase, 57,72

Pyramid of the Moon, 371

Pyramid of the Sun, i7onio

pyramids, I64, 170n8, I70nI2, 265, 268, 275, 284; construction of, 276

pyrite, $\mathrm{I} 37$

Q'anjob'al, I24

Q'anjob'alan, 136

Q'eqchi', I24, I28; Ch'olan and, I34-36; Ch'olti' and, 136

Quechomictlipan Monument, 196, 197 (fig.), 200 nI 4

Queréndaro, I80

Querétaro, 176, 180

Quetzalapa, I84

Quetzalcoatl, IIonı7, 296 (fig.), 300, 301, 308, 374; cult of, 294; feast of, 302 ; prayers to, 302

Quetzalpapalotl Palace, 184, I95

Quiauhteopan, 322

Quiriguá, 16I, I62

Rabinal, I35, 136

radiocarbon dates, $52,63,72$

Rain god, 97, 99 (fig.), I 87

Ramec point style, 254

Rancho Matadamas, 346

Rathje, William L., 343

Rattray, Evelyn, I5I, I52, I54, I58, I59

raw materials, 183, 314, 320, 323, 331, 332; distribution of, 317, 327-28; extraction of, 317,327 ; 
metal production and, 317; metallic, 317; origin of, 327. See also materials recontextualization, 85, 89, 90, 91, 104, 105, Io9nir, 367, 368; iconic, 86-88

Red-on-Buff horizon, 54, 64, 65, 70, 72, 73, 74; development of, 2I

Reents-Budet, Dorie, I59, 160, I6I, I62

Regional Museum of Guadalajara, 319

Reilly, Kent, 89, 97, 218, 368, 373

relationships, 263; exchange, 7, 13, 21, 254; historical, 7, 10; interpersonal, 35; long-distance, 36; multifacted, 22; patron, 324; sign/object, Io 8 n 6

Renfrew, Colin, I2, 22-23ns

Reptile Eye glyph, 2II-I2, 219, 220

Reyna Robles, Rosa María, 176, 190

Río Amatzinac Valley, I80, 184

Río Azul, I39n9, 169n4

Rio Grande/Eastern wild turkey, population of, 132

Río/Lake Catemaco region, 226

Río Nepaxa, I99n 4

Río Peñas Grandes, 19I (fig.), 192

Río Tepango Valley, 226

Río Tlapaneco, 184

Río Verde Valley, 52, 54

ritual economy, theories of, 13

rituals, II, I8, 37, 218, 255, 277, 282, 297, 302, 305, 306, 308; complex, 294, 304, 309; cosmology and, 51; diverse, 274; important, 277; massive, 307

Robertson, Merle Green, I22

Rodríguez Betancourt, Felipe, 190

Rome, 90, 293, 294, 301

root forms, monosyllable, 125

Rosenswig, Robert M., 8, 10, 60, 89, 108n7

Roys, Ralph L., 343

Ruano Suárez, Alberto, 132

Rufino Tamayo collection, monument from, I85, I86 (fig.)

ruler of the year, 93-94

Ruppert, Karl, 214, 22I

Seler-Sachs, Caecilie, 22I

sacrifice, I8I, I82, 349, 372

Sahagún, Fray Bernardino de, 322, 325, 329

Saint of Pedro Cholula, 297

Saint Peter of the Souls, 297

Sakel, Jeanette, 89, IoI
Salinas de los Nueve Cerros, 137

salt, 73, 137, I4In26, 326, 34I, 343

salt beef, 306 (fig.)

San Andrés, 283, 295, 297; cylinder seal, IOI, IO2 (fig.)

San Andrés Tuxtla, 213, 228, 229, 23InI

San Antonio River, 264, 27I

San Bartolo Structure Sub-V, 98 (fig.)

San Francisco, 303

San Gabriel, 303

San Gaspar Chajul, 136

San Jerónimo Tititlán, 347

San José, 60

San José Mogote, 347, 348; map of, 346 (fig.); Monument 3 of, 349 (fig.); public buildings in, 346; wards/barrios of, 345-46

San Juan Cotzal, 136

San Juan del Río Valley, I80

San Lázaro Etla, 98, 100

San Lorenzo, 225, 226, 347

San Lorenzo Tenochtitlán, 215

San Lucas Tzalac, 136

San Luís, 303

San Marcos, 229; point style, 254

San Martine Tilcajete, 348

San Miguel, 303, 304, 307

San Miguel Amuco, 2oons

San Miguel Tianguisnahuac, 292, 294, 302-5, 306; image of, 303 (fig.)

San Miguel Totolapan, 177, 189, 196, 198; stela from, 190 (fig.); Teotihuacan influence on, 190

San Pedro, 295

San Pedro Cholula, 295, 297, 299, 302, 305; main plaza of, 298 (fig.)

San Rafael, 303

Sanders, William T., 343

Santa Clara, 246

Santa Cruz Tayata, 345

Santa Marta, 220, 226

Santiago Papasquiaro, 269

Santiago River Valley, 268, 278

Santisima Cruz, 303

Santley, Robert S., 252

Santo Entierro, 303

Sarabia, Alejandro G., 247

satellite villages, 346,347

saurian heads, 160,162

Sayultepec, I80

SBTC. See Stela, Base, and Throne Complex 
Schaeffer, D. Bryan, 7, 21, 370, 371, 372

Schele, Linda, 193

Schiavitti, Vincent, 266

Schmandt-Besserat, Denise, 107

Schmidt Schoenberg, Paul, 176, 177, 196

Schroeder site, 263

Schulze, Niklas, 375

scribal practices, 18, 19, 83, 98, 104, 106; variability in, $100-\mathrm{IOI}$

scripts, 83; art and, I07n4; Aztec, Io9nı3; development of, 85, 86, 87, 99-100; hieroglyphic, I22, I24, I26; interaction and, 88-9I, 9I-IOI, IOI-6, IO7n3; linguistic diversification and, IO2; Maya, 84, 92, 94, 98, 98 (fig.), IOI, 368; Mesoamerican, 85, 89, 9I-IOI, IO3, I06, Io9nII, IIon22; Mixtec, Io9nI3; Olmec, 98 (fig.); variable conventions in, 102 (fig.); Zapotec, 92, 93, 94, I09nI3

sculpture, 191, 196, 198, 213, 216

Selers, 221, 222

Serpent Wall, 265

serpentine, 69,347

serpents, 196, 268, 272; humanized, 267; plumed, 267,271

Severi, Carlo, 85

shaman-priests, 165

Sharer, Robert J., 353

shells, I37, I83, 196, 245, 343, 347

sherds, 67, 74n2, 270

Sheseña, Alejandro, 22I

shields, I8I-83, I87

Shook panel, 97 (fig.)

Shumla A style, 245, 246

Sierra de las Navajas, 2 II

Sierra de los Tuxtlas, 21I, 213

Sierra del Registro, 276

Sierra Madre, 262, 277, 281, 282, 283, 284

Sierra Tarahumara, 262

signs, IO5; ancestral, 88; constituent, 88 ; iconic, 87 ; identification of, 104; interpretation of, 86; Middle Formative, 97; nonverbal, 85 ; objects and, ro $8 \mathrm{n} 6$; plurality of, $85-86$; recontextualization of, 90 ; transference of, Io8-9n9; transmutation of, 85 ; visual, 85,87

silver, 313, 325

silversmiths, 325, $33 \mathrm{I}$

Sinaloa, 272, 273, 277, 278, 279, 283, 284; comparative chronology for, 269 (fig.)

slaves, 302, 343
Smith, Michael, I6, 23n9, 40, 320, 321

smoke-makers, 330

SNA. See Social Network Analysis

Snake head, 355 (fig.)

Snake Polity, divine lord of, 356

Snarskis, Michael J., 313

social capital, 294, 300, 304, 305, 306, 307, 309, 374, 375, 377; accumulation of, 308 ; notion of, 298-99

social contact, I24, 137

social continuity, 308, 309

social contract, $3, \mathrm{I} 28$

social institutions, 309, 375, 377

Social Network Analysis (SNA), 16, 17, 23n7, 4I; WST and, I4-I5

social problems, 191, 265

social relations, $36,318,345$

social security, 299, 308

social structures, 6, 307

society: egalitarian, 347 ; framework of, 33I;

historical development of, 218; rank, 347;

village, 345

sociocultural characteristics, $5 \mathrm{I}$

sociocultural structure, 18

Soconusco, 52, 68, 74, 216; Barra phase of, 54, 73; ceramics, 62; Early Formative, 64; grater bowls from, 60 ; Locona phase of, 73 ; pottery, 72

Sokean languages, I23

Sotuta, 343

Spanish, 282, 283, 293

Spanish Conquest, 313

Spanish Contact, 315

spear-thrower, 164

Spearthrower Owl, 179, 193

speech, I22; temporal progression of, 85

speech scrolls, I00, 102, 102 (fig.), 267

Speller, Camilla F., I 32

Spence, Michael W., 247

spindle whorls, 279, 28I

spoils of war, 32I-22, 324, $33 \mathrm{I}$

Spondylus shells, I83, 200n 4, 315, 347, 375

star-Tlalocs, 195

starfish, 194

Stein, Gil, 4, 8, 4I

stela, I50, 186, I87, 190, 190 (fig.), 200n6, 219 , 220, 221-22, 373; carved, 177; commemorative function of, 218; erecting, 218 ; unprovenanced, 189 (fig.); visual access to, 216 stela-base, 216, 220, 221, 222 (fig.) 
Stela, Base, and Throne Complex (SBTC), 2II, 216, 217 (fig.), 218-23, 230, 373

Stela C, 214, 222

Stingray Lagoon, 137

Stirling, Matthew, 214

stone, 327; blood, 329; building, 40; carved, 346; chipped, 249; flint, 325; ground, 245; precious, 329

Stone, Andrea, 165-66

Stone M21, 95 (fig.)

Storm god, 179, I81, I86, I87, I88-89, 195, 196, 197, 200nir, 370, 372; black, 190; examples of, I88 (fig.); mask, 190

stratification, I3; social, 5I, I22-23, 267

Stross, Brian, I39n 6

Structure I, 272, 276, 277

Structure 2, 273, 354

Structure 5, 276, 277

Structure 7, 276

Stuart, David, 9I, I39n9, I40nI4, 369, 370

Stubbs, Brian, I 4 In 23

styles, 8, 40, 84, 210, 345; fusion of, 158; iconography and, 89, 90; local, 9I; Olmec, ro8ni, 222; pure, 90, 9I

Sub-Jaguar Tomb, I60, 161, 162, I64

subchiefs, 351

sublords, 355

Suchil ceramics, 267

Suchil Red-on-Buff, 270, 271

Suchil River, 264

Sugiyama, Saburo, 371

Sun God, 372

Sun Pyramid, 265

supports: knoblike, I53; tripod, I54 (fig.), I55

(fig.), 159

symbolism, 19, 37, 84, 108n6, 198, 301, 314, 319, 368; Maya, 372; Olmec, Io; pan-Mesoamerican, 283-84; Teotihuacan, 372

symbols, 8, 37, 294; complex, 106, 315; foreign, I67, 168; material, 366, 367; Postclassic, 98; word-based, 368

Symonds, Stacey, 226

systems: ancestral, 87; prestige, 84; social, 294; traditional, 300

T747b AJAW 'lord' royal title, 97 (fig.)

ta-wi-si-ka-la, 126

Tabasco, 156, 214, 215, 223, 225, 227, 228; interaction with, 2II talud-tablero architecture, I50, I55, 162, I69nI, I69n3, I78, 179, 2II

Tambuco, 197

Tampico, 213

Tamub, 166, I70n9

Tarascan empire, 326, 327

taskscape, concept of, 318

Taube, Karl, I27, I59, I76, I85, I87, I89, 200n9, 274,370

Taylor, William B., 297

technology, 18, 68, 317, 366, 367; bioarchaeological, 36; ceramic, 64; communication of, 6; complex, 320; mining, 327

Tecolote, 246

tecomates, 55, 57, 62, 72, 73

Tecpán, I33, I34, I96

Tedlock, Dennis, 170 n8

Tehuacán Valley, 57, 67, 73, 249, 345

Temple B, 300, 301

Temple of Lady 9 Grass, 98

Temple of Quetzalcoatl, 296; interpretation of, 295 (fig.)

Temple of Skulls, 265

Temple of the Cross group, I70nI2

Temple of the Inscriptions, 126, I28, 129

Temple of the Plumed Serpent, 301

temples, 170n8, I70nI2, 308, 349, 353; burning, 348; Maya-style, 164; supplying, 319, 331; termination of, 331; tribute at, 329

Templo Mayor, 308-10, 314, 371, 375-76; bell collection of, 318-19, 331, 332; building phase of, 330; offerings of, $318-22,320$ (fig.), 328-33

Tenango, 347

Tenochtitlán, 43, 183, 294, 308, 314, 318, 322, 331, 332

Teotepec, 224, 225

Teotihuacan, 7, I4, 21, 43, I19, I28, I49, I5O, I52, 154, 167, 187, 196, 197, 199, 21I, 215, 224, 240, 243, 245, 246, 247, 249, 251, 252-53, 255, 263, 266, 274, 276, 283, 301, 310; Altun Ha and, 344; Cantona and, 24I, 24I (fig.), 242, 248; demise of, 254; diagnostic traits in, 156 ; diaspora of, I5oni8; Early Classic Mesoamerica and, 179-8I; Epiclassic emulations of, I80; fall of, 244; as foreign locale, 168; Guerrero and, $176,177,178$, 179, 198 ; imperial representatives from, I95; influence of, $22 \mathrm{n} 4,127,157$, I80, I8I, I83-84, I93, I97, I98, 200nI2, 219-20, 
268; interaction with, 178-79; Maya and, 5 , I56, I57-64, I68, 169ni, I69n3, I69n5, I76, 179; Monte Albán and, I80; obsidian blades at, 34; population of, 267 ; settlement patterns in, I80; style, 219; Tikal and, 169n3, 343; Veracruz and, 180

Teotihuacan II period, 247

Teotihuacan Valley, 132

Tepalcatepec, 280

Tepantitla, 192

Tepecoacuilco, 176, 177, 183, 184, 198, 322, 323; stelae, $187-88$, 195

Tepecoacuilco Stela I, 187, I88 (fig.)

Tepecoacuilco Stela 2, I87, I88

Tequistlatec, I3I

Terminal Classic period, 223, 275

Tetitla, I87; burials, I55; Corridor 21 of, I88 (fig.)

Teuchitlan, 97

Texcoco A, 246

Texcoco Molded pottery, 212

textual composition, 94, 107ns

Tezeltalan, 120

Tezozomoc, death of, 329

theory of everything, 7-8

Thompson, J.E.S., 210,231

Three Temples Complex, 265

throne-mat kenning, 96, 98 (fig.)

Tierra Caliente, 177, 184, 189-95, 200nı2

Tierras Largas phase, 70, 72, 73, 74nI, 75n3, 367; bowls from, 60; ceramic assemblages from, 54-58, 56 (fig.), 60-64, 74; vessels from, 56, $74 \mathrm{n} 2$; wares from, 67

Tikal, 156-57, 160, 161, 179, 193, 198, 247, 251, 252, 352, 354, 356, 357, 370; burials in, 344; ceramics in, 159; emblem glyph of, 355;

Problematical Deposit 50 at, 164, 167, 168; ritual deposits in, 344; Teotihuacan and, I69n3, 343; tripods in, 163

Tikal Ballcourt Marker, 179, 192

Tikal Project, 179

Tikal ruler, 355,356

Tila Stela B, I20

Tilcajete, 348 ; map of, 346 (fig.)

tin, $317,318,327,328$ (fig.)

Tingambato, 180

Tiquisate, $\mathrm{I} 8 \mathrm{I}$

Tlachco, 323

Tlacolula subvalley, 348

Tlacotepec, 196
Tlacuache phase, 66, 67, 366, 367; bottles from, 63,64 ; ceramic assemblages from, $54-58,55$ (fig.), 59 (fig.), 60-64, 66 (fig.), 72, 73-74; designs, 65; grater bowls from, 60-6I, 6I (fig.); jars from, 56; Oaxaca and, 54; sherds from, 72 ; vessels from, 56,65 ; vessels/percentage, 56 (fig.); wares from, 57, 58, 62, 73

Tlahuizcalpantecuhtli, 126

Tlalchapa, 190

Tlaloc, I57, I69ni, I87, 371; bells from, 280

Tlamimilolpa phase, I55

Tlapa, I84, 197

Tlapacoya, 345

Tlapan, 183

Tlapaneca, 184

Tlapehuala, 184

Tlatelolco market, 326

Tlatilco, 56, 60, 345; bottles from, 62-63; burials at, $62-63$

Tlaxcala Corridor, 240, 249

Tlaxcalantzingo, 303

tobacco, 137

Tohil, I66

tojtole, $\mathrm{I31}, \mathrm{I} 32$

Tollan, 369

Tolstoy, Paul, 246

Toltecs, 295, 300, 301

Toluca Valley, I 84

toma de posesión, concept of, 182

Tomatlán site, 279

Tomb A-I, tripod from, I59, I60 (fig.)

Tomb B-II, I5 8

tombs, 64 , I50, 158, 159, 344, 349

Tonina, 120

Topia, copper bells at, 283

Topiltzin Quetzalcoatl, 300

toponyms, I85, I88, 195

Torquemada, 329

Totoate, 271

Totocapan, 223

Totogal, 212

Totonac, 127

Totonacan, I39ns

Tovar Codex, 91, 93 (fig.)

trade, I2, I3, I5, I7, 58, 68, 165, 227, 28I, 32I, 324-25, $343,345,357,374,375,377$; lexical borrowing and, 137-38; long-distance, 263, 302-3, 305, 309, 376; material, 104; multiyear-long, 305; routes, 314 (fig.), 315 ; traders and, $305-8$ 
traders, 305-8, 310, 315, 325 (fig.)

traditions: artistic, 6, 83, 98; ceramic, 64, 66, 74, 156, 269, 367; cultural, 6, 38, 262, 267; historic, 84; literary, 96; Mesoamerican, 282, 284; micro, 64; regional, 20

traits, 38-39; cultural, 4, 8, 13, I77; diagnostic, I56; iconographic, I82; Maya, 162

transference, $87,107,107 \mathrm{n} 4$

transformation, 315, 317, 345; artistic, 316; historical, 51; material, 318; social/political, 302

translation, 9, 85, 86, 91

transmutation, 85, 86-88, 87, 88, 89, 91, I05, 106

trapeze and ray sign, 185

travel: foreign objects and, 164-67; tripods and, 168

Traxler, Loa P., I6I, 353

Tres Cerritos, I80

Tres Zapotes, 214, 225, 226, 229, 250; monuments in, 216, 218, 222

tribute, $126,313,315,321,322-24,329,331$; extracting, 178 ; levied, 323; metal, 323 (fig.)

Trincheras, 280

Triple Alliance empire, Teotihuacan and, I8I tripods, 60, I5O, I5 I, I5I (fig.), I52 (fig.), I53 (fig.), I58 (fig.), 160 (fig.), 163 (fig.), 164 (fig.), $166,167,187,224$; aesthetic of, 156 , I58; cultural connotations of, I65; curated, 169-70n6; cylindrical, 177, 197; decoration on, I55, I81; examining, I56; foreign, 168; funerary chamber, $170 \mathrm{n} 6$; incised, I52; lidded, I54, I60, I6I (fig.), I62, I69n4, I70n7; Maya and, I56-57, 157-64; origins of, I56-57; painted, 178; scene incised on, 166-67 (fig.); stuccoed, I78; stylistic program of, 152; Teotihuacan, I51-56, 159 (fig.), I60; travel and, 168

Tuitán, 265

Tula, 5, 34, 310

Tulan Zuyua, I66, I70nı2

Tulane Expedition, 213, 214

Tulija River, 120

Tumbalá, 120

Tunal phase, 278, 279, 280, 28I

Tunal River, 276

turkeys, 132, 133

turquoise, 40, 266, 273, 327

turtles, 34I

Tuxcacueso, 280

Tuxpan engraved, 277
Tuxtla Mountains, 213, 214, 230, 373

Tuxtla Statuette, 213-14, 213 (fig.), 23 InI

Tuxtlas, 7, 21, 2II, 2I2, 212 (fig.), 2I 4, 219, 220, 22I, 222, 223, 224, 226, 228, 229, 230, 231; cultural development in, 213; investigations in, 215; Pacific coast and, 216

Tuxtlas Polychrome, 220, 224, 225, 230; examples of, 225 (fig.)

twisted root sign, 185 , 195

Tzeltal, I2O, I28, I3I

Tzeltalan, II9, I2O, I29

Tzotzil, I3I

u-lu-mu, I32

Uaxactún, 210, 215, 352

Uaxactún Stela 5, 179

Ucareo, 69, 255

uchen tinará mutajijón ñuti, $\mathrm{I} 34$

Umberger, Emily, 182

University of Missouri Archaeometry Laboratory (MURR), 68

US Southwest, 132, 263, 272, 274, 279, 280, 283

Uspanteko, I29

Usumacinta River, I37, 184, 227

Uto-Aztecan Nawa, I26, I38ni, I39n7

UV fluorescence studies, 266

Uxmal, 215, 248

Uxul, 35I, 354

Valdivia, 67, 68, 73

Valencia, Rogelio, 22I

Valenzuela, Juan, 215, 221, 229

Valle Grande, 348

Valley of Huamelulpan, 345

Valley of Mexico, I26, I27, 138, 139-40n9, 178

Valley of Oaxaca, 68, 69, 70, 73, 367, 376; case study from, 345-50; map of, 346 (fig.); trade and, 345

Valleys of Durango, 282

values, Io9nir; economic, 313, 321; grammaticallinguistic, 88; linguistic, 88, 9I; phonetic, 88; semantic, 86, 92, 96, 103; symbolic, 313; word, 88

Varela Torrecilla, Carmen, 156, 163

vases, 93 (fig.), IO2; "Arrival," I64; Aztatlan Polychrome, 279; codex-style, 279; Dazzler, I69ni; tripod, I52, 370

Velázquez Castro, Adrián, 331

Venus Tables, 126 
Veracruz, I51, 156, I67, 168, 176, I81, 213, 214, 216, $219,223,224,225,226,227,228,229,230,231$, 245, 252, 347, 372; calendar development in, 215; interaction with, 2II; Maya and, 210, 2II; Teotihuacan and, 180

vessels, 56, 58, 61, 64, 65 (fig.), 197, 371; belted, 65, 67 (fig.); cacao, 62; ceramic, IIonI6, I53, I53 (fig.), I68, 278; effigy, 62, 63 (fig.); Maya, I62, 342; nonlocal, 344; phytomorphic, 55; stuccoed, 157; Teotihuacan-style, 162-63

Vesuvio, 266, 267, 271

Vesuvio-Alta Vista phase, 265, 267

Villa Alta phase, 226

Villa Madero, I90; Sculpture I at, 192 (fig.), 193 (fig.), I94 (fig.)

Villa Union, 267

Virgin of Guadalupe, 297, 303

Virgin of the Remedies, 292-93, 297, 298 (fig.), 303-4, 303 (fig.), 304 (fig.); feast of, 307 (fig.)

Virgin of the Rosary, 303

visual elements, 88, 104; aspects of, I03; syntactical functions of, $\mathrm{IO}_{3}$

visual notation, systems of, 88 , IO2

visual programs, extralocal, 150

visual records, 6

vocabulary: Ch'olan, 126; Mixe-Zoque ritual, 4; Nahuatl, I26; visual, IO3, IO 6; Yukatekan, I21, I26

Waka, 352

Wald, Robert, I2I-22

Wallerstein, Immanuel, 13, 14, 41, 263, 366

war gods, 372

War Serpent, 181, 195

Ward, Sue, 27I

wares, 60, 62, 66, 67, 73, 223, 345-46; ceramic trade, 245; decorated, 58, 269; Fine Thin Orange, 177, 179; gray, 60; Oaxacan, 57; Orange, 245, 344; paste, 25I; utilitarian, 58 warriors, I8I, I85, I89, 356; Teotihuacan, 162, 164, I80, 185

Wastekan, II9

water storage, 352

watercraft, 58

wax, $317,323,327$

Weiant, Clarence W., 229

Weigand, Phillip C., 266

West Ch'olan, I20

West Group, 352
West Mexican Metalworking Zone, 327

West Panel, I28

White and Buff slips, 280

Whittaker, Gordon, 126

Wichmann, Søren, I19, I20, I22, I34, I35, I36, I39n9

\section{WINIK-li, I20}

Winter, Marcus, $74 \mathrm{nI}$

Wite' Naah, 370

Wite' Naah Fire Shrine cult, 372

Witkowski, Stanley R., 124, I25, 136

Wolf, Eric, 35, 38, 39

workshops, 317; biface, 254; metalworking, 327; state, 244; Teotihuacano, 249; Tikal, I60

world devourer, I89, 200 nII

World Systems Theory (WST), 13, 16, 17, 4I, 43, 263, 366, 374; SNA and, I4-15

Wright, Henry, 23, 34

writing, 84, IO2, I08n5, IO9nII, 218; conventions of, 87 , 104; development of, $106-7$; emergence of, 83, 86-88, 91, 101; Epi-Olmec, 85; iconography and, 86; Maya, 91, 94, 99, 170n7, 195; Mesoamerican, 86-88, 98, IOI, IO6-7, I07n4, IIonı;; Middle Formative, 91; Olmec, Io8n7; Teotihuacan, 185, I89, 195, 198, 219;

Zapotec, 94, Io9ni3

WST. See World Systems Theory

Wupatki, 280

X-ray Fluorescence (XRF), 68, 72, 248, 252, 266; results of, 69 (fig.)

xenophobia, 365

Xicalanco, 325

Xinka, I39ns; loanwords for, I 4 In 24

Xipe Totec, 316, 316 (fig.)

Xiuhtecutli, 328

Xiximes, 282

Xochicalco, 244, 254

Xochipala, 196

Xolalpan phase, 154, 159

xonecuilli, 98, IIonı 7

Xoo phase, 60, 93

XRF. See X-ray Fluorescence

Yagul urn, 93 (fig.)

Yak K'uk' Mo', I69ni

Yax Mayuy Chan Chaak, 135

Yax Nuun Ayiin, 156, 157, 179; tomb of, 160

Yaxuna, 371, 372, 392 
Yaxuna Burial 24, 371

year sign, I86, I88

Yegüih, 348; map of, 346 (fig.)

Yerbabuena, 196

Yucatán, 120, I21, 162, 164, 215, 223, 227, 351, 370, 371,372 , 373; exchange in, $341-42$; provinces of, 342 (map); salt in, 326; trade in, 343 yugo, 93 (fig.)

Yukatekan, I19, I28, I29, I34, I35, I39nI, I39n4, I4OnII; Ch'olan and, $120-22$

Yuknoom Ch'een I, 354, 356

Zacatecas, 262, 263, 265, 266, 267, 269, 271, 272, 275, 276, 277, 278, 279, 283, 284, 285nI; Chalchihuites culture in, 264; comparative chronology for, 269 (fig.)
Zacualtipan, 255

Zape, 267, 268, 278, 284

Zapote Fine Orange to Gray, 225

Zapotecs, 92, 94, 97, 105, 348-49, 357; child rearing by, 75n5; Mixtecs and, 5; tradition of, 98

Zaragoza, 69

Zaragoza-Oyameles obsidian, 24I-42, 245, 247 (fig.), 248, 249, 250, 250 (fig.), 251, 252, 253 , 254,255

Zaragoza-Oyameles Regional Obsidian Survey, $243,245-48$

Zeitlin, Robert N., 252

Zihuatanejo, 196

Zohapilco, 56, 63, 70, 71 